\title{
Specific Systems Studies of Battery Energy Storage for Electric Utilities
}

\author{
Abbas A. Akhil \\ Lana Lachenmeyer \\ Storage Batteries Department \\ Sandia National Laboratories \\ Albuquerque, New Mexico 87185
}

S. J. Jabbour

Decision Focus, Inc.

H. K. Clark

Power Technologies, Inc.

\begin{abstract}
Sandia National Laboratories, New Mexico, conducts the Utility Battery Storage Systems Program, which is sponsored by the U.S. Department of Energy's Office of Energy Management. As a part of this program, four utility-specific systems studies were conducted to identify potential battery energy storage applications within each utility network and estimate the related benefits. This report contains the results of these systems studies.
\end{abstract}




\section{Acknowledgments}

The bulk of this report is extracted from reports provided under contract to Sandia National Laboratories by the following:

Salim J. Jabbour, Decision Forus, Inc.

Anders R. Gjerde, Decision Focus, Inc.

Stephen M. Haas, Decision Focus, Inc.

H. K. Clark, Power Technologies, Inc.

John Doudna, Power Technologies, Inc.

T. I. Leksan, Power Technologies, Inc.

F. S. Prabhakara, Power Technologies, Inc.

H. W. Zaininger, Power Technologies, Inc. 


\section{Contents}

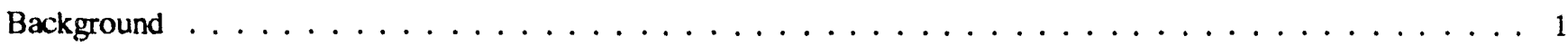

Utility Selection and Study Guidelines $\ldots \ldots \ldots \ldots \ldots \ldots \ldots \ldots \ldots \ldots \ldots \ldots$

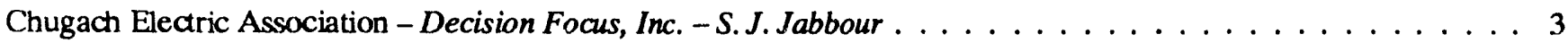

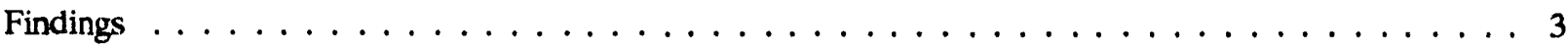

Generation Benefits $\ldots \ldots \ldots \ldots \ldots \ldots \ldots \ldots \ldots \ldots \ldots \ldots \ldots \ldots \ldots \ldots \ldots \ldots$

Reduced Load Shedding . . . . . . . . . . . . . . . . . . . . . . . . 4

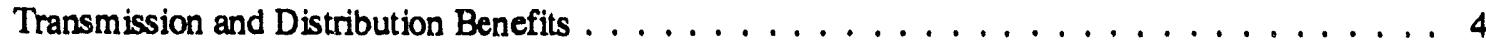

Cost/Benefit Analysis $\ldots \ldots \ldots \ldots \ldots \ldots \ldots \ldots \ldots \ldots \ldots \ldots \ldots \ldots$

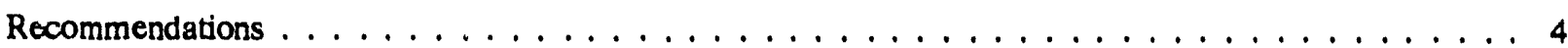

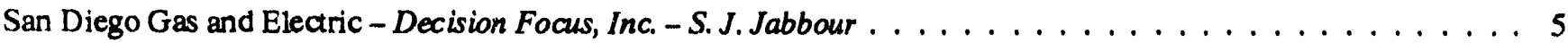

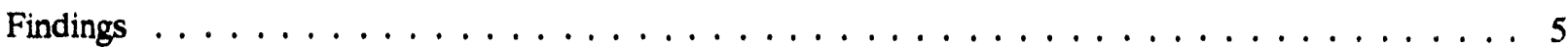

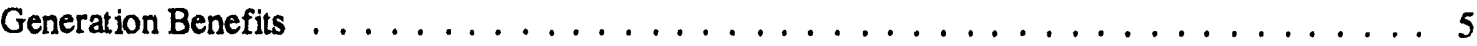

Transmission and Distribution Benefits $\ldots \ldots \ldots \ldots \ldots \ldots \ldots \ldots \ldots$

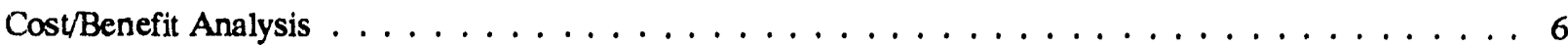

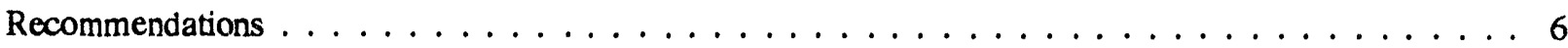

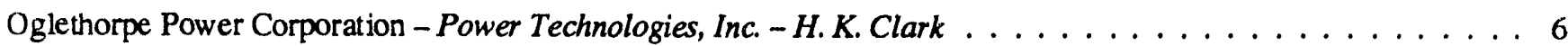

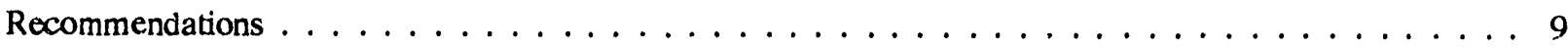

Bonnevile Power Administration Puget Sound Area - Power Technologies, Inc. - H. K. Clark . . . . . . . . . . 10

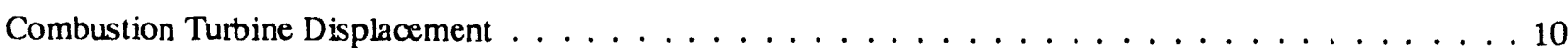

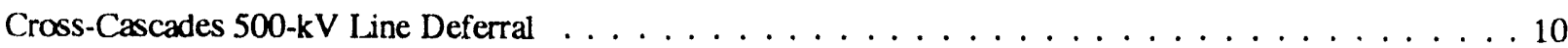

Local Benefits of Battery Energy Storage $\ldots \ldots \ldots \ldots \ldots \ldots \ldots$

Generation Benefits of Battery Energy Storage in the Northwest $\ldots \ldots \ldots \ldots \ldots$

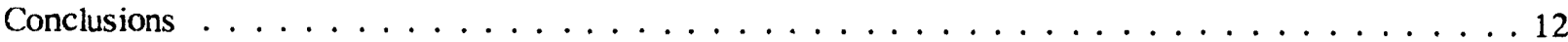

Appendix A - Potential Benefits of Battery Storage to Chugach Electric . . . . . . . . . . . . . A-1

Appendix B - Potential Benefits of Battery Storage to San Diego Gas and Electric . . . . . . . . . . . B-1

Appendix C - An Estimate of Battery Energy Storage Benefits on the Oglethorpe Power System $\ldots \ldots \ldots \ldots$ C-1

\section{Figures}

1 Geographic Distribution of Utility Systems Studies $\ldots \ldots \ldots \ldots \ldots \ldots \ldots \ldots \ldots$

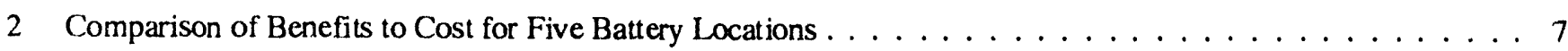

3 Percent of Benefits for Five Battery Locations $\ldots \ldots \ldots \ldots \ldots \ldots \ldots \ldots \ldots$

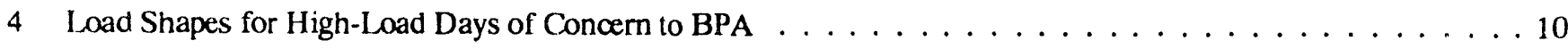

5 Typical Wind Tunnel Load Profile and Battery Energy Required to Limit Load Changes to $50 \mathrm{MW} / \mathrm{min}$. . . . . 11 


\section{Tables}

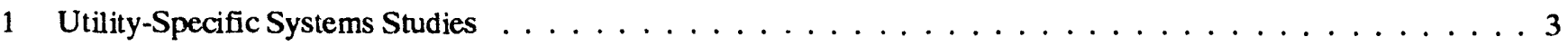

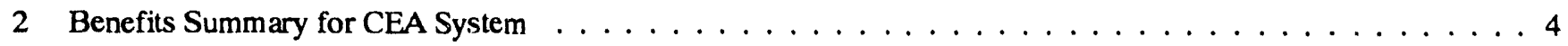

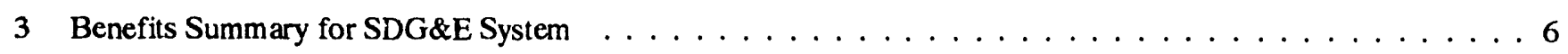

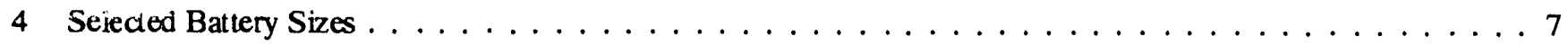

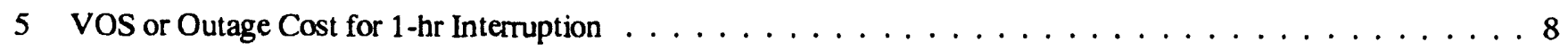

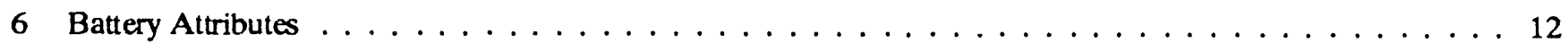




\section{Background}

The Utility Battery Storage Systems Program (UBS) of the U.S. Department of Energy (DOE), Office of Energy Management (OEM), is conducted by Sandia National Laboratories (SNL). UBS is responsible for the engineering development of integrated battery systems for use in utility-energy-storage (UES) and other stationary applications. Development is accomplished primarily through cost-shared contracts with industrial organizations. An important part of the development process is the identification, analysis, and characterization of attractive UES applications.

The results of the Utility Systems Analyses element of the UBS Program are used to identify utility-based applications for which battery siorage can effectively solve existing problems. The results will also specify the engineering requirements for widespread applications and motivate and define needed field evaluations of full-size battery systems.

For several years, battery energy storage has predominantly been considered a load-leveling and peakshaving resource, and its potential for use in other utility applications has been largely overlooked. The fast-response capability of battery energy storage systems combined with other characteristics, such as modularity and ease of siting, makes this technology eminently suitable for providing support to the entire utility network for several applications such as spinning reserve, frequency control, and deferral of transmission and distribution facilities. Until now, the benefits and economic value of battery energy storage only for loadleveling and/or peak-shaving have been well understood. But the application of battery storage and the methodology to evaluate its benefits in the other, nonload-leveling applications has not been as well documented. The Electric Power Research Institute (EPRI) estimated a range of benefits for these applications from general utility information. More specific benefit information derived from utility planning scenarios and operating conditions is necessary to demonstrate the feasibility of this technology for a wide range of utility applications. The widespread application of this technology by the utility industry is predicated on the availability of this information base.

Thus, the objective of the SNL effort was to undertake a set of studies that would identify numerous applications for batteries and estimate their value in the utility network. There were two possible approaches that could be adopted for performing studies to achieve these objectives:

- examine the needs of utilities on a regional basis to identify all possible applications in which battery energy storage can play a role and estimate the value

or

- examine specific utility networks and identify potential battery energy storage applications within each network and estimate the related benefits.

The results from each approach would have different meanings and would be interpreted accordingly. A study performed on the basis of the first approach would yield estimates of the value of battery energy storage at the regional level, based not on the requirements of a particular utility, but on collective, regional conditions derived from general assumptions.

The second approach would be more focused, and identify real applications and estimate the value of the battery system based on utility-specific conditions and assumptions. The results of a study based on this approach would be immediately applicable to the host utility, while preserving the possibility that they are also applicable to other utilities with similar operating conditions. The results obtained from the second approach were deemed to be nore valuable for the DOE/SNL UBS program and the utility community as a whole, and it was decided to structure the systems studies along those lines.

\section{Utility Selection and Study Guidelines}

Utilities with a diverse ownership structure and operating conditions were selected to gain insight into their processes for evaluating and implementing technology options such as battery energy storage. The utilities that were finally selected included:

- Investor-owned utility - San Diego Gas \& Electric (SDG\&E)

- Rural electric cooperative - Oglethorpe Power Corporation (OPC)

- Municipal electric association - Chugach Electric Association (CEA)

- Public power administration - Bonneville Power Administration (BPA)

Figure 1 shows the utility locations.

Each of the four utilities either had an active interest in battery energy storage or had a strong potential for benefiting from its use. Cost-sharing was required from 


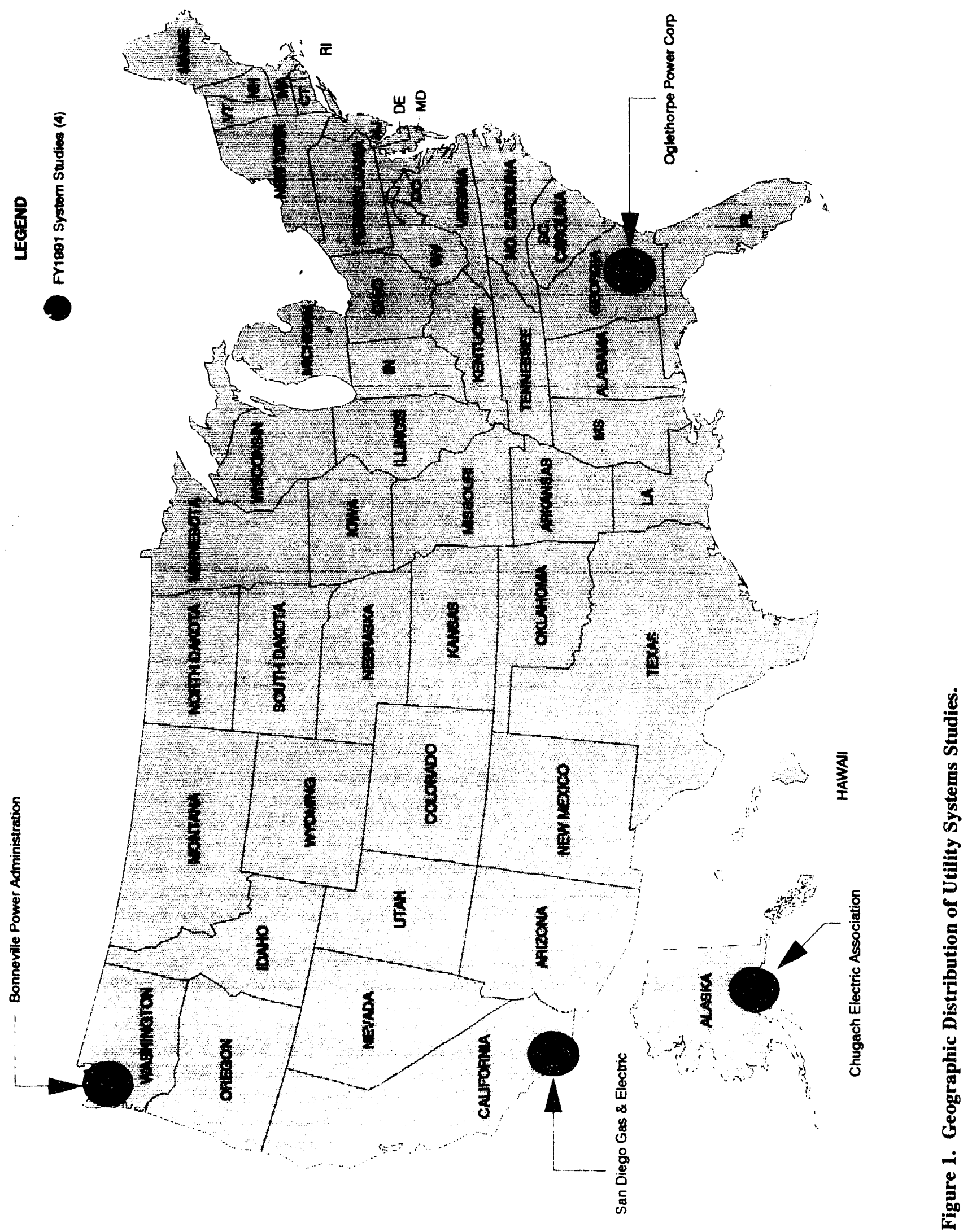


all utilities except BPA. SNL's share of the cost for each study and an approximate cost share from the utilities is shown in Table 1 . This table also shows the start dates of each study. The studies were conducted by utility industry contractors who specialize in serving the utilities involved in the study.

The stuciy period was initially limited to no more than 3 mo. It was felt that a longer duration could lead to a lengthy, iterative refinement process with everchanging input assumptions and planning scenarios in an attempt to obtain better and more accurate results, whereas the 3-nıo time limit established a firm deadline and forced the use of only one set of assumptions and deferred refinement of results to future studies. In practice, the studies extended beyond this planned 3-mo duration. This delay was not caused by the length of time required for the analysis, but by delays in obtaining input $:$ formation and feedback from utilities as the studies progressed.

The findings of each study are summarized in the following subsections. More complete reports for three of the four utilities form the appendices of this document.

\section{Chugach Electric Association Decision Focus, Inc. - S. J. Jabbour}

This section describes the results of a screening study to determine the benefits of adding megawattscale battery energy storage to the CEA system. Generation, transmission, and distribution benefits of storage, with a primary focus on benefits that are typically difficult to quantify, are addressed. The potential benefits to the costs of adding battery storage are also compared.

The CEA analysis was primarily performed by Decision Focus, Inc., with support from Power Technologies, Inc., in the areas of transmission and distribution benefits.

\section{Findings}

\section{Generation Beneflte}

Generation benefits were calculated for six representative days in each of 1994, 1996, and 2000. Projected system operation was based on MAINPLAN (utility system computer simulation) runs. The benefits were calculated for five gas-fired combustion turbine units whose operation is most likely to be affected by the addition of batteries to the system. The focus was on using batteries to provide spinning reserve.

\section{Load-Leveling}

Because the marginal units on the CEA, system are typically gas-fired combustion turbines for all hours, the system marginal energy costs do not differ much betwaen on-peak and off-peak hours. Coupled with the assumed battery efficiency of around $80 \%$, this means that no load-leveling savings could be achieved on the CEA system.

\section{Dynamic Operating}

For each of the 18 days, the potential reductions in load-following, minimum-loading, and start-up costs were calculated for each of the five generation units; reductions in these costs are achievable even though the battery is used only to provide spinning reserve. The most cost-effective unit for decommitment was identified on each day. A value of $\$ 40$ to $\$ 70 / \mathrm{kW}$-yr of battery capacity, levelized in current dollars, appears appropriate for dynamic operating benefits; this estimate was derived by calculating change from the MAINPLAN results that would be made possible by the addition of battery capacity. Of this total, more than twothirds is from reduced minimum-loading costs, and the remainder is from reduced load-following costs.

\section{Table 1. Utility-Specific Systems Studies}

\begin{tabular}{|c|c|c|c|c|}
\hline Utility & Sandia Contract & Utility Cost Share & Start Date & End Date \\
\hline San Diego Gas \& Electric & $\$ 46 K$ & Yes & $8 / 91$ & $12 / 92$ \\
\hline Oglethorpe Power Corp. & $\$ 47 K$ & Yes & $7 / 91$ & $11 / 91$ \\
\hline Chugach Electric (Alaska) & $\$ 43 K$ & Yes & 9/91 & $1 / 92$ \\
\hline $\begin{array}{c}\text { Bonneville Power } \\
\text { Administration }\end{array}$ & $\$ 70 K$ & No & $2 / 91$ & $11 / 91$ \\
\hline
\end{tabular}


Addition of battery storage to the CEA system would be effective in reducing load shedding. The amount of the reduction would depend on the size of the battery. An approximate calculation indicates that the value of the reduced load shedding could be $\$ 8$ to $\$ 16 / \mathrm{kW}$ of battery capacity per year.

\section{Transmission and Distribution Benefits}

Current CEA transmission and distribution (T\&D) facility expansion plans were reviewed to identify T\&D investments that might be avoided or deferred as a result of adding battery storage to the CEA system. Several such investments were identified. The most attractive opportunities are at the Huffman, Hillside, and Girdwood substations and at the village of Hope. Based on a qualitative review of these investments and comparison with more detailed analyses for other utilities, potential T\&D benefits of $\$ 20$ to $\$ 200 / \mathrm{kW}$ of battery capacity appear reasonable. This is equivalent to a $T \& D$ benefit of $\$ 3$ to $\$ 27 / \mathrm{kW}$ of battery capacity per year.

\section{Cost/Benefit Analysis}

Table 2 summarizes the findings. Summing the capacity (value of displacing other capacity additions), generation, reduced load shedding, and T\&D benefits yields levelized current-dollar savings of $\$ 81$ to $\$ 183 / \mathrm{kW}$-y r, compared to a levelized current-dollar cost of $\$ 50$ to $\$ 60 / \mathrm{kW}$-yr. Note: For the purposes of this study, the cost estimates used are from EPRI's Technical Assessment Guide (TAG, 1989). The total cost is $\$ 703 / \mathrm{kW}$ for a 3 -hr battery, including land cost. Reducing the storage component in the TAG cost estimates for a 3-hr battery by two-thirds yields an estimated cost of $\$ 350 / \mathrm{kW}$ for a $1-\mathrm{hr}$ battery. With a levelized fixed charge rate of $13.7 \%$, this is equivalent to $\$ 50$ to batteries would be a cost-effective addition to the CEA system.

Some benefits may be mutually exclusive. The interactions between the various benefits, that is, whether they are additive or mutually exclusive, depends on storage size, location, system load profiles, and load profiles at individual substations and on individual T\&D lines, how the system (including the battery) is operated, and on any equipment deferred as a result of adding batteries.

\section{Recommendations}

Based on the results of this screening-level study, it is recommended that CEA consider the addition of battery storage to its system. This screening study focused only on the benefits of battery storage and it was not intended to calculate the cost of the battery system tha: would provide these potential benefits. A follow-on feasibility study that would provide a preliminary cost estimate of the battery system and include a detailed study to verify and refine the findings of this initial screening study by calculating the benefits more precisely is recommended. Such a study should include the following aspects:

- T\&D expansion studies should be carried out, with and without batteries. Potential sites for installing batteries should be identified. Interactions among the various benefits should be considered to ensure that batteries are not being justified on the hasis of benefits that may be mutually exclusive.

- More detailed calculation of generation-dynamic operating costs and benefits should be carried out, including examination of multiple weeks of system operation during each of a

Table 2. Benefits Summary for CEA System

Category

Annual Benefit $(\$ / \mathrm{kW}-\mathrm{yr})$

- Capacity

30-70

- Generation

Dynamic Operating (Spinning

40-70

Reserve/Unit Decommitment)

- Reduced Load-Shedding

8-16

- T\&D

TOTAL

$81-183$ 
larger number of years than was considered here. Such calculation should fully account for changes in system operation as load grows and should identify all possible operation savings, not only those that arise when a unit is completely decommitted.

- Comparative evaluation of the economics of battery storage with other capacity additions under consideration by CEA should be carried out. Such detailed study would also allow a better assessment of the "optimum" battery size and the best time for addiug tne battery plant to the CEA system.

- Identify a preferred site for locating the battery based on the findings above. Based on these finciings, develop the conceptual design of the battery system and estimate its cost. Perform a cost/benefit evaluation based on the total benefits and battery system cost.

These recommendations were provided to CEA at the conclusion of this study.

\section{San Diego Gas and Electric Decision Focus, Inc. - S. J. Jabbour}

This section describes the results of a screening study to determine the benefits of adding megawattscale battery storage to the SDG\&E system. Generation, transmission, and distribution benefits of storage, with a primary focus on benefits that are typically difficult to quantify, are addressed. The potential benefits to the costs of adding battery storage are also compared.

The SDG\&E analysis was primarily performed by Decision Focus, Inc., with support from Power Technologies, Inc., in the areas of transmission and distribution benefits.

\section{Findings}

\section{Generation Benefits}

Generation benefits were calculated for eight days during 1990 and 1991, one weekday and one weekend day for each season, using actual SDG\&E data. The benefits were calculated for five gas-fired steam turbine units whose operation is most likely to be affected by the addition of batteries to the system. Two modes of battery operation were considered: daily charge/discharge with a 3 -hr battery, and provision of spinning reserve only with a 1-hr battery. The spinning reserve mode appears to be more cost-effective.

\section{Load-Leveling}

Because the marginal units on the SDG\&E system are typically gas-fired steam turbines for all hours, the system marginal energy costs do not differ much between on-peak and off-peak hours. With the assumed battery efficiency of $80 \%$, this means that no load-leveling savings could be achieved on the SDG\&E system.

\section{Dynamic Operatirig}

For each of the eight days, the potential reduction in load following, minimum loadirg, start-up, and spinning reserve costs was calculated for each of the five units. The most cost-effective unit for decommitment was identified on each day. For the 1990-1991 period, the savings were about $\$ 23$ to $\$ 26 / \mathrm{kW}-\mathrm{yr}$ of battery capacity; the biggest component of the savings is from reductions in load-following costs. That is, each kilowatt of battery capacity would reduce annual system operating costs $\$ 23$ to $\$ 26$. Accounting for inflation and increases in natural gas prices, this is equivalent to an annual savings of about $\$ 50$, levelized in current collars, per $\mathrm{kW} / \mathrm{yr}$. The savings are likely to increase in the future as load growth forces increasing utilization of less economic units.

\section{Environmental}

Storage in general, and batteries in particular, has the potential to shift the type and location of emissions of $\mathrm{NO}_{\mathrm{x}}, \mathrm{SO}_{\mathrm{x}}$, and $\mathrm{CO}_{2} ; \mathrm{NO}_{\mathrm{x}}$ is of greatest concern in Southern California. Even if providing only spinning reserve, batteries have the potential to reduce $\mathrm{NO}_{x}$ emissions by allowing the system to be operated more efficiently. The addition of batteries to the system might also make it unnecessary to retrofit expensive pollution controls to an existing gas-fired unit, if that unit's operation would be sharply reduced as a result of adding batteries. These benefits could be worth up to about $\$ 20 / \mathrm{kW}$ of battery capacity per year.

\section{Transmission and Distribution Benefits}

This project identified the potential role battery storage could play in providing equal or better performance than other T\&D options, such as adding new T\&D facilities and equipment. Current SDG\&E T\&D facility expansion study results and transmission and distribution system design practices were reviewed with SDG\&E personnel to identify anticipated and potentially needed transmission additions. 
The findings of this initial study indicate that strategically installing battery storage on the SDG\&E system may result in large $T \& D$ system benefits up to $\$ 1,200 / \mathrm{kW}$, equivalent to as much as $\$ 200 / \mathrm{kW}$ of battery capacity per year. The actual magnitude of the site specific T\&D benefits and corresponding battery storage requirements should be determined on a case-bycusc basis from more detailed analysis. Further analysis should include the development of load profiles for subsiations tixat are candidate battery sites so that the number of hours of storage required for equipment deferral can be determined.

\section{Cost/Benefit Analysis}

Table 3 summarizes the findings. Summing the capacity, generation, environmental, and T\&D benefits yields levelized current-dollar savings of $\$ 100$ to $\$ 370 / \mathrm{kW}-\mathrm{yr}$, compared to a levelized current-dollar cost of $\$ 60$ to $\$ 130 / \mathrm{kW}$-yr. These values suggest that batteries would be a cost-effective addition to the SDG\&E system.

Some benefits may be mutually exclusive. The interactions between the various benefits, that is, whether they are additive or mutually exclusive, depends on storage size, location, system load shapes, and load shapes at individual substations and on individual T\&D lines, how the system (including the battery) is operated, and on any equipment deferred as a result of adding batteries.

\section{Recommendations}

Based on the results of this screening-level study, it is recommended that SDG\&E consider the addition of battery storage to its system. A detailed study to verify the findings of this initial screening study and to calculate the benefits more precisely is recommended. Such a study should include the following aspects:
- More detailed calculations of generation-dynamic operating costs and benefits should be carried out, including examination of multiple weeks of system operation during the course of the year and consideration of how system operation, and especially the operation of marginal units, is likely to change in the future.

- Detailed T\&D expansion studies should be carried out, with and without batteries. Potential sites for installing batteries should be identified. Interactions among the various benefits should be considered to ensure that batteries are not being justified on the basis of benefits that may be mutually exclusive.

- Comparative evaluation of the economics of battery storage with other capacity additions under consideration by SDG\&E should be carried out.

Such detailed study would also allow a better assessment of the "optimum" battery size and the best time for adding the battery plant to the SDG\&E system.

\section{Oglethorpe Power Corporation}

Power Technologies, Inc. - H. K. Clark

The methodology for the OPC study consisted of evaluating and quantifying the reasonable benefits attainable from the battery storage application and comparing the total benefits against the cost of the battery storage system. Several benefits and the particular characteristics of the OPC system were reviewed and analyzed including:

- load profile with and without direct load control,

- Future generation expansion plan,

Table 3. Benefits Summary for SDG\&E System

\begin{tabular}{lc}
\multicolumn{1}{c}{ Category } & Annual Benefit $(\$ / \mathrm{kW}-\mathrm{yr})$ \\
\hline - Capacity & $40-75$ \\
$\quad$ Generation & 0 \\
$\quad$ Load-Leveling & $50-75$ \\
Dynamic Operating & $10-200$ \\
- $\& D$ & $\frac{1-20}{101-370}$ \\
Environmental &
\end{tabular}


- Role of pumped hydro storage and its impact on load leveling,

- Cost of purchased power and energy,

- Future transmission projects,

- Future distribution projects,

- Radial transmission lines/substations,

- $\quad$ Need for backup power source.

Five specific substation locations within the OPC system for battery storage to defer T\&D projects were selected for this study: Habersham (H), Egypt (E), Satilla (S), Vidalia (V), Warrenton (W). The battery sizes used for these five locations are shown in Table 4.

The results of a benefit-to-cost comparison are presented in Figure 2. The methodology used for benefitto-cost comparison is essentially based on calculating the present worth of all the annual cost savings/ benefits accruing due to the battery and the annual cost of owning and operating the corresponding battery plant.

Only four major benefits due to battery storage are included in these benefits-to-cost ratios. They are:
- Generation capacity,

- Transmission deferment,

- Distribution deferment,

- Value of service or cost of outage.

The battery storage application identified in this study is mostly in the form of a backup or reserve source. It is not used in the general sense of load leveling. A generation capacity (kW) credit based on a 10-hr discharge rating is applicable. This battery $\mathrm{kW}$ (based on 10-hr discharge rating) is essentially a generation reserve source. A 10-hr discharge rating is used so that even if this reserve is called upon during the annual peak load condition, the battery will be able to provide the power $(\mathrm{kW})$ equal to the credit it has received for the longest peak load period of $10 \mathrm{hr}$. Thus, for example, a $10-\mathrm{MW}, 1$-hr battery is given a credit of $1 \mathrm{MW}$. The cost of the battery credit is based on the least expensive generation alternative, which is a combustion turbine. The annual cost savings from avoiding the investment in this generation is credited to the battery.

The transmission credit is computed on the basis of the cost of deferring T\&D projects. The actual capital

\section{Table 4. Selected Battery Sizes}

\begin{tabular}{|c|c|c|c|c|c|}
\hline & \multicolumn{5}{|c|}{ OPC Substation Locations (designated by letter code) } \\
\hline & $\mathrm{H}$ & E & s & $V$ & W \\
\hline MWh & 7.5 & 26.0 & 9.0 & 217.0 & 218.0 \\
\hline iNW & 1.5 & 6.5 & 1.5 & 31.0 & 43.6 \\
\hline $\mathrm{hr}$ & 5 & 4 & 6 & 7 & 5 \\
\hline
\end{tabular}

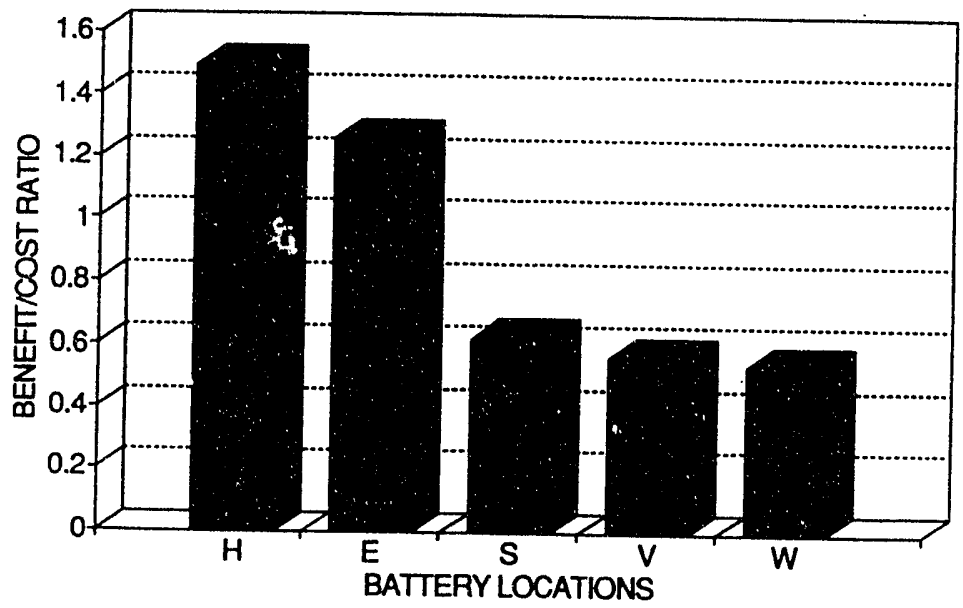

Figure 2. Comparison of Benefits to Cost for Five Battery Locations. 
cost expenditure is considered to be postponed by a number of years. The annual cost savings due to the postponement is credited to the battery benefits. The distribution benefits are also calculated similarly.

The fourth and last benefit computed in this study is the value of service or cost of outages. The interruption cost, or value of service (VOS) data, is considered to be suitable to relate the worth of service reliability to the cost of service. The VOS or outage costs depend upon type of load, frequency and duration of interruption, and timing of the interruption. However, some of these costs have a wide range. The cost range for 1 -hr interruption has been reported in the literature.

The actual cost or VOS used in this study is shown in Table 5. For each of the five types of battery applications analyzed in this study, it is assumed that the total amount of energy not served or $\mathrm{kWh}$ interrupted per year is equal to the total battery $\mathrm{kWh}$ rating. This means that, on the average, the sum of energy supplied to the customers by the battery during the interruptions over a period of 1 yr is equal to its total energy rating.

After computing benefits, the battery storage system costs were calculated. For the battery alone, a dif- ferent life is used ihan for the entire battery storage plant. The operating and maintenance (O\&M) cost used is $0.25 \%$ of the capital cost. Amortizing the capital cost is levelized over the plant life. The salvage value of the battery is included in computing the levelized anuual cost. The replacement cost of battery cells is inclucied as needed. The converter and balance of plant (BOP) are assumed to have a 30 -yr life and no salvage value,

The benefit-to-cost ratio for batteries application at five different locations for T\&D deferment was coniputed. The percentage benefit of the four applications is shown in Figure 3.

- Backup source (considering cost of outage. VOS, or value of unserved energy) credit was the most significant benefit from battery storage. In terms of customer loads on the OPC/electric membership corporation (EMC) system, the poultry industry loads are considered to suffer high damage when service interruption occurs. Hence, some of these egg hatcheries and chicken farms currently provide, or plan to install, backup diesel generation. Application of a 7,500-kWh, 5-hr discharge rating battery at Hollywood substation showed a

\section{Table 5. VOS or Outage Cost for 1-hr Interruption}

\begin{tabular}{llr} 
& \multicolumn{2}{c}{$\$ / \mathrm{kWh}$ Not Served } \\
\cline { 2 - 3 } & Low & High \\
\cline { 2 - 3 } Residential & 0.05 & 5.00 \\
Industrial & 2.00 & 53.00 \\
Commercial & 2.00 & 35.00 \\
Poultry and Eggs & 0.12 & 5.68 \\
\hline
\end{tabular}

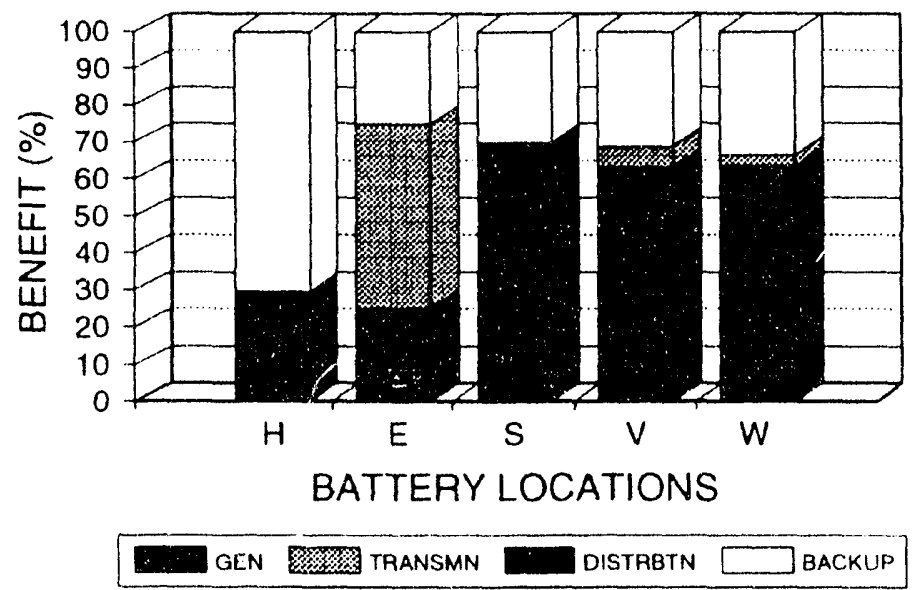

Figure 3. Percent of Benefits for Five Battery Locations. 
benefit-to-cost ratio of 1.5. This was one of the highest benefit-to-cost ratios obtained in this study.

- Whenever there is an outage on a radial line, an interruption of service occurs. If the line is inaccessible or has difficult terrain, repair of the line may be difficult and the corresponding outage may be lengthy. One such example selected for this study was application of a battery for backup instead of building a second transmission line. The benefit-to-cost ratio is 1.26 for this case. This substation is an attractive location (out of the five analyz. -1 ) for the battery and deferment of a second transmission line.

- A third substation was selected for evaluating the deferment of a new distribution trans. former. The bencfit-to-cost ratio turned out to be 0.62 The generation capacity credit was the largest, follc wed by the backup source credit, with distribution credit being the least. No transmission deferment was used in this example. A iligher backup source credit in lieu of a new transmission line credit may be warranted here. The VOS has to be $\$ 8.00 / \mathrm{kWr}$ for breakeven of benefit-to-cost ratio as ce npared to $\$ 2.61 / \mathrm{kWh}$ (used in the base case for the ratio of 0.62).

- Deferment of an additional 140-MVA, 220/115-kV transformer at two substations was evaluated. The benefit-to-cost ratios were 0.57 and 0.54, respectively. Because of parallel $230-\mathrm{kV}$ and $115-\mathrm{kV}$ lines contained by these substations, oversize battery storage capacity was needed to provide a given load reduction on the existing transformers. Hence, the battery and its cost would be about twice that required to reduce load on a radially connectied transformer, in which case the benefit-io-r ost would be nearly break-even.

In addition to base cases, several sensitivity analyses were performed for the highest benefit-to-cosi application. The sensitivity analysis included changing the following parameters, one at a time:

- Battery cost,

- Converter and BOP cost,

- Battery life,

- Salvage value,

- Value of service/cost of outages,
- Extended distribution benefits.

In the first case, the battery's cost can be $60 \%$ higher than the base case for the value of benefits to equal the cost of battery storage. In the second case, the PCS and BOP cost was doubled, and this reduced the balance-to-cost ratio from 1.49 to 1.27 . These two sensitivity cases show that the battery cost has a higher effect on the overall cost as compared to the converter and other costs.

In the third case, the battery life was reduced to 10 yr from $15 \mathrm{yr}$. This means two battery replacements are included in this case as compared to only one battery replacement in the base case. The benefit-to-cost ratio decreased from 1.49 to 1.42 , which is not a substantial reduction. Thus, there may be economic advantages in improving the cycle life of lead-acid batteries, but the chronological life is not significant as compared to the battery cost itself.

In the fourin case, the salvage value was doubled from $20 \%$. Surprisingly, the benefit-to-cost ratio increased to 1.68 . This may be parlly explained by the escalation used in computing replacement battery cost. Essentially, the salvage part of the battery cost is escalated by $4.5 \%$ because at the end of battery life, the trade-in value of the battery is assumed to be equal to the salvage percentage of the new battery cost.

The fifth sensitivity case involved the value of service or backup source credit. As noted earlier, this item contributed most to the battery benefits. This VOS may be about $50 \%$ of the base case for the break-even cost.

In the sixth sensitivity case, the distribution benefits were extended to $30 \mathrm{yr}$. The base case showed the distribution transformer deferment for 10 yr only. Because the battery can be moved to another location, similar distribution benefits may continue to acrue. This case shows an increased benefit-to-cost ratio of 1.58 . The cost of moving the battery and any change in value of service are not recognized in this case.

\section{Recommendations}

Battery energy storage at substations with radial feeds and/or serving critical customer loads may have positive benefits for OPC. OPC has approximately 24 such sites that could be candidates for further, more detailed analysis to determine the benefits of battery energy storage at these sites. A follow-on feasibility study that includes the conceptual design of site-specific battery system(s) and further refines the value of the benefits at each site was recommended to OPC. 


\section{Bonnevile Power Administration Puget Sound Area}

Power Technologies, Inc. - H. K. Clark

In 1989, planning studies at BPA revealed that major additions to the existing transmission system across the rascade Range might be required in the mid-nineties. The studies indicated that 1,600 MW of expected growth in the Puget Sound area peak load between 1993 and 2003 would result in voltage stability problems on the highly stressed $500-\mathrm{kV}$ system across the Cascades.

BPA engineers identified 10 possible solutions to the problems. These included a new double-circuit 500 $\mathrm{kV}$ line across the Cascades, and up to $600 \mathrm{MW}$ of combustion tutbine (CT) capacity in the Puget Sound area. Some partial solutions included water heater fuel switching, time-of-use rates, water heater controls, lowflow shower heads, conservation, curtailment, and voltage support equipment.

SNL initiated this battery application study to determine if battery energy storage could compete with the options being considered by BPA, especially if it could defer a 500-kV transmission line or displace C'T capacity.

\section{Combustion Turbine Displacement}

The daily winter load profile in the Northwest helps make battery energy storage attractive. The load profile from two days of particular concern to BPA are shown in Figure 4. The February 3, 1989, peak is the more difficult one for a battery because it is relatively flat. However, even on this day, the peak could be reduced $200 \mathrm{MW}$ by a battery with just $1.35 \mathrm{hr}$ of storage. A 400-MW peak reduction would require $2.2 \mathrm{hr}$ of storage.

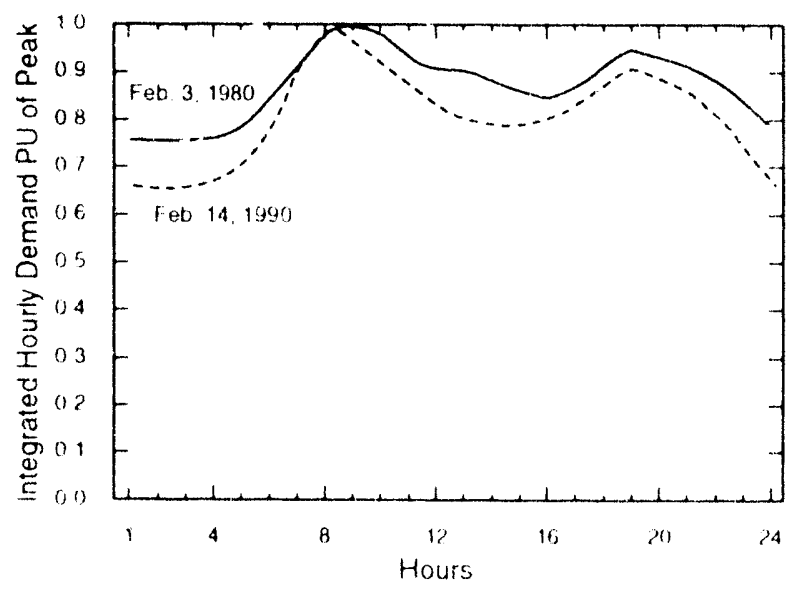

Figure 4. Load Shapes for High-Load Days of Concern to BPA.
One of the problems with the use of CTs to address the Puget Sound voltage problem is that they cannot be started quickly enough to prevent voltage instability following loss of a major $500-\mathrm{kV}$ line. Hence, they must be running when load is high. This adds significantly to the cost of the CT option. Batteries can be switched on and brought to full power in seconds.

A benefit of CTs is that they "firm up" BPA energy commitments. That is, they allow BPA to commit to firm energy deliveries that can be served largely from hydro plants. Should water shortages occur, the CTs can be used to meet those obligations.

Based on recent SNL estimates of battery and converter costs and the instant on-off capability of batteries, batteries could provide the needed peak shaving at less cost than CTs. However, batteries cannot firm up hydro energy sales as can CTs, and thus cannot compete with this significant CT benefit.

\section{Cross-Cascades 500-kV Line Deferral}

'The 500-kV line across the Cascades was the second target of the battery application study. However, continuing $13 \mathrm{PA}$ studies revealed an opportunity to substantially boost the capacity of the existing 500-kV system by adding one $500-k V$ substation, a 20 -mile section of $500-\mathrm{kV}$ line, several large shunt capacitor banks, and Iwo static var compensators. These additions, combined with conservation and load management, have deferred the need for combustion turbines and the new cross-Cascades $500-\mathrm{kV}$ line indefinitely. Further, the cost of thesc options is less than $30 \%$ of the cost of the line. Further study of this option and its cost was deferred because BPA had already commited to the construction of this project.

\section{Local Benefits of Battery Energy Storage}

Batteries need not be located in high-voltage substations to provide transmission benefits. Battery energy storage can be more attractive if it is divided into small units and placed close to customer loads to reap further benefits. The potential for this in the Northwest was assessed through discussions with utilities served by I3PA in the Puget Sound area. Interesting applications in which batteries might relieve the cross-Cascades transmission problem and provide local benefits are as follows:

- Breing Wind Tunnel - At the time of the study Boeing was planning a $300-\mathrm{MW}$ wind tunnel in the Puget Sound area. The facility would require power rising at $150 \mathrm{MW} / \mathrm{min}$ during 
start-up and decaying at $150 \mathrm{MW} / \mathrm{min}$ during shutdown. However, utilities in the Northwest limit customer load variations to $50-\mathrm{MW} / \mathrm{min}$. A battery could be discharged during wind tunnel start-up and charged during shutdown as shown in Figure 5 to reduce load changes to $50-\mathrm{MW} / \mathrm{min}$. A $5-\mathrm{min}$ battery would suffice, though cell life may dictate a somewhat larger battery. The converter rating would be about $125 \mathrm{MW}$.

- Aluminum Plants - BPA serves two aluminum plants through the Seattle City Light (SCL) system. Batteries at the aluminum plants could reduce the risk of very costly aluminum cell freeze-up during power outages. A $30-\mathrm{min}$ battery would prevent freeze-up. The MW level necessary to prevent freeze-up was not determined.

- Distribution Feeder Thermal Limits - SCL designs $26-\mathrm{kV}$ feeders for a $600-\mathrm{A}$ maximum capacity (27 MW) and routes them to carry 300 A during winter cold snaps. Each feeder can thus provide backup to one other feeder. How ever, in one area, feeders and their associated substation are reaching full capacity, and the load continues to grow. One battery, centrally located, could serve a number of feeders. The necessary battery $\mathrm{MW}$ rating and storage time were not determined (depends on load profile).

- Fuel Cells - SCL is looking at fuel cells as a possible long-term solution to the increasing load density in the city. Because fuel cells are dc devices, they might share a power converter with a battery. This would reduce battery energy storage cost, and allow energy from the

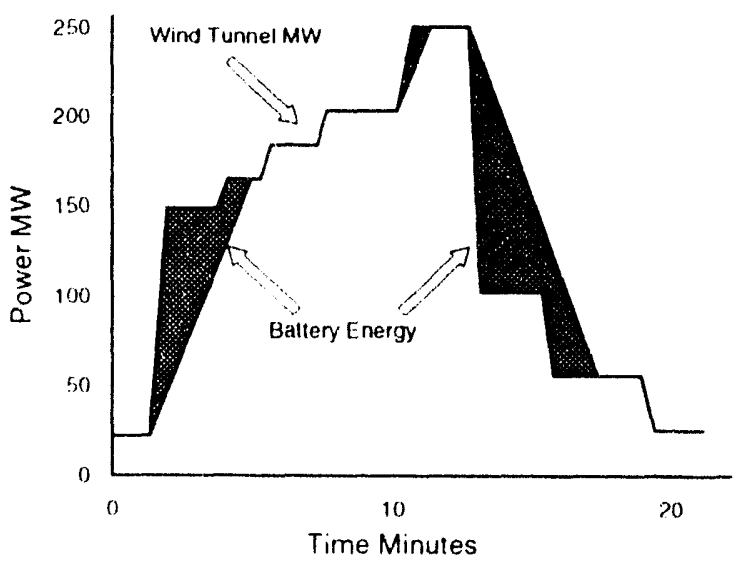

Figure 5. Typical Wind Tunnet Load Profile and Battery Energy Required to Limit Load Changes to 50 MW/min. fuel cell to be stored at night when the system load is low.

- Big Six Customers - Some of SCL's large customers have highly variable loads and thus are subject to demand charges to cover the extra generation and transmission equipment associated with such loads. Batteries could smooth out this load. Sizes were not determined.

- Tacoma Public Utilities - Load is largely commercial and residential; however, an industrial pocket in the tide flats includes Occidental Petroleum (90 MW), Penwalt (60 MW), and others. As much as $400 \mathrm{MW}$ of cogeneration may be developed in the tide flats area, along with $250 \mathrm{MW}$ in the Fredrichsen area. Voltage regulation is an increasing problem in the area, but may be solved by cogeneration. Batteries may provide reliability, load smoothing, and voltage regulation benefits in this area.

- Whidbey Island - The island load is largely residential and is growing. It is fed by two $115-\mathrm{kV}$ lines at the north tip. The $115-\mathrm{kV}$ lines are long and subject to occasional failure. A 28-MW diesel-driven generator is run to regulate voltage when one line is out and supply some of the island load when both lines are out. Rotating blackouts are used to share the diesel among all customers. The diesel cannot be fully loaded because of feeder "cold load pickup." A 230-kV line extending onto Whidbey Island will help after 1995, but reliability will still be low by Puget Power standards. The best solution, a cable tie between Whidbey Island and the Seattle area, would cost about $\$ 10$ million. A battery could supply the 10- to 20$\mathrm{min}$ "cold load" portion of the last feeders to be picked up, thus increasing the load the diesel can serve. It could then smooth the load to further increase diesel loading. A 5- to 10-MW 1 -hr battery would be needed.

- Power Plant Black Start - Puget Power has some power plants that could be restarted more rapidly after a blackout if a nearby source of power were available.

\section{Generation Benefits of Battery Energy Storage in the Northwest}

Discussions were also held with BPA and Puget Sound area utilities to identify generation benefits of battery energy storage. All of the utilities have hydro plants that provide highly flexible scheduling to maxi- 
mize economy and impose few generation constraints on operation.

\section{Conclusions}

There are limited opportunities at present for battery energy storage plants to capture large benefits in the Puget Sound area by deferring major transmission and CT investment because less costly alternatives have been identified. Also, the usual generation benefits of energy storage are not available in the Northwest.

Battery energy storage may, however, still have a place in the study area at the subtransmission and distribution level. It could be attractive by providing distribution system benefits and displacing some of the more costly alternatives that will be used to defer major transmission and $C_{i}^{m}$ investment.
Battery energy storage may also provide a hedge against failure of some of the less well-proven alternatives to major transmission and CT investment. For instance, if conservation, fuel switching, or load management do not limit peak load growth as expected, batteries could be installed quickly and on short notice to serve peak load.

Evaluating the cost-effect iveness of battery energy storage in an environment where there are no large benefits is difficult. It requires careful scrutiny of the many possible beneifts that can be derived from battery attributes (see Table 6). This, in turn, requires close cooperation of all persons or organizations that may recognize a benefit from the installation. In the Puget Sound area, this would include at least several departments within BPA, several from one of BPA's client utilities, and, perhaps, one or more from an industrial customer.

Table 6. Battery Attributes

\author{
No-Cost Start/Stop \\ Fast Response (kW and kvar) \\ Four-Quadrant Operation (simultaneous \\ $\mathrm{kW}$ and kvar) \\ Unmanned (Remote Control) \\ High Reliability/Availability \\ Low Maintenance \\ Short Lead-Time Installation \\ Low Environmental Impact (Siting Flexibility) \\ Limited Space Requirement (Siting Flexibility)
}


Appendix A

Potential Benefits of

Battery Storage to Chugach Electric 


\title{
POTENTIAL BENEFITS OF BATTERY STORAGE TO CHUGACH ELECTRIC -A Screening Study-
}

\author{
Prepared for:
}

Sandia National Laboratories

and

Chugach Electric Association, Inc.

Prepared by:

Anders R. Gjerde

Stephen M. Haas

Salim J. Jabbour

DECIS I O N

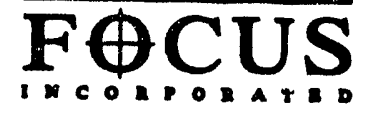

4984 El Camino Real

Los Altos, California 94022

(415) $960-3450$

and

John Doudna

T. I. Leksan

Power Technologies, Inc.

April 1992 


\section{TABLE OF CONTENTS}

Section $\quad \underline{\text { Page }}$

EXECUTIVE SUMMARY S-1

1 INTRODUCTION

Benefits of Battery Energy Storage $1-1$

Lead-Acid Battery Technology $1-2$

Battery Attributes 1-3

Chugach Electric Association Situation 1-11

Overview of This Report $1-12$

2 POTENTIAL GENERATION BENEFTTS

Calculating Generation Benefits of Energy Storage 2-1

Capturing Generation Benefits of Energy Storage 2-4

Study Approach $2-9$

Study Results $\quad 2-10$

3 SPINNING RESERVE/LOAD SHEDDING BENEFITS

Introduction 3-1

Conclusion 3-3

Study Conditions $\quad 3-4$

Spinning Reserve Requirements 3-5

Discussion 3-5

4 T\&D BENEFITS

Huffman Substation 4-1

Hillside Substation $\quad$ 4-2

Girdwood, Indian, and Portage Substations 4-2

Hope 4-3

5 COST/BENEFIT ANALYSIS

Battery Capital Costs $\quad 5-1$

Capacity Value of Battery $5-2$

Comparing Benefits to Costs $\quad 5-2$ 


\section{TABLE OF CONTENTS (Continued)}

$\underline{\text { section }}$

Page

6 CONCLUSIONS AND RECOMMENDATIONS

Generation Benefits

6-1

Reduced Load Shedding Benefits

$6-2$

Transmission and Distribution Benefits

Cost/Benefit Analysis

$6-2$

Recommendations

6-3

Appendix A DAILY CEA SYSTEM LOAD SHAPES AND MARGINAL GENERATION COSTS

A-1

Appendix B GENERATION SCHEDULES FOR STABILITY ANALYSIS SCENARIOS

B-1

Appendix C STABILITY ANALYSIS: SCENARIO 1

C-1

Appendix D STABILITY ANALYSIS: SCENARIO 2

D-1

Appendix E STABILITY ANALYSIS: SCENARIO 3

E-1

Appendix F STABILITY ANALYSIS: SCENARIO 4

F-1

Appendix G STABILITY ANALYSIS: SUMMER LOAD CASE

G-1 


\section{LIST OF ILLUSTRATIONS}

Figure

Page

1-1 Battery Energy Storage System

1-3

1-2 Real and Reactive Operating Range of Battery

$1-7$

2-1 System and Unit Costs

2-3

2-2 Load Following Costs and Minimum Load Costs

$2-4$

2-3 System Marginal Energy Costs

2-5

2-4 Power Output of Unit A

2-5

2-5

Daily Load for Beluga 1 Combustion Turbine Unit

2-12

2-6

Daily Load for Beluga 2 Combustion Turbine Unit

2-13

$2-7$

Daily Load for Bernice 4 Combustion Turbine Unit

2-13

2-8 Net Operating Benefits in 1994

2-9 Net Operating Benefits in 1996

2-14

2-10 Net Operating Benefits in 2000

2-14

A-1 Native Daily Load Shapes-Winter 1994

2-15

A-2

Native Daily Load Shapes-Summer 1994

A-2

A-3

Native Daily Load Shapes-Fall 1994

A-2

A-4 Native Daily Load Shapes-Winter 1996

A-3

A-5

Native Daily Load Shapes-Summer 1996

A-3

A-6 Native Daily Load Shapes-Spring/Fall 1996

A-4

A-7 Native Daily Load Shapes-Winter 2000

A-4

A-8 Native Daily Load Shapes-Summer 2000

A-5

A-9 Native Daily Load Shapes-Spring/Fall 2000

A-5

A-10 System Marginal Cost-Winter 1994

A-6

A-11

System Marginal Cost-Summer 1994

A-6

A-12

A-13

System Marginal Cost-Spring/Fall 1994

A-7

System Marginal Cost-Winter 1996

A-7

A-14 System Marginal Cost-Summer 1996

A-8

A-15

System Marginal Cost-Spring/Fall 1996

A-8

A-16

System Marginal Cost-Winter 2000

A-9

A-17

System Marginal Cost-Summer 2000

A-9

A-18

System Marginal Cost-Spring/Fall 2000

A-10

A-10 


\section{LIST OF TABLES}

Table

Page

1-1 Lead-Acid Battery Cost and Performance Data 1-4

1-2 Cost of Reactive Power 1-9

1-3 CEA Generating Capacity 1-12

2-1 Operating Characteristics of Generation Unit A 2-6

2-2 Using a Battery to Provide Spinning Reserve 2-8

2-3 CEA Generating Unit Characteristics 2-10

2-4 Summary of Generation Benefits-Net Operating Savings 2-11

3-1 Summary of CEA Load Shedding Analysis 3-2

3-2 Loadshedding Responses for Scenario 2 - Amount of Load Shed in Each Utility $\quad 3-7$

3-3 Loadshedding Responses for Scenario 3 with the AMLP

Units Tripped - Amount of Load Shed in Each Utility

3-8

3-4 Loadshedding Responses for Scenario 4 - Amount of Load Shed in Each Utility (MW)

3-5 Loadshedding Responses for Scenarios 5, 6, and 7 Amount of Load Shed in Each Utility (MW) in Addition to Load Shed in Lieu of Spin

5-1 Benefits Summary for CEA System 


\section{EXECUTIVE SUMMARY}

This report describes the results of a screening study to determine the benefits of ad ling megawatt-scale battery energy storage to the Chugach Electric Association (CEA) system. The report addresses generation, transmission, and distribution benefits of storage, with a primary focus on benefits that are typically difficult to quantify. The report also compares the potential benefits to the costs of adding battery storage.

\section{BENEFITS OF BATTERY ENERGY STORAGE}

The addition of a storage unit to a utility system can provide a wide range of benefits that depend on the characteristics of the individual utility, the manner in which the storage unit is operated, and its siting within the utility network as well. Generation load-leveling has long been advocated as the primary reason for adding storage to a utility's generating mix. The most obvious benefit and the easiest to quantify, load-leveling results in the replacement of expensive peak power with cheaper power from base-load plants, increasing the capacity factor of the baseload plants during off-peak periods to displace the use of premium oil/gas fuels during on-peak periods. In the past several years, generation dynamic operating benefits (DOBs) have also been recognized as significant benefits of storage plants. The types of benefits include those accruing from the provision of spinning reserve, reduced minimum loading, and fast response rates. These benefits are overlooked in conventional methods. Another commonly recognized benefit from storage in general, and batteries in particular, is reduction in transmission and distribution (T\&D) costs. T\&D benefits are due in part to the siting flexibility and in part to the rapid response times for batteries. T\&D benefits include deferral of T\&D investment, reduced losses, and voltage regulation, as well as others.

\section{CEA FINDINGS}

\section{Generation Benefits}

Generation benefits were calculated for six representative days in each of 1994, 1996, and 2000. Projected system operation was based on MAINPLAN runs. The benefits were calculated for five gas-fired combustion turbine units whose operation is most likely to be affected by the addition of batteries to the system. The focus was on using batteries to provide spinning reserve.

Load-Leveling. Because the marginal units on the CEA system are typically gas-fired combustion turbines for all hours (usually the Beluga and Bernice Lake units), the system marginal energy costs do not differ much between on-peak and off-peak hours. Coupled with the assumed battery efficiency of around 80 percent, this means that no load-leveling savings could be achieved on the CEA system. 
Dynamic Operating. For each of the 18 days the potential reduction in load following, minimum loading, and startup costs was calculated for each of the five units; reductions in these costs are achievable even though the battery is used only to provide spinning reserve. The most cost-effective unit for decommitment was identified on each day. A value of $\$ 40$ to $\$ 70$ per $\mathrm{kW}$ year of battery capacity, levelized in current dollars, appears appropriate for dynamic operating benefits. Of this total, more than two-thirds is from reduced minimum loading costs, and the remainder is from reduced load following costs..

\section{Reduced Load Shedding}

Addition of battery storage to the CEA system would be effective in reducing load shedding. The amount of the reduction would depend on the size of the battery. A very approximate calculation indicates that the value of the reduced load shedding could be $\$ 8$ to $\$ 16$ per $\mathrm{kW}$ of battery capacity per year.

\section{Transmission and Distribution Benefits}

Current CEA transmission and distribution facility expansion plans were reviewed to identify T\&D investments that might be avoided or deferred as a result of adding battery storage to the CEA system. Several such investments were identified. Based on a qualitative review of these investments and comparison with more detailed analyses for other utilities, potential T\&D benefits of $\$ 20$ to $\$ 200$ per $\mathrm{kW}$ of battery capacity appear reasonable. This is equivalent to a T\&D benefit of $\$ 3$ to $\$ 27$ per $\mathrm{kW}$ of battery capacity per year.

\section{COST/BENEFIT ANALYSIS}

Table S-1 summarizes the findings. Summing the capacity, generation, reduced load shedding, and T\&D benefits yields levelized current-dollar savings of $\$ 81$ to $\$ 183 / \mathrm{kW}$-year, compared to a levelized current-dollar cost of $\$ 50$ to $\$ 60 / \mathrm{kW}$-year. ${ }^{1}$ These values suggest that batteries would be a cost-effective addition to the CEA system.

Some benefits may be mutually exclusive. The interactions between the various benefits, i.e., whether they are additive or mutually exclusive, depends on storage size, location, system load shapes, load shapes at individual substations and on individual transmission and distribution lines, how the system (including the battery) is operated, and on any equipment deferred as a result of adding batteries.

1. For the purposes of this study, the cost estimates used are from EPRI's Technical Assessment Guide (TAG, 1989). The total cost is $\$ 703 / \mathrm{kW}$ for a 3-hour battery, including land cost. Reducing the storage component in the TAG cost estimates for a 3 -hour battery by two thirds yields an estimated cost of $\$ 350 / \mathrm{kW}$ for a 1 -hour battery. With a levelized fixed charge rate of 13.7 percent, this is equivalent to $\$ 50$ to $\$ 60 / \mathrm{kW}$-year for a 1-hour battery. While these estimates are acceptable at this stage, actual system cost information from the Puerto Rico Electric Power Authority $20 \mathrm{MW}$ battery project are discussed in the subsection of Section 1 titled "The PREPA 20 MW Battery Project." 
Table S-1

BENEFITS SUMMARY FOR CEA SYSTEM

\begin{tabular}{lc}
\hline \multicolumn{1}{c}{ Category } & Annual Benefit (\$NW-yoar) \\
\hline Capacity & $30-70$ \\
$\begin{array}{l}\text { Generation } \\
\text { Load Leveling } \\
\text { Dynamic Operating }\end{array}$ & 0 \\
Reduced Load Shedding & $40-70$ \\
T\&D & $8-16$ \\
TOTAL & $3-27$ \\
\end{tabular}

\section{RECOMMENDATIONS}

Based on the results of this screening-level study, it is recommended that CEA seriously consider the addition of battery storage to its system. A detailed study to verify the findings of this initial screening study and to calculate the benefits more precisely is recommended. Such a study should include the following aspects:

1. More detailed calculation of generation dynamic operating costs and benefits should be carried out, including examination of multiple weeks of system operation during each of a larger number of years than was considered here. Such calculation should fully account for changes in system operatior, as load grows, and should identify all possible operation savings, not only those that arise when a unit is completely decommitted.

2. Detailed T\&D expansion studies should be carried out, with and without batteries. Potential sites for installing batteries should be identified. Interactions among the various benefits should be considered to ensure that batteries are not being justified on the basis of benefits that may be mutually exclusive.

3. Comparative evaluation of the economics of battery storage with other capacity additions under consideration by CEA should be carried out. Such detailed study would also allow a better assessment of the "optimum" battery size and the best time for adding the battery plant to the CEA system. 


\section{INTRODUCTION}

This report describes the results of a screening study to determine the benefits of adding megawatt-scale battery energy storage to the Chugach Electric Association (CEA) system. The report addresses generation, transmission, and distribution benefits of battery energy storage, with a primary focus on benefits that are typically difficult to quantify. The potential benefits are compared to the costs of adding battery storage to determine the cost-effectiveness of adding battery energy storage to the CEA system.

\section{BENEFITS OF BATTERY ENERGY STORAGE}

The addition of battery energy storage to a utility system can provide a wide range of benefits that depend on the characteristics of the individual utility, the manner in which the battery storage unit is operated, and its siting within the utility network as well. Generation load-leveling has long been advocated as the primary reason for adding storage to a utility's generating mix. The most obvious benefit and the easiest to quantify, load-leveling results in the replacement of expensive peak power with cheaper power from base-load plants, increasing the capacity factor of the base-load plants during off-peak periods to displace the use of premium oil/gas fuels during on-peak periods.

In the past several years, generation dynamic operating benefits (DOBs) have also been recognized as significant benefits of battery energy storage plants. The types of benefits include those accruing from the provision of spinning reserve, reduced minimum loading, and fast response rates. An EPRI report ${ }^{1}$ provides compelling evidence on the importance of dynamic operating considerations. The three major conclusions of the EPRI report are as follows:

- A large portion of the operating costs of cycling power plants results from fluctuating electric loads. These costs are called dynamic operating costs.

- Technologies that offer operating flexibility at minimal costs (e.g., energy storage power plants) provide power systems with significant operating cost savings. These savings are called dynamic operating benefits.

1. Dynamic Operating Benefits of Energy Storage, EPRI AP-4875. 
- A large fraction (up to two-thirds) of the savings provided by technologies with significani operating flexibility are overlooked in conventional methods.

Another commonly recognized benefit from storage in general, and batteries in particular, is reduction in transmission and distribution (T\&D) costs. T\&D benefits are due in part to the siting flexibility and in part to the rapid response times for batteries. T\&D benefits include deferral of T\&D investment, reduced losses, and voltage regulation, as well as others. ${ }^{2}$

Another category of benefits is what might be termed strategic benefits, those that relate primarily to the changing environment in which utilities operate. This includes reducti $n$ in environmental emissions, greater ability to transact power with other utilities and with nonutility generators, and greater flexibility in general.

This study quantifies the benefits of battery storage in the first two categories-generation and T\&D-for the Chugach Electric Association system. It then compares these benefits to the costs of aduing lead-acici battery storage.

\section{LEAD-ACID BATTERY TECHNOLOGY3}

The najor elements of a lead-acid battery energy storage plant are the battery, the converter, and the balance of the plant. During charging, alternating current electricity is converted to direct current electricity by the converter and stored electrochemically by the battery. Durnng discharge, direct current electricity is drawn from the battery and converted to alternating current electricity for use on the utility grid. Figure 1-1 is a schematic of a battery energy storage system.

Utility battery stornge systems consist of commercially available lead-acid cells similar to those used in subntarines or large telephone switching installations. A typical cell size is 5 to $10 \mathrm{kWh}$. Many cells are combined in a battery unit, with typical storage times of 1 to 5 hours and power capacities of 2 to 100 megawatts. For example, the 4-hour capacity lead-acid battery storage plant at Southern California Edison Company's Chino substation has a capacity of 10 MW; the battery consists of 8,256 cells, each measuring approximately $16 \mathrm{in}$. $(41 \mathrm{~cm})$ long, 14.5 in. $(37 \mathrm{~cm})$ wide, and 25 in. $(65 \mathrm{~cm})$ high, and weighing about $585 \mathrm{lb}$. $(266 \mathrm{~kg})$. The cells are supported on steel frames in groups of 6 to form $12-\mathrm{V}$ modules. The battery is connected to the SCE system at $13.8 \mathrm{kV}$.

2. Potential Economic Benefits of Battery Storage to Electrical Transmission and Distributior jystems, EPRI GS-6687.

3. Research is under way on a number of advanced battery systems, including sodium sulfur, zinc bromine, and others. In this report, however, we focus on and use costs for the one technology that is conimercially available now: lead-acid batteries. 


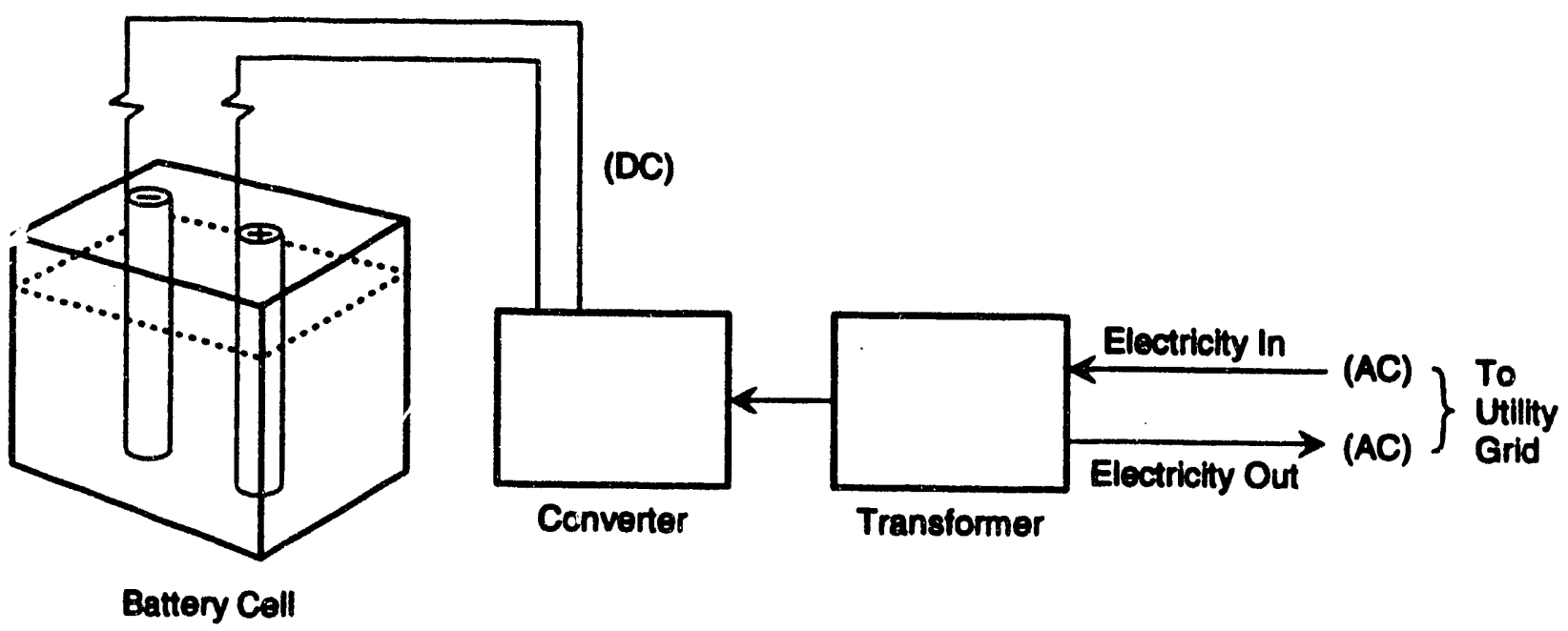

Figure 1-1. Battery Energy Storage System

The AC-DC converter consists of electronic equipment similar to that used in large uninterruptible power supply (UPS) systems, and in wind, photovoltaic, and fuel cell power ganeration systems. The balance of the plant consists of the structural, mechanical, electrical, control, and safety subsystems required to perform system integration and interface of the battery to the utility system.

Battery energy storage plants are truly modular and can be installed quickly, enabling them to match load growth much more easily and accurately than larger, custom-built, sitespecific plants. Construction time for a lead-acid battery plant is less than one year. Batteries are compact, quiet and non-polluting, so they can be sited near population centers. They can operate efficiently over a wide range of loads, and are actually more efficient at part load than at full load. They can also respond to load changes in just 20 milliseconds.

Table 1-1 provides cost and performance data for battery storage sizes of 3 and 5 hours, installed at a $20 \mathrm{MW}$ plant. These data are from the EPRI Technical Assessment Guide ${ }^{\mathrm{TM}}$.

\section{BATTERY ATTRIBUTES}

\section{Ratings}

Batteries have two key ratings. One is the power rating ( $k W$ or MW). It is the maximum power that the battery can provide for an extended period during the discharge part of its cycle. The power rating is dictated by the lowest continuous rating among the components that make up the system: the cells, the busbars, the converter, or the converter transformer. In an optimized design all components will have about the same continuous capability. However, the converter is usually the most limiting device and the one with the least margin. While cell life will be reduced somewhat when a battery is operated above its power rating, GTOs in the 
converter may fail at a power level as little as $10 \%$ above their rating. The converter controls are thus designed to prevent converter overloading.

\section{Table 1-1}

LEAD-ACID BATTERY COST AND PERFORMANCE DATA

\begin{tabular}{lcc} 
& Three Hour & Five Hour \\
\hline Plant Capital Cost, Dec. 1988 \$kW & & \\
Power charging/discharging & 125 & 125 \\
Storage & 510 & 727 \\
Startup, inventory, land & 16 & 21 \\
Total capital requirement & 651 & 873 \\
Operation and Maintenance Costs, Dec. 1988 \$ & & \\
Fixed, \$kW-yr & 0.6 & 1.4 \\
Incremental, mills/kWh & 8.6 & 6.5 \\
Energy Requirements (kWh OutputkWh Input) & & \\
Full bad & 0.73 & 0.76 \\
25\% load & 0.78 & 0.79 \\
Average annual & 0.74 & 0.76 \\
Plant Construction Time, Years & 1 & 1 \\
Unit Life, Years & 30 & 30
\end{tabular}

The maximum continuous charge power level is dictated by the same considerations, and is thus usually the same as the power rating. Note, however, that in practice the charge rate may be lower than the rating to increase battery life if low-cost energy is available over a period sufficient to fully charge the battery at the lower rate.

The second battery rating is its energy storage rating (kWh or MWh). The storage rating is the energy that the battery can provide to the system during a normal daily discharge. In current designs the energy rating is usually $80 \%$ of the energy the battery could provide if discharged fully. The energy rating is solely a function of the individual cell ratings and the number of cell strings in parallel. The battery energy rating can be increased by adding parallel strings of cells.

The batteries produced to date have not been given an overload rating. However, batteries, buswork, transformers, and circuit breakers will all tolerate some overload. Though a converter cannot be significantly overloaded, a converter could be oversized to take advantage of the overload capability of other components.

\section{Cell Types}

Two types of lead-acid cells are in use. The one first used in utility energy storage applications is the 'flooded' cell. It is typically 14 to 18 inches square and 24 to 30 inches tall. It has a vent on the top covered by a filter so that only hydrogen escapes from the battery. The 
Southern California Edison installation uses flooded cells, as will the $20 \mathrm{MW}$ battery that will be installed in Puerto Rico in 1993.

The second type is the "sealed" or "Valve Regulated" Lead Acid (VRLA) battery which is a relatively recent derivative of the traditional "flooded" cell battery. In this design the electrolyte is immobilized as a gel or absorbed in a glass mat between the positive and negative plates of the cell. This allows the battery to be sealed and removes the need for water addition during its operating life. The sealed construction offers greater flexibility in configuring the layout of a battery energy storage plant while reducing O\&M costs. San Diego Gas \& Electric recently purchased a $210 \mathrm{~kW} / 420 \mathrm{kWn}$ VRLA battery for a commuter trolley peak-shaving demonstration project which is expected to commence operation by mid-1992. This project will be the first use of a VRLA battery in a utility application. The selection of a VRLA battery was driven by the limited land availability at the project location. A comparable flooded cell type of battery would not have been able to meet the restrictive space requirements.

\section{Cycle and Battery Life}

The normal 'load-leveling' cycle for a battery is a diurnal one in which the battery is charged at night and discharged to follow load during the day. In most load-leveling applications, batteries are cycled only on weekdays. In spinning reserve applications there are no regular charge-discharge cycles, but the battery is discharged to replace generation lost due to an unscheduled outage. In some special applications, such as frequency regulation, multiple shallow charge-discharge cycles may occur over periods of minutes or hours.

Batteries can be cycled daily to 'shift' load from peak hours to off-peak hours. However, because battery life is reduced as the depth of discharge is increased, there is an optimum depth of discharge for each application. The optimum depth occurs where the incremental benefit of load-leveling equals the cost of incremental battery loss of life. Though the relationship of the depth of discharge and life loss is not well defined, current practice with flooded cells is to limit the depth of discharge to $80 \%$ of the full battery capacity (the battery rated capacity may be defined as the capacity that can be used regularly while achieving a stated battery life).

Sealed batteries presently have a shorter life than flooded cells for the same depth of discharge. New designs may reduce this difference in performance between the two types. Of course, sealed batteries require less maintenance, and this may offset the shorter life. If the reduced life is a constraint for sealed batteries, the sealed types may have an advantage where cycling is infrequent or only partial cycles are needed, and spinning reserve or other uses are the primary function.

In some applications there will be value to the ability to discharge a battery fully. The cell capacity that remains after a normal-depth discharge may be used for spinning reserve or to backup transmission or distribution equipment. Manufacturers indicate that flooded cells can be discharged fully on occasion without significant loss of life. Sealed or valve regulated 
batteries may eventually have this capability. To achieve full discharge, the power converter must be capable of operating at the end-of-discharge battery voltage.

Flooded cell lead acid batteries are capable of more than 2,000 cycles in load-leveling applications to an $80 \%$ depth-of-discharge. Battery manufacturers will guarantee such performance with warranties that extend four years or more based on the number of cycles the battery is expected to perform in a given period. For similar cycle duty, a VRLA battery will offer a lower cycle life.

For applications such as frequency regulation, the battery experiences a shallow depth-ofdischarge, and it is generally accepted that such light discharges do not affect battery life. The Puerto Rico Electric Power Authority (PREPA) $20 \mathrm{MW}$ frequency regulation/spinning reserve duty battery (discussed later in this chapter), has a commercial warranty of 8 years. This battery will perform the shallow discharge frequency regulation on a continuous basis and be available for a deeper discharge to meet the spinning reserve requirements approximately once every week.

\section{Rapid Cycling}

There are two benefits that batteries can provide that will require the battery to be cycled more than once per day. One is frequency regulation and the other is tie line control or area control error ( $A C E)$ corrections. Frequency regulation will require many shallow cycles lasting only seconds or minutes. Tie line control cycles will be of modest depth, and will typically last 5 or 10 minutes. These cycles may be in addition to a normal diurnal storage cycle.

Batteries are useful for frequency regulation only in systems of modest size where variations in customer load are large compared to the total on-line generation. In these systems frequency will vary from second to second and minute to minute unless one or more generators are assigned to tightly control frequency. This kind of duty on generators reduces plant equipment life and increases maintenance. And, even the fastest plants may have difficulty following load, and some utilities do not attempt to regulate frequency tightly because of the cost. Batteries provide very rapid response to load changes. Batteries can easily meet the rapid load change response required for tight frequency control applications. A $17 \mathrm{MW} / 14 \mathrm{MWh}$ battery has been used in Berlin since 1986 by the Berliner-Kraft-und Licht (BEWAG) for frequency regulation/spinning reserve applications. This battery has not shown any signs of capacity or life degradation and continues to operate as originally designed.

Large interconnected systems inherently control frequency well. Even the largest customer load variations are small compared to the mass of many turbine-generator rotors, and thus will not measurably change frequency. However, in these systems each utility has a responsibility of limiting variations in tie flow, or correcting variations quickly when they do occur. Tie flow variations can result from variations in customer load or unscheduled changes in the loading of generating plants. Batteries could provide a significant benefit by taking over the load following task from generators. 


\section{Response}

A battery system can also be moved almost instantaneously from one operating point to another within its real and reactive operating range shown in Figure 1-2. In addition, it can continuously move about its operating region in response to a stabilizer or voltage regulator.

Fast response makes the battery a candidate to:

- Respond rapidly to generation shortages or transmission overload (via control signals from control center software or operators),

- Provide LFC or Area Regulation (via control signals from control center software),

- Tightly regulate voltage for the benefit of nearby customers or a larger load area,

- Regulate voltage for improved voltage stability in areas with little generation,

- Provide a damping component of power to raise transfer limits imposed by dynamic stability,

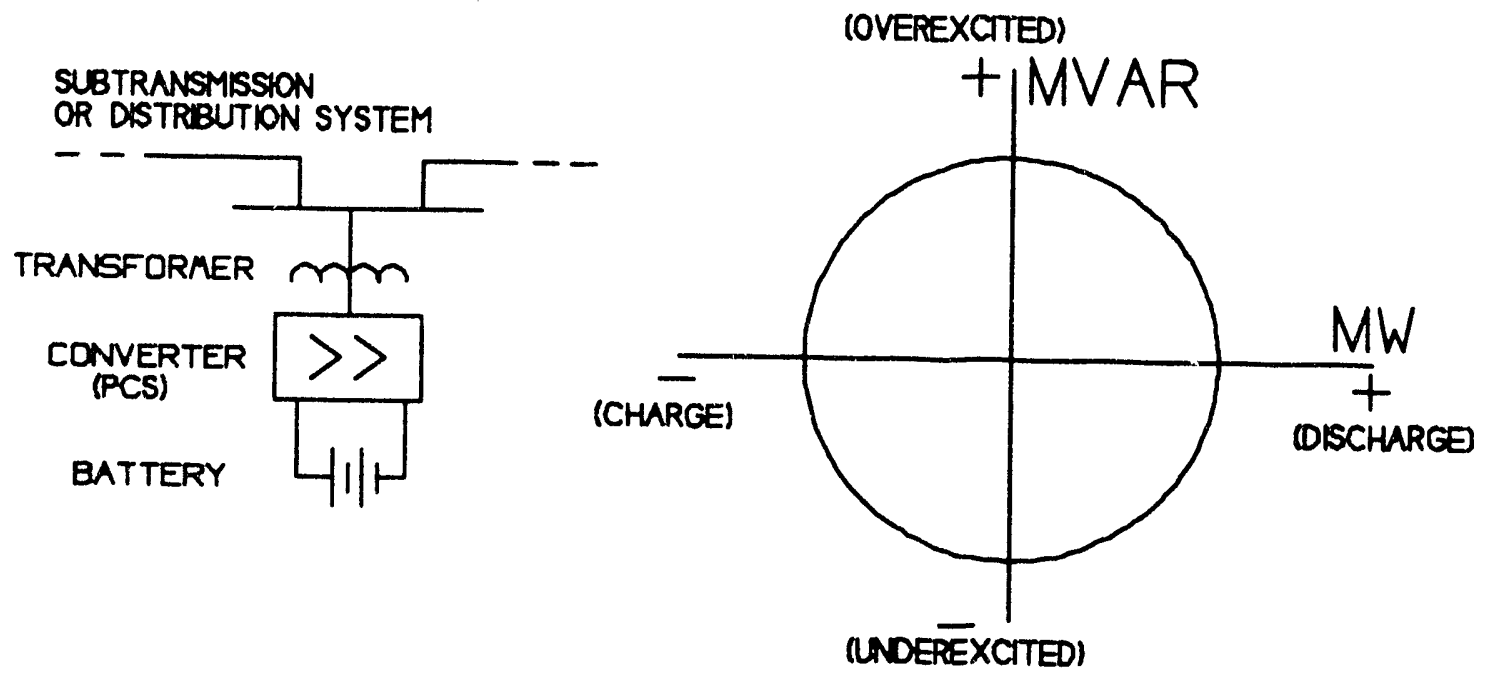

Figure 1-2. Real and Reactive Operating Range of Battery

In supplying reactive power to control voltage, the battery system is competing directly with Static Var Systems (SVSs) and generators. The battery system has an advantage over generators in that generators can rarely be sited where voltage control is needed, while batteries 
$1-8$ Introduction

are very likely to be sited in areas needing voltage control. A battery system also responds much more quickly to system voltage changes than a generator can.

The reactive capability of a battery system converter is quite similar to that of an SVS. More information on this is in the next section.

\section{Batteries as a Source of Reactlve Power}

A converter can supply reactive power to defer capacitors. It can also regulate voltage to improve power quality and system stability. Variations in voltage have become less tolerable to all customers so the contribution to power quality may be very significant.

GTO and transistor based power converters can provide or absorb reactive power as well as move active power into or out of the battery. The reactive power can be controlled rapidly just as the active power can, and thus allows a converter to regulate voltage. A battery cannot provide reactive power when the converter is being fully utilized to handle active power (charge or discharge), but can provide significant reactive power and voltage control at other times. However, a modest increase in converter rating will allow it to provide a large amount of reactive power while also operating at maximum battery charge or discharge rating.

Table 1-2 shows the cost of reactive power from a converter that costs $\$ 150$ per $\mathrm{kVA}$ overall, but can be increased in size for $\$ 100$ per $\mathrm{kVA}$. The first column is the converter $\mathrm{kVA}$ rating per $\mathrm{kW}$ of battery rating, the second column is the dynamic kvar range per $\mathrm{kW}$ of battery rating that would be provided, the third column is the incremental kvar per $\mathrm{kW}$ at that converter kVA rating, the fourth column is the battery/converter power factor rating, the fifth column is the cost per incremental kvar, and the sixth column is the overall cost per kvar. A converter could, for example, be increased to 1.2 times the battery active power rating and still be competitive with an SVS that provides incremental kvar at $\$ 40 /$ kvar. If the battery and its converter allow the SVS to be completely avoided, then the battery can be credited with the overall SVS cost which is on the order of $\$ 60 /$ kvar. In this situation, the battery converter might be an attractive alternative to an SVS at well over twice the battery active power rating.

\section{Equalization Charge}

About once per week a cycled battery must be 'overcharged' a modest amount for several hours. This brings all cells to their maximum capacity, including 'slower' cells that may not achieve full charge during the daily cycle. The several hour period of overcharge does not damage or increase the charge in the 'faster' cells, but brings the 'slower' cells up to their maximum charge level. Both flooded and sealed cells need an occasional equalization charge. 
Table 1-2

COST OF REACTIVE POWER

\begin{tabular}{cccccc}
\hline $\begin{array}{c}\text { Converter } \\
\text { kVA }\end{array}$ & $\begin{array}{c}\text { Total kvar } \\
\text { par kW }\end{array}$ & $\begin{array}{c}\text { incromental } \\
\text { kvar/kVA }\end{array}$ & $\begin{array}{c}\text { Power } \\
\text { Factor }\end{array}$ & $\begin{array}{c}\text { Cost por } \\
\text { incremental } \\
\text { kvar }\end{array}$ & $\begin{array}{c}\text { Overall } \\
\text { Cost por } \\
\text { kvar }\end{array}$ \\
\hline 1.00 & 0.0 & & 1.00 & & \\
1.05 & 0.6 & 6.5 & 0.95 & $\$ 15$ & $\$ 8$ \\
1.10 & 0.9 & 4.8 & 0.91 & 21 & 11 \\
1.15 & 1.1 & 4.0 & 0.87 & 25 & 13 \\
1.20 & 1.3 & 3.6 & 0.83 & 28 & 15 \\
1.25 & 1.5 & 3.3 & 0.80 & 30 & 17 \\
1.30 & 1.7 & 3.1 & 0.77 & 32 & 18 \\
1.35 & 1.8 & 3.0 & 0.74 & 34 & 19 \\
1.40 & 2.0 & 2.9 & 0.71 & 35 & 20 \\
1.45 & 2.1 & 2.8 & 0.69 & 36 & 21 \\
1.50 & 2.2 & 2.7 & 0.67 & 37 & 22 \\
1.55 & 2.4 & 2.6 & 0.65 & 38 & 23 \\
1.60 & 2.5 & 2.6 & 0.63 & 39 & 24 \\
1.65 & 2.6 & 2.5 & 0.61 & 40 & 25 \\
1.70 & 2.7 & 2.5 & 0.59 & 40 & 25 \\
1.75 & 2.9 & 2.4 & 0.57 & 41 & 26 \\
1.80 & 3.0 & 2.4 & 0.56 & 42 & 28 \\
1.85 & 3.1 & 2.4 & 0.54 & 42 & 28 \\
1.90 & 3.2 & 2.4 & 0.53 & 43 & 28 \\
& & & & &
\end{tabular}

\section{Efficiency}

There are losses in the power converter and its associated transformers during both charging and discharging. There are also 'turn-around' losses within the battery in the form of heat during charging and discharging. Turn-around losses can be as high as $20 \%$ if the battery is charged and discharged at its maximum rate. Other losses include auxiliaries such as ventilation and lighting. Turn-around efficiency may be as low as $75 \%$ in daily deep cycle applications. Of course, losses will be very low in spinning reserve applications where the battery 'floats' much of the time.

\section{Rellablity}

Battery energy storage systems have the potential to be very reliable. The three major components, the solid state power converter, the converter transformer, and the batteries, all have proven reliability records.

- The converter is much like a static var systems, an HVDC converter, and an adjustable speed drive converter. These devices have proven to be very reliable.

- The converter transformer is not significantly different from conventional transformers, and no different from the transformers associated with 
HVDC converters. Life expectancy is 30 to 40 years and forced outage rates are negligible.

- Lead acid batteries are well proven in power plant, substation, automotive, and telephone, UPS, and other applications. The sealed cells for utility energy storage applications that are now being tested will almost totally eliminate routine maintenance. Sealed cells also eliminate watering mechanisms and filters that require routine maintenance. In addition, batteries are installed in 'strings' that can be removed for service with no impact on battery system power, and only modest impact on storage capacity.

The reliability and availability of battery systems must be high if all of their benefits are to be recognized. For instance, if a battery system in a distribution substation is to be allowed to defer transformer capacity in the station, it must provide reliability equal to that provided by larger transformers. Planners applying today's deterministic planning criteria may interpret this to mean that the battery system must be as reliable as the transformers in the station. This is unlikely to occur. However, a valid comparison of reliability is not provided by comparing the battery system to transformers. The battery, when charged, is a separate source of power, and is not affected by transmission outages upstream of the substation as is a transformer.

\section{Avallabllity}

As noted in the reliability section, the battery availability is high because cells are arranged in strings so that one string can be maintained or repaired while others are operating. Transformer and circuit breaker failures are rare and should not measurably affect battery availability. The component most likely to cause outages is the converter. A single thyristor failure will take the battery out of service for several hours until replaced. A conservative design should reduce outages due to thyristor failures to one per year or less. Today thousands of adjustable speed drives (motors fed by converters to reduce energy use or provide speed control) are operating with very high availability, indicating that the very similar battery converters should be able to do the same.

\section{Environmental}

Lead acid batteries do contain hazardous materials, primarily lead. However, these materials are well contained and existing hazard control procedures cover their usage.

Acid spills are possible with flooded cell batteries, but the amount of acid contained in each battery module is small and easily handled by industrial spill containment kits. Acid spills do not occur with the VRLA battery because the acid is immobilized in the glass mat or in gel form. 
Battery disposal at the end of battery life can be handled by a contractual disposal agreement with the battery supplier or a certified salvager. The lead acid battery manufacturing industry is actively involved in environmentally safe recycling of lead and has a large, regionally dispersed recycling infrastructure in place. According to recycling statistics compiled by the Battery Council International, a non-profit trade association, the recycling rate for lead acid batteries during 1989 was $95.3 \%$.

\section{Siting Flexibility}

Flooded cell batteries carry only modest risk of harmful spills, while the sealed types carry essentially no risk of harmful spills. Gas release is minimal with the flooded cells and nonexistent with other types. Hence with public understanding there should be only modest concern with flooded cells, and little or no concern with other cell types. Hence placing batteries near residential or commercial areas is feasible, as illustrated by San Diego Gás and Electric's recent successful locating of a battery for a trolley project in a good residential area.

Battery systems may require less than an acre for the sizes that might be placed in areas where land values are high (20 to $40 \mathrm{MWH}$ ). Less land may be required where two floors can be used, perhaps one at grade level and one below grade level. Less land per kWh will be required for larger sizes.

\section{The PREPA 20 MW Battery Project}

The Puerto Rico Electric Power Authority (PREPA) battery project marks a significant milestone in the application of batteries by electric utilities in the U.S. because it is being undertaken as a purely commercial venture by PREPA. Outside cost-sharing or other financial support was not used to enhance the economic viability of the project, and internally it has been treated as a resource addition, not an $R \& D$ project.

The electric network in Puerto Rico experiences severe voltage drops due to the geographic location of load centers and the generation units. The system also needs additional reserve capacity to meet load growth in recent years. The options faced by PREPA were to install additional combustion turbines in several locations, or use battery energy storage systems. Their internal economic analysis, combined with the reliable operating experience of the BEWAG battery for frequency regulation, provided the basis for their choice in favor of the battery. The planning projections indicate that a total installed capacity of $120 \mathrm{MW}$ is needed to meet PREPA's spinning reserve requirements. This total capacity will be installed in 6 blocks of 20 MW battery energy storage systems over the next few years. Each $20 \mathrm{MW}$ battery will be sited in a different location in the PREPA network, so that it serves both the spinning reserve requirements as well as the frequency control function at key locations determined by the existing transmission network and the distribution of load centers. 
According to the current schedule, the first battery will be on-line by mid-1993. The battery, power conversion system, main transformer and the AC switchgear have been purchased. The costs for these components are shown in Table 1-3, and reflect "actual" battery costs at the present time. However, the cost of the power conversion system, Item 3, Table 1-3, is very high. General Electric (GE) was the only supplier that submitted a bid for this subsystem. The design proposed by GE is identical to the power conversion system they designed for Southern California Edison's Chino Battery. This design was developed for that project in the early 1980's, and has not been reproduced since then. Thus, GE quotes this as a one-of-a-kind, high cost item. It is reasonable to expect that this subsystem cost can be substantially reduced for future battery projects, both due to refinements in design as well as increased vendor competition. A mature power conversion system should cost out at approximately $\$ 150-\$ 170 / \mathrm{kW}$, compared to the current cost of $\$ 270 / \mathrm{kW}$. This reduction in this subsystem cost will reduce the cost of the overall battery system substantially.

Table 1-3

PREPA 20 MW BATTERY PROJECT COSTS

\begin{tabular}{lrr}
\hline \multicolumn{1}{c}{ Item } & \multicolumn{1}{c}{ Cost } & Unit Cost \\
\hline 1. Engineering Design & $\$ 1,000,000$ & \\
2. Battery (14.1 MWh) & $\$ 4,500,000$ & $\$ 319 / \mathrm{kWh}$ \\
3. Power Conversion System (20 MW) & $\$ 5,400,000$ & $\$ 270 \mathrm{~kW}$ \\
4. Main Transformer & $\$ 360,000$ & \\
5. AC Switchgear & $\$ 190,000$ & \\
6. DC Switchgear & $\$ 650,000$ & \\
7. Facility Control System & $\$ 800,000$ & \\
8. Construction Contract & $\$ 4,000,000$ & \\
TOTAL PROJECT COSTS & $\$ 16,900,000$ & $\$ 1,199 / \mathrm{kWh}$
\end{tabular}

\section{CHUGACH ELECTRIC ASSOCIATION SITUATION}

Chugach Electric Association's generation mix consists largely of natural gas-fired units as shown in Table 1-4. Cooper is hydroelectric; all other units are gas-fired. In addition to the CEA-owned units shown in the table, CEA receives substantial amounts of power and energy from the Bradley and Eklutna hydroelectric stations.

The CEA system is heavily winter-peaking. Winter peak is currently about $350 \mathrm{MW}$, while summer peak is about $220 \mathrm{MW}$. Under CEA's mid-case projection, winter peak is expected to grow to around $400 \mathrm{MW}$ by the year $2000 .^{4}$ Annual load factor is about 63 percent. During the winter the daily peak occurs around $7 \mathrm{pm}$ to $8 \mathrm{pm}$; during the summer it occurs about 12 noon to $1 \mathrm{pm}$.

4. These load figures include obligations to HEA, MEA, and SEA as well as CEA's own load. 
Spinning reserve requirements are $38 \mathrm{MW}$. Although CEA currently "sells its spin" to Golden Valley Electric Association (GVEA), no such sales are included in the current analysis. The horizon of this analysis is the 25- to 30 -year life of a battery system, beginning in the mid1990s. GVEA sales may not be a significant factor during much of this horizon. ${ }^{5}$

Table 1-4

CHUGACH ELECTRIC ASSOCIATION GENERATING CAPACITY

\begin{tabular}{|c|c|c|}
\hline Unit & Plant Type & Capacity (MW) \\
\hline $\begin{array}{l}\text { Beluga } 1 \\
\text { Beluga } 2 \\
\text { Beluga } 3 \\
\text { Beluga } 4 \\
\text { Beluga } 5 \\
\text { Beluga } 6 \\
\text { Beluga } 7 \\
\text { Beluga } 8\end{array}$ & $\begin{array}{c}\text { Combustion Turbine } \\
\text { Combustion Turbine } \\
\text { Combustion Turbine } \\
\text { Combustion Turbine } \\
\text { Combustion Turbine } \\
\text { Combustion Turine }^{6} \\
\text { Combustion Turbine }^{6} \\
\text { Steam Turbine }^{6}\end{array}$ & $\begin{array}{r}17 \\
17 \\
55 \\
9 \\
66 \\
78 \\
75 \\
54\end{array}$ \\
\hline $\begin{array}{l}\text { Bernice Lake } 1 \\
\text { Bernice Lake } 2 \\
\text { Bernice Lake } 3 \\
\text { Bernice Lake } 4\end{array}$ & $\begin{array}{l}\text { Combustion Turbine } \\
\text { Combustion Turbine } \\
\text { Combustion Turbine } \\
\text { Combustion Turbine }\end{array}$ & $\begin{array}{r}8 \\
18 \\
25 \\
25\end{array}$ \\
\hline $\begin{array}{l}\text { International } 1 \\
\text { International } 2 \\
\text { International } 3\end{array}$ & $\begin{array}{l}\text { Combustion Turbine } \\
\text { Combustion Turbine } \\
\text { Combustion Turbine }\end{array}$ & $\begin{array}{l}16 \\
16 \\
19\end{array}$ \\
\hline \multirow[t]{2}{*}{ Cooper } & Hydro & 17 \\
\hline & TOTAL & 510 \\
\hline
\end{tabular}

\section{OVERVIEW OF THIS REPORT}

Section 2 quantifies the generation benefits of batteries on the Chugach Electric Association system. Section 3 describes in detail the potential for reduced load shedding. Section 4 describes potential transmission and distribution investment deferral that could result from the addition of battery energy storage. Section 5 compares these benefits to the cost of installing batteries. Section 6 summarizes the results and recommends further steps.

5. In 1996 a $50 \mathrm{MW}$ coal-fired unit is planned to go on-line at Healey. GVEA plans to take the total output from this plant, reducing the need to purchase economy energy from CEA.

6. The Beluga 6 and 7 combustion turbine units power the Beluga 8 steam unit through heat recovery, with the three units together forming a combined cycle plant. Either or both of the CTs can be operated independently without running the steam unit, and either $C T$ can be operated along with the steam unit at some reduced output. 


\section{2}

\section{POTENTIAL GENERATION BENEFITS}

This section estimates the magnitude of three kinds of generation benefits-load-leveling benefits, dynamic operating benefits, and environmental benefits-of adding battery storage to the Chugach Electric Association system. The section discusses the logic behind the calculations, describes the approach taken for the Chugach analysis, and presents the results.

\section{CALCULATING GENERATION BENEFITS OF ENERGY STORAGE}

\section{Load-Leveling Benefits}

Energy storage makes it possible to generate electricity during off-peak hours and use it during peaking-hours, commonly referred to as load-leveling. Typically, system lambda (the marginal cost of energy) is lower during off-peak hours than during on-peak hours; the load-leveling savings is the difference between the lambda during peaking hours when the storage would be discharged and the lambda for the off-peak hours, when the storage would be charged, adjusted for the efficiency loss from the battery.

$$
\begin{aligned}
& \text { Load Leveling Benefits }=\lambda_{\text {on-peak }}-\lambda_{\text {off-peak }} / \text { storage efficiency } \\
& (\$ / \mathrm{MWh}) \quad(\$ / \mathrm{MWh}) \quad(\$ / \mathrm{MWh})
\end{aligned}
$$

If this number is positive, then there are load-leveling savings. This will be true if the battery efficiency exceeds the ratio of off-peak lambda to on-peak lambda.

\section{Dynamic Operating Benefits}

Dynamic operating costs (DOCs) are the portion of total operating costs of an electric power system required to meet dynamic operating requirements. Technologies that offer operating flexibility at minimal costs, such as energy storage plants, provide power systems $v$;ith significant operating cost savings. These savings are called dynamic operating benefits (DOBs). Potential DOBs are measured as reductions in dynamic operating costs (DOCs). DOCs include:

- Startup costs, the costs of shutting down and starting up power plants.

- Load Following costs, increased fuel costs due to operations in load following mode. 
- Minimum Load costs, costs due to foregone economic generation because of minimum load constraints.

- Ramping costs, the costs due to foregone economic generation because of ramping constraints.

- Frequency Regulation costs, costs of foregone economic generation due to externally constraining the loading ranges of some units to provide frequency regulation capabilities.

This study estimated the benefits associated with reducing the first three types of dynamic operating costs: startup costs, load following costs, and minimum load costs, all of which have a solid technical foundation based on common utility operations. Other categories of DOBs are likely to be smaller but can only add to the DOBs quantified in this study.

Startup Cost Benefits. The cost of starting a steam unit that has been shut down completely can be as much as several thousand dollars. Compared to the total daily operating cost of such a unit, this is not insignificant. By modifying unit commitment, the addition of battery storage can make it possible to avoid this startup cost for one or more units. Since CEA has no steam unit except for Beluga 8 , which is part of a combined cycle plant, steam unit startup costs are not relevant to this study.

Load Following Benefits. Load fluctuation requires that some generation be able to meet changes in, or follow, the load. As a result of this requirement, the units used for load following will most of the time be loaded at levels other than their most efficient loadings, at points where their a verage fuel costs are higher than at their most efficient loadings and higher than system marginal cost. Load following benefits occur when a unit operating in load following mode is decommitted. The benefits or savings are equal to the difference in average energy cost of the unit and the system marginal energy cost.

Load following costs of a unit are the costs which could have been avoided were the system able to decommit the unit and replace its energy at the system marginal energy cost. These are calculated for hours where the unit is operated at part load (not on minimum load):

$$
\begin{aligned}
& \text { Load Following } \\
& \text { Costs of a Unit } \\
& (\$ / h r)
\end{aligned}=\left(\begin{array}{cc}
\text { Average Energy } & \text { System Marginal } \\
\text { Cost of the Unit } & \begin{array}{c}
\text { Energy Cost } \\
(\$ / M W h)
\end{array} \\
(\$ / M W h)
\end{array}\right) * \begin{gathered}
\text { Loading of Unit } \\
(\mathrm{MWh} / \mathrm{MWr})
\end{gathered}
$$

The daily load following costs are the sum of the hourly load following costs (for the hours in load following mode). 
Minimum Load Benefits. Thermal units have minimum loading constraints. When they are committed, they must be operated at or above this minimum load. Operation at minimum loading generally results in the least efficient generation. Units are normally operated at their minimum load only because the constraint prohibits even lower loading. Minimum loading benefits o sur when a unit operating at its minimum load is decommitted. The benefits or savings are equal to the difference in average energy cost of the unit and the system marginal energy cost.

Minimum loading costs of a unit are the r:osts which could have been avoided were the system able to decommit the unit and replace its energy at the system marginal energy cost, calculated for hours where the unit is on minimum load:

$$
\begin{gathered}
\text { Minimum Load } \\
\text { Costs of a Unit } \\
(\$ / h r)
\end{gathered}=\left(\begin{array}{cc}
\text { Average Energy } & \text { System Marginal } \\
\text { Cost of the Unnit } & \begin{array}{c}
\text { Energy Cost } \\
(\$ / M W h)
\end{array} \\
(\$ / M W h)
\end{array}\right) \begin{gathered}
\text { Minimum } \\
\text { Loading of Unit } \\
(M W h / h r)
\end{gathered}
$$

The daily minimum load costs are the sum of the hourly minimum load costs (for the hours at minimum load).

Figures 2-i and 2-2 illustrate how minimum load and load following costs are calculated and how significant they can be. Although the figures are for a hypothetica! unit in a hypothetical system, they are typical of actual units. The unit operates at its minimum load for hours $0-4$ and 20-24, at its maximum load for hours 8-16, and in load-following mode during the other 8 hours. The daily load following cost of the unit is the dark shaded area in Figure 2-2; the light shaded area is the unit daily minimum load cost. The difference between unit average cost, which is the cost actually incurred, and system marginal cost, the cost that would be incurred if this unit could be shut down, is substantial.

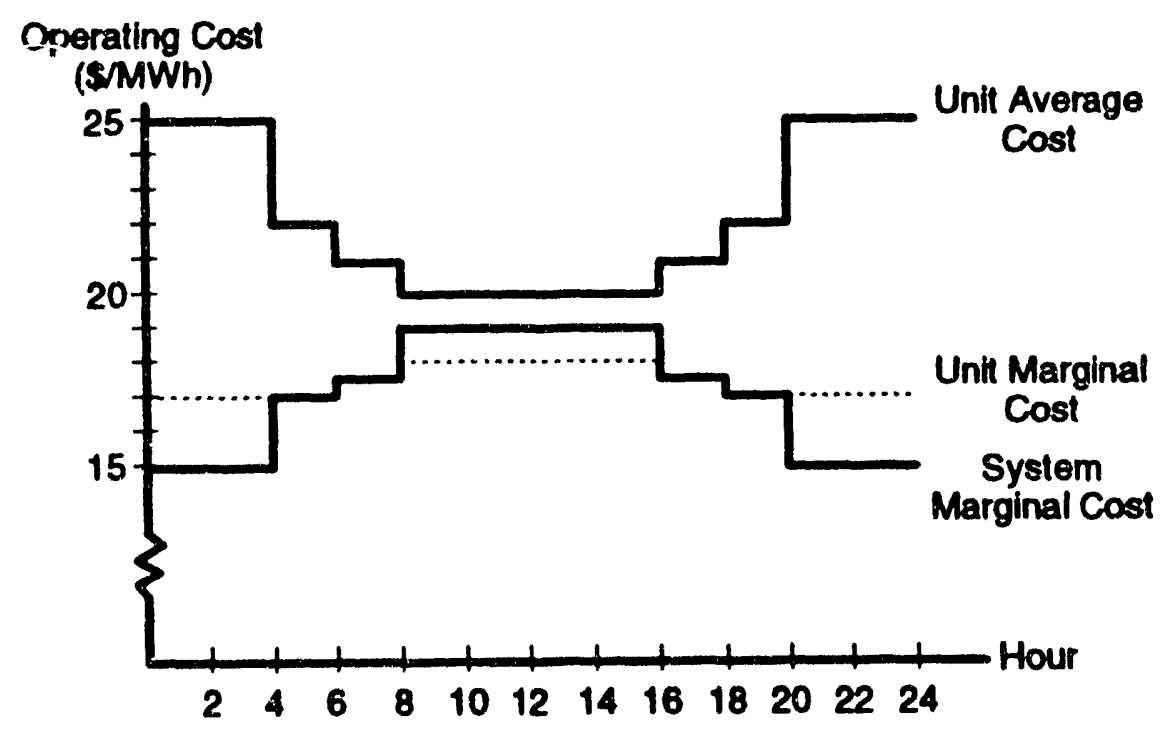

Figure 2-1. System and Unlt Costs 


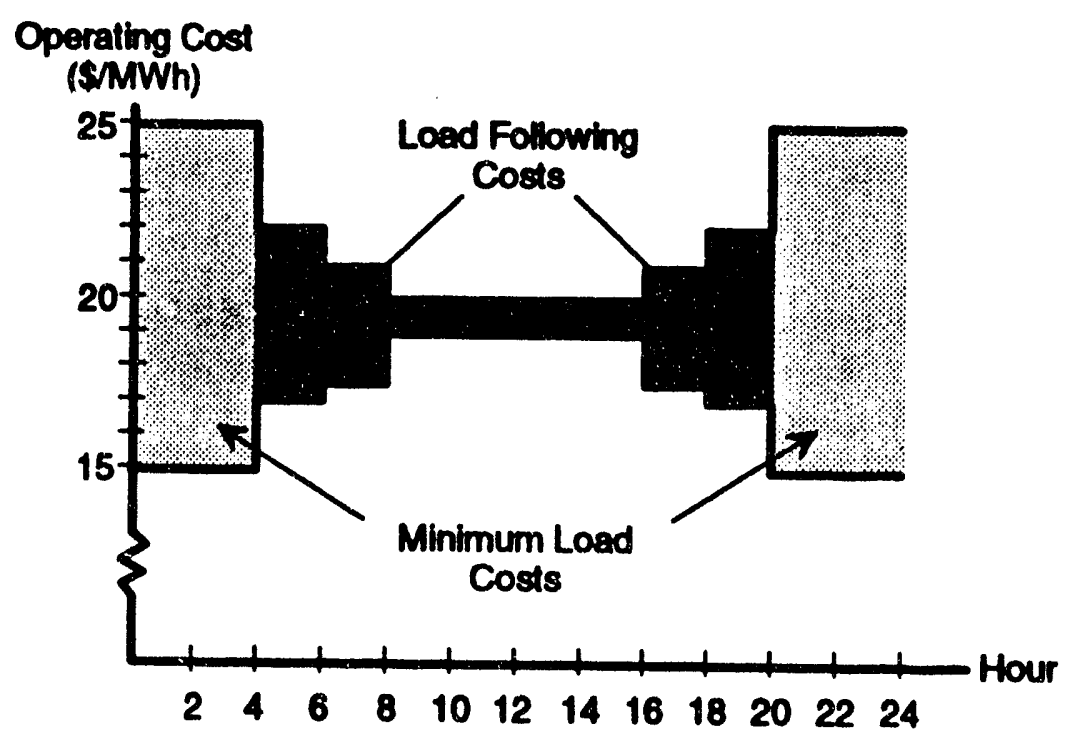

Figure 2-2. Load Following Costs and Minimum Load Costs

\section{CAPTURING GENERATION BENEFITS OF ENERGY STORAGE}

There are two primary modes in which storage can be operated:

- On a regular charge/discharge basis

- To provide spinning reserve only

Both modes are discussed below.

\section{Charge/Discharge Appllcation}

Operated in this mode, storage provides not only load-leveling but also the reduction in dynamic operating costs made possible by decommitting a unit and operating remaining units at more efficient levels. The storage would most likely be operated on a daily cycle, with charging at night and discharging during the daily peak. In order to maximize benefits per kilowatt of battery capacity, it is necessary to install both enough power capacity (MW) and storage capacity (MWh or hours of storage) to permit decommitting one or more units.

To illustrate the importance of including dynamic operating costs in calculating generation benefits, consider a hypothetical system with two time periods per day, a peak period of 8 hours, and an off-peak period of 16 hours. The system marginal energy costs are $\$ 18 / \mathrm{MWh}$ during the peak period and $\$ 17 / \mathrm{MWh}$ during the off-peak period. Figure 2-3 illustrates these marginal energy costs and Table 2-1 illustrates the operating characteristics of one generation 
unit (called Unit A). Unit A operates at minimum load (50 MW) during the off-peak period and at $100 \mathrm{MW}$ during the peak period. Figure 2-4 illustrates the power output of Unit A.

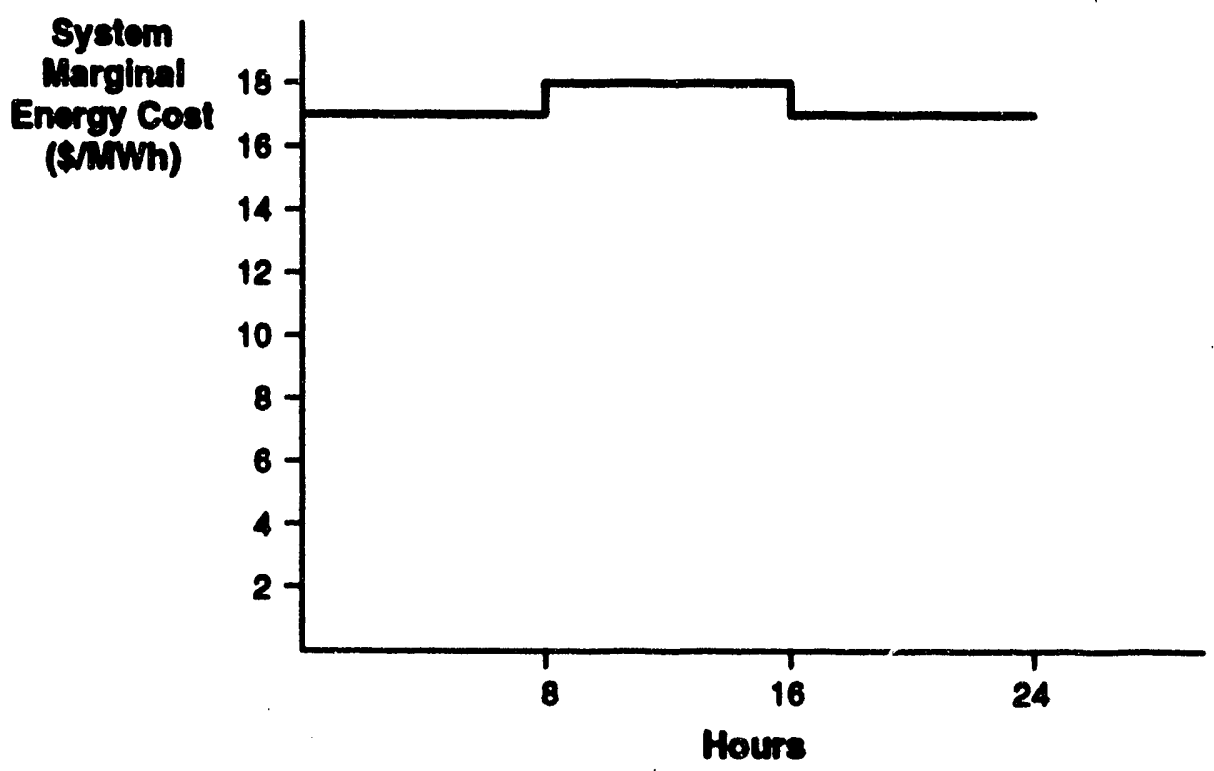

Figure 2-3. System Marginal Energy Costs

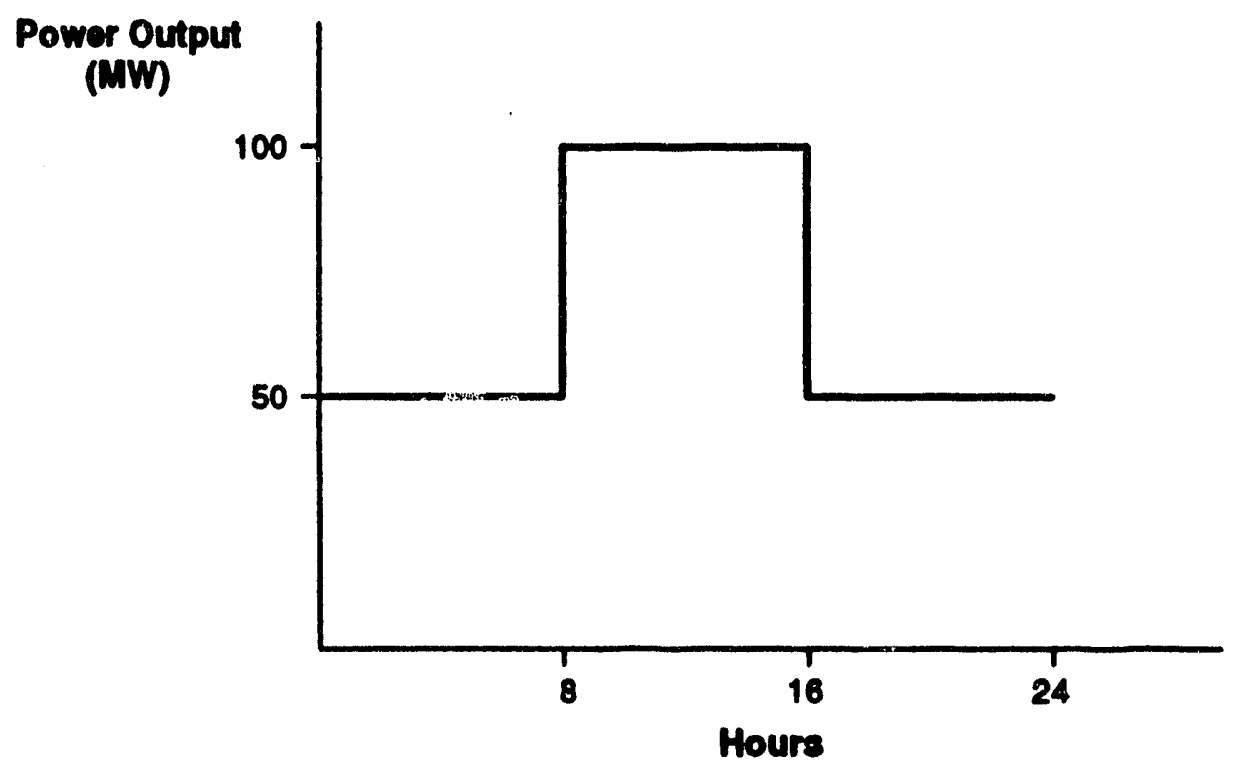

Flgure 2-4. Power Output of Unit A 
Table 2-1

OPERATING CHARACTERISTICS OF GENERATION UNIT A

\begin{tabular}{ccc}
\hline Power Output (MW) & Average (\$MWh) & Marginal (\$MWh) \\
\hline 50 & 25.0 & \\
100 & 21.0 & 17.0 \\
150 & 20.0 & 18.0
\end{tabular}

Would a storage unit with a 77 percent cycle efficiency provide this system with any operating savings? Using the conventional approach (that does not include dynamic operating considerations), the benefit to cost ratio of storage operatings is calculated as follows:

$$
\begin{aligned}
B / C & =0.77 \times \frac{\text { Marginal Energy Cost During the Peak Period }}{\text { Marginal Energy Cost During the Off-Peak Period }} \\
& =0.77 \frac{18.0}{17.0} \\
& =0.815<1.0
\end{aligned}
$$

Therefore, according to this calculation, storage operation is not economically feasible and would not provide any operating savings. To check the validity of this calculation, the benefit to cost ratio of operating the storage unit is explicitly calculated as:

$$
B / C=\frac{\text { Operating Savings of Energy Storage }}{\text { Operating Costs of Energy Storage }}
$$

The operating savings and costs of energy storage depend on the operations of the storage unit. One operating option is to charge during the off-peak period and discharge during the peak period to replace Unit $A$ (we assume that there is enough power available during the off-peak period to provide the energy required for charging the storage unit and to replace the off-peak energy output of Unit A). The benefit to cost ratio of this operating option is calculated as follows:

$$
\begin{aligned}
\text { Required Charging } & =\frac{100 \mathrm{MW} \times 8 \mathrm{hrs}}{0.77}=1,039 \mathrm{MWh} \\
\text { Charging Costs } & =1039 \mathrm{MWh} \times \$ 17 / \mathrm{MWh} \\
& =\$ 17,663
\end{aligned}
$$




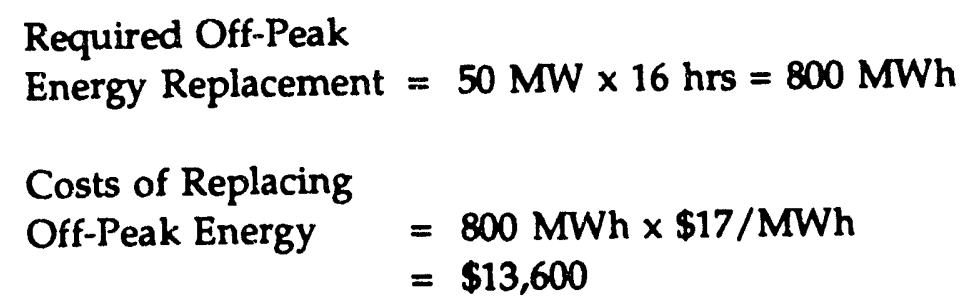

\section{Total Costs of}

Replacing Unit A $=17,663+13,600=\$ 31,263$

Total Savings by

Replacing Unit A $=$ Total Operating Costs of Unit A

$=100 \mathrm{MW} \times 8 \mathrm{hrs} \times \$ 21 / \mathrm{MWh}$

$+50 \mathrm{MW} \times 16 \mathrm{hrs} \times \$ 25 / \mathrm{MWh}$

$=\$ 36,800$

The benefit to cost ratio of operating the storage unit to replace Unit $A$ is therefore:

$$
\begin{aligned}
B / C & =\frac{36,800}{31,263} \\
& =1.177
\end{aligned}
$$

Therefore, storage operation is economically feasible and would provide the system with operating savings. The implied dynamic operating benefits term, $\mu$, which is missing fron, the conventional equation, can be calculated as:

$$
B / C=1.177=0.77 \frac{18.0+\mu}{17.0}
$$

or

$$
\begin{aligned}
\mu & =\frac{1.177 \times 17.0}{0.77}-18.0 \\
& =\$ 7.98 / \mathrm{MWh} .
\end{aligned}
$$

\section{Spinning Reserve Application}

As an alternative to using the battery as a charge/discharge unit, a utility could use a battery purely to provide spinning reserve with the following potential benefits: shut down least heat rates. 
The following example illustrates the benefits from using a battery as spinning reserve. Consider a system consisting of three thermal units (Units 1, 2 and 3). System load is $200 \mathrm{MW}$, ard spinning reserve of at least $40 \mathrm{MW}$ is required. Table $2-2 \mathrm{a}$ shows the system dispatch without a battery. Without a spinning reserve requirement, units 1 and 2, the most efficient units, would have been able to meet the system load of 200 MW. Because of the spinning reserve requirement, all three units are operated; units 1 and 2 operate at $90 \mathrm{MW}$ each and unit 3 , the least efficient, is operated at its minimum load of $20 \mathrm{MW}$.

Table 2-2

USING A BATTERY TO PROVIDE SPINNING RESERVE

(a) Untt Loadings and Operating Costs Without Battery

\begin{tabular}{lccccccc}
\hline & $\begin{array}{c}\text { Min. Load } \\
\text { (MW) }\end{array}$ & $\begin{array}{c}\text { Max. Load } \\
\text { (MW) }\end{array}$ & $\begin{array}{c}\text { Ave. Cost at } \\
\text { Max. Load } \\
\text { (\$MWh) }\end{array}$ & $\begin{array}{c}\text { Actual } \\
\text { Load } \\
\text { (MW) }\end{array}$ & $\begin{array}{c}\text { Ave. Cost at } \\
\text { Actual Load } \\
\text { (\$NWh) }\end{array}$ & $\begin{array}{c}\text { Spinning } \\
\text { Reserve } \\
\text { (MW) }\end{array}$ & $\begin{array}{c}\text { Total } \\
\text { Cost } \\
\text { (\$/hr) }\end{array}$ \\
\hline Unit 1: & 20 & 100 & 24.5 & 90 & 25 & 10 & 2,250 \\
Unit 2: & 20 & 100 & 24.5 & 90 & 25 & 10 & 2,250 \\
Unit 3: & 20 & 40 & 30 & 20 & 40 & 20 & 800 \\
\hline Total & & & & 200 & & 40 & 5,300
\end{tabular}

(b) Unit Loadings and Operating Costs With Battery

\begin{tabular}{|c|c|c|c|c|c|c|c|}
\hline & $\begin{array}{l}\text { Min. Load } \\
\text { (MW) }\end{array}$ & $\begin{array}{l}\text { Max. Load } \\
\text { (MW) }\end{array}$ & $\begin{array}{l}\text { Ave. Cost at } \\
\text { Max. Load } \\
\text { (\$MWh) }\end{array}$ & $\begin{array}{l}\text { Actual } \\
\text { Load } \\
\text { (NW) }\end{array}$ & $\begin{array}{l}\text { Ave. Cost at } \\
\text { Actual Load } \\
\text { (\$NMWh) }\end{array}$ & $\begin{array}{l}\text { Spinning } \\
\text { Roserve } \\
\text { (MW) }\end{array}$ & $\begin{array}{l}\text { Total } \\
\text { Cost } \\
\text { (S/hr) }\end{array}$ \\
\hline Unit 1: & 20 & 100 & 24.5 & 100 & 24.5 & 0 & 2,450 \\
\hline Unit 2: & 20 & 100 & 24.5 & 100 & 24.5 & 0 & 2,450 \\
\hline Unit 3: & 20 & 40 & 30 & 0 & 0 & 0 & 0 \\
\hline Battery: & 0 & 40 & $0^{*}$ & 0 & $0^{\circ}$ & 40 & 0 \\
\hline Total: & & & & 200 & & 40 & 4,000 \\
\hline
\end{tabular}

- The operating cost of a battery providing only spinning reserve is really the fuel cost of keeping the battery charged. However, this cost is negligible in this context.

Dynamic operating costs resulting from the spinning reserve requirement are of two types. First, there is the cost of operating Units 1 and 2 at other than their most efficient level. Second, there is the extra cost of operating Unit 3, which is the difference between the average generation cost at Unit 3 and what it would have cost to generate the same load at Units 1 and 2.

Adding a battery changes the system operation, as displayed in Table 2-2b. Units 1 and 2 can now operate at full capacity, and Unit 3 is shut down entirely; the battery provides the required spinning reserve. For the particular hour shown in the tables, the savings per $\mathrm{MWh}$ of spinning reserve is $(\$ 5300-\$ 4900) / 40 \mathrm{MWh}=\$ 10 / \mathrm{MWh}$. 
The spinning reserve benefits of using a battery in this manner can be summarized as follows: Unit 3, the least efficient unit, can be shut down and units 1 and 2 do not have to provide spinning reserve, and can operate at their most efficient loadings. The battery provides all required spinning reserves, and the system total operating costs are substantially lower.

\section{STUDY APPROACH}

The potential generation benefits from adding battery storage to Chugach Electric Association's system were determined by examining planned system operations as determined by running the production simulation model MAINPLAN for the Chugach Electric Association system. For the years 1994, 1996, and 2000, 6 representative days in each year were selected, a weekday and a weekend day during winter, summer, and fall/spring. The study focused on the marginal units (defined below) on these 18 days and determined how the operation of these units could be economically modified if sufficient battery storage were present on the system. Since previous studies ${ }^{1}$ had shown the high cost of providing spinning reserve, this study focused on using batteries only to provide spinning reserve.

Hourly system loads for the 18 days are shown in Appendix A. For most of the days, baseload units operate 24 hours a day, and are supplemented by peaking units and firm purchases during the day, usually from about 7 am to $12 \mathrm{pm}$. The daily peak typically occurs between $5 \mathrm{pm}$ and $11 \mathrm{pm}$. For some days, none of the thermal peaking units are operated at all. On those days, hydroelectric units and firm purchases provide the necessary peaking power.

Chugach Electric Association's marginal energy costs (system lambda) for the same 18 days, shown in Appendix $B_{1}^{2,3}$ generally change very little during a 24-hour period. Typically, however, system marginal costs are lower during off-peak hours than during on-peak hours, but not by enough to make load-leveling economic. For Chugach Electric Association, the marginal cost is roughly proportional to natural gas prices, which increase from year to year; the average nominal fuel price is about $\$ 1$ per million Btu in 1994, $\$ 2$ in 1996, and $\$ 2.50$ in 2000 .

Generating benefits of energy storage were for 5 gas-fired units on Chugach Electric Association's system for each of the 18 days. These five units were selected as the marginal units whose operation would most likely be affected by the addition of batteries to the system. That is, they would be potential candidates for decommitment. Larger gas-fired units were

1. Pailbelt Intertie Reconnaissance Study, prepared by Decision Focus Incorporated for the Alaska Power Authority, June 1989; Economic Feasibility of the Proposed 138 kV Transmission Lines in the Reilbelt, prepared by Decision Focus Incorporated for Railbelt Electric Utilities, December 1989; 2/15/90 memorandum from Tim Newton, Planning Engineer, Chugach Electric Association.

2. The hourly marginal costs are for on-system units only.

3. System load shapes and information on individual units were all provided by Chugach Electric Association. The hourly system marginal costs were calculated by multiplying the fuel price times the marginal heat rate of the least efficient operating unit for each hour of the day. 
excluded because they were too large to be replaced by batteries. Smaller units, including IGT 1,2 , and 3, were excluded because they did not operate at all on the 18 days considered. The key cost/performance characteristics of the units included in this study are displayed in Table 2-3.

Table 2-3

CHUGACH ELECTRIC ASSOCIATION GENERATING UNIT CHARACTERISTICS

\begin{tabular}{lccccc}
\hline & $\begin{array}{c}\text { Minimum } \\
\text { Load } \\
\text { (MW) }\end{array}$ & $\begin{array}{c}\text { Maximum } \\
\text { Load } \\
(\mathrm{MW})\end{array}$ & $\begin{array}{c}\text { Startup } \\
\text { Cost }(\$)\end{array}$ & $\begin{array}{c}\text { Meat Rate at } \\
\text { Minimum Load } \\
(\text { BtukWh) }\end{array}$ & $\begin{array}{c}\text { Heat Rate at } \\
\text { Maximum Load } \\
\text { (BtukWh) }\end{array}$ \\
\hline Beluga 1 & 3 & 17 & 0 & 35,573 & 15,304 \\
Boluga 2 & 3 & 17 & 0 & 38,928 & 13,250 \\
Bernice 2 & 3 & 18 & 0 & 36,626 & 14,835 \\
Bernice 3 & 3 & 25 & 0 & 42,810 & 13,462 \\
Bernice 4 & 7 & 25 & 0 & 24,126 & 13,815
\end{tabular}

\section{STUDY RESULTS}

\section{Load-Levelling Beneflts}

As shown in Appendix A, system lambda is relatively flat across the 24 hours in each day. Combined with a battery efficiency of 75 to 80 percent, this means that there would be no load-leveling savings from batteries in the CEA system.

Many previous studies on energy storage have used only the load-leveling savings in quantifying the value of energy storage. Doing so here would lead to the conclusion that batteries are clearly uneconomic, and should not be considered further. As shown below and in the next sections, however, there can be significant savings from batteries even if load-leveling is uneconomic.

\section{Dynamic Operating Beneflts}

The generation benefits resulting from adding batteries to the Chugach Electric Association system are summarized in Table 2-4. For each of the 18 days considered, the table shows the dynamic operating savings-in current year dollars-that could be realized if enough battery capacity were added to completely decommit the unit labelled "displaced unit". 
Table 2-4

CHUGACH ELECTRIC ASSOCIATION SUMMARY OF GENERATION BENEFITS NET OPERATING BENEFITS

\begin{tabular}{|c|c|c|c|c|c|c|}
\hline Year & Season & Day & Day Type & Date & $\begin{array}{c}\text { Net Operating } \\
\text { Benefits } \\
\text { (\$/KW-year) }\end{array}$ & $\begin{array}{c}\text { "Displaced } \\
\text { Unit" }\end{array}$ \\
\hline 1994 & $\begin{array}{l}\text { Winter } \\
\text { Summer } \\
\text { Spring/Fall }\end{array}$ & $\begin{array}{l}\text { Sunday } \\
\text { Thursday } \\
\text { Sunday } \\
\text { Thursday } \\
\text { Sunday } \\
\text { Thursday }\end{array}$ & $\begin{array}{l}W \text {-end } \\
W \text {-day } \\
W \text {-end } \\
W \text {-day } \\
W \text {-end } \\
W \text {-day }\end{array}$ & $\begin{array}{l}01 / 30 / 1994 \\
02 / 03 / 1994 \\
06 / 26 / 1994 \\
06 / 30 / 1994 \\
10 / 02 / 1994 \\
10 / 06 / 1994\end{array}$ & $\begin{array}{r}25.09 \\
24.00 \\
0.00 \\
0.00 \\
20.14 \\
25.12\end{array}$ & $\begin{array}{l}\text { Boluga } 1 \\
\text { Boluga } 1 \\
\\
\text { Boluga } 2 \\
\text { Boluga } 2\end{array}$ \\
\hline \multicolumn{5}{|c|}{ Estimated Annual Not Operating Savings } & 17.92 & \\
\hline 1996 & $\begin{array}{l}\text { Winter } \\
\text { Summer } \\
\text { Spring/Fall }\end{array}$ & $\begin{array}{l}\text { Sunday } \\
\text { Thursday } \\
\text { Sunday } \\
\text { Thursday } \\
\text { Sunday } \\
\text { Thursday }\end{array}$ & $\begin{array}{l}\text { W-end } \\
W \text {-day } \\
W \text {-end } \\
W \text {-day } \\
W \text {-end } \\
W \text {-day }\end{array}$ & $\begin{array}{l}02 / 04 / 1996 \\
02 / 08 / 1996 \\
06 / 30 / 1996 \\
07 / 04 / 1996 \\
10 / 06 / 1996 \\
10 / 10 / 1996\end{array}$ & $\begin{array}{r}5.86 \\
61.78 \\
66.18 \\
43.05 \\
43.04 \\
74.63 \\
\end{array}$ & $\begin{array}{l}\text { Bernice } 4 \\
\text { Beluga } 2 \\
\text { Beluga } 2 \\
\text { Bernice } 4 \\
\text { Bernice } 4 \\
\text { Bernice } 4\end{array}$ \\
\hline \multicolumn{5}{|c|}{ Estimated Annual Not Operating Benofits } & 54.99 & \\
\hline 2000 & $\begin{array}{l}\text { Winter } \\
\text { Summer } \\
\text { Spring/Fall }\end{array}$ & $\begin{array}{l}\text { Sunday } \\
\text { Thursday } \\
\text { Sunday } \\
\text { Thursday } \\
\text { Sunday } \\
\text { Thursday }\end{array}$ & $\begin{array}{l}\text { W-end } \\
W \text {-day } \\
W \text {-end } \\
W \text {-day } \\
W \text {-end } \\
\text { W-day }\end{array}$ & $\begin{array}{l}01 / 30 / 2000 \\
02 / 03 / 2000 \\
06 / 25 / 2000 \\
06 / 29 / 2000 \\
10 / 01 / 2000 \\
10 / 05 / 2000\end{array}$ & $\begin{array}{r}7.41 \\
65.87 \\
7.10 \\
50.99 \\
0.00 \\
0.00\end{array}$ & $\begin{array}{c}\text { Bernice } 4 \\
\text { Beluga } 1 \\
\text { Bernice } 4 \\
\text { Bernice } 3\end{array}$ \\
\hline
\end{tabular}

The "displaced unit" is the unit for which the greatest savings could be obtained by decommitting the unit. The column in Table 2-4 labelled "Net Operating Benefits" expresses the savings in terms of dollars per year of battery capacity, assuming that the battery is the same size as the displaced unit and that all 365 days of the year were identical to the one for which the calculation is being made. The "annual net operating benefit" value is the weighted average of the daily values based on the number of weekdays and weekend days in each season during the entire year. ${ }^{4}$

As defined in Table 2-4, net operating benefits include all dynamic operating benefits, i.e., load following cost savings and minimum load cost savings. Most of the dynamic operating cost savings from Chugach Electric Association's system result from minimum load cost savings, which are on the order of thousands of dollars per day for each of the five marginal units. Load

4. The definitions of the seasons were as follows:

$\begin{array}{ll}\text { Winter } & 4 \text { months } \\ \text { Summer } & 3 \text { months } \\ \text { Fall/Spring } & 5 \text { months }\end{array}$


llowing costs are in the order of hundreds to thousands of dollars per day for each of the five units.

Figures 2-5, 2-6, and 2-7 show the actual MW loadings for three of the marginal units for the days on which the dynamic operating cost savings would be greatest from decommitting these units. Most of the time, the units operate far from their most efficient loadings (17 MW for Beluga 1 and 2, and $25 \mathrm{MW}$ for Bernice 4).

The dynamic operating benefits for each day are shown graphically in Figures 2-8, 2-9, and 2-10, for the years 1994, 1996, and 2000, respectively. As a result of higher utilization of peaking units during weekdays, dynamic operating benefits are generally higher on weekdays than during the weekend.

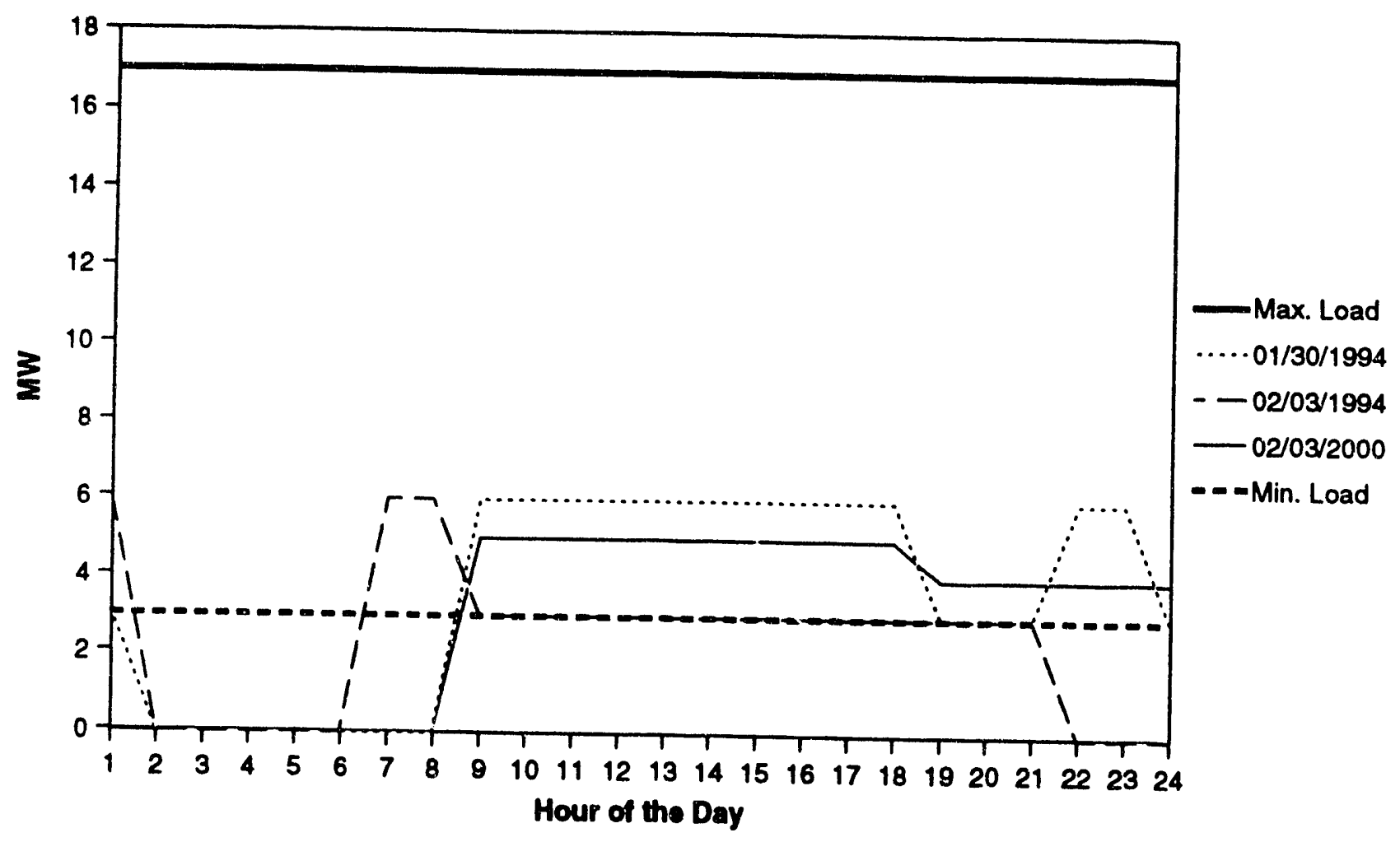

Figure 2-5. Dally Load for Beluga 1 Combustion Turbine Unit 
Potential Generation Benefits 2-13

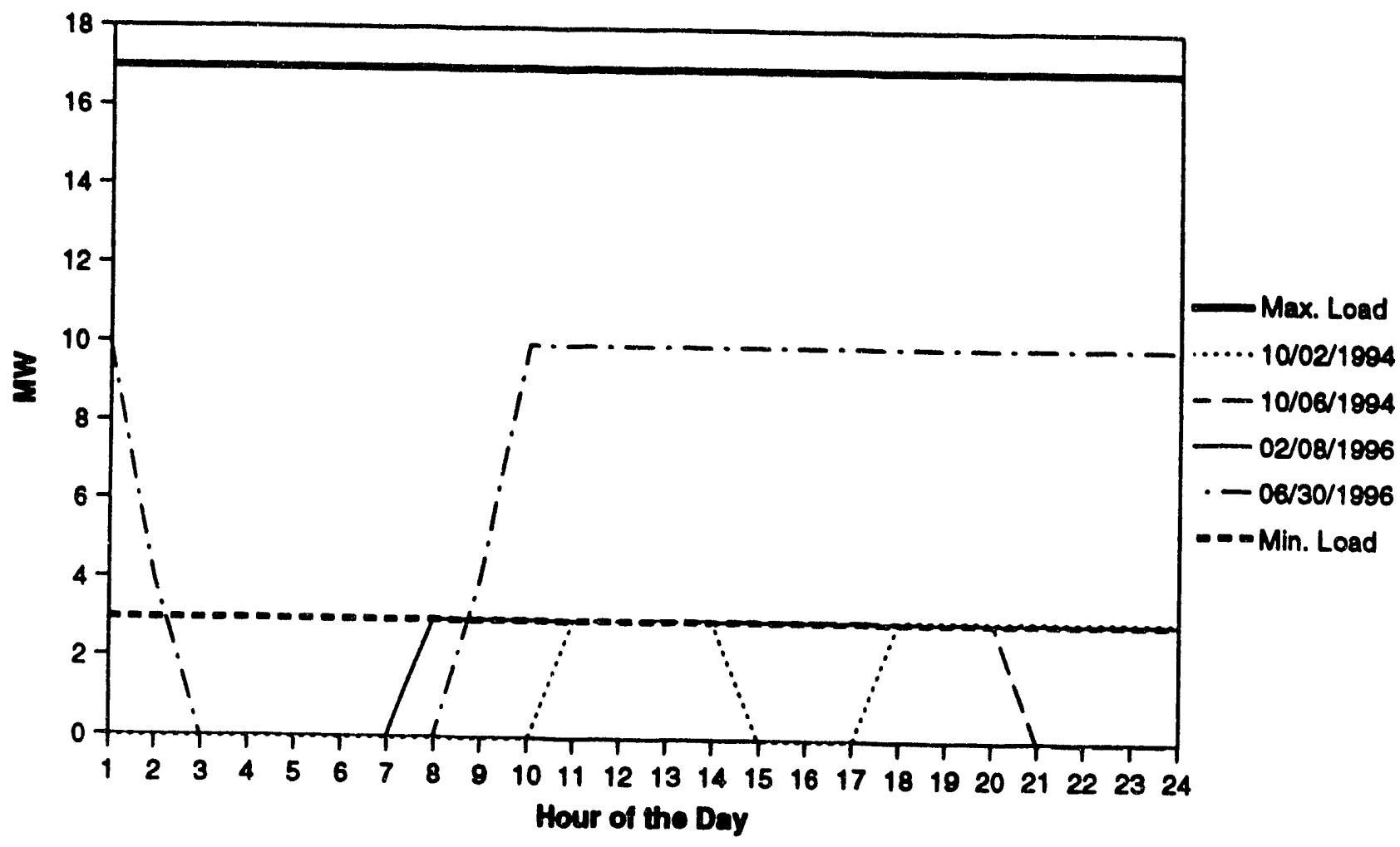

Figure 2-6. Dally Load for Beluga 2 Combustion Turbine Unit

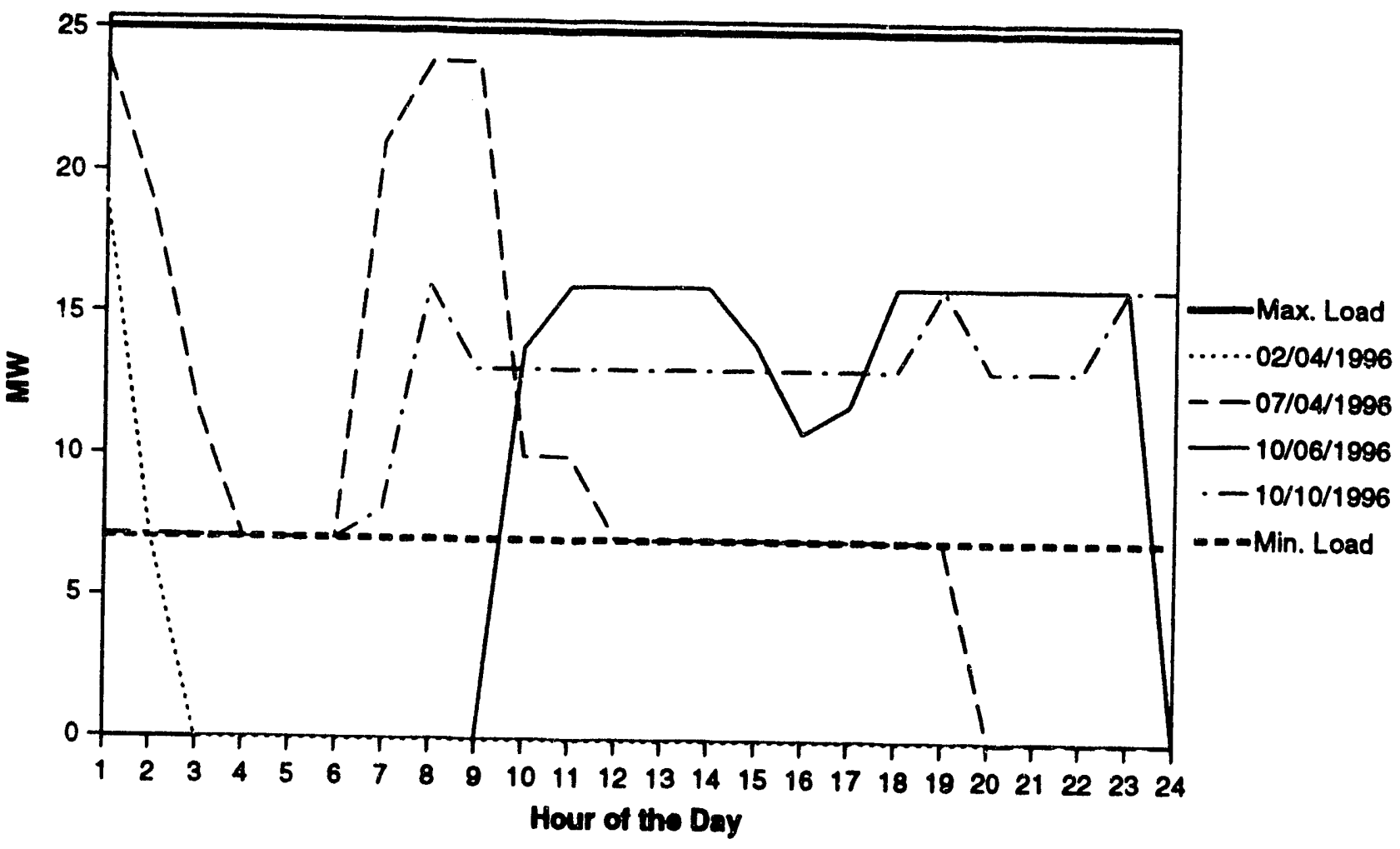

Figure 2-7. Dally Load for Bernice 4 Combustion Turbine Unit 


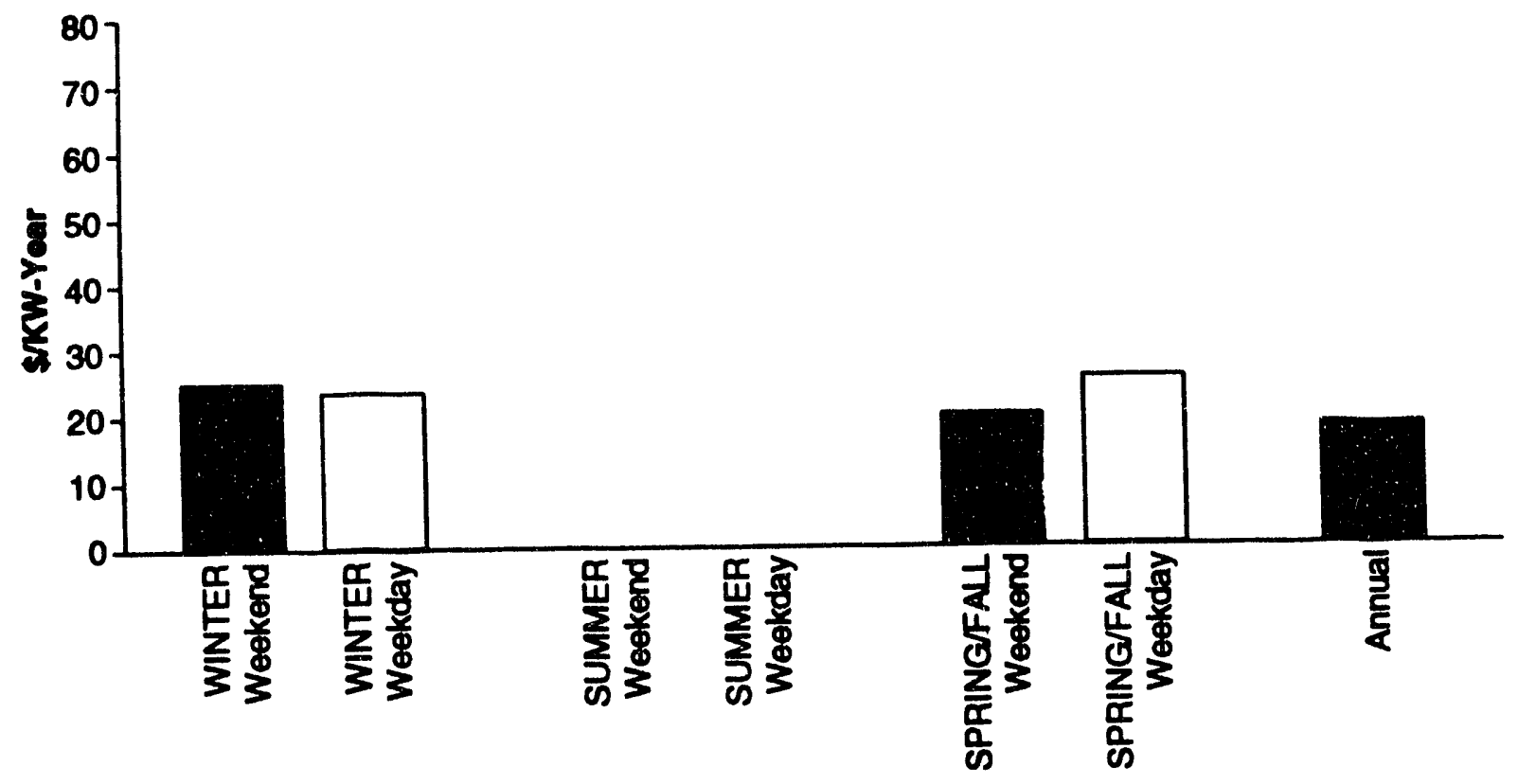

Flgure 2-8. Net Operating Benefits In 1994

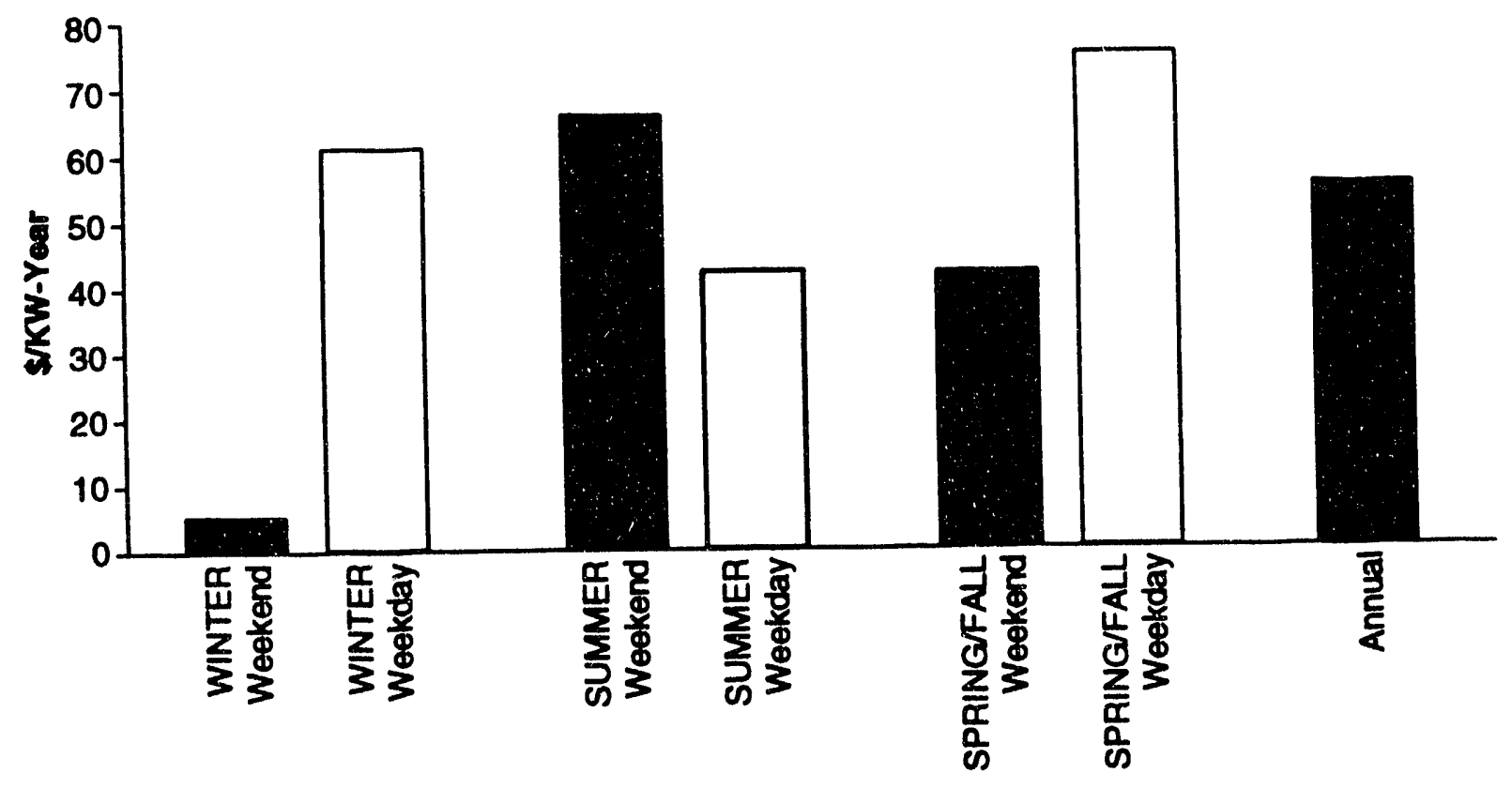

Figure 2-9. Net Operating Benefits in 1996 


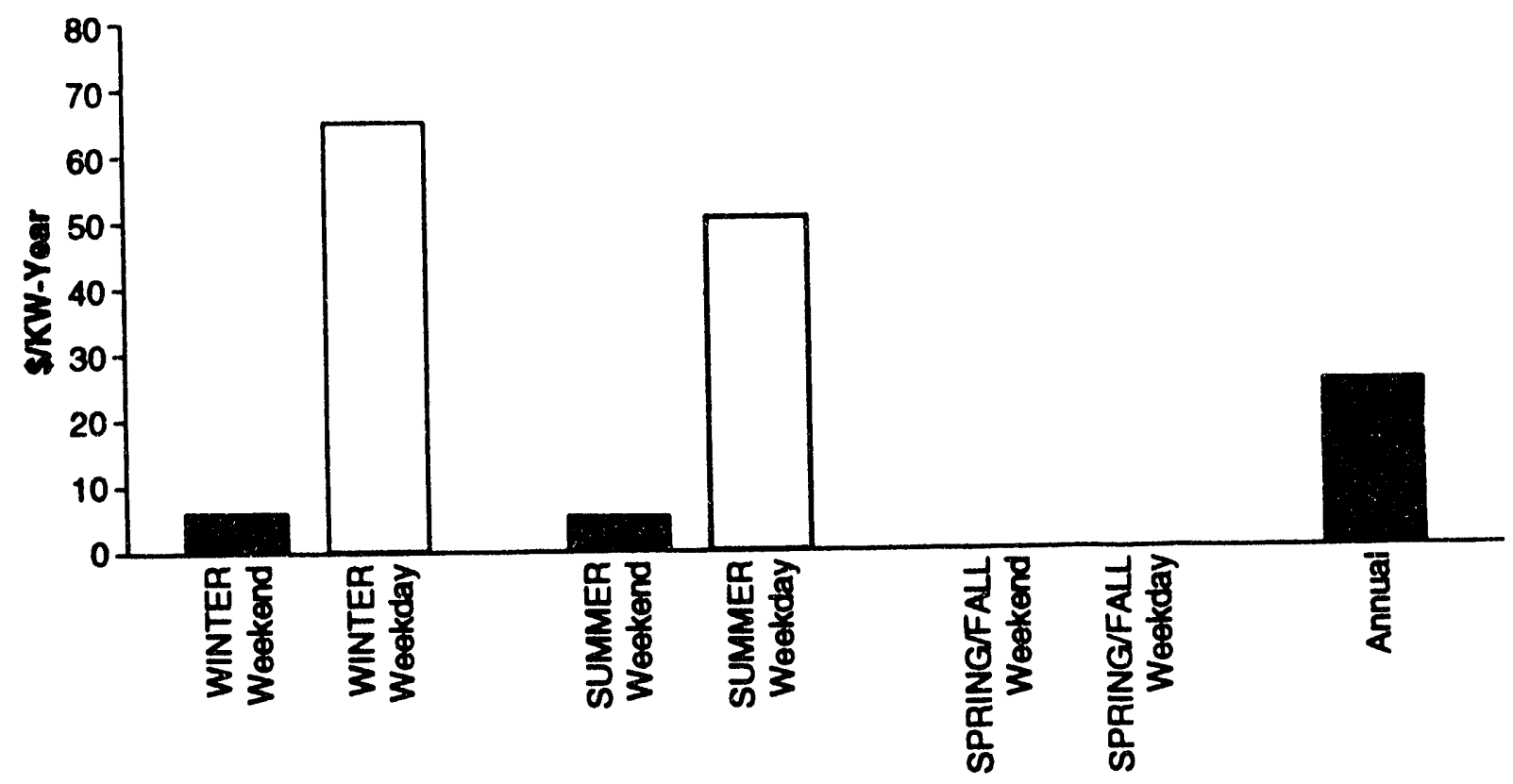

Figure 2-10. Net Operating Benefits in 2000

Why do the net operating benefits vary so much from year to year and even from day to day within each year? Why are they substantial on some days and zero on others? The variation is due primarily to four factors:

1. Increases in natural gas prices from year to year.

2. Differences in loads between weekdays and weekends.

3. Differences in loads among seasons.

4. Load growth from year to year.

Higher natural gas prices mean higher system lambdas and higher average fuel costs. Since net operating benefits are roughly proportional to the difference between average fuel cost and system lambda, both of which are roughly proportional to fuel price, higher fuel prices translate directly to higher net operating benefits.

The differences in loads across days, seasons, and years translate directly to differences in system operation. In particular, the units identified as marginal are sometimes operated 24 hours of the day, sometimes only a few hours of the day, and sometimes not at all. This is the direct cause of the huge variation in net operating benefits. In particular, for the days with no benefits, none of the marginal units operated at all. 
One might expect that as load grows, the marginal units would be operated more hours. This is not necessarily the case, however. In general, MAINPLAN or any other production simulation operates the set of units that minimizes costs. Since larger units typically are more efficient, operating a few large units is preferred to operating many small units. For the CEA system at relatively low loads (Summer, 1994), only the two largest, most efficient thermal units operate, and there are no potential savings from batteries. At higher loads (Spring/Fall, 1994), smaller, less efficient units must also operate to provide spinning reserve; these units could be decommitted if the system contained enough battery storage, yielding substantial benefits. At still higher loads (Spring/Fall, 2000), the smaller thermal units are replaced by a third large, efficient unit (Beluga 3), and there are no small units to decommit. At yet higher loads (Winter, all three years), smaller units are again required, and there are potential savings from decommitting these smaller units if there is enough battery capacity. Thus, for the CEA system as simulated by MAINPLAN, there is no simple correlation between load levels and the operation of smaller units.

Three limitations were made necessary by the screening nature of this analysis. First, we considered only a limited number of days in each year, leading to "all or nothing" results, best exemplified by the values of net operating benefits for the different days in the year 2000 . As a result of looking at such a small number of days, chosen before examining system operation and before calculating the benefits of storage on these days, the benefits for 1994 and 2000 are probably underestimatea, while those for 1996 are probably overestimated.

Second, the results are based on the outputs of a production simulation model, which indicate that on many days the marginal units do not operate at all. In practice, the marginal units may operate more than indicated by the production simulation, yielding greater benefits from using batteries to decommit the marginal units.

Third, we calculated benefits only when it was possible to decommit a marginal unit for the whole day in question. However, it is possible that even on days when none of the five marginal units operates, operation of other units could be modified to produce operating benefits. For example, on October 1, 2000, none of the marginal units operates. However, three thermal units-Beluga 3, Beluga 68, and Beluga 78-are all operating with substantial slack capacity for several hours. With 20 to $25 \mathrm{MW}$ of battery capacity on the system, Beluga 3 could be replaced by the excess capacity of the other two units from 2 am to $9 \mathrm{pm}$, providing substantial dynamic operating benefits.

Taking these limitations into account, annual net operating benefits of $\$ 40$ to $\$ 70$ per $\mathrm{kW}$ of battery capacity per year, levelized in current dollars, would seem a reasonable estimate of the generation benefits of adding battery capacity to the CEA system. 


\section{SPINNING RESERVE/LOAD SHEDDING BENEFITS}

\section{INTRODUCTION}

This section describes the effectiveness of utilizing a battery energy storage facility in lieu of carrying actual spinning reserve on the combustion turbines of the Chugach Electric Association (CEA) system. Cases have been run to determine how various battery facility sizes will affect load shedding in the CEA system when combined with various levels of combustion turbine spinning reserve on the Railbelt system.

Load shedding may occus following the loss of a generating unit in the Railbelt system. The load shedding which occurs is a function of the number of generating units on-line and the amount of spinning reserve. As an alternative to carrying spinning reserve on generators, a battery of sufficient size can be used to reduce the frequency decay following a resource deficiency and prevent load shedding. To study the effectiveness of a battery, a number of parametric case studies have been executed. In each case, a loss of generation is introduced and the frequency decay and load shedding responses are observed.

Previous studies of the Railbelt system have shown that generator spinning reserve must be delivered quickly following a resource deficiency in order to minimize load shedding. Combustion turbines are the only type of resource on the Railbelt system which can provide "fast spin." Therefore, in this study, only combustion turbine spinning reserve was considered when calculating available spinning reserve levels. Hydroelectric and steam units were considered to have too slow of a response to provide sufficient spinning reserve to prevent or reduce load shedding.

ivinter peak and summer normal load conditions have been evaluated. The winter peak load condition corresponds to the highest load level and therefore the highest levels of generation (i.e., largest number of on-line generators and maximum system inertia levels). Loss of a heavily loaded jenerator under such conditions will cause a modere te decrease in frequency at a relatively slow rate. Underfrequency load shedding in the CEA system can occur under such conditions if combustion turbine spin is not adequate. However, overshedding of load is usually not a problem.

Under summer normal load conditions, the number of generators on line is at a minimum. Loss of a 'arge generating unit is a problem due to the lack of inertia on the system. 
Under such conditions, large frequency deviations are likely with a fast rate of frequency decay. This can result in overshedding of load (i.e., load shedding greater than necessary.)

For the winter peak load condition, four scenarios have been studied. These scenarios differ by the amount of combustion turbine spinning reserve on the Railbelt system and/or the amount of load shed in lieu of actual spin. In all four scenarios, the disturbance consists of moderate size loss of generation (Beluga $\# 8$ at $54 \mathrm{MW}$ ). For two scenarios, a $95 \mathrm{MW}$ loss of generation (AMLP \#6 \& 7) is also studied.

For the summer load condition, three scenarios are studied. These three scenarios differ by the amount of combustion turbine spirining reserve on the system and the number of combustion turbines which are used to provide the spin. From these case studies, the effectiveness of a battery storage facility to provide spinning reserve for the CEA system is determined. The scenarios considered in this study are summarized in Table 3-1.

Table 3-1

SUMMARY OF CEA LOAD SHEDDING ANALYSIS

Spinning Reserve Requirement of Rallbelt System $=112 \mathrm{MW}$

\begin{tabular}{|c|c|c|c|c|}
\hline $\begin{array}{l}\text { Initlal } \\
\text { Conditions }\end{array}$ & $\begin{array}{c}\text { CT Spinning Reserve } \\
\text { Deflet. or Surplus w/o } \\
\text { Battery (NW) }\end{array}$ & $\begin{array}{l}\text { Battory Slzes } \\
\text { (NMW) }\end{array}$ & $\begin{array}{c}\text { Loses of } \\
\text { Ceneration (MW) }\end{array}$ & $\begin{array}{l}\text { Load } \\
\text { (MW) }\end{array}$ \\
\hline \multicolumn{5}{|c|}{ Winter Peak Load } \\
\hline $\begin{array}{l}\text { Scenario 1: Railbelt Spinning } \\
\text { Reserve Requirements Met }\end{array}$ & $\begin{array}{l}\text { CEA }=-15.6 \\
\text { AMPL }=+26.3 \\
\text { GVEA+FMUS }=-9.2 \\
\text { Total }=+1.5\end{array}$ & $\begin{array}{c}0,15,20,25 \\
30\end{array}$ & 54 & 692 \\
\hline $\begin{array}{l}\text { Scenario 2: Railbelt Spin Not } \\
\text { Met; CEA Deficit of } 15 \mathrm{MW}\end{array}$ & $\begin{array}{l}\text { CEA }=-15.4 \\
\text { AMLP }=-4.7 \\
\text { GVEA+FMUS }=-9.2 \\
\text { Total }=-29.3\end{array}$ & $\begin{array}{c}0,15,20,25 \\
30\end{array}$ & 54 & 692 \\
\hline $\begin{array}{l}\text { Scenario 3: Spin Not Met; } \\
\text { CEA Deficit of } 15 \text { MW; GVEA } \\
\text { Load Shed in Lieu of Spin }\end{array}$ & $\begin{array}{l}\text { CEA }=-15.4 \\
\text { AMLP }=-4.7 \\
\text { GVEA+FMUS }=-9.2 \\
\text { Total }=-29.3\end{array}$ & $\begin{array}{c}0,15,20,25 \\
30,40\end{array}$ & 54,95 & 692 \\
\hline $\begin{array}{l}\text { Scenario 4: Spin Not Met; } \\
\text { CEA Deficit of } 40 \text { MW; GVEA } \\
\text { Load Shed in Lieu of Spin }\end{array}$ & $\begin{array}{l}\text { CEA }=-39.6 \\
\text { AMLP }=-4.7 \\
\text { GVEA+FMUS }=-9.2 \\
\text { Total }=-53.5\end{array}$ & $\begin{array}{c}0,15,20,25,30 \\
40,50\end{array}$ & 54,95 & 692 \\
\hline \multicolumn{5}{|c|}{ Summer Load } \\
\hline $\begin{array}{l}\text { Scenario 5: Spin Not Met; } \\
\text { Beluga \#1 \& \#2 On; GVEA } \\
\text { Load Shed in Lieu of Spin }\end{array}$ & $\begin{array}{l}\text { CEA }=+11.1 \\
\text { AMLP }=-9.2 \\
\text { GVEA+FMUS }=-9.2 \\
\text { Total }=-7.3\end{array}$ & $0,15,20,25$ & 50 & 254 \\
\hline $\begin{array}{l}\text { Scenario 6: Spin Not Met; } \\
\text { Beluga \#1 On, \#2 OH; GVEA } \\
\text { Load Shed in Lieu of Spin }\end{array}$ & $\begin{array}{l}\text { CEA }=-4.9 \\
\text { AMLP }=-9.2 \\
\text { GVEA+FMUS }=-9.2 \\
\text { Total }=-23.3\end{array}$ & $0,15,20,25$ & 50 & 254 \\
\hline $\begin{array}{l}\text { Scenario 7: Spin Not Met; } \\
\text { Beluga \#1 \& \#2 OH; GVEA } \\
\text { Load Shed in Lieu of Spin }\end{array}$ & $\begin{array}{l}\text { CEA }=-19.9 \\
\text { AMLP }=-9.2 \\
\text { GVEA+FMUS }=-9.2 \\
\text { Total }=-38.3\end{array}$ & $0,15,20,25$ & 50 & 254 \\
\hline
\end{tabular}


It should be noted that in some of the scenarios shown in Table 3-1, the Railbelt as a whole or particular utilities are deficient in the required amount of spinning reserve. In some scenarios, it is assumed that surplus spin in one utility is used to cover the spinning reserve requirements of another. These scenarios are a departure from the way the spinning reserve is handled in actual practice. These scenarios were established merely to create varying levels of spinning reserve on the Railbelt system for analysis of battery size options and benefits. Thus, the feasibility and cost/benefits of reserve sharing were not considered in the analysis.

\section{CONCLUSION}

For both load conditions studied, a battery storage facility is effective in reducing or preventing load shedding in the CEA system. For the lightly loaded system condition, a battery facility of sufficient size to eliminate load shedding on the CEA system also eliminates load shedding in the Fairbanks area.

A battery installed in the CEA system provides the following benefits in the event of a moderate loss of generation ( $54 \mathrm{MW}$ ) on a heavily loaded system. The $15 \mathrm{MW}$ battery will provide enough spinning reserve to prevent load shedding if the CEA system has a $15 \mathrm{MW}$ deficit in its combustion turbine spinning reserve requirement and the rest of the system is no more than $5 \mathrm{MW}$ deficient. In the event that the CEA system is $40 \mathrm{MW}$ deficient of combustion turbine spinning reserve, a $25 \mathrm{MW}$ battery will prevent load shedding on the CEA system. A $25 \mathrm{MW}$ battery will also prevent load shedding in the CEA system if CEA is $15 \mathrm{MW}$ deficient and the remainder of the Railbelt system is $15 \mathrm{MW}$ deficient in combustion turbine spinning reserve.

In the event of a large loss of generation ( $95 \mathrm{MW}$ ) on a heavily loaded system, the battery facility provides the following benefits. For Scenario 3, where there is a $29 \mathrm{MW}$ deficit (without the battery) in the Railbelt system combustion turbine spinning reserve, a $30 \mathrm{MW}$ battery will reduce CEA load shedding to $23 \mathrm{MW}$ and a $35 \mathrm{MW}$ battery will eliminate CEA load shedding. For Scenario 4, which has a $54 \mathrm{MW}$ spinning reserve deficit (without the battery), a $40 \mathrm{MW}$ battery will limit CEA load shedding to $23 \mathrm{MW}$. This is compared to $62 \mathrm{MW}$ of load shedding that occurs in the CEA system if only a $30 \mathrm{MW}$ battery is used.

For the lightly loaded system, replacing part of the spinning reserve provided by combustion turbines with a battery eliminates or reduces the amount of load shedding in the CEA system. The more spinning reserve that is provided by battery energy storage in lieu of combustion turbine spinning reserve, the less load shedding that will occur. This is the case even when system inertia is reduced by removing the combustion turbine units which are carrying the spin. This is due to the extremely fast response of the battery as compared to the response of the combustion turbines. 


\section{STUDY CONDITIONS}

A battery storage facility, as modeled in this study, can provide its full rating nearly instantaneously. Moreover, the output of a battery facility can be cycled around some desired operating point continuously on a repetitive basis. The amount of power that the battery supplies is directly proportional to the frequency deviation in the system. The droop setting of the battery controller can be set to provide full battery response to small underfrequency deviations. Thus, the nature and characteristics of a battery storage facility allow droop settings as low as 0.5 to $1.0 \%$. A controller droop setting of $1.0 \%$, for example, would allow a battery to go from zero to full output as the frequency decreases from $60 \mathrm{~Hz}$ to $59.4 \mathrm{~Hz}$.

Generators are a mechanical system and have some finite "cycling" capability. Furthermore, for parallel operation, some significant amount of droop is necessary in generator governors in order to achieve control stability. Thus, generators in the Railbelt system have droops of approximately 4 to $5 \%$. Also, since generators have some finite response rate capabilities, smaller droops would not necessarily translate to a faster response to frequency deviations. Smaller droops would only minimize the steady-state frequency deviation. Smaller droops would also increase the "cycling" of the generators in response to system frequency deviations.

Because the first stage of load shedding in the CEA system operates at $59.3 \mathrm{~Hz}$ (i.e., backup load shedding relays), a droop of $1 \%$ appears to be a reasonable objective for a battery storage facility. This assures the battery will supply its full rating before load shedding relays in the CEA system operate.

The droop of the controller of the battery can be reduced. Generally the lower the droop setting, the lower the overall system frequency deviation. Moreover, since the speed of response of a battery storage facility is (for all practical purposes) unlimited, smaller droops also reduce the rate of frequency decay following a resource deficiency. Cases were run to validate this assumption.

A battery with smaller droop was not always found to be advantageous. In certain situations, a battery with a very small droop ( $0.5 \%)$ deferred the actuation of "load shed in lieu of spin" in the GVEA area thereby increasing load shedding in the CEA area. Thus, from the perspective of the CEA system, the optimum battery facility droop will be one which causes the battery to reach full output before the CEA load shedding relays operate, but will not delay load shedding which should occur elsewhere in the Railbelt system. Based on current load shedding relay settings, $1 \%$ appears to be the best droop setting for a battery facility on the CEA system.

For this study, the effectiveness of batteries ranging in size from 15 to $50 \mathrm{MW}$ is studied. In some cases, the battery cannot prevent load shedding. However the battery can reduce the amount of load shedding in the CEA system. By running the same case without a battery, this reduction in load shedding is determined. 
The effectiveness of a battery to reduce load shedding, as summarized in Tables 3-2 through 3-5 below, would be different if the first load shedding point used on the CEA system were lower. The representation of CEA's backup relays which operate at $59.3 \mathrm{~Hz}$ require the use of a larger battery in order to eliminate load shedding on the CEA system. If the first step of load shedding on the CEA system occurred at $59.2 \mathrm{~Hz}$ (the first stage of CEA's normal load shedding relays), smaller size batteries would appear more beneficial. Moreover, load shedding in the CEA system would occur at the same point as load shedding in the AMLP system. As shown in Tables 3-2 through 3-5, the use of CEA's backup relays accounts for the load shedding in the CEA system when none occurs in the AMLP system.

The following response data is plotted for each case: frequency and voltage at the International $34.5 \mathrm{kV}$ bus, battery power output, and battery controller output. The simulations were performed using PSS/E, the Power System Simulator for Engineering, developed by Power Technologies, Inc.

\section{SPINNING RESERVE REQUIREMENTS}

The spinning reserve requirement for the Railbelt system is equal to the capacity of the largest on-line unit, or unit pair in the case of combined cycle units. For these studies, the largest "unit" is the AMLP Unit \#6 and \#7 combined cycle pair. Winter capacity of these units is $112 \mathrm{MW}$ and summer capacity is $95 \mathrm{MW}$.

For the two load conditions considered in this study, the spinning reserve requirements for each utility are as follows. For simplicity, the GVEA and FMUS system are combined.

\begin{tabular}{lr}
\multicolumn{2}{c}{ WINTER PEAK LOAD } \\
GVEA + FMUS & $=19.2 \mathrm{MW}$ \\
CEA & $44.9 \mathrm{MW}$ \\
AMLP & $47.9 \mathrm{MW}$ \\
\hline TOTAL & $=112.0 \mathrm{MW}$
\end{tabular}

\begin{tabular}{lr}
\multicolumn{2}{c}{ SUMMER NORMAL LOAD } \\
GVEA + FMUS & $=19.5 \mathrm{MW}$ \\
CEA & $32.3 \mathrm{MW}$ \\
AMLP & $43.2 \mathrm{MW}$ \\
\hline TOTAL & $-95.0 \mathrm{MW}$
\end{tabular}

\section{DISCUSSION}

\section{Winter Peak Load}

The winter peak load scenarios studied are outlined in Table 3-1. This section covers each scenario in more detail and identifies the effectiveness of using various size battery facilities. The generation schedule for each scenario are given in Appendix B. Also, for Scenarios 3 and 4, the GVEA system provides $9.2 \mathrm{MW}$ of load shedding in lieu of spin to compensate for its lack of combustion turbine spinning reserve. 


\section{Scenario 1}

In Scenario 1, Golden Valley and Fairbanks have $10 \mathrm{MW}$ of combustion turbine spinning reserve. Therefore they have a spinning reserve deficit of $9.2 \mathrm{MW}$. CEA has $29.3 \mathrm{MW}$ of combustion turbine spinning reserve without the battery for a deficit of 15.6 MW. AMLP has 74.2 MW of combustion turbine spinning reserve and therefore has $26.3 \mathrm{MW}$ extra. Thus the Railbelt system as a whole has combustion turbine spinning reserves of $113.5 \mathrm{MW}$; a slight surplus.

For Scenario 1, the initial case is run without a battery. Loadshed in lieu of spin in the GVEA system is not utilized. Four different battery sizes are also represented $(15,20,25$ and $30 \mathrm{MW})$, and two different droop settings $(0.5 \%$ and $1 \%)$, are used. A disturbance is produced by tripping the Beluga $\# 8$ unit $(54 \mathrm{MW})$. The plotted responses are shown in Appendix $C$. It can be seen that for all cases with a battery, load shedding does not occur in any utility. If no battery is used, load shedding occurs as follows:

$\begin{array}{cccc}\text { FMUS sheds } & 2.7 \mathrm{MW} & \text { GVEA sheds } & 11.5 \mathrm{MW} \\ \text { CEA sheds } & 0 \mathrm{MW} & \text { AMLP sheds } & 0 \mathrm{MW}\end{array}$

This load shedding is limited to the Fairbanks area, but it slightly exceeds the amount of load which would need to be shed as "load shed in lieu of spin." As expected, frequency deviation decreases as battery size increases. With the $15 \mathrm{MW}$ battery, frequency settles at $59.4 \mathrm{~Hz}$. With the $25 \mathrm{MW}$ battery, frequency settles at $59.6 \mathrm{~Hz}$. Marginally superior performance for all cases is achieved if the battery droop is set at $0.5 \%$. The frequency deviations are smaller and the steady state frequency is slightly higher.

\section{Scenarlo 2}

Scenario 2 differs from Scenario 1 by the amount of spinning reserve available to the system as shown in Table 3-1. AMLP Unit \#8 (85 MW capability), running at $23.8 \mathrm{MW}$ in Scenario 1, is replaced with Units \#1 and \#5 which have a $17 \mathrm{MW}$ and $37 \mathrm{MW}$ capability respectively. This reduces the spinning reserve of AMLP by $32 \mathrm{MW}$ with respect to the Scenario 1. AMLP is now 4.7 MW deficient in combustion turbine spin, CEA is still 15.4 MW deficient without a battery, and GVEA and FMUS are still 9.2 MW deficient. The Railbelt system as a whole is deficient by $29.3 \mathrm{MW}$ without a battery.

Studies were run without a battery and with $15,20,25$ anc $30 \mathrm{MW}$ batteries at $0.5 \%$ and $1 \%$ droop. A disturbance is introduced by tripping the Beluga $\# 8$ unit ( $54 \mathrm{MW}$ ). The plotted responses are shown in Appendix D. Again, loadshed in lieu of spin is not used in the GVEA system. The load shedding responses for each case are given in Table 3-2.

A $15 \mathrm{MW}$ battery is able to reduce CEA load shedding (from the no battery case) only if a $0.5 \%$ droop is used. Increasing the battery size to $20 \mathrm{MW}$ will reduce CEA load shedding 
from 23 to $17 \mathrm{MW}$, and this reduction is not sensitive to the droop used on the battery. However, a $25 \mathrm{MW}$ battery is needed to prevent load shedding on the CEA system. This larger battery also eliminates load shedding in the Fairbanks area. A greater safety margin and smaller frequency deviation are obtained with a $30 \mathrm{MW}$ battery.

In this scenario, except for the $15 \mathrm{MW}$ battery case, a lower droop setting on the battery facility has no effect on load shedding. By analyzing the frequency plots though, one can see that smaller frequency deviations occur with a lower droop setting.

Table 3-2

LOADSHEDDING RESPONSES FOR SCENARIO 2 AMOUNT OF LOAD SHED IN EACH UTILITY (MW)

\begin{tabular}{cccccc}
\hline $\begin{array}{c}\text { BATTERY SIZE } \\
\text { (MW) }\end{array}$ & $\begin{array}{c}\text { DROOP } \\
\text { SETTING(\%) }\end{array}$ & CEA & AMLP & GVEA & FMUS \\
\hline No Battery & No Battory & 23 & 0 & 23 & 2.7 \\
15 & 1.0 & 23 & 0 & 11.5 & 2.7 \\
15 & 0.5 & 17 & 0 & 11.5 & 2.7 \\
20 & 1.0 & 17 & 0 & 11.5 & 2.7 \\
20 & 0.5 & 17 & 0 & 11.5 & 2.7 \\
25 & 1.0 & 0 & 0 & 0 & 0 \\
25 & 0.5 & 0 & 0 & 0 & 0 \\
30 & 1.0 & 0 & 0 & 0 & 0 \\
30 & 0.5 & 0 & 0 & 0 & 0
\end{tabular}

\section{Scenarlo 3}

Scenario 3 has the same generation condition as Scenario 2. However, in this scenario, the GVEA load shed in lieu of spin is activated. This increases the effective spinning reserve in GVEA and in the system by $9.2 \mathrm{MW}$. These relays are activated at $59.7 \mathrm{iz}$ and shed the required amount of load in two seconds. Cases are run with battery sizes of 15, 20 and $25 \mathrm{MW}$ and droops of $0.5 \%$ and $1 \%$. A "no battery" case is also considered. The Beluga \#8 unit is tripped to initiate the frequency decay. The plotted responses are shown in Appendix E. Load shedding occurs only for the case without a battery as follows:

$$
\begin{aligned}
\text { CEA } & =17 \mathrm{MW} & \text { AMLP } & =0 \mathrm{MW} \\
\text { GVEA } & =23 \mathrm{MW} & \text { FMUS } & =2.7 \mathrm{MW}
\end{aligned}
$$

The amount of load shed in the GVEA system is in addition to the $9.2 \mathrm{MW}$ of load shed in lieu of spin. It is seen that a $15 \mathrm{MW}$ battery will prevent load shedding in the CEA system. Either a $0.5 \%$ droop or a $1 \%$ droop will prevent load shedding in this scenario. In general, the cases with the lower droop setting have smaller transient frequency deviations. However, the final steady state frequency is approximately equal for either droop setting. 
Cases were also run with the AMLP \#6 and \#7 units tripped. This represents the largest generation loss (95 MW) for the winter peak load condition. The plotted responses are also given in Appendix E. The load shedding responses are given in Table 3-3. If a $30 \mathrm{MW}$ battery is used, load shedding in the CEA system is reduced to $23 \mathrm{MW}$. A $35 \mathrm{MW}$ battery will eliminate load shedding.

Table 3-3
LOAD SHEDDING RESPONSES FOR SCENARIO 3 WITH THE AMLP
UNITS TRIPPED - AMOUNT OF LOAD SHED IN EACH UTILITY (MW)
\begin{tabular}{ccccccc}
\hline BATTERY & DROOP & & & & \\
SIZE (MW) & $(\%)$ & CEA & AMLP & GVEA & FMUS \\
\hline 15 & 1.0 & 23 & 0 & 11.5 & 2.7 \\
20 & 1.0 & 23 & 0 & 11.5 & 2.7 \\
25 & 1.0 & 23 & 0 & 8.8 & 2.7 \\
30 & 1.0 & 23 & 0 & 8.8 & 2.7 \\
35 & 1.0 & 0 & 0 & 8.8 & 2.7 \\
40 & 1.0 & 0 & 0 & 8.8 & 2.7
\end{tabular}

\section{Scenario 4}

In Scenario 4, spinning reserve is reduced further from the Scenario 3 level by taking the Bernice Lake unit off-line. The spinning reserve in the CEA system without a battery is reduced to 5.3 MW. CEA is now deficient 39.6 MW of combustion turbine spinning reserve. The system as a whole is deficient by $44.3 \mathrm{MW}$. The following cases are run: battery size of 15, 20, 25 and $30 \mathrm{MW}$ with droop set at $0.5 \%$ and $1 \%$. Also a case is run without a battery. The Beluga \#8 unit (54 MW) is tripped. The plotted responses are shown in Appendix F. The load shedding responses of the system for each battery size are given in Table 3-4.

With a $20 \mathrm{MW}$ battery and a $0.5 \%$ droop setting, $17 \mathrm{MW}$ of load shedding occurs in the CEA system. With a $25 \mathrm{MW}$ battery, CEA sheds no load. Thus, $25 \mathrm{MW}$ is the minimum size required to prevent load shedding in the CEA system under this scenario.

In previous scenarios, a droop setting of $0.5 \%$ was marginally superior to the $1 \%$ droop setting. However, in this scenario, the $0.5 \%$ droop setting causes a greater amount of load shedding in the CEA system than if a $1 \%$ droop is used (for the case with a $20 \mathrm{MW}$ battery.) A $20 \mathrm{MW}$ battery with a $0.5 \%$ droop delays load shed in lieu of spin in the GVEA system. This results in the load shedding relays on the CEA system operating. Therefore, a $1 \%$ droop setting is suggested for the battery controller. This scenario is also run with AMLP Units \#6 and 7, (95 MW) tripped.

The plotted responses are also given in Appendix $\mathrm{E}$. The load shedding responses are given in Table 3-4. For this large generation loss, even a 40 or $50 \mathrm{MW}$ battery cannot prevent load shedding in the CEA system. However, the amount of load shedding can be reduced. From Table 3-4, it can be seen that a $30 \mathrm{MW}$ battery allows $62.5 \mathrm{MW}$ of load shedding, whereas a $40 \mathrm{MW}$ battery reduces load shedding to $23 \mathrm{MW}$. Even though a $40 \mathrm{MW}$ battery may not be 
feasible due to economic constraints, a $10 \mathrm{MW}$ change in battery size can reduce load shedding considerably.

Table 3-4

LOAD SHEDDING RESPONSES FOR SCENARIO 4 -

AMOUNT OF LOAD SHED IN EACH UTILITY (MW)

\begin{tabular}{|c|c|c|c|c|c|}
\hline $\begin{array}{l}\text { BATTERY } \\
\text { SIZE (MW) }\end{array}$ & DROOP (\%) & CEA & AMLP & GVEA & FMUS \\
\hline \multicolumn{6}{|c|}{ S4 MW GENERATON LOSS } \\
\hline $\begin{array}{c}\text { No Battery } \\
15 \\
15 \\
20 \\
20 \\
25 \\
25 \\
30 \\
30\end{array}$ & $\begin{array}{c}\text { No Battery } \\
1.0 \\
0.5 \\
1.0 \\
0.5 \\
1.0 \\
0.5 \\
1.0 \\
0.5\end{array}$ & $\begin{array}{c}23 \\
23 \\
23 \\
0 \\
17 \\
0 \\
0 \\
0 \\
0 \\
\ldots \ldots \ldots . .\end{array}$ & $\begin{array}{l}0 \\
0 \\
0 \\
0 \\
0 \\
0 \\
0 \\
0 \\
0\end{array}$ & $\begin{array}{c}27.4 \\
8.8 \\
8.8 \\
7 \\
8.8 \\
7 \\
8.8 \\
0 \\
0\end{array}$ & $\begin{array}{l}2.7 \\
2.7 \\
2.7 \\
2.7 \\
2.7 \\
2.7 \\
2.7 \\
0 \\
0\end{array}$ \\
\hline \multicolumn{6}{|c|}{95 MW GENERATION LOSS } \\
\hline $\begin{array}{l}20 \\
30 \\
40 \\
50\end{array}$ & $\begin{array}{l}1.0 \\
1.0 \\
1.0 \\
1.0\end{array}$ & $\begin{array}{c}62.5 \\
62.5 \\
23 \\
23\end{array}$ & $\begin{array}{c}11.8 \\
0 \\
0 \\
0\end{array}$ & $\begin{array}{c}30.1 \\
11.5 \\
30.1 \\
8.8\end{array}$ & $\begin{array}{l}2.7 \\
2.7 \\
2.7 \\
2.7\end{array}$ \\
\hline
\end{tabular}

\section{Summer Normal Load}

The summer normal load scenarios studied are outlined in Table 3-1. Under the summer normal load condition, the effectiveness of the battery is analyzed by introducing a disturbance consisting of the loss of the largest "unit", the AMLP Unit \#6 and \#7 combined cycle pair at 50 MW total output. This provides a comparable generation loss to the one simulated for the winter load condition (54 MW). However, AMLP \#7 is also carrying $34 \mathrm{MW}$ of the $95 \mathrm{MW}$ of spin, so the system spin is reduced when this unit is tripped.

The composition and amount of the spinning reserve in the system is changed in each of the three scenarios. In all summer load scenarios, load shedding in lieu of spin is utilized in the GVEA system. Also, the battery droop setting in all three scenarios is $1 \%$. The plotted responses for each scenario are given in Appendix G. The load shedding responses are given in Table 3-5.

\section{Scenarlo 5}

In Scenario 5, Beluga units \#1 and \#2 are on-line. They operate primarily to provide the necessary combustion turbine spinning reserve. Cases are run without a battery and with battery sizes of 15,20 and $25 \mathrm{MW}$. In the case without a battery, all of the spinning reserve 
comes from the combustion turbines. The spinning reserve is at least as large as the largest generation loss, but load shedding is not prevented.

From Table 3-5, for the case without a battery, the CEA system sheds 19 MW of load. With a $15 \mathrm{MW}$ battery, load shedding is reduced to 5.1 MW in the CEA system. A $20 \mathrm{MW}$ battery is of sufficient size to eliminate all load shedding in the Railbelt system.

\section{Scenario 6}

For Scenario 6, Beluga \#2, is removed. This effectively reduces spinning reserve by 15 MW. The system inertia in this scenario is also smaller than that of Scenario 5 due to the removal of this machine. Cases are run with no battery and with battery sizes of 15, 20 and 25 MW.

When no battery is used, $19 \mathrm{MW}$ of load shedding occurs in the CEA system. Adding a $15 \mathrm{MW}$ battery decreases load shedding to $7 \mathrm{MW}$ in the CEA system. With a $20 \mathrm{MW}$ battery, load shedding is eliminated in the entire Railbelt system.

By comparing the results of Scenarios 5 and 6, the effectiveness of battery spinning reserve vs. combustion turbine spinning reserve can be observed. The combustion turbine is replaced with a $15 \mathrm{MW}$ battery (Scenario 5 without a battery vs. Scenario 6 with a $15 \mathrm{MW}$ battery) and load shedding is limited to $7 \mathrm{MW}$ in the CEA system. This reduction in load shedding occurs even though the total amount of spinning reserve has not changed and the system inertia is reduced.

\section{Scenario 7}

For Scenario 7, Beluga \#1 and \#2 are removed. This effectively reduces the spinning reserve in the Railbelt system by $31 \mathrm{MW}$. The system inertia is also reduced due to the removal of the two machines. Cases are run with no battery and with battery sizes of 15, 20 and $25 \mathrm{MW}$.

In the case with no battery, $19 \mathrm{MW}$ of load is shed in the CEA system. By the addition of a 15 or $20 \mathrm{MW}$ battery, load shedding is reduced to $7 \mathrm{MW}$ in the CEA system. Load shedding is eliminated from the Railbelt system if a $25 \mathrm{MW}$ battery is used.

By comparing the results of Scenarios 5 and 7, (Scenario 5 without a battery vs. Scenario 7 with a $15 \mathrm{MW}$ battery) the effectiveness of replacing combustion turbine spin with battery spin can again be observed. It is seen that by replacing Beluga $\# 1$ and $\# 2$ with a $15 \mathrm{MW}$ battery, load shedding is reduced from 19 to $7 \mathrm{MW}$ in the CEA system. This occurs even though the total spinning reserve is reduced by $16 \mathrm{MW}$ and the system inertia is also reduced.

By replacing Beluga \#1 and 2 with a $25 \mathrm{MW}$ battery, (Scenario 5 without a battery vs. Scenario 7 with a $25 \mathrm{MW}$ battery) load shedding in the CEA system is eliminated. This is the 
case even though the total spinning reserve has been reduced by $5 \mathrm{MW}$ and the total system inertia is smaller.

Table 3-5

LOAD SHEDDING RESPONSES FOR SCENARINS 5, 6 AND 7 . AMOUNT OF LOAD SHED IN EACH UTILITY (MW) IN ADDITION TO LOAD SHED IN LIEU OF SPIN

\begin{tabular}{cccccc}
\hline & $\begin{array}{c}\text { BATTERY } \\
\text { SAZE (MW) }\end{array}$ & CEA & AMLP & GVEA & FWUS \\
\hline SCENARIO 5 & 0 & 19 & 5.1 & 10.9 & 3.1 \\
& 15 & 5.1 & 0 & 4.1 & 1.2 \\
& 20 & 0 & 0 & 0 & 0 \\
SCENARIO 6 & 25 & 0 & 0 & 0 & 0 \\
& 0 & 19 & 5.1 & 10.9 & 3.1 \\
& 15 & 7 & 0 & 4.1 & 1.2 \\
SCENARIO 7 & 20 & 0 & 0 & 4.1 & 1.2 \\
& 25 & 0 & 0 & 0 & 0 \\
& 15 & 19 & 5.1 & 10.9 & 3.1 \\
& 20 & 7 & 0 & 10.9 & 3.1 \\
& 25 & 7 & 0 & 10.9 & 1.2 \\
& 0 & 0 & 0 & 0 & 0
\end{tabular}




\section{T\&D BENEFITS}

CEA provided information about its long-range plans and about specific projects where a battery storage facility might play a significant T\&D role. After review of the CEA long range plan information, it is believed that the CEA system could recognize some very significant T\&D benefits from the applications of batteries. These T\&D benefits combined with the spinning reserve and reduced load shedding benefits may help justify the application of batteries on the CEA system. The T\&D benefits may also help justify the application of more battery capacity than can be economically supported by just the spinning reserve and reduced load shedding benefits.

The following subsections discuss some specific T\&D projects on the CEA system where battery facilities may provide some significant benefits. It is suggested that these projects be evaluated more thoroughly to quantify the economics of battery facilities for each of these projects.

\section{HUFFMAN SUBSTATION}

The existing Huffman 34.5/12.5 kV Substation serves a significant portion of load in the southeast Anchorage area (see Hillside item below). This substation and the $34.5 \mathrm{kV}$ system which feeds it are heavily loaded. The $34.5 \mathrm{kV}$ system feeding this substation does not have adequate reserve margin to provide adequate service to this substation under single contingency conditions. Two $138 \mathrm{kV}$ transmission lines and a $138 / 34.5 \mathrm{kV}$ transformer at Huffman are proposed to provide support to the $34.5 \mathrm{kV}$ system and the underlying distribution network.

A battery facility at Huffman at the $12.5 \mathrm{kV}$ level could provide several benefits. It could provide voltage support under normal and single contingency conditions which would extend the usefulness of the existing $34.5 \mathrm{kV}$ system thus deferring the need for the $138 / 34.5 \mathrm{kV}$ transformer. Further, it could reduce the var loading on the Huffman load transformer thus increasing its ability to serve area loads. Although the $138 \mathrm{kV}$ feed into Huffman would eventually be required for termination of the second Kenai intertie, a battery facility at Huffman may make it feasible to minimize $138 \mathrm{kV}$ additions (e.g., eliminate or defer the need for the Huffman-University $138 \mathrm{kV}$ line). A battery facility at Huffman used primarily for voltage support (i.e., vars, not real power support) would not undermine or erode the spinning reserve benefits provided by this battery. However, a battery facility at Huffman could provide real power service to loads following transformer failures until distribution switching could be performed. 


\section{HILLSIDE SUBSTATION}

Loss of the Huffman transformer makes it impossible to maintain acceptable distribution voltages in the perimeter areas now served from the Huffman substation. The Hillside $34.5 / 12.5 \mathrm{kV}$ substation (fed via a $34.5 \mathrm{kV}$ line from Huffman) has been proposed to shift load from Huffman. Upgrading of an existing distribution feeder between Huffman and Hillside via an underbuild on the $34.5 \mathrm{kV}$ line is proposed to facilitate back-up during transformer failures at either substation.

The Hillside substation has been built, but the $34.5 \mathrm{kV}$ feed to it has been delayed due opposition by area residents. This has necessitated the use of a $34.5 \mathrm{kV}$ cable circuit instead of an overhead line. This eliminates the possibility of the distribution underbuild to replace the existing distribution feeder. Further, the public opposition may circumvent the possibility of rebuilding the existing distribution feeder as well as constructing a second $34.5 \mathrm{kV}$ feed into the Hillside substation. This may leave Hillside with a single $34.5 \mathrm{kV}$ feed and minimal back up capability via the distribution system.

A battery facility at Hillside and located at the $12.5 \mathrm{kV}$ level could provide two distinct benefits. First, the voltage support provided by a battery may make it feasible to back up the Hillside loads from Huffman over the existing distribution feeder. With a battery facility also at Huffman, the reverse situation may also be true. Thus, battery facilities at Hillside along with Huffman could eliminate or reduce the necessity of rebuilding or replacing the existing Huffman-Hillside distribution feeder. Further, a battery at Hillside may also defer or eliminate the need to build the second $34.5 \mathrm{kV}$ feed into Hillside. As with the battery suggested for Huffman, a battery facility at Hillside would primarily play a var support role thus not undermining the potential spinning reserve benefits. However, it could provide real power support during transformer outages until distribution switching is performed to restore connection to the system.

\section{GIRDWOOD, INDIAN AND PORTAGE SUBSTATIONS}

These substations are taps off of the University-Daves Creek $115 \mathrm{kV}$ line. Even with the presently proposed additions at these locations, service to Indian, Girdwood and Portage loads will be interrupted during outage of the $115 \mathrm{kV}$ line.

Growing loads associated with the ski resort will result in the Girdwood transformer becoming overloaded. A second transformer at Girdwood is proposed, but requires rebuild of the substation. A $25 \mathrm{kV}$ distribution connection between Girdwood and Indian is also proposed. With the proposed additions, Girdwood can back up the Indian loads, but Indian can provide only marginal back up to Girdwood even with the proposed single-phase transformer and regulator additions at Indian. ${ }^{1}$ The Portage substation is proposed for conversion from $12.5 \mathrm{kV}$

1. The Girdwood and Indian distribution systems presently are not in phase. Hot transfer of loads, even with the proposed feeder, will not be possible unless the transformer addition at Indian also corrects the phasing problem. 
to $25 \mathrm{kV}$. Four single phase transformers and regulators are proposed as part of this conversion. Under the present plan, the proposed Portage changes have no impact on Girdwood.

A battery facility at Girdwood could defer the transformer capacity addition at Girdwood. A battery of sufficient size could reduce the var loading and could be used for peak shaving to extend the useful capability of the Girdwood transformer. Further, it could provide service to the important Girdwood loads during outages of the University-Daves Creek $115 \mathrm{kV}$ line or the Girdwood transformer. The battery could be sized to provide load service time sufficient to do sectionalizing of the $115 \mathrm{kV}$ line or to transport portable generation to Girdwood. A battery at Girdwood could also possibly defer the need for the distribution feeder to Indian.

Alternatively, a battery facility at Girdwood could enhance the usability of the pruposed Girdwood-Indian distribution feeder if it is built. Further, it would make feasible the installation of a large, 3-phase LTC transformer at Indian versus the medium sized single phase transformers and regulators now proposed. Thus, the Indian substation via the proposed feeder would be able to back up all of the Girdwood load with battery facility support at Girdwood. Replacing the transformers at Indian with a large unit would eliminate the need to rebuild the Girdwnod substation.

In the long range, a battery facility at Girdwood would also make feasible the use of a larger transformer at Girdwood and the interconnection of the Girdwood and Portage distribution systems. With a $25 \mathrm{kV}$ circuit between Girdwood and Portage (in addition to the Girdwood-Indian tie) and sufficient transformer capacity at Portage (e.g., 14 MVA), a battery facility at Girdwood would provide the ability to back up the loss of a 15/20/25 MVA transformer at Girdwood by using both the Indian and Portage sources. In addition, a Girdwood-Portage tie would provide the necessary back up to the Portage loads. Thus, a battery at Girdwood would facilitate the full interconnection of the Indian, Girdwood and Portage distribution systems, support full back up of Girdwood load from the adjacent substations, and allow the use of single, large, 3-phase LTC transformers at Indian, Girdwood and Portage (e.g., 14, 25 and 14 MVA, respectively). This would minimize (physical) substation expansions at any of these locations which would otherwise be required if multiple transformers are used of if single-phase transformers and regulators are used.

\section{HOPE}

The Village of Hope if fed via a 19 mile long, single-phase line from a simple tap substation on the University-Daves Creek $115 \mathrm{kV}$ line. Due to growing loads at Hope, voltage drop is becoming a problem. In-line voltage regulators for voltage improvement are the proposed near-term solution. The long-term solution is to replace the existing line with a 3phase line and completely rebuild the Hope $115 \mathrm{kV}$ substation. Hope would still have only a single feed after these proposed additions.

A battery facility at the Village of Hope would provide some significant benefits. First, it would provide the necessary voltage support to extend the usefulness of the existing single- 
Thase feed. This would avoid the cost of the regulators and the longer-term costs associated with the line and substation rebuild. Second, a battery facility could provide service security to Hope during outages of the $115 \mathrm{kV}$ line or the radial distribution feed. The battery could be sized to provide 4-8 hour back up capability. This should be sufficient to allowi sisst line repairs to be effected or to bring in portable generation equipment.

A further beneit of a battery facility is that it could provide 3-phase service to Hope from the r xisting single-phase feeder. The single-phase line could power a charger for the battery facility, and the battery power conversion equipment could produce three-phase power for the village. Thus, a battery facility could essentially eliminate the need to perform the proposed conversions, and it would provide reliability benefits which would not be provided by the proposed conversions. 


\section{5}

\section{COST/BENEFIT ANALYYSIS}

In this section the dollar value of the benefits described in the previous three sections is compared to the cost of installing batteries. Following common industry practice, costs and benefits are expressed in 1990 dollars per kilowatt of capacity or dollars per kilowatt-year of capacity; the latter is a current dollar levelized cost over the battery unit's life.

\section{BATTERY CAPITAL COSTS}

Because there are currently only a handful of utility battery installations in operation or planned, there are no commonly accepted estimates for battery storage system costs. In addition, costs are very dependent not only on power capacity and storage capacity, but also on frequency with which the battery is to be charged and discharged and the depth of discharge.

The cost estimates used here are from EPRI's Technical Assessment Guide (TAG). They have already been described in Section 1 of this document. Adjusted for inflation, the total cost is $\$ 703 / \mathrm{kW}$ for a 3-hour battery and $\$ 943 / \mathrm{kW}$ for a 5 -hour battery, including land cost. The TAG does not provide a cost estimate for a one-half or 1-hour battery that could provide spinning reserve but would have minimal energy capacity; we estimate that such a battery would cost $\$ 350 / \mathrm{kW}$. This is based on the EPRI TAG numbers, but reducing the storage component of the 3-hour battery cost by two-thirds.

Using a fixed charge rate of $13.7 \%^{1}$ to convert overnight capital costs to current dollar levelized annual battery costs yields the following:

\begin{tabular}{cc}
\hline $\begin{array}{c}\text { Size } \\
\text { (hours) }\end{array}$ & $\begin{array}{c}\text { Levellzed Capltal Cost } \\
\text { (\$/kW-year) }\end{array}$ \\
\hline 1 & $\$ 49$ \\
3 & $\$ 97$ \\
\hline
\end{tabular}

1. Suggested by CEA for equipment with a 30-year life. 
The cost estimates in the EPRI TAG do not include cell replacement during the life of the battery system; the individual cells do not last as long as the entire system. Depending on the number of cycles per year that the battery is operated, cell replacement costs could add on the order of $\$ 100 / \mathrm{kW}$ to the battery cost, or about $\$ 15 / \mathrm{kW}$-year; for batteries operated primarily to provide spinning reserve, cell replacement costs should be much smaller. In addition, the operating and maintenance (O\&M) costs for the battery system should be included in a detailed analysis; they are ignored in this screening-level analysis.

\section{CAPACITY VALUE OF BATTERY}

Another potential benefit or savings that can be attributed to batteries, not discussed in the previous sections, results from the battery's contribution to total system generating capacity. The addition of battery capacity to a utility system frequently allows a reduction in investment in other new generation. Since the Anchorage area is expected to face a generation capacity shortage around $1995,{ }^{2}$ battery capacity may be able to replace some of the new generation capacity that will be required. However, a battery with only one hour of storage may not merit the same capacity value of a unit such as a combustion turbine. A capacity credit of $\$ 67 / \mathrm{kW}$ year, ${ }^{3}$ based on the cost of a combustion turbine, is an upper bound for the capacity value of a battery.

\section{COMPARING BENEFITS TO COSTS}

The annual costs just described can now be compared to the benefits estimated in Sections 2, 3, and 4. Recall that, as described in Section 2, there were no load-leveling benefits on the CEA system. This resulted from the relative flatness of the hourly system marginal costs (system lambda).

Because there are no load-leveling benefits, the battery system considered here would have minimal storage capacity and would be used only to provide spinning reserve. In order to maximize the net operating benefits, enough battery capacity must be added to allow the decommitment of one of the marginal units; this would require 20 to $25 \mathrm{MW}$ of battery capacity. As described in Section 2, some of the smaller combustion turbines are frequently operated at loadings far from their most efficient ones in order to provide spinning reserve. Addition of battery storage to the CEA system would allow decommitting these smaller units, providing substantial dynamic operating benefits. Because of the limitations imposed by the screening nature of this analysis, it was difficult to determine precise, consistent estimates of these benefits, However, a value of $\$ 40$ to $\$ 70$ per $\mathrm{kW}$-year, levelized in current dollars, appears appropriate.

2. Economic Feasibility of the Proposed $138 \mathrm{kV}$ Transmission Lines in the Railbelt, prepared by Decision Focus Incorporated for Railbelt Electric Utilities, December 1989.

3. $\$ 490$ per $\mathrm{kW}$ combustion turbine capital cost times current dollar levelized fixed charge rate of $13.7 \%$. 
Section 3 described how the addition of battery storage to the CEA system could reduce load shedding. We can estimate the dollar value of this reduced load shedding as follows:

1. Unserved energy in the Anchorage area has been about $655 \mathrm{MWh} /$ year. ${ }^{4}$

2. The value of unserved energy is about $\$ 5 / \mathrm{kWh}^{5}$

3. Assume that the addition of a $20 \mathrm{MW}$ battery to the system reduces unserved energy by 5-10 percent.

Combining these assumptions yields a reduced load shedding benefit of $\$ 8$ to $\$ 16$ per $\mathrm{kW}$ of battery capacity per year. ${ }^{6}$

Time and budget constraints, together with the direction taken early in the project, made it impossible to calculate potential T\&D investment deferral benefits in any detail. However, based on a qualitative analysis and detailed analyses for other utilities, potential T\&D benefits of $\$ 20$ to $\$ 200$ per $\mathrm{kW}$ of battery capacity would appear reasonable. Using the same levelized fixed charge rate used above for levelizing battery capital costs yields a T\&D benefit of $\$ 3$ to $\$ 27$ per $\mathrm{kW}$ of battery capacity per year.

Benefits in all categories are summarized in Table 5-1. In a screening level analysis such as this, it is not possible to be more precise. For example, the T\&D benefits are very site-specific and can not be precisely calculated without identifying sites for battery installations and then carrying out detailed T\&D expansion plans with and without batteries.

Table 5-1

BENEFITS SUMMARY FOR CEA SYSTEM

\begin{tabular}{lc}
\hline \multicolumn{1}{c}{ Category } & Annual Benefit (\$/kW-year) \\
\hline Capacity & $30-70$ \\
Generation & $40-70$ \\
Reduced Load Shedding & $8-16$ \\
T\&D & $\underline{3-27}$ \\
TOTAL & $81-183$
\end{tabular}

4. Economic Feasibility of the Proposed $138 \mathrm{kV}$ Transmission Lines in the Railbelt, prepared by Decision Focus Incorporated for Railbelt Electric Utilities, December 1989.

5. Ibid.

6. $655 \mathrm{MWh} /$ year $\times 1000 \mathrm{kWh} / \mathrm{MWh} \times \$ 5 / \mathrm{kWh} \times 5-10 \% \div 20,000 \mathrm{~kW}=\$ 8-16 / \mathrm{kW}$-year. 
Comparing total benefits to the battery costs, which are roughly $\$ 50$ to $\$ 60$ per $k W$-year for a 1-hour battery, indicates that batteries may be quite economic on the CEA system. 


\section{6}

\section{CONCLUSIONS AND RECOMMENDATIONS}

In this study several types of benefits that would occur from the addition of batteries to the CEA system were calculated: generation (load-leveling, dynamic operating, and environmental) and transmission and distribution. These benefits were also compared to the costs of adding batteries. The results suggest that savings in dynamic operating costs and T\&D costs may justify the addition of batteries to the system.

\section{GENERATION BENEFITS}

Generation benefits were calculated for 18 days: in each of three years (1994, 1996, and 2000), one weekday and one weekend day for each season (with spring and fall combined), using data from CEA MAINPLAN runs. The benefits were calculated for five gas-fired combustion turbine units whose operation is most likely to be affected by the addition of batteries to the system. The primary emphasis was on provision of spinning reserve with a one-hour battery.

\section{Load-Leveling Benefits}

Because the marginal units on the CEA system are gas-fired combustion turbines (the Beluga and Bernice units) for all hours, the system marginal energy costs do not differ much between on-peak and off-peak hours. Coupled with the assumed battery efficiency of around 80 percent, this means that no load-leveling savings could be achieved on the CEA system.

\section{Dynamic Operating Benefits}

A large portion of the operating costs of power plants results from fluctuating loads. These costs are called dynamic operating costs, and include such things as startups, minimum loading, load following, and ramping. Technologies such as batteries that can reduce these costs are said to provide dynamic operating benefits.

For each of the 18 days the potential reduction in load following, minimum loading, startup, and spinning reserve costs was calculated for each of the five units. The most costeffective unit for decommitment was identified on each day. By accounting for the relative occurrence of each of the "day types" during the year, an annual savings was calculated. The biggest component of the savings is from reductions in minimum loading costs. Averaging out 
the effect of load growth and accounting for inflation and increases in natural gas prices, this is equivalent to an annual savings of about $\$ 50$, levelized in current dollars, per kilowatt per year. The savings may increase in the future as load growth forces increasing utilization of less economic units. The annual savings were about $\$ 18 / \mathrm{kW}$-year in $1994, \$ 55 / \mathrm{kW}$-year in 1996 , and $\$ 25 / \mathrm{kW}$-year in 2000 . The fluctuations arise from increases in natural gas prices and load growth. Savings go up as gas prices increase, and can go up or down as load grows.

\section{Environmental Benefits}

Atmospheric emissions from fossil-fuel combustion in generation units are not much of a concern in the Railbelt at this time. Should they become a concern, the capability of batteries to reduce or otherwise modify emissions should be quantified. Similarly, if land use is a significant concern, the potential for batteries to eliminate or defer new transmission lines should be considered.

\section{REDUCED LOAD SHEDDING BENEFITS}

As described in Section 2, addition of battery storage to the CEA system would be effective in reducing load shedding. The amount of the reduction would depend on the size of the battery. A very approximate calculation indicates that the value of the reduced load shedding could be $\$ 8$ to $\$ 16$ per $\mathrm{kW}$ of battery capacity per year.

\section{TRANSMISSION AND DISTRIBUTION BENEFITS}

Current CEA transmission and distribution facility expansion plans were reviewed to identify T\&D investments that might be avoided or deferred as a result of adding battery storage to the CEA system. Several such investments were identified. Based on a qualitative review of these investments and comparison with more detailed analyses for other utilities, potential T\&D benefits of $\$ 20$ to $\$ 200$ per $\mathrm{kW}$ of battery capacity appear reasonable. This is equivalent to a T\&D benefit of $\$ 3$ to $\$ 27$ per $\mathrm{kW}$ of battery capacity per year.

\section{COST/BENEFIT ANALYSIS}

Summing the capacity, generation, load shedding, and T\&D benefits yields levelized current-dollar savings of $\$ 81$ to $\$ 183 / \mathrm{kW}$-year, compared to a levelized current-dollar cost of $\$ 50$ to $\$ 60 / \mathrm{kW}$-year. These values suggest that batteries would be a cost-effective addition to the CEA system.

Some benefits may be mutually exclusive. The interactions between the various benefits, i.e., whether they are additive or mutually exclusive, depends on storage size, location, system load shapes, load shapes at individual substations and on individual transmission and 
distribution lines, how the system (including the battery) is operated, and on any equipment deferred as a result of adding batteries.

\section{RECOMMENDATIONS}

Based on the results of this screening-level study, it is recommended that CEA seriously consider the addition of battery storage to its system. A detailed study to verify the findings of this initial screening study and to calculate the benefits more precisely is recommended. Such a study should include the following aspects:

1. More detailed calculation of generation dynamic operating costs and benefits should be carried out, including examination of multiple weeks of system operation during each of a larger number of years than was considered here. Such calculation should fully account for changes in system operation as load grows, and should identify all possible operation savings, not only those that arise when a unit is completely decommitted.

2. More detailed $T \& D$ analysis should be carried out to verify the assumptions and findings discussed here.

3. Particular care should be paid to the interactions among the various benefits, to ensure that batteries are not being justified on the basis of benefits that may be mutually exclusive.

4. Comparative evaluation of the economics of battery storage with other capacity additions under consideration by CEA. Such detailed study would also allow a better assessment of the "optimum" battery size and the best time for adding the battery plant to the CEA system.

5. A broader perspective, which looks at the benefits of battery storage to the Railbelt utilities as a whole, should be considered. The broader perspective might show increased benefits, while there would be no change in battery costs. In particular, because of CEA's arrangements for selling economy energy to the Golden Valley Electric Association, the reduced spinning reserve costs made possible by batteries might be more valuable to one of the other Railbelt utilities than to CEA. 
A

DAILY CEA SYSTEM LOAD SHAPES AND MARGINAL GENERATION COSTS 


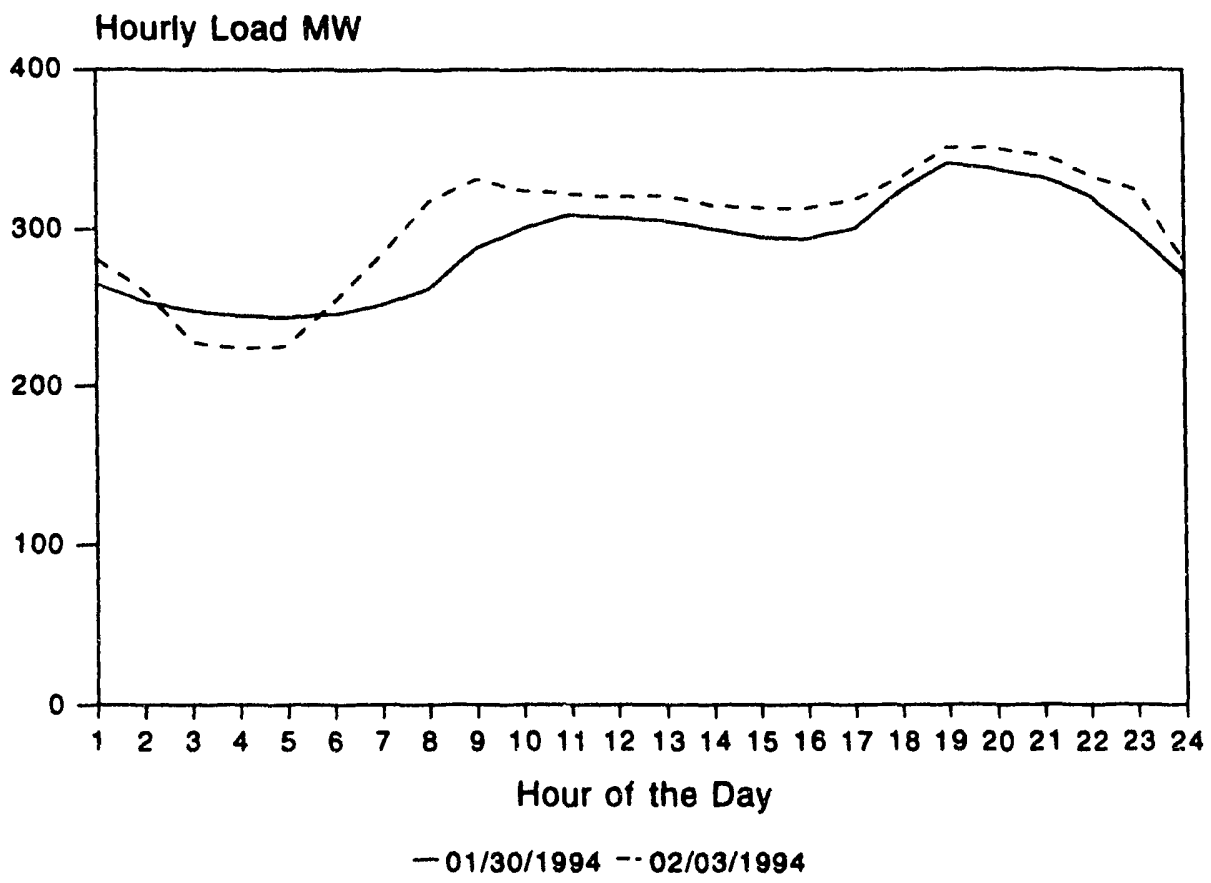

Figure A-1. Native Dally Load Shapes-Winter 1994

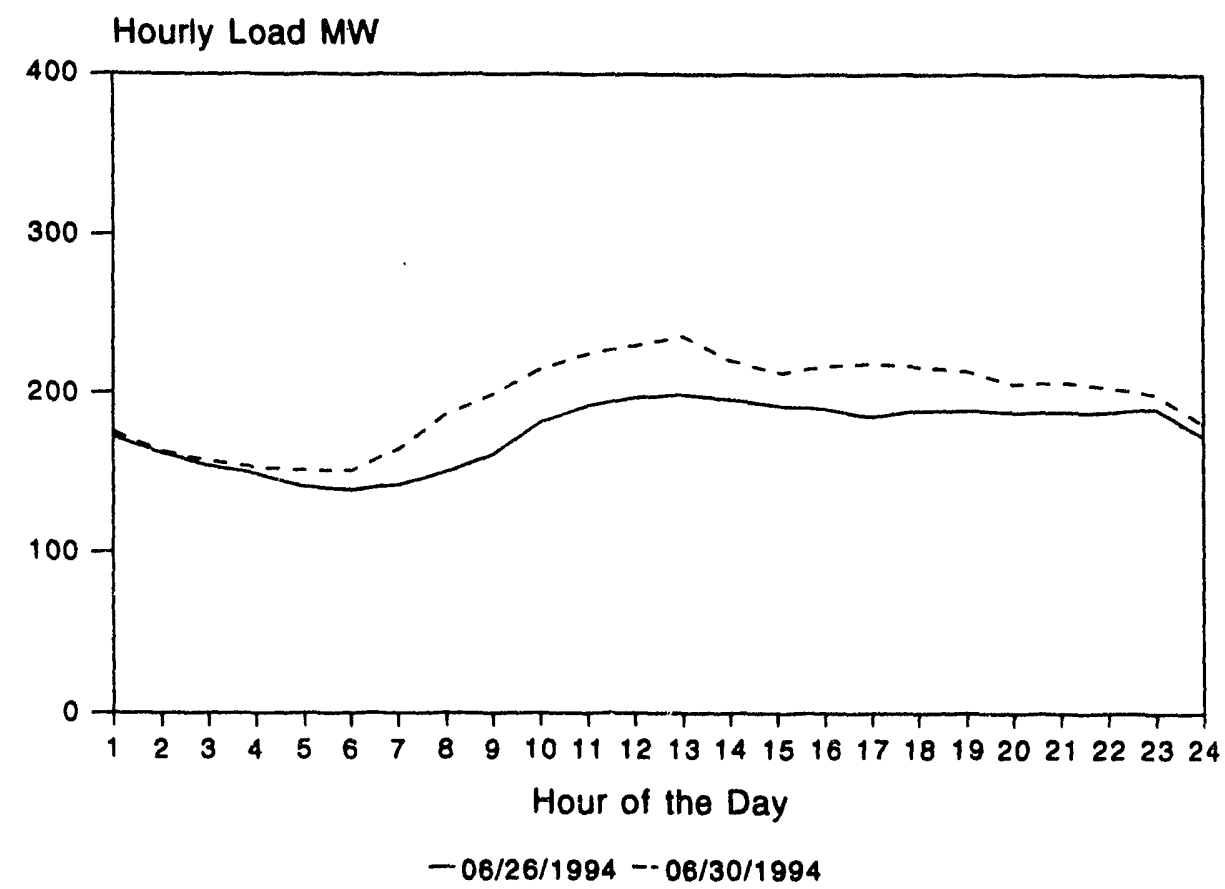

Figure A-2. Native Dally Load Shapes_Summer 1994 


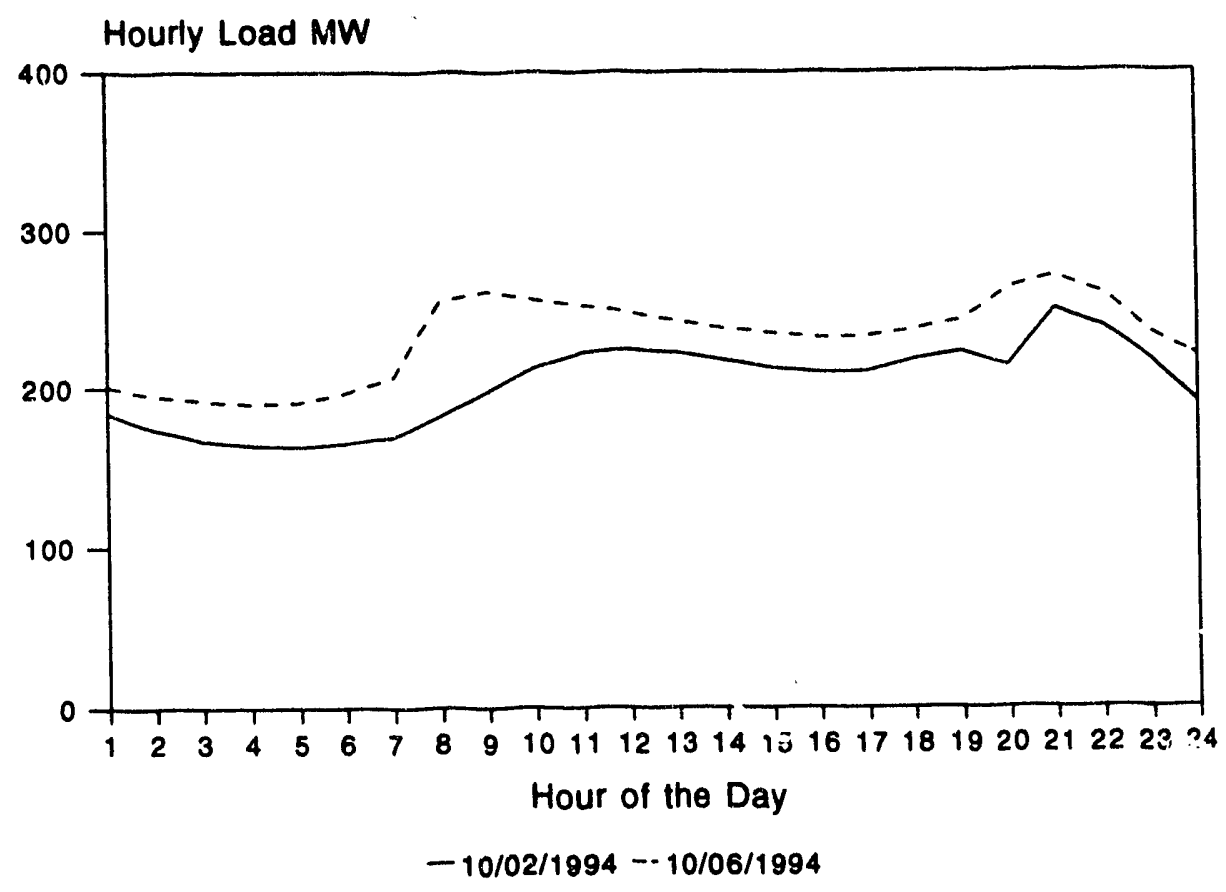

Flgure A-3. Native Daily Load Shapes-Spring/Fall 1994

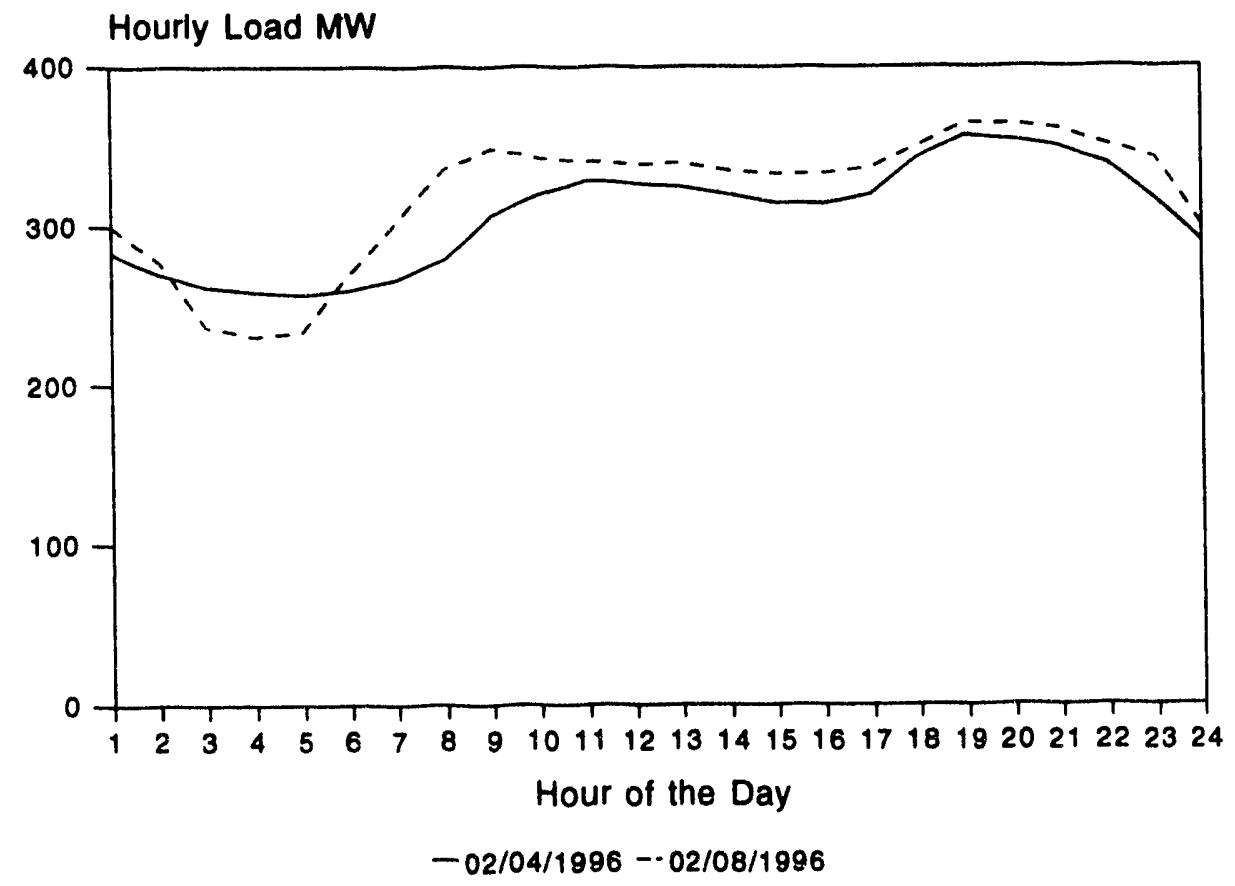

Figure A-4. Native Dally Load Shapes-Winter 1996 


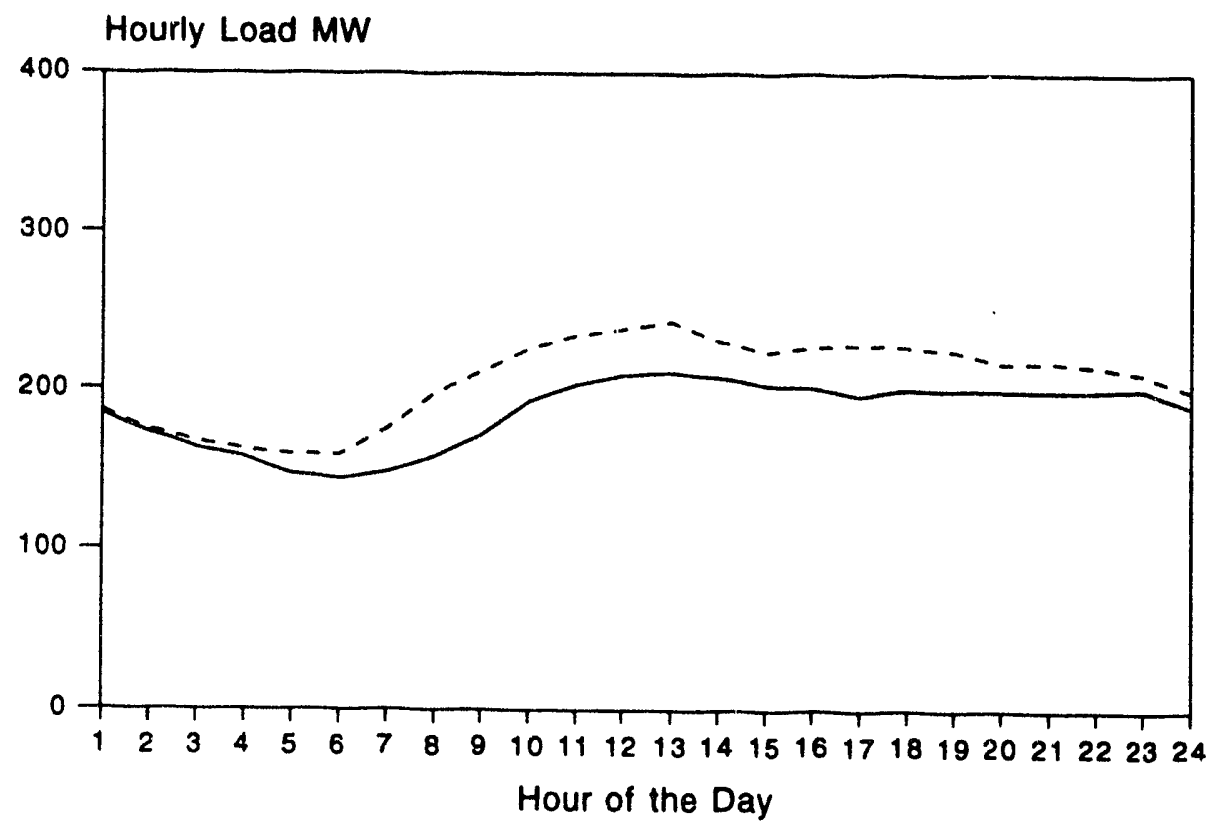

$-06 / 30 / 1996--07 / 04 / 1996$

Figure A-5. Native Dally Load Shapes-Summer 1996

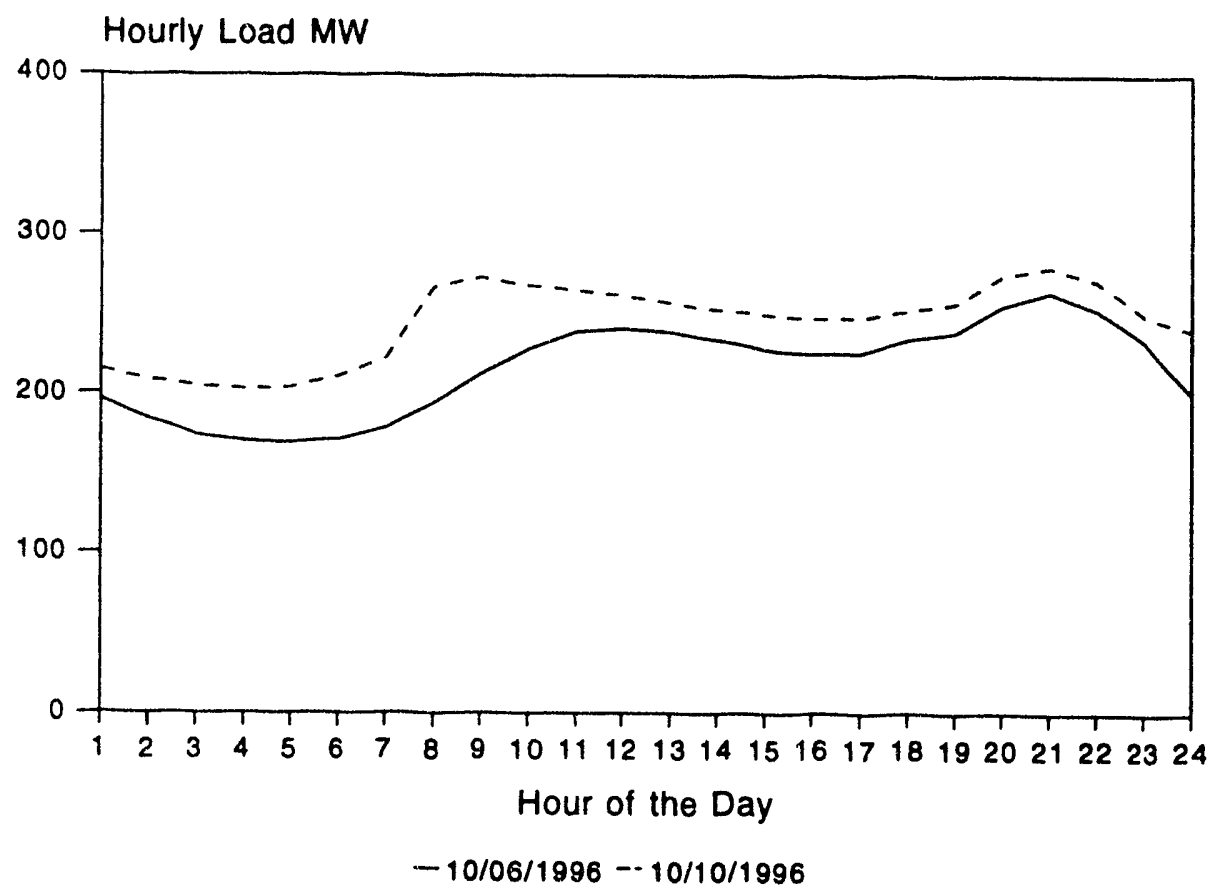

Figure A-6. Native Daily Load Shapes-Spring/Fall 1996 


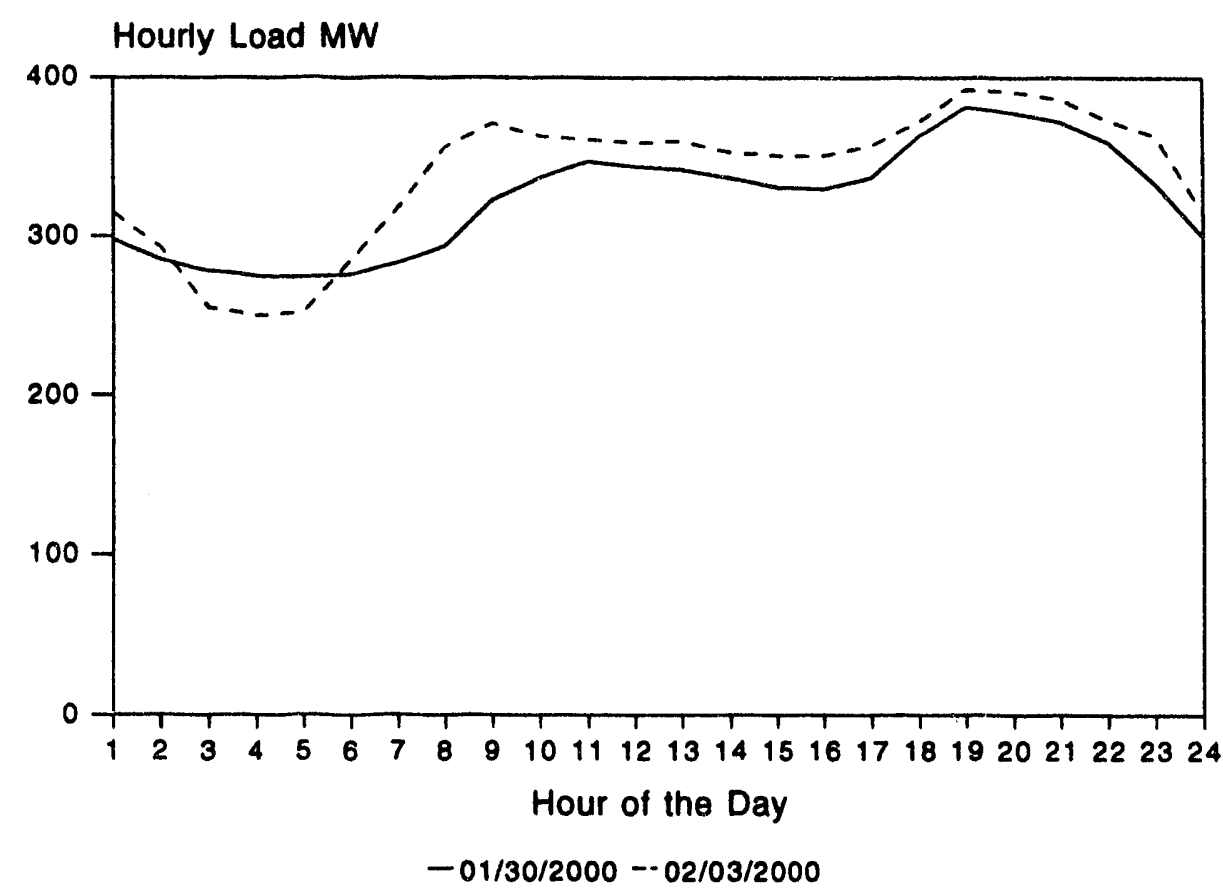

Figure A-7. Native Dally Load Shapes-Winter 2000

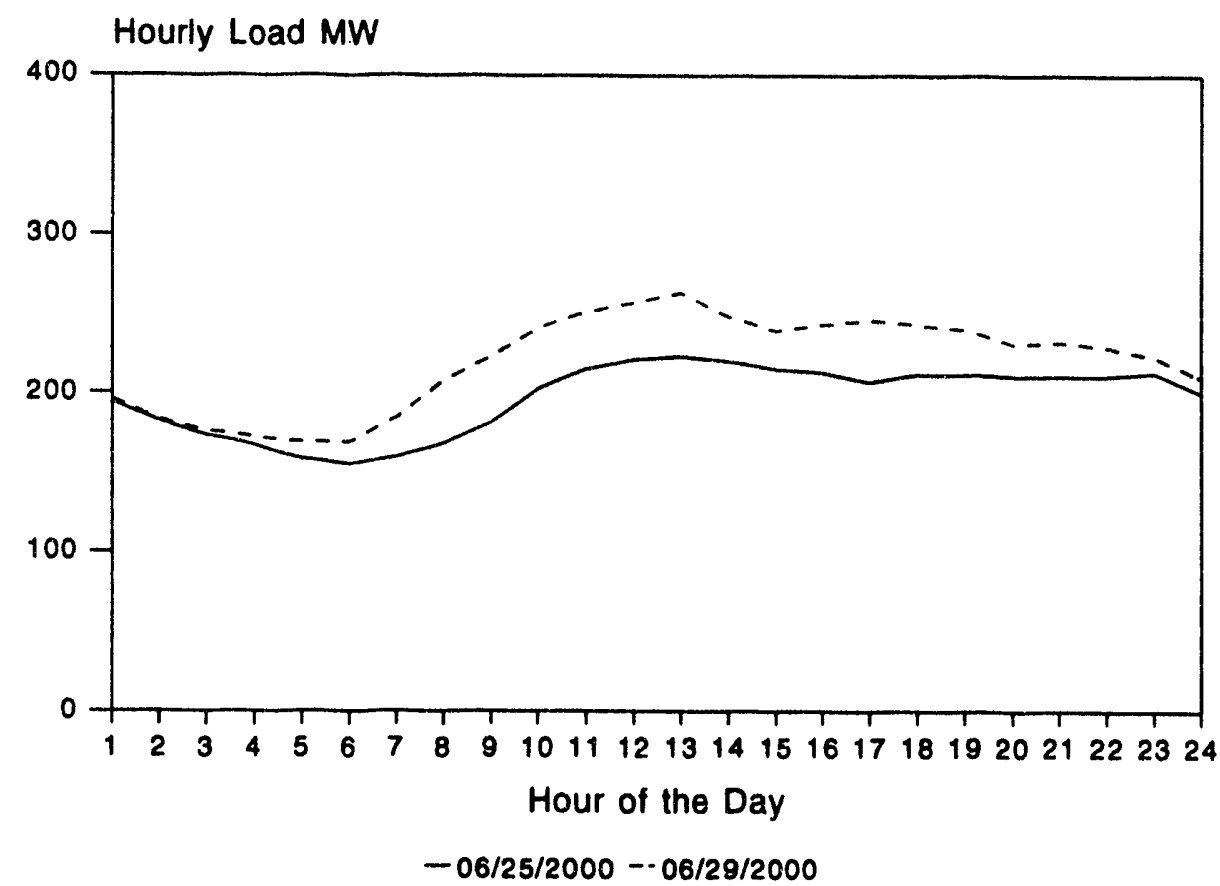

Figure A-8. Native Dally Load Shapes-Summer 2000 
Hourly Load MW

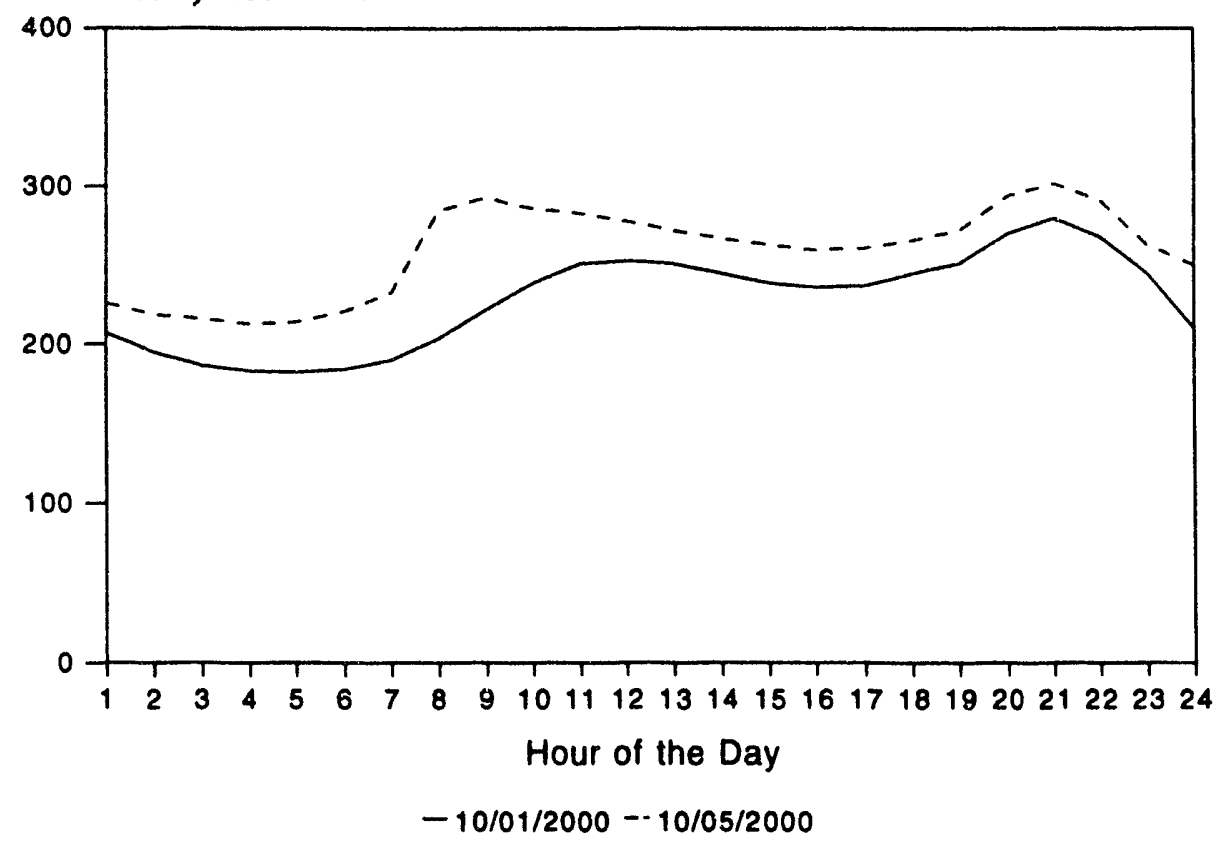

Figure A-9. Native Dally Load Shapes-Spring/Fall 2000

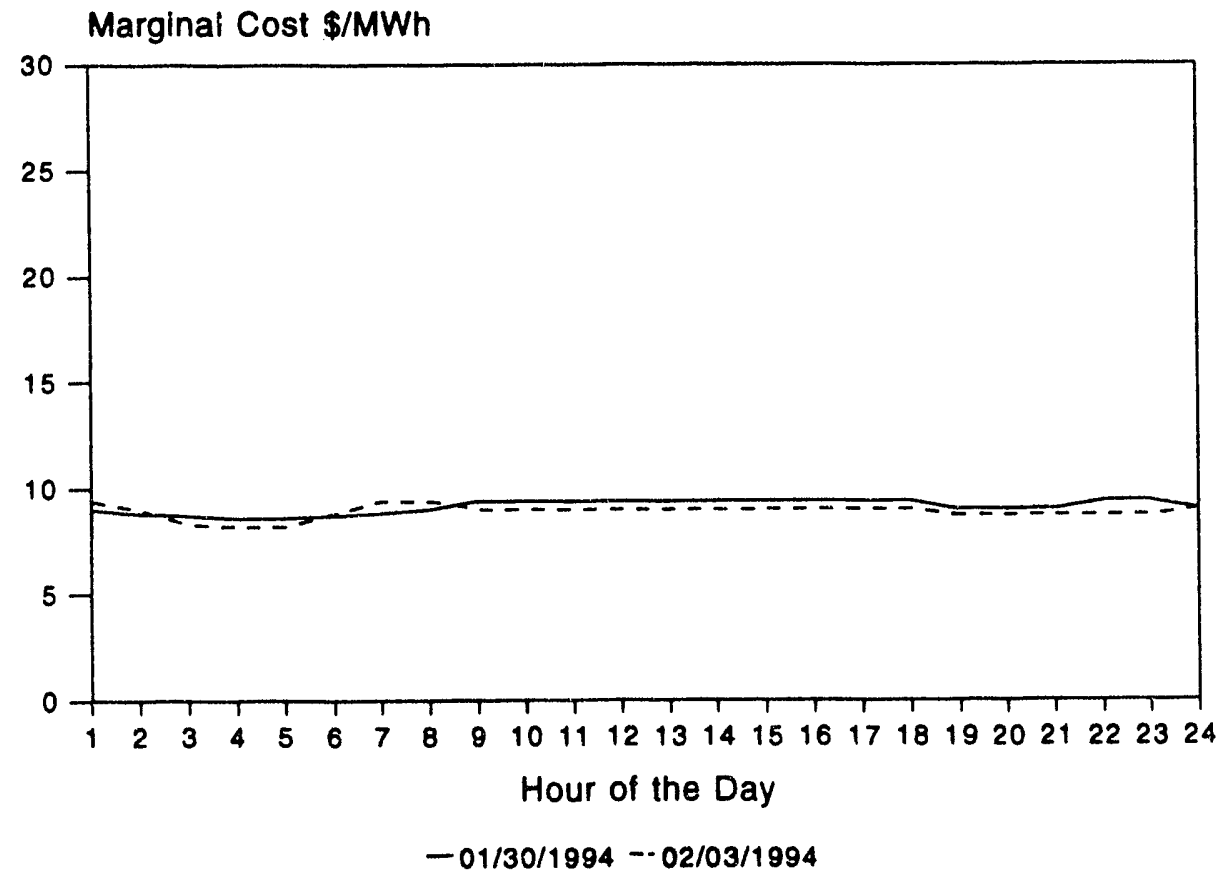

Figure A-10. System Marginal Cost-Winter 1994 
Marginal Cost $\$ / M W h$

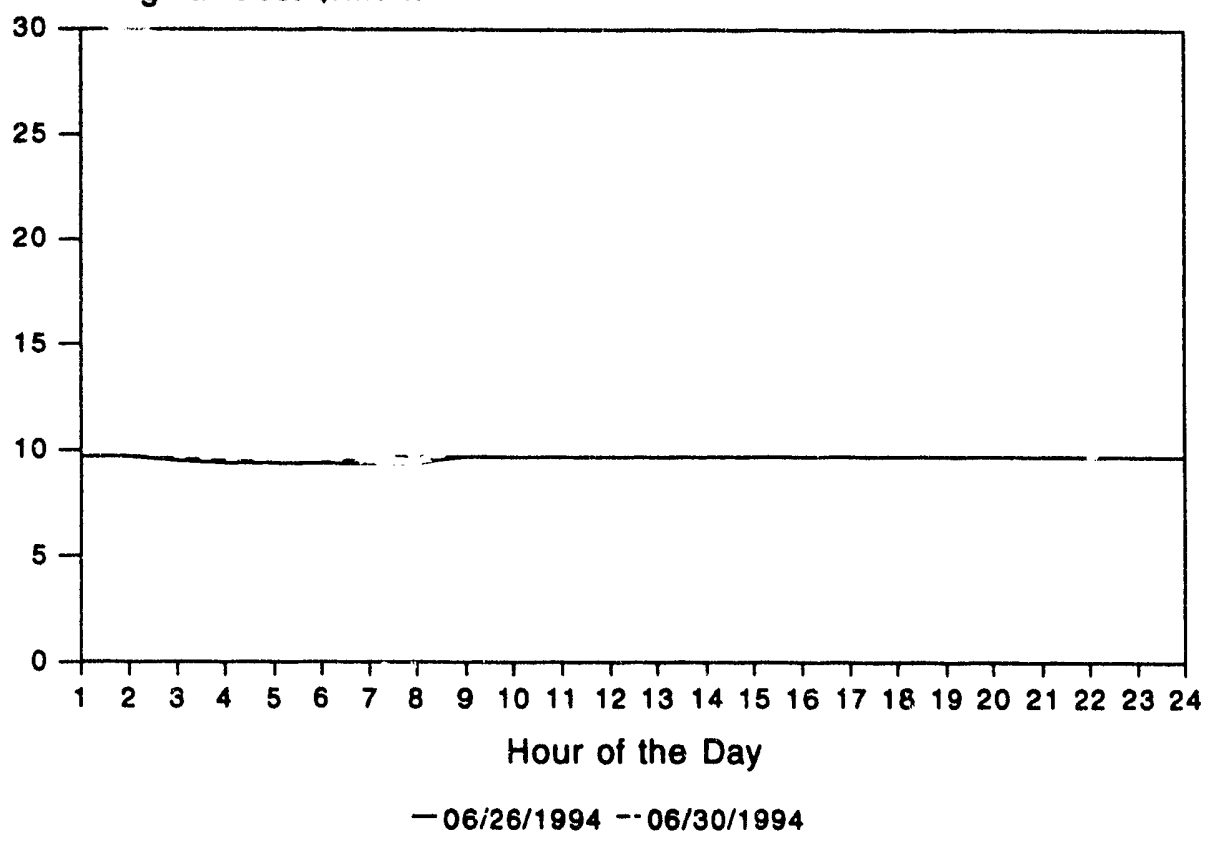

Figure A-11. System Marginal Cost-Summer 1994

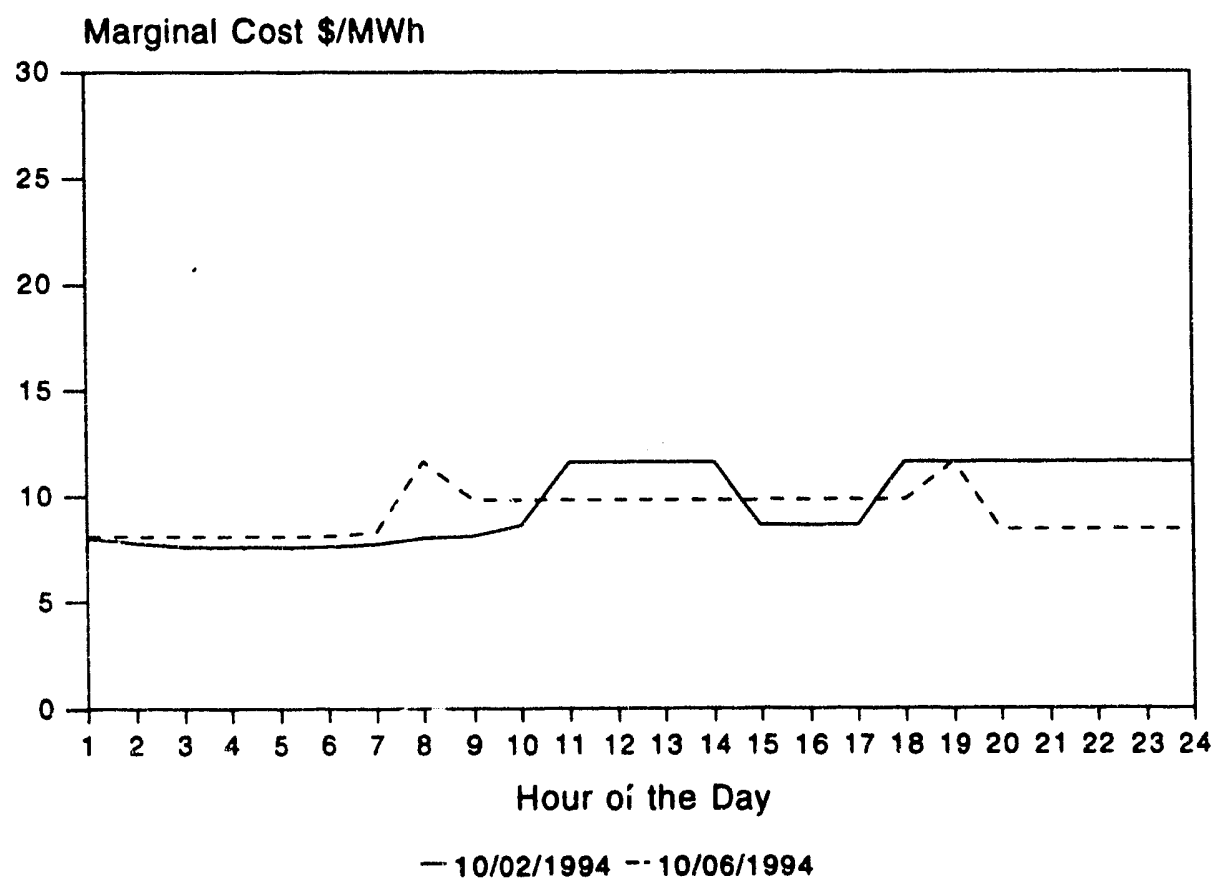

Figure A-12. System Marginal Cost-Spring/Fall 1994 


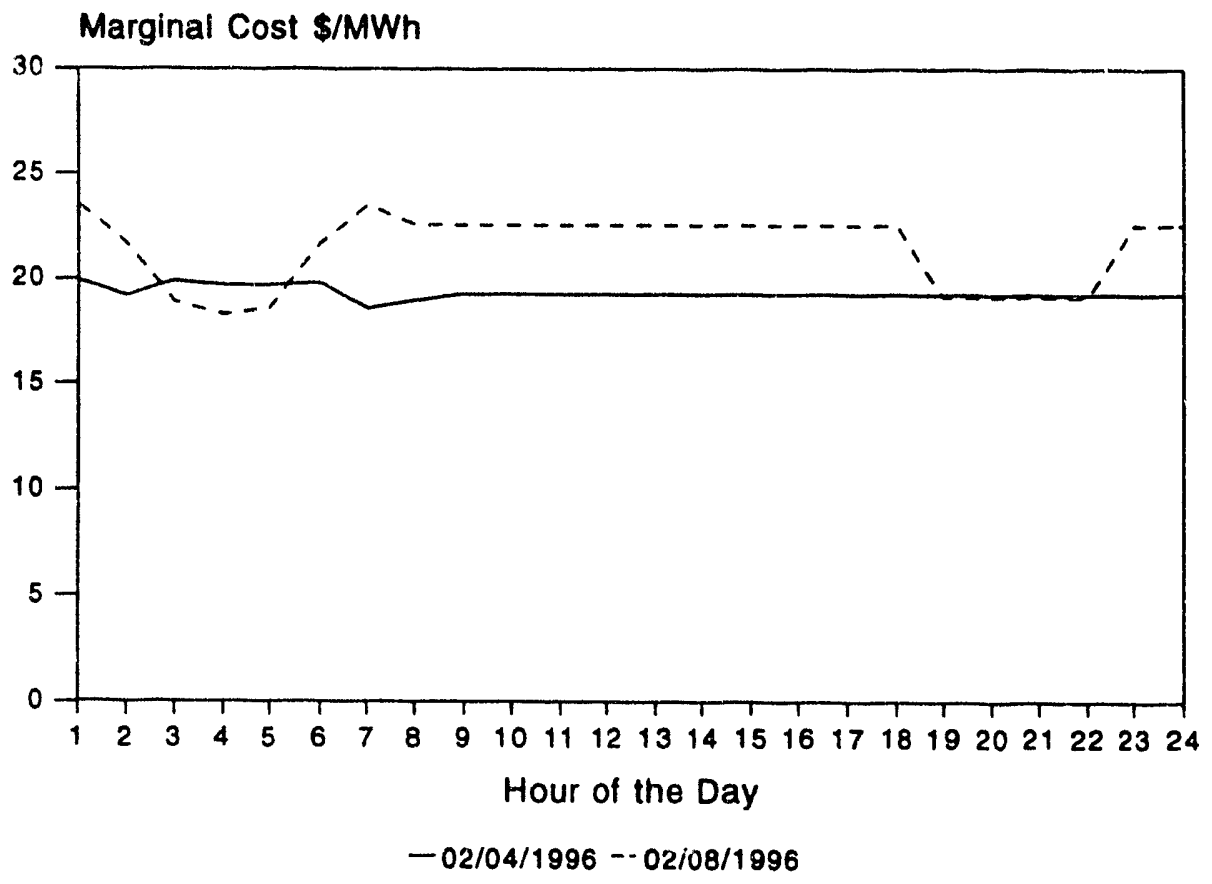

Figure A-13. System Marginal Cost-Winter 1996

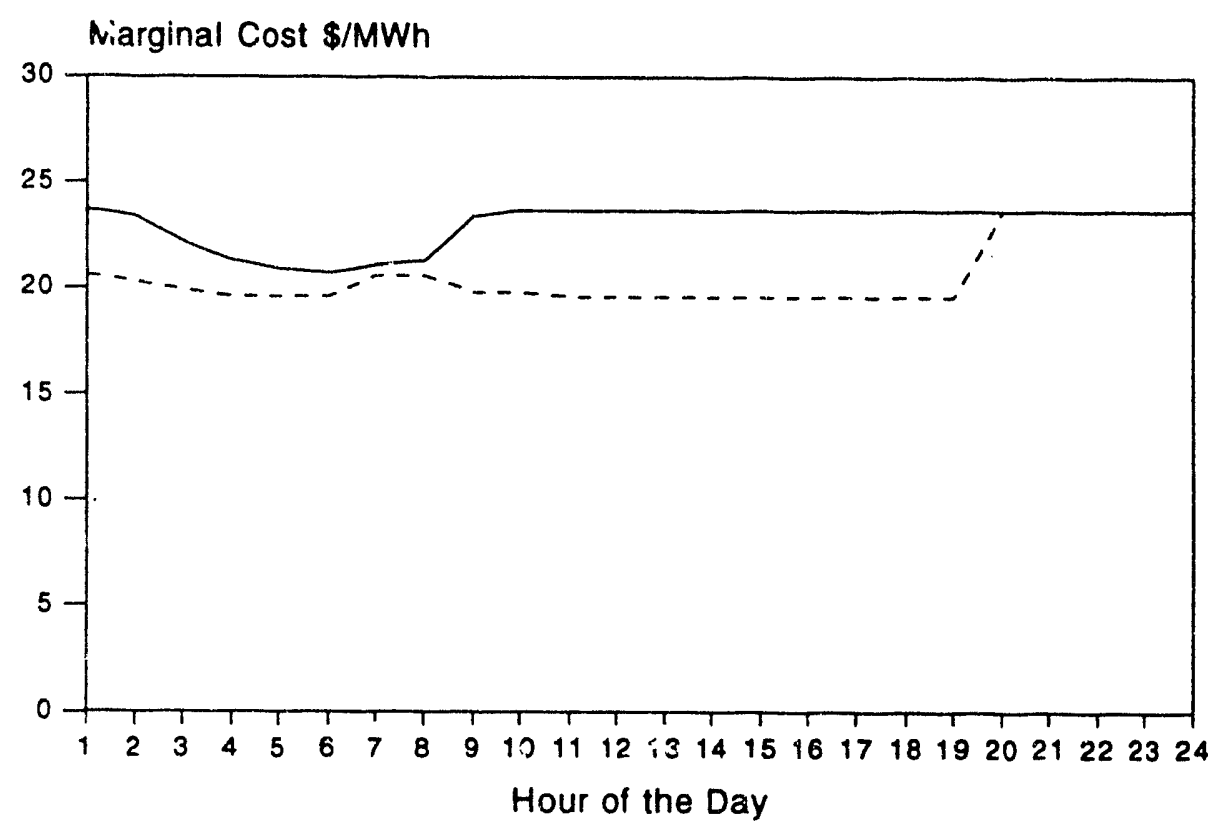

Figure A-14. System Marginal Cost-Summer 1996 


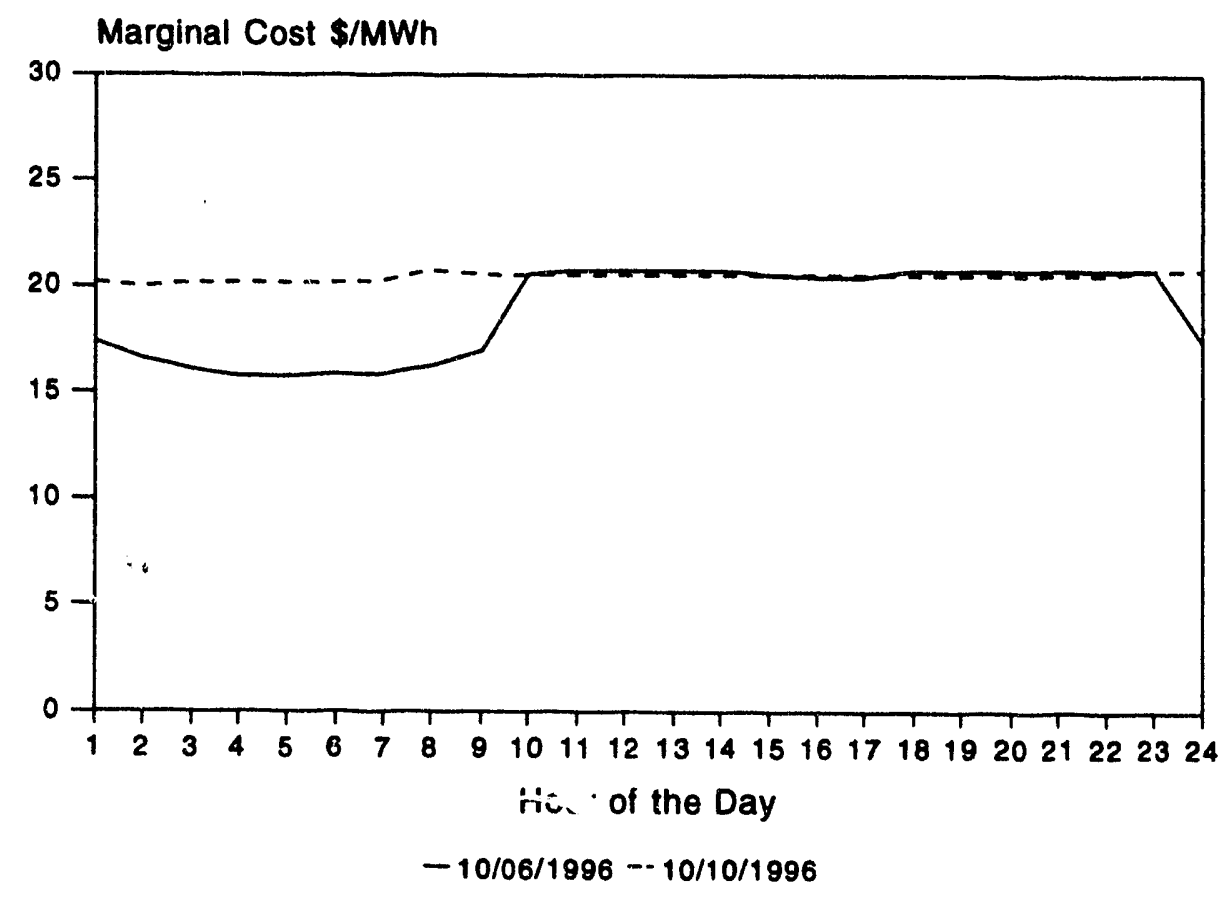

Figure A-15. System Marginal Cost-Spring/Fall 1996

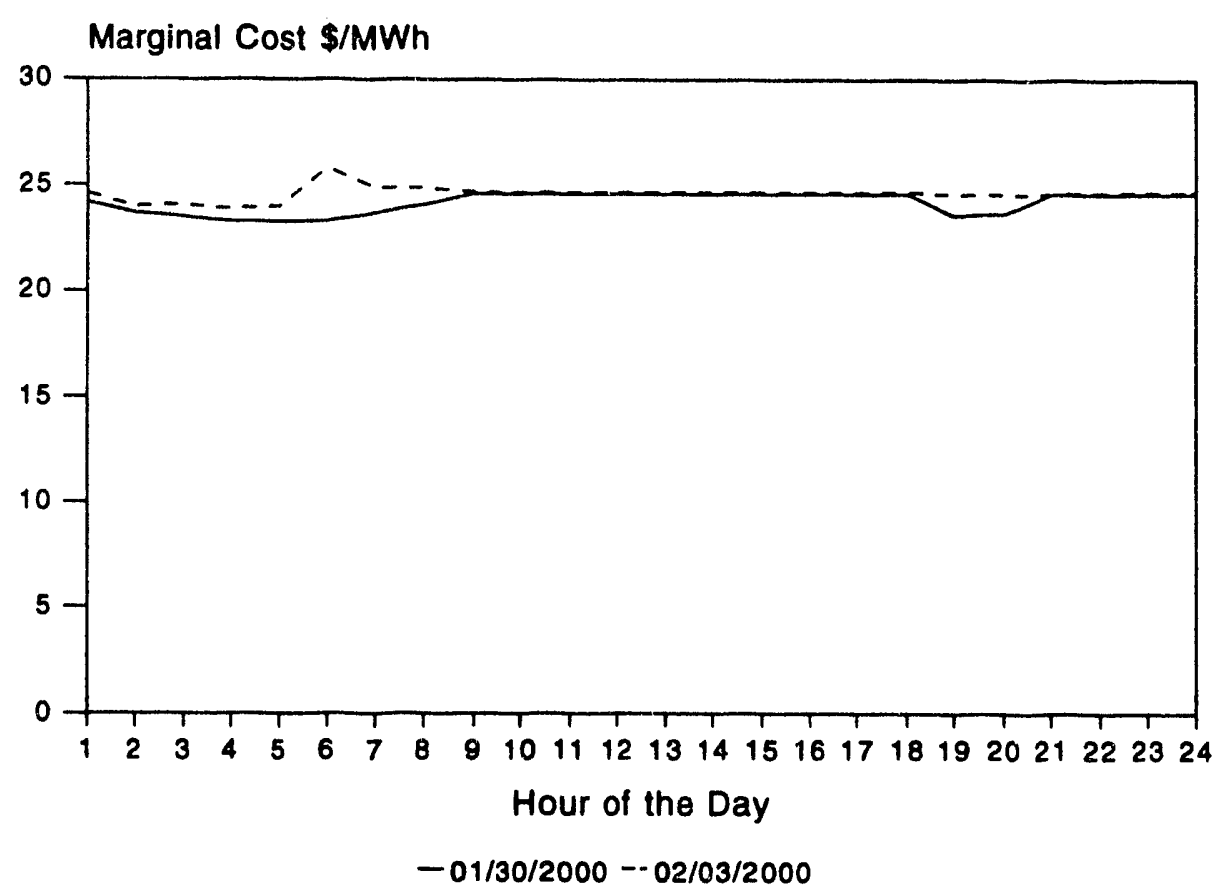

Figure A-16. System Marginal Cost-Winter 2000 


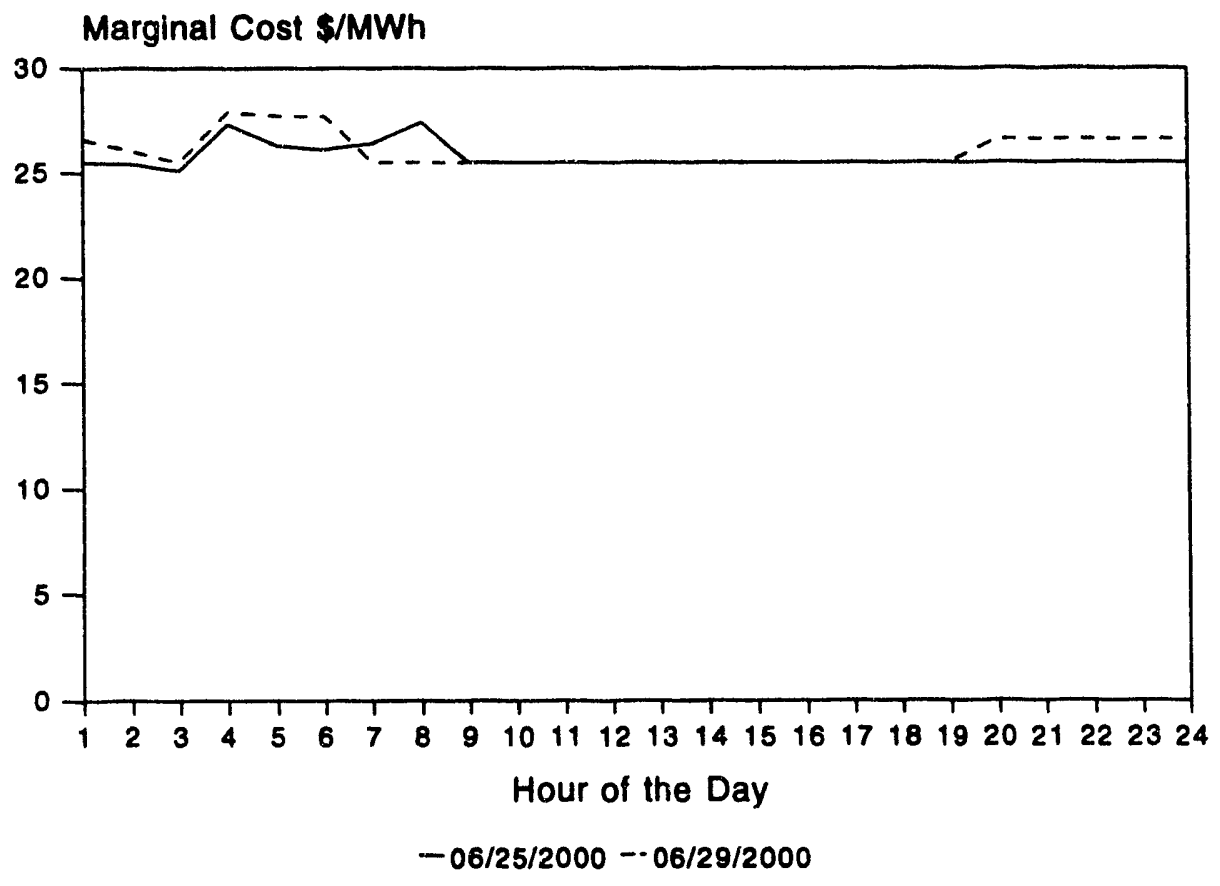

Figure A-17. System Marginal Cost-Summer 2000

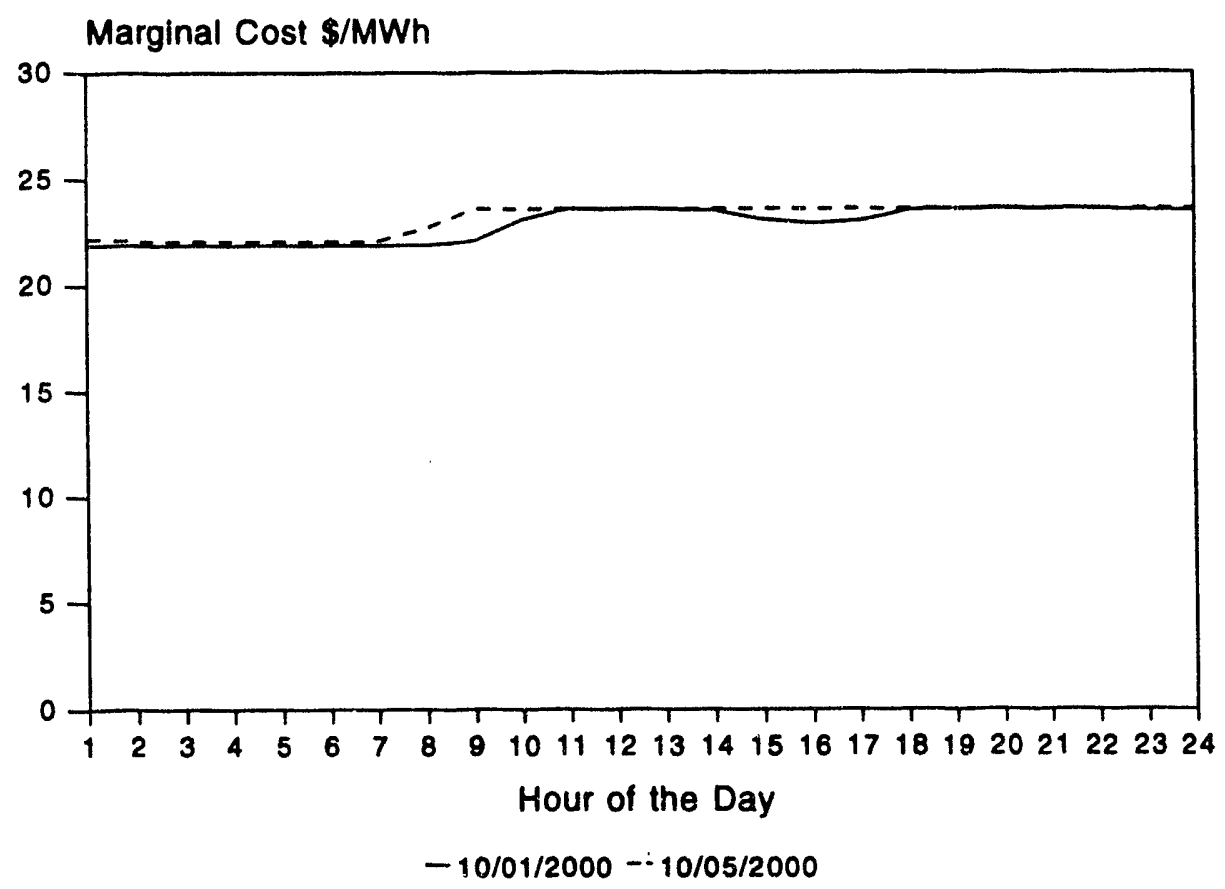

Figure A-18. System Marginal Cost-Spring/Fall 2000 


\section{GENERATION SCHEDULES FOR STABILITY ANALYSIS SCENARIOS}

This appendix presents the generation schedule for each scenario studied in this report.

For the winter load case: Beluga \#5,6,7 and 8, the Bradley and Eklutna units, Healy and Chena 5 are at their maximum capacity. North Pole is at $50 \mathrm{MW}$ (60 MW capacity), AMLP Unit 7 is at $72 \mathrm{MW}$ (85 MW capacity) and AMLP Unit 6 is at $23 \mathrm{MW}$.

Scenario 1: Beluga 3 at $55.7 \mathrm{MW}$, Bernice Lake at $10 \mathrm{MW}$, Cooper 1 \& 2 at $13 \mathrm{MW}$ and AMLP Unit 8 at $23.8 \mathrm{MW}$.

Scenario 2 \& 3: Beluga 3 at $55.7 \mathrm{MW}$, Bernice Lake at $10 \mathrm{MW}$ and Cooper 1 \& 2 at 13 MW. In this scenario, AMLP Unit 8 is taken off line and its generation replaced with AMLP Unit 1 at 5MW (17 MW capacity) and AMLP Unit 5 at $18.8 \mathrm{MW}$ (37 MW capacity).

Scenario 4: Bernice Lake taken off-line. Beluga 3 is therefore at $62.7 \mathrm{MW}$ and Cooper \#1 $\&$ \#2 are at their maximum capacity of $16 \mathrm{MW}$. The AMLP units are as in Scenario 2 and 3.

For the summer load case: Beluga 6, Beluga 8 and Healy are at maximum capacity, Eklutna is at $7 \mathrm{MW}$ (16 MW capacity), Chena 5 is at $12.5 \mathrm{MW}$ (18 MW capacity), Bradley 1 \& 2 are at $15 \mathrm{MW}$ each, AMLP Unit \#6 is at $12 \mathrm{MW}$, and AMLP Unit \#7 is at $38 \mathrm{MW}$ (72 MW capacity).

Scenario 5: Beluga 1 at $5 \mathrm{MW}$ (15 MW capacity), Beluga 2 at $5 \mathrm{MW}$ (16 MW capacity), and Beluga 3 at $31.6 \mathrm{MW}$. MW.

Scenario 6: Beluga 1 at $5 \mathrm{MW}$ (15 MW capacity), Beluga 2 off-line and Beluga 3 at 36.6

Scenario 7: Beluga 1 and 2 off-line and Beluga 3 at $41.6 \mathrm{MW}$. 
PTI INTERACTIVE PONER SYSTEM SIMUIATOR--PSS/E 1991 WINTER PEAK LOAD. NO BATTERY AT INTL. 34.5. GOVERNORS DISABLED AT BELUGA 5,6,7, CHENA 5, HEALY.

GENERATOR SUMMARY :

\begin{tabular}{|c|c|c|c|}
\hline \\
\hline & BELOGA3G1 3.8 & 1 & \\
\hline & BELUGA5G13.8 & & \\
\hline$\epsilon$ & BELUGA 6GI & & \\
\hline 7 & BELUC & & \\
\hline 8 & BELUGA8C & & \\
\hline 24 & EKLOT 2G & & \\
\hline & EKLOT $1 \mathrm{GE}$ & & \\
\hline 3 & TEELAND & & \\
\hline 6 & BERN 3G & & \\
\hline 79 & COOP1E2G4 & & \\
\hline 121 & FORT พ. 12.4 & & \\
\hline 20 & GLDHLSVS1: & & \\
\hline 210 & N. POLE & & \\
\hline 213 & CHENA & & \\
\hline 368 & BEALYSVS 12.0 & & \\
\hline 370 & HEALY $1 G 13.8$ & & \\
\hline & BRADLY1G13.8 & & \\
\hline & BRADLY2 & & \\
\hline & PLNT2 6G & & \\
\hline & PLNT2 7G1 & 1 & \\
\hline & PLNT2 8G1 & 1 & \\
\hline & TESORO1G24 & 1 & \\
\hline
\end{tabular}

$\begin{array}{rr}\text { MW } & \text { MVAR } \\ 55.7 & 6.4 \\ 59.0 & 5.6 \\ 78.0 & 7.7 \\ 75.0 & 5.3 \\ 54.0 & 5.6 \\ 16.0 & 3.0 \\ 16.0 & 3.0 \\ 0.0 & 6.7 \\ 10.0 & 8.7 \\ 13.0 & 3.4 \\ 7.5 & 1.7 \\ 0.0 & 33.0 \\ 50.0 & 7.7 \\ 20.0 & 9.9 \\ 0.0 & 7.1 \\ 25.0 & 3.1 \\ 45.0 & 3.6 \\ 45.0 & 3.7 \\ 23.0 & 12.2 \\ 72.0 & 32.2 \\ 23.8 & 52.3 \\ 4.1 & 1.5 \\ 692.1 & 223.5\end{array}$

\section{QMAX}

24.8

33.0

$$
37.1
$$

37.1

30.0

7.3

7.3

22.0

13.9

14.7

5.4

33.0

34.8

12.2

22.0

15.5

19.7

19.7

20.5

49.7

52.3

1.5

513.4
SUN, DEC 291991

$13: 13$

SEENARRIO 1
QMIN VSCHED VACTUAL REM $-12.41 .01501 .0150$

$-16.51 .01501 .0150$

$-11.11 .01801 .0180$

$-11.1 \quad 1.01501 .0150$

$-15.01 .01501 .0150$

$-2.21 .00001 .0000$

$-2.21 .00001 .0000$

$-22.01 .00501 .0050$

$-6.91 .03001 .0300$

$\begin{array}{rl}-9.2 & 1.03001 .0300\end{array}$

$-2.61 .05001 .5500$

$-5.01 .02801 .01 .9$

$\begin{array}{llll}-17.4 & 0.9860 & 0.9860\end{array}$

$\begin{array}{lll}-4.0 & 1.0350 & 1.0350\end{array}$

$-33.01 .02201 .0220$

$-7.51 .01401 .0140$

$-19.71 .00001 .0000$

$-19.71 .00001 .0000$

$-10.21 .02001 .0200$

$-24.81 .00001 .0000$

$-26.11 .03201 .0292$

1.51 .03001 .0235

-277.1 MVABASE=
15

202

37

1100.3 
PTI INTERACTIVE PONER SYSTEM SIMUIATOR--PSS/E

SUN, DEC 291991

$13: 13$

1991 WINTER PEAK LOAD. AMLP $\$ 8$ IS OFF, AMLP \$1 \$5 ARE ON.

ScENArio

2,3 NO BATTERY AT INTL $34.5 \mathrm{KV}$.

\begin{tabular}{|c|c|c|c|c|c|}
\hline 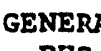 & OR SUMMARY & & & & \\
\hline BUS & NAME BSVLT & IMAC & TYP & $\mathbf{M N}$ & MVAR \\
\hline 3 & BELUGA3G13.8 & 1 & 3 & 55.5 & .3 \\
\hline 5 & BELUGA5G13.8 & 1 & 2 & 59.0 & \\
\hline 6 & BELUGA6G13.8 & 1 & 2 & 78.0 & \\
\hline 7 & BELUGA 7G13.8 & 1 & 2 & 75.0 & \\
\hline 8 & BELUGA8G13.8 & 1 & 2 & 54.0 & $\bullet$ \\
\hline 24 & EKLOT 2G6.90 & 1 & 2 & 16.0 & \\
\hline 25 & EKLUT $1 \mathrm{G6} .90$ & 1 & 2 & 16.0 & \\
\hline 34 & TEEIAND 13.8 & 1 & 2 & 0.0 & \\
\hline 67 & BERN 3G 13.8 & 1 & 2 & 10.0 & 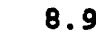 \\
\hline 79 & COOP $1 \leftarrow 2 G 4.20$ & 2 & 2 & 13.0 & \\
\hline 121 & FORT พ. 12.4 & 4 & 2 & 7.5 & 2. \\
\hline 201 & GIDHLSVS13.8 & 1 & -2 & 0.0 & \\
\hline 210 & N. POLE 13.8 & 2 & 2 & 50.0 & 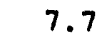 \\
\hline 213 & CHENA & 3 & 2 & 20.0 & \\
\hline 368 & AEALYSVS12.0 & 1 & 2 & 0.0 & .1 \\
\hline 370 & HEALY $1 G 13.8$ & 1 & 2 & 25.0 & \\
\hline 501 & BRADLY1G13.8 & 1 & 2 & 45.0 & \\
\hline 502 & BRADIY2G13.8 & 1 & 2 & 45.0 & \\
\hline 600 & PINT2 $5 \mathrm{G} 13.8$ & 1 & -2 & 18.8 & \\
\hline 601 & PLNT2 $6 \mathrm{G} 13.8$ & 1 & 2 & 23.0 & \\
\hline 602 & PINT2 7G13.8 & 1 & 2 & 72.0 & \\
\hline 607 & PLNT1 1613.8 & 1 & 2 & 5.0 & \\
\hline 691 & TESORO1G24.9 & 1 & -2 & 4.1 & \\
\hline JBSYS & STEM TOTALS & & & 91.9 & 223 \\
\hline
\end{tabular}

$$
\begin{array}{r}
\text { QMAX } \\
24.8 \\
33.0 \\
37.1 \\
37.1 \\
30.0 \\
7.3 \\
7.3 \\
22.0 \\
13.9 \\
14.7 \\
5.4 \\
33.0 \\
34.8 \\
12.2 \\
22.0 \\
15.5 \\
19.7 \\
19.7 \\
17.1 \\
20.5 \\
49.7 \\
9.4 \\
1.5 \\
487.6
\end{array}
$$

QMIN VSCHED VACTUAL REM

$-12.41 .01501 .0150$

$-16.51 .01501 .0150$

$-11.11 .01801 .0180$

$-11.11 .01501 .0150$

$-15.01 .01501 .0150$

$-2.21 .00001 .0000$

$-2.21 .00001 .0000$

$-22.01 .00501 .0050$

$-6.91 .03001 .0300$

- .21 .03001 .0300

$-2.61 .05001 .0500$

$\begin{array}{lll}-5.0 & 1.0280 & 1.0199\end{array}$

$-17.40 .98600 .9860$

$\begin{array}{lll}-4.0 & 1.03501 .0350\end{array}$

$-33.01 .02201 .0220$

$-7.51 .01401 .0140$

$-19.71 .00001 .0000$

$-19.71 .00001 .0000$

$\begin{array}{lll}-8.5 & 1.0150 & 0.9965\end{array}$

$-10.21 .02001 .0200$

$-24.81 .00001 .0000$

$-4.71 .02001 .0200$

1.51 .03001 .0227

-264.2 MVABASE- 1055.8 
PTI INTERACTIVE POWER SYSTEM SIMULATOR--PSS/E

SUN, DEC $291991 \quad 13: 13$

1991 WINTER PEAK LOAD. AMLP $\$ 8$ IS OFF, AMLP 1 \& $\$ 5$ ARE ON. SCEWARIO 4 NO BATTERY. GOVS DISABLED. BERNICE LAKE UNIT IS OFF.

GENERATOR SUMMARY:

\begin{tabular}{|c|c|c|c|}
\hline . & NAME BS & (5) & \\
\hline 3 & BELUGA3G13.8 & 1 & \\
\hline & BELUGA5G13.8 & 1 & \\
\hline & BELUGA 6G13 & 1 & \\
\hline & BELUGA 7G] & 1 & \\
\hline 8 & BELUGA8G13.8 & 3 & \\
\hline 24 & EKLUT 2G6.90 & 1 & \\
\hline & EKLUT $1 G 6.90$ & & \\
\hline & TEELAND 1 & - & \\
\hline 7 & COOP $1 \& 2 G 4$ & 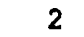 & \\
\hline & FORT ผ. 12.4 & 4 & \\
\hline & GLDHLSVS 13.8 & 1 & \\
\hline & N. POLE 13.8 & & \\
\hline & CHENA & 3 & \\
\hline & HEALYSVS 12.0 & 1 & \\
\hline & HEALY $1 G 13.8$ & 1 & \\
\hline & BRADLY1G13.8 & 1 & \\
\hline & BRADLY2 & & \\
\hline & PLNT2 $5 \mathrm{G} 13.8$ & & \\
\hline & PLNT2 $6 \mathrm{G} 13.8$ & 1 & \\
\hline & PLNT2 $7 \mathrm{G} 13.8$ & 1 & \\
\hline & PLNT1 $1 \mathrm{G} 13.8$ & 1 & \\
\hline & 4 & 1 & \\
\hline
\end{tabular}

SUBSYSTEM TOTALS

$\begin{array}{rrr}\text { MW } & \text { MVAR } & \text { QMAX } \\ 62.7 & 8.9 & 24.8 \\ 59.0 & 7.3 & 33.0 \\ 78.0 & 9.9 & 37.1 \\ 75.0 & 7.9 & 37.1 \\ 54.0 & 8.2 & 30.0 \\ 16.0 & 4.3 & 7.3 \\ 16.0 & 4.3 & 7.3 \\ 0.0 & 10.1 & 22.0 \\ 16.0 & 5.7 & 14.7 \\ 7.5 & 1.7 & 5.4 \\ 0.0 & 33.0 & 33.0 \\ 50.0 & 7.7 & 34.8 \\ 20.0 & 9.9 & 12.2 \\ 0.0 & 7.1 & 22.0 \\ 25.0 & 3.1 & 15.5 \\ 45.0 & 7.7 & 19.7 \\ 45.0 & 7.8 & 19.7 \\ 18.8 & 17.1 & 17.1 \\ 23.0 & 18.4 & 20.5 \\ 72.0 & 40.2 & 49.7 \\ 5.0 & 6.4 & 9.4 \\ 4.1 & 1.5 & 1.5 \\ 692.1 & 228.4 & 473.7\end{array}$

QMIN VSCHED VACTUAL REM

$-12.41 .01501 .0150$

$-16.51 .01501 .0150$

$-11.11 .01801 .0180$

$-11.11 .01501 .0150$

$-15.01 .01501 .0150$

$-2.21 .00001 .0000$

$-2.21 .00001 .0000$

$-22.01 .00501 .0050$

$-9.21 .03001 .0300$

$-2.61 .05001 .0500$

$\begin{array}{lll}-5.0 & 1.02801 .0199\end{array}$

$\begin{array}{llll}-17.4 & 0.9860 & 0.9860\end{array}$

$-4.01 .03501 .0350$

$-33.01 .02201 .0220$

$-7.51 .01401 .0140$

$-19.71 .00001 .0000$

$-19.71 .00001 .0000$

$\begin{array}{llll}-8.5 & 1.0150 & 0.9958\end{array}$

$-10.21 .02001 .0200$

$-24.81 .00001 .0000$

$-4.71 .02001 .0200$

1.51 .03001 .0237

$692.1 \quad 228.4$

473.7

-257.3 MVABASE $=$ 
PTI INTERACTIVE POWER SYSTEM SIMULATOR--PSS/E 1989 SUMMER NORMAL LOAD. BELUGA 1 \& 2 AT 5MN EACH. NO BATTERY AT INTL $34.5 \mathrm{KV}$.

\begin{tabular}{|c|c|c|c|}
\hline ENER & ATOR SOMMP & & \\
\hline BUS & NAME BSVIT & $\because M A C$ & TYP \\
\hline 1 & BELUGA1G13.8 & 1 & 2 \\
\hline 2 & BELUGA2G13.8 & 1 & 2 \\
\hline 3 & BELUGA3G13.8 & 1 & 3 \\
\hline 6 & BELUGA $6 G 13.8$ & 1 & -2 \\
\hline 8 & BEIUGA8G13.8 & 1 & -2 \\
\hline 24 & EKLUT $2 \mathrm{G} 6.90$ & 1 & -2 \\
\hline 34 & TEELAND 13.8 & 1 & -2 \\
\hline 121 & FORT $\% .12 .4$ & 4 & 2 \\
\hline 201 & GLDHLSVS 13.8 & 1 & 2 \\
\hline 213 & CHENA & 3 & 2 \\
\hline 368 & HEALYSVS1 2.0 & 1 & 2 \\
\hline 370 & HEALY $1 \mathrm{G} 13.8$ & 1 & 2 \\
\hline 501 & BRADIY1G13.8 & 1 & 2 \\
\hline 502 & BRADLY2G13.8 & 1 & 2 \\
\hline 601 & PLNT2 6G13.8 & 1 & 2 \\
\hline 602 & PLNT2 $7 G 13.8$ & 1 & 2 \\
\hline 691 & TESORO1G24.9 & 1 & -2 \\
\hline
\end{tabular}

QMAX
SUN, DEC 291991

$13: 14$

SCENARIO 5

$\begin{array}{rr}\text { MW } & \text { MVAR } \\ 5.0 & -3.6 \\ 5.0 & -4.5 \\ 31.6 & -15.8 \\ 59.0 & -11.1 \\ 24.0 & -15.0 \\ 7.0 & -2.2 \\ 0.0 & -22.0 \\ 5.9 & 0.1 \\ 0.0 & 15.9 \\ 12.5 & 2.0 \\ 0.0 & -19.7 \\ 25.0 & 3.1 \\ 15.0 & -7.1 \\ 15.0 & -7.1 \\ 12.0 & -6.4 \\ 38.0 & 6.9 \\ 4.1 & 1.5 \\ 259.0 & -85.1\end{array}$

9.9

9.9

24.8

37.1

30.0

7.3

22.0

5.4

33.0

12.2

22.0

15.5

19.7

19.7

20.5

49.7

1.5

340.2
QMIN VSCBED VACTUAL $-4.91 .01501 .0150$

$-4.91 .01001 .0100$ $-12.41 .01501 .0150$

$-11.11 .01801 .0233$

$\begin{array}{lll}-15.0 & 1.0150 & 1.0202\end{array}$

$-2.2 \quad 1.00001 .0218$

$\begin{array}{lll}-22.0 & 1.00501 .0253\end{array}$

$-2.61 .05001 .0500$

$-5.01 .02801 .0280$

$-4.01 .03501 .0350$

$-33.01 .02201 .0220$

$-7.51 .01401 .0140$

$-19.71 .00001 .0000$

$-19.71 .00001 .0000$

$-10.21 .02001 .0200$

$-24.81 .00001 .0000$

1.51 .03001 .0441

-197.5 MVABASE=
REM

202

37

749.9

$B-5$ 
PTI INTERACTIVE POWER SYSTEM SIMULATOR--PSS/E

SUN, DEC $291991 \quad 13: 14$ 1989 SULOAER NORMAL LOAD. BELUGA 1 AT 5M. 15 MVA BATTERY AT INTL $34.5 \mathrm{KV}$, $O \mathrm{MW}$ OUTPOT.

scLunario 6

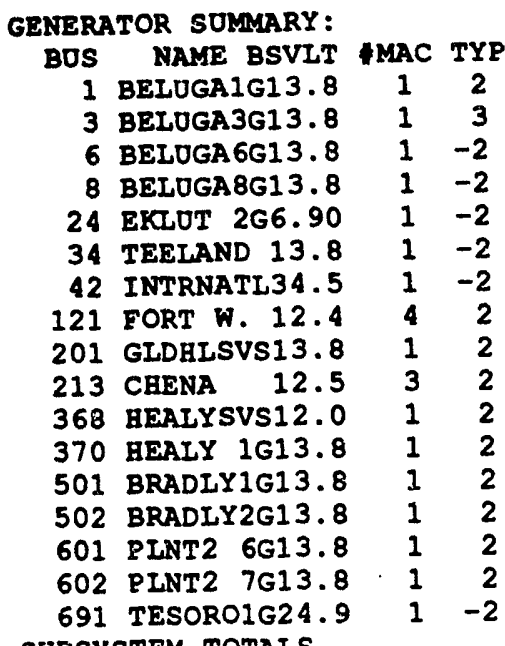

SUBSYSTEM TOTALS

\begin{tabular}{rr}
\multicolumn{1}{c}{ MW } & MVAR \\
5.0 & -4.1 \\
36.6 & -17.9 \\
59.0 & -11.1 \\
24.0 & -15.0 \\
7.0 & -2.2 \\
0.0 & -22.0 \\
0.0 & 0.0 \\
5.9 & 0.1 \\
0.0 & 15.8 \\
12.5 & 2.0 \\
0.0 & -20.0 \\
25.0 & 3.1 \\
15.0 & -7.3 \\
15.0 & -7.3 \\
12.0 & -7.2 \\
38.0 & 5.9 \\
4.1 & 1.5 \\
259.1 & -85.6
\end{tabular}

QMAX

9.9

24.8

37.1

30.0

7.3

22.0

0.0

5.4

33.0

12.2

22.0

15.5

19.7

19.7

20.5

49.7

1.5

330.3

QMIN VSCAED VACTUAL

REM

$-4.91 .01501 .0150$

$-12.41 .01501 .0150$

$\begin{array}{llll}-11.1 & 1.0180 & 1.0267\end{array}$

$\begin{array}{lll}-15.0 & 1.0150 & 1.0235\end{array}$

$-2.21 .00001 .0238$

$\begin{array}{lll}-22.0 & 1.0050 & 1.0274\end{array}$

0.01 .00001 .0531

15

$-2.61 .05001 .0500$

$\begin{array}{lll}-5.0 & 1.0280 & 1.0280\end{array}$

$-4.0 \quad 1.03501 .0350$

$-33.01 .02201 .0220$

$-7.51 .01401 .0140$

$-19.71 .00001 .0000$

$-19.71 .00001 .0000$

$-10.2 \quad 1.02001 .0200$

$-24.81 .00001 .0000$

1.51 .03001 .0449

-192.6 MVABASE-

761.1

$$
\text { B- } 6
$$


PTI INTERACTIVE POWER SYSTEM SIMULATOR--PSS/E SUN, DEC 291991

$13: 15$ 1989 SUMER NORMAL LOAD. BRADLEY 1 \& 2 EACH AT 15M. 30 MVA BATTERY AT INTL $34.5 \mathrm{KV}, 0 \mathrm{MW}$ OUTPOT.

ScENPRIO 7

GENERATOR SUMMARY:

$\begin{array}{rlcc}\text { BUS } & \text { NAME BSVIT } & \text { MAC } & \text { TYP } \\ 3 & \text { BELOGA3G13.8 } & 1 & 3 \\ 6 & \text { BELUGA 6G13.8 } & 1 & -2 \\ 8 & \text { BELOGABG13.8 } & 1 & -2 \\ 24 & \text { EKLUT 2G6.90 } & 1 & -2 \\ 34 & \text { TEELAND } 13.8 & 1 & -2 \\ 42 & \text { INTRNATL34.5 } & 1 & -2 \\ 121 & \text { FORT } \text { W. } 12.4 & 4 & 2 \\ 201 & \text { GLDHLSVS13.8 } & 1 & 2 \\ 213 & \text { CHENA } 12.5 & 3 & 2 \\ 368 & \text { BEALYSVS12.0 } & 1 & 2 \\ 370 & \text { GEALY 1G13.8 } & 1 & 2 \\ 501 & \text { BRADLY1G13.8 } & 1 & 2 \\ 502 & \text { BRADLY2G13.8 } & 1 & 2 \\ 601 & \text { PLNT2 6G13.8 } & 1 & 2 \\ 602 & \text { PLNT2 7G13.8 } & 1 & 2 \\ 691 & \text { TESORO1G24.9 } & 1 & -2\end{array}$

\begin{tabular}{rr}
\multicolumn{1}{c}{ MW } & MVAR \\
41.6 & -20.0 \\
59.0 & -11.1 \\
24.0 & -15.0 \\
7.0 & -2.2 \\
0.0 & -22.0 \\
0.0 & 0.0 \\
5.9 & 0.1 \\
0.0 & 15.9 \\
12.5 & 2.0 \\
0.0 & -20.2 \\
25.0 & 3.1 \\
15.0 & -7.4 \\
15.0 & -7.4 \\
12.0 & -8.0 \\
38.0 & 4.8 \\
4.1 & 1.5 \\
259.1 & -86.0
\end{tabular}

QMAX

24.8

37.1

30.0

7.3

22.0

0.0

5.4

33.0

12.2

22.0

15.5

19.7

19.7

20.5

49.7

1.5

320.4
QMIN VSCHED VACTUAL REM $-12.41 .01501 .0150$ $-11.11 .01801 .0300$

$\begin{array}{llll}-15.0 & 1.01501 .0269\end{array}$

$-2.21 .00001 .0260$

$-22.01 .00501 .0295$

0.01 .00001 .0558

$-2.61 .05001 .0500$

$-5.01 .02801 .0280$

$-4.01 .03501 .0350$

$-33.01 .02201 .0220$

$-7.51 .01401 .0140$

$-19.71 .00001 .0000$

$-19.71 .00001 .0000$

$-10.21 .02001 .0200$

$-24.81 .00001 .0000$

1.51 .03001 .0458 SUBSYSTEM TOTALS
$259.1-86.0$ 
-

$\bullet$

-

B-8 


\section{STABILITY ANALYSIS: SCENARIO 1}

This appendix contains the simulations of Scenario 1. Battery sizes from 15 to $30 \mathrm{MW}$ and droop settings of $0.5 \%$ and $1 \%$ were used. A simulation case was also run in which no battery was used. In this scenario, the disturbance consisted of a $54 \mathrm{MW}$ loss of generation. 
1991 WINTER PEAK LOAD. NO MVA BATTERY AT INTL. 34.5. GOVERNORS DISABLED AT BELUGA 5,6,7, CHENA 5, HEALY.

TRIP BELUGA \#8 AT $54 \mathrm{MW}$ AT $\mathrm{T}=0.5$ SECONDS.

FILE : GD-00. CHN

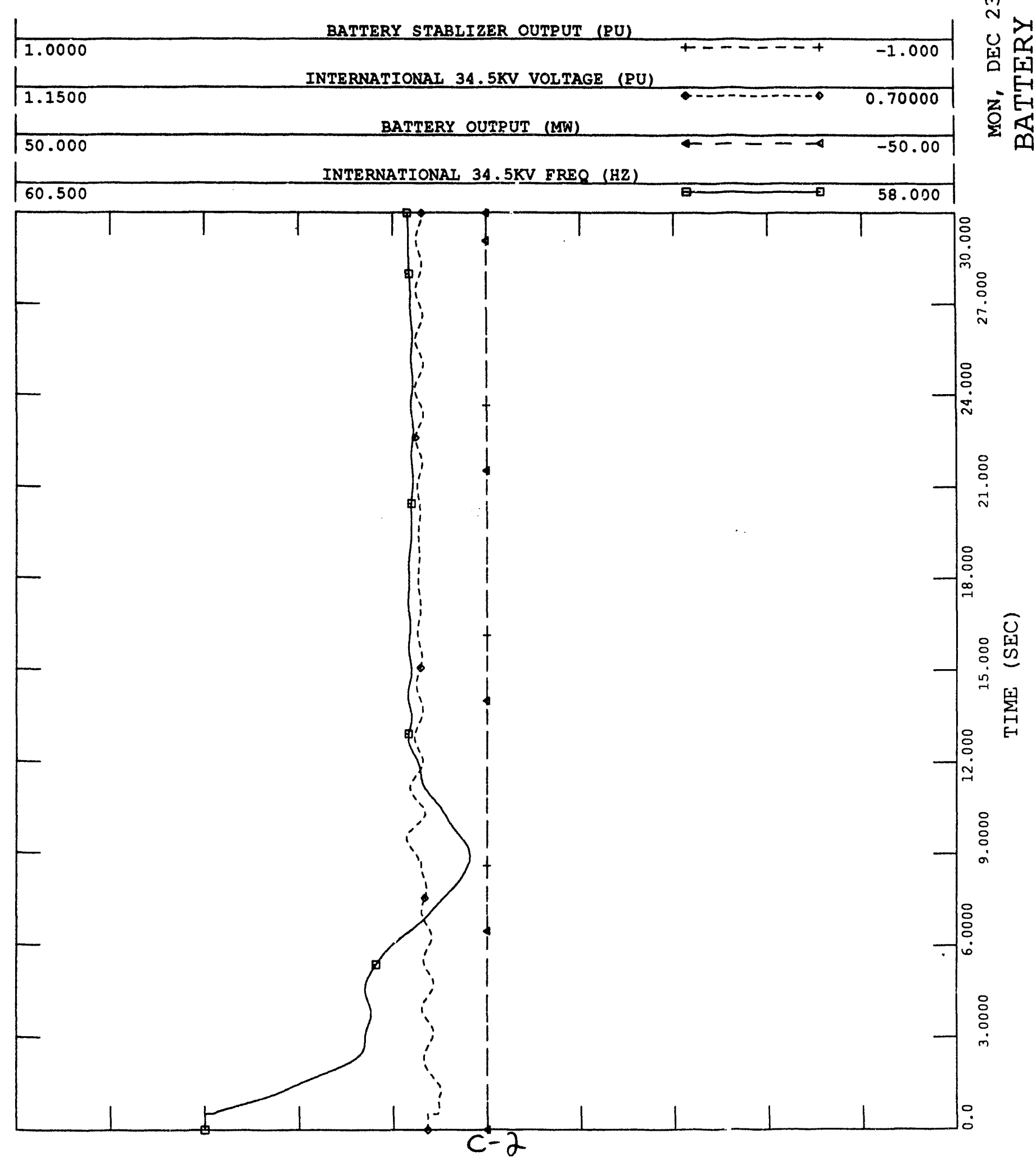




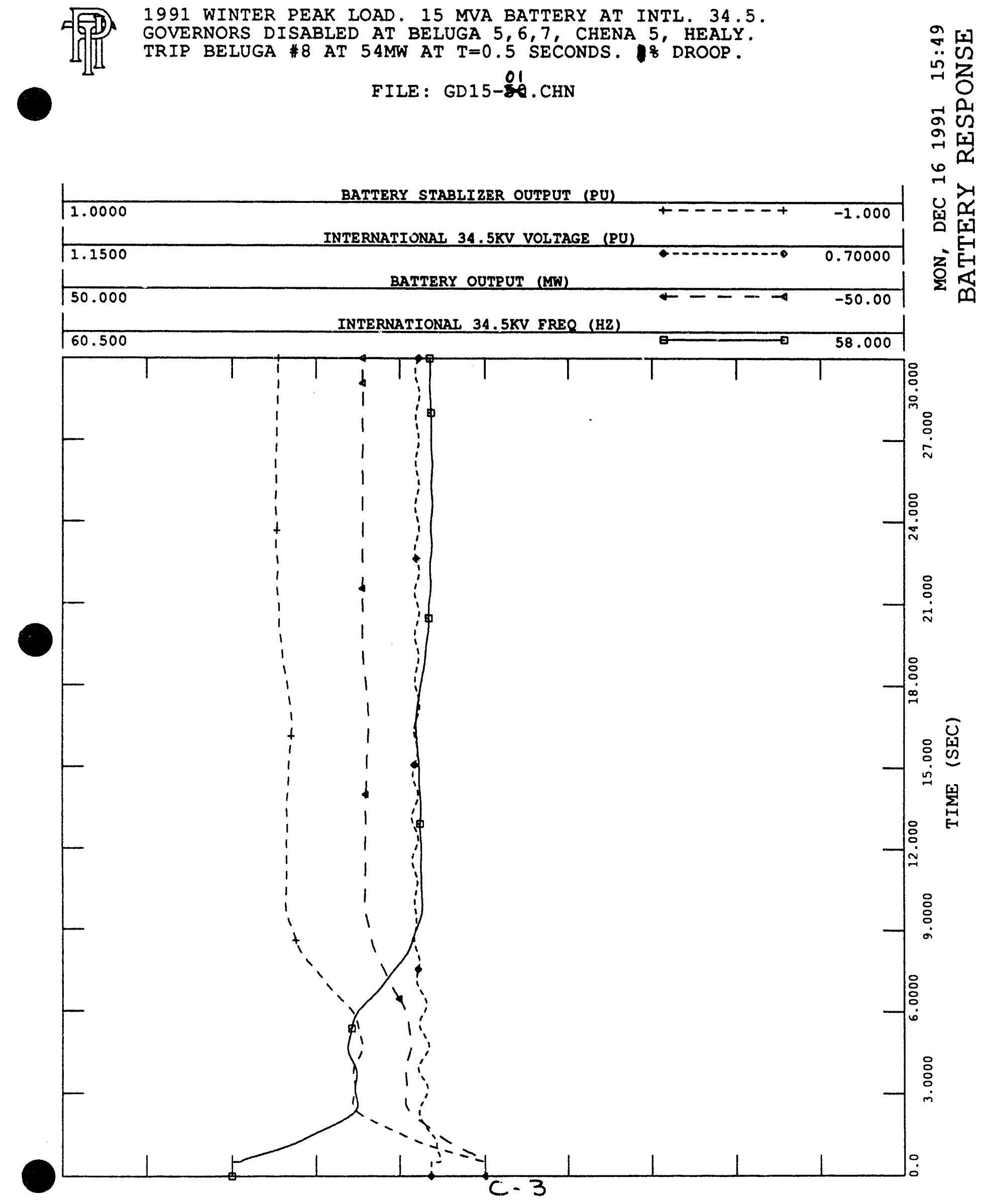


1991 WINTER PEAK LOAD. 15 MVA BATTERY AT INTL. 34.5.

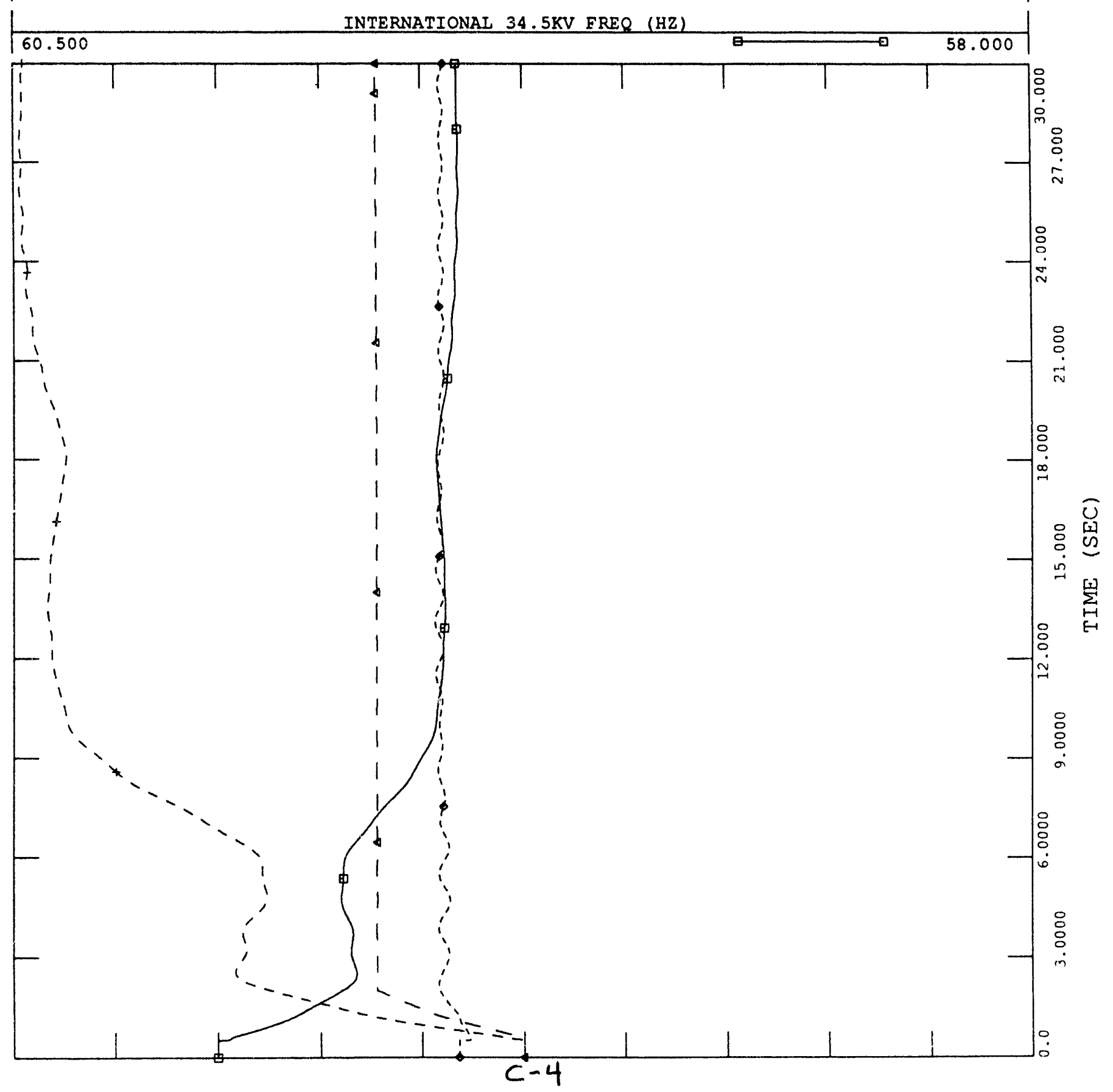




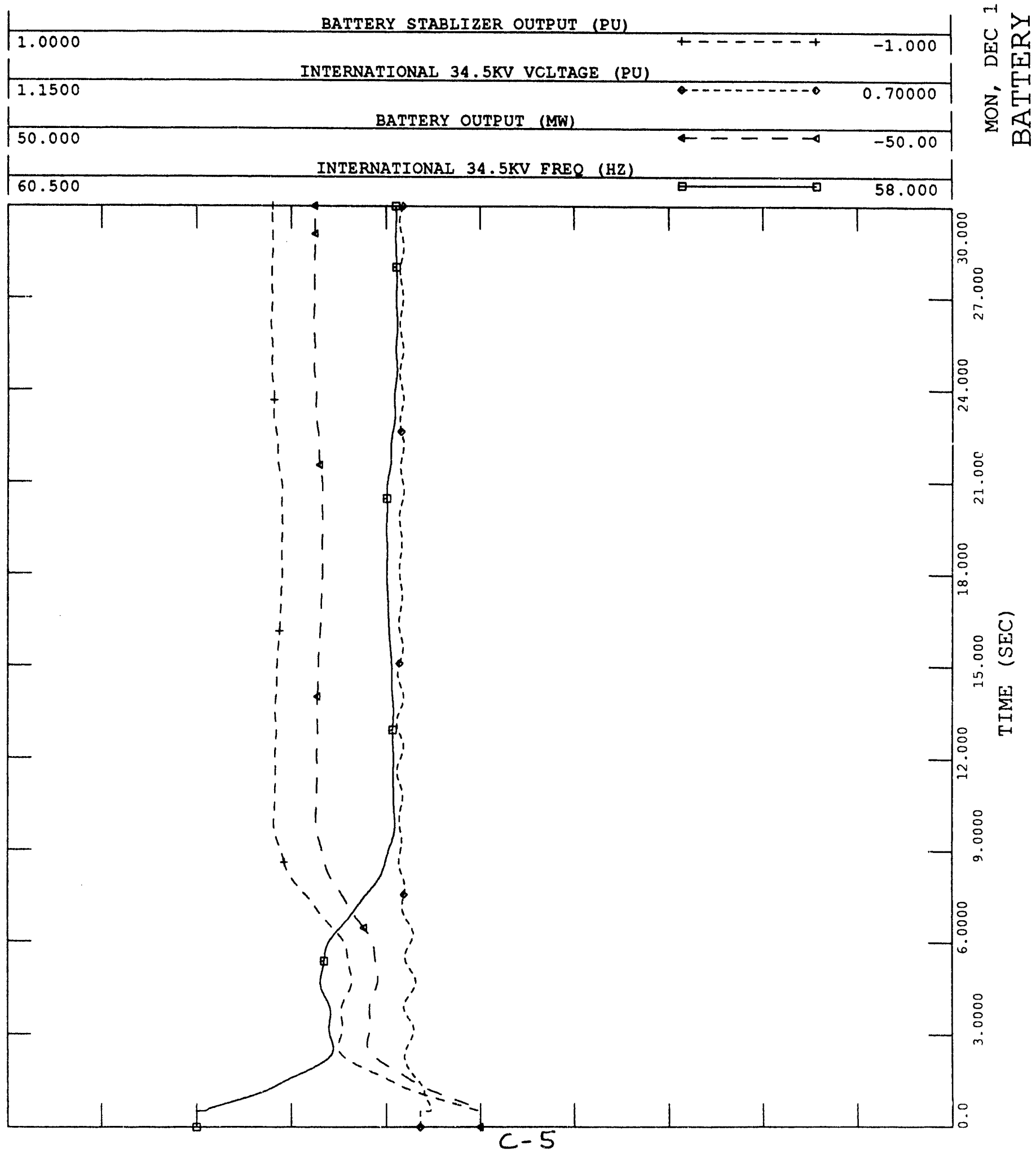




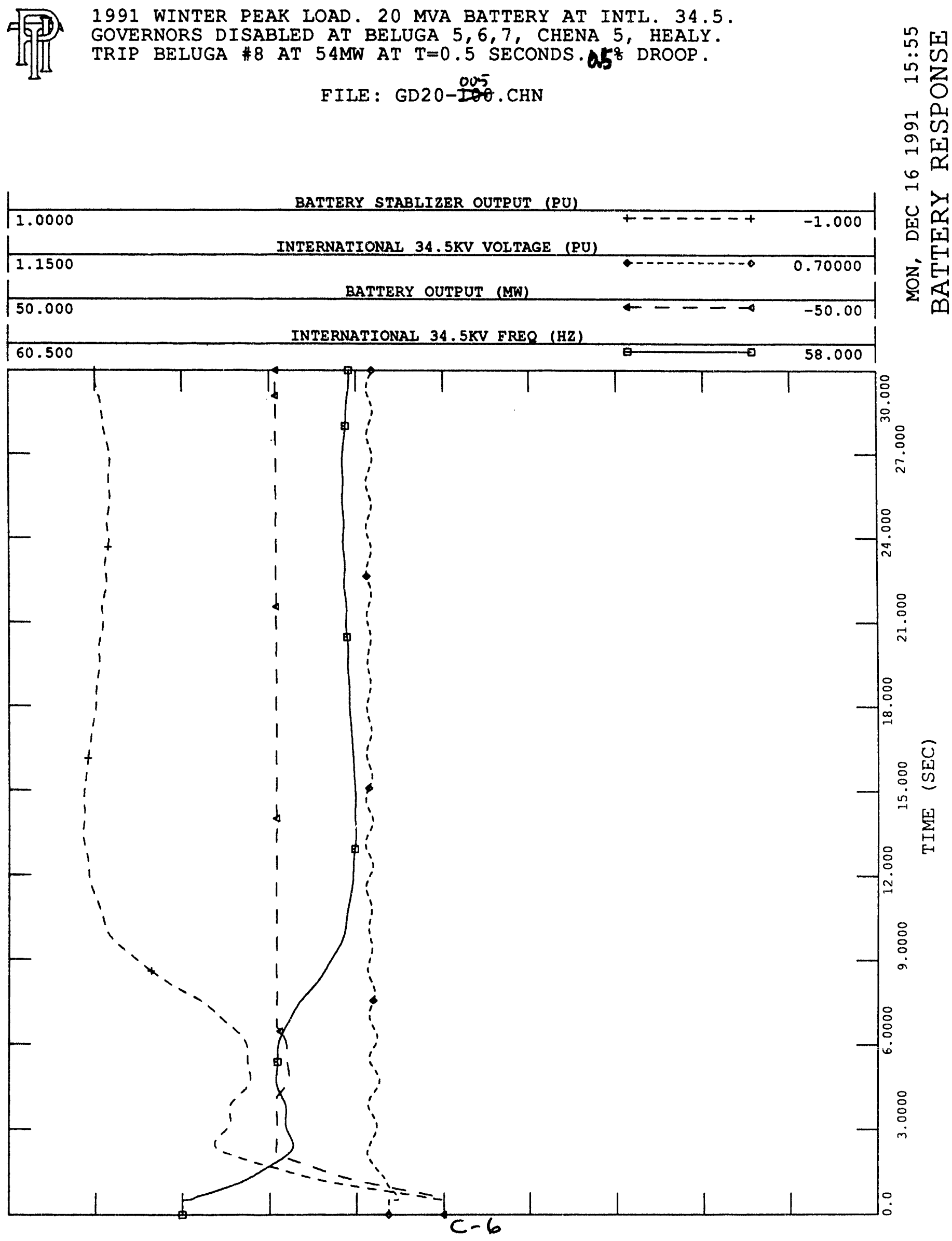


1991 WINTER PEAK LOAD. 25 MVA BATTERY AT INTL. 34.5. GOVERNORS DISABLED AT BELUGA $5,6,7$, CHENA 5, HEALY. TRIP BELUGA $\$ 8$ AT $54 \mathrm{MW}$ AT T=0.5 SECONDS. $1 \%$ DROOP.

FILE : GD25-01. CHN

$\infty$ 미

$\because$ 的

a

u

임

E-1

D E-

要

m

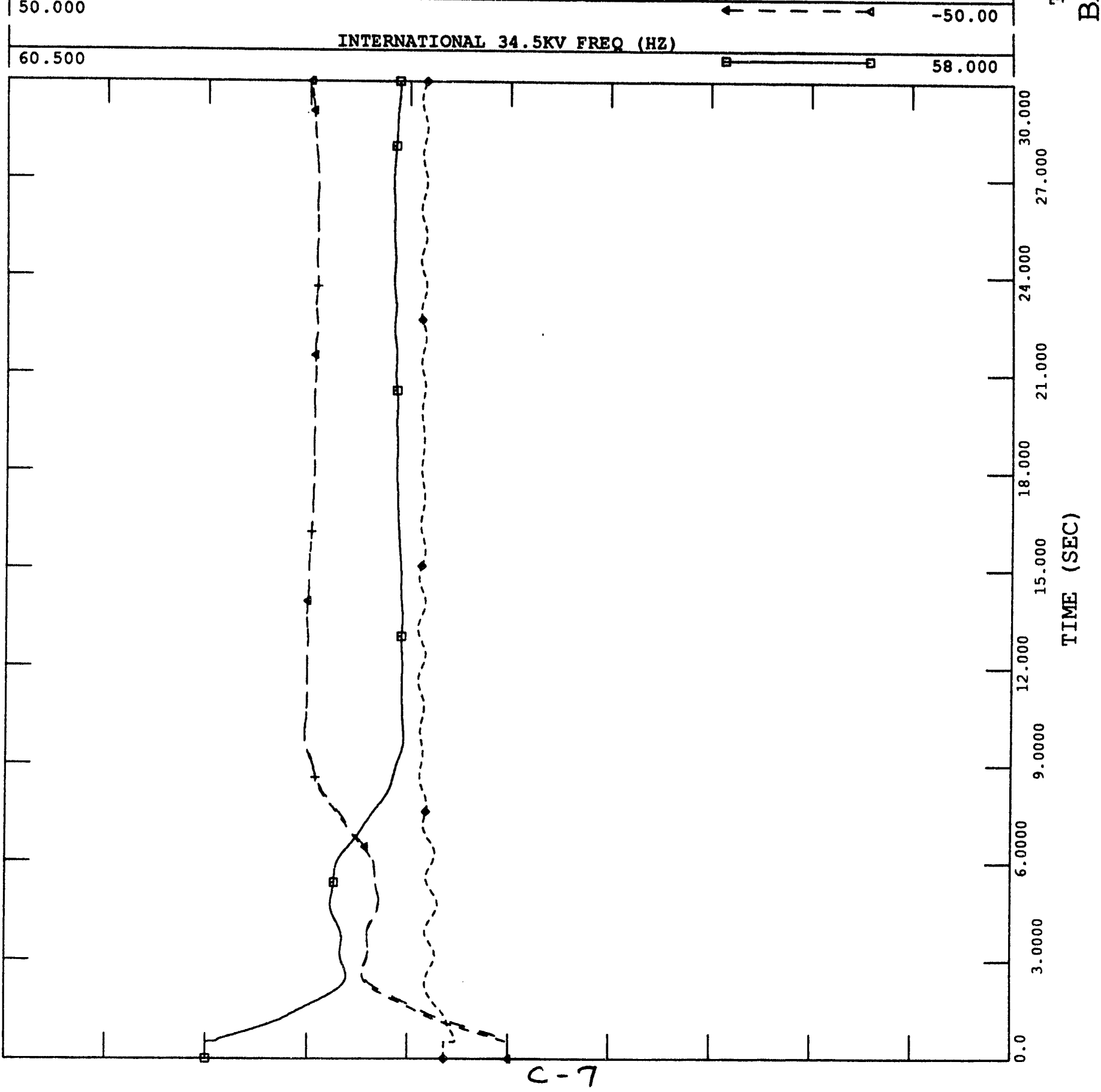




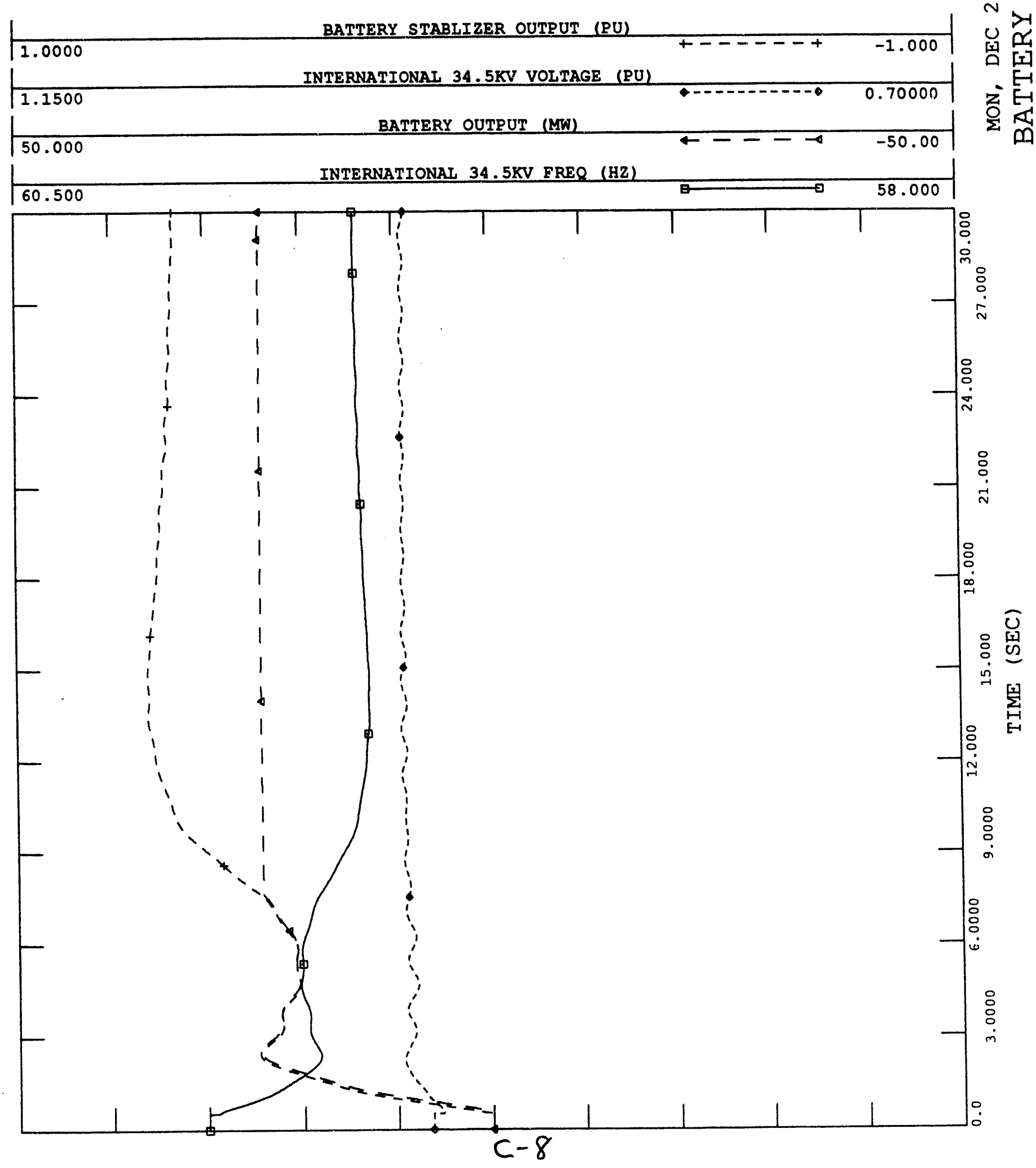




\begin{tabular}{|c|c|c|c|}
\hline 1.0000 & BATTERY STABLIZER OUTPUT (PU) & +-----+ & -1.000 \\
\hline & INTERNATIONAL $34.5 \mathrm{KV}$ VOLTAGE (PU) & & \\
\hline 1.1500 & & 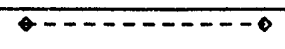 & 0.70000 \\
\hline & BATTERY OUTPUT (MW) & & \\
\hline
\end{tabular}

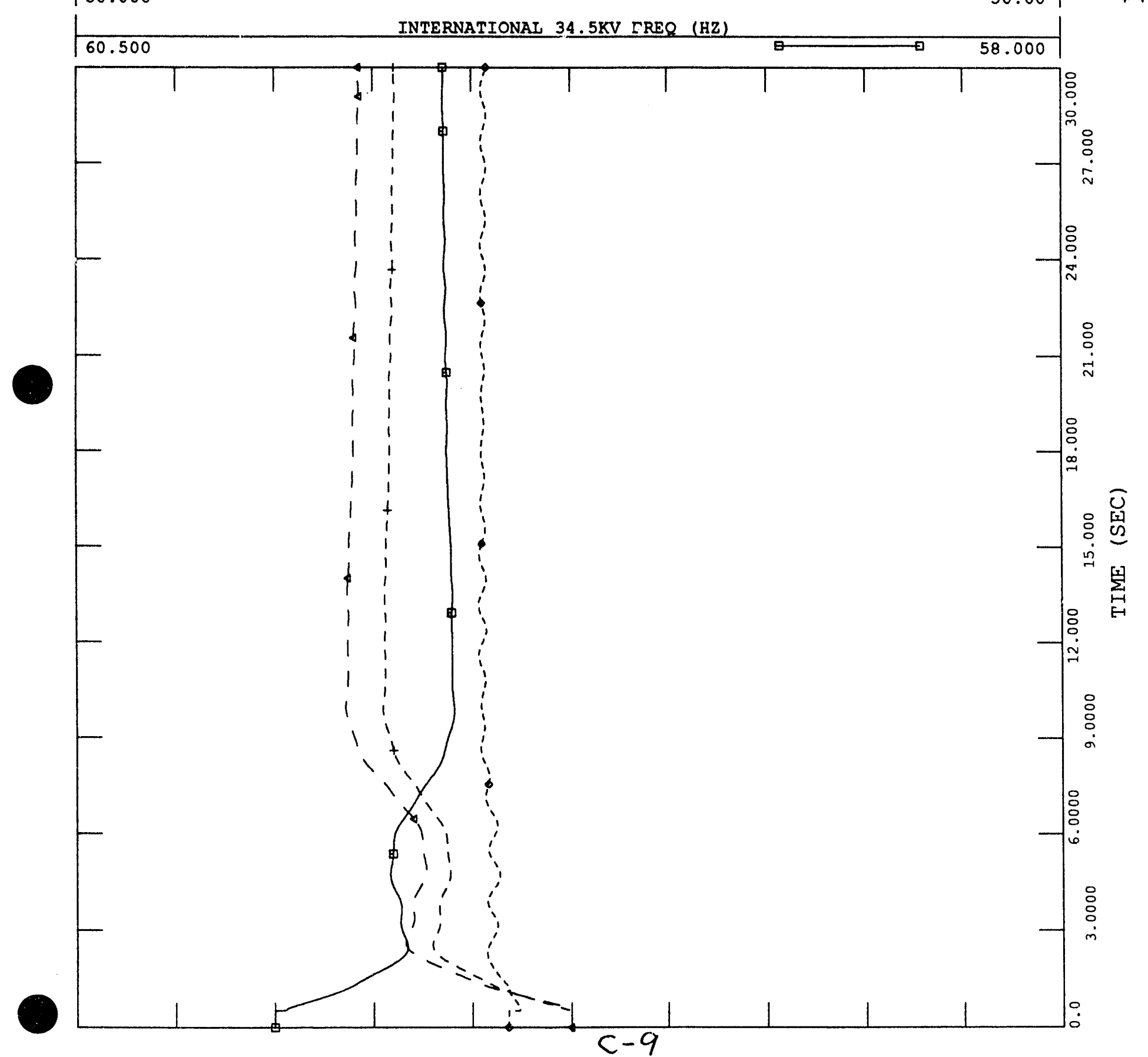


BATTERY STABLIZER OUTPUT LPU

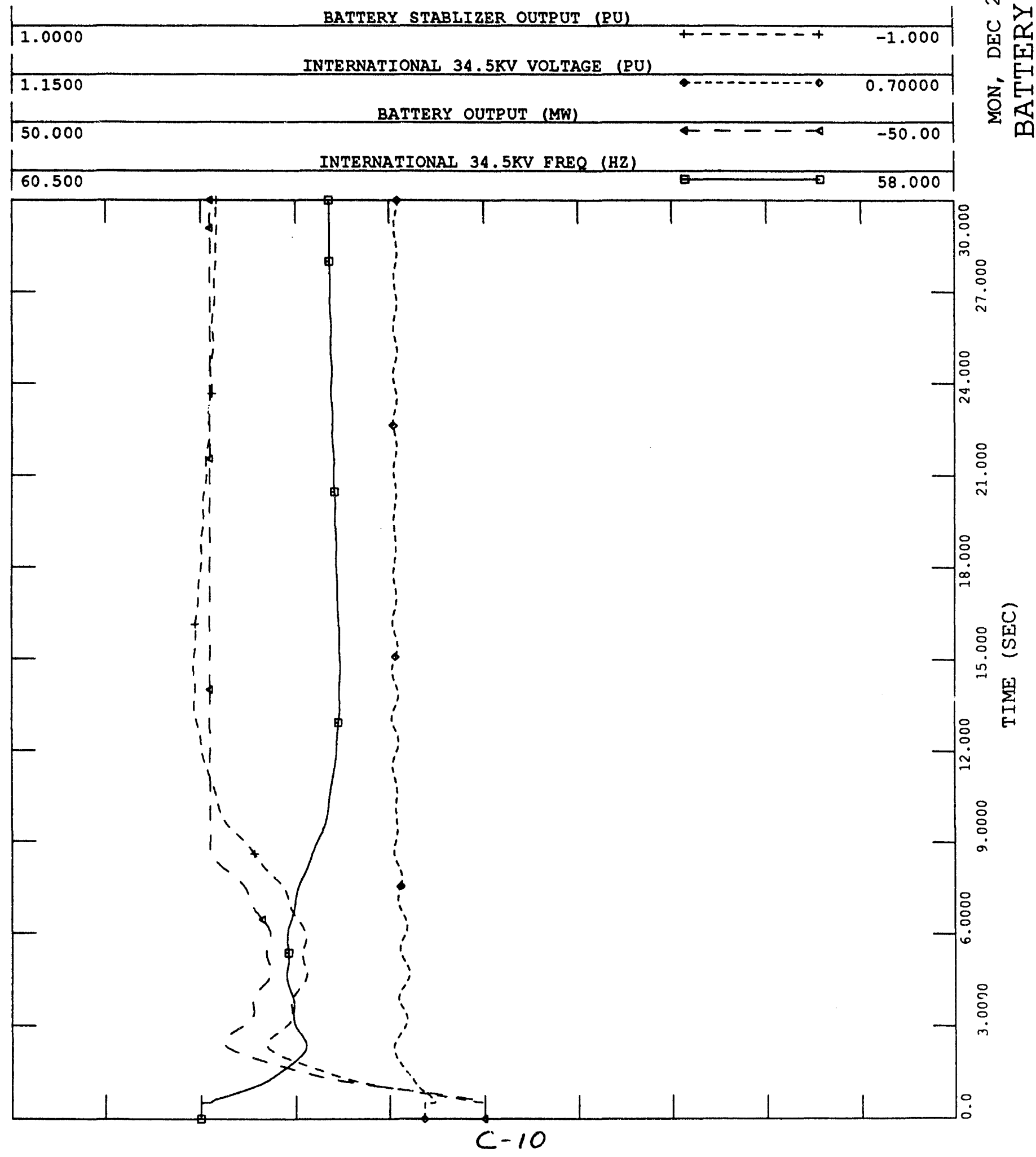




\section{D}

\section{STABILITY ANALYSIS: SCENARIO 2}

This appendix contains the simulations of Scenario 2. Battery sizes from 15 to $30 \mathrm{MW}$ and droop settings of $0.5 \%$ and $1 \%$ were used. A simulation case was also run in which no battery was attached. For this scenario, the disturbance consisted of a $54 \mathrm{MW}$ loss of generation. 
FILE: $A M-00 . C H N$

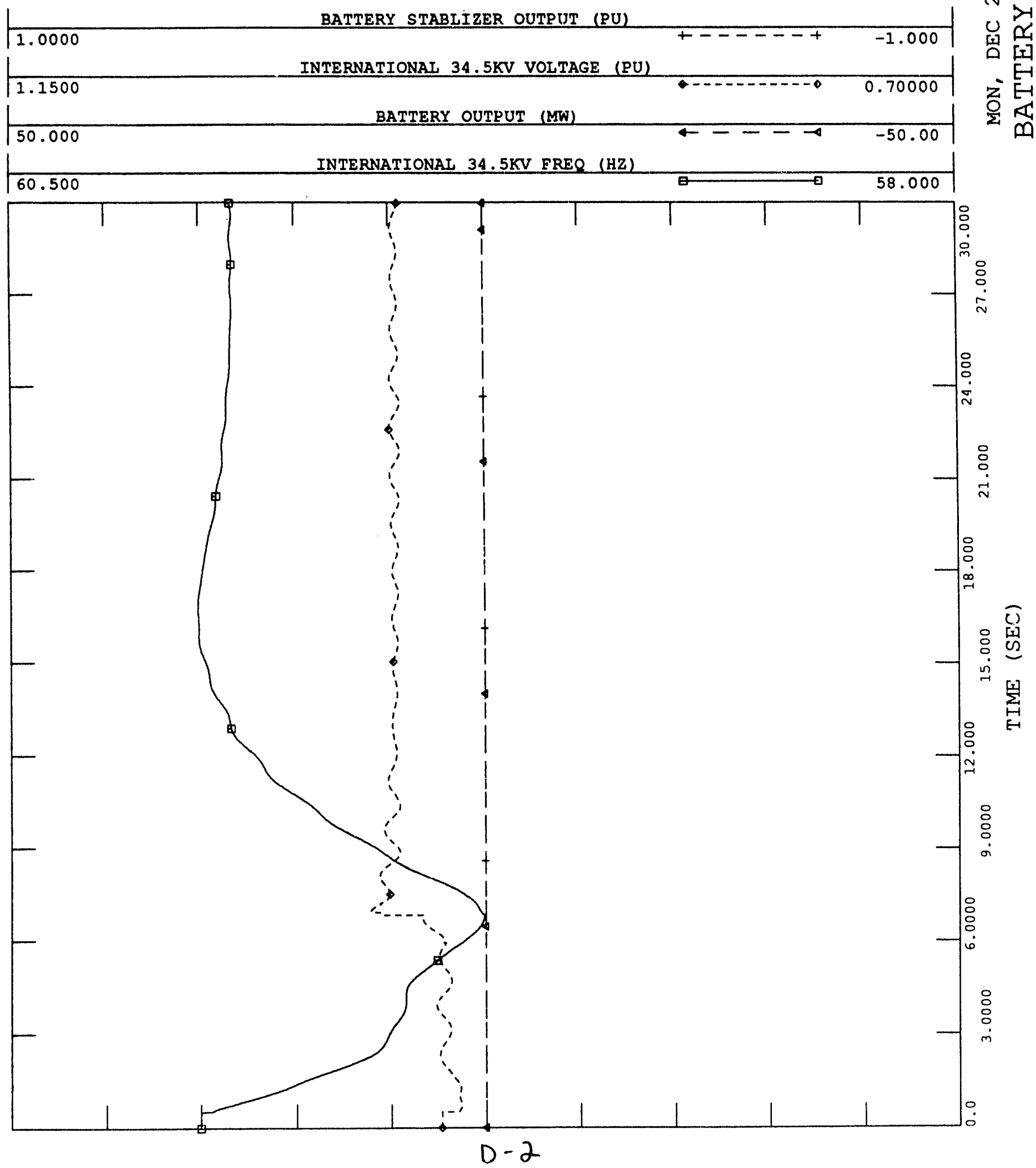




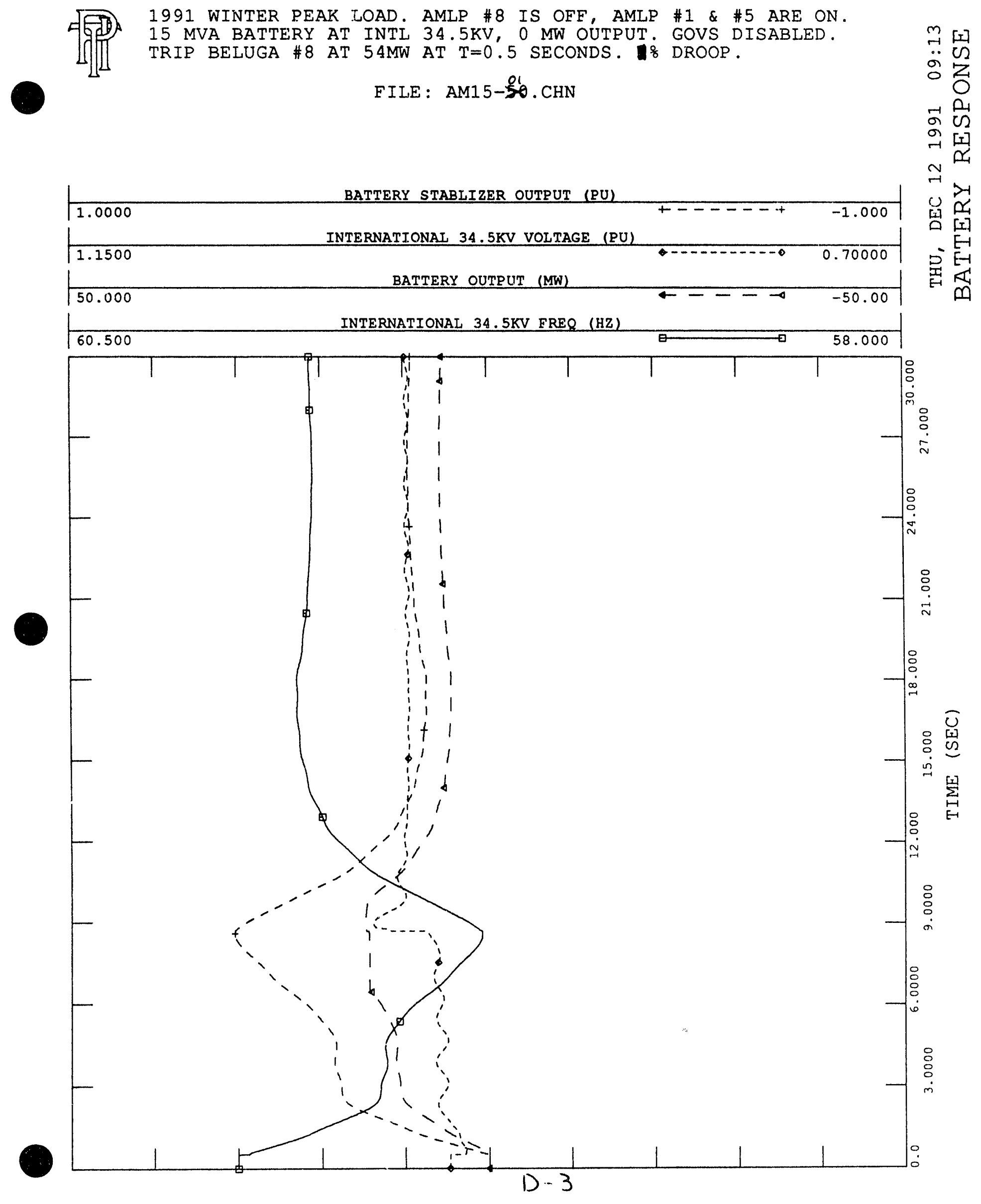




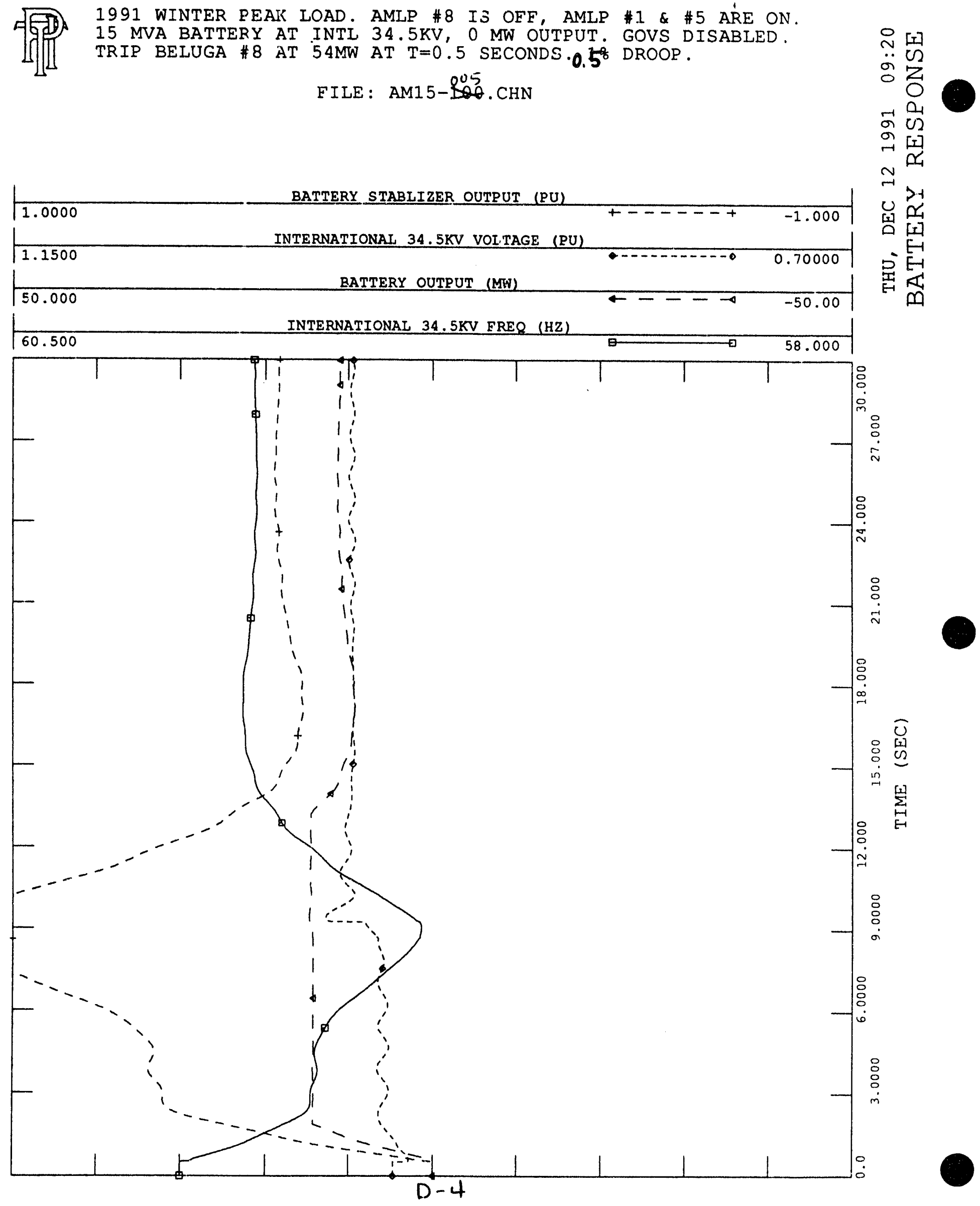


1991 WINTER PEAK LOAD. AMLP \#8 IS OFF, AMLP \#1 \#5 ARE ON. 20 MVA BATTERY AT INTI $34.5 \mathrm{KV}, 0 \mathrm{MW}$ OUTPUT. GOVS DISABLED. TRIP BELUGA \#8 AT 54MW AT $T=0.5$ SECONDS. 8 DROOP.

$$
\text { FILE: AM20-\$6. CHN }
$$
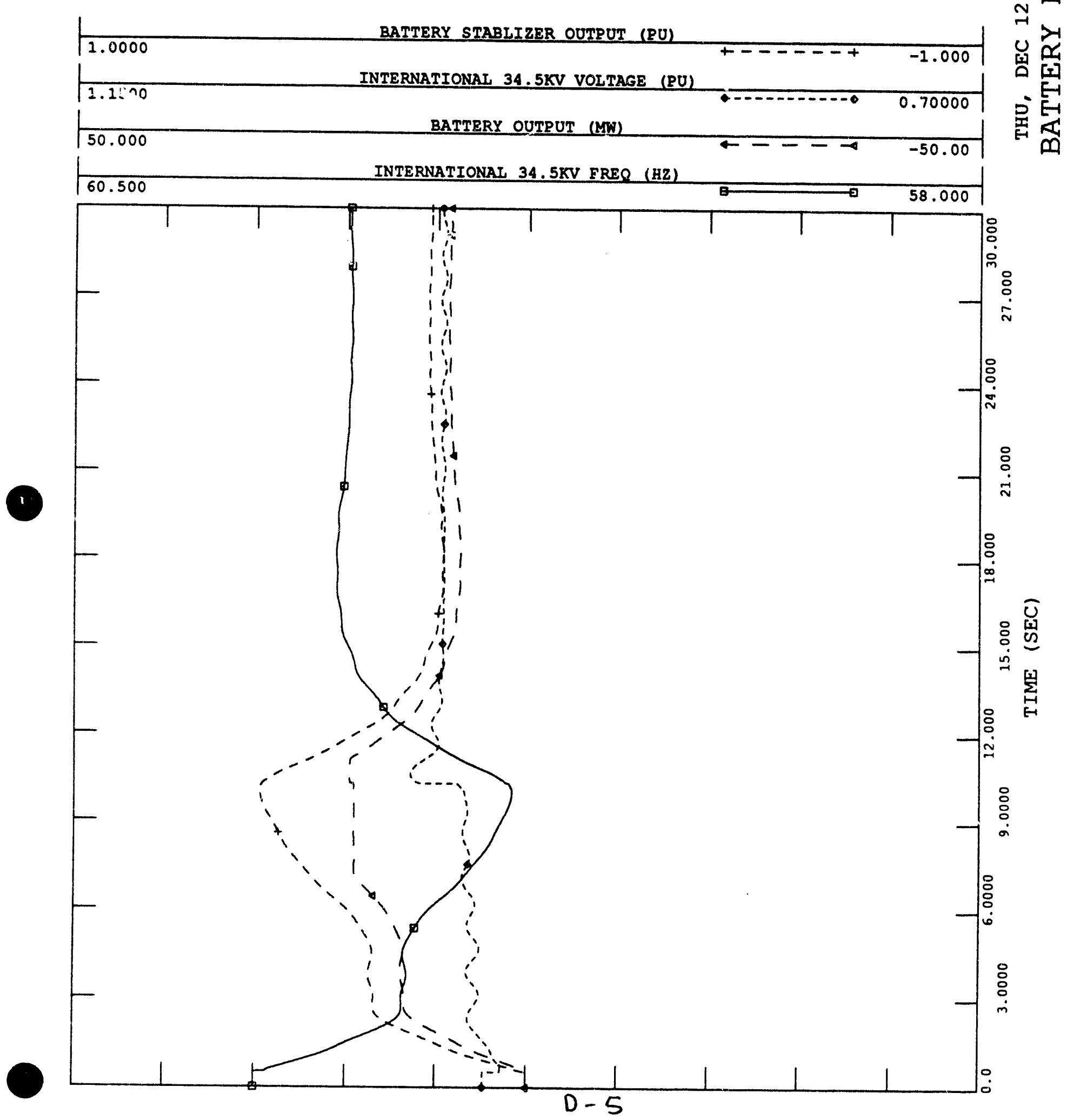
1991 WINTER PEAK LOAD. AMLP \#8 IS OFF, AMLP \#1\& \#5 ARE ON.

\begin{tabular}{|c|c|c|c|}
\hline & BATTERY STABLIZER OUTPUT (PU) & +-----1 & \\
\hline 1.0000 & INTERNATIONAI $34.5 \mathrm{KV}$ VOLTAGE (PU) & +-----+ & -1.000 \\
\hline 1.1500 & BATTERY OUTPUT (MW) & 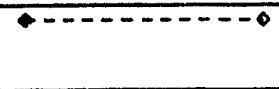 & 0.70000 \\
\hline
\end{tabular}

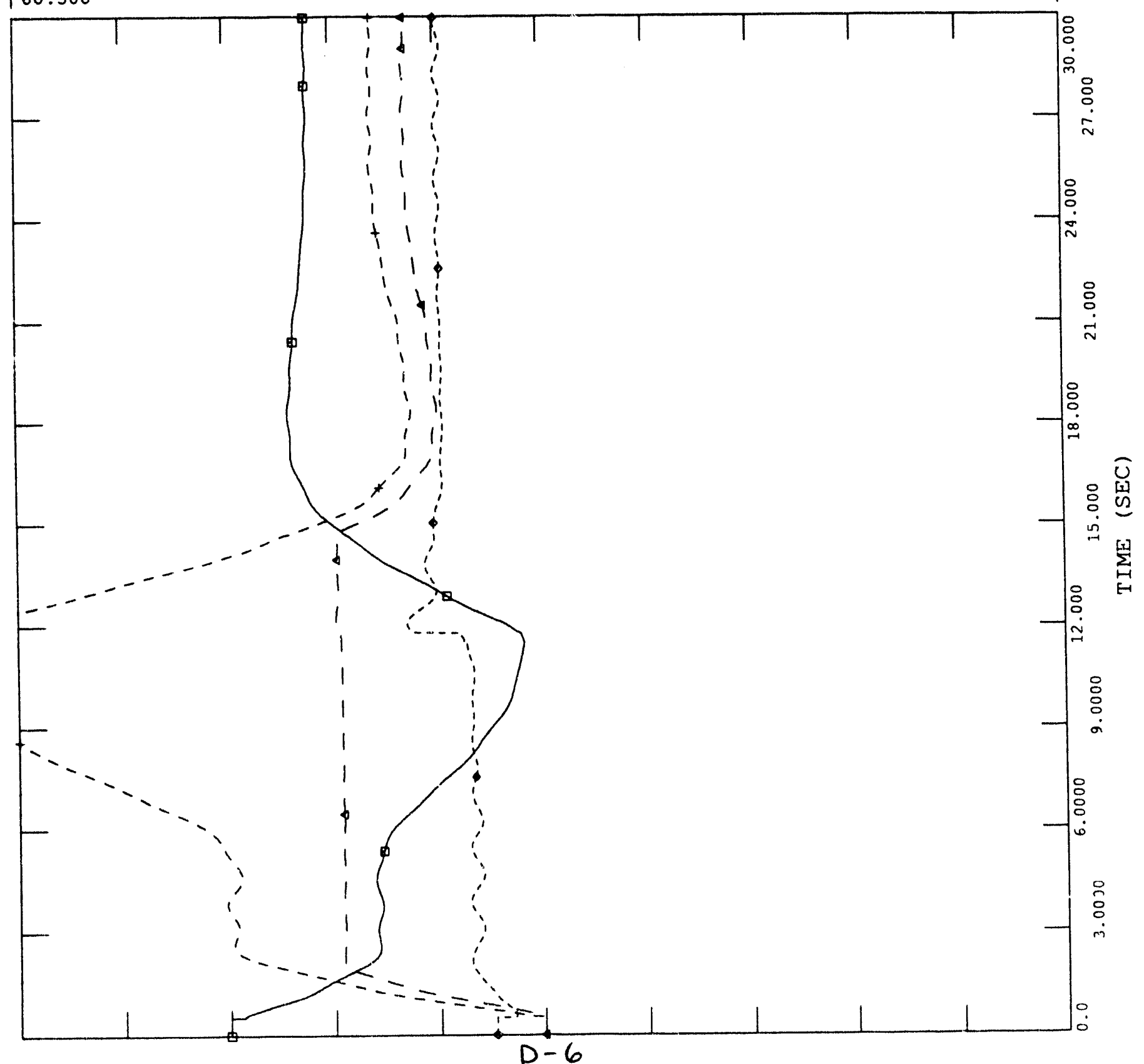


FILE : AM25-01. CHN

응디

$\ddot{\sim} v$

$-1$

ب

高 [x] E-1 突

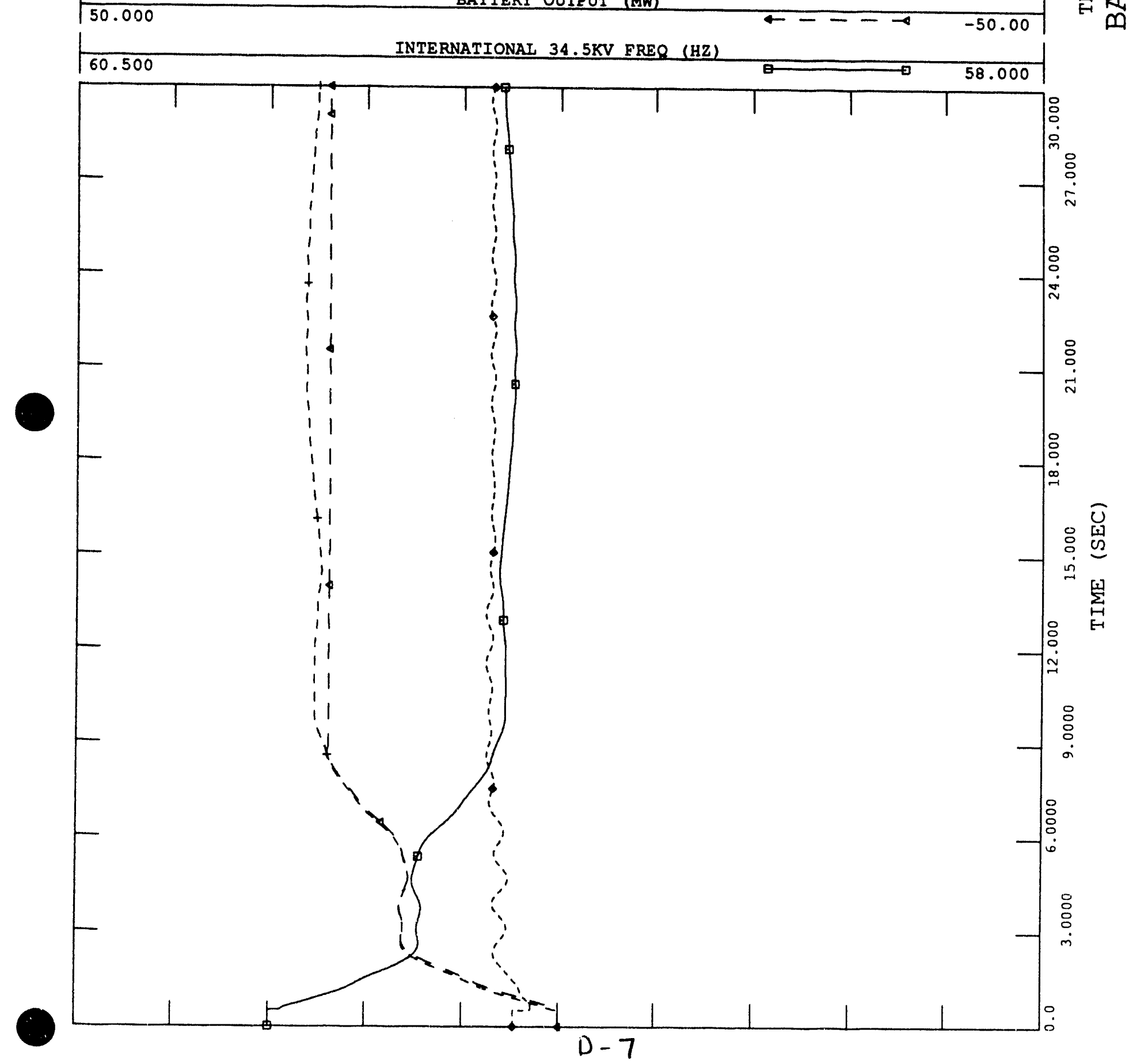


(7) 1991 WINTER PEAK LOAD. AMLP \#8 IS OFF, AMLP \#1 \& \#5 ARE ON.

FIIE: AM25-05. CHN

min

$\because$ थ

$m_{i \rightarrow 1} Z$

D

नूँ

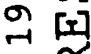

స

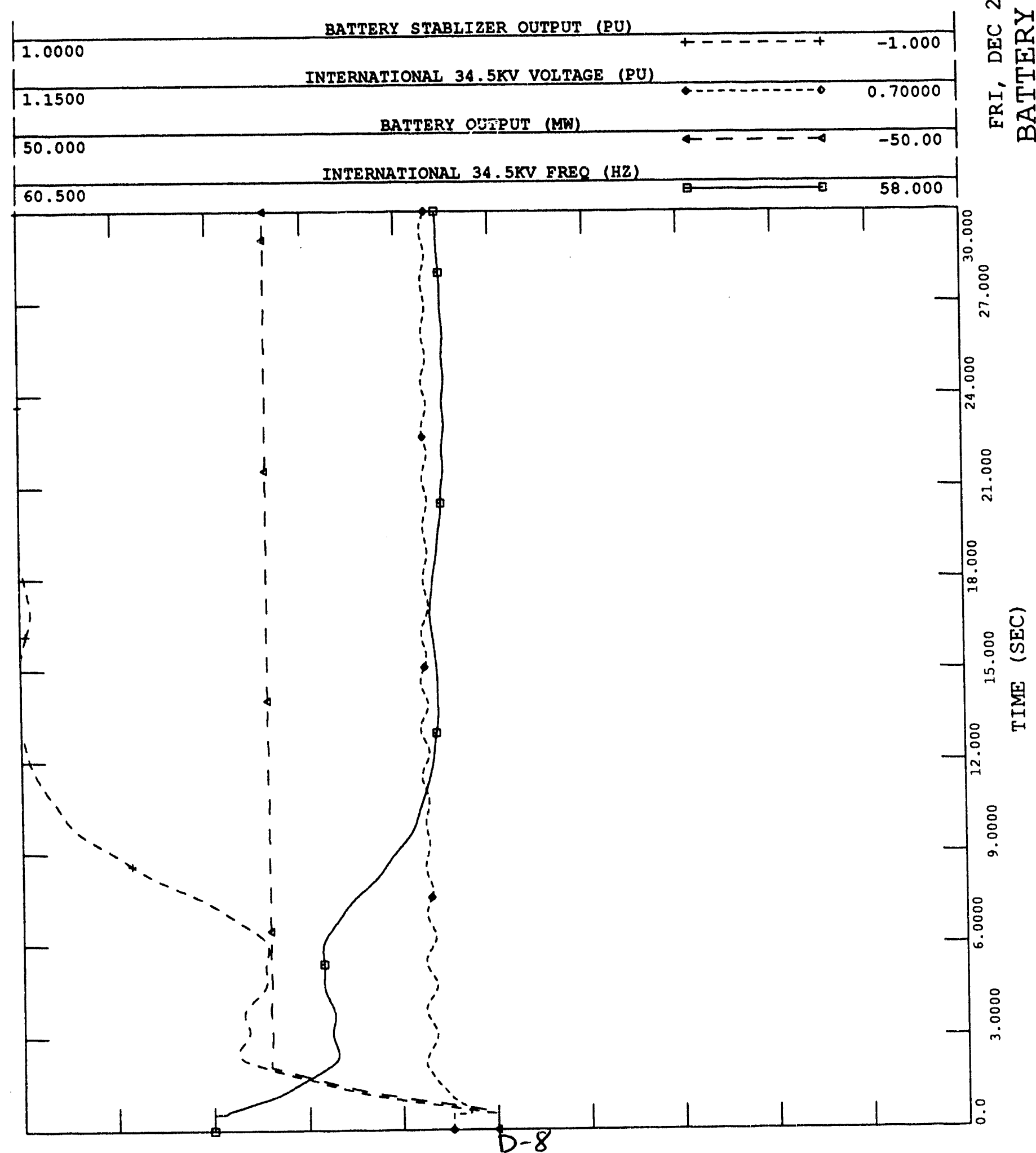


FILE: AM30-01. CHN

\begin{tabular}{|c|c|c|c|}
\hline 1.0000 & INTERNATIONAL $34.5 \mathrm{KV}$ VOLTAGE (PU) & $+-----1+$ & -1.000 \\
\hline 1.1500 & & 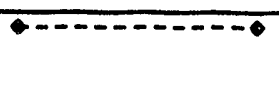 & 0.70000 \\
\hline
\end{tabular}

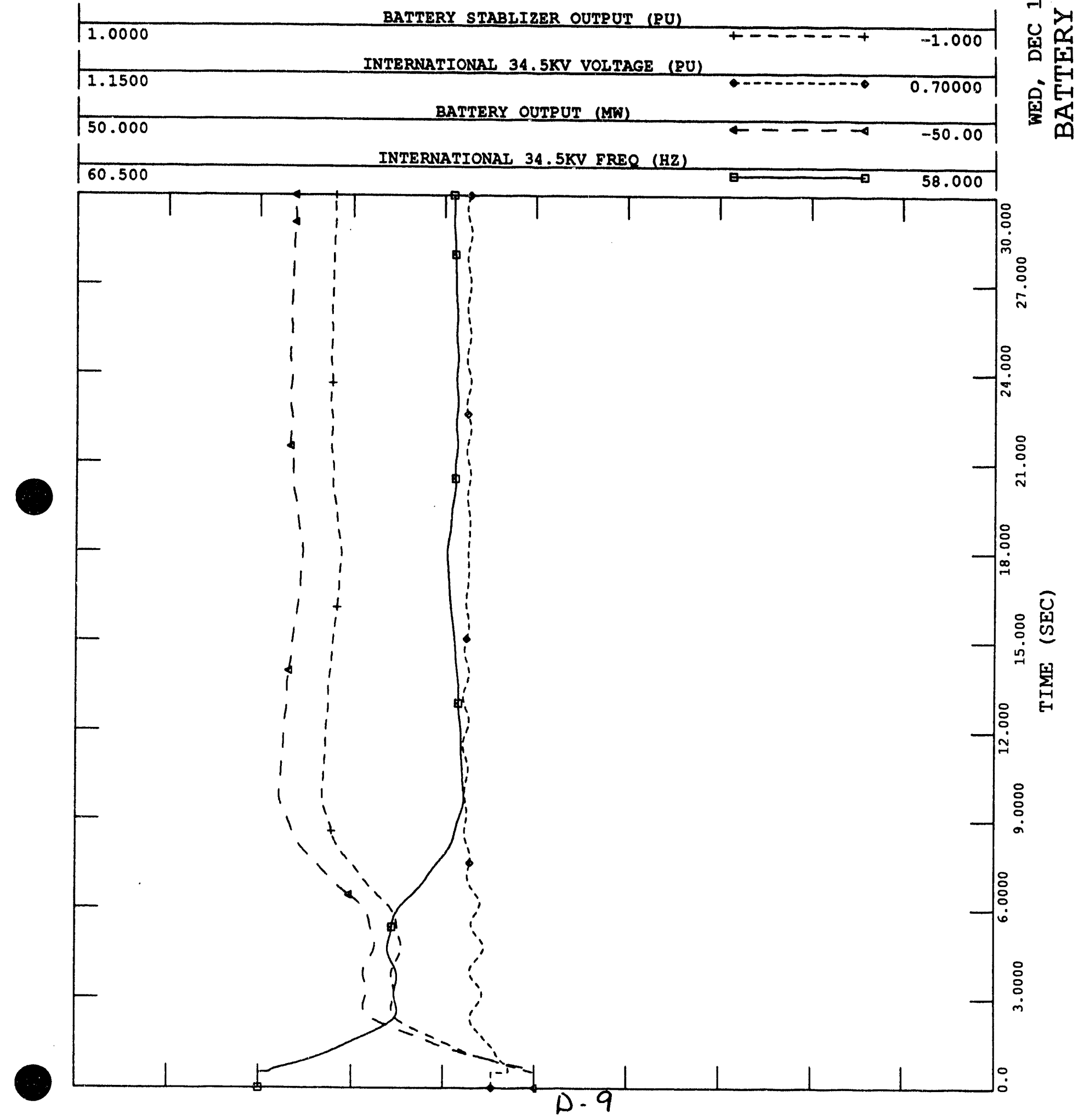



57D. 1991 WINTER PEAK LOAD. AMLP \#8 IS OFF, AMLP \#1\& \#5 ARE ON.

$1]$ TRIP BELUGA $\# 8$ AT 54 MW AT T=0.5 SECONDS.

FILE: AM30-05. CHN

ํํㅁㄷㅚ

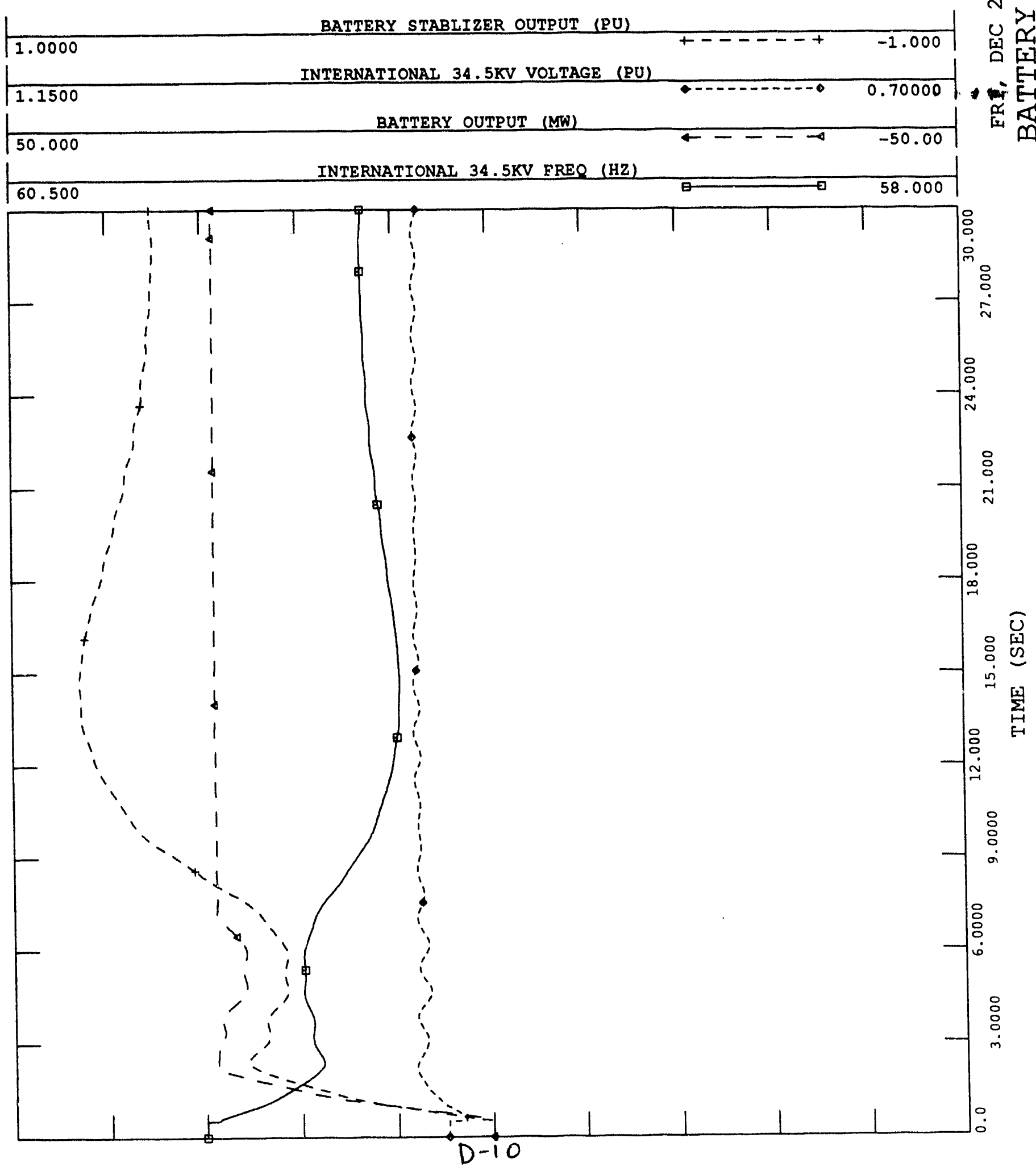




\section{$\mathbf{E}$}

\section{STABILITY ANALYSIS: SCENARIO 3}

This appendix contains the simulations of Scenario 3. Battery sizes from 15 to $25 \mathrm{MW}$ and droop settings of $0.5 \%$ and $1 \%$ were used. A simulation case was also run in which no battery was used. In this scenario, two disturbances were studied: a $54 \mathrm{MW}$ loss of generation and a $95 \mathrm{MW}$ loss of generation. 
1991 WINTER PEAK LOAD. AMLP \#8 IS OFF, AMLP \#1\& \#5 ARE ON. NO BATTERY AT INTL $34.5 \mathrm{KV}$.

TRIP BELUGA \#8 AT $54 \mathrm{MW}$ AT $\mathrm{T}=0.5$ SECONDS.

$\approx$ ○ี

भโ्या

FILE : AML-00. CHN

o

नू थ

ने [듬

$\stackrel{m}{N}$

BATTERY STABLIZER OUTPUT (PU)

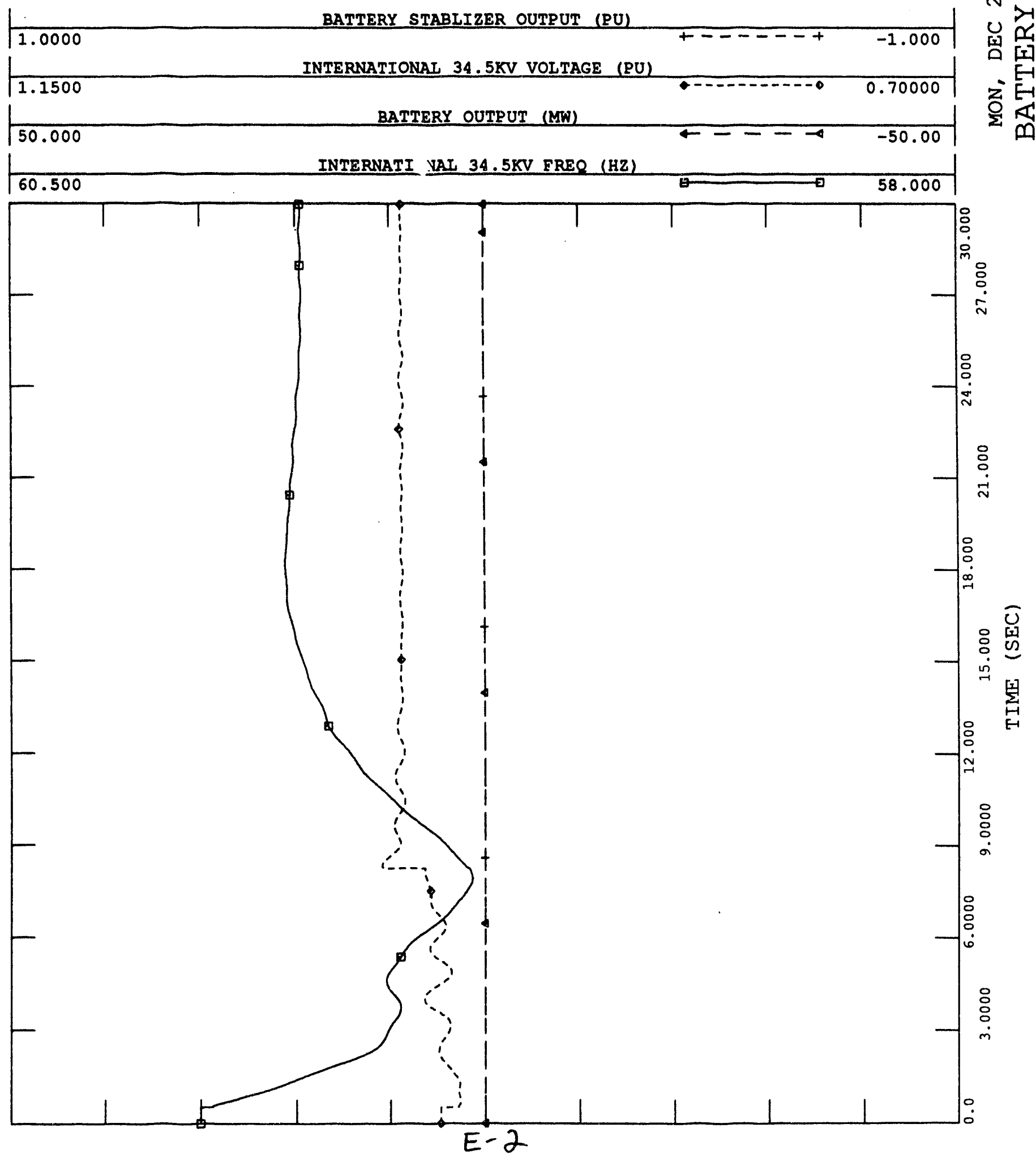

垔

E-1

언 
AmL15-01

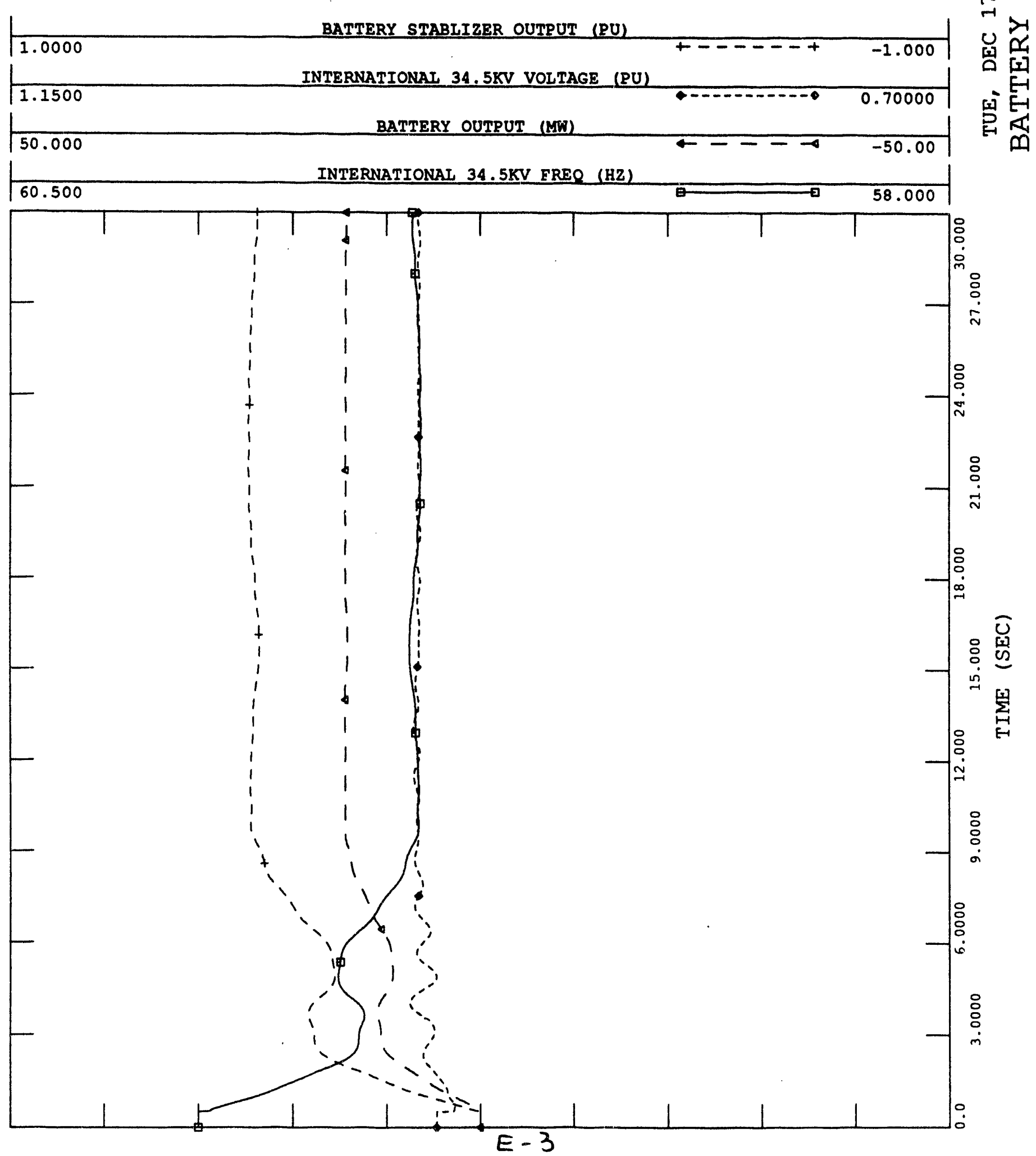


FILE : 5-1 CHN

AmL15-005

BATTERY STABLIZER OUTPUT (PU)

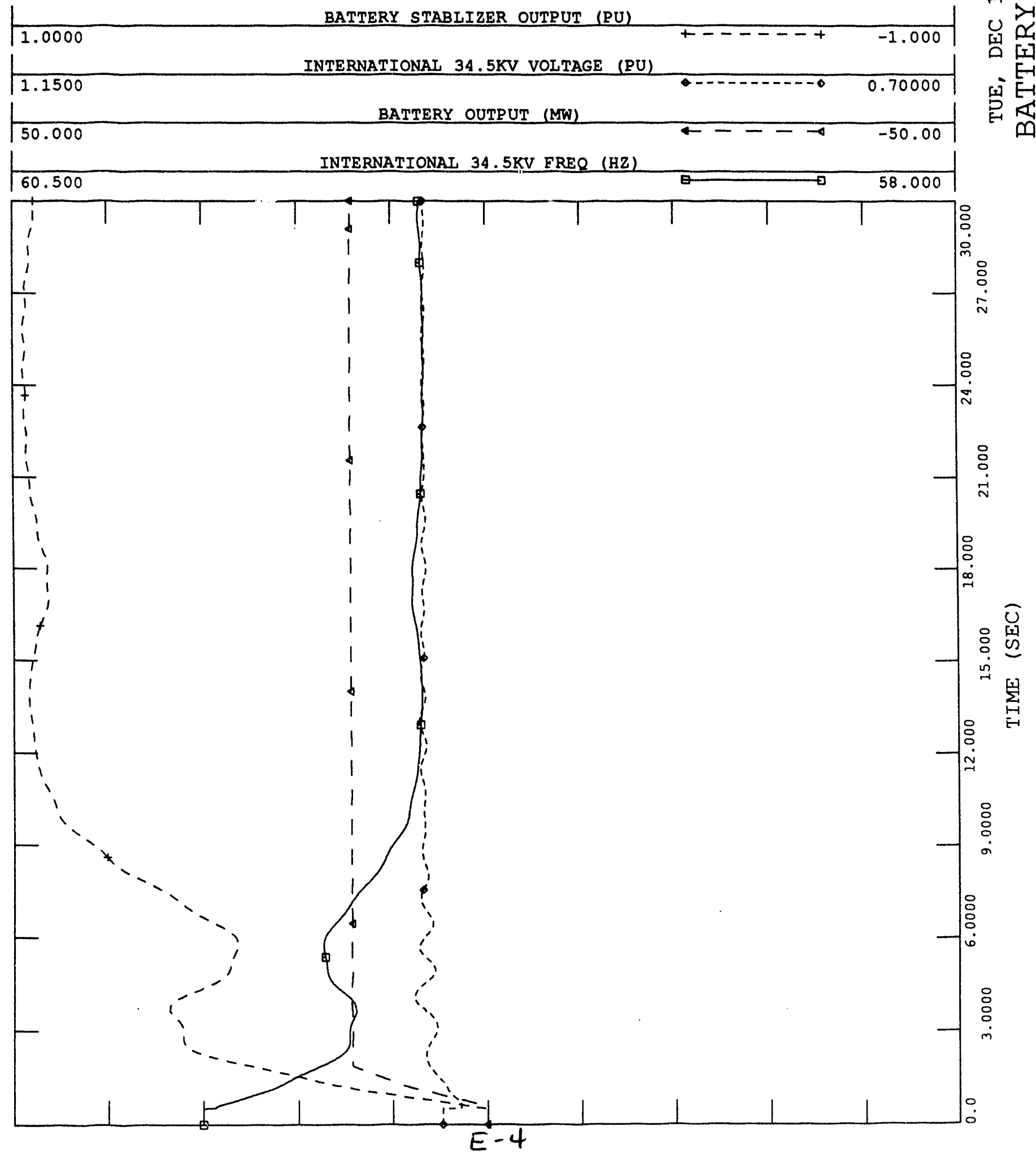


FILE : $20-50$. CHN

AmL20-01

\begin{tabular}{|c|c|c|c|}
\hline 1.0000 & 12 & $+-=--+$ & -1.000 \\
\hline & INTERNATIONAL $34.5 \mathrm{KV}$ VOLTAGE (RU) & & \\
\hline 1.1500 & & 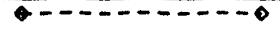 & 0.70000 \\
\hline & BATTERY OUTPUT (MW) & & \\
\hline
\end{tabular}

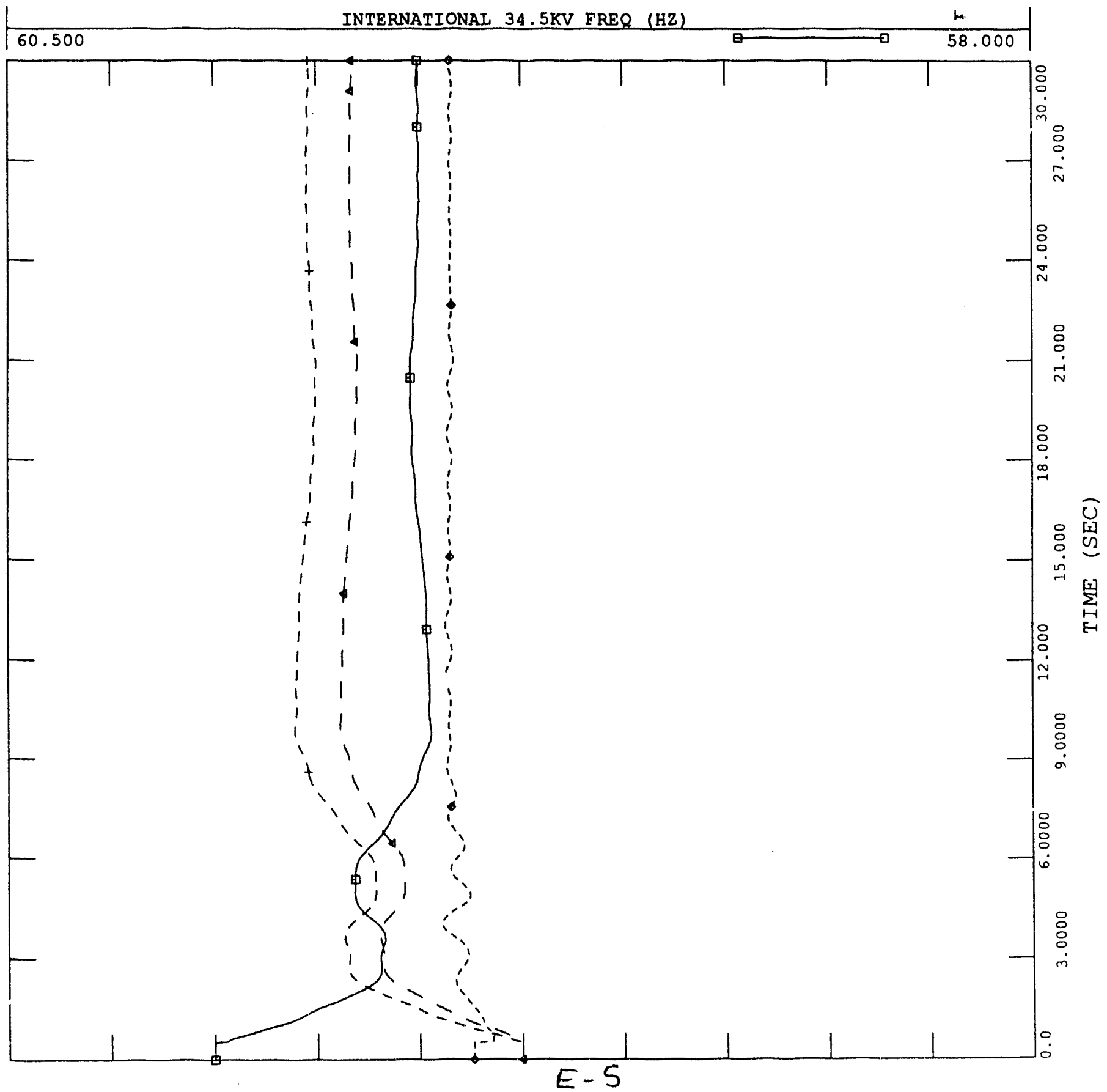


PML 20-005

$r$

$7>$

BATTERY STABLIZER OUTPUT (RU)

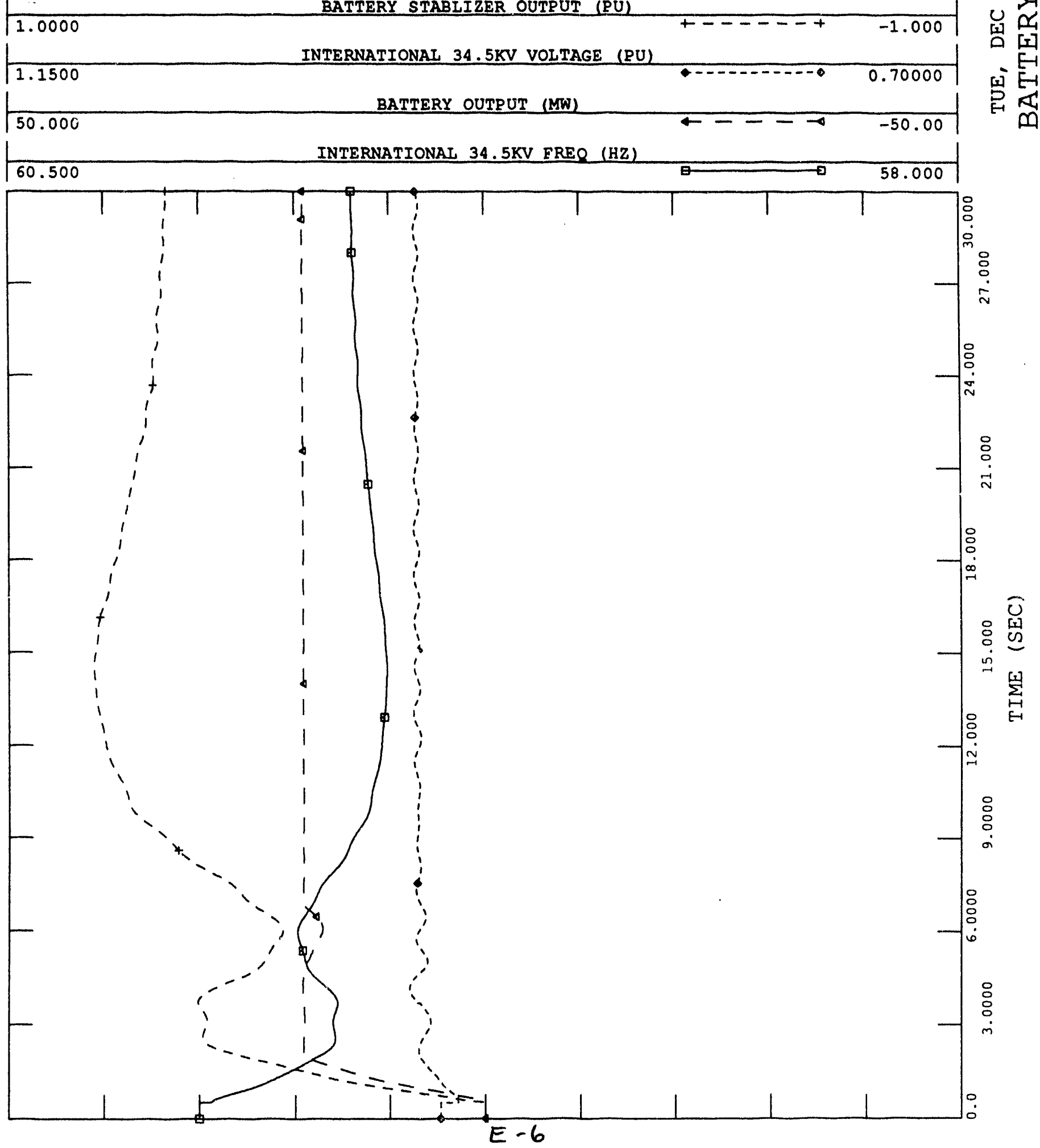


雷

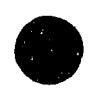
1991 WINTER PEAK LOAD. AMLP \#8 IS OFF, AMLP \#1\& \#5 ARE ON. 25 MVA BATTERY AT INTL $34.5 \mathrm{KV}, 0$ MW OUTPUT. GOVS DISABLED. TRIP BELUGA \#8 AT $54 \mathrm{MW}$ AT $\mathrm{T}=0.5$ SECONDS. $\%$ DROOP. LOAD SHED RELAYS AT BUS 204 ACTIVATED.

FILE : 50 - CHN

PInL25-01

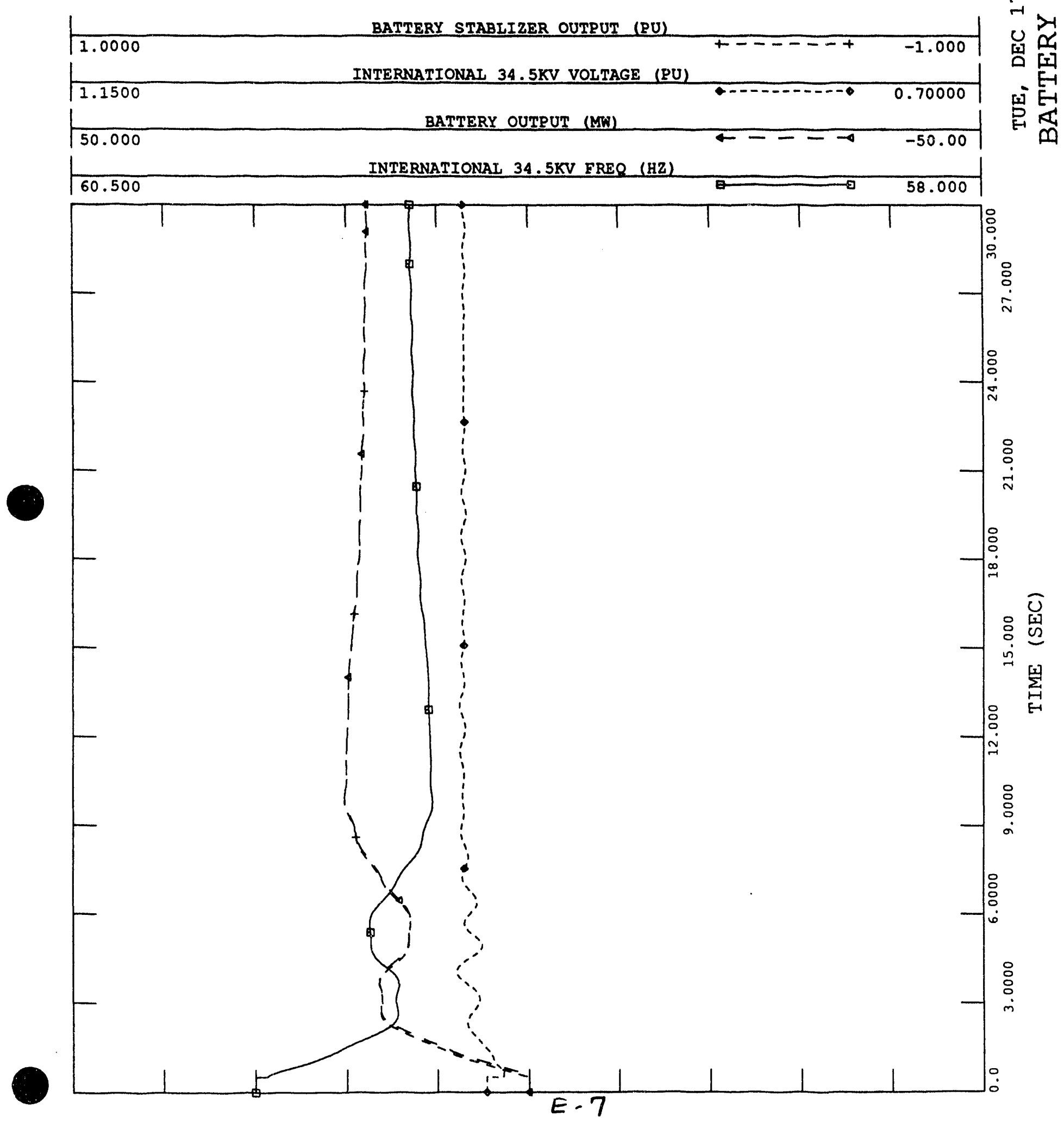

옴디

02

$-104$

ôे थ

$\stackrel{1}{\rightarrow-1}$

I-

计

i

$\stackrel{M}{M}$ 
FILE : $25-1 \mathrm{HI}$ CHN

PmL25-005

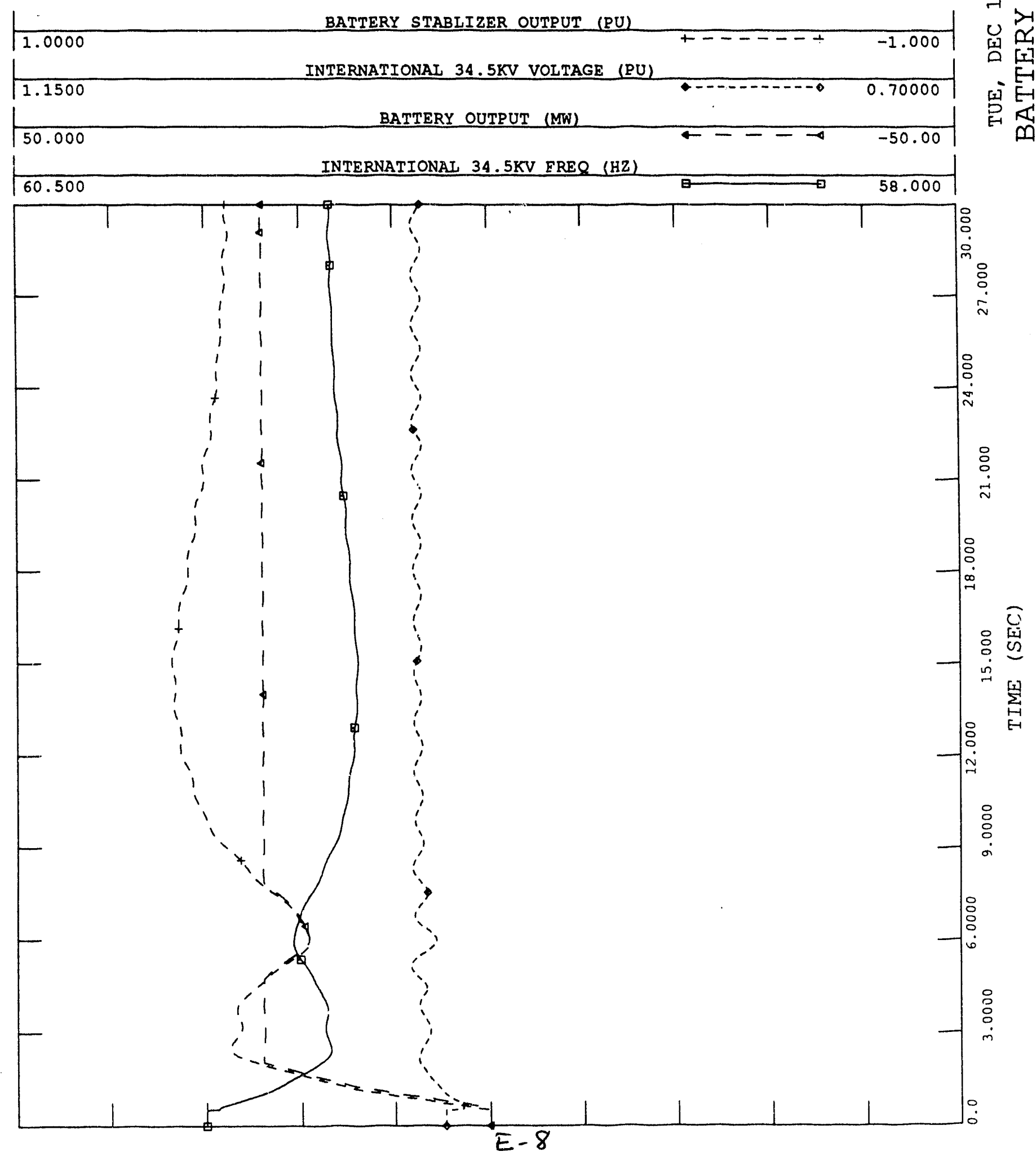

\begin{tabular}{|lll|}
\hline \multicolumn{4}{|c|}{ INTERNATIONAL 34.5KV EREQ (HZ) } \\
\hline 60.500 & 58.000
\end{tabular}


跍

1991 WINTER PEAK LOAD. AMLP \# $\varepsilon$ IS OFF, AMLP \#1\& \#5 .ARE ON. 15 MVA BATTERY AT INTL $34.5 \mathrm{KV}, 0 \mathrm{MW}$ OUTPUT. GOVS DISABLED.

TRIP AT MW AT T=0.5 SECONDS. 190 DROOP. UNIT $\# 6,7 \quad 95$

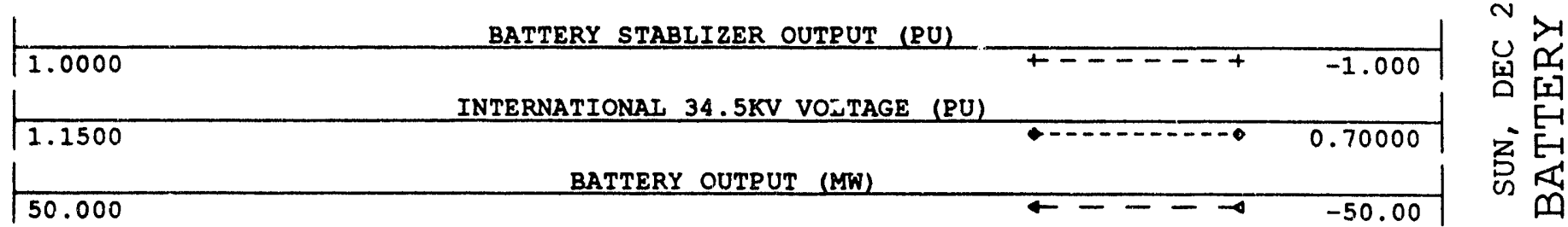

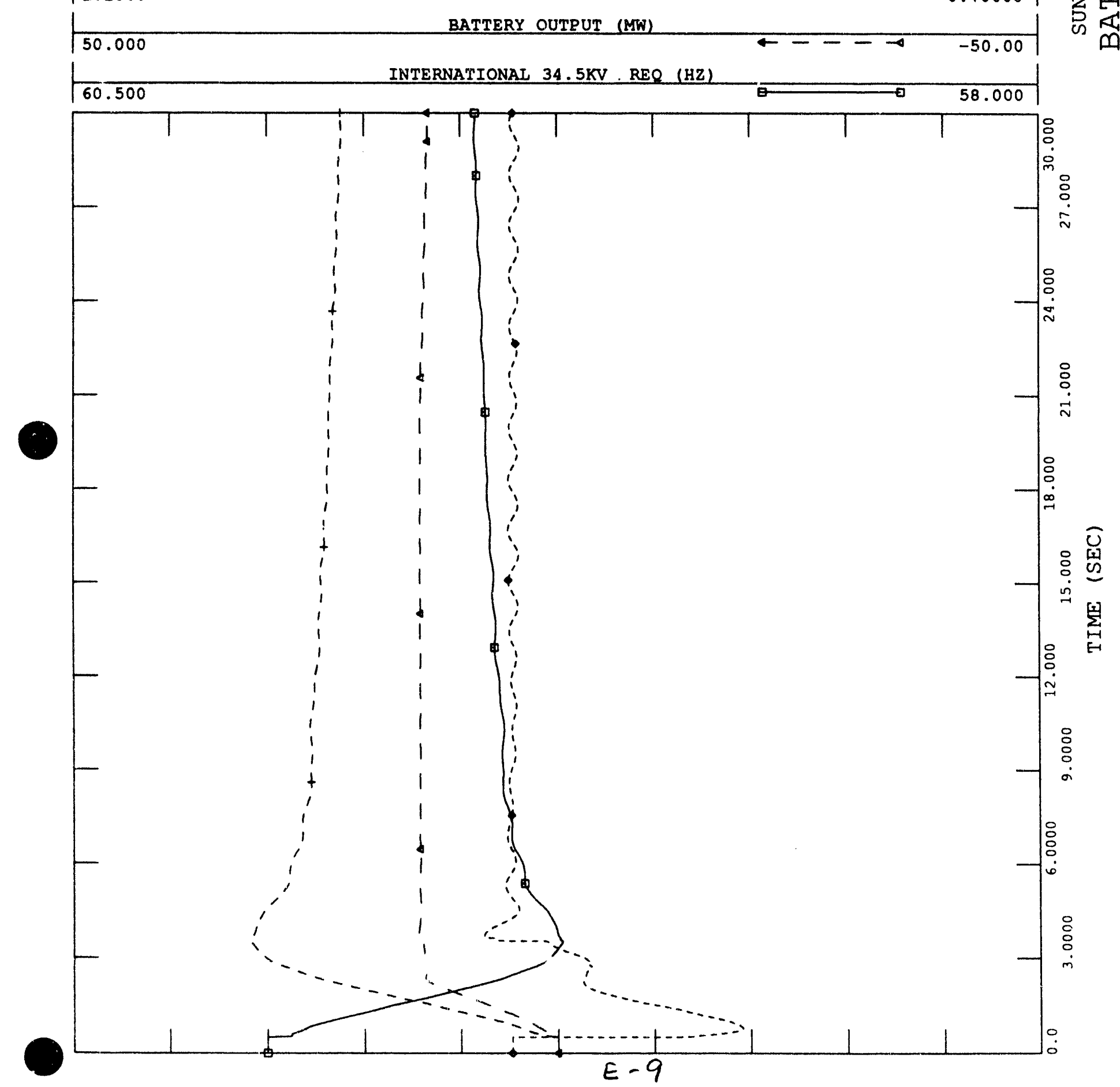




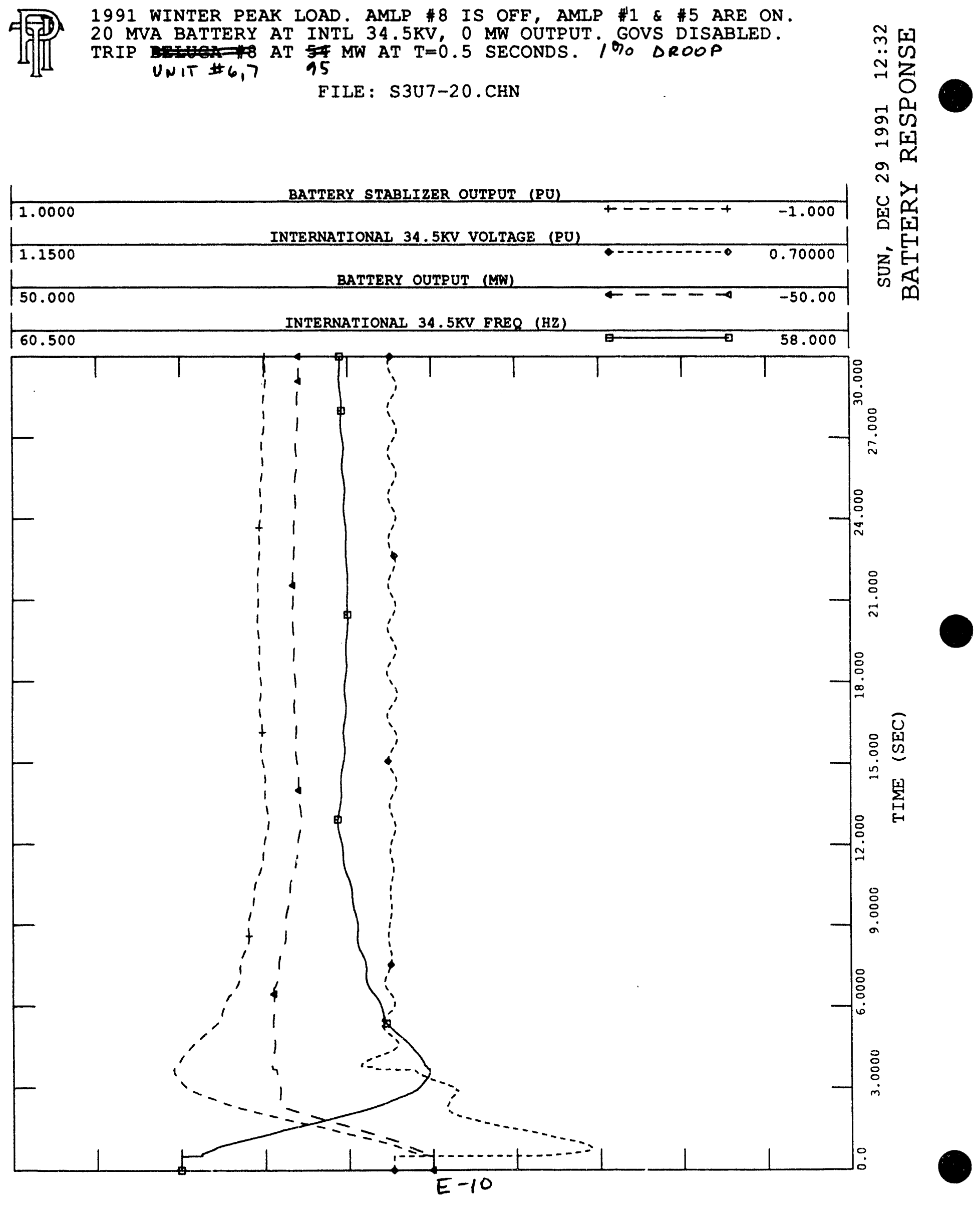




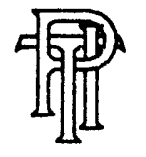

1991 WINTER PEAK LOAD

25 MVA BATTERY

TRIP
AT INTL $34.5 \mathrm{KV}$

AT

FILE: S3U7-25.CHN

암되 $\because \tilde{c}$ 学 - 0 का [1] 2ิ

ง น 的 EZ 㔻

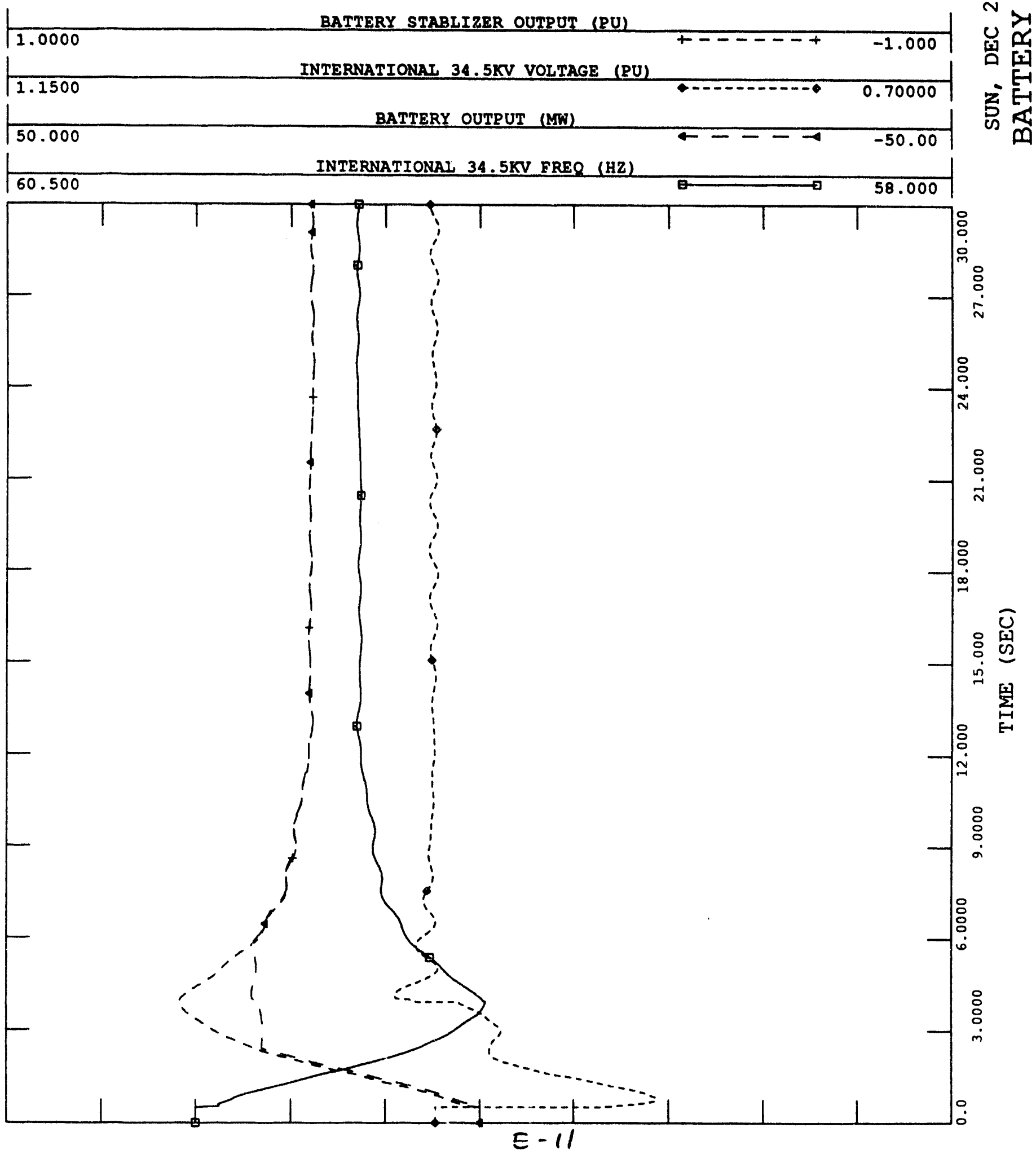




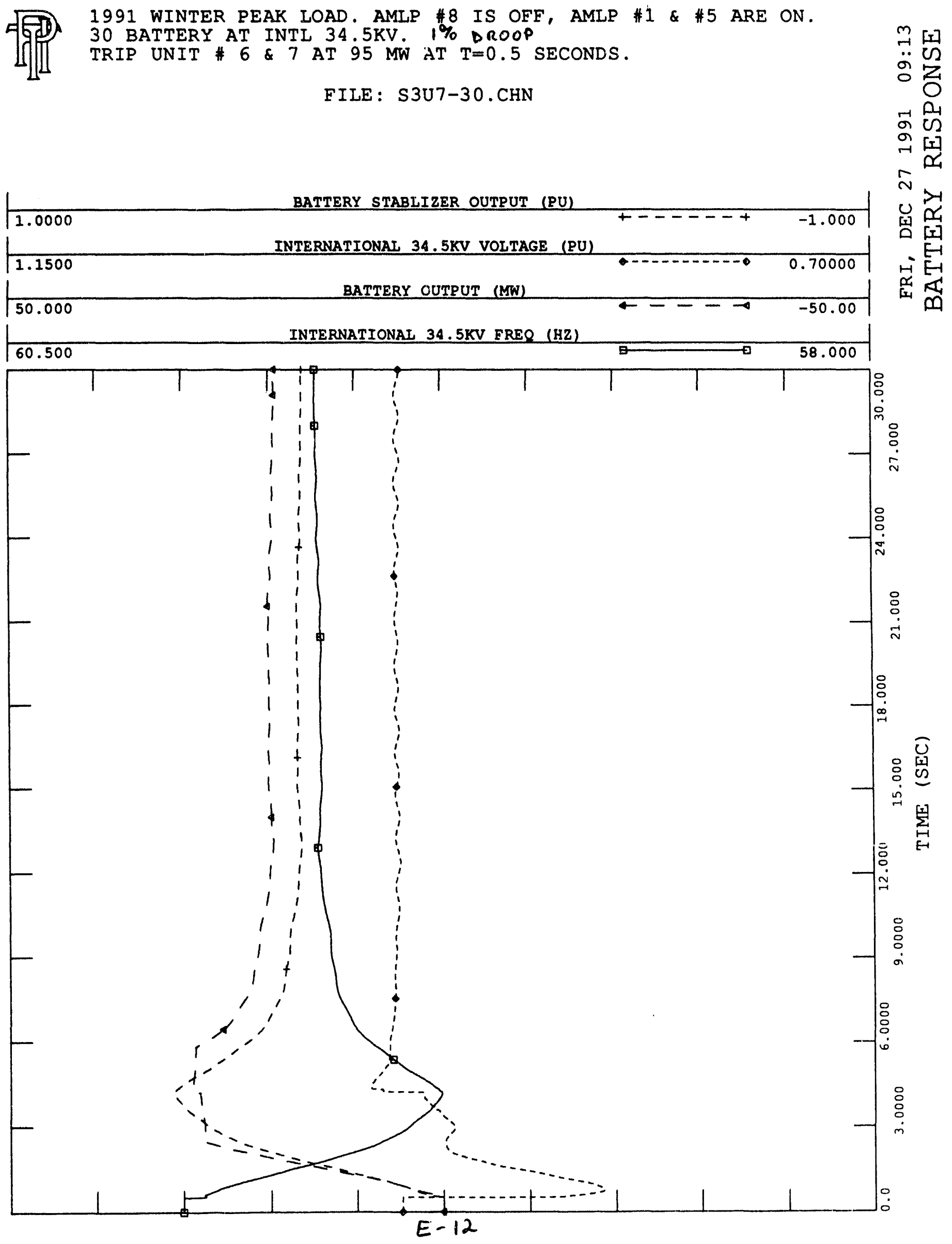


(7) 1991 WINTER PEAK LOAD. AMLP \#8 IS OFF, AMLP \#1 \& \#5 ARE ON. 35 BATTERY AT INTL $34.5 \mathrm{KV}$. $1 \%$ D DROOP TRIP UNIT \#6 \& 7 AT 95 MW AT T=0.5 SECONDS.

BATTERY STABLIZER OUTPUT (PU)

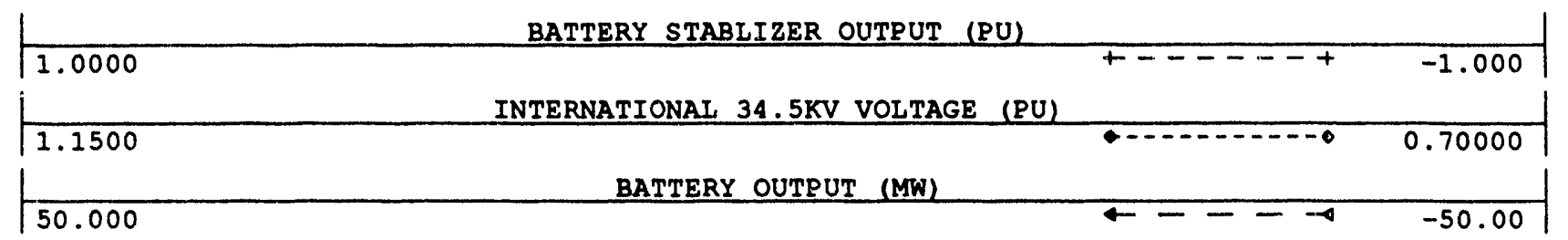

m

บ ${ }^{-1}$

[돔 [I]

Z E

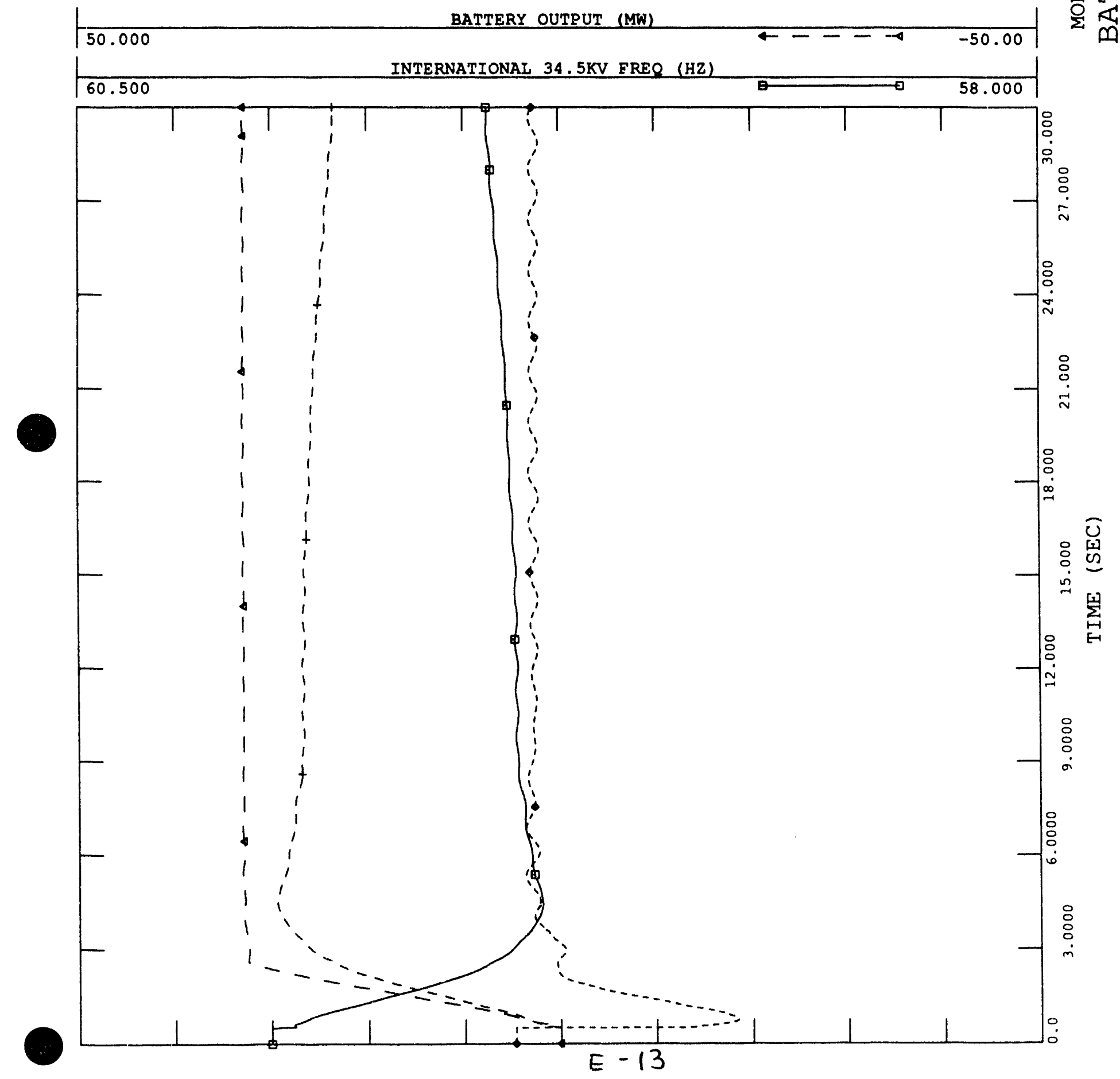


FILE: S3U7-40.CHN

$\underset{-1}{6}[1$

$\therefore$ 田

के

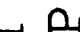

नू थि

$\rightarrow\left[\begin{array}{cc}-1 \\ \sigma_{1}\end{array}\right.$

i

$\sim$

资

임

E-1

HiE-

舤

BATTERY OUTPUT (MW)

INTERNATIONAL $34.5 \mathrm{KV}$ FREO (HZ)

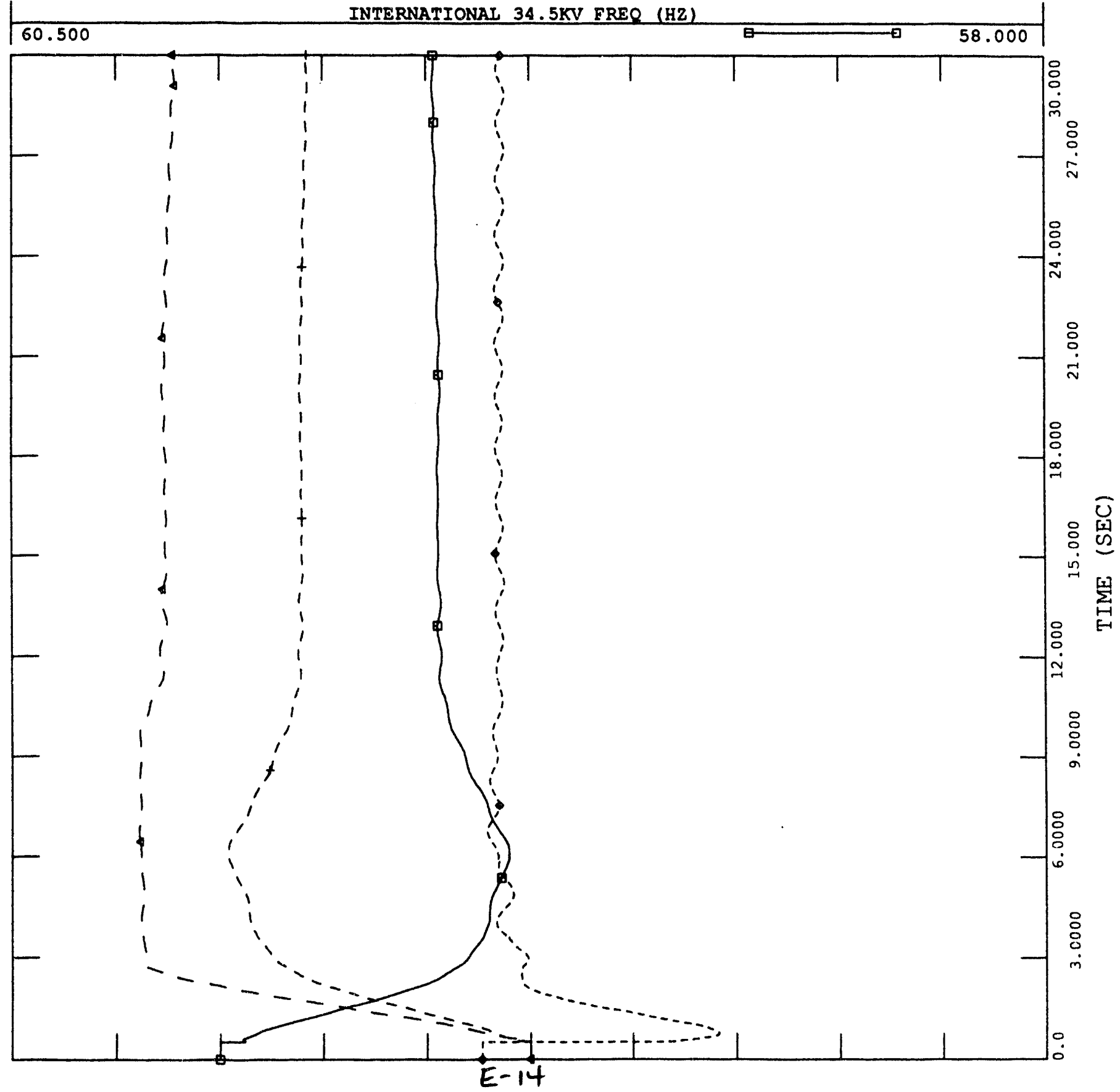


FILE: CEA-00.CHN

FILE: CEA-OO.CHN

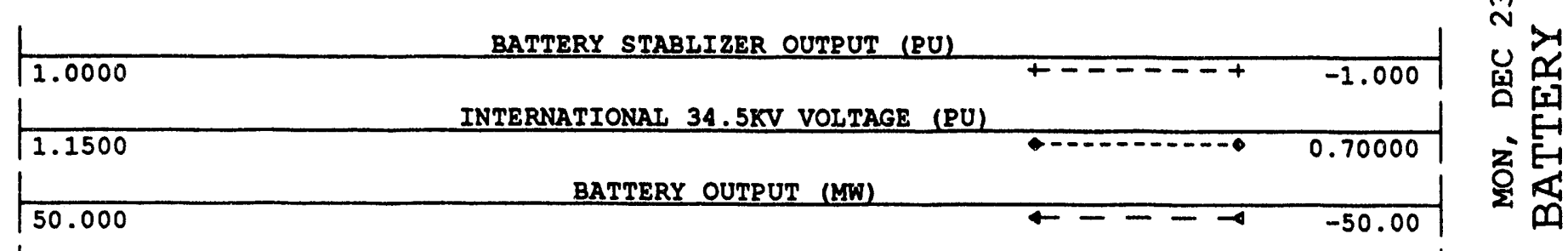

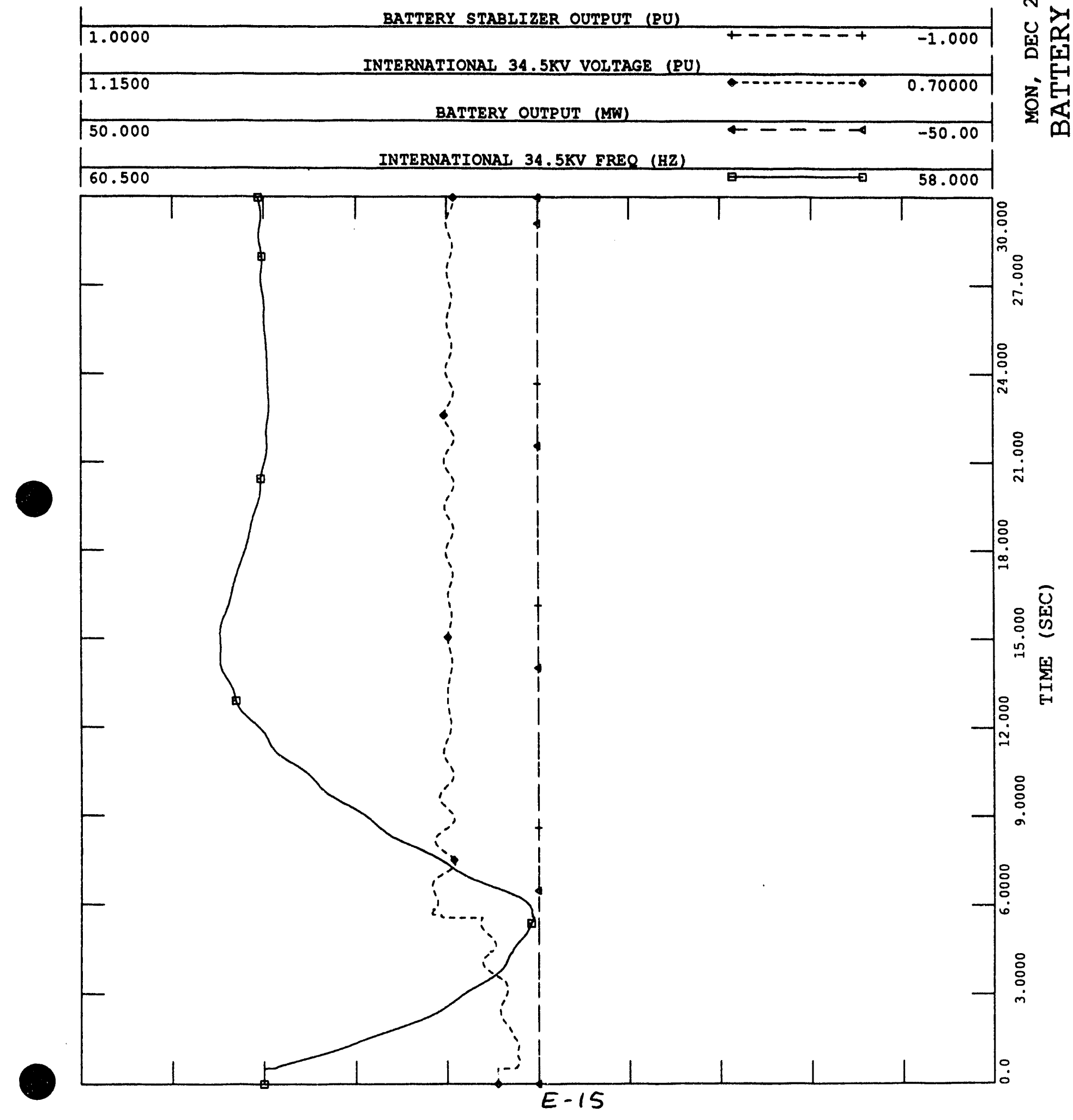


$\mathbf{F}$

\section{STABILITY ANALYSIS: SCENARIO 4}

This appendix contains the simulations of Scenario 4. Battery sizes from 15 to $50 \mathrm{MW}$ and droop settings of $0.5 \%$ and $1 \%$ were used. A simulation case was also run in which no battery was used. In this scenario, two disturbances were studied: a $54 \mathrm{MW}$ loss of generation and a $95 \mathrm{MW}$ loss of generation. 
BATTERY STABLIZER OUTPUT (PU)

\begin{tabular}{|c|c|c|c|}
\hline & BATTERY STABLIZER OUTPUT (RU) & & \\
\hline 1.0000 & & $+----t$ & -1.000 \\
\hline & TERNATIONAL $34.5 \mathrm{KV}$ & & \\
\hline
\end{tabular}

거

옹

- E-

品

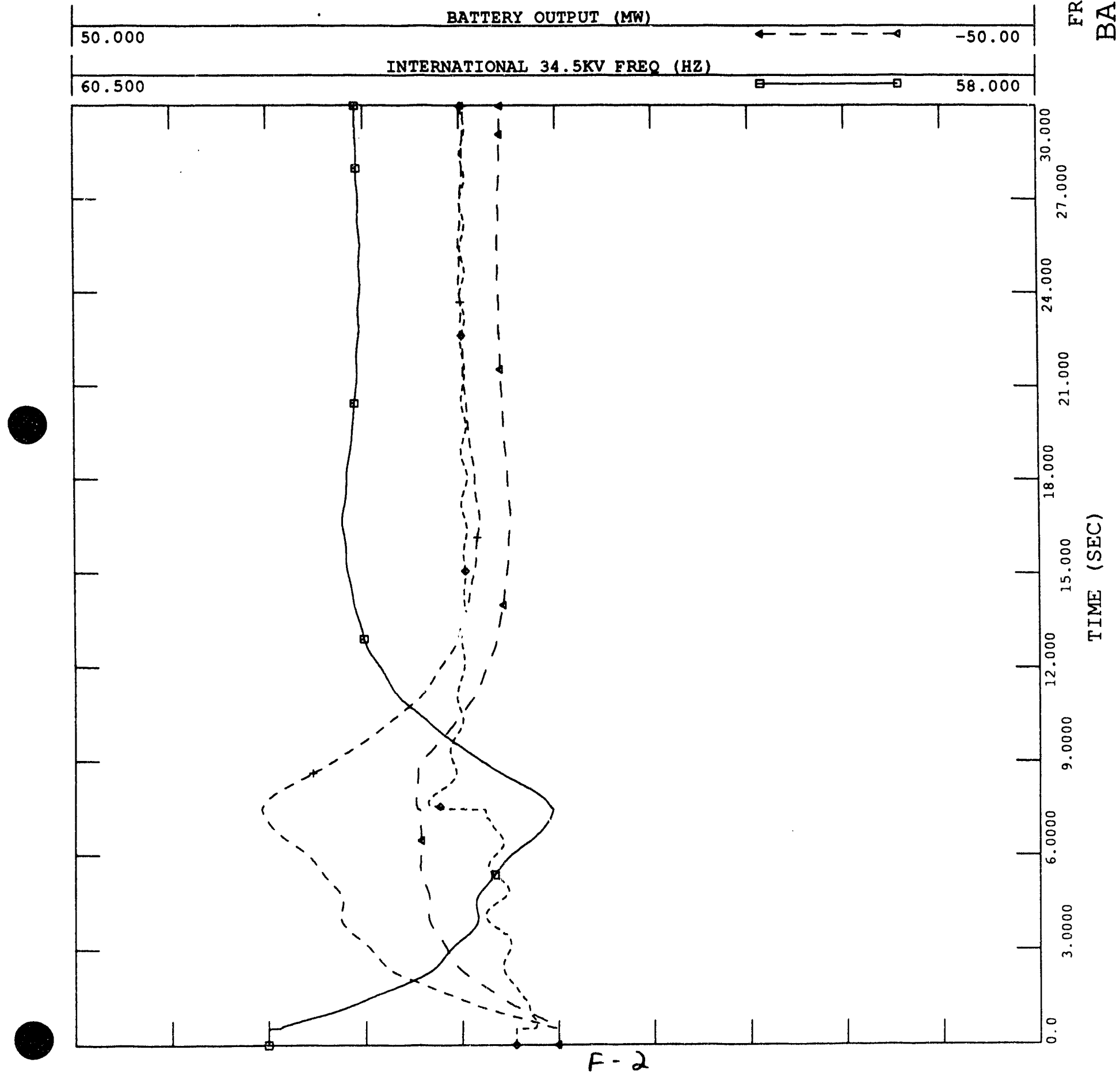


1991 WINTER PEAK LOAD. AMLP \#8 IS OFF, AMLP \#1\& \#5 ARE ON. 15 MVA BATTERY, O MW OUTPUT, GOVS DISABLED. BERNICE IS OFF. TRIP BELUGA $\# 8$ AT $54 \mathrm{MW}$ AT $T=0.5$ SECONDS. $0.5 \%$ DROOP

FILE : CEA15-05. CHN

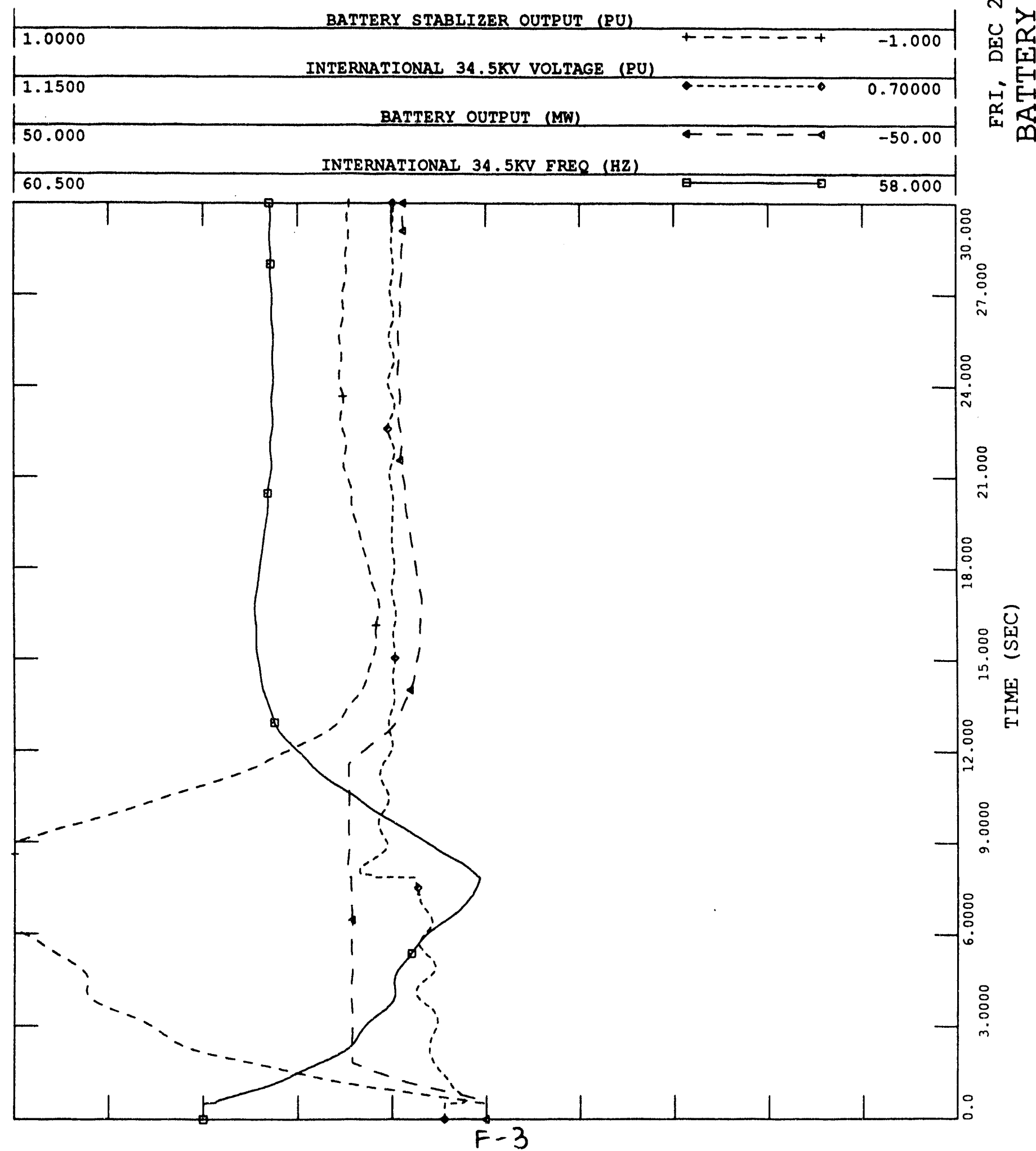


FILE: CEA20-01.CHN

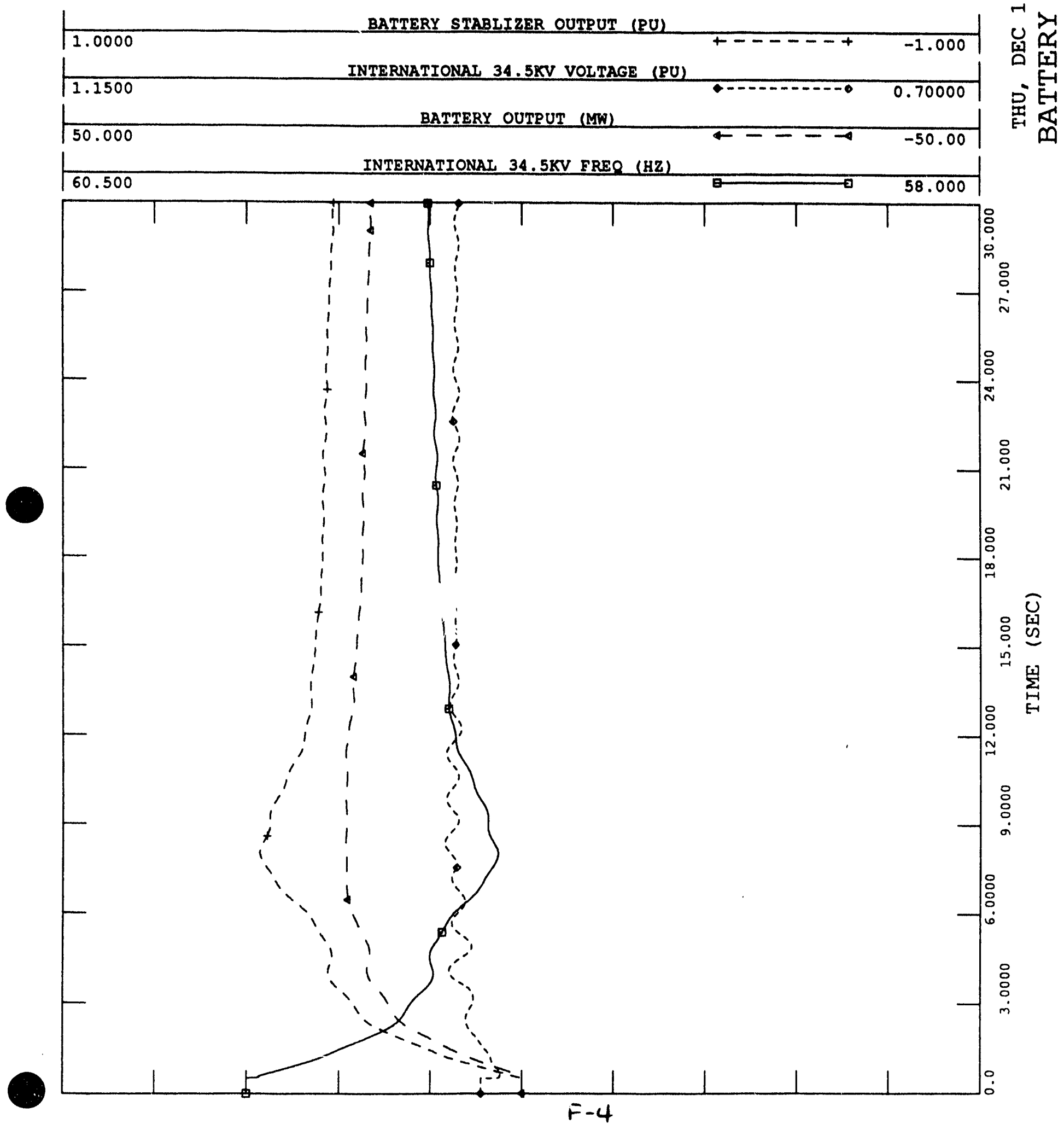



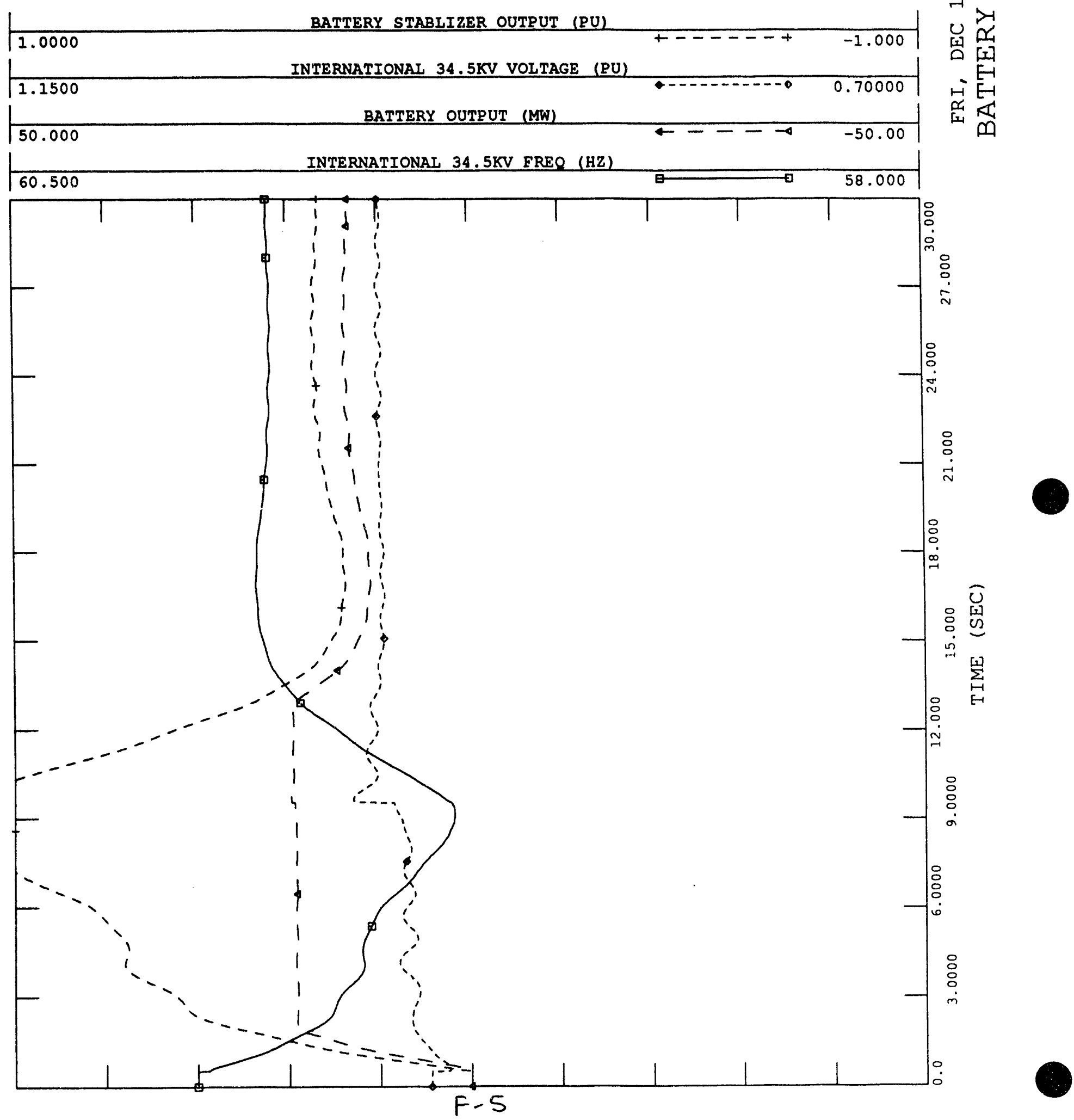
FILE : CEA25-01.CHN

BATTERY STABLIZER OUTPUT (PU)

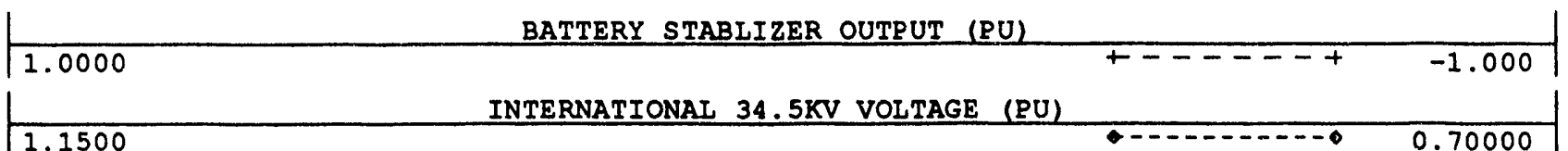

c)

됨 도

E-1

贫

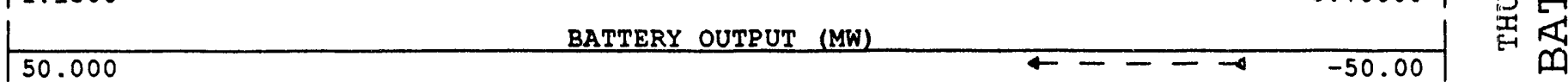

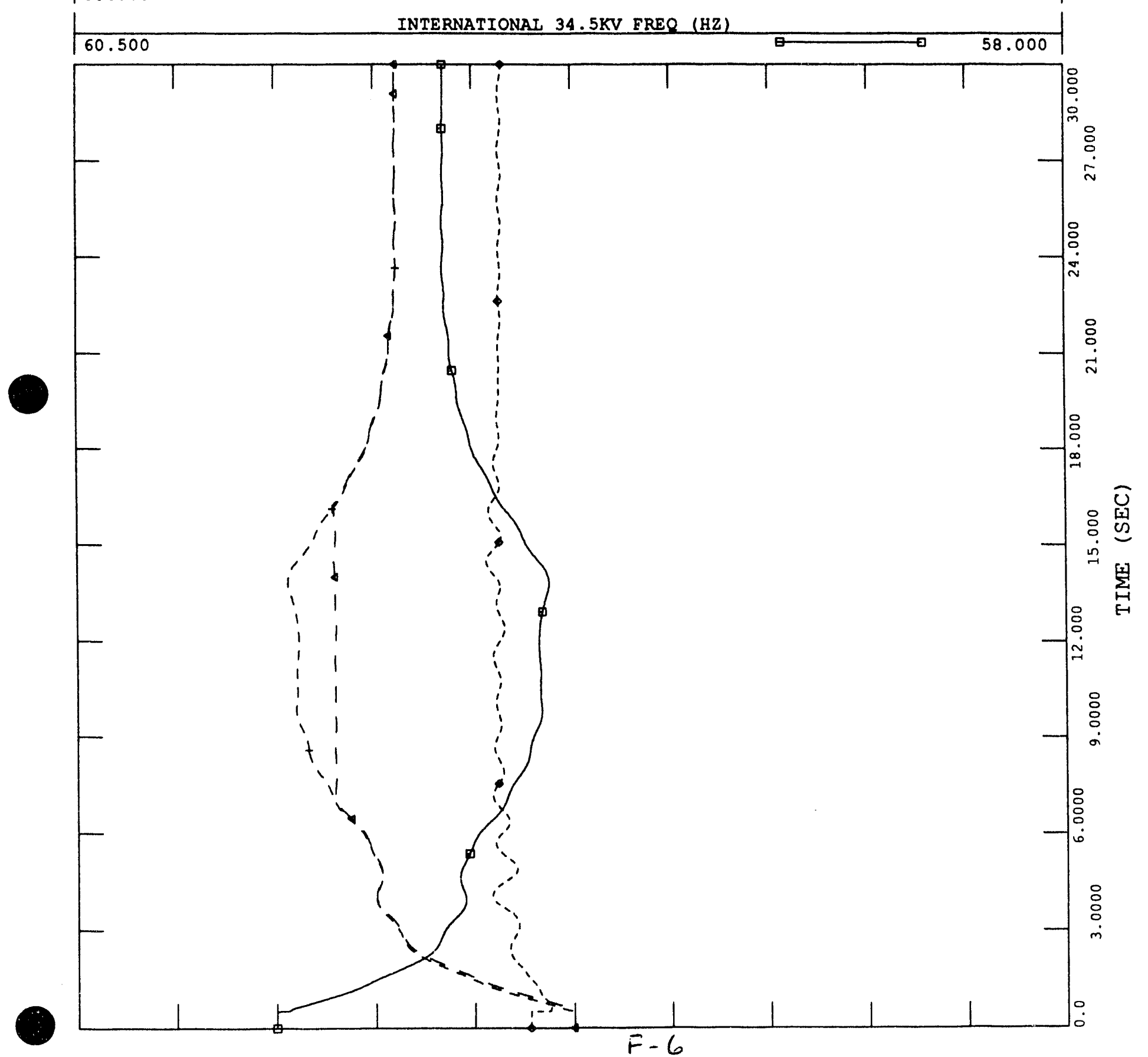




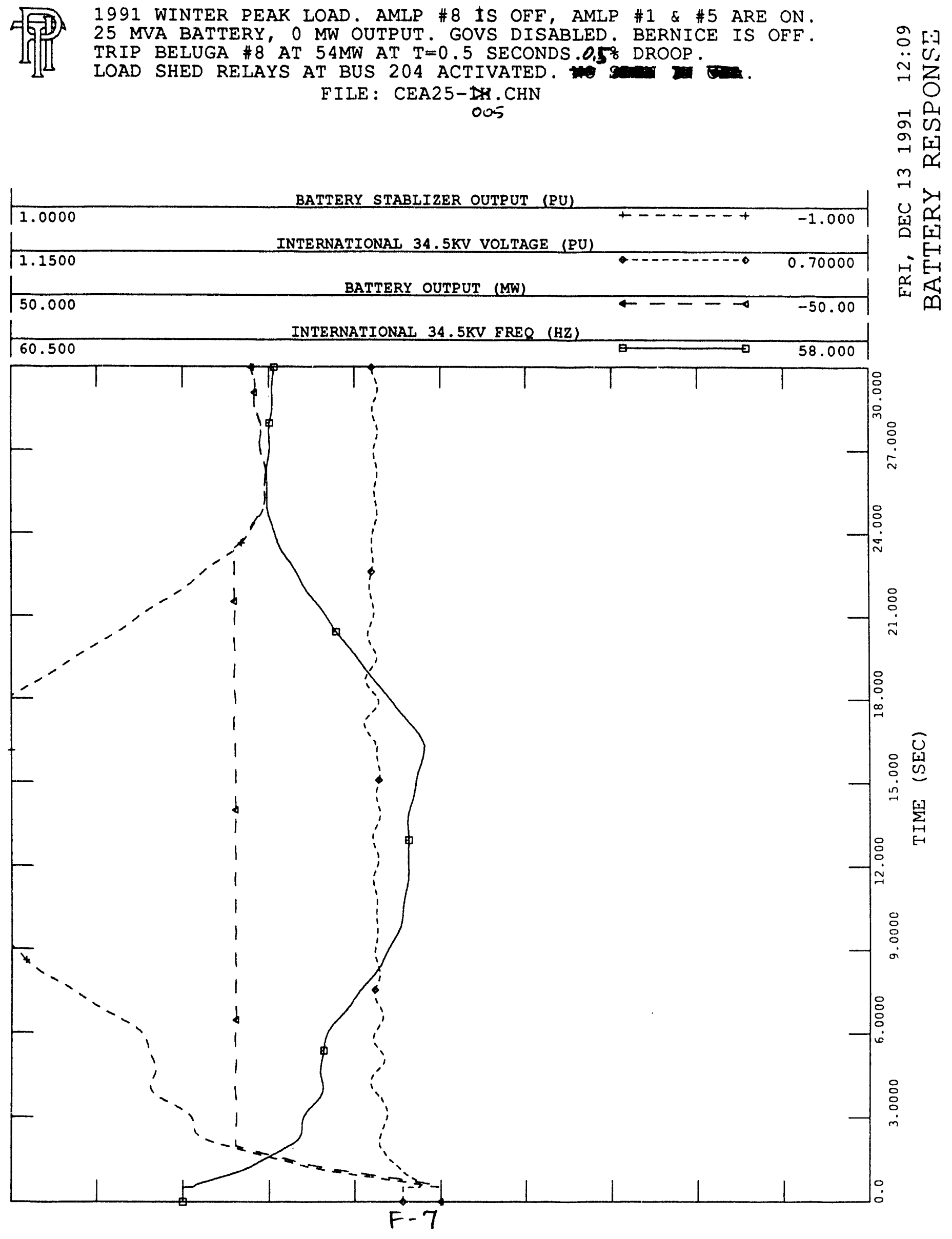


1991 WINTER PEAK LOAD. AMLP \#8 IS OEF, AMLP \#1\& \#5 ARE ON.
30 MVA BATTERY, O MW OUTPUT. GOVS DISABLED. BERNICE IS OFF. TRIP BELUGA \#8' AT $54 \mathrm{MW}$ AT $\mathrm{T}=0.5$ SECONDS. $1 \%$ DROOP.

FILE: CEA30-01.CHN

BATTERY STABLIZER OUTPUT (PU)

\begin{tabular}{|c|c|c|c|}
\hline 1.0000 & RY STABLIZER OUIRUI (RO) & $+-----t$ & -1.000 \\
\hline & INTERNATIONAL $34.5 \mathrm{KV}$ VOLTAGE (PU) & & \\
\hline 1.1500 & & 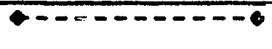 & 0.70000 \\
\hline & BATTERY OUTPUT (MW) & & \\
\hline
\end{tabular}

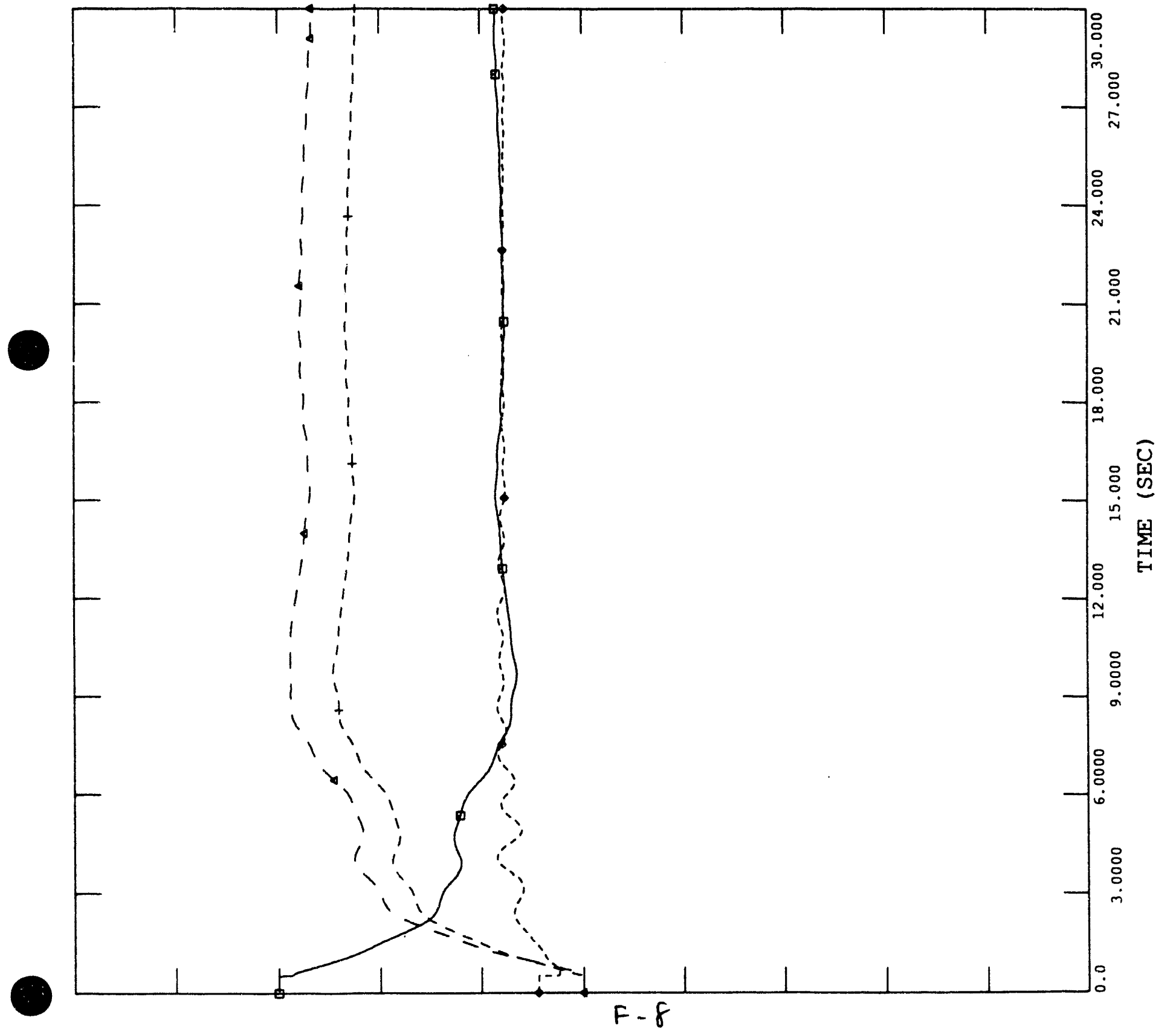



1991 WINTER PEAK LOAD. AMLP \#8 IS OFF, AMLP \# 1 \& \#5 ARE ON. 30 MVA BATTERY, O MW OUTPUT. GOVS DISABLED. BERNICE IS OFF. TRIP BELUGA \#8 AT $54 \mathrm{MW}$ AT $\mathrm{T}=0.5$ SECONDS .0.5\% DROOP. LOAD SHED RELAYS AT BUS 204 ACTIVATED.

FILE: CEA30-DA.CHN

$\stackrel{N}{m}[\mathrm{I}$

$\therefore$ 约

o

$-\rho^{-1}$

ने के

or [x]

$\rightarrow$

$\rightarrow-1$

里

田

- E-1

E-1

在

$-50.00$

\begin{tabular}{|l|l|}
\hline \multicolumn{4}{|c|}{ INTERNATIONAL 34.5KV FREQ (HZ) } \\
\hline 60.500 & 58.000
\end{tabular}

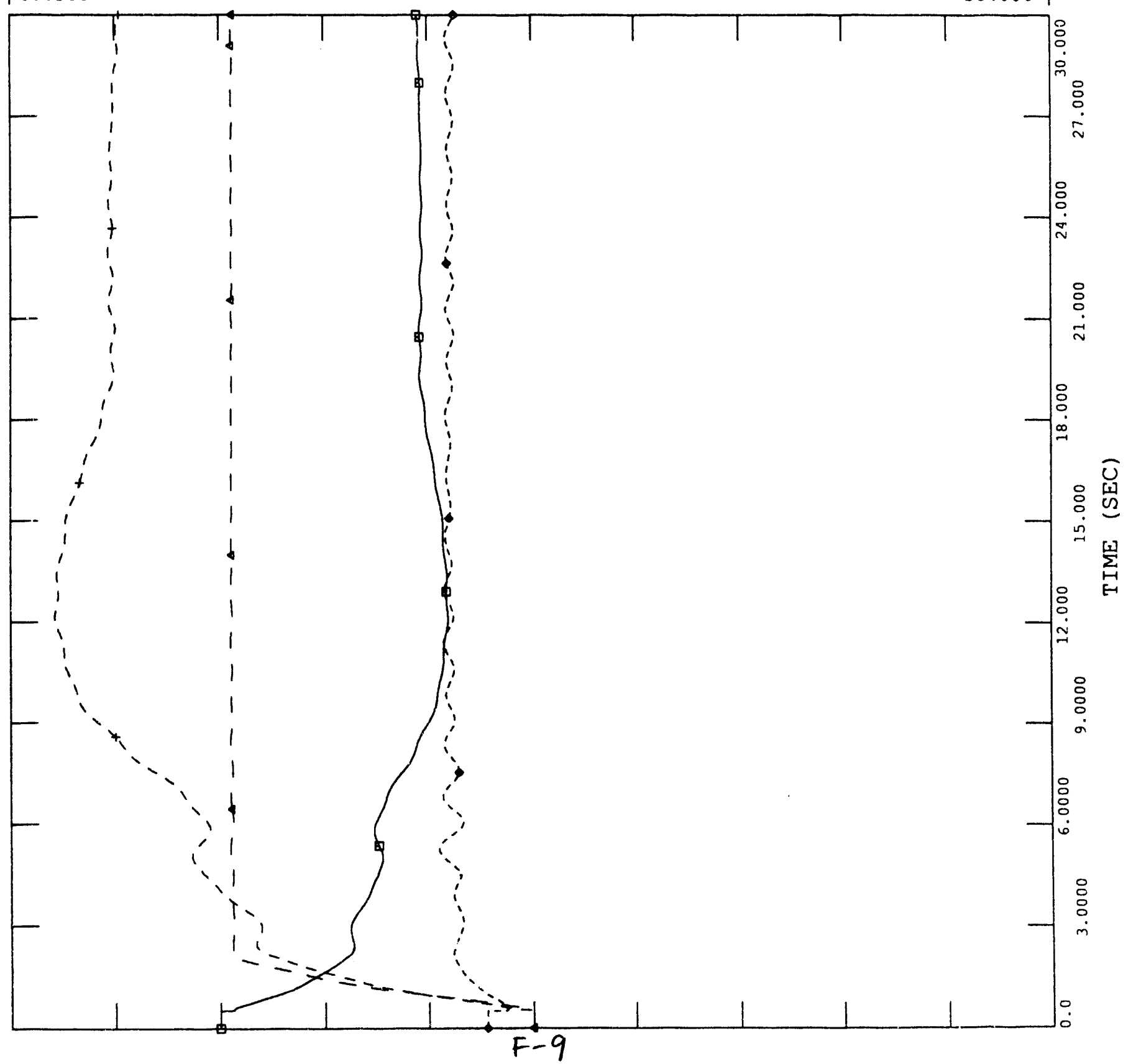




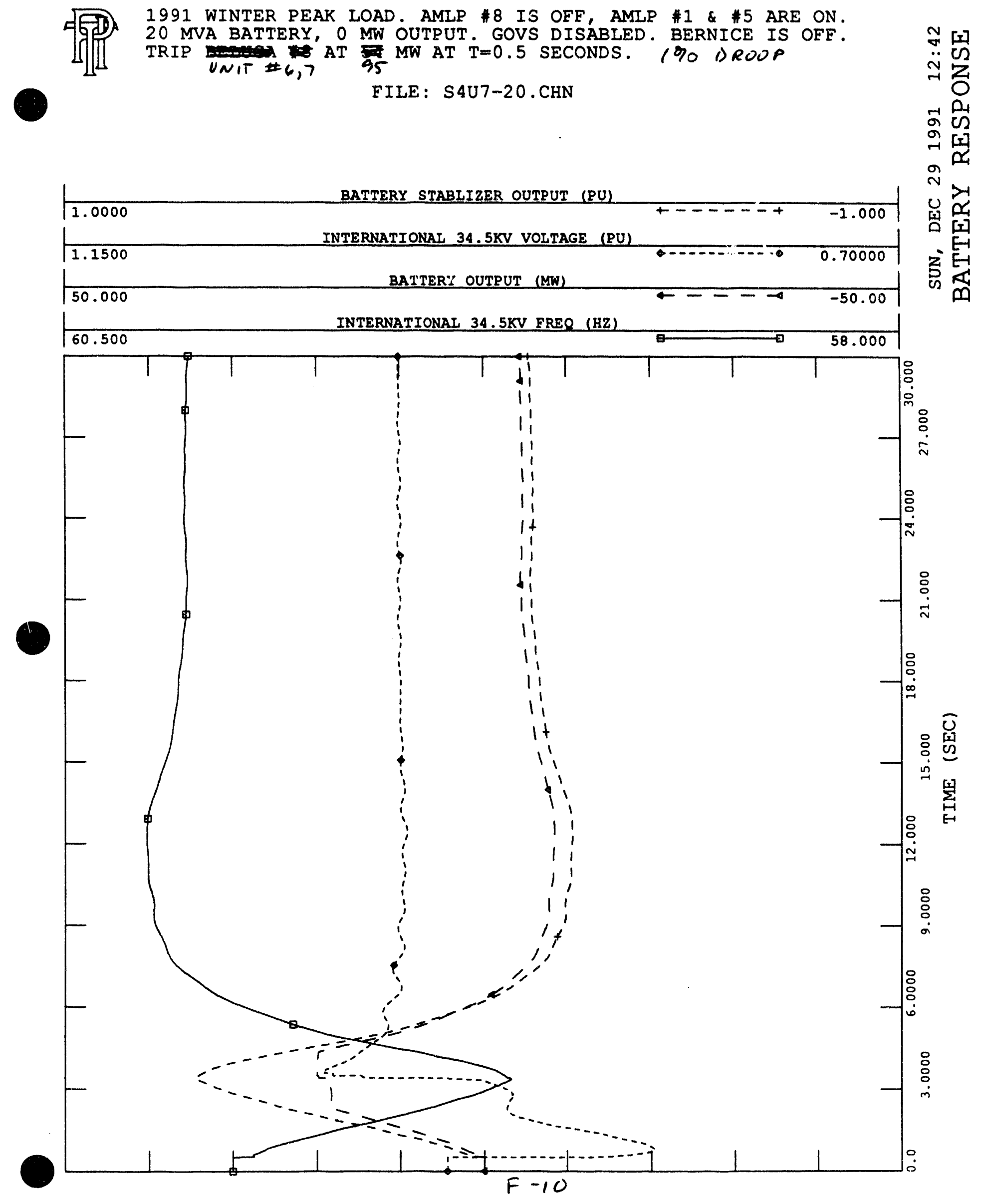




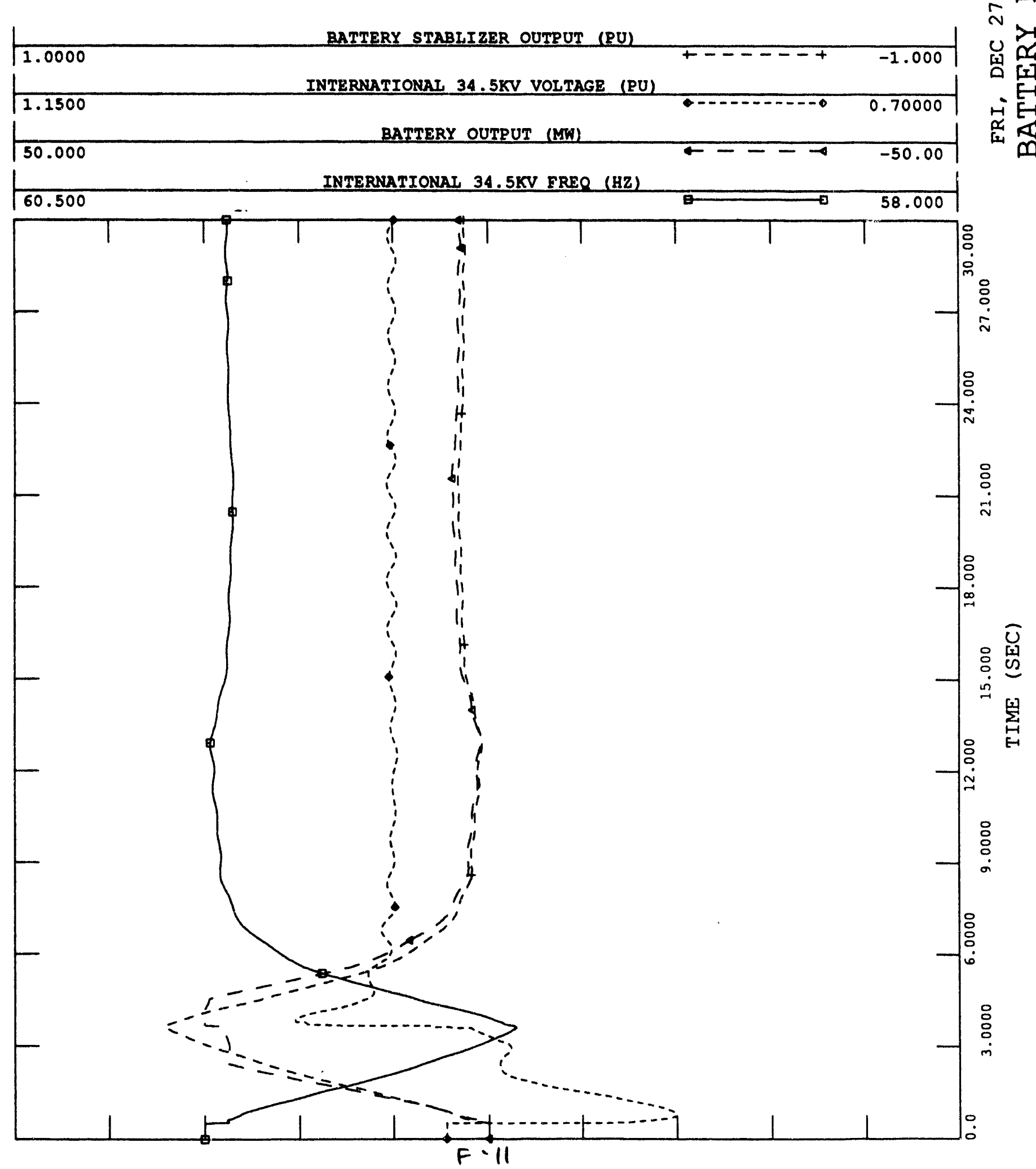


FILE : S4U7-40.CHN

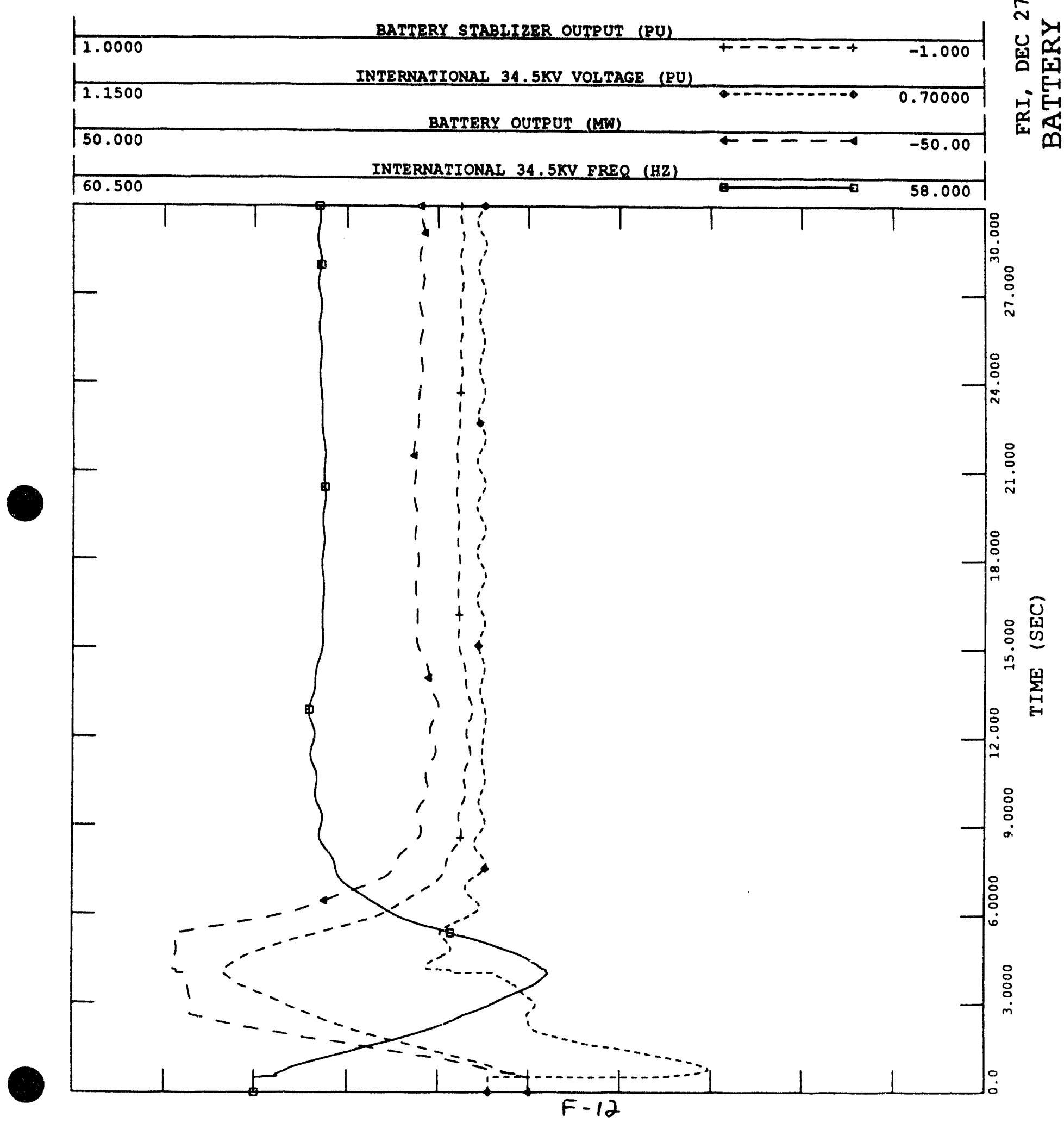



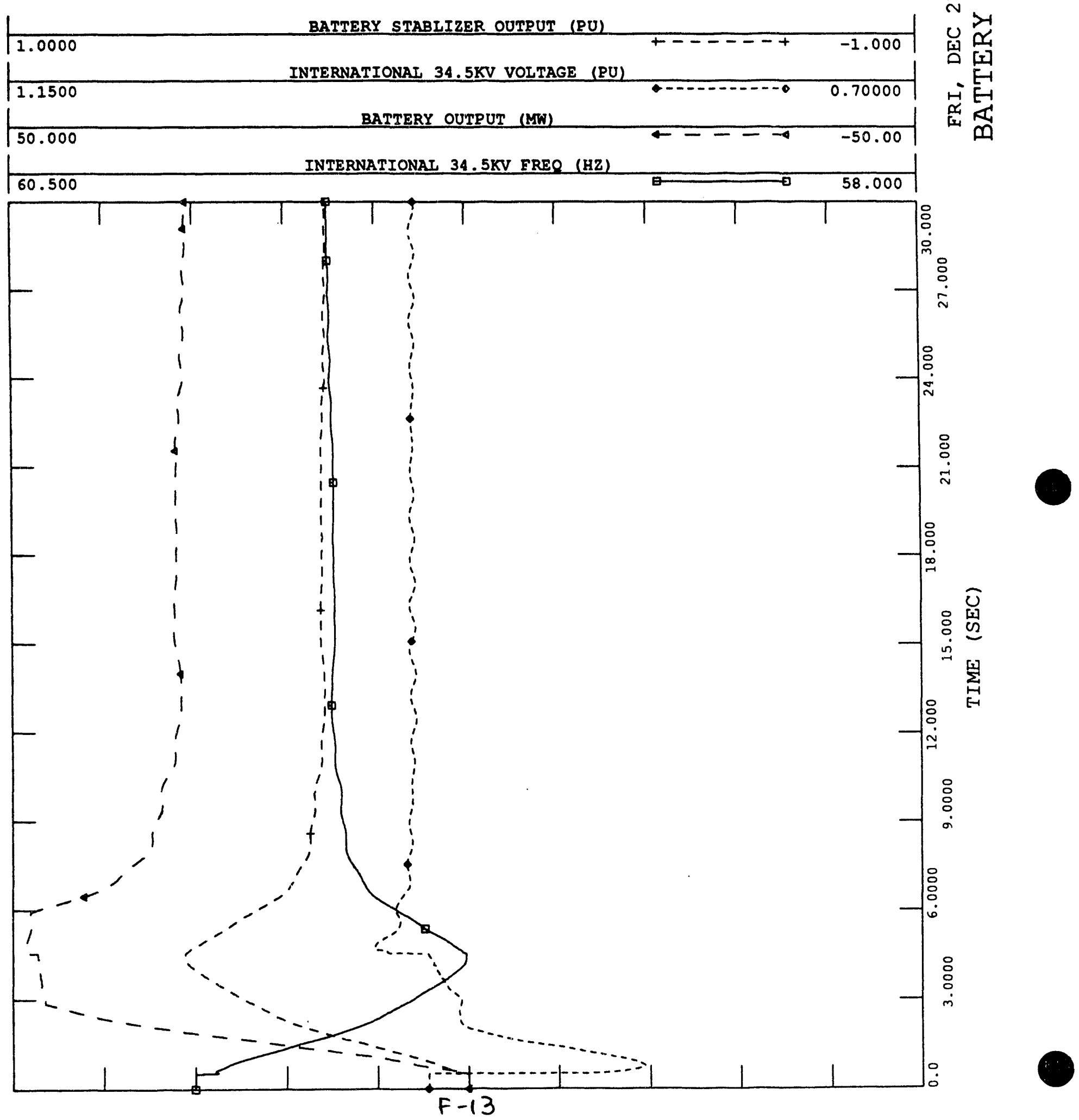


\section{G}

\section{STABILITY ANALYSIS: SUMMER LOAD CASE}

In this appendix, the simulations of the summer load case are presented. Under the summer load case, three scenarios were studied. In each scenario, the effects of various battery sizes, from 15 to $25 \mathrm{MW}$ were examined. A simulation is also run without a battery. A disturbance consisting of a $50 \mathrm{MW}$ loss of generation is used. 
1989 SUMMER NORMAL LOAD. BELUGA 1 \& 2 AT 5MW EACH. NO BATTERY AT INTL $34.5 \mathrm{KV}$.

TRIP UNIT \#6\&7 AT $50 \mathrm{MW}$ AT $\mathrm{T}=0.5$ SECONDS.

FILE: B12U7-00.CHN

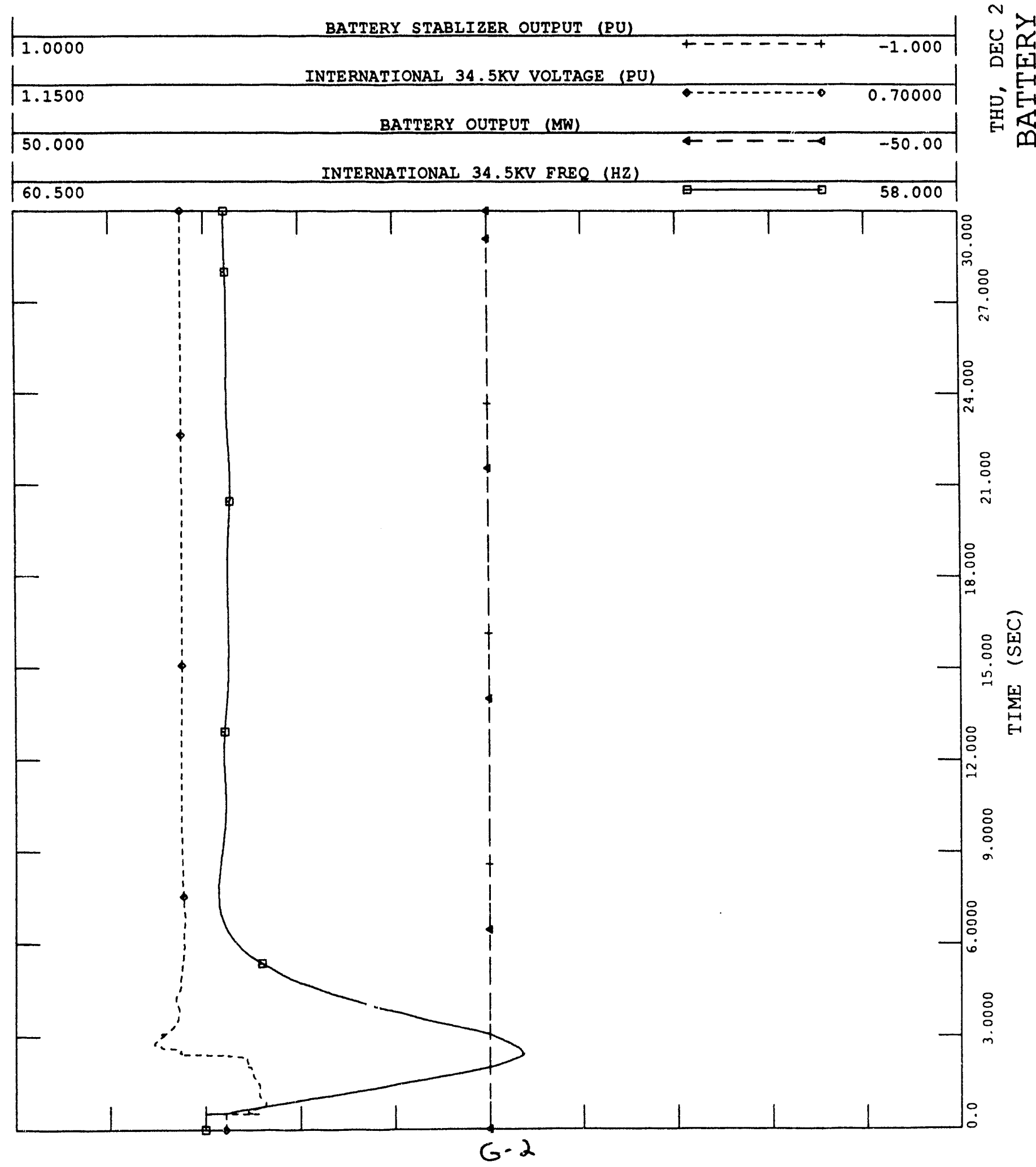

告 
FILE : B12U7-20.CHN

$\stackrel{m}{\sigma}[\sqrt{2}$

$\because$ U

$\infty$

$\rightarrow \infty$

कू थ

$\rightarrow\left[\begin{array}{cc}0 \\ \rightarrow\end{array}\right.$

$\stackrel{m}{\sim}$

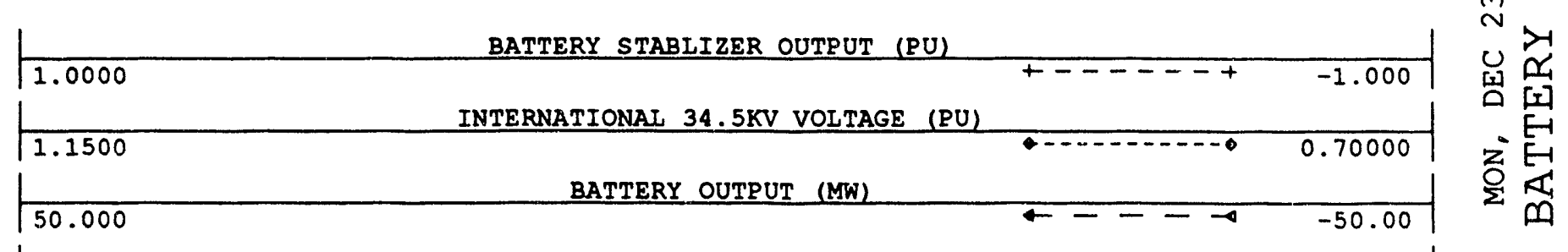

\begin{tabular}{|l|l|}
\hline \multicolumn{5}{|c|}{ INTERNATIONAL $34.5 \mathrm{KV}$ FREQ $(\mathrm{HZ})$} \\
\hline 60.500 & 58.000 \\
\hline
\end{tabular}

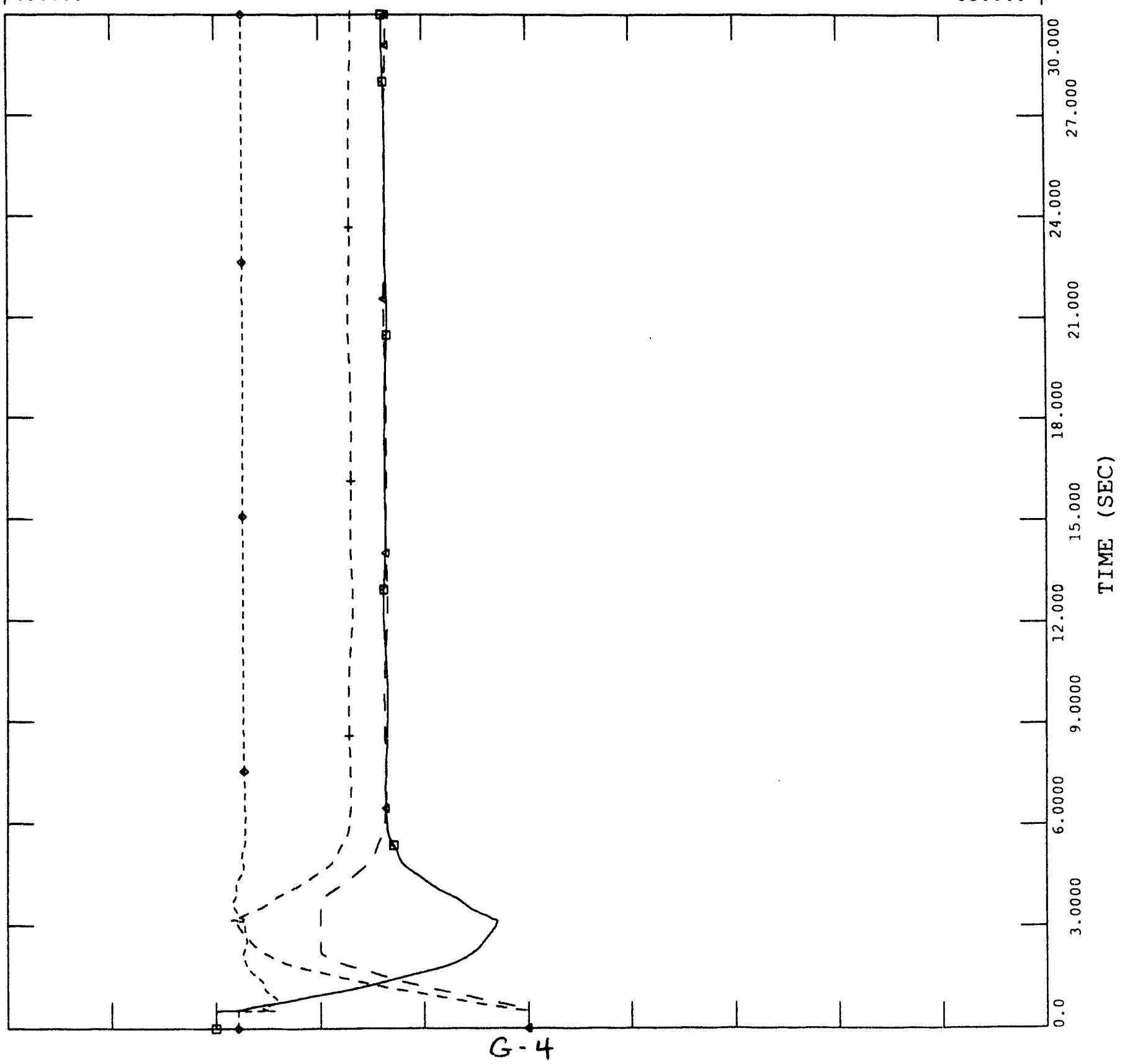


1989 SUMMER NORMAL LOAD. BELUGA $1 \& 2$ EACH AT 5MW.

25 MVA BATTERY AT INTL $34.5 \mathrm{KV}, 0 \mathrm{MW}$ OUTPUT. $1 \%$ DROOP.

TRIP UNIT \#6\& \#7 AT $\$ 5 \mathrm{MW}$ AT $\mathrm{T}=0.5$ SECONDS.

$1 \%$ DROOP.

FILE: B12U7-25.CHN

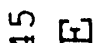

$\because v$

$\infty$

$-1$

ने लि

$\Rightarrow \frac{[x}{\alpha}$

$m$

$\stackrel{\sim}{\sim}$

BATTERY STABLIZER OUTPUT (PU)

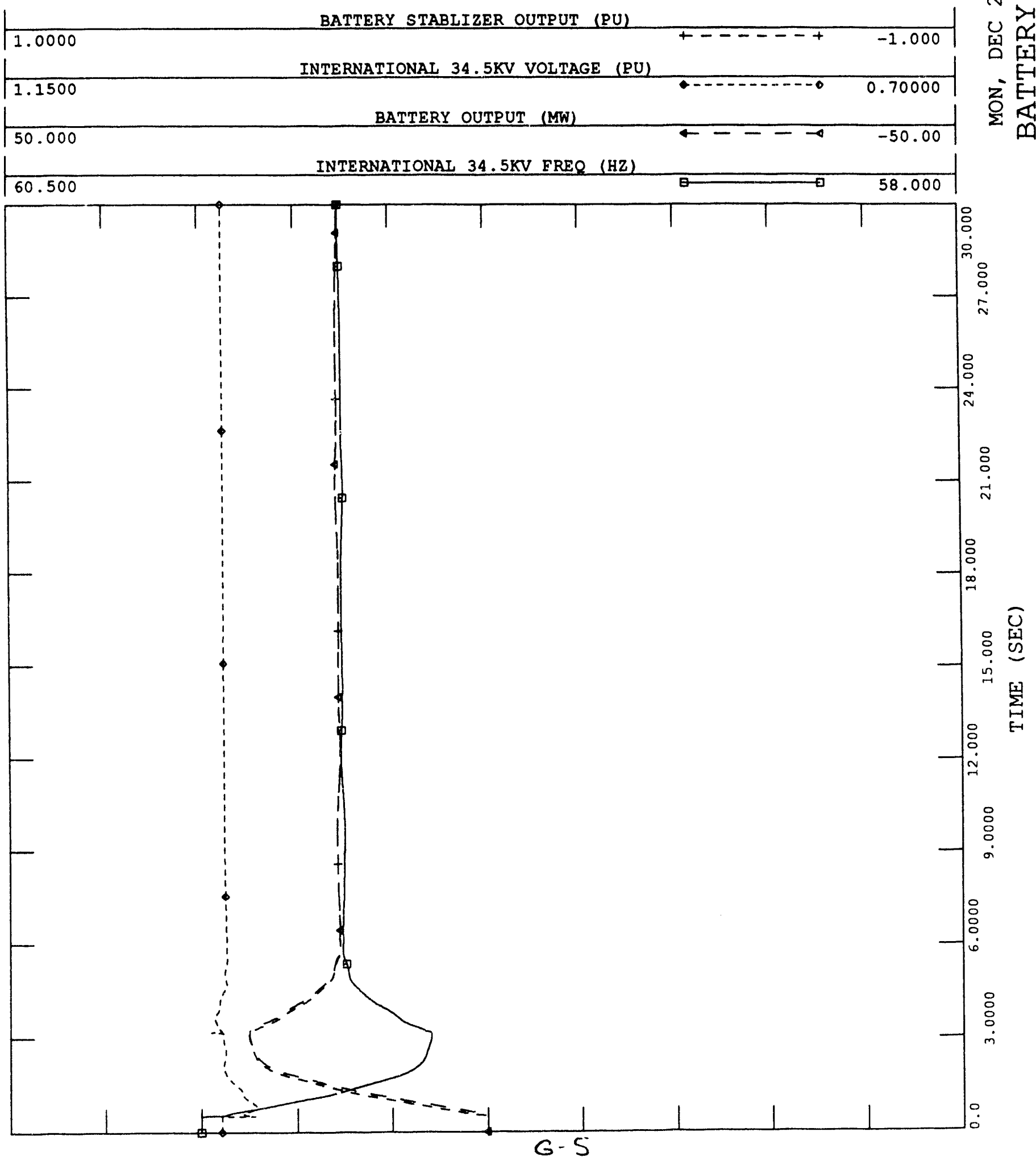




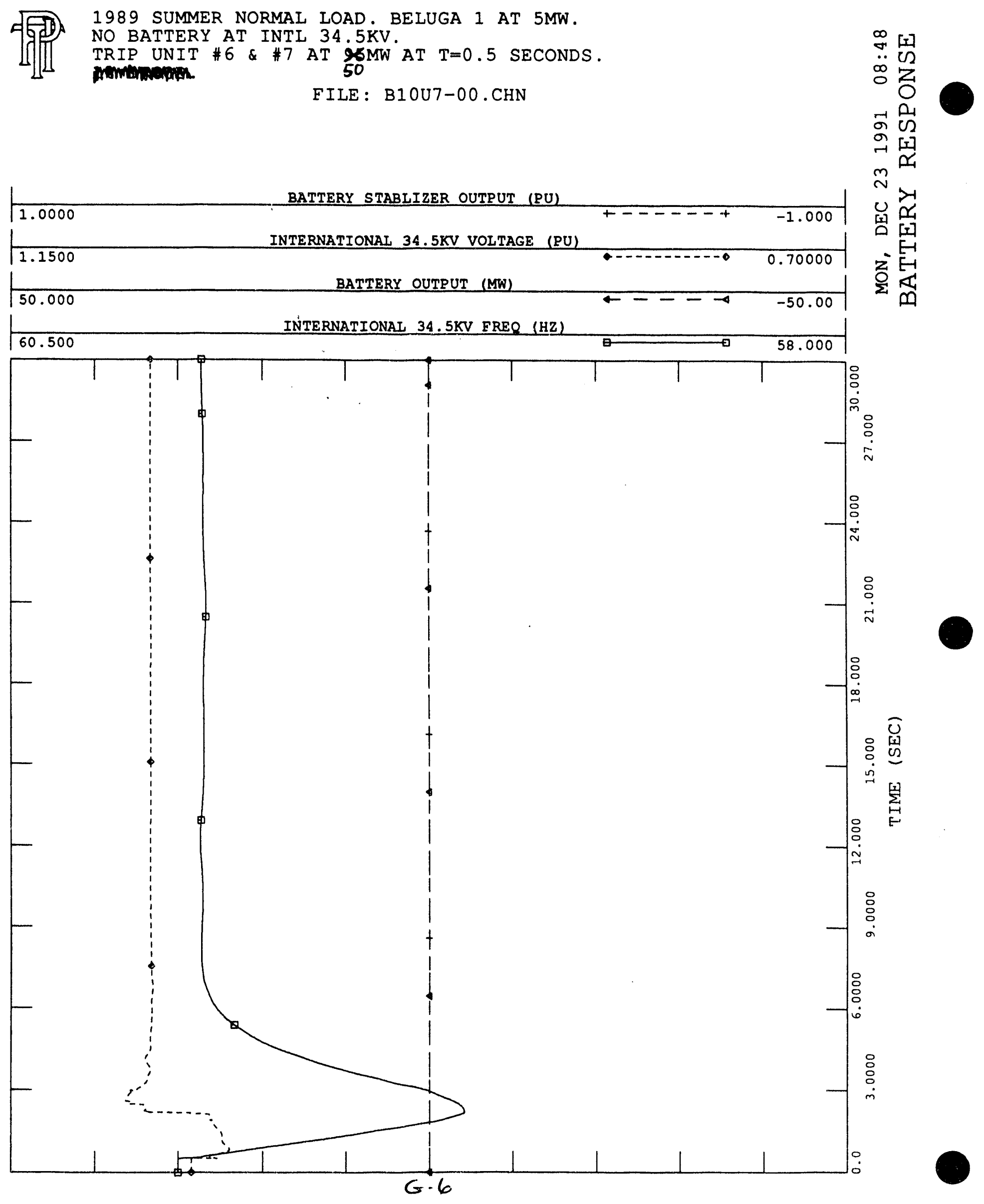


1989 SUMMER NORMAL LOAD. BELUGA 1 AT 5MW.

15 MVA BATTERY AT INTL 34.5KV, 0 MW OUTPUT. 190 DROOP.

TRIP UNIT \# $6 \& 7$ AT $50 \mathrm{MW} \mathrm{AT} \mathrm{T=0.5}$ SECONDS.

FILE: BIOU7-15.CHN

BATTERY STABLIZER OUTPUT (PU)

\begin{tabular}{|c|c|c|c|}
\hline$\longdiv { 1 . 0 0 0 0 }$ & BATTERY STABLIZER OUTPUT (PU) & \multirow{2}{*}{\multicolumn{2}{|c|}{--+.000}} \\
\hline & INTERNATIONAL $34.5 \mathrm{KV}$ VOLTAGE (PU) & & \\
\hline 1.1500 & BATTERY OUTPUT (MW) & 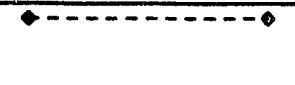 & 0.70000 \\
\hline
\end{tabular}

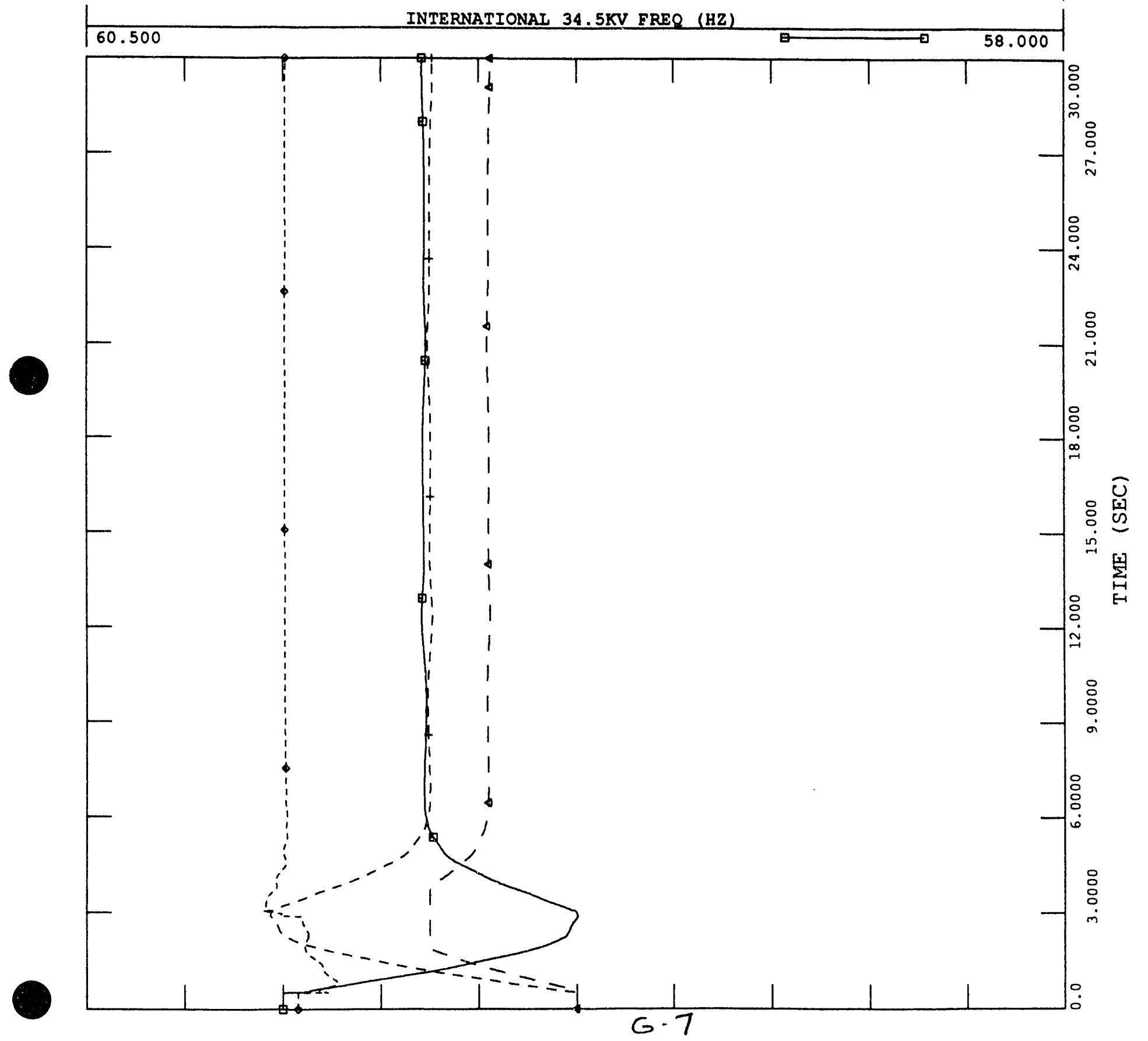


1989 SUMMER NORMAL LOAD. BELUGA 1 AT 5MW. 20 MVA BATTERY AT INTL $34.5 \mathrm{KV}, 0$ MW OUTPUT. TRIP UNIT \#6\& \#7 AT \& $5 \mathrm{MW}$ AT $\mathrm{T}=0.5$ SECONDS. $1 \%$ DROOP.

FILE: B10U7-20.CHN

กำ

$\because$ ก

$\infty$ 岁

- 10

$\rightarrow[1$

舟

$\stackrel{m}{\sim}$

$>1$

똔

口[I]

毕

E

$\Sigma$

\begin{tabular}{|c|c|}
\hline 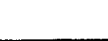 & BATTERY OUTP \\
\hline
\end{tabular}

INTERNATIONAL $34.5 \mathrm{KV}$ FREQ (HZ)

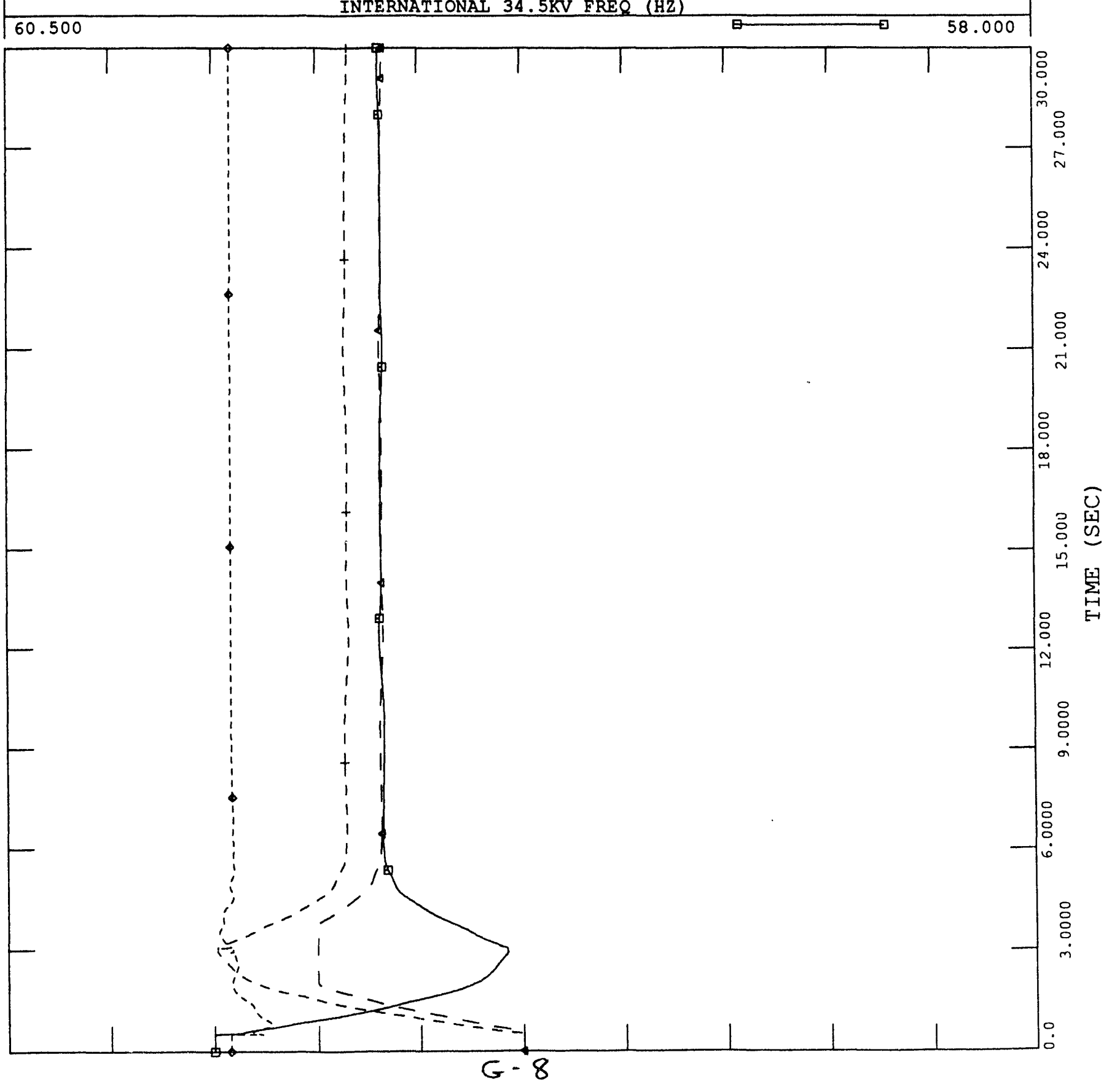


1989 SUMMER NORMAL LOAD. BELUGA 1 AT 5MW.

25 MVA BATTERY AT INTL $34.5 \mathrm{KV}, 0 \mathrm{MW}$ OUTPUT.

TRIP UNIT \#6 \& $\# 7$ AT 50 MW AT $\mathrm{T}=0.5$ SECONDS.
$1 \%$ DROOP.

in [ᄃ]

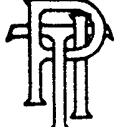

FILE : B10U7-25.CHN

$\because v$

Z

$\rightarrow$ A

ने ले

ने [1

$\stackrel{m}{\sim}$

\begin{tabular}{|c|c|c|c|}
\hline 1.0000 & & +-----+ & -1.000 \\
\hline & INTERNATIONAL $34.5 \mathrm{KV}$ VOLTAGE (PU) & & \\
\hline 1.1500 & & 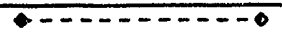 & 0.70000 \\
\hline & BATTERY OUTPUT (MW) & & \\
\hline
\end{tabular}

资

回 田

z- E-1

空

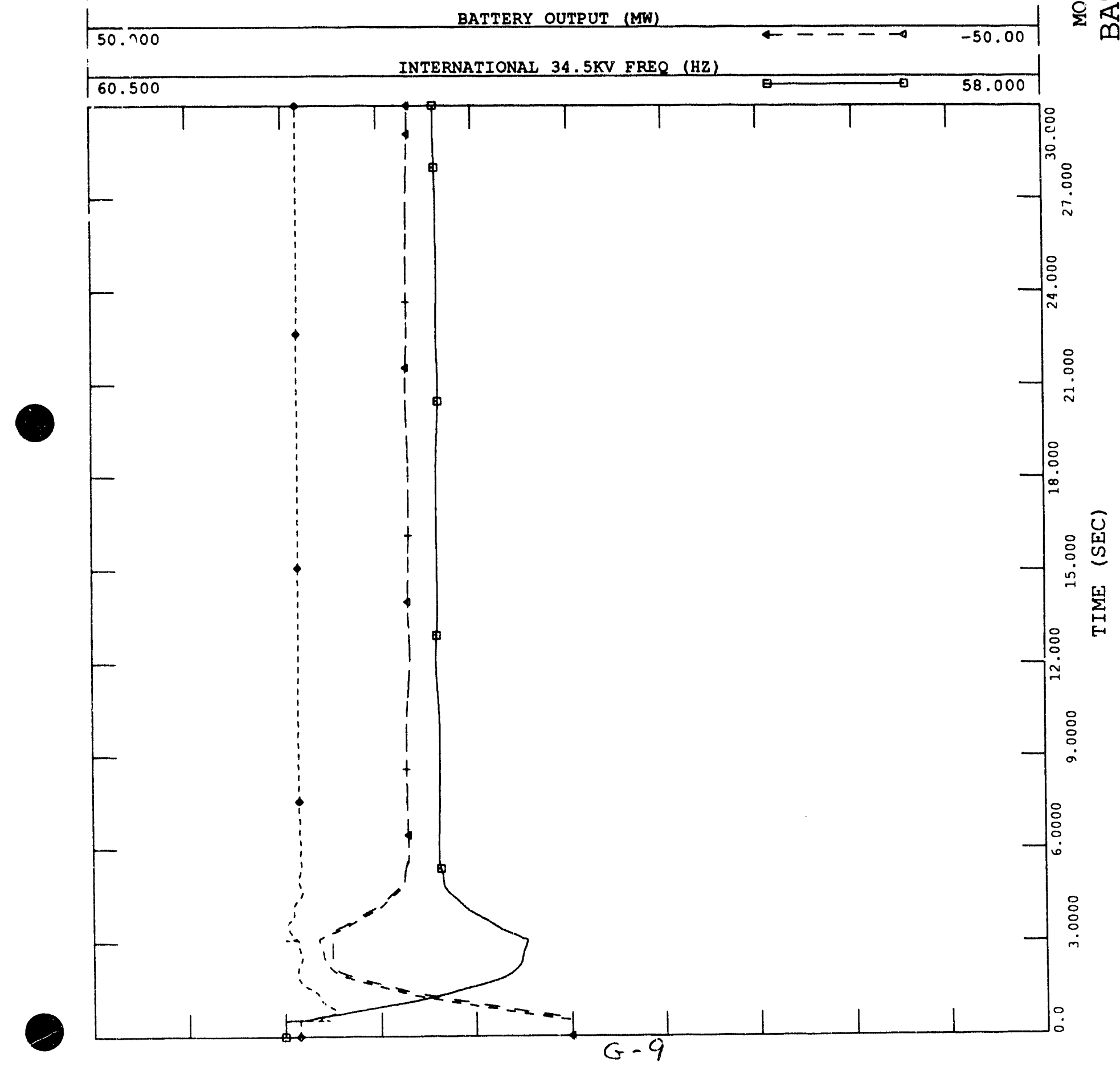


1989 SUMMER NORMAL LOAD. BRADLEY $1 \& 2$ EACH AT 15MW.

NO BATTERY AT INTI $34.5 \mathrm{KV}$.

TRIP UNIT \#6\&7 AT of MW AT T=0.5 SECONDS.

- 19

$\because$ U

$\stackrel{\circ}{\circ}$

FILE: S89U7-00.CHN

BATTERY STABLIZER OUTPUT (PU)

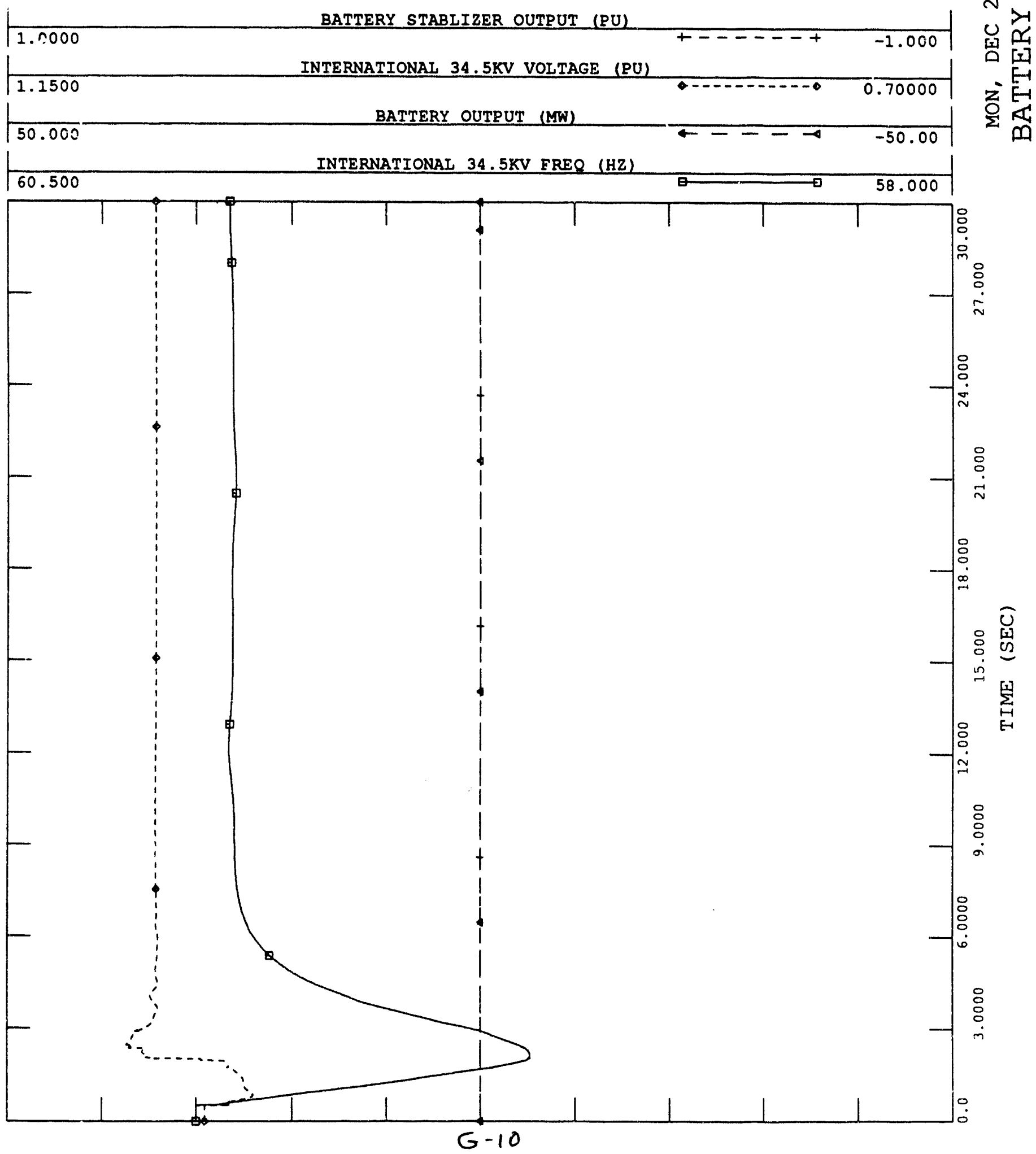


1989 SUMMER NORMAL LOAD. BRADLEY 1 \& 2 EACH AT 15MW. 15 MVA BATTERY AT INTL 34.5KV, 0 MW OUTPUT. TRIP UNIT \#6\& \#7 AT $\$ 5$ MW AT T=0.5 SECONDS. $1 \%$ DROOP.

$$
\text { FILE : S89U7-15.CHN }
$$

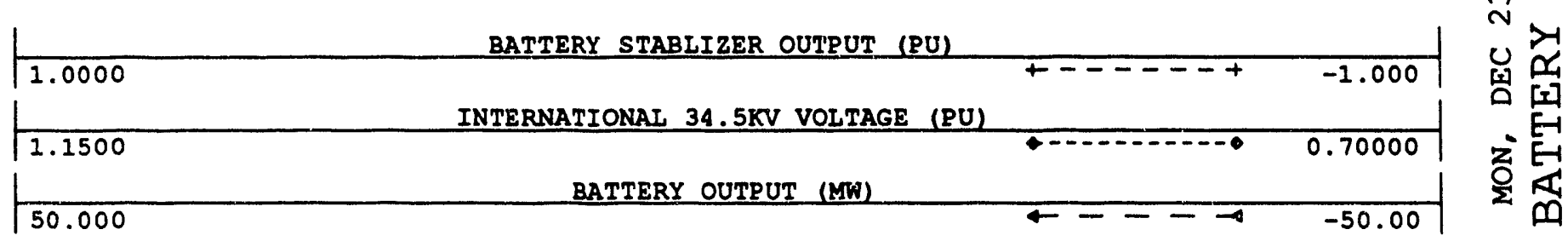

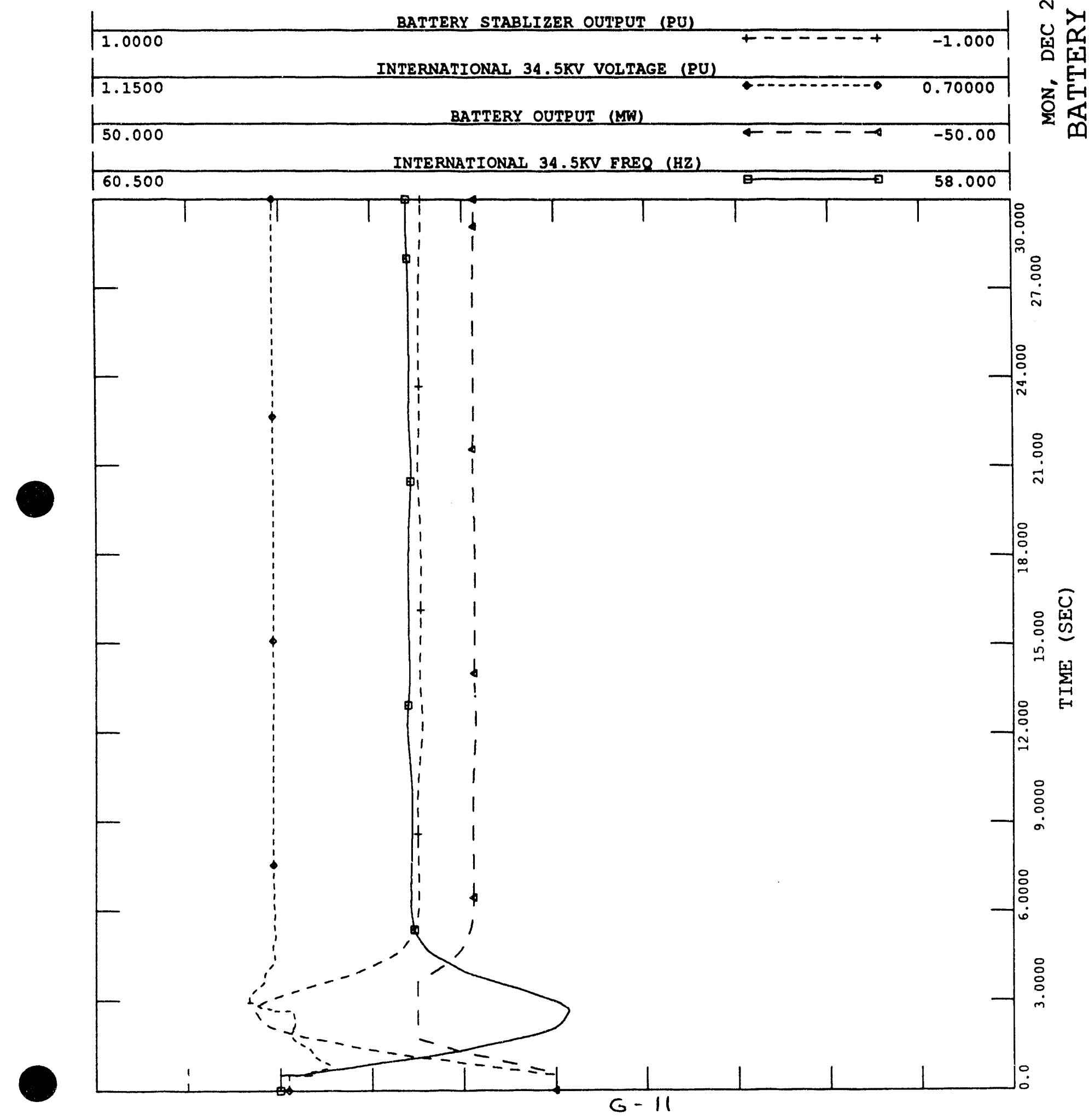


1989 SUMMER NORMAI LOAD. BRADLEY 1 \& 2 EACH AT 15MW.

BATTERY STABLIZER OUTPUT (PU)
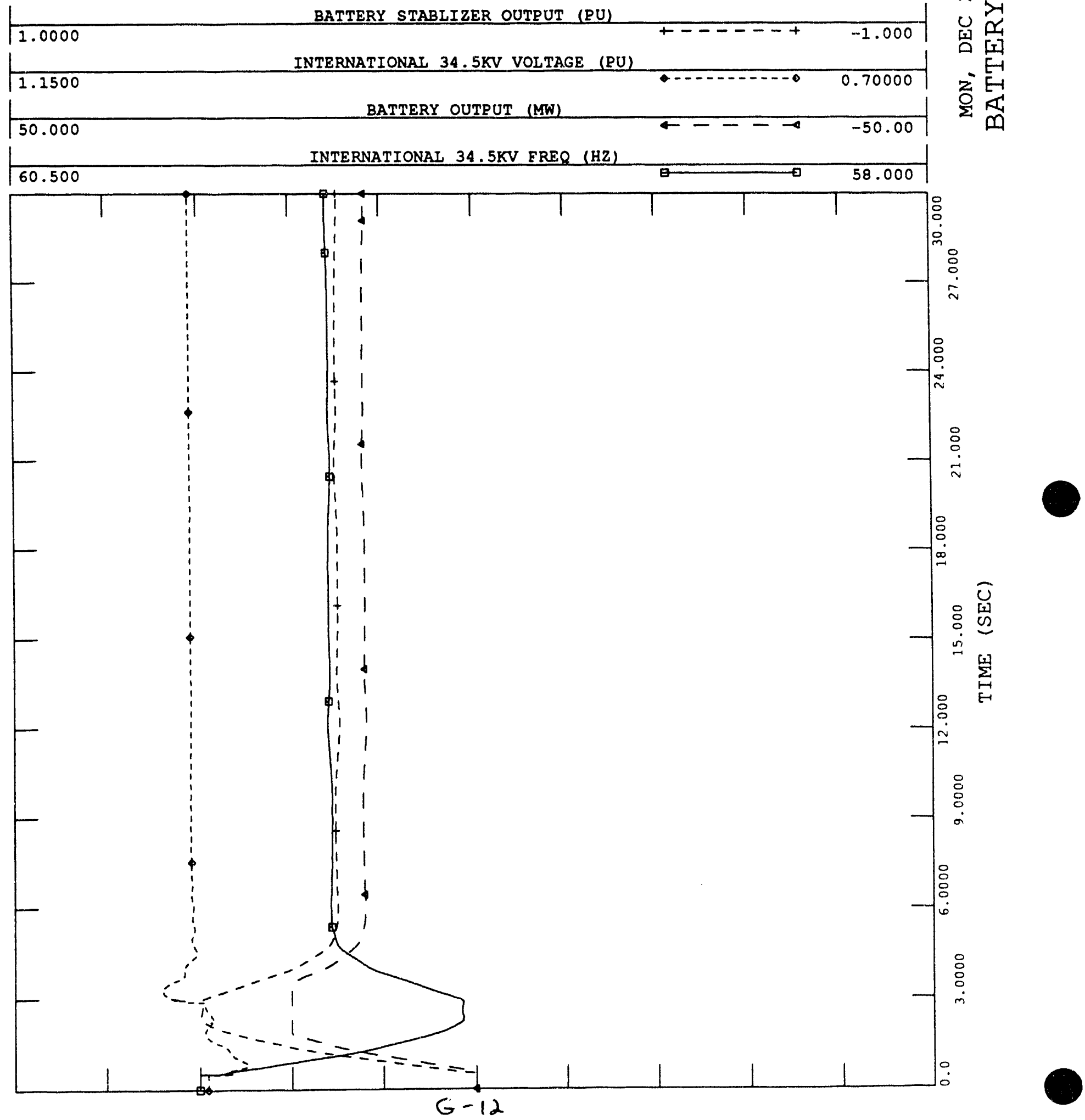


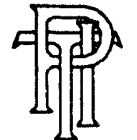

1989 SUMMER NORMAL LOAD. BRADLEY 1 \& 2 EACH AT 15MW.

25 MVA BATTERY AT INTL $34.5 \mathrm{KV}, 0$ MW OUTPUT.

TRIP UNIT \#6\& \#7 AT $55 \mathrm{MW}$ AT $\mathrm{T}=0.5$ SECONDS.
$1 \%$ DROOP.
웄디

$\because$ U

宓

0

ने ڤि

of []

$m$

$\stackrel{m}{\sim}$

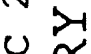

至

的

$z E$

Z

更

\begin{tabular}{|c|c|} 
BATTERY OUTPUT (MW) \\
\hline 50.000 \\
INTERNATIONAL 34.5KV FREQ (HZ)
\end{tabular}

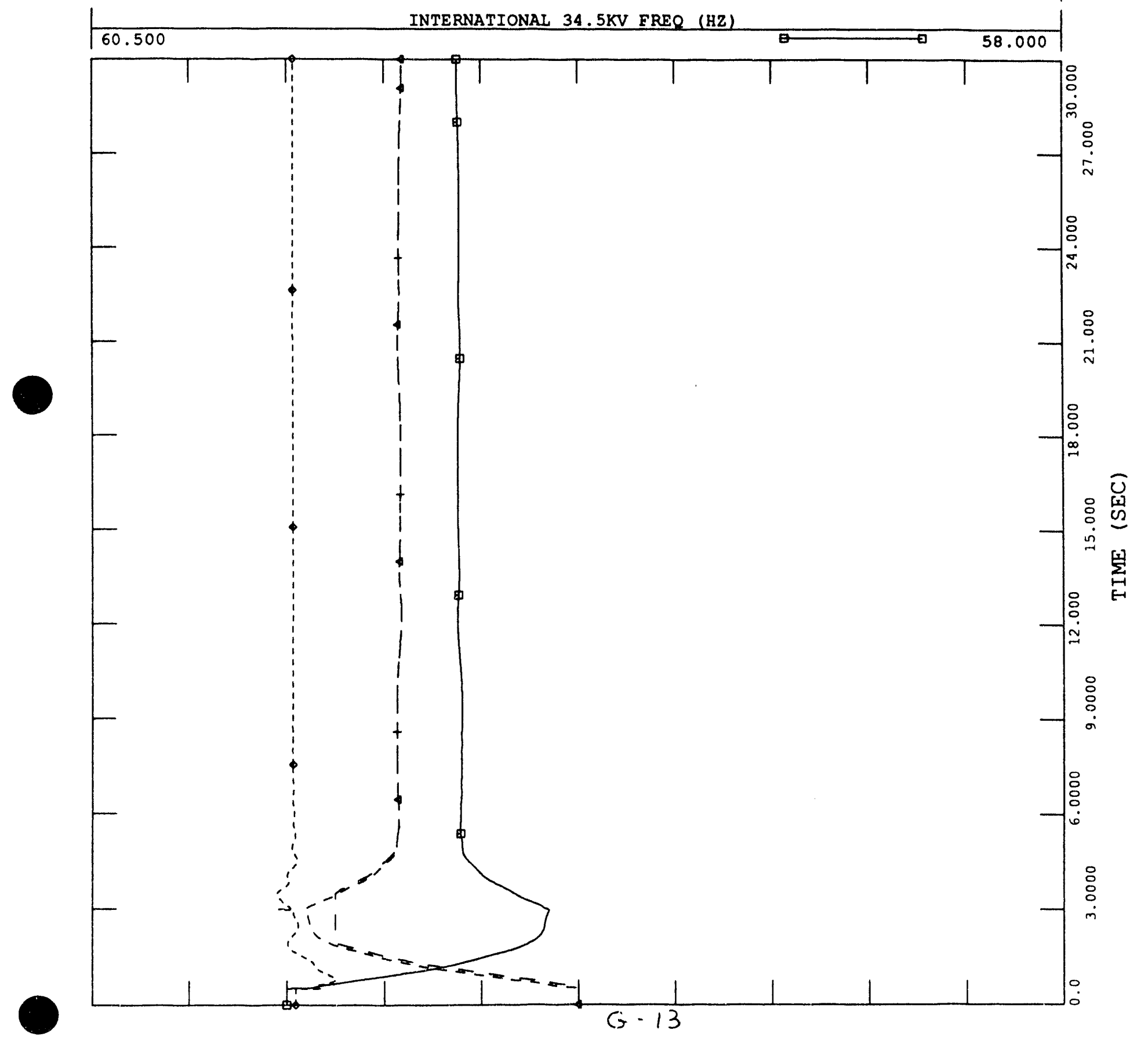




\author{
Appendix B \\ Potential Benefits of \\ Battery Storage to \\ San Diego Gas and Electric
}




\title{
POTENTIAL BENEFITS OF \\ BATTERY STORAGE TO \\ SAN DIEGO GAS AND ELECTRIC \\ -A Screening Study-
}

\author{
Prepared for: \\ Sandia National Laboratories \\ Department of Energy/Office of Energy Management \\ and \\ San Diego Gas and Electric \\ Prepared by: \\ Anders R. Gjerde \\ Stephen M. Haas \\ Salim J. Jabbour \\ DECISION \\ F. \\ 4984 El Camino Real \\ Los Altos, California 94022 \\ (415) $960-3450$ \\ and \\ H. W. Zaininger \\ H. C. Clark \\ Power Technologies, Inc. \\ January 1992
}




\section{TABLE OF CONTENTS}

Section

Page

EXECUTIVE SUMMARY

INTRODUCTION

Benefits of Energy Storage

Lead-Acid Battery Technology

SDG\&E Situation

$1-4$

Overview of This Report

2 POTENTIAL GENERATION BENEFITS

Calculating Generation Benefits of Energy Storage 2-1

Capturing Generation Benefits of Energy Storage 2-4

Study Approach $2-9$

Study Results $\quad 2-10$

3 POTENTIAL TRANSMISSION SYSTEM BENEFITS

New Transmission Projects 3-1

Transmission System Reliability Criteria 3-2

Potential Line and Transformer Deferral Benefits 3-2

Loss Reduction 3-6

Voltage Regulation 3-8

Other Potential Battery Storage T\&D Benefits 3-11

Other Considerations and Issues 3-12

4 POTENTIAL DISTRIBUTION SYSTEM BENEFITS

New Distribution Projects 4-1

Distribution System Reliability Criteria 4-2

Potential Distribution Substation Transformer Deferral

Benefits

Potential $12 \mathrm{kV}$ Feeder Deferral Benefits

Loss Reduction $\quad \mathbf{4 - 4}$

Voltage Regulation $\quad 4-5$

Other Battery Storage T\&D Benefits, Considerations and Issues

$5 \quad$ COST/BENEFIT ANALYSIS

Battery Capital Costs

5-1

Capacity Value of Battery 5-2

Comparing Benefits to Costs $\quad 5-2$ 
TABLE OF CONTENTS (Continued)

Section

Page

6 CONCLUSIONS AND RECOMMENDATIONS

Generation Benefits

6-1

Transmission and Distribution Benefits

$6-2$

Cost/Benefit Analysis

6-3

Recommendations

6-4

Appendix A TRANSMISSION FACILITY ASSUMPTIONS

Appendix B DAILY SDG\&E SYSTEM LOAD SHAPES AND MARGINAL GENERATION COSTS

A-1

Appendix C TYPICAL DAILY SDG\&E DISTRIBUTION SUBSTATION LOAD

B-1 SHAPES

C-1 


\section{LIST OF TABLES}

Table

Page

S-1 Benefits Summary for SDG\&E System S-3

1-1 Lead-Acid Battery Cost and Performance Data 1-3

1-2 Preferred Plan Resource Additions 1-4

2-1 Operating Characteristics of Generation Unit A 2-6

2-2 Using a Battery to Provide Spinning Reserve 2-8

2-3 SDG\&E Generating Unit Characteristics 2-10

2-4 Summary of Generation Benefits-Net Operating Savings 2-11

2-5 Load Leveling Savings, Dynamic Operating Benefits, Net Operating Benefits 2-11

3-1 Typical SDG\&E Transmission Line Cost 3-3

3-2 Typical SDG\&E Row Width and Land Cost 3-3

3-3 Potential Benefit from Deferring New Transmission Facilities 3-4

4-1 Typical Range SDG\&E Distribution Substation Transformer Cost 4-2

4-2 Typical SDG\&E $12 \mathrm{kV}$ Feeder Costs

4-3 SDG\&E Shunt Capacitor Cost Estimate 4-5

5-1 Benefits Summary for SDG\&E System 5-3

6-1 Range of Potential Annual T\&D Savings to SDG\&E 6-3

6-2 Example T\&D Battery T\&D Benefits at SDG\&E 6-3

A-1 Typical Transmission Line Construction Cost Estimates A-2

A-2 Approximate Line Ratings and Impedance Data A-3

A-3 Bulk Power Transformer and Breaker Cost Estimates A-3 


\section{EXECUTIVE SUMMARY}

This report describes the results of a screening study to determine the benefits of adding megawatt-scale battery storage to the San Diego Gas and Electric (SDG\&E) system. The report addresses generation, transmission, and distribution benefits of storage, with a primary focus on benefits that are typically difficult to quantify. The report also compares the potential benefits to the costs of adding battery storage.

\section{BENEFITS OF ENERGY STORAGE}

The addition of a storage unit to a utility system can provide a wide range of benefits that depend on the characteristics of the individial utility, the way in which the storage unit is operated, and the siting of the storage unit as well. Generation load-leveling has long been advocated as the primary reason for adding storage to a utility's generating mix. The most obvious benefit and the easiest to quantify, load-leveling results in the replacement of expensive peak power with cheaper power from base-load plants, increasing the capacity factor of the baseload plants during off-peak periods to displace the use of premium oil/gas fuels during on-peak periods. In the past several years, generation dynamic operating benefits (DOBs) have also been recognized as significant benefits of storage plants. The types of benefits include those accruing from the provision of spinning reserve, reduced minimum loading, and fast response rates. These benefits are overlooked in conventional methods. Another commonly recognized benefit from storage in general, and batteries in particular, is reduction in transmission and distribution (T\&D) costs. T\&D benefits are due in part to the siting flexibility and in part to the rapid response times for batteries. T\&D benefits include deferral of T\&D investment, reduced losses, and voltage regulation, as well as others.

\section{SDG\&E FINDINGS}

\section{Generation Benefits}

Generation benefits were calculated for eight days during 1990-1991, one weekday and one weekend day for each season, using actual SDG\&E data. The benefits were calculated for five gas-fired steam turbine units whose operation is most likely to be affected by the addition of batteries to the system. Two modes of battery operation were considered: daily charge/discharge with a three-hour battery, and provision of spinning reserve only with a onehour battery.

Load-Leveling. Because the marginal units on the SDG\&E system are typically gas-fired steam turbines for all hours (usually the Encina and South Bay units), the system marginal energy costs do not differ much between on-peak and off-peak hours. Coupled with the assumed battery efficiency of around 80 percent, this means that no load-leveling savings could be achieved on the SDG\&E system. 
Dynamic Operating. For each of the eight days the potential reduction in load following, minimum loading, startup, and spinning reserve costs was calculated for each of the five units. The most cost-effective unit for decommitment was identified on each day. For the 1990-1991 period, the savings was about $\$ 23-26$ per kilowatt per year of battery capacity; the biggest component of the savings is from reductions in load-following costs. That is, each kilowatt of battery capacity would reduce annual system operating costs 23 to 26 dollars. Accounting for inflation and increases in natural gas prices, this is equivalent to an annual savings of about $\$ 50$, levelized in current dollars, per kilowatt per year. The savings are likely to increase in the future as load growth forces increasing utilization of less economic units.

Environmental. Storage in general, and batteries in particular, have the potential to shift the type and location of emissions of $\mathrm{NO}_{x^{\prime}} \mathrm{SO}_{x^{\prime}}$ and $\mathrm{CO}_{2} ; \mathrm{NO}_{\mathrm{x}}$ is of greatest concern in Southern California. Even if providing only spinning reserve, batteries have the potential to reduce $\mathrm{NO}_{x}$ emissions by allowing the system to be operated more efficiently. The addition of batteries to the system might also make it unnecessary to retrofit expensive pollution controls to an existing gas-fired unit, if that units operation would be sharply reduced as a result of adding batteries.

\section{Transmission and Distrlbution Beneflts}

This project identified the potential role battery storage could play in providing equal or better performance than other transmission and distribution (T\&D) options, such as adding new $T \& D$ facilities and equipment. Current SDG\&E transmission and distribution facility expansion study results and transmission and distribution system design practices were reviewed with SDG\&E personnel to identify anticipated and potentially needed transmission additions.

The findings of this initial study indicate that strategically installing battery storage on the SDG\&E system may result in large T\&D system benefits-up to $\$ 1200 / \mathrm{kW}$. The actual magnitude of the site specific $T \& D$ benefits and corresponding battery storage requirements should be determined on a case-by-case basis from more detailed analysis. Further analysis should include the development of load profiles for substations that are candidate battery sites so that the number of hours of storage required for equipment deferral can be determined.

\section{COST/BENEFIT ANALYSIS}

Table S-1 summarizes the findings. Summing the capacity, generation, environmental, and T\&D benefits yields levelized current-dollar savings of $\$ 100$ to $\$ 370 / \mathrm{kW}$-year, compared to a levelized current-dollar cost of $\$ 60$ to $\$ 130 / \mathrm{kW}$-year. ${ }^{1}$ These values suggest that batteries would be a cost-effective addition to the SDG\&E system.

1. There are no commonly accepted estimates for battery storage system costs. The cost estimates used here are from EPRI's Technical Assessment Guide (TAG, 1989). The total cost is $\$ 703 / \mathrm{kW}$ for a 3-hour battery, including land cost. Reducing the storage component in the TAG cost estimates for a 3-hour battery by two thinds yields an estimated cost of $\$ 350 / \mathrm{kW}$ for a 1-hour battery. With a levelized fixed charge rate of 16 percent, this is equivalent to $\$ 60 / \mathrm{kW}$-year for a 1-hour battery and $\$ 130 / \mathrm{kW}$-year for a 3-hour battery. 
BENEFITS SUMMARY FOR SDG\&E SYSTEM

\begin{tabular}{lc}
\hline \multicolumn{1}{c}{ Category } & Annual Bonofth (\$NW-year) \\
\hline Capacity & $40-75$ \\
Generation & $50-75$ \\
T\&D & $10-200$ \\
Environmontal & $1-20^{*}$ \\
TOTAL & $100-370$
\end{tabular}

"For charging with on-system units.

Some benefits may be mutually exclusive. The interactions between the various benefits, i.e., whether they are additive or mutually exclusive, depends on storage size, location, system load shapes, load shapes at individual substations and on individual transmission and distribution lines, how the system (including the battery) is operated, and on any equipment deferred as a result of adding batteries.

\section{RECOMMENDATIONS}

Based on the results of this screening-level study, it is recommended that SDG\&E seriously consider the addition of battery storage to its system. A detailed study to verify the findings of this initial screening study and to calculate the benefits more precisely is recommended. Such a study should include the following aspects:

1. More detailed calculation of generation dynamic operating costs and benefits should be carried out, including examination of multiple weeks of system operation during the course of the year and consideration of how system operation, and especially the operation of marginal units, is likely to change in the future.

2. Detailed T\&D expansion studies should be carried out, with and without batteries. Potential sites for installing batteries should be identified. Interactions among the various benefits should be considered to ensure that batteries are not being justified on the basis of benefits that may be mutually exclusive.

3. Comparative evaluation of the economics of battery storage with other capacity additions under consideration by SDG\&E should be carried out.

Such detailed study would also allow a better assessment of the "optimum" battery size and the best time for adding the battery plant to the SDG\&E system. 


\section{INTRODUCTION}

This report describes the results of a screening study to determine the benefits of adding megawatt-scale battery storage to the San Diego Gas and Electric (SDG\&E) system. The report addresses generation, transmission, and distribution benefits of battery energy storage, with a primary focus on benefits that are typically difficult to quantify. The potential benefits are compared to the costs of adding battery storage to determine the cost-effectiveness of adding battery energy storage to the SDG\&E system.

\section{BENEFITS OF ENERGY STORAGE}

The addition of battery energy storage to a utility system can provide a wide range of benefits that depend on the characteristics of the individual utility, the manner in which the battery storage unit is operated, and its siting within the utility network as well. Generation load-leveling has long been advocated as the primary reason for adding storage to a utility's generating mix. The most obvious benefit and the easiest to quantify, load-leveling results in the replacement of expensive peak power with cheaper power from base-load plants, increasing the capacity factor of the base-load plants during off-peak periods to displace the use of premium oil/gas fuels during on-peak periods.

In the past several years, generation dynamic operating benefits (DOBs) have also been recognized as significant benefits of battery energy storage plants. The types of benefits include those accruing from the provision of spinning reserve, reduced minimum loading, and fast response rates. An EPRI report ${ }^{1}$ provides compelling evidence on the importance of dynamic operating considerations. The three major conclusions of the EPRI report are as follows:

- A large portion of the operating costs of cycling power plants results from fluctuating electric loads. These costs are called dynamic operating costs.

- Technologies that offer operating flexibility at minimal costs (e.g., energy storage power plants) provide power systems with significant operating cost savings. These savings are called dynamic operating benefits.

- A large fraction (up to two-thirds) of the savings provided by technologies with significant operating flexibility is overlooked in conventional methods.

1. Dynamic Operating Benefits of Energy Storage, EPRI AP-4875. 
Another commonly recognized benefit from storage in general, and batteries in particular, is reduction in transmission and distribution (T\&D) costs. T\&D benefits are due in part to the siting flexibility and in part to the ispid response times for batteries. T\&D benefits include deferral of T\&D investment, reduced losses, and voltage regulation, as well as others. ${ }^{2}$

Another category of benefits is what might be iermed strategic benefits, those that relate primarily to the changing environment in which utilities operate. This includes reduction in environmental emissions, greater ability to buy power from other utilities and from non-utility generators and to sell power to other utilities, and greater flexibility in general.

This study quantifies the benefits of battery storage in the first two categories - generation and T\&D-for the SDG\&E system. ${ }^{3}$ It then sompares these benefits to the costs of adding leadacid battery storage.

\section{LEAD-ACID BATTERY TECHNOLO NY $Y^{4}$}

The major elements of a lead-acid battery energy storage plant are the battery, the co: erter, and the balance of the plant. During charging, alternating current electricity is converted to direct current electricity by the converter and stored electrochemically by the battery. During discharge, direct current electricity is drawn from the battery and converted to alternating current electricity for use on the utility grid. Figure 1-1 is a schematic of a battery energy storage system.

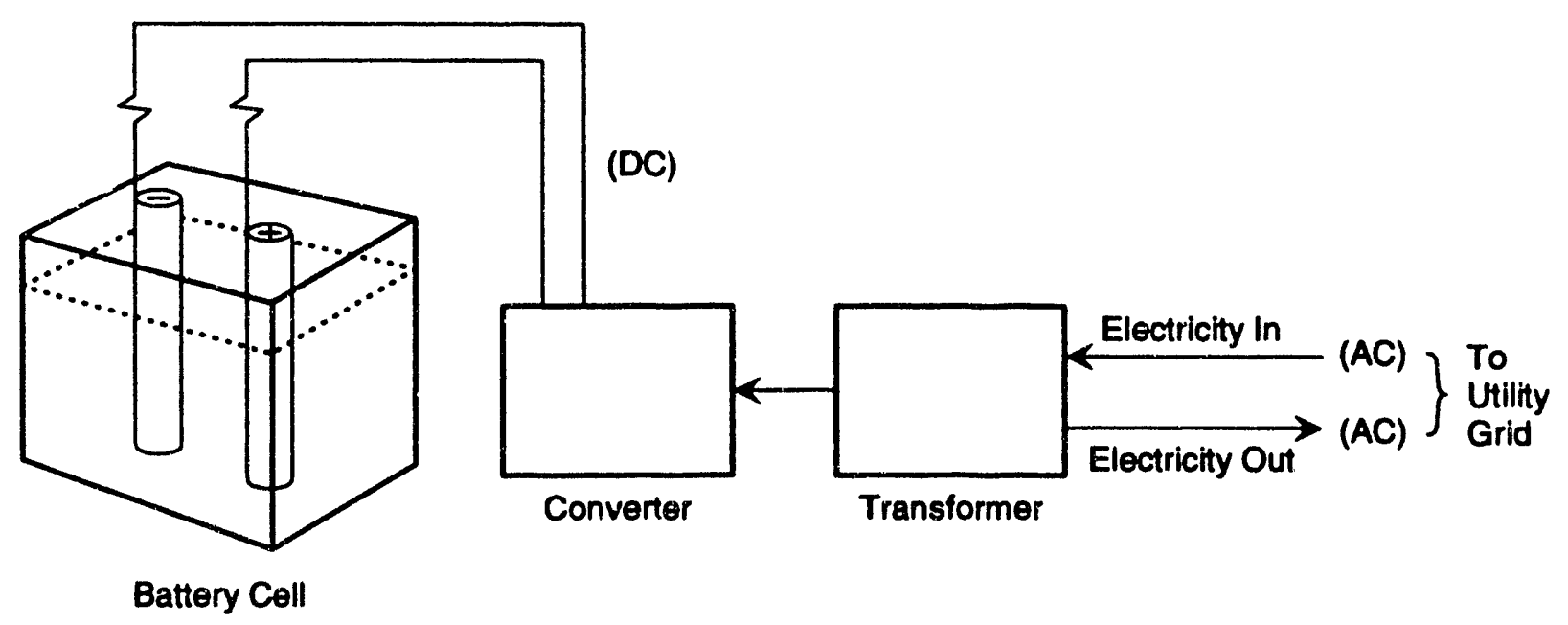

Figure 1: 1 . Battery Energy Storage System

2. Potential Economic Benefits of Battery Storage to Electrical Transmission and Distribution Systems, EPRI GS-6687.

3. A back-of-the envelope assessment of environmental benefits is also included.

4. Research is under way on a number of advanced battery systems, including sodium sulfur, zinc bromine, and others. In this report, however, we focus on and use costs for the one technology that is commercially available now: lead-acid batteries. 
Utility battery storage systems consist of commercially available lead-acid cells similar to those used in submarines or large telephone switching installations. A typical cell size is 5 to $10 \mathrm{kWh}$. Many cells are combined in a battery unit, with typical storage times of 1 to 5 hours and power capacities of 2 to 100 megawatts. For example, the 4-hour capacity lead-acid battery storage plant at Southern California Edison Company's Chino substation has a capacity of 10 MW; the battery consists of 8,256 cells, each measuring approximately 16 in. $(41 \mathrm{~cm})$ long, 14.5 in. $(37 \mathrm{~cm}$ ) wide, and $25 \mathrm{in}$. $(65 \mathrm{~cm})$ high, and weighing about $585 \mathrm{lb}$. (266 kg). The cells are mounted on steel frames in groups of 6 to form $12-\mathrm{V}$ modules. The battery is connected to the SCE system at $13.8 \mathrm{kV}$.

The AC-DC converter consists of electronic equipment similar to that used in large uninterruptible power supply (UPS) systems, and in wind, photovoltaic, and fuel cell power generation systems. The balance of the plant consists of the structural, mechanical, electrical, control, and safety subsystems required to perform system integration and interface of the battery to the utility system.

Battery energy storage plants are truly modular and can be installed quickly, enabling them to match load growth much more easily and accurately than larger, custom-built, sitespecific plants. Construction time for a lead-acid battery plant is less than one year. Batteries are compact, quiet and non-polluting, so they can be sited near population centers. They can operate efficiently over a wide range of loads, and are actually more efficient at part load than at full load. They can also respond to load changes in just $\mathbf{2 0}$ milliseconds.

Table 1-1 provides cost and performance data for battery storage sizes of 3 and 5 hours, installed at a $20 \mathrm{MW}$ plant. These data are from the EPRI Technical Assessment Guide ${ }^{\mathrm{TM}}$.

\section{Table 1-1}

LEAD-ACID BATTERY COST AND PERFORMANCE DATA

\begin{tabular}{lcc} 
& Three Hour & Five Hour \\
\hline Plant Capital Cost, Dec. 1988 \$kW & 125 & 125 \\
Power charging/discharging & 510 & 727 \\
Storage & 16 & 21 \\
Startup, inventory, land & 651 & 873 \\
Total capital requirement & & \\
Operation and Maintenance Costs, Dec. 1988 \$ & 0.6 & 1.4 \\
Fixed, \$kW-yr & 8.6 & 6.5 \\
Incremental, mills/kWh & & \\
Energy Requirements (kWh OutputkWh Input) & 0.73 & 0.76 \\
Full bad & 0.78 & 0.79 \\
25\% load & 0.74 & 0.76 \\
Average annual & 1 & 1 \\
Plant Construction Time, Years & 30 & 30 \\
Unit Life, Years & &
\end{tabular}




\section{SDG\&E SITUATION}

SDG\&E's generation mix consists of nuclear, gas-fired units, and purchased power. From the perspective of adding battery storage to the system, the important point is that both now and perhaps for the rest of the 1990s, the marginal units are almost always, both on-peak and offpeak, gas-fired units. These are the units whose operation would be affected by the additions of batteries. ${ }^{5}$ This means that, for on-system units, there is relatively little difference in incremental energy costs between peak and off-peak periods, so that from a load-leveling perspective, there is not much benefit from adding batteries. Other types of benefits, such as T\&D and dynamic operating, will be required if the addition of batteries is to be economically justified.

Based on SDG\&E's current biennial resource plan update (BRPU), which is filed every two years with the state Public Utilities Commission (PUC), the preferred plan resource additions for SDG\&E are shown in Table 1-2.

Table 1-2

\begin{tabular}{|c|c|}
\hline Yoar & Projected Generation Additions \\
\hline 1997 & $\begin{array}{l}\text { Repower South Bay Unit Number 3: } 455 \text { added MW. } \\
\text { Additional Purchased Power: } 372 \text { added MW. } \\
\text { Geothermal: } 100 \text { added MW. }\end{array}$ \\
\hline 1999 & Repower Encina unit \#1: 273 added MW. \\
\hline 2001 & $\begin{array}{l}\text { Repower one Encina unit or construct combined cycle } \\
\text { plant on SDG\&E site in Blythe }\end{array}$ \\
\hline $1991-2000$ & Non-utility generation: $800 \mathrm{MW}$ \\
\hline Yoar & Projected DSM Savinge \\
\hline 1995 & $240 \mathrm{MW}$ \\
\hline 2000 & $360 \mathrm{MW}$ \\
\hline
\end{tabular}

\section{OVERVIEW OF THIS REPORT}

Section 2 quantifies the generation benefits of batteries on the SDG\&E system. Sections 3 and 4 do the same for transmission and distribution, respectively. Section 5 compares these benefits to the cost of installing batteries. Section 6 summarizes the results and recommends further steps.

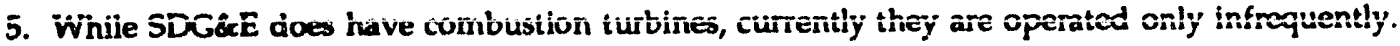




\section{2}

\section{POTENTIAL GENERATION BENEFITS}

This section estimates the magnitude of three kinds of generation benefits-load-leveling benefits, dynamic operating benefits, and environmental benefits - of adding battery storage to the SDG\&E system. The section discusses the logic behind the calculations, describes the approach taken for the SDG\&E analysis, and presents the results.

\section{CALCULATING GENERATION BENEFITS OF ENERGY STORAGE}

\section{Load-Leveling Benefits}

Energy storage makes it possible to generate electricity during off-peak hours and use it during peaking-hours, commonly referred to as load-leveling. Typically, system lambda (the marginal cost of energy) is lower during off-peak hours than during on-peak hours; the load-leveling savings is the difference between the lambda during peaking hours when the storage would be discharged and the lambda for the off-peak hours, when the storage would be charged, adjusted for the efficiency loss from the battery.

$$
\underset{(\$ / \mathrm{MWh})}{\operatorname{Load} \text { Leveling Benefits }}=\underset{\substack{(\$ / \mathrm{MWh}) \\ \lambda_{\text {on-peak }}}}{(\$ / \mathrm{MWh})}
$$

If this number is positive, then there are load-leveling savings. This will be true if the battery efficiency exceeds the ratio of off-peak lambda to on-neak lambda.

\section{Dynamic Operating Benefits}

Dynamic operating costs (DOCs) are the portion of total operating costs of an electric power system required to meet dynamic operating requirements. Technologies that offer operating flexibility at minimal costs, such as energy storage plants, provide power systems with significant operating cost savings. These savings are called dynamic operating benefits (DOBs). Potential DOBs are measured as reductions in dynamic operating costs (DOCs). DOCs include:

- Startup costs, the costs of shutting down and starting up power plants.

- Load Following costs, increased fuel costs due to operations in load following mode. 
- Minimum Load costs, costs due to foregone economic generation because of minimum load constraints.

- Ramping costs, the costs due to foregone economic generation because of ramping constraints.

- Frequency Regulation costs, costs of foregone economic generation due to externally constraining the loading ranges of some units to provide frequency regulation capabilities.

This study estimated the benefits associated with reducing the first three types of dynamic operating costs: startup costs, load following costs, and minimum load costs, all of which have a solid technical foundation based on common utility operations. Other categories of DOBs are likely to be smaller but can only add to the DOBs quantified in this study.

Startup Cost Benefits. The cost of starting a steam unit that has been shut down completely is typically several thousand dollars. Compared to the total daily operating cost of such a unit, typically tens of thousands of dollars per day, this is not insignificant. By modifying unit commitment, the addition of battery storage can make it possible to avoid this startup cost for one or more units.

Load Following Benefits. Load fluctuation requires that some generation be able to meet changes in, or follow, the load. As a result of this requirement, the units used for load following will most of the time be loaded at levels other than their most efficient loadings, at points where their average fuel costs are higher than at their most efficient loadings and higher than system marginal cost. Load following benefits occur when a unit operating in load following mode is decommitted. The benefits or savings are equal to the difference in average energy cost of the unit and the system marginal energy cost.

Load following costs of a unit are the costs which could have been avoided were the system able to decommit the unit and replace its energy at the system marginal energy cost. These are calculated for hours where the unit is operated at part load (not on minimum load):

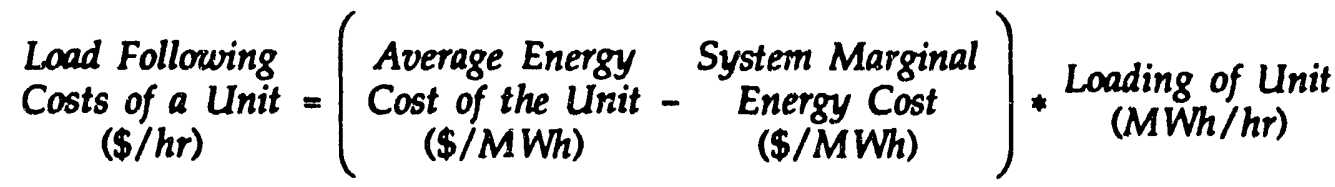

The daily load following costs are the sum of the hourly load following costs (for the hours in load following mode). 
Minimum Load Benefits. Thermal units have minimun loading constraints. When they are committed, they must be operated at or above this minimum load. Operation at minimum loading generally results in the least efficient generation. Units are normally operated at their minimum load only because the constraint prohibits even lower loading. Minimum loading benefits cccur when a unit operating at its minimum load is decommitted. The benefits or savings are equal to the difference in average energy cost of the unit and the system marginal energy cost.

Minimum loading costs of a unit are the costs which could have been avoided were the system able to decommit the unit and replace its energy at the system marginal energy cost, calculated for hours where the unit is on minimum load:

$$
\begin{gathered}
\text { Minimum Load } \\
\text { Costs of a Unit } \\
(\$ / \mathrm{hr})
\end{gathered}=\left(\begin{array}{cc}
\text { Average Energy } & \text { System Marginal } \\
\text { Cost of the Unit } & \begin{array}{c}
\text { Energy Cost } \\
(\$ / M W h)
\end{array} \\
(\$ / M W h)
\end{array}\right) * \begin{gathered}
\text { Minimum } \\
\text { Loading of Unit } \\
(\mathrm{MWh} / \mathrm{hr})
\end{gathered}
$$

The daily minimum load costs are the sum of the hourly minimum load costs (for the hours at minimum load).

Figures 2-1 and 2-2 illustrate how minimum load and load following costs are calculated and how significant they can be. Although the figures are for a hypothetical unit in a hypothetical system, they are typical of actual units. The unit operates at its minimum load for hours $0-4$ and 20-24, at its maximum load for hours 8-16, and in load-following mode during the other 8 hours. The daily load following cost of the unit is the dark shaded area in Figure 2-2; the light shaded area is the unit daily minimum load cost. The difference between unit average cost, which is the cost actually incurred, and system marginal cost, the cost that would be incurred if this unit could be shut down, is substantial.

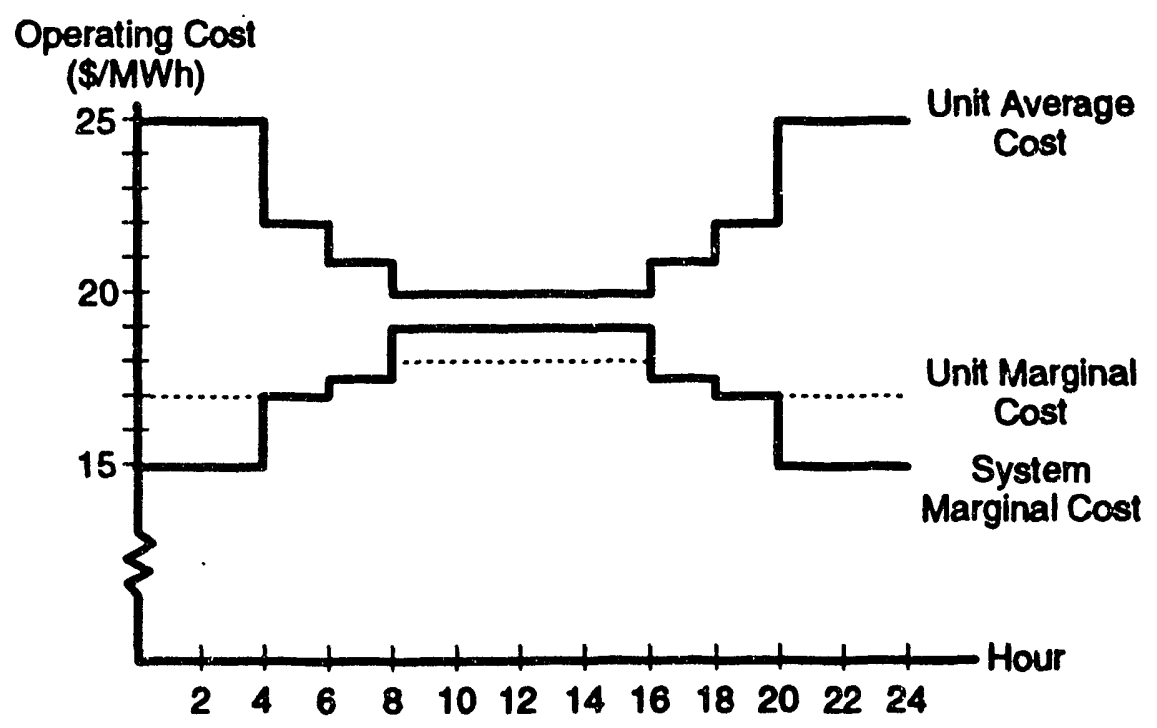

Figure 2-1. System and Unit Costs 


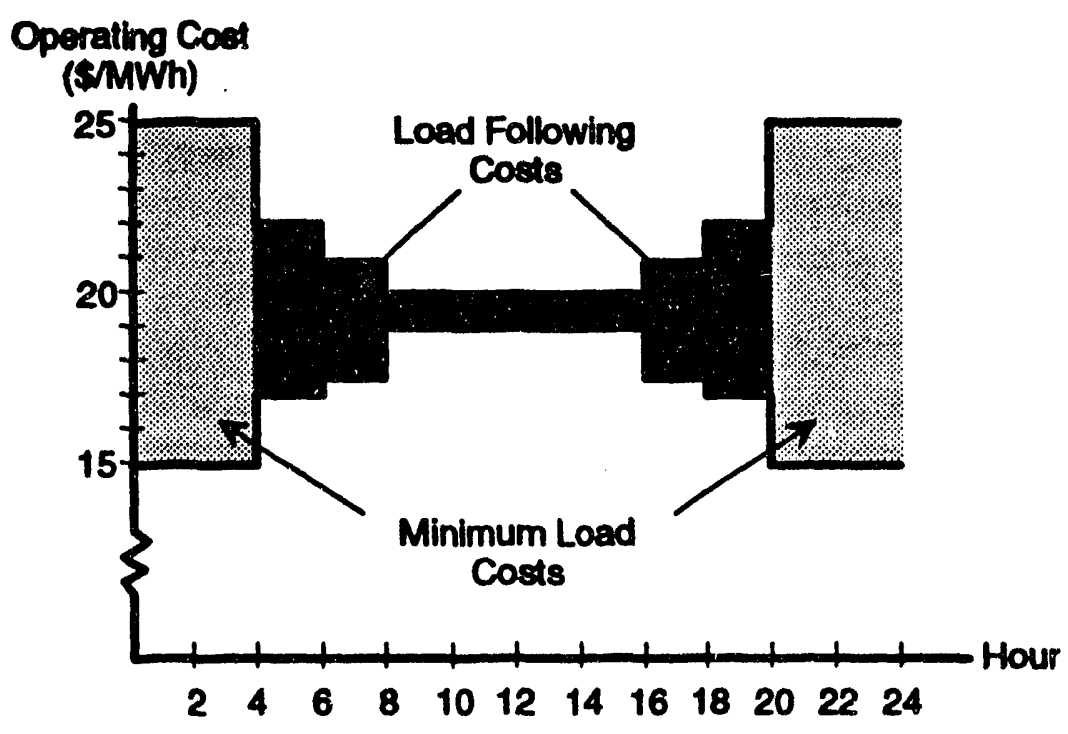

Figure 2-2. Load Following Costs and Minimum Load Costs

\section{CAPTURING GENERATION BENEFITS OF ENERGY STORAGE}

There are two primary modes in which storage can be operated:

- On a regular charge/discharge basis

- To provide spinning reserve only

Both modes are discussed below.

\section{Charge/Discharge Application}

Operated in this mode, storage provides not only load-leveling but also the reduction in dynamic operating costs made possible by decommitting a unit and operating remaining units at more efficient levels. The storage would most likely be operated on a daily cycle, with charging at night and discharging during the daily peak. In order to maximize benefits per kilowatt of battery capacity, it is necessary to install both enough power capacity (MW) and storage capacity (MWh or hours of storage) to permit decommitting one or more units.

To illustrate the importance of including dynamic operating costs in calculating generation benefits, consider a hypothetical system with two time periods per day, a peak period of 8 hours, and an off-peak period of 16 hours. The system marginal energy costs are $\$ 18 / \mathrm{MWh}$ during the peak period and $\$ 17 / \mathrm{MWh}$ during the off-peak period. Figure 2-3 illustrates these marginal energy costs and Table 2-1 illustrates the operating characteristics of one generation 
unit (called Unit A). Unit A operates at minimum load (50 MW) during the off-peak period and at $100 \mathrm{MW}$ during the peak period. Figure 2-4 illustrates the power output of Unit A.

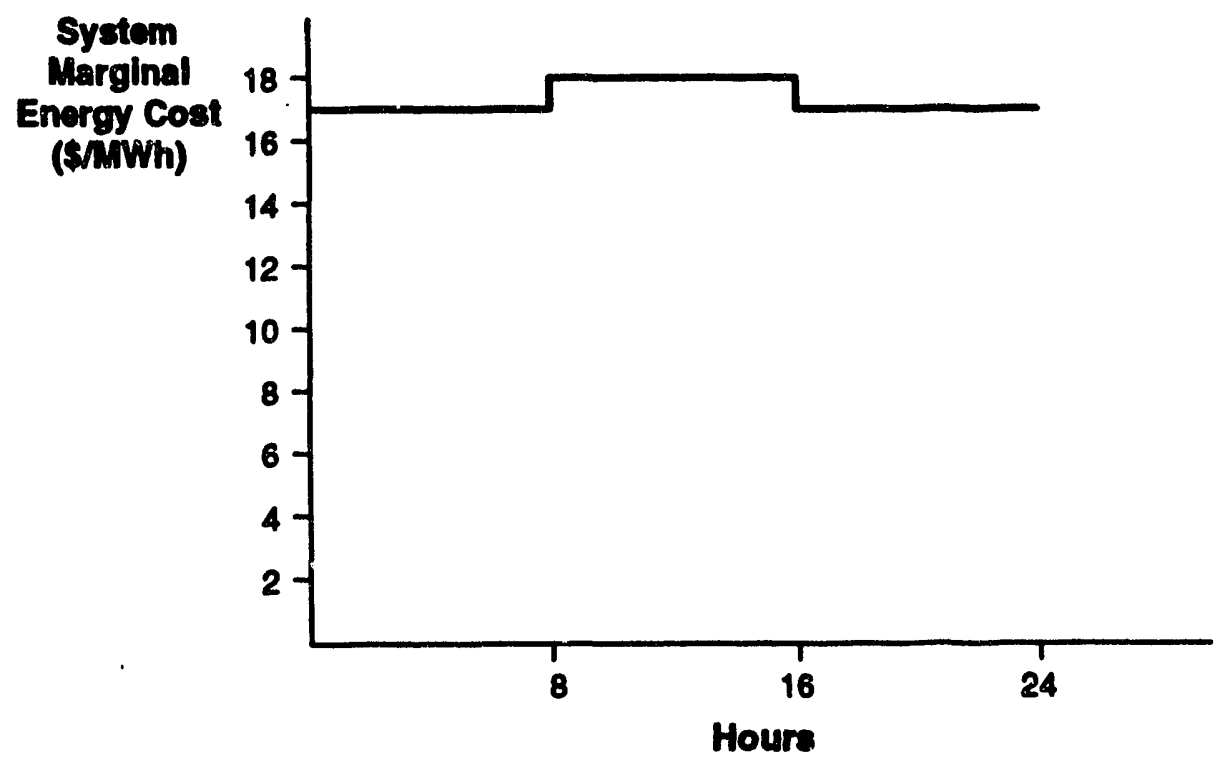

Figure 2-3. System Marginal Energy Costs

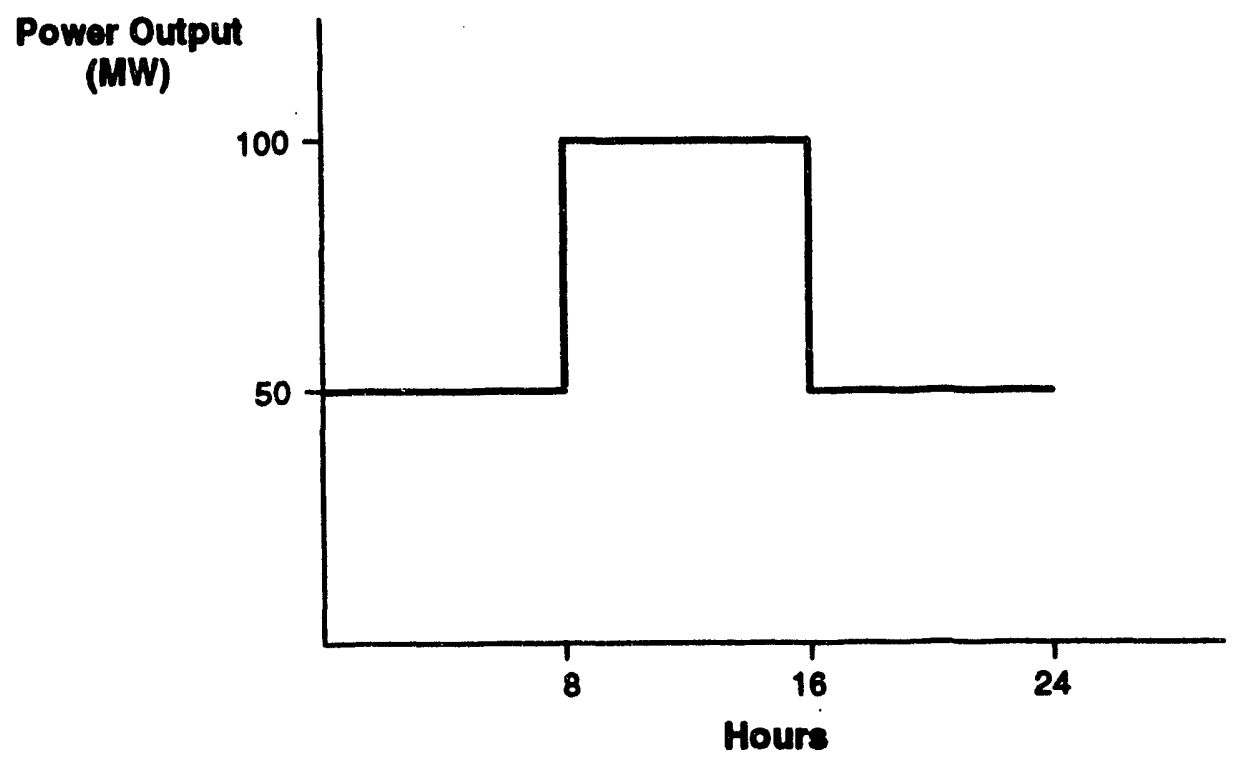

Figure 2-4. Power Output of Unit A 
Table 2-1

OPERATING CHARACTERISTICS OF GENERATION UNIT A

\begin{tabular}{ccc}
\hline Power Output (MW) & Averege (SMWWh) & Marginal (SMWW) \\
\hline 50 & 25.0 & \\
100 & 21.0 & 17.0 \\
150 & 20.0 & 18.0
\end{tabular}

Would a storage unit with a 77 percent cycle efficiency provide this system with any operating savings? Using the conventional approach (that does not include dynamic operating considerations), the benefit to cost ratio of storage operatings is calculated as follows:

$$
\begin{aligned}
B / C & =0.77 \times \frac{\text { Marginal Energy Cost During the Peak Period }}{\text { Marginal Energy Cost }} \overline{\text { During the Off-Peak Period }} \\
& =0.77 \frac{18.0}{17.0} \\
& =0.815<1.0
\end{aligned}
$$

Therefore, according to this calculation, storage operation is not economically feasible and would not provide any operating savings. To check the validity of this calculation, the benefit to cost ratio of operating the storage unit is explicitly calculated as:

$$
B / C=\frac{\text { Operating Savings of Energy Storage }}{\text { Operating Costs of Energy Storage }}
$$

The operating savings and costs of energy storage depend on the operations of the storage unit. One operating option is to charge during the off-peak period and discharge during the peak period to replace Unit $A$ (we assume that there is enough power available during the off-peak period to provide the energy required for charging the storage unit and to replace the off-peak energy output of Unit A). The benefit to cost ratio of this operating option is calculated as follows:

$$
\begin{aligned}
\text { Required Charging } & =\frac{100 \mathrm{MW} \times 8 \mathrm{hrs}}{0.77}=1,039 \mathrm{MWh} \\
\text { Charging Costs } & =1039 \mathrm{MWh} \times \$ 17 / \mathrm{MWh} \\
& =\$ 17,663
\end{aligned}
$$




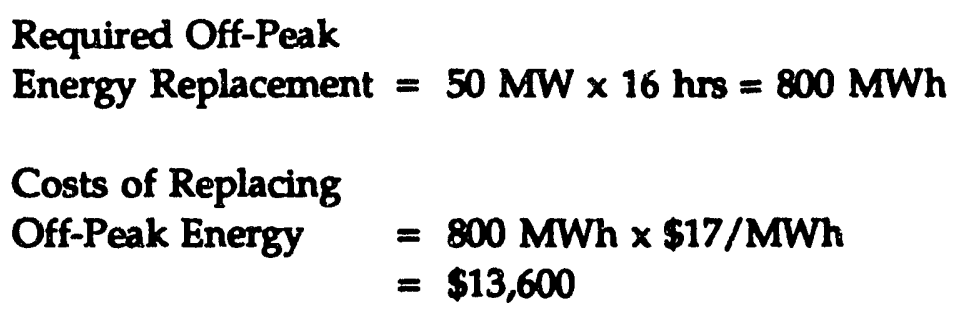

Total Costs of

Replacing Unit A $\quad=17,663+13,600=\$ 31,263$

Total Savings by

Replacing Unit A = Total Operating Costs of Unit A

$=100 \mathrm{MW} \times 8 \mathrm{hrs} \times \$ 21 / \mathrm{MWh}$

$+50 \mathrm{MW} \times 16 \mathrm{hrs} \times \$ 25 / \mathrm{MWh}$

$=\$ 36,800$

The benefit to cost ratio of operating the storage unit to replace Unit $A$ is therefore:

$$
\begin{aligned}
B / C & =\frac{36,800}{31,263} \\
& =1.177
\end{aligned}
$$

Therefore, storage operation is economically feasible and would provide the system with operating savings. The implied dynamic operating benefits term, $\mu$, which is missing from the conventional equation, can be calculated as:

$$
B / C=1.177=0.77 \frac{18.0+\mu}{17.0}
$$

or

$$
\begin{aligned}
\mu & =\frac{1.177 \times 17.0}{0.77}-18.0 \\
& =\$ 7.98 / M W h .
\end{aligned}
$$

\section{Splnning Reserve Application}

As an alternative to using the battery as a charge/discharge unit, a utility could use a battery purely to provide spinning reserve with the following potential benefits: shut down least efficient units and allow generating units to operate at a higher load, thus reducing their average heat rates. 
The following example illustrates the benefits from using a battery as spinning reserve. Consider a system consisting of three thermal units (Units 1, 2 and 3). System load is $200 \mathrm{MW}$, and spinning reserve of at least $40 \mathrm{MW}$ is required. Table 2-2a shows the system dispatch without a battery. Without a spinning reserve requirement, units 1 and 2, the most efficient units, would have been able to meet the system load of $200 \mathrm{MW}$. Because of the spinning reserve requirement, all three units are operated; units 1 and 2 operate at $90 \mathrm{MW}$ each and unit 3 , the least efficient, is operated at its minimum load of $20 \mathrm{MW}$.

Table 2-2

USING A BATTERY TO PROVIDE SPINNING RESERVE

(a) Unit Loadings and Operating Costs Without Battery

\begin{tabular}{|c|c|c|c|c|c|c|c|}
\hline & $\begin{array}{l}\text { Min. Loed } \\
\text { (MW) }\end{array}$ & $\begin{array}{l}\text { Max. Load } \\
\text { (MW) }\end{array}$ & $\begin{array}{l}\text { Ave. Cost at } \\
\text { Max. Load } \\
\text { (\$MWWh) }\end{array}$ & $\begin{array}{l}\text { Actual } \\
\text { Lond } \\
\text { (MiN) }\end{array}$ & $\begin{array}{l}\text { Ave. Cost at } \\
\text { Actual Load } \\
\text { (SMWWh) }\end{array}$ & $\begin{array}{l}\text { Splnning } \\
\text { Reserve } \\
\text { (WW) }\end{array}$ & $\begin{array}{l}\text { Total } \\
\text { Cost } \\
\text { (E/hr) }\end{array}$ \\
\hline Unit 1: & 20 & 100 & 24.5 & 90 & 25 & 10 & 2,250 \\
\hline Unit 2: & 20 & 100 & 24.5 & 90 & 25 & 10 & 2,250 \\
\hline Unit 3: & 20 & 40 & 30 & 20 & 40 & 20 & 800 \\
\hline Total & & & & & & 40 & 5,300 \\
\hline
\end{tabular}

(b) Unit Loadings and Operating Costs With Battery

\begin{tabular}{|c|c|c|c|c|c|c|c|}
\hline & $\begin{array}{l}\text { Min. Load } \\
\text { (MW) }\end{array}$ & $\begin{array}{l}\text { Max. Load } \\
\text { (NiW) }\end{array}$ & $\begin{array}{l}\text { Ave. Cost at } \\
\text { Max. Load } \\
\text { (\$MWWh) }\end{array}$ & $\begin{array}{l}\text { Actual } \\
\text { Load } \\
\text { (MW) }\end{array}$ & $\begin{array}{l}\text { Ave. Cost at } \\
\text { Actual Load } \\
\text { (\$NWWh) }\end{array}$ & $\begin{array}{l}\text { Spinning } \\
\text { Reserve } \\
\text { (MW) }\end{array}$ & $\begin{array}{l}\text { Total } \\
\text { Cost } \\
\text { (\$/hr) }\end{array}$ \\
\hline Unit 1: & 20 & 100 & 24.5 & 100 & 24.5 & 0 & 2,450 \\
\hline Unit 2: & 20 & 100 & 24.5 & 100 & 24.5 & 0 & 2,450 \\
\hline Unit 3: & 20 & 40 & 30 & 0 & 0 & 0 & 0 \\
\hline Battery: & 0 & 40 & 0 & 0 & $0^{\circ}$ & 40 & 0 \\
\hline Total: & & & & & & 40 & 4,900 \\
\hline
\end{tabular}

- The operating cost of a battery providing only spinning reserve is really the fuel cost of keeping the battery charged. However, this cost is negligible in this context.

Dynamic operating costs resulting from the spinning reserve requirement are of two types. First, there is the cost of operating Units 1 and 2 at other than their most efficient level. Second, there is the extra cost of operating Unit 3, which is the difference between the average generation cost at Unit 3 and what it would have cost to generate the same load at Units 1 and 2.

Adding a battery changes the system operation, as displayed in Table 2-2b. Units 1 and 2 can now operate at full capacity, and Unit 3 is shut down entirely; the battery provides the required spinning reserve. For the particular hour shown in the tables, the savings per MWh of spinning reserve is $(\$ 5300-\$ 4900) / 40 \mathrm{MWh}=\$ 10 / \mathrm{MWh}$. 
The spinning reserve benefits of using a battery in this manner can be summarized as follows: Unit 3, the least efficient unit, can be shut down and units 1 and 2 do not have to provide spinning reserve, and can operate at their most efficient loadings. The battery provides all required spinning reserves, and the system total operating costs are substantially lower.

\section{STUDY APPROACH}

The potential generation benefits from adding battery storage to the SDG\&E system were determined by examining actual system operating log records for eight representative days during 1990-1991, a weekday and a weekend day in each season. The study focused on the marginal units (defined below) on these eight days and determined how the operation of these units could be economically modified if sufficient battery storage were present on the system. Two potential applications of batteries were considered:

- Daily charge/discharge with three hours of storage

- Spinning reserve

Hourly system loads for the eight days are shown in Appendix B. For most of the days, the daily peak occurs between $5 \mathrm{pm}$ and $8 \mathrm{pm}$. The peak appears sharp enough that a battery of 200-300 MW and a three-hour storage capacity could shave 200-300 MW off the peak on these days. This is not the case on the summer weekday, when the peak occurs earlier in the day and is much broader.

The SDG\&E hourly marginal energy costs (system lambda) for the same eight days, shown in Appendix $B, 12$ generally change very little during a 24-hour period. Typically, however, system marginal energy costs are substantially lower during the off-peak hours than during on-peak hours. For SDG\&E, differences between days are larger than the differences within each day. The primary reason for the differences between days is variation in natural gas prices, from a low of $\$ 2.11$ per million Btu in summer to a high of $\$ 3.73$ per million Btu in winter.

Generating benefits of energy storage were calculated based on five gas-fired steam turbine units on the SDG\&E system for each of the eight days. These five units were selected as the marginal units whose operation would most likely be affected by the addition of batteries to the system. That is, they would be potential candidates for decommitment. Larger gas-fired and nuclear units were excluded because they were too large to be replaced by batteries. Smaller units, including combustion turbines, were excluded because they did not operate at all

1. The hourly marginal costs are for on-system units only. Including off-system purchases (typically available at costs lower than system costs, particularly during off-peak hours) could only increase the potential storage benefits calculated here (because the costs of charging the battery would be reduced).

2. System load shapes, hourly marginal costs, and information on individual units were all provided by SDG\&E. 
on the eight days considered. The key cost/performance characteristics of these five units are shown in Table 2-3.

Table 2-3

SDG\&E GENERATING UNIT CHARACTERISTICS

\begin{tabular}{lccccc}
\hline \multicolumn{1}{c}{ Unt } & Min. Losd (MW) & Max. Load (MW) & $\begin{array}{c}\text { Hot } \\
\text { Startup } \\
\text { Cost (\$) }\end{array}$ & $\begin{array}{c}\text { Moat Rato at } \\
\text { Min. Load } \\
\text { Btu/kWh }\end{array}$ & $\begin{array}{c}\text { Hoat Raic at } \\
\text { Max. Load } \\
\text { Btu/kWh }\end{array}$ \\
\hline Encina 2 & 20 & 104 & 2500 & 13,343 & 10,832 \\
Encina 3 & 20 & 110 & 2500 & 13,872 & 10,957 \\
South Bay 1 & 30 & 147 & 3500 & 12,142 & 9,904 \\
South Bay 2 & 30 & 150 & 3500 & 12,073 & 9,788 \\
South Bay 3 & 30 & 171 & 3500 & 14,308 & 10,361
\end{tabular}

\section{STUDY RESULTS}

\section{Load-Leveling Benefits}

For load-leveling, a battery with three hours storage capacity was assumed to be charged at night and discharged during the daily peak. Actual system lambdas were used to calculate potential savings or benefits. For a three-hour battery with an efficiency of 80 percent, loadleveling savings were negative for all 8 days. As shown in Figures B-5 to B-8, system lambda is relatively flat across the 24 hours in each day, because the same gas-fired steam turbines are the marginal units for all 24 hours, although at different loadings. As a result there are no load-leveling savings from the use of batteries on the SDG\&E system. Unless there were other reasons for operating the battery in this mode, it would simply not be operated, making loadleveling savings zero.

Many previous studies on energy storage have used only the load-leveling savings in quantifying the value of energy storage. Doing so here would lead to the conclusion that batteries are clearly uneconomic, and should not be considered further. As shown below and in the next sections, however, there can be significant savings from batteries even if load-leveling is uneconomic.

\section{Dynamic Operating Benefits}

The generation benefits resulting from adding batteries to the SDG\&E system are summarized in Tables 2-4 and 2-5. Table 2-4 shows, for each of the eight days considered, the dynamic operating savings that could be realized if enough battery capacity were added to completely decommit the unit labelled "displaced unit". 


\begin{tabular}{|c|c|c|c|c|c|c|c|c|}
\hline \multirow[b]{3}{*}{ Eencon } & \multirow[b]{3}{*}{ Month } & \multirow[b]{3}{*}{ Day } & \multirow[b]{3}{*}{$\begin{array}{l}\text { Day } \\
\text { Type }\end{array}$} & \multirow[b]{3}{*}{ Date } & \multicolumn{4}{|c|}{ Applleation } \\
\hline & & & & & \multicolumn{2}{|c|}{3 Hour Chandolechares } & \multicolumn{2}{|c|}{ Solonler Reacene } \\
\hline & & & & & $\begin{array}{l}\text { Not Oper. } \\
\text { saving } \\
(\text { SKW-YT) }\end{array}$ & $\begin{array}{l}\text { "Olepleeed } \\
\text { Unlir" }\end{array}$ & $\begin{array}{l}\text { Not Oper. } \\
\text { Saving } \\
\text { (BKW-y) }\end{array}$ & $\begin{array}{l}\text { "Displeoed } \\
\text { Unir" }\end{array}$ \\
\hline Fall & October & Sunday & $W$-End & $10 / 1400$ & 14.00 & South Bay 3 & 15.84 & South Bay 3 \\
\hline Fell & October & Friday & W-Day & $10 / 19100$ & 11.22 & Encina 3 & 14.16 & Encina 3 \\
\hline Winter & December & Tuesday & W-Day & $12 / 04190$ & 59.87 & Encina 2 & 63.92 & Encina 2 \\
\hline Wintar & December & Saturday & W-End & 1200900 & 30.50 & South Bey 3 & 44.97 & South Bay 3 \\
\hline Spring & April & Monday & W-Day & $0408 / 90$ & 25.24 & Encina 3 & 28.68 & Encina 3 \\
\hline Spring & April & Saturday & W-End & $04 / 13 / 80$ & 15.55 & Encina 2 & 20.59 & Encina 2 \\
\hline Summer & July & Sunday & $W$-End & $07 / 21 / 90$ & 7.85 & South Bay 3 & 11.87 & South Bay 3 \\
\hline Summer & July & Wednesday & W-Day & $07 / 24 / 90$ & 0.00 & - & 3.68 & South Bay 2 \\
\hline Eotimater & sual I & ating & & & 23.23 & & 28.80 & \\
\hline
\end{tabular}

Table 2-5

LOAD LEVELING SAVINGS, DYNAMIC OPERATING BENEFITS, NET OPERATING BENEFITS

\begin{tabular}{|c|c|c|c|c|c|c|c|}
\hline \multirow[b]{2}{*}{ Soacon } & \multirow[b]{2}{*}{ Month } & \multirow[b]{2}{*}{ Day } & \multirow[b]{2}{*}{$\begin{array}{l}\text { Day } \\
\text { Type }\end{array}$} & \multirow[b]{2}{*}{ Date } & \multicolumn{3}{|c|}{3 Hour Chargel Discharge } \\
\hline & & & & & $\begin{array}{l}\text { Losd- } \\
\text { Loveling } \\
\text { Benofits } \\
\text { (BNMWh) }\end{array}$ & $\begin{array}{c}\text { Net } \\
\text { Operating } \\
\text { Benefits } \\
\text { (S/MWh) }\end{array}$ & $\begin{array}{l}\text { Dynamle Operauno } \\
\text { Benofits (\$NWWh) }\end{array}$ \\
\hline Fall & October & Sunday & $W$-End & $10 / 14 / 90$ & -2.30 & 22.77 & 24.06 \\
\hline Fall & October & Friday & W-Day & $10 / 19 / 90$ & -2.36 & 18.11 & 21.54 \\
\hline Winter & Decomber & Tuesday & W-Day & $12 / 04 / 80$ & 3.56 & 73.85 & 76.25 \\
\hline Winter & December & Saturday & W-End & $12 / 08 / 90$ & -3.74 & 59.12 & 64.02 \\
\hline Spring & April & Monday & W-Day & $0403 / 81$ & 3.31 & 43.44 & 46.91 \\
\hline Spring & April & Saturday & $W$-End & $04 / 13 / 80$ & -3.78 & 31.88 & 40.85 \\
\hline Summer & July & Sunday & W-End & $07 / 21 / 91$ & -3.35 & 12.77 & 17.92 \\
\hline Summer & July & Wednesday & W-Day & $07 / 24 / 91$ & -2.78 & 0.00 & 0.00 \\
\hline
\end{tabular}

Two operating modes or applications are considered: a three-hour battery that is charged and discharged on a daily basis, and a battery with a smaller storage capacity that is used to provide only spinning reserve. On each day and for each operating mode a "displaced unit" is identified; this is the unit for which the greatest savings could be obtained by decommitting the unit. The columns labelled "net operating benefits" express the savings in terms of dollars per year per kilowatt of battery capacity, assuming that the battery is the same size as the displaced 
urit and that all 365 days of the year were identical to the one for which the calculation is being made. The "annual net operating benefits" values are weighted averages of the daily values, based on the number of weekdays and weekend days in each season during an entire year. ${ }^{3}$

As defined in Table 2-4 and 2-5, net operating benefits include all aynamic operating benefits (startup costs savings, load following cost savings, minimum load cost savings), less increased costs resulting from having to charge the battery for the daily charge/discharge operating mode. For the spinning reserve operating mode, the net operating savings are simply the reduction in total operating costs. Because the load-leveling savings are regative on each i.: itie eight days, net operating savings are less in charge/discharge mode than in spinning reserve mode on each day.

Mos f the dynamic operating cost savings on the SDG\&E system result from reductions in load following costs and minimum loading costs. Load following costs for the SDG\&E units considered in this study are on the order of thousands of dollars per day for each of the five marginal units. Minimum load costs are on the order of hundreds of dollars per day for each of the five units. Figures 2-5 and 2-6 show the actual MW loadings for two of the marginal units for the days on which the dynamic operating cost savings would be greatest from decommitting these units. Most of the time the units operate far from their most efficient loadings ( $96 \mathrm{MW}$ for Encina 2 and $136 \mathrm{MW}$ for South Bay 3!

Since this study is based on data from a selection of discrete days (a week-day and a weekena-day for four different weeks), the only startups accounted for are those taking place within a 24 hour period, i.e., only hot startup costs. However, three out of the four sample weeks show that at least one unit is shut down and replaced by arother sometime between the two days examined in that week. As a result, the startup costs may be under-estimated, because they miss these changes between days. There were very few startups on the eight days in generation, so startup cost savings are a very small part of the net operating savings shown in the tables.

The same results are expressed in a different format in Table 2-5, for the 3 hour charge/discharge mode. Instead of on a \$ per kilowatt per year basis, the results are expressed in $\$ /$ MWh displaced during the three hours that the battery is discharging. The important point here is that the magnitude of the dynamic operating benefits is much larger than the magnitude of the load-leveling savings. These $n$ umbers can be compared to system marginal energy costs, which are mostly in the range of $\$ 20.0 \$ 30$ per $\mathbf{M W h}$; as a result of decommitting a unit, savings higher-sometimes much higher-than system margina': energy costs are possible.

3. The definitions of the seasons were as follows:

$\begin{array}{ll}\text { Fall } & \text { October 16-November } 30 \\ \text { Winter } & \text { December 1-February } 28 \\ \text { Spring } & \text { March 1-June } 30 \\ \text { Summer } & \text { July 1-October } 15\end{array}$




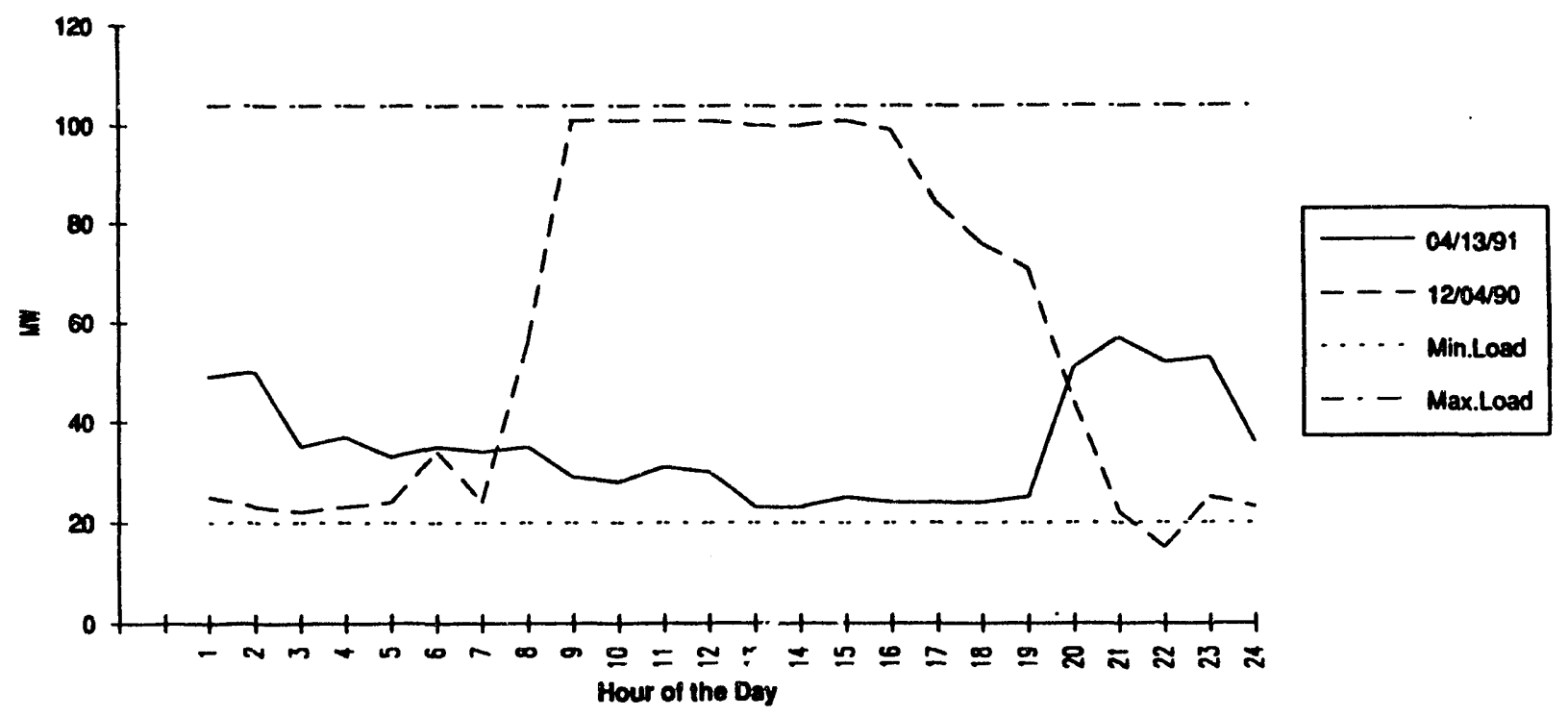

Figure 2-5. Dally Load for Encina 2 Steam Turbine Unit

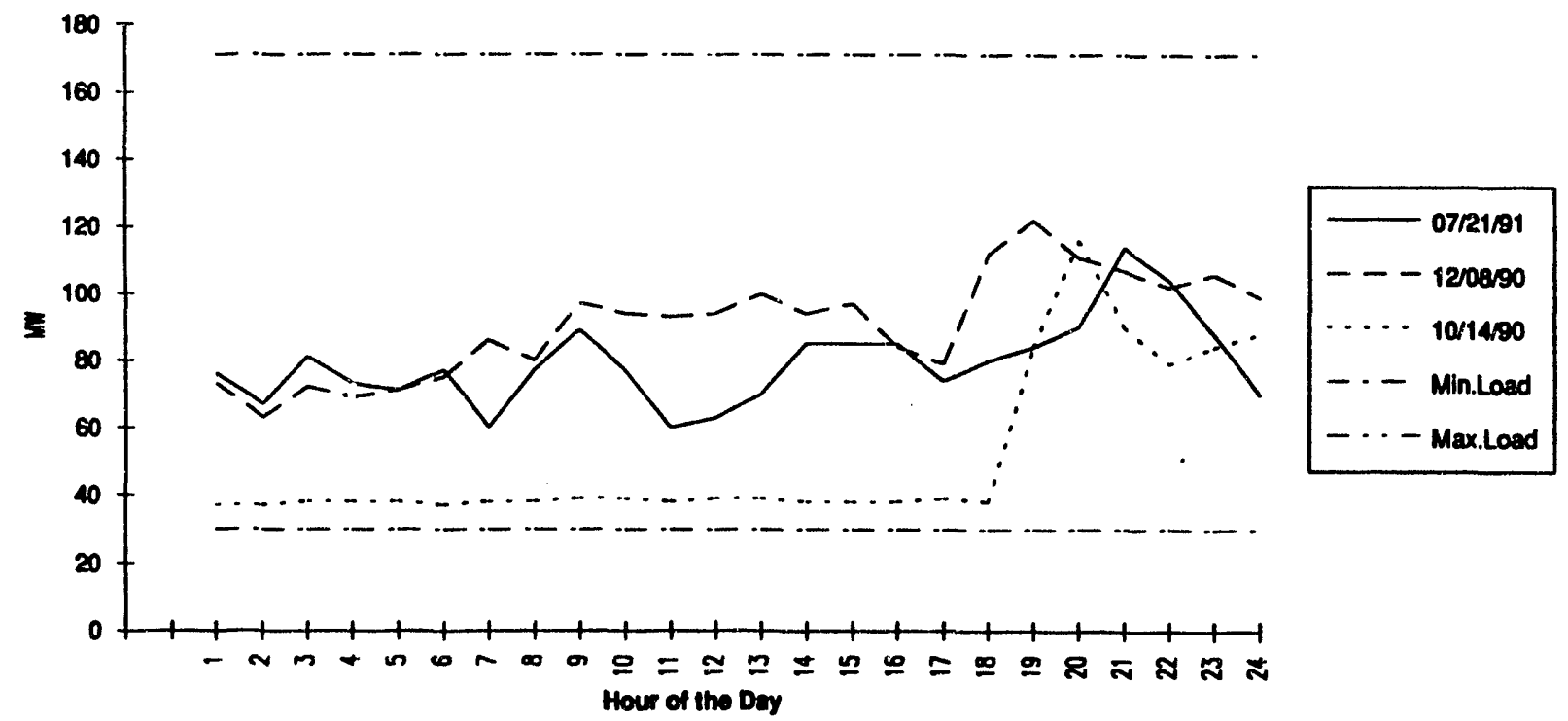

Figure 2-E. Dally Load for South Bay 3 Steam Turbine Unit

The same information is also presented in Figures 2-7 and 2-8. Figure 2-7 shows how net operating benefits savings vary by day, in dollars per kilowatt per year if all 365 days looked just like the day in question. Figure 2-8 presents the information in terms of dollar per MWh displaced by the battery during the three hours the battery opcrates. Savings are highest in winter, lowest in summer, and intermediate in spring and fall. 


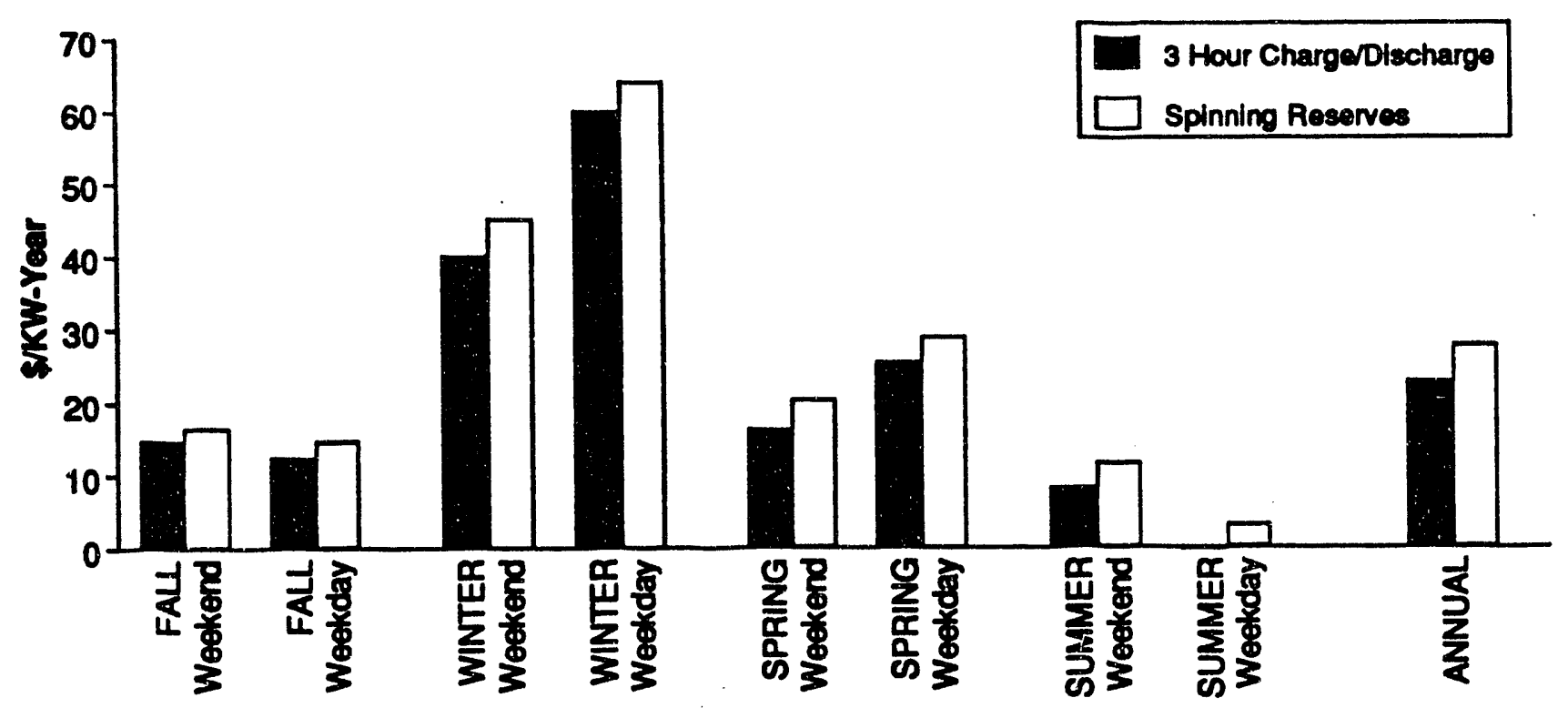

Figure 2-7. Net Operating Benefits

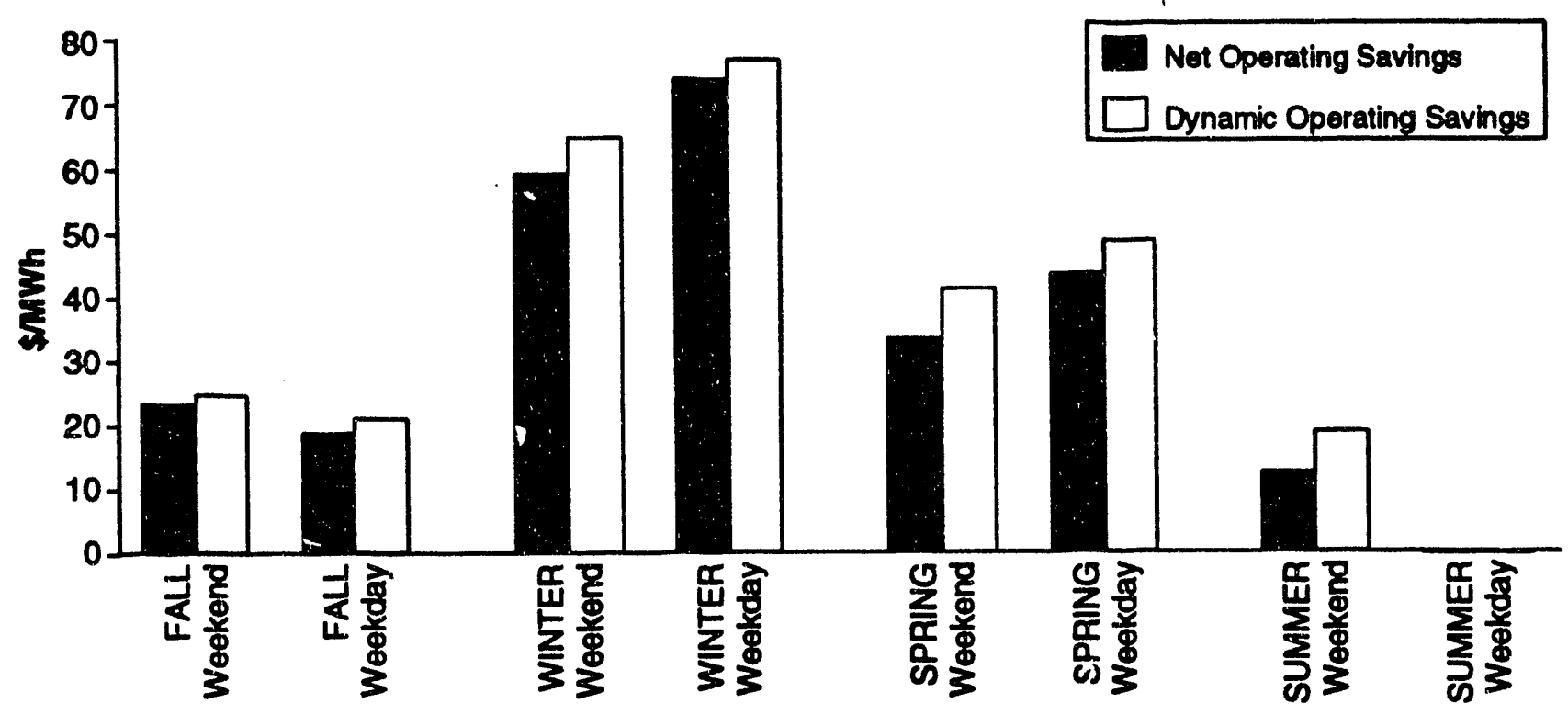

Flgure 2-8. Net Operating Benefits for 3 Hour Charge/Discha Battery

Why do the net operating benefits vary so much between days? There are two principal reasons. First, the biggest difference results from changes in fuel prices. Higher fuel prices mean higher system lambdas and higher avarage fuel costs. Since net operating benefits is roughly proportional to the difference between average fuel cost and system lambda, both of which are roughily proportionai to fuel price, higher fuei prices transiate directiy to higher net 
operating savings. The second reason is the difference between average fuel cost and system lambda. This difference depends on many factors, among them fuel prices and unit loadings. The greater the difference, the greater the net operating savings. The difference is particularly small on the two summer days, resulting in low net operating savings on the weekend day and no operating savings at all on the weekday.

Keep in mind that all of the calculations assumed that any replacement energy or capacity would come from on-system units. This potentially underestimates the savings from adding batteries and should be considered a conservative approach.

If a steam turbine unit is decommitted as the result of adding batteries, combustion turbines are likely to be used more frequently in outage situations, rather than increasing the loadings of committed steam turbines. This may slightly reduce the dynamic operating savings resulting from changing the unit commitment. For example, if the addition of $100 \mathrm{MW}$ of batteries causes a $100 \mathrm{MW}$ combustion turbine to operate 100 hours more per year and has an average heat rate of $3000 \mathrm{Btu} / \mathrm{kWh}$ higher than that of the decommitted steam turbine, the increased cost would be $\$ 0.75 / \mathrm{kW}$ of battery capacity per year. ${ }^{4}$

\section{Environmental Benefits}

Storage in general, and batteries in particular, have the potential to reduce the environmental emissions associated with generation. By allowing operation of fossil-fired units closer to their most efficient operating loadings, batteries can reduce system emissions. They can also allow the substitution of one fuel fc another or one generating location for another. In determining the environmental impacts of adding batteries, it is critical to determine the locations, fuel types, and marginal heat rates for the unit that would be used to charge the battery and the unit that would be replaced by the battery, for load-leveling operation. Fuel type is obviously important because different fossil fuels have different emision coefficients, while nuclear and hydro emit no $\mathrm{NO}_{x^{\prime}}, \mathrm{SO}_{x^{\prime}}$ or $\mathrm{CO}_{2}$. Location is important, especially for $\mathrm{NO}_{x^{\prime}}$ because $\mathrm{NO}_{x}$ emissions in a densely populated urban area such as San Diego may be much more harmful than an equal amount of emissions in a sparsely populated area such as northern Arizona.

Consider the potential benefits from a battery used only to provide spinning reserve, assuming that only on-system units are affected. The externality value of $\mathrm{NO}_{x}$ emissions is $\$ 1-12$ per pound, while the current emission rate for $\mathrm{NO}_{x}$ from SDG\&E gas-fired units is 1-1.5 pounds per MWh. ${ }^{5}$ Assuming that the addition of batteries improves generation efficiency by 10

4. $100 \mathrm{MWCT} \times 100$ hours/year $\times 3000 \mathrm{Btu} / \mathrm{kWh} \times \$ 2.50 /$ million Btu $100 \mathrm{MW}$ batteries

5. Values provided by Harry Bishop, SDG\&E. 
percent, at a capacity factor of 60 percent, the battery provides $\mathrm{NO}_{\mathrm{x}}$ reduction benefits of $\$ 1$ to $\$ 10$ per $\mathrm{kW}$ of battery capacity per year. ${ }^{6}$

This approximate calculation is based on current $\mathrm{NO}_{\mathrm{x}}$ emission rates. It is likely that regulations may require retrofitting control equipment that will sharply reduce these emission rates. Adding batteries to the system could make it unnecessary to add expensive controls such as selective catalytic reduction (SCR) to a generating unit whose utilization would be sharply reduced by the addition of batteries. Avoiding the costs of SCR for a unit could be worth substantially more than the $\$ 1-10 / \mathrm{kW}$-year calculated above. 
3

\section{POTENTIAL TRANSMISSION SYSTEM BENEFITS}

\section{NEW TRANSMISSION PROJ}

In general, the primary purpose of the bulk power transmission system is to reliably deliver power from local and remote generating units to the utility load centers; in this case, the city of San Diego. Future transmission systems must provide adequate capability to accommodate expected power purchases from remote generation sources as well as deliver power from local generation to SDG\&E customers. New transmission additions are a function of both the generation or resource expansion plan adopted by San Diego Gas and Electric (SDG\&E), and the areas of high load growth.

The preferred San Diego Gas and Electric plan of resource additions in its biennial resource plan update (BRPU) appears to consist primarily of adding or repowering generation locally. At this time, review of existing transmission expansion plans with the transmission planning department indicates that there are a limited number of anticipated or potentially needed transmission additions based on this local generation expansion plan. In fact, the resource expansion plan is so recent that transmission planning studies corresponding to the BRPU have not been completed. Hence, there were no specific major transmission facility additions to the SDG\&E system over the near term planning horizon that could be targeted for this study.

One potential SDG\&E $69 \mathrm{kV}$ transmission expansion project, to add a line in 1994 into a substation serving approximately a $35 \mathrm{MW}$ peak load, was identified. ${ }^{1}$ Two alternative $69 \mathrm{kV}$ transmission expansion plans have been identified to serve this need. The first alternative is to add $21 / 2$ miles of $69 \mathrm{kV}$ line at a cost of approximately $\$ 4$ million, with $11 / 2$ miles consisting of underground construction and 1 mile consisting of overhead construction. The second alternative is to install an underwater feed from a remote power source at a cost of $\$ 10$ million.

Although the transmission system expansion plans for SDG\&E over the near term horizon are incomplete at this time, SDG\&E planners indicated the potential need for new short $69 \mathrm{kV}$ and $230 \mathrm{kV}$ transmission lines with line lengths ranging up to about 15 miles. No new $500 \mathrm{kV}$ lines are anticipated. Hence for this study, potential line deferral benefit calculations for new 15 mile $69 \mathrm{kV}$ and $230 \mathrm{kV}$ (generic) transmission line additions are evaluated to estimate the potential transmission line deferral benefit to SDG\&E.

1. SDG\&E prefers to not release details regarding this substation or the customers it serves. 


\section{TRANSMISSION SYSTEM RELIABILITY CRITERIA}

The need for new transmission facilities will be generally determined by SDG\&E transmission planning on a case by case basis, based on the evaluation of a number of appropriate design contingencies. The objective of these transmission planning studies is to provide a reliable system considering appropriate outage criteria, risks and costs. The SDG\&E transmission system is normally designed to meet or exceed the following basic reliability criteria.

The basic transmission system reliability criteria for $69 \mathrm{kV}$ consists of designing for a single contingency outage at annual system peak. For transmission voltages above $69 \mathrm{kV}$, the basic SDG\&E transmission system single contingency reliability criteria is increased to include appropriate double contingency outage criteria, including outage considerations selected on a case by case basis, such as two lines or a transformer and line, etc. out of service at the same time. The basic transmission system voltage criteria is to maintain a 0.95 per unit minimum voltage level during normal operating conditions and a 0.9 per unit voltage level during an abnormal contingency event.

\section{POTENTIAL LINE AND TRANSFORMER DEFERRAL BENEFITS}

In future specific line and transformer deferral studies, determining potential battery benefits will require detailed transmission expansion studies. These studies will need to evaluate appropriate transmission equipment outages with and without batteries in specific transmission system locations. They will also need to recognize the significant differences between batteries and lines and transformers in terms of their contribution to reliability. The resulting transmission expansion plans with and without batteries will have to meet appropriate SDG\&E transmission and reliability standards, described above.

For this generic assessment, judiciously placed batteries are assumed to provide a local power source near loads that can act as backup to existing transmission facilities and thereby reduce the transmission redundancy required to meet SDG\&E transmission reliability criteria. The batteries are, effectively, spinning reserve, but are used to cover transmission outages. For this application, judiciously placed batteries may provide the desired transmission deferral benefit while at the same time providing additional non-site-specific generation system benefits.

SDG\&E standard transmission line voltages are $500 \mathrm{kV}, 230 \mathrm{kV}, 138 \mathrm{kV}$ and $69 \mathrm{kV}$. As stated previously, presently there are no plans for new $500 \mathrm{kV}$ transmission line additions. For this study, potential benefits of adding battery storage to defer new generic 15 mile $230 \mathrm{kV}$ lines and $69 \mathrm{kV}$ lines will be evaluated, along with the potential savings associated with deferring the proposed $199469 \mathrm{kV}$ expansion project described above.

SDG\&E transmission line cost assumptions for typical $69 \mathrm{kV}$ and $230 \mathrm{kV}$ line construction types are summarized in Table 3-1. These assumptions are derived from detailed transmission facility cost and other assumptions obtained from SDG\&E transmission planners and presented 
in Appendix A. Since new line right-of-way (ROW) is difficult to obtain and costly, battery storage benefits associated with both underground (UG) and overhead (OH) $69 \mathrm{kV}$ line designs are being evaluated in this study. In addition, it is likely that most new $230 \mathrm{kV}$ lines will consist of double circuit steel pole construction because of ROW limitations and costs.

Table 3-1

TYPICAL SDGRE TRANSMISSION LINE COST

\begin{tabular}{|c|c|}
\hline $\begin{array}{l}\text { Tranemiacion } \\
\text { Lin Construction Type }\end{array}$ & $\begin{array}{l}1900 \text { Dollar inetalled Cost } \\
\text { (\$1000/min) }\end{array}$ \\
\hline $\begin{array}{l}69 \mathrm{kV} \text {, Undergrouind, } 1750 \mathrm{AL} \\
\text { New Conduit } \\
\text { Existing Condult }\end{array}$ & $\begin{array}{r}1,419 \\
567\end{array}$ \\
\hline $\begin{array}{l}69 \text { kV, Wood Pole, 1-1033.5 ACSRJAW } \\
\text { Single Circuit } \\
\text { Double Circuit }\end{array}$ & $\begin{array}{l}178 \\
320\end{array}$ \\
\hline $\begin{array}{l}230 \text { kV, Double Circuit, Steel Pole, 2-1033.5 ACSRJAW } \\
\text { Single Circuit } \\
\text { Double Circuit }\end{array}$ & $\begin{array}{l}1,158 \\
1,389\end{array}$ \\
\hline
\end{tabular}

Typical ROW width and land cost data for single pole transmission line construction are presented in Table 3-2. These land cost assumptions are based on the current ROW purchase costs obtained from the SDG\&E land purchase department. The low land cost assumption of $\$ 0.50 / \mathrm{ft}^{2}$ applies to new lines installed in rural desert areas, while the high land cost assumption applies to higher land value areas, which are prevalent in the SDG\&E service territory. ROW cost will apply to portions of new lines installed outside of the SDG\&E City of San Diego franchise area.

Table 3-2

TYPICAL SDG\&E ROW WIDTH AND LAND COST

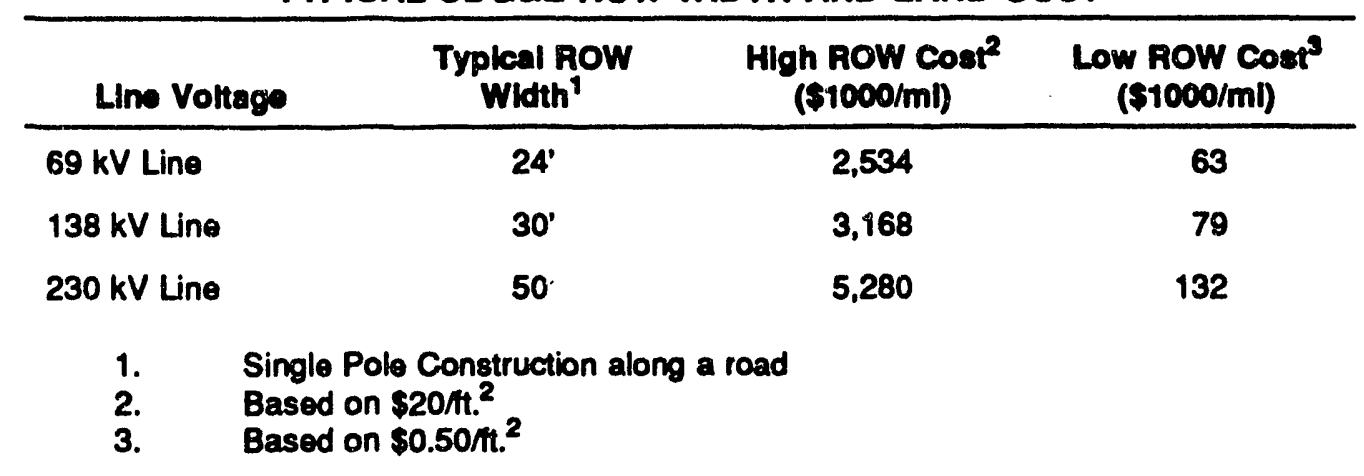


For this study, batteries installed on the SDG\&E system are expected to be installed at the $12 \mathrm{kV}$ distribution primary level or higher. Thus, potential tismission line deferrals are expected to apply to new transmission lines of $69 \mathrm{kV}$ and above. Potential bulk power transformer deferrals are expected to include both $230 / 138 \mathrm{kV}$ and $230 / 69 \mathrm{kV}$ transformer banks. Example transmission deferral benefits are considered for $230 \mathrm{kV}$ transmission lines, $230 / 69 \mathrm{kV}$ bulk power transformer banks, and $69 \mathrm{kV}$ lines in this section. Deferral of $69 / 12 \mathrm{kV}$ distribution substation transformer banks and $12 \mathrm{kV}$ feeders are considered in Section 3.

Potential line and transformer deferral benefits resulting from judicious placement of batteries on the SDG\&E system are summarized in Table 3-3 for typical economic assumptions used in current SDG\&E transmission planning studies. For the proposed $199469 \mathrm{kV}$ project potential annual line deferral benefits range from $\$ 654,000$ per year to $\$ 1,635,000$ per year depending on the selected transmission alternative being deferred. For other potential $15 \mathrm{mi} 69$ kV line additions, annual line deferral benefits range from $\$ 591,000$ per year to $\$ 8,361,000$ per year. For potential $15 \mathrm{mi}$. $230 \mathrm{kV}$ line additions, annual line deferral benefits range from $\$ 3,163,000$ per year to $\$ 16,356,000$ per year. And if a potential $224 \mathrm{MVA} 230 / 69 \mathrm{kV}$ transformer addition (in an existing substation without ROW) can be deferred, annual benefits range from $\$ 1,039,000$ per year to $\$ 1,116,000$ per year. Note that ROW costs dominate capital investment requirements for new SDG\&E transmission in much of the SDG\&E service area and are the cause of the wide line cost variations.

Table 3-3

POTENTIAL BENEFIT FROM DEFERRING NEW TRANSMISSION FACILITIES (1990 dollars)

\begin{tabular}{|c|c|c|}
\hline Line and Transformer Description & $\begin{array}{l}\text { Total Capltal } \\
\text { Investment }(\$ 1000)\end{array}$ & $\begin{array}{l}\text { Annual Benefit } \\
\text { (\$1000/yr) }\end{array}$ \\
\hline $\begin{array}{l}\text { Proposed } 199469 \text { kV Project, Alt. } 1 \text { - } 2.5 \text { mi Line Ext } \\
\text { Proposed } 199469 \text { kV Project, Att. } 2 \text { - Underwater Feed }\end{array}$ & $\begin{array}{r}4,000 \\
10,000\end{array}$ & $\begin{array}{r}654 \\
1,635\end{array}$ \\
\hline $\begin{array}{l}69 \mathrm{kV}, 15 \mathrm{mi} \text {. OH, Low ROW, Single Circuit } \\
69 \mathrm{kV}, 15 \mathrm{mi} \text {. OH, Low ROW, Double Circuit } \\
69 \mathrm{kV}, 10 \mathrm{mi} \text {. OH, } 5 \mathrm{mi} \text {. UG, High ROW, Single Circuit } \\
69 \mathrm{kV}, 10 \mathrm{mi} \text {. OH, } 5 \mathrm{mi} \text {. UG, High ROW, Double Circuit }\end{array}$ & $\begin{array}{r}3,615 \\
5,745 \\
46,885 \\
51,410\end{array}$ & $\begin{array}{r}591 \\
939 \\
7,666 \\
8,361\end{array}$ \\
\hline $\begin{array}{l}230 \mathrm{kV}, 15 \mathrm{mi} \text {. OH, Low ROW, Single Circuit } \\
230 \mathrm{kV}, 15 \mathrm{mi} \text {. OH, High ROW, Single Circuit } \\
230 \mathrm{kV}, 15 \mathrm{mi} \text {. OH, Low ROW, Double Circuit } \\
230 \mathrm{kV}, 15 \mathrm{mi} \text {. OH, High ROW, Double Circuit }\end{array}$ & $\begin{array}{r}19,350 \\
96,570 \\
22,815 \\
100,035\end{array}$ & $\begin{array}{r}3,163 \\
15,789 \\
3,730 \\
16,356\end{array}$ \\
\hline $\begin{array}{l}\text { 230/69 kV } 224 \text { MVA Transformer, } 3 \text { Breakers } \\
230 / 69 \text { kV } 224 \text { MVA Transformer, } 4 \text { Breakers }\end{array}$ & $\begin{array}{l}6,354 \\
6,826\end{array}$ & $\begin{array}{l}1,039 \\
1,116\end{array}$ \\
\hline
\end{tabular}

Potential'y large transmission savings are indicated by these numbers, especially when costly ROW is required. Significant benefits may accrue where batteries can be judiciously placed on the SDG\&E system to defer specific line and transformer additions under SDG\&E planning design conditions. However, quantifying line and transformer deferral benefits of batteries will require comparative planning studies with and without batteries. 
For example, assume SDG\&E has a $69 \mathrm{kV} / 12 \mathrm{kV}$ distribution substation with a current annual 68 MVA peak load, presently being served by two $69 \mathrm{kV}$ transmission lines, each containing single $336 \mathrm{MCM}$ ACSR conductors with a line rating of 68 MVA. SDG\&E's transmission reliability criteria indicates that with either $69 \mathrm{kV}$ line out of service the other 69 $\mathrm{kV}$ line must be capable of serving the annual peak load. Hence, any distribution substation load growth will require an additional $69 \mathrm{kV}$ line to reliably serve this distribution substation. Assuming the worst case, an expensive new 15 mile $69 \mathrm{kV}$ line $(10 \mathrm{mi}$. OH and $5 \mathrm{mi}$. UG in Table 3-3) may cost up to $\$ 51,140,000$. Assuming a discount rate of $11.6 \%$ and a fixed charge rate of $16.35 \%$, the resulting (PWRR) present worth of revenue requirements to perpetuity are about $\$ 72,081,000$.

Assume that SDG\&E plans to install a $20 \mathrm{MW}$ battery and judiciously locates the battery at this substation. This battery can provide an alternate source of power, and satisfy SDG\&E's single contingency reliability criteria until the annual peak substation load increases an additional $20 \mathrm{MW}$. At 3\% per year load growth, the new expensive 15 mile $69 \mathrm{kV}$ line addition can be deferred about nine years, saving over $\$ 8$ million per year in annual fixed charges for the nine years. Assuming 4\% inflation, the resulting PWRR associated with deferring the expensive new $15 \mathrm{mi}$. $69 \mathrm{kV}$ line is $\$ 38,207,000$ resulting in a line deferral PWRR savings benefit of $\$ 33,874,000$.

On a capital investment basis, this example transmission deferral benefit translates, after accounting for the PWRR and discounting calculations, into a battery storage credit of up to $\$ 1200 / \mathrm{kW}$ for the $20 \mathrm{MW}$ battery depending on cost of the new line addition being deferred. If the expensive new line were constructed with only one circuit strung the resulting battery storage benefit would still be about $\$ 1100 / \mathrm{kW}$ for the $20 \mathrm{MW}$ battery.

The specifications for a battery to defer this 15 mile $69 \mathrm{kV}$ line will depend heavily on the substation load shape. If the substation load shape is similar to the system-wide load shape, 6 or 8 hours of storage may be needed to cover the $20 \mathrm{MW}$ load growth. However, most substations do not exhibit the system-wide load shape. Figure C-2 in Appendix B shows one example of a substation load shape. Comparing it with Figure C-1 shows that individual substations can be different from the system-wide load shape. This example is the SDG\&E Cabrillo substation which serves a Navy base. This load is essentially an industrial load and exhibits the relatively flat day time load profile when load is high. In spite of it being an industrial type of load, a 2 to 3 hour peak does occur on the annual peak day. Residential loads tend to exhibit an evening peak, and, where air conditioning is a large share of the load, an afternoon peak. If the substation in question above has a several hour peak on the peak load day, a 2 to 3 hour battery would be sufficient to defer the 15 mile $69 \mathrm{kV}$ line for some years. Though load shape data is not available for a range of individual SDG\&E substations, it is anticipated that many will exhibit load shapes that would require less than four hours of battery energy storage to meet line deferral requirements.

A battery that is to "back-up" a transmission line must be recharged while the line is out if the failed line must remain out of service for several days. In the example above, each line is capable of $68 \mathrm{MVA}$, and the battery is suggested to cover only $20 \mathrm{MW}$ of load growth, or 
provide for a total substation load of 88 MVA. To do this the load must drop below 68 MVA at night for a time sufficient to allow the battery to be fully recharged as shown in the example in Figure 3-1. In this example there is ample time to recharge the battery. However, it is clear that the load profile could limit use of a battery if the substation load factor is high. The load profile is thus a key parameter in determining how long a line or transformer can be deferred.

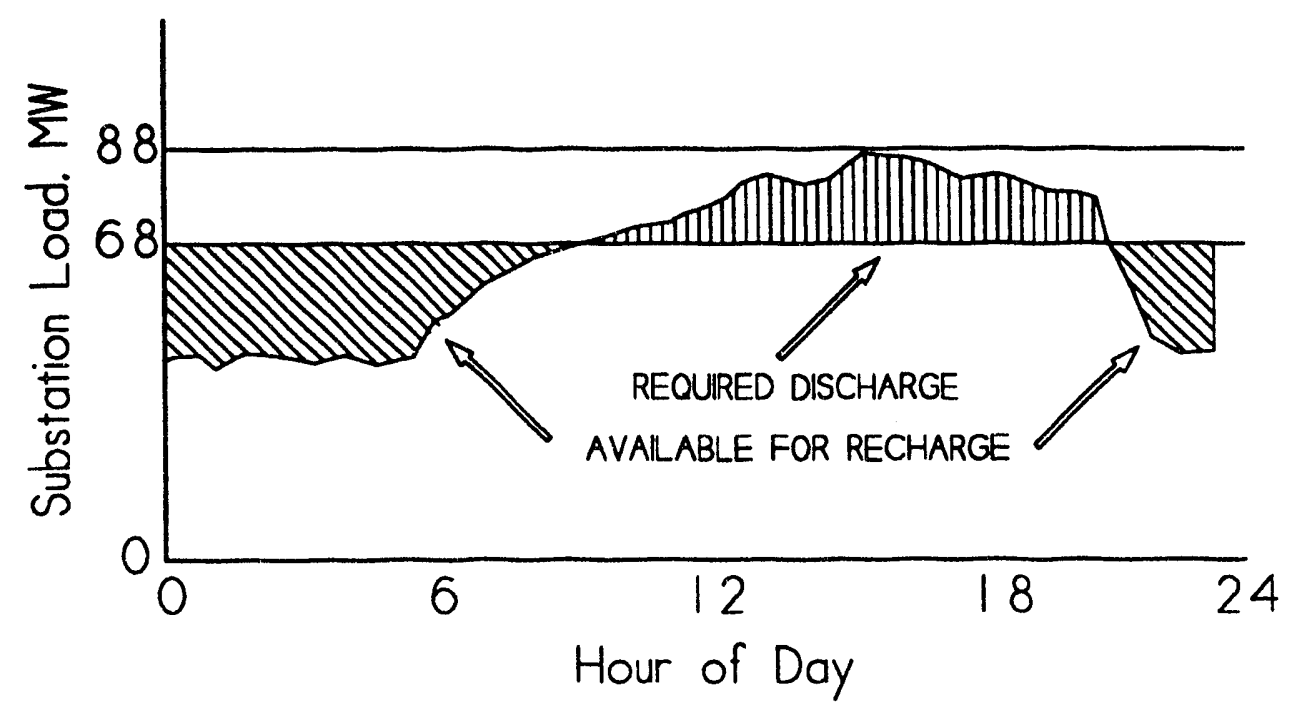

Flgure 3-1. Load Shape For Battery Recharge at Substation

\section{LOSS REDUCTION}

As part of a transmission system benefit assessment or other battery application benefit assessm.ent, relative transmission losses with and without battery storage should be considered. Batteries can reduce transmission losses by shifting load from the peak period to the off-peak period. This results from the square law that governs resistive losses. Reducing transmission system loading during daily peak load times by discharging batteries reduces peak load losses by more than they are increased at night when the batteries are recharged.

The potential loss reduction benefit is fully available only if batteries are not used to defer transmission. When transmission is deferred, it is possible for batteries to increase losses and cause a loss penalty. This can occur if the load shape is significantly flattened by batteries, so that av erage transmission loading is high. The !evels of battery penetration that are likely in the foreseeable future will usually reduce losses.

Evaluation results for the relative magnitude of system losses is expected to vary for specific battery storage applications on the SDG\&E system. Previous experience indicates that 
the magnitude of the potential loss benefit or penalty can vary widely, and must be evaluated on a case by case basis.

There are a number of important issues which should be considered before determining whether relative losses need to be considered, and if so, how detailed an evaluation will be required.

First, if the proposed application requires the battery to be cycled frequently, consideration of losses will be more important than in applications where the batteries are to be cycled only occasionally, or where only small amounts of energy are involved. Of course, if the loss benefits themselves are significant, they should be a factor in determining the frequency of cycling.

Second, the location of the generation used to charge the batteries and the location of the generation displaced when the batteries are discharged will each have a significant impact on the relative magnitude of the losses and resulting relative cost of losses.

Third, on a site-specific basis the daily load shape characteristics of the local transmission system in the vicinity of the battery and the daily battery charge discharge cycle may or may not be similar to the native daily SDG\&E load shape. Section 2 contains plots of SDG\&E daily native load shapes for typical weekdays and weekend days in the spring, summer, fall and winter seasons over the past year. Appendix B contains plots of daily loads at one of SDG\&E's distribution substations during summer and winter peak load days. Note that the daily load shapes differ significantly. When the two are different, the loss reduction near the battery may be higher than the loss reduction in the bulk systems. However, so long as the substation peak falls within the system native load peak, both portions of the system will experience lower losses when the battery is cycled.

In battery storage applications where transmission loss benefits are to be determined, the best available marginal generation costs and corresponding marginal loss factors should be determined. Appendix B contains plots of SDG\&E's daily native load shapes and corresponding hourly SDG\&E system marginal energy ccst. Although the daily load shapes fluctuate significantly, the hourly marginal generation costs are relatively constant on a daly on-peak/off-peak basis for the different seasons. Thus, on the SDG\&E system, relative cost of transmission losses may be quickly estimated using incremental on-peak/off-peak transmission loss calculations, without resorting to hourly production simulation.

For example, the $S D G i Q E$ on-system peak transmission losses are about $2 \%$ of system load. That is, losses are about $40 \mathrm{MW}$ when system load is at $2000 \mathrm{MW}$. Incremental losses are thus about $4 \%$. Hence reducing peak load by $10 \mathrm{MW}$ would reduce losses by $0.4 \mathrm{MW}$ or 400 $\mathrm{kW}$. The system load is about $1000 \mathrm{MW}$ at low load, and losses are about $0.5 \%$ (about $2 \%$ incremental). Charging the battery at night would thus cause losses of about $200 \mathrm{~kW}$. Taking into account battery efficiency, about 160 .Wh of energy is saved for each hour the battery is discharged during the load peak and charged at night. 
The above estimates consider only the reduction of losses on SDG\&E owned lines. Much of the power imported by SDG\&E is transported over long lines from Arizona and New Mexico. Though losses associated with this long-distance transmission are not recognized by SDG\&E, they nevertheless do occur and are included in the cost of energy purchased by SDG\&E. A full accounting of the loss reduction available from shifting transfers from peak periods to off-peak periods would have to include an analysis of all parties to the transaction. It would also have to take into account the way loss costs are distributed among the transmission system users. Because loss costs are shared among several users, their true impact is not recognized. That is, no party is acknowledged to be responsible for the incremental transfer and the incremental losses that can reach 20 to $30 \%$.

The peak load losses on the lines from Arizona to California are on the order of 20 to $25 \%$ incremental. A $10 \mathrm{MW}$ battery would thus save 2 to $2.5 \mathrm{MW}$ of losses if it were used to reduce flows from Arizona to California under high transfer conditions. However, the lines from Arizona to California remain fairly heavily loaded at night, so there is only modest savings by shifting energy transfer from peak periods to off-peak periods. Nevertheless, the loss reduction could be very significant if it could be determined and credited to the battery.

\section{VOLTAGE REGULATION}

Regulation is the drop in voltage that occurs when a load is thrown on the system. The larger the voltage change, the poorer the regulation. When system impedance is high (the system is weak), regulation will be poor. Adding lines and transformers can strengthen the system, but are a costly way to solve poor voltage regulation problems. Conventional voltage control devices such as generators, synchronous condensers, switched capacitor banks, static var systems (SVS), and load tap changers on transformers 'regulate' voltage and improve regulation. The voltage regulation response times for the various voltage control devices are:

$\begin{array}{ll}\text { LTC } & 1 \text { to } 2 \text { minutes } \\ \text { Capacitors } & 1 \text { to } 2 \text { minutes } \\ \text { Generators } & 1 \text { to } 2 \text { seconds } \\ \text { Condenser } & 1 \text { to } 2 \text { seconds } \\ \text { SVS } & 0.1 \text { to } 0.2 \text { seconds }\end{array}$

The SVS is clearly the most effective because it is so quick. An SVS consists of some combination of thyristor switched shunt capacitors and thyristor controlled shunt reactors. An SVS can respond to a drop in voltage before it becomes a problem for voltage-sensitive equipment or before a person can see the voltage drop in the light outpu، of fictures. Generators are often located too far from the load to be useful. Condensers are no longer competitive compared to SVS. LTCs and capacitors are slow, but are economical and very effective at combating slow changes in voltage, such as those resuling from normal load variations. 
Judiciously placed batteries can improve voltage regulation in two ways. One is by supplying power locally when heavy transmission loading or transmission outages are the cause of the low voltage. Increasing battery power to reduce line loading will improve voltage. Each MW of battery power is typically equivalent to 2 to 3 Mvar of reactive power in terms of its impact on voltage.

Batteries can also improve voltage regulation through reactive supply from their gate-turn-off (GTO) or similar power converters. The converters between the ac system and the battery dc bus can be designed to behave like an SVS while charging or discharging the battery. A modest increase in converter rating, over that required to supply full battery power, is necessary to supply reactive power during charging or discharging operation. For example, an 11 MVA converter on a $10 \mathrm{MW}$ battery can provide up to $4.6 \mathrm{Mvar}$ of capacitive or inductive reactive power while operating at $10 \mathrm{MW}$. The reactive power is also continuously variable and controllable with a voltage regulator. The extra $1 \mathrm{MVA}$ of converter capacity thus provides the same dynamic range as a 9.2 Mvar SVS. Because most SVSs provide primarily capacitive reactive power, a 4.6 Mvar capacitor is required to make the converter fully comparable to an SVS. However, even with the cost of the capacitor, and recognizing that GTO based converters are more costly (per MVA) than thyristor based SVS, the battery converter is a very economical alternative to SVS capacity.

To maintain proper voltage level SDG\&E is presently planning to add either 600 Mvar of capacitors at the transmission voltage level of $69 \mathrm{kV}$ and above, or 400 Mvar of capacitors at the $12 \mathrm{kV}$ distribution level by the year 2000 . Transmission planning indicates that probably SDG\&E will add the capacitors at the $12 \mathrm{kV}$ level as this alternative is more economical. SDG\&E is considering the addition of SVS as well as conventional fixed and switched capacitors, although there is no specific quantity of SVS planned.

SDG\&E has estimated that installed cost for new conventional capacitor banks installed at the transmission voltage level will be $\$ 30 /$ kvar. $^{2}$ SVS is estimated to cost three times as much or about $\$ 90 / \mathrm{kvar}$. Both numbers are reasonable, though some utilities are finding actual ccsts of conventional capacitor banks to be up to $50 \%$ higher where land costs are high. The $\$ 90 /$ kvar number for SVS is for relatively large SVS (above 100 MVAR). Costs can be much higher where space or system requirements dictate SVS sizes under 100 MVAR.

A $10 \mathrm{MW}$ battery is likely to have a converter cost of about $\$ 150 / \mathrm{kVA}$. Assuming that the incremental cost of converter capacity is $2 / 3$ of this overall $\$ / \mathrm{kVA}$ cost, an incremental $\mathrm{kVA}$ would cost about $\$ 100$. As described above, adding an additional MVA of converter capacity will provide $4.6 \mathrm{Mvar}$ of capacitive reactive power (more at reduced MW output) at a cost of about $\$ 100,000$. The cost of 4,600 kvar from a $10 \mathrm{MW}$ battery converter is thus about $\$ 22$ per kvar. The battery converter thus appears economically competitive ( $\$ 8$ kvar savings) with switched shunt capacitors installed at the transmission level on the SDG\&E sy_tem.

2. Though this is a typical cost figure, some utilities are finding transmission capacitor banks to be up to $50 \%$ higher than this because of land costs.

23727: 
Hence a $10 \mathrm{MW}$ battery could eliminate 4.6 Mvar of capacitors at a PWRR savings of $\$ 51,869$ if conventional shunt capacitors were displaced. The dynamic capability and equal inductive range would be a bonus, and may have a large value if batteries are compared against SVS, which may cost $\$ 90 /$ kvar or more.

A 10 MW battery needs 4.6 Mvar of switched shunt capacitors to be equivalent to 9.2 Mvar of SVS capacity. At $\$ 30 / \mathrm{kvar}$ for $4.6 \mathrm{Mvar}$ of capacitors, and $\$ 22 / \mathrm{kvar}$ for the other 4.6 Mvar, 9.2 Mvar of dynamic range is available for $\$ 25 / \mathrm{kvar}$, less than $1 / 3$ the cost of conventional SVS capacity (from a large SVS). If SVS were displaced a PWRR savings of $\$ 880,000$ would occur from each $10 \mathrm{MW}$ battery. On a capital investment basis, these example PWRR benefits translate into battery storage credits of $\$ 4 / \mathrm{kW}$ and $\$ 62 / \mathrm{kW}$ for shunt capacitors and SVS displacement respectively.

Figure 3-2 presents additional irformation on the economics of reactive power and voltage control. This example in the figure is for a $10 \mathrm{MW}$ battery and a converter in the range 10 MVA to 15 MVA. The figure shows the reactive power that is available when the battery is not charging or discharging, and the reactive power that is available when the battery is operating at its full power rating. Only the capacitive (or inductive) portion is shown. Total kvar range from capacitive to inductive would be twice the numbers shown. The dollar per kvar curve is based on an assumed incremental battery converter cost of $\$ 125$ per kva and just the capacitive kvar supplied by the $c$ inverter. The dollar per kvar amount in terms of SVS capacity would be half that shown (because total kvar would be doubled).

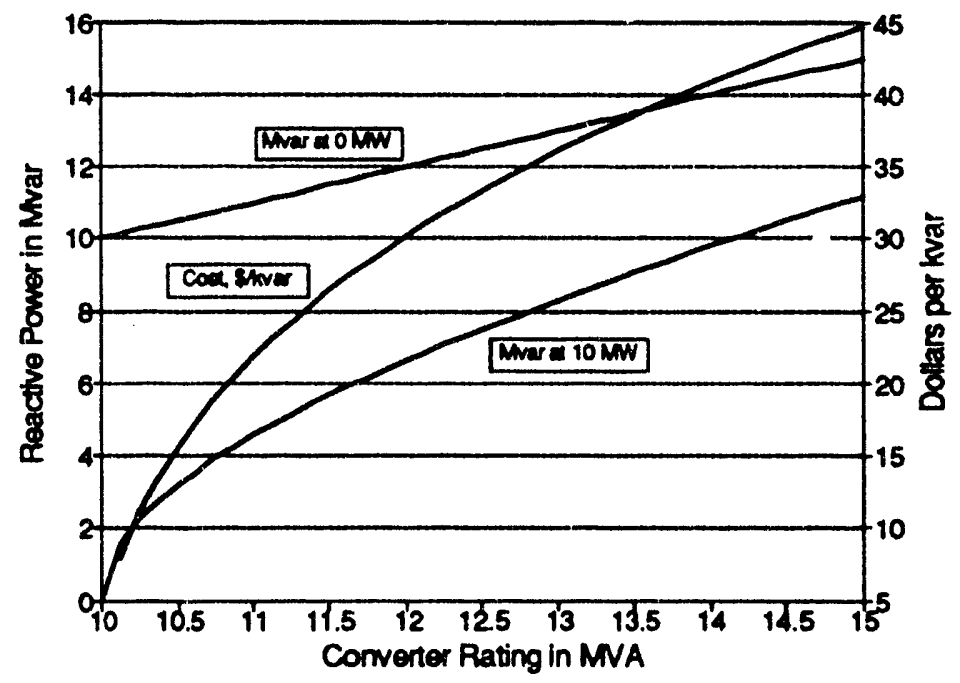

Figure 3-2. Reactive Power Can Be Economically Provided By Increasing the Size of the Battery System Power Converter

The reactive power from a GTO based power converter could be controlled in several ways. One would be to have operators at the system or distribution control center set kvar output. The controller on the battery system would hold the scheduled kvar level regardless of 
system voltage. Operators could use the battery kvar as needed for local power factor correction or to improve voltage in the upstream subtransmission system. Another would be to provide the converter with a voltage regulator. Kilovars would be produced as needed, up to the converter capability, to hold the desired voltage. The voltage regulator could control substation primary or secondary voltage. It might be connected to control primary voltage to help ensure good voltage levels and voltage stability in the subtransmission system. It could do this even though it is connected to the substation secondary bus. In this mode of operation the substation LTC would continue to regulate secondary voltage. If set to control secondary voltage, the converter control would be coordinated with the substation LTC transformer control so that the LTC would move only when the converter reactive power is insufficient to hold substation secondary voltage.

\section{OTHER POTENTIAL BATTERY STORAGE T\&D BENEFITS}

\section{Voltage Stablilty or Voltage Collapse}

Discussion with SDG\&E engineers indicates that voltage instability or voltage collapse problems are not presently being experienced and are not anticipated in the future on the SDG\&E system. There are three reasons for this. First there is a significant amount of local generation in and near the SDG\&E service territory. The second reason is SDG\&E's practice of controlling distribution voltages with capacitors to provide power factor correction to near unity power factor at distribution substations. Third, SDG\&E mairitains a transmission system minimum voltage criteria of 0.9 or higher.

At this time the ability of batteries to provide rapid dynamic voltage control like an SVS does not appear to be needed by SDG\&E. However, SDG\&E planners are studying potential future applications of SVS on the SDG\&E system, possibly in the late 1990s, as the system load grows. Batteries are a potentially cost effective alternative to SVS in solving future voltage control problems requiring SVS, because batteries can improve voltage stability in two ways. They can supply real power near loads thus reducing the loading on a stressed or weakened system. They can also provide reactive power and regulate voltage at about $\$ 22 / \mathrm{kvar}$ versus $\$ 90 / \mathrm{kvar}$ as discussed in the previous two sections.

\section{Damping and First Swing Stabllity}

Damping and first swing stability problems were not identified as potential SDG\&E transmission system expansion problems during discussions with SDG\&E engineers. Hence, no battery storage stability benefits were identified as part of this study. However, damping and first swing stability problems are a concern in determining power transfer limits into the Southern California region. Previous experience indicates that batteries can provide a significant amount of damping and improve first swing stability limits if batteries are located near the "receiving end" of a transmission system; and provision is made to modulate battery storage MW output in the millisecond time frame. If SDG\&E installs batteries on their system, the 
batteries will be located at the receiving end of this regional transmission system for power imports from Arizona and the Northwest. Hence, in the future, additional damping and first swing stability economic benefits may be identified for future SDG\&E batteries, based on increased regional power transfer capability.

\section{OTHER CONSIDERATIONS AND ISSUES}

Previous sections of this report show there are significant potential economic benefits associated with the installation of batteries to defer new facilities on heavily loaded SDG\&E T\&D systems. However, obtaining these potential battery storage benefits may require changes in present SDG\&E T\&D planning practices which do not include battery storage characteristics.

\section{Rellability}

The first issue is reliability. Present SDG\&E transmission planing criteria is deterministic, and has been developed over the years to address the outage frequency and duration characteristics of transmission equipment. SDG\&E distribution planning criteria includes consideration of customer outage frequency and duration.

Future batteries and power conversion systems should provide the reliability level that HVDC lines, SVSs, and adjustable speed drives do today. Hence battery storage component failures should cause just a few battery outage events per year, and outage duration should be just a few days or less per year. In this regard batteries will rival transmission lines and distribution lines, but may not compete with transformers.

However, beyond providing reliability similar to transmission and distribution lines, batteries may have an additional reliability advantage. A battery is a 'local source' and thus is not dependent on upstream components as is, for instance, the substation transformer. The battery is, in effect, an independent source of power and thus may make a more significant contribution to reliability than its outage rate and duration statistics would seem to indicate. It is an independent source because it is not part of a series string of devices, any one of which can cause an outage or reduce capacity.

However, unlike transformers and transmission and distribution lines, batteries are not necessarily "available" just because they are on-line. Batteries thus may need to be in a charged state, and have a specific energy storage capability to be considered reliable backup to various T\&D facilities. On the other hand, a battery that is normally discharged to $20 \%$ of capacity but can be discharged to 90 or $100 \%$ in an emergency may provide reliability by supplying energy for the time needed for switching actions to restore or re-structure lines and transformers to carry the full substation load.

A probabilistic reliability assessment may be needed to fully recognize a battery's contribution to reliability. Utilities still depend heavily on deterministic criteria, and thus may 
have difficulty measuring the reliability of a substation load served in part from a battery. The contribution a battery can make in meeting utility distribution reliability criteria has not, to our knowledge, been analyzed.

\section{Short-Term Transformer Loadings}

The second issue is short-term transformer loadings. Existing SDG\&E allowable shortterm transformer loadings are significantly above normal MVA ratings. These short-term ratings are based on appropriate assumptions about the thermal impact of the typical transformer loading cycle. The thermal time constant of the massive transformer allows significant overloading without significant loss of life if the period of heavy loading is balanced by a previous period of light loading. The typical substation load cycle provides the alternating light and heavy loading that makes transformer overloading practical.

The charging of batteries during off-peak periods will increase off-peak transformer loading, but discharging them will reduce the on-peak loading. Because on-peak transformer losses are higher than off-peak losses, the flatter loading curve will reduce transformer losses overall, and thus reduce transformer heating. This will increase the average power a transformer can handle. Hence at the same time a battery can defer transformer capacity and increase the load that can be placed on existing transformers. This benefit has not been quantified and would require analysis that has not been done.

\section{Land Use}

The third issue is land use. Sections 2 and 3 presented land use requirements and costs for T\&D facilities. Judicious placement of batteries in the SDG\&E T\&DD system to defer new T\&D facilities also requires space. This space will be required in high land cost areas, especially for batteries placed within the urban San Diego area. Discussions with SDG\&E engineers indicate that there may be problems obtaining space in some locations, and discussions with SDG\&E land purchase personnel indicate that the land cost will be high. These factors must be considered as part of the application of batteries in the SDG\&E T\&D system.

Review of recent modular battery storage designs indicate that a $500 \mathrm{kWh}$ battery storage system with dimensions of $26^{\prime}$ long by $9^{\prime}$ wide by $12^{\prime}$ high may soon be commercially available. Preliminary layout of these modules assuming $5^{\prime}$ spacing indicates combination of several modules require about $1250 \mathrm{ft}^{2}$ per $\mathrm{MWh}$. At $\$ 20 / \mathrm{ft}^{2}$ land cost this results in a battery storage land use cost of about $\$ 25,000$ per MWh of battery storage installed. 


\section{4}

\section{POTENTIAL DISTRIBUTION SYSTEM BENEFITS}

\section{NEW DISTRIBUTION PROJECTS}

In general, the purpose of the distribution system is to reliably distribute power within load centers. Since the SDG\&E distribution system, like that of other utilities, consists of many distribution circuits delivering small amounts of power, new distribution projects are planned, designed, and installed regularly by SDG\&E. SDG\&E plans and designs these circuits in accordance with its distribution design standards. ${ }^{1}$ These SDG\&E standard designs are used for developing appropriate new distribution project characteristics considered in this study.

Some or all of $20 \mathrm{MW}$ of batteries in the transmission example presented in Section 2 could provide transmission benefits while located at the $12 \mathrm{kV}$ bus of the $69 / 12 \mathrm{kV}$ distribution substation. Or, since batteries are modular, some of the batteries could be distributed out in the $12 \mathrm{kV}$ distribution system in several smaller battery installations, probably in the range $1 \mathrm{MW}$ to $5 \mathrm{MW}$. Siting batteries in the distribution system can affect distribution system reliability and power flow, resulting in potential distribution system benefits.

In this study, potential benefits of 1 to $5 \mathrm{MW}$ battery applications are considered. Therefore, potential distribution system benefits associated with the judicious siting of batteries are confined to $69 / 12 \mathrm{kV}$ (or $138 / 12 \mathrm{kV}$ ) distribution substations and $12 . \mathrm{kV}$ primary distribution feeders.

A standard SDG\&E 100 MVA $69 / 12$ kV distribution substation design consists of 4-28 MVA transformers. Generic new distribution substation projects are considered, including deferring the addition of a 28 MVA transformer to an existing substation and deferring the construction of a new substation containing a single 28 MVA transformer.

Standard SDG\&E $12 \mathrm{kV}$ distribution feeder capacity is 9 to $10 \mathrm{MVA}$ and typical feeder lengths are 5 to 10 miles. This study considers deferring the addition of a 5 mile 9 to 10 MVA distribution feeder.

1. Electric Distribution Design Manual, San Diego Gas and Electric, effective 1/1/91 to 12/31/91. 


\section{DISTRIBUTION SYSTEM RELIABILITY CRITERIA}

Distribution system reliability criteria are defined in detail in the SDG\&E Distribution Design Manual. In particular, regarding overload capacity, 28 MVA transformers are allowed to be routinely loaded to $30 \mathrm{MVA}$ during summer peak loading conditions. After a transformer failure during summer conditions, substation loading must be reduced to $38 \mathrm{MVA}$ in 15 minutes and to 32 MVA in 4 hours for a two transformer substation; to 76 MVA in 15 minutes and to 70 MVA in 4 hours for a three transformer substation; to $110 \mathrm{MVA}$ in 15 minutes and to $104 \mathrm{MVA}$ in 4 hours for a four transformer substation. Allowable transfonner loadings are increased during winter conditions.

At SDG\&E, distribution feeders are generally radial with normally open ties to other distribution circuits to provide backup. Feeders can be broken into sections by opening line switches and other tie switches closed to shift load to other feeders or reach customers beyond faulted feeder sections. The number of feeders and requirements for new feeders are determined on a case by case basis from customer outage frequency and duration calculations, voltage spread limits, and substation and feeder MVA capacity.

Allowable voltage spread is 114 to $120 \mathrm{v}$ at the customer service points throughnut the distribution system. This requires consideration of both distribution primary and secondary system voltage drops during both peak and light loading conditions. Other SDG\&E voltage policy includes the addition of shunt capacitors in the distribution system to maintain a power factor of 0.995 at the distribution substation.

\section{POTENTIAL DISTRIBUTION SUBSTATION TRANSFORMER DEFERRAL BENEFITS}

Typical SDG\&E distribution substation transformer installed cost assumptions are presented in Table 4-1. Adding a new 28 MVA transformer may cost anywhere from $\$ 700,000$ to $\$ 8$ million dollars depending on the site-specific circumstances. As with transmission expansion described in Section 2, a large component of this cost is land. The standard area requirement for a 100 MVA distribution substation is $450^{\prime} \times 550^{\prime}$ ( 5.6 acres). Assuming a high land cost of $\$ 20 / \mathrm{ft}^{2}$, this translates into $\$ 4,950,000$. At $\$ 25 / \mathrm{ft}^{2}$ land costs for a 100 MVA distribution substation can exceed $\$ 6,000,000$.

Table 4-1

TYPICAL RANGE SDG\&E DISTRIBUTION SUBSTATION TRANSFORMER COST

\begin{tabular}{lc}
\hline Transformer Addition & 1990 Dollar Installed Cost (\$1000) \\
\hline Add 28 MVA Transformer to Existing Substation & $700-2,000$ \\
Add 28 MVA Transformer at New Substation & $2,000-8,000$
\end{tabular}

To put these costs in perspective, consider the potential distribution substation transformer deferral benefit at an existing two-transformer substation loaded to $60 \mathrm{MW}$ and 
approaching its capacity limit. Assuming a load growth of 3\%, a third 28 MVA transformer addition costing about $\$ 2$ million may be able to be deferred about 3 years by adding a battery which can reliably supply about $5 \mathrm{MW}$ at the $12 \mathrm{kV}$ bus during the annual peak load. Assuming a $\mathbf{1 6 . 3 5 \%}$ fixed charge rate, the potential battery storage benefit to defer the third transformer totals $\$ 981,000$ or $\$ 327,000$ per year for three years. Assuming a discount rate of $11.6 \%$ and $4 \%$ inflation, the resulting transiormer deferral PWRR savings benefit associated with deferring the third transformer three years is $\$ 538,000$.

In a substation with a lower growth rate, for instance, $1.5 \%$, the same $5 \mathrm{MW}$ battery would defer the transformer 6 years. In this case the potential battery storage benefit totals $\$ 1,962,000$ or $\$ 327,000$ per year for six years. The resulting transformer deferral PWRR savings benefit associated with deferring the third transformer six years is $\$ 973,000$.

On a capital investment basis, this example transformer deferral benefit translates into a battery storage credit of $\$ 76 / \mathrm{kW}$ benefit for the $5 \mathrm{MW}$ battery if the transformer is deferred 3 years, and $\$ 138 / \mathrm{kW}$ if it is deferred six years.

Consider a larger four-trensformer distribution substation approaching capacity at 120 MW and a 3\% load growth assumption. Adding a battery which can reliably supply $10 \mathrm{MW}$ at the $12 \mathrm{kV}$ bus during annual peak load may allow deferral of a $28 \mathrm{MVA}$ transformer and a new distribution substation site for a period of 3 years. If the new transformer addition costs $\$ 8$ million and the fixed sharge rate is $16.35 \%$, the potential battery storage benefit for deferring this new transformer addition totals $\$ 3,924,000$ or $\$ 1,308,000$ per year for three years. Again assuming a discount rate of $11.6 \%$ and $4 \%$ inflation, the resulting transformer deferral PWRR savings benefit associated with deferring the new transformer three years is $\$ 1,408,000$.

On a capital investment basis, this example transformer deferral benefit translates into a battery storage credit of $\$ 100 / \mathrm{kW}$ for the $10 \mathrm{MW}$ battery.

Deferring the new substation six years for a $1.5 \%$ growth rate case would give the $10 \mathrm{MW}$ battery a PWRR savings benefit of $\$ 3,891,000$ and a battery energy storage credit of $\$ 276 / \mathrm{kW}$.

\section{POTENTIAL 12 KV FEEDER DEFERRAL BENEFITS}

Typical SDG\&E $12 \mathrm{kV}$ feeder cost assumptions are presented in Table 4-2. Typical $12 \mathrm{kV}$ feeder costs vary from about $\$ 250,000$ per mile to $\$ 800,000$ per mile.

For this study, potential benefits associated with deferring a generic 5 mile underground feeder addition (with conduit) will be evaluated. This new $12 \mathrm{kV}$ feeder will be assumed to be installed within the city of San Diego franchise area where no ROW purchase is required. 
TYPICAL SDG\&E $12 \mathrm{kV}$ FEEDER COSTS

\begin{tabular}{lc}
\hline 12 kV Foeder Construction Type & 1990 Dollar Installod Cos** (\$1000/ml) \\
\hline Overhead Construction & 250 \\
Underground, With Conduit & 800 \\
Underground, Existing Conduit & 250 \\
& \\
- Without Land Cost &
\end{tabular}

The generic 5 mile, $12 \mathrm{kV}$ feeder is expected to cost about $\$ 4,000,000$. For this study, assume that a judiciously placed reliable $2 \mathrm{MW}$ battery within the distribution system can defer this new feeder addition 3 years. (Note that future site specific distribution studies meeting SDG\&E reliability criteria will be required to determine potential feeder deferral benefits on a case by case basis.) Assuming a $16.35 \%$ fixed charge rate, the potential battery storage benefit associated with deferring the feeder totals $\$ 1,962,000$ or $\$ 654,000$ per year for three years. Assuming a discount rate of $11.6 \%$ and a $4 \%$ inflation rate, the resulting feeder deferral PWRR savings benefit is $\$ 704,000$.

On a capital investment basis, this 5 mile, $12 \mathrm{kV}$ feeder deferral benefit translates into a battery storage credit of $\$ 250 / \mathrm{kW}$ for the $2 \mathrm{MW}$ battery. Note that the potential battery storage credit would be significantly higher if ROW costs were required for the $12 \mathrm{kV}$ feeder addition.

\section{LOSS REDUCTION}

The loss reduction consideration and issues described in Section 3 for transmission also apply to distribution systems. However, the important issues concerning loss reduction considerations on distribution systems are slightly different.

First, on distribution systems, the location of the generation used to charge the batteries and the location of the generation displaced when the batteries are discharged is not expected to have a significant impact on the relative magnitude of the losses and the resulting relative cost of losses.

Second, it is likely that the daily load shape characteristics of individual feeders may vary significantly from the coincident daily native SDG\&E system load shape.

Appendix B presents plots of composite daily load curves for commercial and residential substation loads plus example summer and winter daily load shape plots for one of SDG\&E's distribution substations. These distribution substation daily load shapes vary significantly from the total native system load shapes in Section 2 as measured at SDG\&E generating units and tie lines. And individual feeders connected to this substation are also expected to have different daily load shapes. These plots verify the second issue raised above. 


\section{VOLTAGE REGULATION}

The voltage regulation consideration and issues described in Section 3 for transmission also apply to distribution systems. Table 4-3 presents SDG\&E cost estimates for conventional capacitor banks installed at the $12 \mathrm{kV}$ distribution level. Overhead capacitors cost about $\$ 12.50$ per kvar and pad mounted capacitors cost $\$ 25$ per kvar.

\begin{tabular}{lc}
\multicolumn{2}{c}{ Table 4-3 } \\
SDG\&E SHUNT CAPACITOR COST ESTIMATE \\
\hline Capacltor Type & Installed Cost $\$$ \\
\hline $1200 \mathrm{kvar}$, Overhead & 15,000 \\
$12000 \mathrm{kvar}$, Pad Mounted & 30,000
\end{tabular}

As described in Section 2 batteries are expected to provide capacitance at about $\$ 22$ per kvar. Thus batteries appear to be economically competitive with pad mounted conventional shunt capacitors installed on the $12 \mathrm{kV}$ distribution system, and batteries are significantly more economical if their presence avoids the need for SVS capacity (Batteries in the SDG\&E distribution system will displace SVS capacity in the SDG\&E transmission system because SDG\&E does not apply automatic LTCs in its distribution substation).

\section{OTHER BATTERY STORAGE T\&D BENEFITS, CONSIDERATIONS AND ISSUES}

The last two subsections of Section 3 (transmission) dealt with related issues such as voltage stability, T\&D system reliability, and land use. These issues are common to transmission and distribution; most of the material from these two subsections of Section 3 applies equally to distribution. 


\section{5}

\section{COST/BENEFIT ANALYSIS}

In this section the dollar value of the benefits described in the previous three sections is compared to the cost of installing batteries. Following common industry practice, costs and benefits are expressed in $\mathbf{1 9 9 0}$ dollars per kilowatt of capacity or dollars per kilowatt-year of capacity; the latter is a current dollar levelized cost over the battery unit's life.

\section{BATTERY CAPITAL COSTS}

Because there are currently only a handful of utility battery installations in operation or planned, there are no commonly accepted estimates for battery storage system costs. In addition, costs are very dependent not only on power capacity and storage capacity, but also on frequency with which the battery is to be charged and discharged and the depth of discharge.

The cost estimates used here are from EPRI's Technical Assessment Guide (TAG). They have already been described in Section 1 of this document. Adjusted for inflation, the total cost is $\$ 703 / \mathrm{kW}$ for a 3 -hour battery and $\$ 943 / \mathrm{kW}$ for a 5 -hour battery, including land cost. The TAG does not provide a cost estimate for a one-half or 1-hour battery that could provide spinning reserve but would have minimal energy capacity; we estimate that such a battery would cost $\$ 350 / \mathrm{kW}$. This is based on the EPRI TAG numbers, but reducing the storage component of the 3-hour battery cost by two-thirds.

Using a fixed charge rate of $16.35 \%$, as suggested by SDG\&E, to convert overnight capital costs to current dollar levelized annual battery costs yields the following:

\begin{tabular}{cc}
\hline $\begin{array}{c}\text { Size } \\
\text { (hours) }\end{array}$ & $\begin{array}{c}\text { Levellzed Capltal Cost } \\
\text { (\$/kW-year) }\end{array}$ \\
\hline 1 & $\$ 57.20$ \\
3 & $\$ 114.94$ \\
\hline
\end{tabular}

The cost estimates in the EPRI TAG do not include cell replacement during the life of the battery system; the individual cells do not last as long as the entire system. Depending on the number of cycles per year that the battery is operated, cell replacement costs could add on the order of $\$ 100 / \mathrm{kW}$ to the battery cost, or about $\$ 15 / \mathrm{kW}$-year. In addition, the operating and maintenance 
(O\&M) costs for the battery system should $b \varepsilon$ included in a detailed analysis; they are ignored in this screening-level analysis.

\section{CAPACITY VALUE OF BATTERY}

Another potential benefit or savings that can be attributed to batteries, but not discussed in the previous sections, results from its contribution to total system generating capacity. If the addition of batteries allowed SDG\&E to reduce new combustion turbine purchases or purchase less firm capacity, then a capacity credit on the order of $\$ 40$ to $\$ 75 / \mathrm{kW}_{\text {-year }}{ }^{1}$ would be appropriate. SDG\&E is planning additions to generating capacity during the next decade, so such a capacity credit appears warranted.

\section{COMPARING BENEFITS TO COSTS}

The annual costs just described can now be compared to the bentrits estimated in Sections 2, 3, and 4. Recall that, as described in Section 2, there were no load-leveling benefits on the SDG\&E system. This resulted from the relative flatness of the hourly system marginal costs (system lambda).

Two operating modes or applications were considered for calculating dynamic operating benefits: a three-hour battery operated in a daily charge/discharge mode, and a battery with much smaller storage capacity used only to provide spinning reserve. In order to maximize the net operating benefits, enough battery capacity must be added to allow the decommitment of one of the marginal units; this could require about $100 \mathrm{MW}$ of battery capacity. The net cperating benefits were greater when the battery is used to provide spinning reserve; in this case, they were calculated to be $\$ 26.89 / \mathrm{kW}$-year. However, a battery with only minimal storage capacity might not be able to provide all of the T\&D benefits described in Sections 3 and 4, especially deferral of $T \& D$ investinents. The three-hour battery provided net operating benefits of $\$ 23.23 / \mathrm{kW}$-year when operated in charge/discharge mode.

It is necessary to account for the fact that the net operating benefits, which were calculated only for 1990-1991, will escalate over time with inflation and with increasing natural gas prices. For inflation of 4 percent per year and real escalation of natural gas prices of 1.5 percent per year, the effect is to roughly double the 1990-1991 value to yield net operating benefits of about $\$ 50 / \mathrm{kW}$-year levelized in current dollars. This is a conservative estimate that could be higher in the future as load growth forces increasing utilization of less economic units.

T\&D investment deferral benefits range as high as $\$ 1200$ per $k W$, depending on the investment deferred; the $\$ 1200$ figure is admittedly extreme. Different hours of storage capacity will likely be required for different T\&D applications; in particular, the $\$ 1200 / \mathrm{kW}$ benefit is

1. Combustion turbine cost of $\$ 400 / \mathrm{kW}$ times levelized fixed charge rate of $16.35 \%=\$ 65 / \mathrm{kW}$-year. Life extension and capacity purchases will probably cost less; combined cycles will cost more. 
associated with deferral of a $69 \mathrm{KV}$ transmission line and would require more storage capacity, which would be more expensive. Using the same levelized fixed charge rate used above for levelizing battery capital costs, and assuming that the battery would be sited to capture at least moderate T\&D benefits, yields a T\&D value of $\$ 10$ to $\$ 200$ per $k W$ of battery capacity per year.

Benefits in all categories are summarized in Table 5-1. In a screening level analysis such as this, it is not possible to be more precise. The T\&D benefits in particular are very sifi-specific and can not be precisely calculated without identifying sites for battery installations and then carrying out detailed T\&D expansion plans with and without batteries.

Table 5-1

BENEFITS SUMMARY FOR SDG\&E SYSTEM

\begin{tabular}{lc}
\hline \multicolumn{1}{c}{ Category } & Annual Benefit (\$NW-year) \\
\hline Capacity & $40-75$ \\
Generation & $50-75$ \\
T\&D & $10-200$ \\
Environmental & $1-20^{*}$ \\
TOTAL & $100-370$
\end{tabular}

For chargin a with on-system units.

Comparing total benefits to the battery costs, which are roughly $\$ 60$ to $\$ 130$ per $\mathrm{kW}$-year depending on the number of hours of storage indicates that batteries may be quite economic on the SDG\&E system. 


\section{6}

\section{CONCLUSIONS AND RECOMMENDATIONS}

In this study several types of benefits that would occur from the addition of batteries to the SDG\&E system were calculated: generation (load-leveling, dynamic operating, and environmental) and transmission and distribution. These benefits were also compared to the costs of adding batteries. The results suggest that savings in dynamic operating costs and T\&D costs may justify the addition of batteries to the system.

\section{GENERATION BENEFITS}

Generation benefits were calculated for eight days during 1990-1991, one weekday and one weekend day for each season, i sing actual SDG\&E data. The benefits were calculated for five gas-fired steam turbine units wiose operation is most likely to be affected by the addition of batteries to the system. Two modes of battery operation were considered: daily charge/discharge with a three-hour battery, and provision of spinning reserve only with a onehour battery.

\section{Load-Leveling Beneflits}

Because the marginal units on the SDG\&E system are typically gas-fired steam turbines for all hours (usually the Encina and South Bay units), the system marginal energy costs do not differ much between on-peak and off-peak hours. Coupled with the assumed battery efficiency of around 80 percent, this means that no lcad-leveling savings could be achieved on the SDG\&E system.

\section{Dynamic Operating Benefits}

A large portion of the operating costs of power plants results from fluctuating loads. These costs are called dynamic operating costs, and include such things as startups, minimum loading, load following, and ramping. Technologies such as batteries that can reduce these costs are said to provide dynamic operating benefits.

For each of the eight days the potential reduction in load following, minimum loading, startup, and spinning reserve costs was calculated for each of the five units. The most costeffective unit for decommitment was identified on each day. By accounting for the relative 
occurrence of each of the eight "day types" during the year, an annual savings was calculated. For the 1990-1991 period, the savings was about \$23-26 per kilowatt per year of battery capacity; the biggest component of the savings is from reductions in load-following costs. That is, each kilowatt of battery capacity would reduce system operating costs 23 to 26 dollars. Accounting for inflation and increases in natural gas prices, this is equivalent to an annual savings of about $\$ 50$, levelized in current dollars, per kilowatt per year. The savings are likely to increase in the future as load growth forces increasing utilization of less economic units.

\section{Environmental Benefits}

Storage in general, and batteries in particular, have the potential to shift the type and location of emissions of $\mathrm{NO}_{x}, \mathrm{SO}_{x^{\prime}}$ and $\mathrm{CO}_{2} ; \mathrm{NO}_{x}$ is of greatest concern in Southern California at this time. Even if providing only spinning reserve, batteries have the potential to reduce $\mathrm{NO}_{x}$ emissions by allowing the system to be operated more efficiently. The addition of batteries to the system might also make it unnecessary to retrofit expensive pollution controls such as SCR to an existing gas-fired unit, if that unit's operation would be sharply reduced as a result of adding batteries.

\section{TRANSMISSION AND DISTRIBUTION BENEFITS}

This project identified the potential role battery storage could play in providing equal or better performance than other transmission and distribution (T\&D) options, such as adding new $T \& D$ facilities and equipment. Current SDG\&E transmission and distribution facility expansion study results and transmission and distribution system design practices were reviewed with appropriate SDG\&E personnel to identify anticipated and potentially needed transmission additions.

The results of this initial study indicate that strategically installing battery storage on the SDG\&E system may result in large T\&D system benefits-up to $\$ 1200 / \mathrm{kW}$. The actual magnitude of the site specific T\&D benefits and corresponding battery storage requirements should be determined on a case-by-case basis from more detailed analysis. Further analysis should include the development of load profiles for substations that are candidate battery sites so that the number of hours of storage required for equipment deferral can be determined.

Table 6-1 presents a summary of the range of annual potential savings to SDG\&E associated with the deferral of various new transmission and distribution facilities. Table 6-2 presents a summary of the magnitude of potential benefits and associated battery storage credits associated with T\&D application of batteries on the SDG\&E system. Several applications have storage credits in the range of several hundred dollars of battery capacity per kilowatt; for a specific $69 \mathrm{kV}$ transmission line the credit exceeds $\$ 1,000$ per kilowatt. 
Table 6-1

RANGE OF POTENTIAL ANNUAL TED SAVINGS TO SDG\&E

\begin{tabular}{lr}
\hline \multicolumn{1}{c}{ New T\&D Project } & $\begin{array}{c}\text { Range of Annual Savings } \\
(\$ 1000 / \mathrm{rr})\end{array}$ \\
\hline Defer Proposed 1994 69 kV Project & $654-1,635$ \\
Defer 15 mi. $69 \mathrm{kV}$ Line & $591-8,361$ \\
Defer $15 \mathrm{mi}$. 230 kV Line & $3,163-16,356$ \\
Defer 230/69 kV Transformer Existing Sub & $1,039-1,116$ \\
Defer 69/12 kV Transformer Existing Sub & $114-\quad 327$ \\
Defer 69/12 kV Transformer Now Sub & $327-1,308$ \\
Defer 5 mi. 12 kV Underground Foeder & 654 \\
Defer 4.6 MVAR of Shunt Capacitors & 6 \\
Defer 9.2 MVAR of SVS & 102
\end{tabular}

Table 6-2

EXAMPLE T\&D BATTERY T\&D BENEFITS AT SDG\&E

\begin{tabular}{|c|c|c|c|}
\hline Battery Application & $\begin{array}{l}\text { Battery Size } \\
\text { (MW) }\end{array}$ & $\begin{array}{l}\text { PWRA Savings } \\
(\$ 1000)\end{array}$ & $\begin{array}{l}\text { Battery Credit } \\
(\$ / \mathrm{kW})\end{array}$ \\
\hline $\begin{array}{l}\text { 1. Defer } 15 \text { mi. } 69 \mathrm{kV} \text { Line } 9 \text { years } \\
\text { Single Circuit } \\
\text { Double Circuit }\end{array}$ & $\begin{array}{l}20 \\
20\end{array}$ & $\begin{array}{l}31,057 \\
33,874\end{array}$ & $\begin{array}{l}1100 \\
1200\end{array}$ \\
\hline $\begin{array}{l}\text { 2. Deler } 28 \text { MVA } 69 / 12 \mathrm{kV} \text { Transformer } 3 \text { years } \\
\text { Existing Sub } \\
\text { New Sub }\end{array}$ & $\begin{array}{r}5 \\
10\end{array}$ & $\begin{array}{r}538 \\
1,408\end{array}$ & $\begin{array}{r}76 \\
100\end{array}$ \\
\hline $\begin{array}{l}\text { Defer } 28 \text { MVA } 69 / 12 \text { kV Transformer } 6 \text { years } \\
\text { Existing Sub } \\
\text { New Sub }\end{array}$ & $\begin{array}{r}5 \\
10\end{array}$ & $\begin{array}{r}973 \\
3,891\end{array}$ & $\begin{array}{l}138 \\
276\end{array}$ \\
\hline $\begin{array}{l}\text { 3. Defer } 5 \text { mi. } 12 \mathrm{kV} \text { Feeder } \\
3 \text { years }\end{array}$ & 2 & 704 & 250 \\
\hline $\begin{array}{l}\text { 4. Defer 4.6 MVAR of Capacitors to Perpetuity } \\
\text { Shunt Capacitors } \\
\text { SVS }\end{array}$ & $\begin{array}{l}10 \\
10\end{array}$ & $\begin{array}{r}47 \\
880\end{array}$ & $\begin{array}{r}4 \\
62\end{array}$ \\
\hline
\end{tabular}

\section{COST/BENEFIT ANALYSIS}

Summing the capacity, generation, environmental, and T\&D benefits yields levelized current-dollar savings of $\$ 100$ to $370 / \mathrm{kW}$-year, compared to a levelized current-dollar cost of $\$ 60$ to $\$ 130 / \mathrm{kW}$-year. These values suggest that batteries would be a cost-effective addition to the SDG\&E system.

Some benefits may be mutually exclusive. This is true both for different T\&D benefits and for T\&D benefits versus dynamic operating benefits. For example, the load-leveling that batteries make possible can reduce T\&D losses, but this benefit may be lost if investment is 
deferred as a result of adding batteries. The interactions between the various benefits, i.e., whether they are additive or mutually exclusive, depends on storage size, location, system load shapes, load shapes at individual substations and on individual transmission and distribution lines, how the system (including the battery) is operated, and on any equipment deferred as a result of adding batteries.

\section{RECCMMENDATIONS}

Based on the results of this screening-level study, it is recommended that SDG\&E seriously consider the addition of battery storage to its system. A detailed study to verify the findings of this initial screening study and to calculate the benefits more precisely is recommended. Such a study should include the following aspects:

1. More detailed calculation of generation dynamic operating costs and benefits should be carried out, including examination of multiple weeks of system operation during the course of the year and consideration of how system operation, and especially the operation of marginal units, is likely to change in the future.

2. Detailed T\&D expansion studies should be carried out, with and without batteries. Potential sites for installing batteries should be identified.

3. Particular care should be paid to the interactions among the various benefits, to ensure that batteries are not being justified on the basis of benefits that may be mutually exclusive.

4. Comparative evaluation of the economics of battery storage with other capacity additions under consideration by SDG\&E.

Such detailed study would also allow a better assessment of the "optimum" battery size and the best time for adding the battery plant to the SDG\&E system. 
A

TRANSMISSION FACILITY ASSUMPTIONS

Appendix A contains a listing of the detailed assumptions supplied by SDG\&E transmission planning personnel for use in this analysis. Table A-1 presents a listing of typical transmission line construction cost estimates for alternative overhead and underground transmission line construction types and phase conductor sizes. Table A-2 presents a listing of appropriate line ratings and impedance data for the various transmission construction types. Table A-3 presents typical bulk power transformer plus breaker installed cost estimates used for current SDG\&E transmission planning studies. 
Table A-1

TYPICAL TRANSMISSION LINE CONSTRUCTION COST ESTIMATES

Single circuit 636 ACSR/AW

Single circuit 1033.5 ASCRUAW

Twin circuit single conductor 1033.5 ASCR/AW

Single circult overbuild 1033 ASCR/AW w/4W636 $12 \mathrm{kV} \quad 353$

Single circuit re-conductor (1/0 Cu. $-336 \mathrm{al}$.) 148

Single circuit re-conductor (1/10 cu. -636 al.) 162

Single circuit re-conductor (1/0 cu. - 1033 al.) 178

Single circult re-conductor (4/0 cu. -636 al.) 154

Single circult re-conductor (4/0 cu. -1033 al.) 146

2. 138 kV Wood Poles:

Single circuit single conductor 1033.5 ACSR/AW $\quad \$ 170$

3. Wood H-Frame Structures (1033.5 ACSR/AW):

$138 \mathrm{kV}$ single circuit bundled conductor $\quad$. 344

$230 \mathrm{kV}$ single circuit bundled conductor $\quad 369$

4. $230 \mathrm{kV}$ Lattice Tower (1033.5 ACSR/AW):

Single circuit single conductor $\quad 565$

Twin circuit single conductor

Twin circuit bundled conductor $\quad 889$

5. $230 \mathrm{kV}$ Steel Poles (1033.5 ACSR/AW):

Single circuit single conductor

Twin circuit bundled conductor $\quad 1,158$

Bundle existing single circuit 1033.5 on stoel structures 100

Add single circuit single conductor 1033.5 to steel structures 132

Add single circuit bundled conductor 1033.5 to steel structures 231

6. $500 \mathrm{kV}$ Lattice Towers (2156 ACSR/AW):
Single circuit, bundled conductor

7. $69 \mathrm{kV}$ Underground:

Install 1750 MCM A1 cable direct buried in an existing open trench $\quad 549$

Install 1750 MCM A1 cable in existing ducts

Trench for oirect buried cable

Trench for direct buried cable w/4" duct for telecommunication 757

Installation twin circuit duct bank (trench and substructures only) $\quad 1,396$

Install twin circuit duct bank w/4" duct for telecommunication (trench and $\quad \mathbf{1 , 4 1 9}$ substructures only)

- Estimates include AFDC, interest, local engineering, engineering support, P\&W, and 15\% contingency. 
Table A-2

APPROXIMATE LINE RATINGS AND IMPEDANCE DATA $69,138,230 \& 500 \mathrm{kV}$

\begin{tabular}{|c|c|c|c|c|c|c|c|}
\hline $\begin{array}{l}\text { Voltingol } \\
\text { Conductor }\end{array}$ & & 120 & $\begin{array}{c}\text { Max. (1) } \\
\text { Ampactiy }\end{array}$ & $\begin{array}{l}\text { (2) } \\
\text { INA }\end{array}$ & $\begin{array}{c}\text { (2) } \\
\mathbf{R}(\mathrm{pu})\end{array}$ & $\begin{array}{l}\text { (2X(3) } \\
x(\mathrm{pu})\end{array}$ & $b / 2(p u)$ \\
\hline $\begin{array}{l}60 k V \\
\text { Single } \\
\text { Single } \\
\text { Bundled } \\
\text { Single } \\
\text { Single } \\
\text { Bundled } \\
\text { Single } \\
\text { Bundled } \\
\text { Single } \\
1750 \mathrm{MCM}\end{array}$ & $\begin{array}{c}1 / 0 \\
4 / 0 \\
4 / 0 \\
1 / 0 \\
336 \\
336 \\
636 \\
636 \\
1033 \\
A 1\end{array}$ & $\begin{array}{c}\text { Cu } \\
\text { Cu } \\
\text { Cu } \\
\text { ACSR } \\
\text { ACSR } \\
\text { ACSR } \\
\text { ACSR } \\
\text { ACSR } \\
\text { ACSR } \\
\text { Cable }\end{array}$ & $\begin{array}{r}270 \\
421 \\
842 \\
269 \\
571 \\
1142 \\
854 \\
1708 \\
1145 \\
(4)\end{array}$ & $\begin{array}{r}32 \\
50 \\
101 \\
32 \\
68 \\
136 \\
102 \\
204 \\
137 \\
(4)\end{array}$ & $\begin{array}{l}.012750 \\
.006360 \\
.003180 \\
.023520 \\
.006440 \\
.003220 \\
.003400 \\
.001700 \\
.002180 \\
.001440\end{array}$ & $\begin{array}{l}.016770 \\
.016060 \\
.011200 \\
.018480 \\
.014050 \\
.010500 \\
.013250 \\
.009870 \\
.013600 \\
.007183\end{array}$ & $\begin{array}{l}.0001284 \\
.0001364 \\
.0001865 \\
.0001350 \\
.0001510 \\
.0002000 \\
.0001605 \\
.0002130 \\
.0001570 \\
.0039600\end{array}$ \\
\hline $\begin{array}{l}138 \text { kV } \\
\text { Single } \\
\text { Bundled } \\
\text { Single } \\
\text { Bundled } \\
\text { Bundled }\end{array}$ & $\begin{array}{c}636 \\
636 \\
1033 \\
1033 \\
1590\end{array}$ & $\begin{array}{l}\text { ACSR } \\
\text { ACSR } \\
\text { ACSR } \\
\text { ACSR } \\
\text { ACSR }\end{array}$ & $\begin{array}{r}854 \\
1708 \\
1145 \\
2290 \\
3006\end{array}$ & $\begin{array}{l}204 \\
408 \\
274 \\
547 \\
719\end{array}$ & $\begin{array}{r}.000886 \\
.000424 \\
.000542 \\
.000271 \\
.000179\end{array}$ & $\begin{array}{l}.003810 \\
.002760 \\
.003960 \\
.002920 \\
.002740\end{array}$ & $\begin{array}{l}.0004500 \\
.0007550 \\
.0005350 \\
.0007150 \\
.0007625\end{array}$ \\
\hline $\begin{array}{l}230 \mathrm{kV} \\
\text { Single } \\
\text { Bundled } \\
\text { Single } \\
\text { Bundled }\end{array}$ & $\begin{array}{l}1033 \\
1033 \\
1590 \\
1590\end{array}$ & $\begin{array}{l}\text { ACSR } \\
\text { ACSR } \\
\text { ACSR } \\
\text { ACSR }\end{array}$ & $\begin{array}{l}1145 \\
2290 \\
1503 \\
3006\end{array}$ & $\begin{array}{r}456 \\
912 \\
599 \\
1198\end{array}$ & $\begin{array}{l}.000196 \\
.000098 \\
.000130 \\
.000342\end{array}$ & $\begin{array}{l}.001425 \\
.001045 \\
.001380 \\
.001010\end{array}$ & $\begin{array}{l}.0014850 \\
.0020250 \\
.0015400 \\
.0020750\end{array}$ \\
\hline $\begin{array}{l}500 \mathrm{kV} \\
\text { Bundled }\end{array}$ & 2156 & ACSR (5) & (6) & (6) & .000110 & .000238 & .0088000 \\
\hline
\end{tabular}

(1) Max. Ampacity at Ambient Temperature $=100^{\circ}$, and a maximum conductor temperature of 2 FPS wind of $167^{\circ}$ for Copper and $194^{\circ}$ for Aluminum. (Temperatures are assumed to be degrees Fahrenheit).

(2) On 100 MVA base.

(3) Total 3 phase line-charge.

(4) Varies, dependent on manufacturer and design configurations.

(5) Base on no series compensation; degrees=40.5; phase-space=32.

(6) Not provided

Table A-3

BULK POWER TRANSFORHER AND BREAKER COST ESTIMATES

\begin{tabular}{|c|c|c|}
\hline & & 1890 Dollar Installed Cost (\$1000) \\
\hline $\begin{array}{c}\text { 1. Transformer, } 2 \mathrm{Hig} \\
500 / 230 \mathrm{kV} \\
230 / 138 \mathrm{kV} \\
230 / 69 \mathrm{kV}\end{array}$ & $\begin{array}{l}\text { iide Breakers } \\
1000 \text { MVA } \\
392 \text { MVA } \\
224 \text { MVA }\end{array}$ & $\begin{array}{r}11,119 \\
7,612 \\
6,354\end{array}$ \\
\hline $\begin{array}{l}\text { 2. Transformer, } 2 \mathrm{Hig} \\
500 / 230 \mathrm{kV} \\
230 / 138 \mathrm{kV} \\
230 / 69 \mathrm{kV}\end{array}$ & $\begin{array}{l}\text { ide Breakers } \\
1000 \text { MVA } \\
392 \text { MVA } \\
224 \text { MVA }\end{array}$ & $\begin{array}{r}13,988 \\
8,084 \\
6,826\end{array}$ \\
\hline
\end{tabular}




\section{B}

DAILY SDG\&E SYSTEM LOAD SHAPES AND MARGINAL GENERATION COSTS 


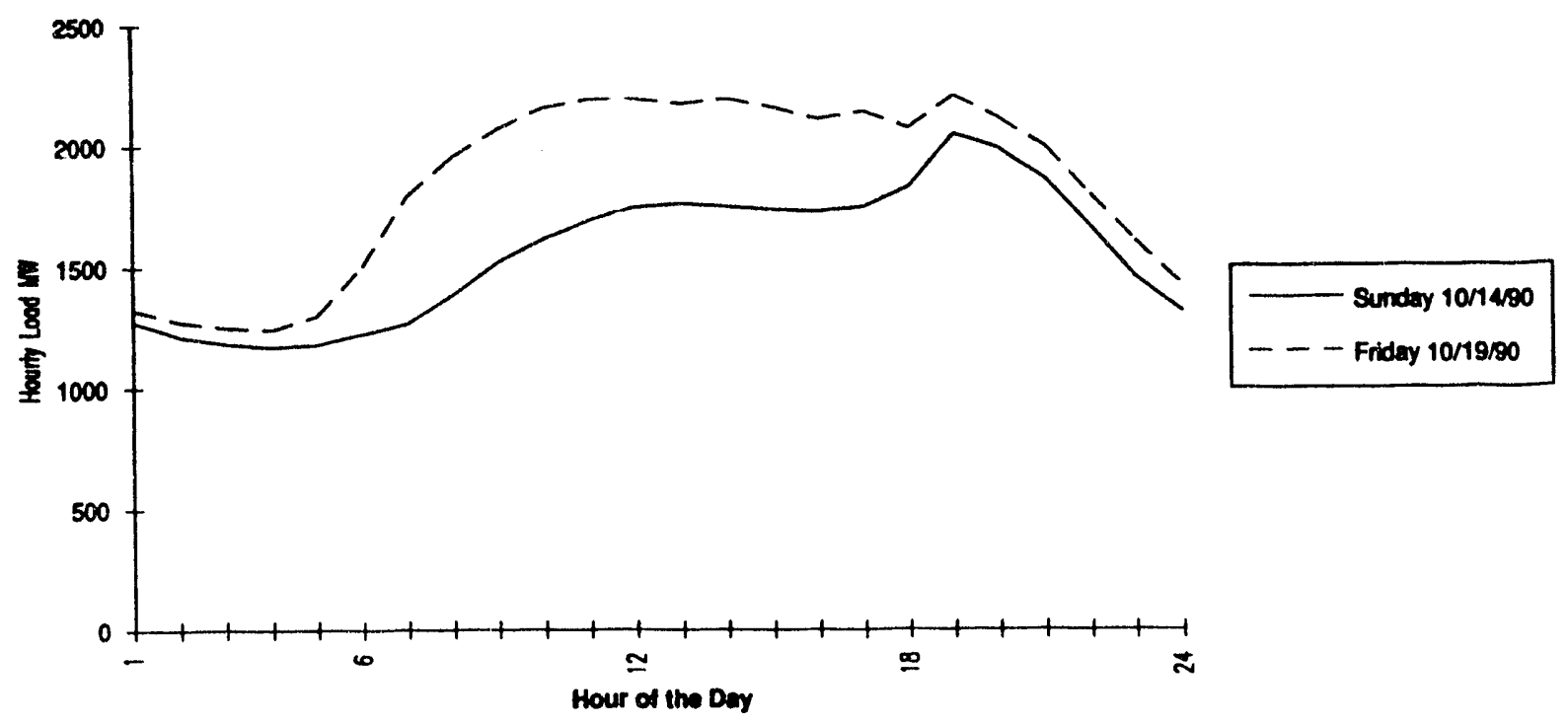

Flgure B-1. Native Dally Load Shapes-Fall 1990

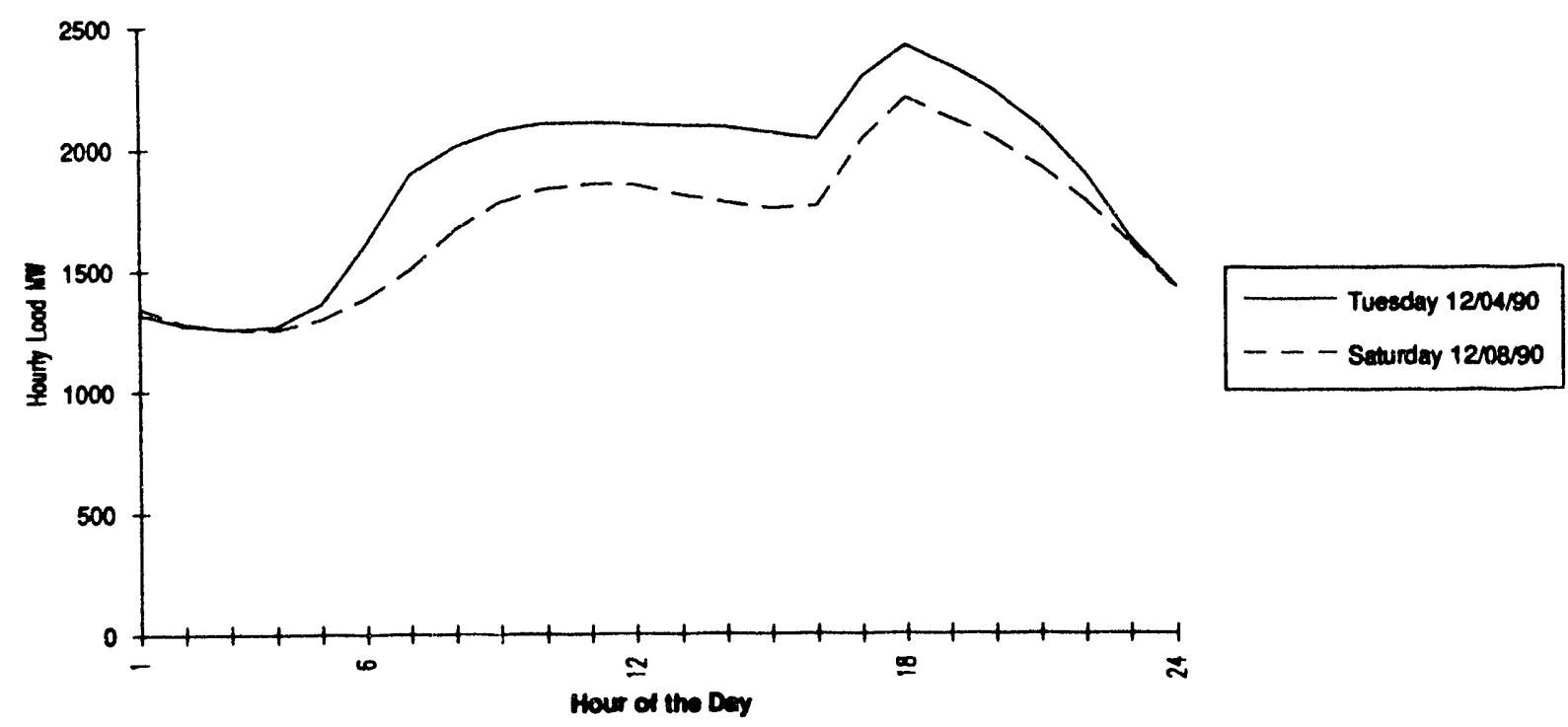

Figure B-2. Native Dally Load Shapes-Winter 1990 


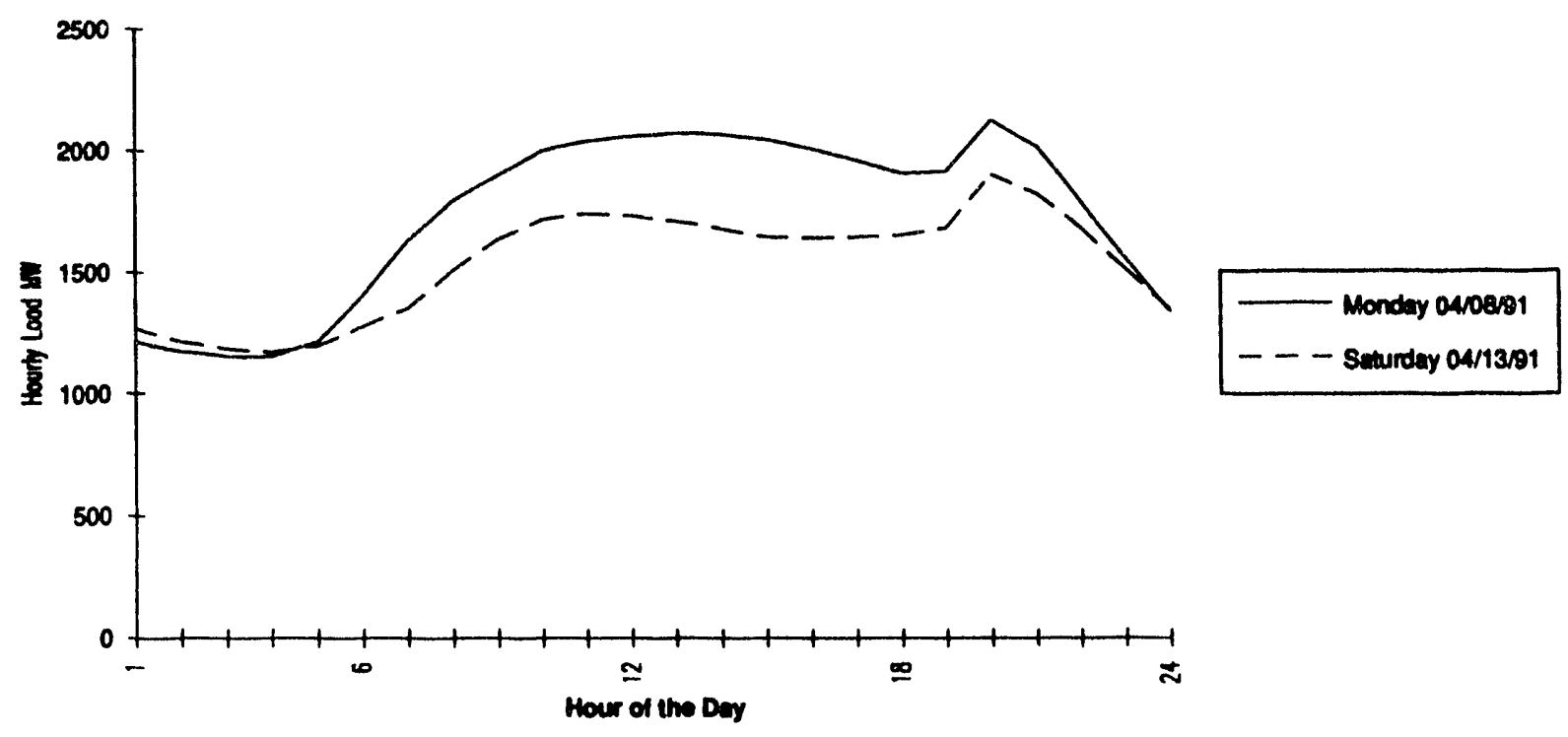

Figure B-3. Native Dally Load Shapes-Spring 1991

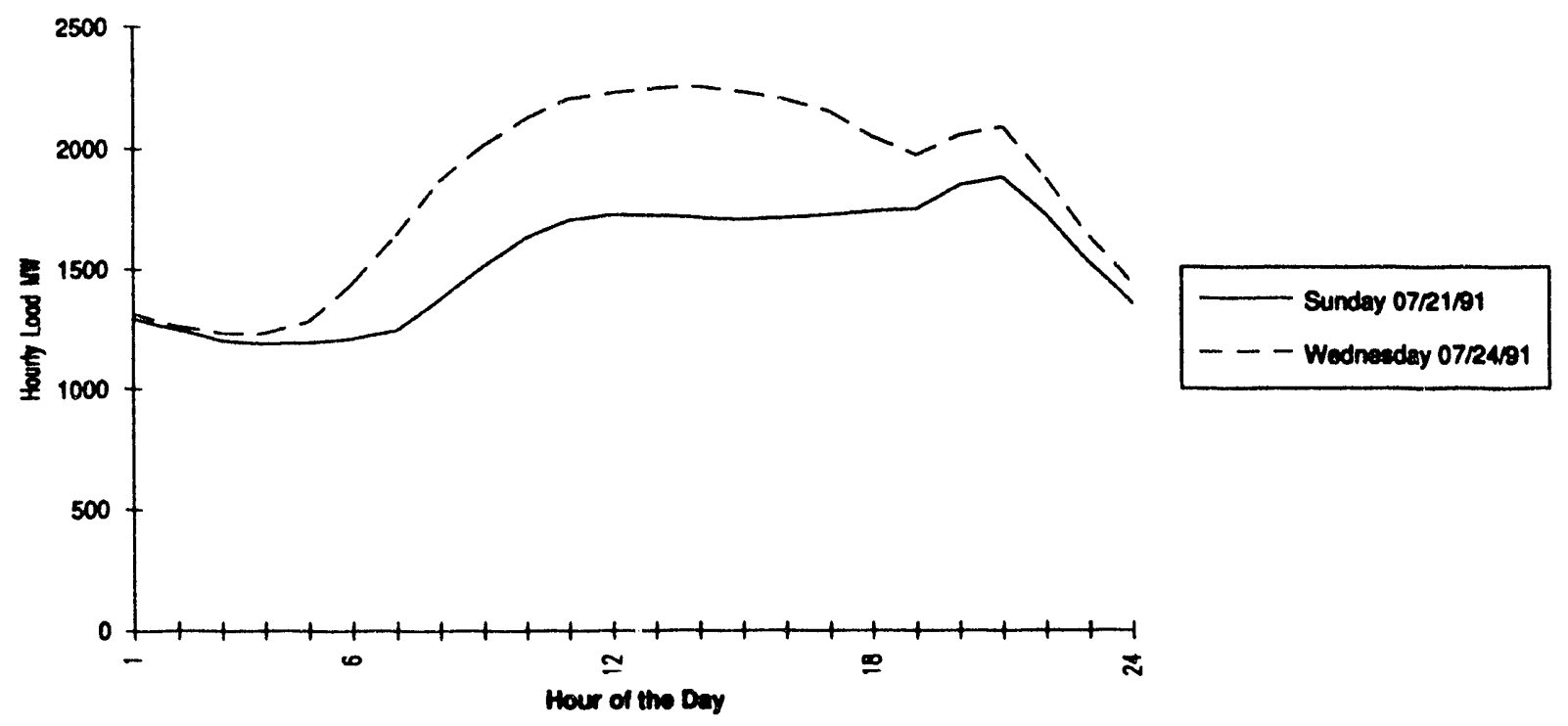

Flgure B-4. Native Dally Loed Shapes-Summer 1991 


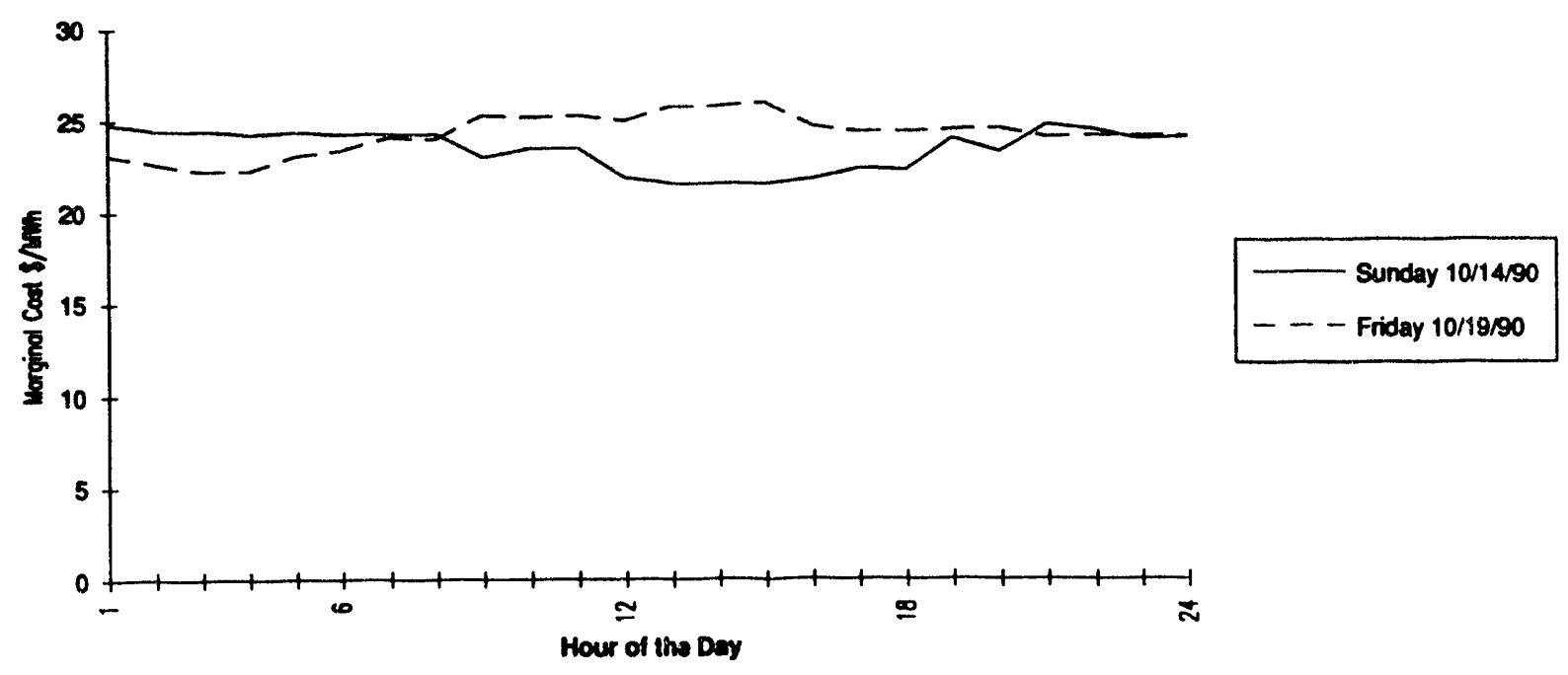

Figure B-5. Hourly Marginal Cost"-Fall 1990 Fuel Price $=\$ 2.44 / \mathrm{MMBtu}$

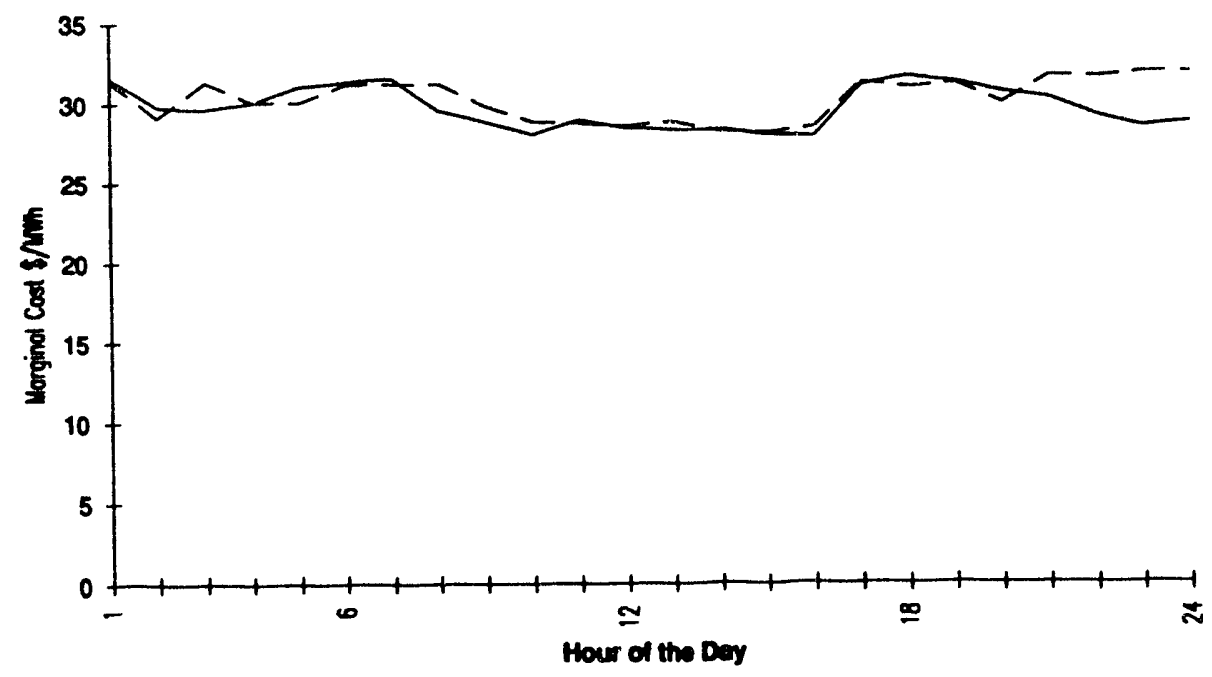

Figure B-6. Hourly Marginal Cost"-Wimter 1990

$$
\text { Fuel Price }=\text { \$3.73/MMBtu- }
$$

-For on-system units only. Excludes off-system purchases. 


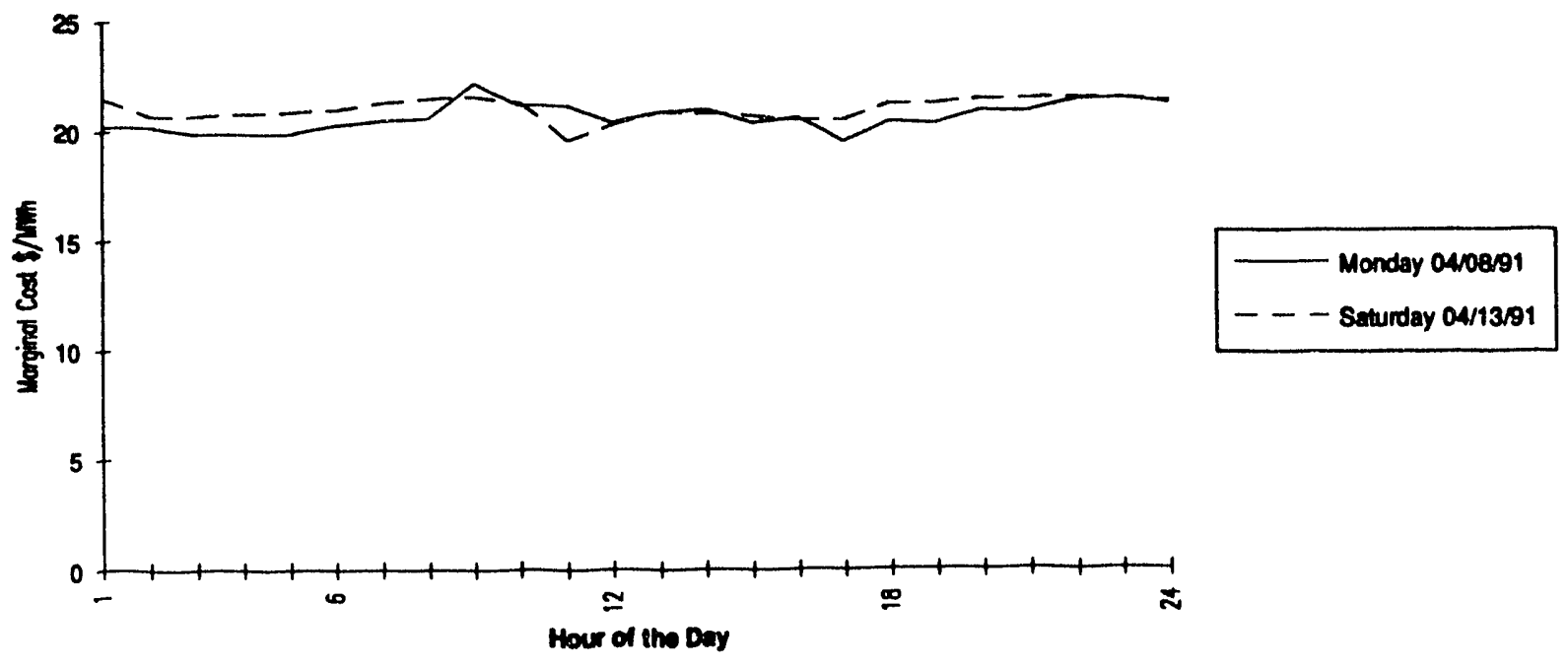

Figure B-7. Hourly Marginal Cost"-Spring 1991

Fuel Price $=\$ 2.35 / M M B t u-$

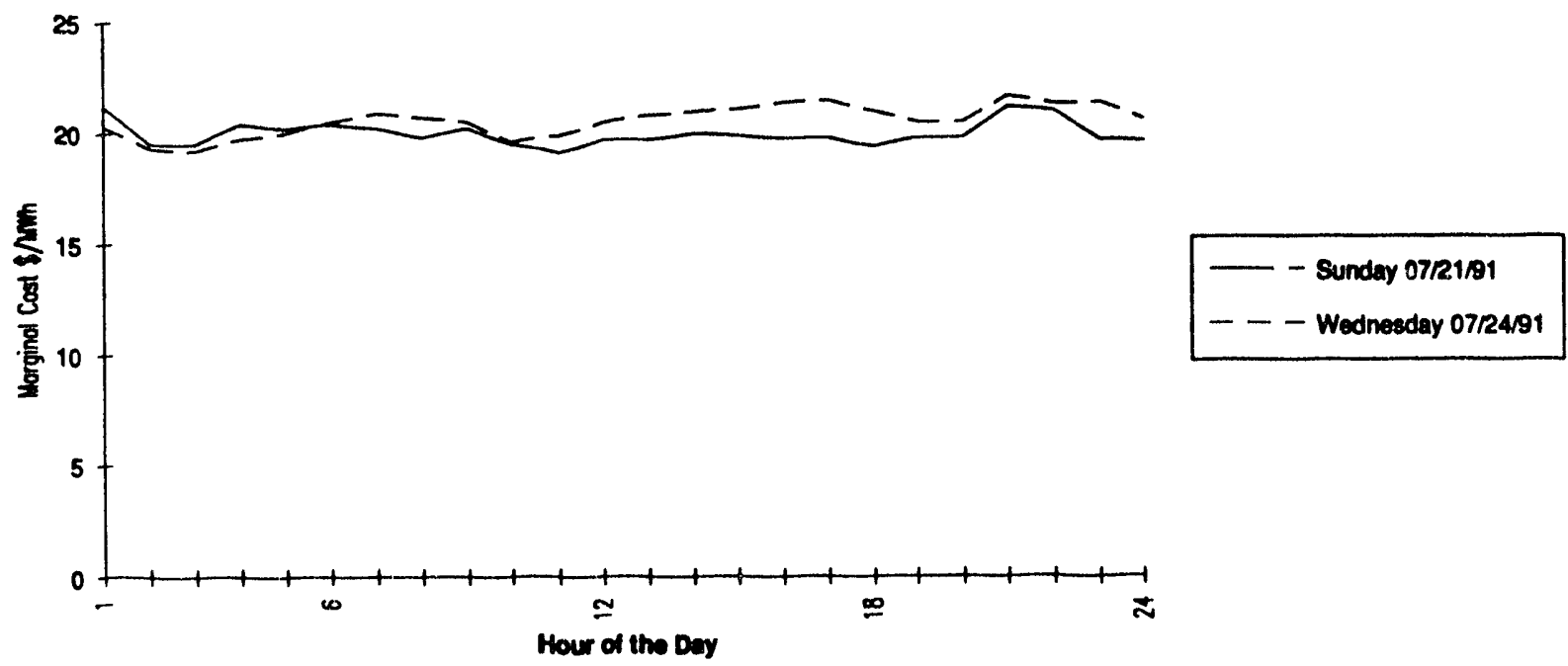

Figure B-8. Hourly Marginal Cost"-Summer 1991

-Fuel Price $=\$ 2.11 / M_{M B t u}$

"For on-system units only. Excludes off-system purchases. 


\section{TYPICAL DAILY SDG\&E DISTRIBUTION SUBSTATION LOAD SHAPES}

Appendix C presents typical daily SDG\&E distribution substation load shapes. Figure C-1 presents the daily load for composite SDG\&E commercial loads and residential loads. Figure C-2 presents the daily load shapes for the annual peak load day in September 1990 and for the monthly peak day in December 1989 for one of SDG\&E's distribution substations. 


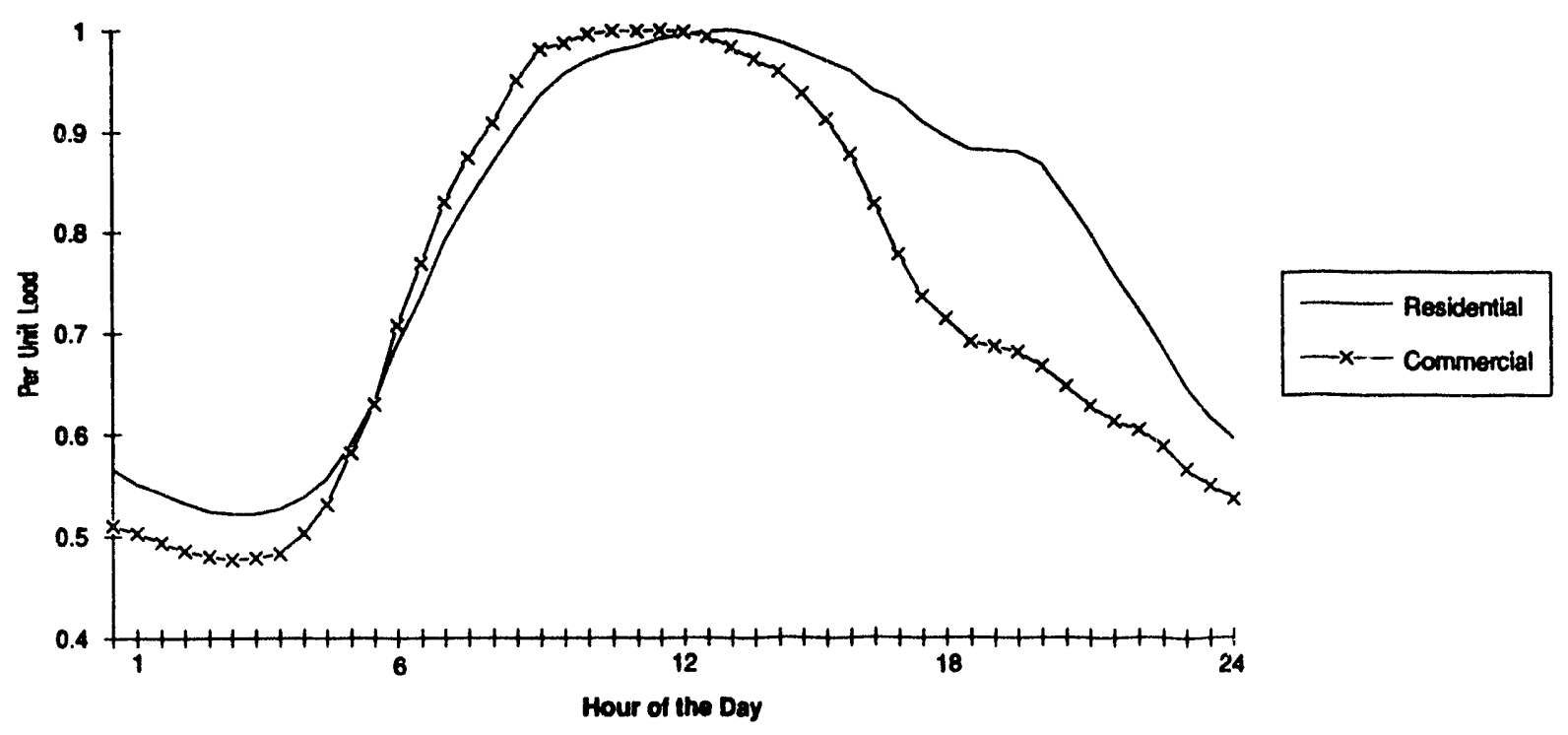

Figure C-1. Composite Dally Residential and Commercial Loads In $1 / 2$ Hour Intervals

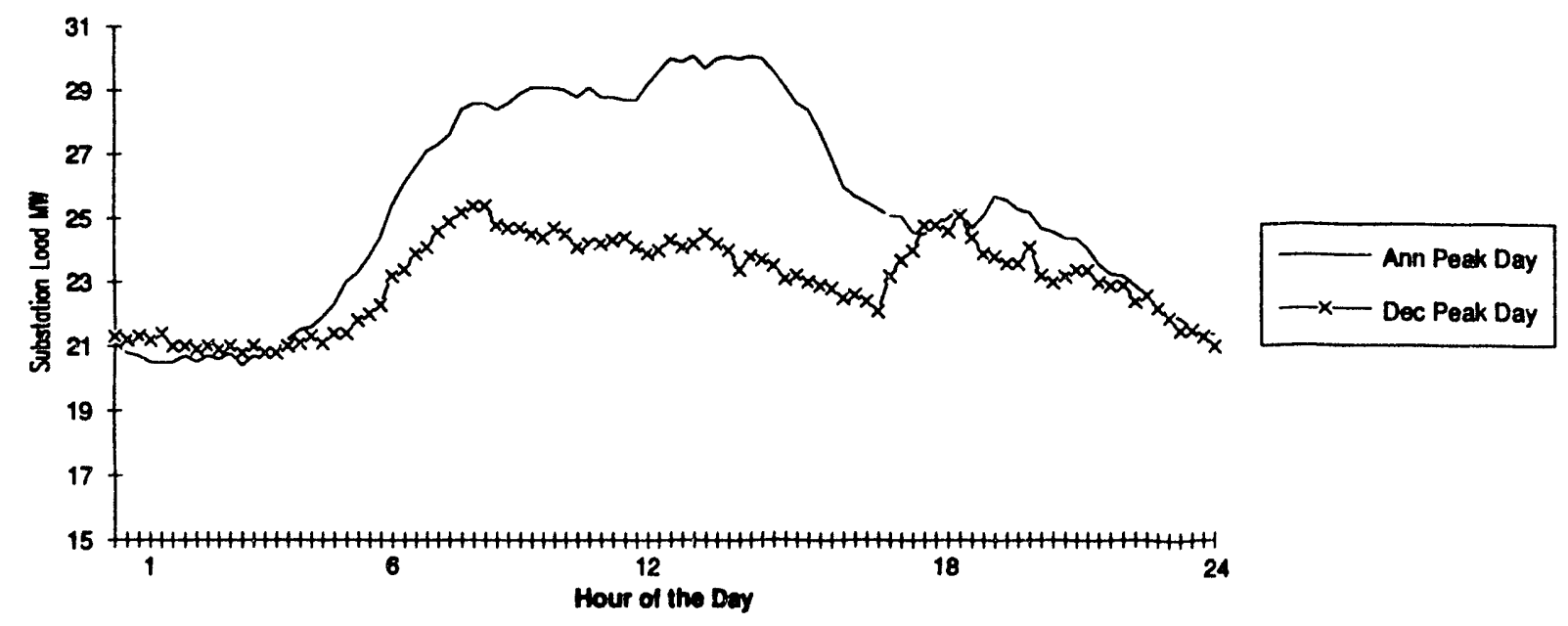

Figure C-2. Example SDG\&E Substation 1/4 Hour MW Load For Annual Peak Day and December Peak Day 


\title{
Appendix C
}

\author{
An Estimate of \\ Battery Energy Storage Benefits \\ on the Oglethorpe Power System
}




\title{
NN ESTIMATE OF \\ BATTERY ENERGY STORAGE BENEFTIS \\ ON THE OGLETHOPPE POWER SYSTEM
}

PTI Report No. 147-92

\author{
Prepared for: \\ Sandla National Laboratory \\ Albuquerque, NM \\ and \\ Oglethorpe Power Corporation \\ Tucker, GA
}

Prepared by:

F.S. Prabhakara

H.K. Clark

POWER TECHNOLOGIES, INC.

Schenectady, New York

December 30, 1992 


\section{AN ESTMUATE OF \\ BATTERY ENERGY STORAGE BENEFTS \\ ON THE OCLETHORPE POWER SYSTEM}

\section{Table of Contents}

EXECUTTVE SUMMARY $\ldots \ldots \ldots \ldots \ldots \ldots \ldots \ldots \ldots \ldots \ldots \ldots \ldots \ldots$

$1.0 \quad$ INTRODUCTION $\ldots \ldots \ldots \ldots \ldots \ldots \ldots \ldots \ldots \ldots \ldots \ldots \ldots \ldots$

$2.0 \quad$ CONCLUSIONS $\ldots \ldots \ldots \ldots \ldots \ldots \ldots \ldots \ldots \ldots \ldots \ldots \ldots \ldots$

3.0 THE G\&T PERSPECTIVE $\ldots \ldots \ldots \ldots \ldots \ldots \ldots \ldots \ldots \ldots \ldots \ldots \ldots$

4.1 Load Characteristics $\ldots \ldots \ldots \ldots \ldots \ldots \ldots \ldots \ldots \ldots \ldots$. 9

$4.2 \quad$ Generation $\ldots \ldots \ldots \ldots \ldots \ldots \ldots \ldots \ldots \ldots \ldots \ldots \ldots \ldots$

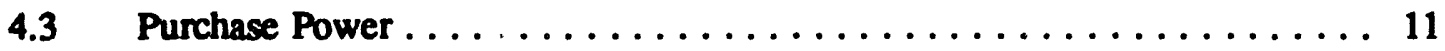

4.4 Load Management $\ldots \ldots \ldots \ldots \ldots \ldots \ldots \ldots \ldots \ldots \ldots \ldots \ldots \ldots$

4.5 Integrated Transmission System $\ldots \ldots \ldots \ldots \ldots \ldots \ldots \ldots \ldots \ldots \ldots$

5.0 GENERATION RELATED BENEFTTS $\ldots \ldots \ldots \ldots \ldots \ldots \ldots \ldots \ldots \ldots \ldots$

5.1 Generation System Reliability Benefit on the OPC System ......... 13

$5.2 \quad$ Production Cost Savings $\ldots \ldots \ldots \ldots \ldots \ldots \ldots \ldots \ldots \ldots \ldots \ldots$

5.2.1 Differential Cost of Energy . . . . . . . . . . . . . . 20

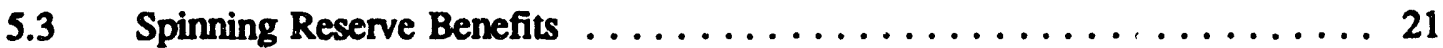

5.4 Other Generation Related Benefits $\ldots \ldots \ldots \ldots \ldots \ldots \ldots \ldots$

6.0 POTENTIAL TRANSMISSION BENEFITS $\ldots \ldots \ldots \ldots \ldots \ldots \ldots \ldots \ldots$

6.1 Background on Battery T\&D Benefits . . . . . . . . . . . . 26

6.2 Transmission System Reliability Criteria . . . . . . . . . . . . . . 28

$6.3 \quad$ New Transmission Projects . . . . . . . . . . . . . . . . 28

6.3.1 Vidalia $230 / 115 \mathrm{kV}$ Project .................. 30

6.3.2 Warrenton $230 / 115 \mathrm{kV}$ Project $\ldots \ldots \ldots \ldots \ldots \ldots \ldots \ldots \ldots$

6.4 Loss Reduction . . . . . . . . . . . . . . . . . 35

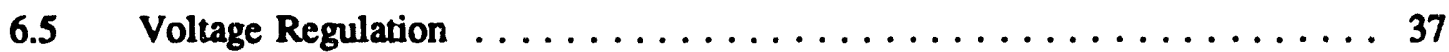

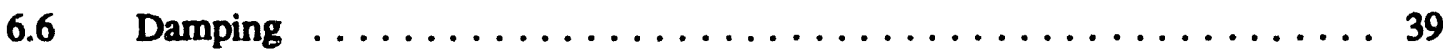

6.6.1 Backgmund $\ldots \ldots \ldots \ldots \ldots \ldots \ldots \ldots \ldots \ldots \ldots \ldots \ldots \ldots \ldots \ldots \ldots$

6.6.2 Damping in the Oglethorpe System ............. 41

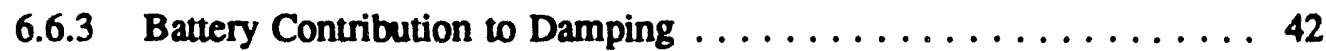

6.6.4 Battery Contribution to Damping on the Oglethorpe System . . . . . 44 
7.0 POTENTIAL SUBTRANSMISSION AND DISTRIBUTION

SYSTEM BENEFTTS $\ldots \ldots \ldots \ldots \ldots \ldots \ldots \ldots \ldots \ldots \ldots \ldots \ldots$

7.1 Subtransmission System $\ldots \ldots \ldots \ldots \ldots \ldots \ldots \ldots \ldots \ldots \ldots$

7.2 Backup Source Reliability Credit for Battery Storage $\ldots \ldots \ldots \ldots \ldots . . .45$

7.2.1 Battery Availability . . . . . . . . . . . . . . 46

7.2.2 Value or Cost of Interruption $\ldots \ldots \ldots \ldots \ldots \ldots \ldots \ldots \ldots \ldots$

7.3 Habersham Hollywood Metering Point $\# 8$ Substation $\ldots \ldots \ldots \ldots \ldots \ldots 47$

7.3.1 Deferment of Substation Transformer Replacement ..........48

7.3.2 Losses .......................... 50

7.3.3 Backup Power Supply Credit . . . . . . . . . . . . 50

7.4 Satilla EMC Metering Point $\# 12$ Lanes Bridge Substation .......... 51

7.4.1 Deferment of Substation Transformer . . . . . . . . . . 52

$7.5 \quad$ Planters $\$$ Egypt Substation $\ldots \ldots \ldots \ldots \ldots \ldots \ldots \ldots \ldots \ldots \ldots$

7.5.1 Deferment of $46 / 12 \mathrm{kV}$ transformer ............. 54

7.5 .2 Another Supply Source .................. 55

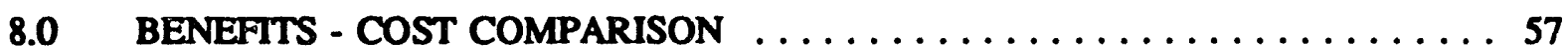

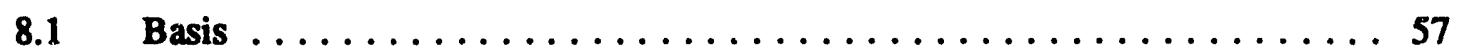

8.2 Summary of Five Application Cases $\ldots \ldots \ldots \ldots \ldots \ldots \ldots \ldots$

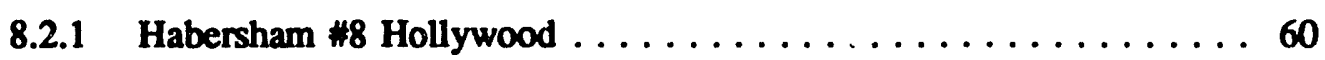

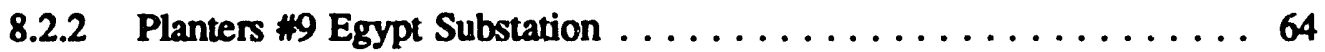

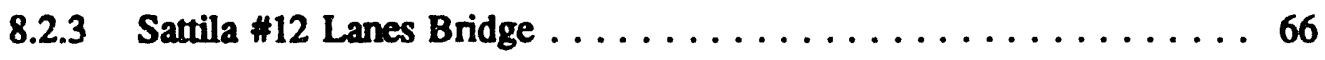

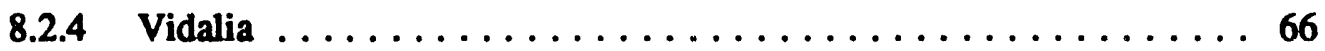

8.2.5 Warrenton ......................... 69

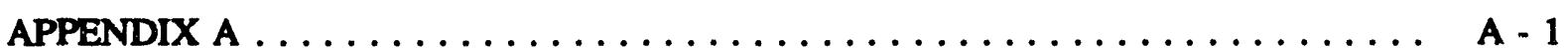

APPENDIX B $\ldots \ldots \ldots \ldots \ldots \ldots \ldots \ldots \ldots \ldots \ldots \ldots \ldots \ldots \ldots \ldots \ldots$

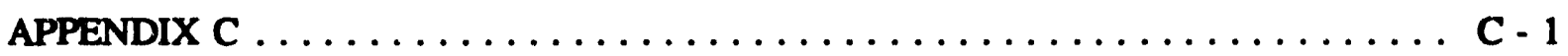

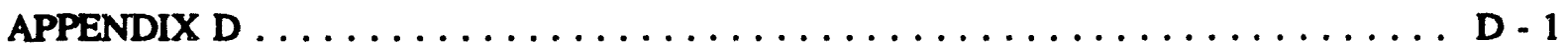

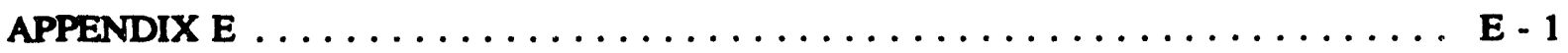

APPENDIX F $\ldots \ldots \ldots \ldots \ldots \ldots \ldots \ldots \ldots \ldots \ldots \ldots \ldots \ldots \ldots \ldots \ldots \ldots$ 


\section{LIST OF FIGURES}

No. Title

E-1 Comparison of benefits to cost for 5 battery locations $\quad$ E-2

E-2 Percent of benefits for 5 battery locations $\quad$ E-5

4.1 OPC system daily peaks in pu 10

4.2 Peak day load shape in 1991 with w/o direct load control 10

5.1 Peakday load shape with \& w/o direct load control 16

5.2 Winter weekly load shape with \& w/o psh 18

5.3 Summer weekly load shape with \& w/o psh 19

5.4 Peakday load shape with dlc \& psh 22

6.1 Vidalia 230/115 kV project 31

6.2 Peak load shape - Vidalia 230/115 kV transformer 31

6.3 Warrenton-Thomson $115 \mathrm{kV}$ project 34

6.4 Peakday load shape - Warrenton $230 / 115 \mathrm{kV}$ transformer 35

7.1 Summer peakday load shape - Habersham \#8 Hollywood substation 49

7.2 Daily peak load - Habersham Hollywood substation 49

7.3 Summer peakday load shape - Satilla Lanesbridge substation 53

7.4 Daily peak load - Satilla Lanesbridge substation 53

7.5 Summer peakday load shape - Planters *9 Egypt substation 55

7.6 Daily peak load - Planters *9 Egypt substation 56 


\section{LIST OF TABLES}

No. Title Page

E-1 Selected battery sizes $\quad$ E-2

E-2 Value of service or outage cost for one hour interruption E-4

4.1 Monthly component block rates for year $1991 \quad 11$

5.1 Oglethorpe Power Company load forecast dated March 13, 1991

5.2. Peak energy requirements with direct load control 17

5.3 Peak energy requirements (without direct load control) 17

5.4 Ratio of on-peak to off-peak purchased energy cost 20

6.1 Oglethorpe battery storage study transmission lines/substations projects list 29

6.2 Vidalia battery rating requirements, one transformer capacity $=140,000 \mathrm{kva}$

6.3 Warrenton battery rating requirements, one transformer capacity $=140,000 \mathrm{kva} \quad 34$

6.4 Cost comparison of battery converter, shunt capacitor \& svs 39

7.1 Value of service or outage cost for one hour interruption 47

7.2 Habersham Hollywood metering point \#8, battery rating requirements, existing 48 transformer capacity 10,500 kva

7.3 Outage statistics summary 51

7.4 Satilla \#12 EMC battery rating requirements, existing transformer capacity $7000 \mathrm{kva} 52$

8.1 General economic parameters $\quad 58$

8.2 Battery storage costs for base cases 59

8.3 Summary of net present value $\quad 60$

8.4 Estimated value of benefits and battery costs for Habersham \#8 Hollywood 61

8.5 Results of sensitivity analysis for Habersham *8 Hollywood 62

8.6 Estimated value of benefits and battery storage costs for Planters \#9 Egypt 65

8.7 Estimated value of benefits and battery storage costs for Satilla \#12 Lanesbridge 67

8.8 Estimated value of benefits and battery storage costs for Vidalia 68

8.9 Estimated value of benefits and battery costs for Warrenton 70 
Power Technologies, Inc.

\section{ACKNOWLEDGEMENT}

Power Technologies, Inc. wishes to acknowledge the help and cooperation received from many engineers and other staff members of Oglethorpe Power Corporation in supplying data and discussing their system characteristics and performance. The review and direction provided by both the Project Managers from Sandia National Laboratories and Oglethorpe Power Corporation was very helpful during the course of this study. 


\section{AN ESTIMATE OF BATTERY ENERGY STORAGE BENEFITS ON THE OGLETHORPE POWER SYSTEM}

\section{EXECUTIVE SUMMARY}

Sandia National Laboratories sponsored this study, with cofunding from Oglethorpe Power Corporation (OPC), to determine if battery energy storage may be competitive with other options on the OPC system. Sandia's broader interest is to be a catalyst in the evolution of a market for battery energy storage technology among rural electric cooperatives (RECs) in particular and other utilities in general.

In this study, the potential role which battery energy storage could play

a) in providing a backup power source or an alternative to traditional fossil fuel distributed generation, and

b) deferment of new transmission and distribution facilities

in the Oglethorpe Power (OPC and EMCs) System were investigated.

The methodology consisted of evaluating and quantifying the reasonable benefits attainable from the battery storage applications and comparing the total benefits against the cost of the battery storage. Several benefits and the particular characteristics of the OPC system were reviewed and analyzed including:

- Load shape with and without direct load control

- Future generation expansion plan

o Role of pumped storage hydro and its impact on load leveling

- Cost of purchased power and energy

- Future transmission projects

- Future distribution projects

- Radial transmission lines/substations

- Need for backup power source.

$$
\text { E - } 1
$$


Five specific locations within the OPC system, for the battery storage applications to defer transmission and distribution projects, were selected for this study. The battery sizes used for these five locations are shown in Table E-1.

TABLE E-1

SELECTED BATTERY SIZES

\begin{tabular}{|l|c|c|c|c|c|}
\hline \multirow{2}{*}{ ITEMS } & \multicolumn{5}{|c|}{ LOCATIONS } \\
\cline { 2 - 6 } & H & E & S & V & W \\
\hline \hline MWH & 7.5 & 26.0 & 9.0 & 217.0 & 218.0 \\
\hline MW & 1.5 & 6.5 & 1.5 & 31.0 & 43.6 \\
\hline HOURS & 5 & 4 & 6 & 7 & 5 \\
\hline
\end{tabular}

The results of a benefit to cost comparison are presented in Figure E-1. The methodology used for benefit to cost comparison is essentially based on calculating the present worth of all the annual cost savings/benefits accruing due to the battery application and the annual cost of owning and operating the corresponding battery plant.

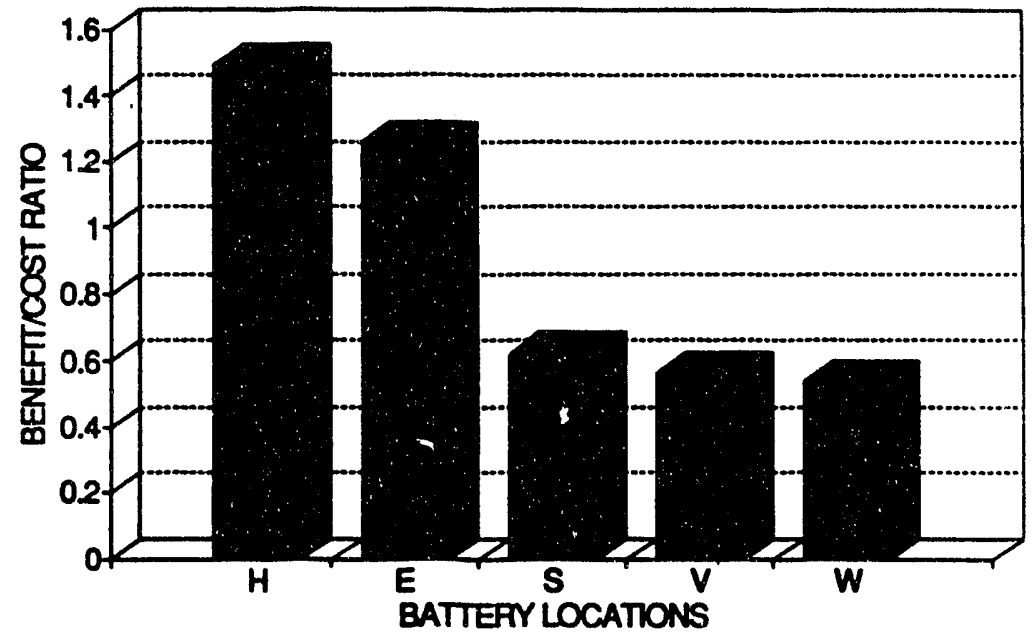

FIGURE E-1

COMPARISON OF BENEFITS TO COST

for 5 Battery Locations

$$
\text { E - } 2
$$


Only four major benefits due to battery storage application are included in these benefits to cost ratios. They are:
- Generation capacity
- Transmission deferment
- Distribution deferment
- Value of service or cost of outage.

The battery storage identified in this study is mostly in the form of a backup or reserve source. It is not used in the general sense of load leveling. A generation capacity (KW) credit based on a 10 hour discharge rating is applicable. This battery $\mathrm{KW}$ (based on 10 hour discharge rating) is essentially a generation reserve source. A 10 hour discharge rating is used so that even if this reserve is called upon during the annual peak load condition, the battery will be in a position to provide the power (KW) equal to the credit it has received for the longest peak load period of 10 hours. Thus, for example, a $10 \mathrm{MW}, 1$ hour battery is given a credit of $1 \mathrm{MW}$. The cost of the battery credit is based on the least expensive or the preferred generation alternative, which is a combustion turbine. The annual cost savings from avoiding the investment in this generation is credited to the battery.

The transmission credit is basically computed on the basis of the cost of deferring the project. The actual capital cost expenditure is considered to be postponed by a number of years. The annual cost savings due to the postponement is credited to the battery benefits. The distribution benefits are also calculated similarly.

The fourth and last benefit computed in this study is the value of service or cost of outages. The interruption cost or value of service (VOS) data is considered to be suitable to relate the worth of service reliability to the cost of service. The value of service or outage costs depends upon type of load, frequency and duration of interruption and timing of the interruption. However, some of these costs have a wide range. The cost range for one hour interruption has been reported in the literature. 
The actual cost or value of service used in this study is shown in Table E-2. For each of the five candidates of battery application analyzed in this study, it is assumed that the total amount of energy not served or KWH interrupted per year is equal to the total battery KWH rating. This means that, on the average, the sum of energy supplied to the customers by the battery during the interruptions over a period of one year is equal to its total energy rating.

TABLE E-2

VALUE OF SERVICE OR OUTAGE COST FOR ONE HOUR INTERRUPTION

\begin{tabular}{||l|c|c||}
\hline & \multicolumn{2}{|c|}{ \$/KWH Not Served } \\
\hline \hline 1 & Low & High \\
\hline Residential $^{2}$ & 0.05 & 5.00 \\
\hline Industrial $^{2}$ & 2.00 & 53.00 \\
\hline Commercial $^{2}$ & 2.00 & 35.00 \\
\hline Poultry \& Eggs $^{1}$ & 0.12 & 5.68 \\
\hline
\end{tabular}

After computing benefits, the battery storage system costs were calculated. For the battery alone a different life is used than for the entire battery storage plant. The O\&M used is $0.25 \%$ of the capital cost. Amortising the capital cost is levelized over the plant life. The salvage value of the battery cells is included in computing the levelized annual cost. The replacement cost of battery cells is included as needed. The converter and balance of plant are assumed to have a 30 year life and no salvage value.

Benefit to cost ratio for battery application at five different locations for T\&D deferment have been computed. The percentage benefit the four items are shown in Figure E-2.

1 G. Walker and R. Billinton, "Farm Losses Resulting from Electric Service Interruptions - A Canadian Survey," IEEE Transactions on Power Systems, Vol. 4, No. 2, May 1989, pp 472-478.

2 A.P. Sanghvi et al, "Power System Reliability Planning Practices in North America", IEEE Transactions on Power Systems, Vol. 6, No. 4, Nov. 1991, pp 1485-1492.

$$
\text { E }-4
$$




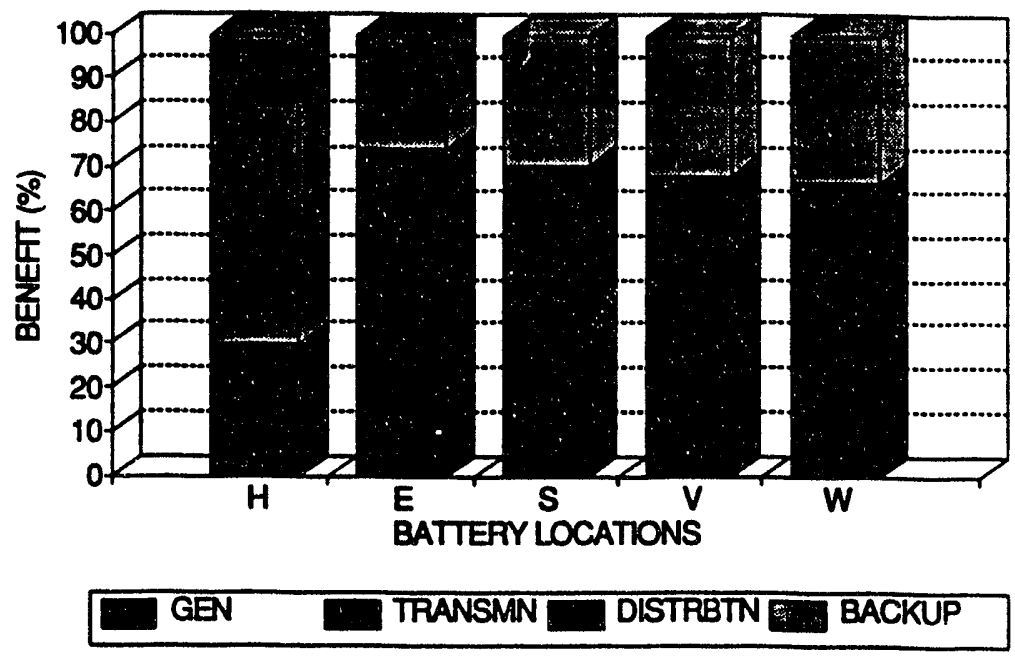

FIGURE E-2

PERCENT OF BENEFITS

for 5 Battery Locations

- Backup source (considering cost of outage, value of service or value of unserved energy) credit was the most significant benefit from battery storage. In terms of customer loads on the OPC/EMC system, the poultry industry loads are considered to suffer high damage when service interruption occurs. Hence, some of these egg hatcheries and chicken farms currently provide, or plan to install backup diesel generation. Application of a 7,500 KWH, 5 hours discharge rating battery at Hollywood substation showed a benefit to cost ratio of 1.5 . This was one of the highest benefit to cost ratios obtained in this study.

- Whenever there is an outage on a radial line, an interruption of service occurs. If the line is inaccessible or has difficult terrain, then repair of the line may be difficult and corresponding outage may be lengthy. One such example selected for this study was the application of a battery for backup instead of building a second transmission line. The benefit to cost ratio is 1.26 for this case. This

$$
\text { E - } 5
$$


substation is an attractive location (out of the 5 analyzed) for the battery application and deferment of a second transmission line.

- A third substation was selected for evaluating the deferment of a new distribution transformer. The benefit to cost ratio turned out to be 0.62 . The generation capacity credit was the largest, followed by the backup source credit with distribution credit being the least. No transmission deferment was used in this example. A higher backup source credit in lieu of new transmission line credit may be warranted here. The value of service has to be $\$ 8.00 / \mathrm{KWH}$ for breakeven of benefit to cost ratio as compared to $\$ 2.61 / \mathrm{KWH}$ (used in the base case for the ratio of $\mathbf{0 . 6 2 )}$.

o Deferment of an additional $140 \mathrm{MVA}, 220 / 115 \mathrm{kV}$ transformer at two substations were evaluated. The benefit to cost ratios were 0.57 and 0.54 respectively. Because of parallel $230 \mathrm{kV}$ and $115 \mathrm{kV}$ lines connected to these substations, oversize battery storage capacity was needed to provide a given load reduction on the existing transformers. Hence, the size of the battery and its cost would be about twice that required to reduce load on a radially connected transformer, in which case the benefit to cost would be nearly breakeven.

In addition to base cases, several sensitivity analyses were performed for the highest benefit to cost application. The sensitivity analysis included changing the following parameters, one at a time:

- Battery cost

- Converter and balance of plant cost

o Battery life

- Salvage value

- Value of service/cost of outages

o Extended distribution benefits. 
In the first case, the battery's cost can be $60 \%$ higher than the base case, for the value of benefits to equal the cost of battery storage. In the second case, the converter and balance of plant (PCS + BOP) cost was doubled and this reduced the benefit to cost ratio from 1.49 to 1.27. These two sensitivity cases show that the battery cells cost has a higher effect on the overall cost as compared to the converter and other costs.

In the thi:d case, the battery life was reduced to 10 years from 15 years. This means two battery replacements are included in this case- 3 as compared to only one battery replacement in the base case. The benefit to cost ratio decreased from 1.49 to 1.42 which is not a substantial reduction. Thus, there may be economic advantages in improving the cycle life of lead acid batteries, but the chronological life is not significant as compared to the battery cost itself.

In the fourth case, the salvage value was doubled from $20 \%$. Sirprisingly, the benefit to cost ratio increased to 1.68 . This may be partly explained by the escalation used in computing replacement battery cost. Essentially, the salvage part of the battery cost is escalated by $4.5 \%$ because at the end of battery life, the trade-in value of the battery is assumed to be equal to the salvage percentage of the new battery cost.

The fifth sensitivity case involved the value of service or backup source credit. As noted earlier, this item contributed most to the battery benefits. This value of service may be about $50 \%$ of the base case for the breakeven cost.

In the sixth sensitivity case, the distribution benefits were extended to 30 years. The base case showed the distribution transformer deferment for 10 years only. Because the battery can be moved to another location, similar distribution benefits may continue to accrue. This case shows an increased benefit to cost ratio of 1.58 . The cost of moving the battery and any change in value of service are not recognized in this case. 


\section{AN ESTIMATE OF \\ BATTERY ENERGY STORAGE BENEFTTS \\ ON THE OGLETHORPE POWER SYSTEM}

\subsection{INTRODUCTION}

The purpose of this study was to identify the potential role battery storage could play in providing equal or better performance than other traditional transmission and distribution (T\&D) options, such as adding new T\&D facilities and equipment in the Oglethorpe Power System.

Sandia National Laboratories sponsored this study, with cofunding from Oglethorpe Power Corporation (OPC), to determine if battery energy storage may be competitive with other options on the OPC system. Sandia's broadir interest is to be a catalyst in the evolution of a market for battery energy storage technology among rural electric cooperatives (RECs); in particular and other utilities in general.

This study verified recent concurrence that justification of battery energy storage shiould be analyzed differently as compared to most other utility equipment, including other forms of storage. Most utility equipment serves only a single purpose, and is justified only if it serves that purpose. Examples are generating plants which serve only a single purpose regardless of where they are located. A distribution substation also serves just one purpose, though it must be in the proper place to do so. Batteries, potentially, provide several 'resource' beneíits, several T\&D benefits, and even some 'strategic' benefits. A proper evaluation requires that every possible benefit be investigated and quantified. A battery is justified if the sum of all of the benefits exceeds its cost.

The approach through most of this study is thus to avoid comparing battery costs with individual benefits. In fact, the cost of a battery is not given any consideration until all possible benefits have been identified and estimated.

This study is not thorough enough to truly 'quantify' all the benefits of batteries on the OPC system. Indeed, the intent of the study is to estimate the benefits with sufficient accuracy to determine whether more in-depth studies are warranted. 
The main conclusions from this study are presented in Section 2.0. The generation and transmission perspective for this type of study is discussed in Section 3.0. Section 4.0 describes the characteristics of the Oglethorpe Power System. The generation related benefits from battery storage are discussed in Section 5.0. Potential transmission and distribution benefits are evaluated in Sections 6.0 and 7.0 respectively. Summation of these benefits and cost-benefit comparison are presented in Sections 8.0. Four appendices contain brief descriptions of battery storage benefits, terms, attributes, and hardware and control. 


\subsection{CONCLUSIONS}

In this study, the potential role which battery energy storage could play

a) in providing a backup power source or an alternative to traditional fossil fuel distributed generation, and

b) deferment of new transmission and distribution facilities

in the Oglethorpe Power (OPC and EMCs) System were investigated.

The methodology consisted of evaluating and quantifying the reasonable benefits attainable from the battery storage application and comparing the total benefits against the cost of the battery storage. Several benefits and the particular characteristics of the OPC system were reviewed and analyzed including

- Load shape with and without direct load control

o Future generation expansion plan

- Role of pumped storage hydro and its impact on load leveling

- Cost of purchased power and energy

- Future transmission projects

- Future distribution projects

- Radial transmission lines/substatioris

- Need for backup power source.

The detailed results from this review and analysis for five specific locations within the OPC system are presented in this report. The main conclusions are:

i. Backup source (considering cost of outage, value of service or value of unserved energy) credit was the most significant benefit from battery storage. In terms of customer loads on the OPC/EMC system, the poultry industry loads are considered to suffer high damage when service interruption occurs. Hence, some of these egg hatcheries and chicken farms 
currently provide, or plan to install backup diesel generation. Habersham \#8 (Hollywood) Substation serves a substantial number of these chicken farms. Application of a 7,500 KWH, 5 hours discharge rating battery at Hollywood substation showed a benefit to cost ratio of 1.5 . This was one of the higher benefit to cost ratios obtained in this study.

ii. The OPC system has approximately 24 substations served by radial subtransmission lines. Whenever there is an outage on a radial line, an interruption of service occurs. If the line is inaccessible or has difficult terrain, then repair of the line may be difficult and corresponding outage may be lengthy. One such example selected for this study is Planters \#9 (Egypt) substation. Application of a battery for backup instead of building a second transmission line was analyzed. The benefit to cost ratio is 1.26 . This Egypt substation is an attractive location (out of the 5 analyzed) for the battery application.

iii. Satilla \#12 (Lanes bridge) substation was selected for evaluating the deferment of a new distribution transformer. The benefit to cost ratio turned out to be $\mathbf{0 . 6 2}$. The generation capacity credit was the largest, followed by the backup source credit with distribution credit being the least. No transmission deferment was used in this example. A higher backup source credit in lieu of new transmission line credit may be warranted here. The value of service has to be $\$ 8.00 / \mathrm{KWH}$ for breakeven of benefit to cost ratio as compared to $\$ 2.61 / \mathrm{KWH}$ (used in the base case for the ratio of 0.62 ).

iv. Deferment of an additional $140 \mathrm{MVA}, 220 / 115 \mathrm{kV}$ transformer at both Vidalia and Warranton substations were evaluated. The benefit to cost ratios were 0.57 and 0.54 respectively. Because of parallel $230 \mathrm{kV}$ and $115 \mathrm{kV}$ lines connected to these substations, oversize battery storage capacity was needed to provide a given load reduction on the existing transformers. Hence, the size of the battery and its cost would be about twice that required to reduce load on a radially connected transformer; in which case the benefit to cost would be nearly breakeven. 
v. High on-peak energy purchase price makes a load leveling type of application very attractive. However, the existing direct load control (DLC) and the Rocky Mountain pumped storage hydro (PSH) plant under construction provide most of the load leveling function for the OPC transmission system. Battery Energy Storage would be more appropriate for Distribution.

vi. Analysis for peak load shape, after factoring the DLC and PSH, shows that a generation reserve capacity credit for the battery storage based on a ten hour discharge period may be given. For example, a $10 \mathrm{MWH}$ battery rated for 1 hour discharge may be given $1 \mathrm{MW}$ generation reserve capacity credit.

vii. Other generation credits such as spinning reserve, load following and area regulation are present. But these benefits are considered to be small and difficult to quantify. The future operation of PSH will provide considerable spinning reserve benefits. Any leftover benefits for the battery storage will be insignificant. 


\subsection{THE G\&T PERSPECTIVE}

Rural Electric Cooperatives, (RECs), are consumer-owned utilities established to provide electricity service to rural America. Historically, most U.S. farms were without electric power until the mid-1930s because large, investor-owned utilities could not economically justify building distribution lines to the low customer density rural areas. In 1935, President Franklin D. Roosevelt signed an executive order creating the Rural Electrification Administration (REA), an arm of the New Deal that worked to form rural America into cooperatives to put up their own power lines. As a result of the order, more than 1,000 distribution cooperatives were formed, and they immediately began constructing lines to rural areas. By 1939, over 100,000 miles of power lines had been completed and more than one million rural residents received electricity. Today, over half the electric distribution lines in the U.S. are owned and maintained by cooperatives. These cooperatives distribute about 7 percent of the nation's electricity.

Typical rural electric cooperatives maintain almost 2,000 miles of line and serve close to 8,000 customers. Residential customers account for about 90 percent of the cooperative's total customers, while approximately 8 percent of the cooperative's customers are commercial. Rural electric cooperatives (RECs) average five consumers per mile. Investor-owned utilities average 31 customers per mile of line.

The low customer density on rural electric transmission and distribution systems makes RECs cost of transmission and distribution much higher, per customer, per $\mathrm{Kw}$ of peak load, or per Kwh sold, than that of most municipal or investor owned electric utilities. T\&D costs are also high for RECs because T\&D systems must be designed to accommodate the local peak load, and many REC systems have a relatively poor load factor. Because battery energy storage can be used to defer T\&D investments, its $T \& D$ deferral benefit on REC systems may be very significant.

The rural low density nature of REC systems also affects the reliability that can be economically justified. Similarly, because of extensive line exposure, maintaining power quality is difficult on rural REC systems. Batteries can provide a local source of power, 
largely independent of the transmission system, and thus can be used to improve reliability and power quality.

Another consequence of long lines and low customer density is high T\&D losses. By charging batteries at night and discharging them during the peak load hours, T\&D losses can be measurably reduced.

Among all types of rural electric cooperatives, the generation and transmission cooperatives (G\&T) appear to be the most likely to adop: battery energy storage. There are over 60 G\&T cooperatives, ranging in size from the smallest, serving about 6,000 customers with an annual operating revenue of $\$ 5$ million, to the largest, Oglethorpe Power, serving nearly 900,000 customers (through distribution cooperatives) with annual revenue of about one billion dollars.

Generation and transmission cooperatives have the construction and operation experience that would allow them to successfully build and maintain battery energy storage systems. In 1988, G\&T cooperatives had 239 generating plants with an overall generating capacity (nameplate) of over $30,000 \mathrm{MW}$. Steam generating plants are the G\&T cooperatives' chief source of energy, producing 86 percent of the total generated. Generation at internal combustion plants accounted for 2.5 percent of the total, while nuclear and hydroelectric production amounted to 11.3 percent and 0.2 percent respectively. With their considerable experience in generation, cooperatives would have no foreseeable difficulties designing, constructing, operating and maintaining battery energy storage facilities.

In summary, rural electric cooperatives have many of the aspects of large, sophisticated electricity customers. Many of them pay significant demand, energy, and/or power factor correction charges which can yield significant savings when peak demand is reduced. Generation and transmission cooperatives have the size, strength, and experience to construct and operate a battery storage facility and are in a position to take advantage of reduced capital costs and operating flexibility. The introduction of battery energy storage to the electric utility industry through this market segment can be an effective strategy. 


\subsection{CHARACTERISTICS OF THE OGLETHORPE POWER SYSTEM}

Oglethorpe Power Corporation (OPC) was formed in 1974 by 39 of Georgia's 42 electric membership corporations (EMCs) for the purpose of supplying electricity to its founding members. Today, OPC serves over 71 percent of the area in the State of Georgia and is one of the largest generation and transmission (G\&T) cooperatives in terms of number of ultimate customers and annual kilowatt hour sales.

Oglethorpe Power's generation capacity has traditionally been provided by joint ownership and lease agreements with the local investor-owned utility. Most of the base load capacity is provided by the Hatch and Vogtle nuclear, and Scherer and Wansly coal plants. However, load growth has primarily been in the form of peaking power. In 1988, peak demand grew by 8.6 percent while energy demand increased by 5.8 percent. Furthermore, system growth provided the incentive for Oglethorpe Power Corporation to build its own generation facilities. Thus, OPC has pursued a course of building facilities that best provide peaking power. This includes the $2.1 \mathrm{MW}$ Walter $\mathrm{H}$. Harrison hydroelectric plant and the $760 \mathrm{MW}$ Rocky Mountain pumped storage plant which is under construction.

The cooperatives supplied by OPC are spread throughout the State of Georgia. Along with the other utilities, OPC shares about 15,000 miles of transmission network. OPC, along with other participants, have pioneered the concept of an integrated transmission system (ITS). The ITS agreement allows the participants to use any transmission line or substation on the network. Each participant buys into the existing transmission system based on the contribution to the coincident and non-coincident annual amount of power the supplier transmitted over the system. Thus, there is considerable incentive to reduce the annual peak load imposed on the transmission system by each participant.

OPC is in another unique situation. In the State of Georgia, customers with connected loads greater than $900 \mathrm{kw}$ (referred to as "customer choice load") can select their power supply from any EMC or other utility within the state. Thus, here is considerable competition for these "customer choice loads." Obviously, cost, reliability, and quality power are important in winning these "choice customer loads". This competitive factor, 
not an influential factor for most electric utilities, is an important factor for OPC and its member cooperatives.

The investigation and adoption of advanced technologies, such as Battery Energy Storage, is a natural outcome of OPC's need to supply peaking power, minimize cost of extensive transmission system, and compete for customer choice loads. Battery energy storage is promising to Oglethorpe Power Corporation because of unique features such as:

- Peaking power without new generation capacity construction;

- Flexible size (modular) and siting (existing substation locations);

- Additional value to customers such as improved power quality and/or reliability;

O Offers system operation benefits and flexibility;

- Transmission and distribution benefits such as substation or line deferral;

- ITS parity benefits.

OPC, jointly with Electric Power Research Institute, is also investigating other options. A parallel study entitled "Assessment of the Benefits of Distributed Fuel-cell and Diesel Generators" is also underway.

\subsection{Load Characteristics}

OPC had a peak load of 3,883 MW in 1991. The load is forecast to grow to nearly 6,000 MW by the year 2000 . The load is summer peaking. During winter, the daily peaks are sharp, but the peaks are lower than summer peaks (Figure 4.1). The summer peaks are almost flat and last 6-8 hours in the afternoons (Figure 4.1). The winter load profile has twin peaks, with the early morning peak sharper and higher than the evening peak. The annual load factor of the native load is about 45 percent. Most (95 percent) of the ultimate customers are residential, accounting for about 75 percent of the annual energy, and hence the low load factor. Out of 74 substations which were examined, 12 substations showed sharp peaks. In terms of future load, OPC forecasts that about 7 EMCs may contribute about 70 percent of the growth. 


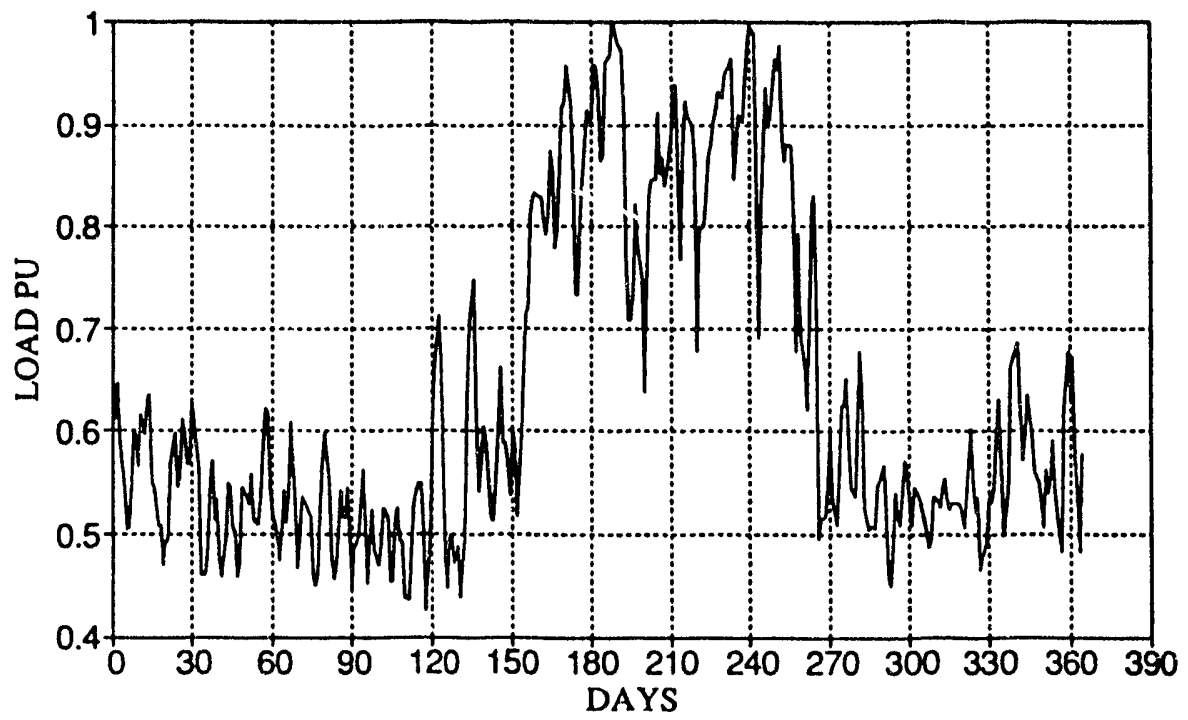

FIGURE 4.1

OPC SYSTEM DAILY PEAKS IN PU

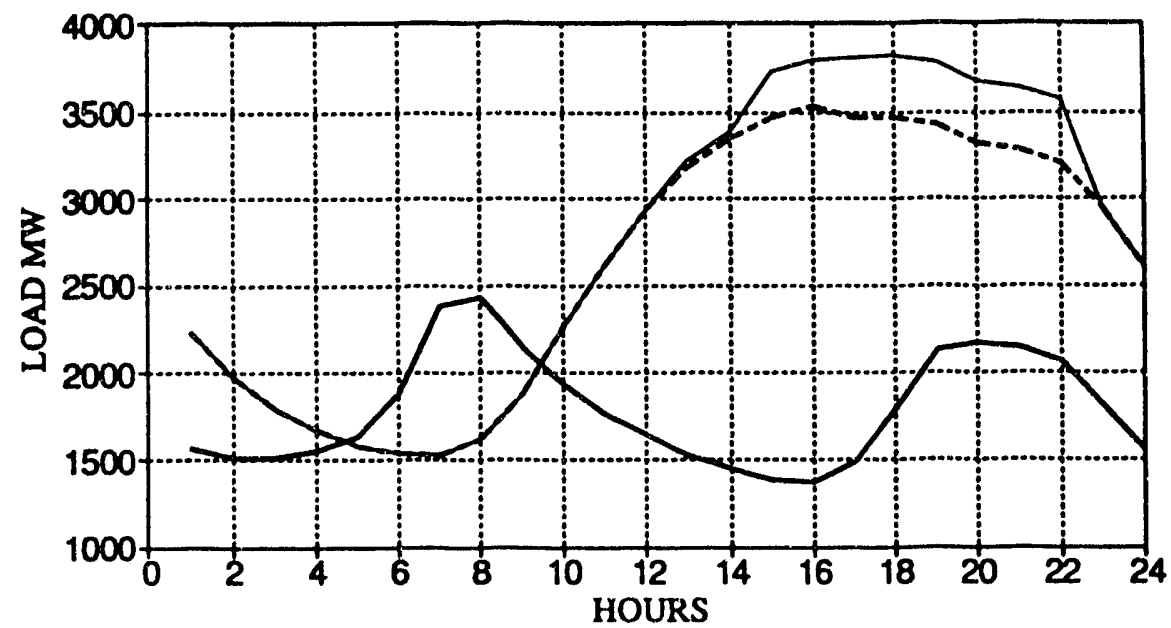

- SUMMER $\quad-\cdots$ SUMMER WIDLC - WINTER

FIGURE 4.2

PEAK DAY LOAD SHAPE IN 1991 WTTH \& W/O DIRECT LOAD CONTROL 


\subsection{Generation}

OPC's generation mix includes part ownership in two nuclear power plants amounting to $1155 \mathrm{MW}$ by the year 1994, some base load coal plant capacity, and hydro power purchase from federal agencies (up to $542 \mathrm{MW}$ ). The remaining requirement is purchased from other utilities. OPC is building a pumped storage facility called Rocky Mountain Project with $760 \mathrm{MW}$ of capacity. This plant is expected to be in service in 1996 and OPC owns a capacity of $651 \mathrm{MW}$.

\subsection{Purchase Power}

OPC purchases power to meet part of the load requirements of its member cooperatives. The purchased power is in blocks of $250 \mathrm{MW}$ each with about 15 percent reserve (35 MW) included in this block. A notice of 12-24 hours is required to purchase base load capacity and energy. Otherwise, the purchased power is considered to be peaking capacity and energy which has a higher energy charge.

TABLE. 4.1

MONTHLY COMPONENT BLOCK RATES FOR YEAR 1991

$\begin{array}{llll}\text { Blocks 1 - 3 } & 250 \mathrm{MW} & \$ 6.50 / \mathrm{kw} / \text { month } & 20.93-23.79 \$ / \mathrm{MWH} \\ \text { Block 4 } & 250 \mathrm{MW} & \$ 7.10 / \mathrm{kw} / \text { month } & 27.52 \$ / \mathrm{MWH} \\ \text { Blocks 5 -6 } & 215 \mathrm{MW} & \$ 1.25 / \mathrm{kw} / \text { month } & 70.15 \$ / \mathrm{MWH}\end{array}$

\subsection{Load Management}

Nearly 300,000 direct load control (DLC) switches have been installed to control airconditioners and water heaters in most of the EMCs. The water heaters can be shut off for long periods (hours). Airconditioners are cycled at 7 minute intervals. The peak load reduction provided by load management in 1991 is estimated to be $350 \mathrm{MW}$. The peak day load profile with and without load management for the year 1991 is shown in Figure 4.2. OPC estimates that there may be another $150 \mathrm{MW}$ of load management potential available within the system by expanding the direct load control. 
Power Technologies, Inc.

\subsection{Integrated Transmission System}

OPC, along with other utilities in the state, has implemented the concept of an integrated transmission system (ITS). The concept is based on the assumption that each user buys into the existing transmission system based on the amount of power each transmits over the system. The noncoincident peaks are used in calculating the required investment for all participants except for Georgia Power Company. Annual fixed charges of owner companies are used in calculating the parity payments for each participant should a participant be over or under invested in the ITS. The load management system presently used by OPC fits into this strategy very well. Any other demand side option will also be useful for this purpose. 


\subsection{GENERATION RELATED BENEFITS}

Three generation related benefits assigned to battery storage when used for load leveling are:

1. battery storage MW capacity credit associated with displacing other generation alternatives in the resource plan,

2. production cost savings associated with daily cycling (charge/discharge) of batteries, and

3. dynamic benefits from reduced unit startup and shutdown to meet spinning reserve and load following obligations.

These three benefits, as applicable to the OPC system in particular, are discussed in the next three sections.

\subsection{Generation System Reliability Benefit on the OPC System}

Generation system reliability criteria used to deırmine the required installed generation capacity consists of both deterministic and probabilistic criteria. This criteria varies from utility to utility. Generally, deterministic reliability criteria may include:

\footnotetext{
o Percent MW Capacity Reserve

- Percent Mwh Energy Reserve (Adverse Hydro Condition)

- Combination of above
} 
Probabilistic criteria may include:

- LOLE (Loss of Load Expectation)

- Expected Unserved Energy

- Frequency and Duration

Generally, in order for a battery to obtain credit and defer generation additions, a utility must need new generation capacity in the time frame being studied. For example, batteries cannot obtain capacity credit if a utility already has excess capacit;' installed, even though batteries may further increase generation system reliability. Also, in order to obtain capacity credit, batteries must meet the generation reliability criteria.

Batteries do not necessarily have to operate on a daily charge/discharge cycle to obtain capacity credit. However, to provide this benefit batteries may need several hours of storage. For example, assume a utility uses a deterministic percent reserve criteria, or a basic LOLE criteria using only daily one-hour peak MW loads. Because batteries are energy limited, it's unlikely that a one hour battery will be acceptable when common sense is applied, although it may technically meet the reliability criteria.

The peak load forecast for the OPC system, with and without direct load control (DLC) is shown in Table 5.1. As evident from this table, OPC needs additional capacity in the future years, so if batteries are applied, then a capacity credit is certainly applicable. 
Power Technologies, Inc.

TABLE 5.1

OGLETHORPE POWER COMPANY

\section{LOAD FORECAST DATED MARCH 13, 1991}

\begin{tabular}{|c|c|c|c|c|}
\hline Year & $\begin{array}{l}\text { Peak } \\
\text { Load } \\
\text { (MW) }\end{array}$ & $\begin{array}{l}\text { Annual } \\
\text { Energy } \\
\text { (GWH) }\end{array}$ & $\begin{array}{l}\text { Peak MW } \\
\text { With DLC } \\
\text { (a) }\end{array}$ & $\begin{array}{l}\text { Additional } \\
\text { Capacity } \\
\text { Needs (MW) }\end{array}$ \\
\hline 1992 & 4,281 & 16,978 & 3,936 & 158 \\
\hline 1993 & 4,465 & 17,696 & 4,102 & 156 \\
\hline 1994 & 4,671 & 18,458 & 4,289 & 297 \\
\hline 1995 & 4,863 & 19,219 & 4,462 & (171) \\
\hline 1996 & 5,049 & 20,023 & 4,630 & 37 \\
\hline 1997 & 5,280 & 20,846 & 4,843 & 298 \\
\hline 1998 & 5,516 & 21,687 & 5,060 & 564 \\
\hline 1999 & 5,767 & 22,629 & 5,293 & 849 \\
\hline 2000 & 6,044 & 29,174 & 5,551 & 1,165 \\
\hline 2001 & 6,330 & 24,692 & 5,819 & 1,515 \\
\hline 2002 & 6,606 & 25,743 & 6,076 & 1,963 \\
\hline 2003 & 6,873 & 26,842 & 6,324 & 2,303 \\
\hline 2004 & 7,171 & 27,996 & 6,604 & 2,838 \\
\hline 2005 & 7,473 & 29,174 & 6,887 & 3,185 \\
\hline 2006 & 7,774 & 30,230 & 7,169 & 3,515 \\
\hline 2007 & 8,137 & 31,549 & 7,514 & 4,000 \\
\hline 2008 & 8,501 & 32,875 & 7,860 & 4,424 \\
\hline 2009 & 8,814 & 34,237 & 8,154 & 4,837 \\
\hline 2010 & 9,127 & 35,643 & 8,449 & 5,237 \\
\hline
\end{tabular}

The next question is to determine what capacity credit is applicable to the battery. In principle, the capacity credit or benefit will equal the lowest cost new generation alternative, which is combustion turbine. 
As mentioned earlier, capacity credit may not be reasonable if the battery has just one hour of storage. A discharge rating such as one hour may not be sufficient to avoid a new peak or the need to purchase power in blocks 5 or 6 over the relatively long peak load period. However, the deterministic criteria of $15 \%$ reserve is based on peak load only. Thus, only the peak day load shape needs to be examined to determine the number of hours of battery capacity required to qualify for credit. Peak load shape for the year 1991 is shown in Figure 5.1. Both the native load and the lisad after load management (direct load control) are shown. Based on this load shape, the following hour ratings are required to qualify for capacity credit.

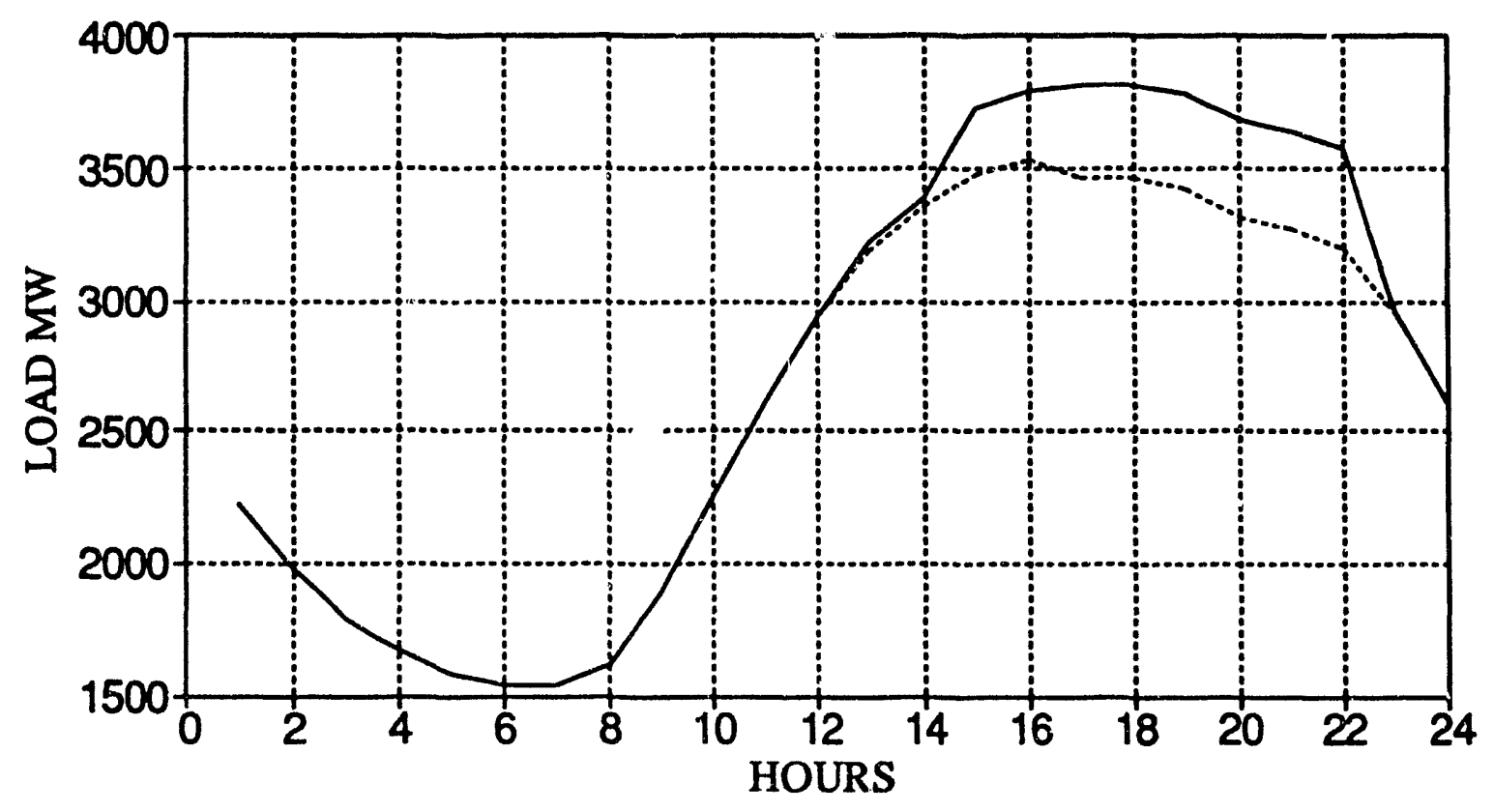

- SUMMER $\quad$-..... SUMMER W/DLC:

FIGURE 5.1

PEAKDAY LOAD SHAPE WITH \& W/O DIRECT LOAD CONTROL 
TABLE 5.2

PEAK ENERGY REQUIREMENTS WITH DIRECT LOAD CONTROL

\begin{tabular}{|c|c|c|c||}
\hline \multicolumn{2}{|c|}{ Capacity (MW) } & Discharge Hours & $\begin{array}{r}\text { Total } \\
\text { MWH } \\
\text { Rating }\end{array}$ \\
\hline Block & Cumulative & 2 & 120 \\
\hline 60 & 60 & 4 & 136 \\
\hline next 4 & 64 & 5 & 356 \\
\hline next 44 & 108 & 6 & 770 \\
\hline next 69 & 177 & & \\
\hline
\end{tabular}

TABLE 5.3

PEAK ENERGY REQUIREMENTS (WITHOUT DIRECT LOAD CONTROL)

\begin{tabular}{||c|c|c|c||}
\hline \multicolumn{2}{|c|}{ Capacity (MW) } & \multirow{2}{*}{ Discharge Hours } & $\begin{array}{c}\text { Total } \\
\text { MWH } \\
\text { Rating }\end{array}$ \\
\hline \hline Block & Cumulative & & 7 \\
\hline 7 & 7 & 1 & 43 \\
\hline next 18 & 25 & 2 & 85 \\
\hline next 14 & 39 & 3 & 277 \\
\hline next 48 & 87 & 4 & 527 \\
\hline next 52 & 139 & 5 & 743 \\
\hline next 36 & 175 & 6 & 7 \\
\hline
\end{tabular}

The amount of load reduction due to load management is very much weather dependent. There is also a saturation effect of load management. Thus, battery storage may supplement DLC and also act as a reserve capacity.

The discharge hours shown in the above two tables are applicable only until the end of 1995. OPC is constructing a pumped storage hydro (PSH) facility with an in-service date of late 1995 or early 1996. The weekly load shapes for both summer and winter are shown 
in Figures 5.2 and 5.3 respectively. The PSH discharge and pumping shown in these figures have been determined by using Production Costing Program, and hence, all restrictions and economics have been enforced. The use of the PSH facility flattens the peak load to more than 10 hours. Thus, any capacity credit for a battery on the OPC system beyond 1996 requires a ten hour discharge rating. The MW capacity attributable to the battery will be based on this discharge requirement. However, some credit is justified even for a 1 hour battery. For instance, a $10 \mathrm{MW} 1$ hour battery could provide $1 \mathrm{MW}$ for 10 hours, and will be given a $1 \mathrm{MW}$ capacity credit.

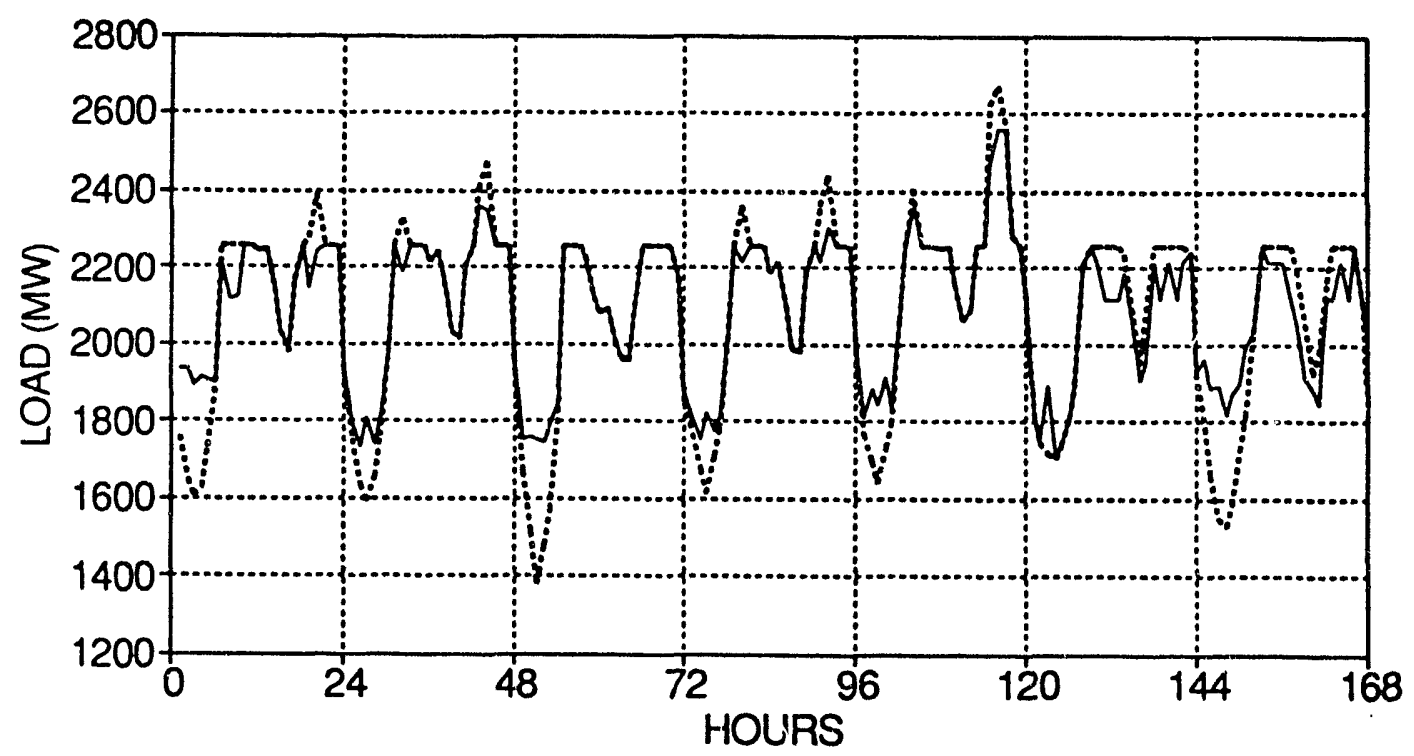

$\cdots \cdot \cdots$ NATIVELOAD - WITHPSH

FIGURE 5.2

WINTER WEEKLY LOAD SHAPE WTTH \& W/O PSH 


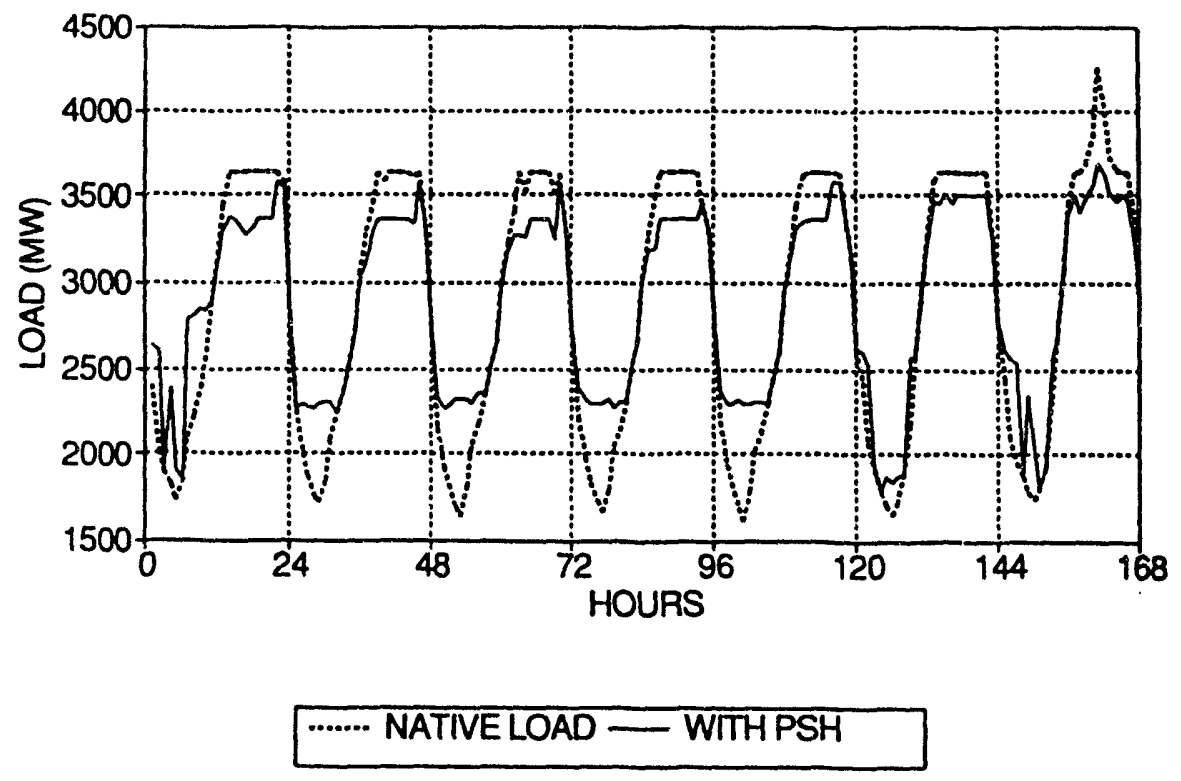

FIGURE 5.3

SUMMER WEEKLY LOAD SHAPE WTTH \& W/O PSH

\subsection{Production Cost Savinos}

Production cost savings are generally determined by running a production cost program over a period of time with and without batteries to determine the fuel savings associated with charging and discharging the battery on a daily cycle. Batteries operating on a regular daily charge/discharge cycle (load leveling) will significantly reduce system production cost if there is significant fuel cost differential between peak and off-peak load periods.

Production cost savings from battery energy storage is conditioned on:

1. A cost differential between on-peak and off-peak energy cost sufficient to cover battery turn-around losses,

2. A modest peak load duration (several hours or less),

3. Good battery life under cycling duty. 
The on-peak energy cost (usually the cost of burning oil or gas in combustion turbines) is higher than the off-peak energy cost on the OPC system. Battery storage systems typically have a turnaround efficiency of $70 \%$ to $80 \%$. Hence, the ratio of the off-peak and on-peak energy cost should be greater than 1.25 (assuming $80 \%$ efficiency) to result in any production cost savings.

\subsubsection{Differential Cost of Energy}

OPC purchases a part of its power need from other utilities. The forecast of cost of purchased energy and corresponding ratio of on-peak to off-peak energy is shown in Table 5.4.

TABLE 5.4

RATIO OF ON-PEAK TO OFF-PEAK PURCHASED ENERGY COST

$\begin{array}{lrcr}\text { YEAR } & \begin{array}{c}\text { ON-PEAK } \\ \text { mills/kwh }\end{array} & \begin{array}{c}\text { OFF-PEAK } \\ \text { mills/kwh }\end{array} & \text { RATIO } \\ 1992 & 70.15 & 20.93 & 3.4 \\ 1993 & 70.20 & 21.87 & 3.2 \\ 1994 & 84.05 & 19.28 & 4.4 \\ 1995 & 100.62 & 17.78 & 5.7 \\ 1996 & 107.88 & 18.50 & 5.8 \\ 1997 & 115.61 & 19.31 & 6.0 \\ & & & \\ 1998 & 123.89 & 20.13 & 6.2 \\ 1999 & 132.76 & 20.97 & 6.3 \\ 2000 & 142.27 & 28.05 & 5.1 \\ 2001 & 149.97 & 29.35 & 5.1 \\ 2002 & 163.35 & 30.76 & 5.3 \\ 2003 & 173.03 & 32.27 & 5.4\end{array}$


Assuming round trip battery efficiency of $75 \%$ (middle of $70 \%-80 \%$ range), ratio of onpeak to off-peak energy cost of 1.33 is a break-even point. The ratios shown in the above table are considerably higher than the break-even point. Thus, the purchased energy cost differential is very favorable. For example, for every kwh of discharge from the battery, the savings are

$$
70.15-(20.93 / 0.75)=42.24 \mathrm{mills} / \mathrm{kwh}
$$

using 1992 purchased energy costs.

Recognizing the big cost differential between peak and off-peak energy costs, OPC is constructing a PSH facility due for commissioning in 1996. OPC's share of this PHS is about $650 \mathrm{MW}$. The PSH will function similarly to the battery and a typical peak day load shape before and after the PSH use is shown in Figure 5.4. As discussed earlier, the final load shape, after load management (this is seasonal) and PSH load leveling, becomes flat for periods of $\mathbf{1 0}$ hours or longer. The available charging off-peak capacity and energy which is economical also becomes limited. Thus, any potential credit due to capacity peaking reduction and peak energy savings through battery storage is negligible for OPC.

\subsection{Spinning Reserve Benefits}

Operating reserve criteria vary from utility to utility and NERC region to NERC region. Operating reserve policy generally consists of on-line MW spinning reserve requirements plus additional off-line quick start generation capable of responding within a specified time period (10-30 minutes). Spinning reserve typically includes unused MW capability of generators operating at partial load to provide area regulation plus additional on-line units operated at partial load to cover sudden loss of generation. 


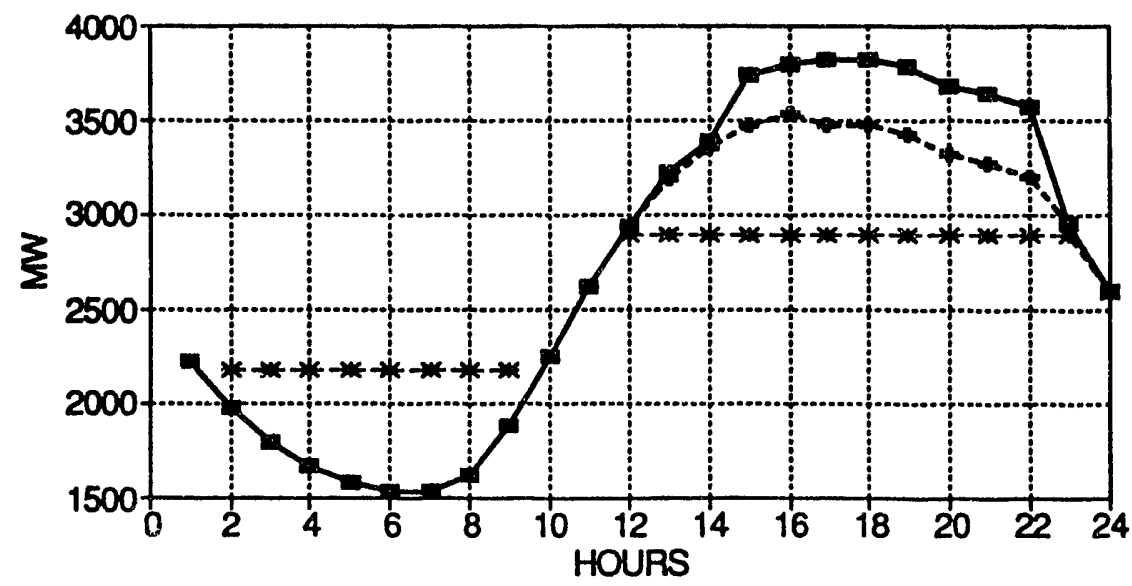

NATIVE LOAD - - W/LDMGMT - WTHPSH

FIGURE 5.4

PEAKDAY LOAD SHAPE WTTH DLC \& PSH

Since batteries have the capability to be quickly started or changed from charging to discharging in the millisecond time frame, batteries can be used to supply the spinning reserve requirement. The potential benefit will depend on the type of generation used for spinning reserve.

Potential economic benefits from battery storage systems are expected to include:

- More efficient operation of units that would otherwise operate at partial load to provide spinning reserve,

- Cost savings from not running higher cost units that would otherwise have to operate to provide spinning reserve. 
Batteries would be expected to operate infrequently to supply MW spinning reserve capability. It is also expected that batteries used for this application would only have to operate until other generation could be started or purchased after sudden loss of a generating unit. Hence, batteries used for spinning reserve would probably not require large MWh storage capability.

The Southern subregion has adopted a policy of using 1.5 times the capability of the largest in-service generating unit as a "target" Operating Reserve. Oglethorpe Power will be responsible for a portion of the Southern subregion "target" Operating Reserve proportional to its responsibility for the Southern subregion's peak load.

The Southern subregion policy further stipulates that at least $50 \%$ of the Operating Reserve must be Spinning Reserve to provide for normal regulating margin and a portion, more than $50 \%$, of the loss of generation that would result from the most severe single contingency.

Based on the peak loads of Southern Company and OPC for the year 1991 and the largest generating unit size of $1113.5 \mathrm{MW}$, the spinning reserve responsibility for OPC is 189 $\mathrm{MW}$. OPC is using $200 \mathrm{MW}$ as spinning reserve requirement.

Calculation of potential economic benefits associated with using batteries for spinning reserve requires determination of expected costs resulting from operating Southern Company and OPC generating units, with and without spinning reserve requirements shifted to batteries. Unfortunately, in large systems of 30,000 MW plus capacity, small battery storage installations of a few MW rating would show a very small or no change in the production cost. The production cost difference may be in the same range as the confidence in the magnitude of the total production cost of the system. Besides, OPC may anticipate a spinning reserve credit for Rocky Mountain Pumped Storage Facility especially during pumping and other times, due to the hydro units fast startup capability. Also, once load management can be directly effected by Oglethorpe Power's System Control Operators, the interruptible load can be credited towards Oglethorpe Power's Operating Reserve. Hence, no production costing simulations were made to determine the spinning 
reserve credit. For battery systems of a few MW rating on the OPC system, spinning reserve credit may be considered negligible.

\subsection{Other Generation Related Benefits}

There are at least four more readily identifiable benefits which may be attributable to battery energy storage systems. They are:

-- $\quad$ reduced minimum load problems

-- provide area and frequency regulation

-- reduce operating constraints

-- $\quad$ reduce deviations from economic dispatch

These benefits are sometimes referred to as "dynamic" benefits of battery storage.

Utility systems, with large base load units and a relatively low minimum load, experience difficulty in dispatching during off peak hours. Economic dispatch, unit minimum load limits and minimum down time requirements of base load units cause this problem.

Batteries may be employed to more economically solve these daily dispatch problems. For example, batteries may be ramped (from full charge to full discharge) at a high rate during the morning load pick-up and ramped in the opposite direction during the evening load drop-off period. In addition, charging batteries at night can increase night generation levels and reducing daily cycling constraints.

Batteries may only require one to two hours of storage to relieve unit ramping constraints during morning pick-up and evening drop-off periods. However, several hours of energy storage are required to relieve daily generation unit cycling constraints. 
Presently, OPC purchases a part of its power needs from other utilities. This permits OPC to schedule its resources and purchases according to its needs. Thus, there are no obvious daily dispatch problems such as ramping or minimum load dispatch.

Area and frequency regulation is another potential battery benefit. Battery power can be quickly and smoothly changed from full charge to full discharge under control of an automatic generation control (AGC) or load frequency control (LFC) system. A battery is thus an ideal device to perform the area regulation function. A battery can also relieve the need to operate costly generation capacity at, less than optimum loadings. Another benefit is reduced thermal stress on generating units responding to load variations. There is no appreciable loss of life in a battery due tr, rapid changes in power.

Batteries would be expected to continuously shuttle between charging and discharging modes on a minute-to-minute basis to perform this area regulation function. Hence batteries used only for area regulation would need only modest MWh storage capability. Also, batteries used for other purposes such as spinning reserve and load leveling could probably simultaneously provide some area regulation service.

The Southern Company area including OPC is dispatched as one area. Thus, the area control area (ACE) for this large system may be in the range of 0-50 MW. Thus, a battery storage system should be rated nearly $50 \mathrm{MW}$ or higher to make significant economic contribution to the area regulation function. In addition, the location of this battery storage system should be easily accessible for dispatch by systems operations control center.

In conclusion, other generation related benefits are not significant within the OPC system at the present time. 


\subsection{POTENTIAL TRANSMISSION BENEFITS}

Battery storage systems, connected at advantageous locations to a transmission system, can provide many benefits as discussed in Appendix A. Some or all of these benefits may be applicable to a given system based on actual system conditions. An evaluation of transmission benefits applicable to the OPC transmission system has been performed. Some background and the results of this evaluation are presented below.

\subsection{Backeround on Battery T\&D Benefits}

A fair evaluation of $T \& D$ benefits of battery energy storage requires recognition that Batteries do not fit conventional, deterministic, T\&D planning criteria well. An open mind is needed to recognize where a battery can be advantageously applied. There are definite situations where a battery is most likely to successfully displace other equipment. Some or all of the following conditions are needed for a battery to accrue significant T\&D benefits:

- The battery can be located close to customers so that benefits at several upstream voltage levels can be realized,

- The substation or feeder load shape is not very flat so that:

- The daily low-load period is low enough for the battery to be recharged with a line or transformer out of service,

- The peak duration is a few hours or less so that a large Mwh capacity is not required,

- Right-of-Way (ROW) is costly or simply unavailable,

- Lines are long or heavily loaded so that losses are high,

- Voltage regulation is a problem so reducing feeder load or providing voltage support is useful, 
- Lines are long, radial or highly exposed so that reliability is low,

- Special customer reliability needs exist,

- Blackstart or standby power is needed for a limited amount of customer load, and

- There is space available for the battery.

Where enough of these conditions are encouraging, a preliminary evaluation is warranted. If T\&D planning studies to meet the expected load growth are complete, then the analysis is straight-forward. It includes several steps:

- determine the expected load level on the day in which the T\&D additions are expected to be in place,

- $\quad$ select a battery $\mathrm{Kw}$ and $\mathrm{Kwh}$ rating that will defer that load level for a small integer number of years,

- calculate the economic value of deferring the T\&D addition for that number of years.

- Repeat for larger integer numbers of years, taking into account these possible limitations:

if a transformer is to be deferred, flattening the load shape with a battery may not reduce transformer effective loading in proportion to the reduction in the load peak (where transformers are routinely overloaded during contingencies, maximum load is dictated by the load profile).

load must be below equipment ratings at night long enough to allow full recharge of the battery. 


\subsection{Transmission System Reliability Criteria}

The need for new transmission facilities will be generally determined by OPC transmission planning engineers on a case by case basis, based on the evaluation of a number of appropriate design contingencies. The objective of these transmission planning studies is to provide a reliable system considering appropriate outage criteria, risks and costs. The OPC transmission system is normally designed to meet or exceed the following basic reliability criteria.

The basic transmission system reliability criteria for circuits $115 \mathrm{kV}$ and above consists of designing for a single contingency outage during the annual system peak. The basic transmission system voltage criteria is to maintain voltages above $95 \%$ of nominal during normal operating conditions and above $90 \%$ of nominal during a single contingency event.

\subsection{New Transmission Projects}

In general, the primary purpose of OPC's bulk power transmission system is to reliably deliver power from local and remote generating units to the EMCs. Future transmission systems must provide adequate capability to accommodate expected power purchases from remote generation sources, accommodate new generation projects, and to deliver that power to EMC substations. New transmission additions are a function of both the generation or resource expansion plan adopted by OPC and the need to provide reliable service to areas of high load growth.

OPC keeps a current Project Development Plan that is updated monthly. A recent plan was furnished to PTI. Based on this information, a short list (Table 6.1) of future transmission and substation projects was prepared. Procedures used to make this list are:

-- All released projects are considered to have begun and cannot be substituted with, or deferred by, battery storage systems.

-- Only future projects with the expected starting date of January 1993 or later can be considered to be candidates for possible cancellation or postponement. 


\section{TABLE 6.1}

OGEITORPE BATTERY STORAGE STUDY TRANSMISSION LINESISUBSTAONS PROIECTS LIST

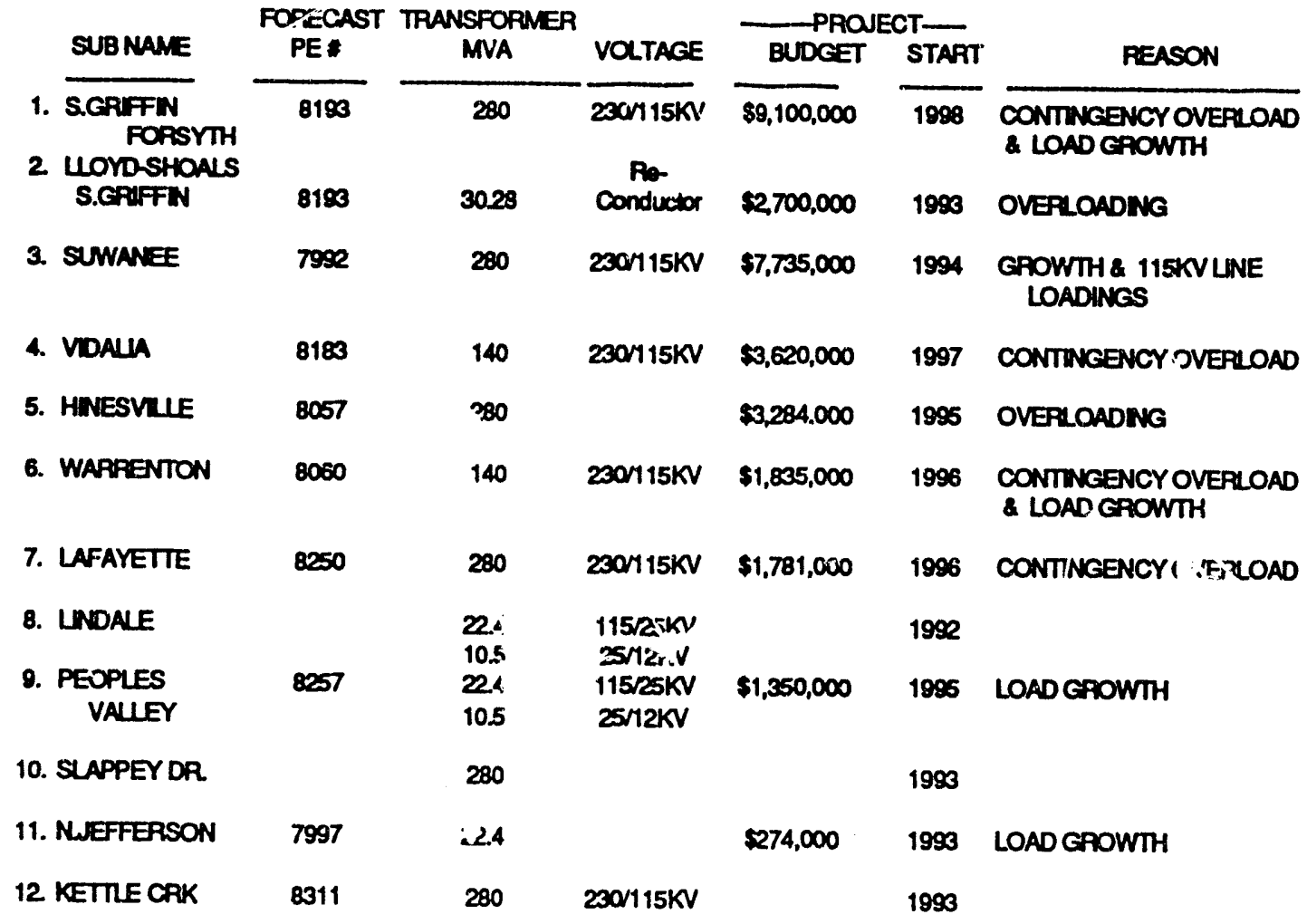

For generic assessment of representative cases, judiciousiy placed batteries are considered to provide a local power source near loads that can act as backup to existing transmission facilities and thereby reduce the transmission redundancy required to meet OPC transmission reliability criteria. The batteries are, effectively, floating on the system, but are used to cover transmission outages. For this application, judiciousiy placed batteries may provide the desired transmission deferral benefit while at the same time providing additionsl non site-specific generation system benefits. Based on the 12 projects listed in Table 6.1, OPC selected two specific uransformer projects for further study. The results for these two candidates for deferral are presented in this section. 


\subsubsection{Vidalia $230 / 115 \mathrm{kV}$ Project}

This project consists of installing a third $140 \mathrm{MVA}, 230 / 115 \mathrm{kV}$ transformci at Vidalia substation. According to the present forecast, upon loss of one of the existing two transformers, the remaining transformer will be overloaded after the year 1997. Installation of the third transformer at a budgeted cost of $\$ 3,620,000$ is being planned for the year 1997.

The $230 \mathrm{kV}$ and $115 \mathrm{kV}$ transmission lines connected to Vidalia substation are shown in Figure 6.1. The installation of a third transformer is being planned as a backup to cover an outage of the existing transformer, as per the deterministic planning criteria.

The overloading of the second transformer occurs only during peak load conditions and if an outage of a cransformer occurs. If an alternative method of supplying the local load during this peak and outage period is possible, then the overloading of the remaining transformer can be avoided and hence the installation of the additional transformer can be postponed. Even though transformers are highly reliable, any failure takes weeks to months to repair and bring them back to service. Thus, batteries should be sized so that they are suitable to supply the peak load of the peak day of the year. The peak day load shape for Vidalia substation is shown in Figure 6.2. Both the native load shape and load shape with battery discharge are shown in this figure. Maximum possible peak shaving load, with charging and discharging are included in this evaluation. 


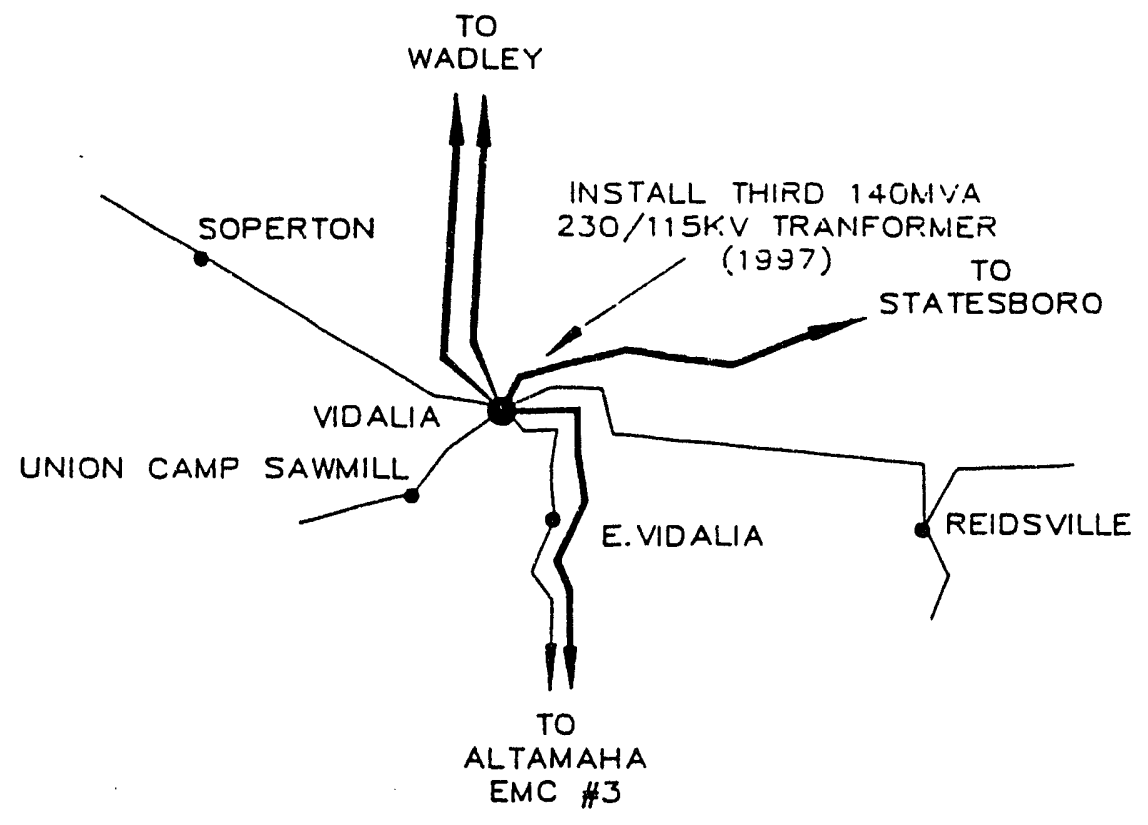

FIGURE 6.1

VIDALIA 230/115 KV PROJECT

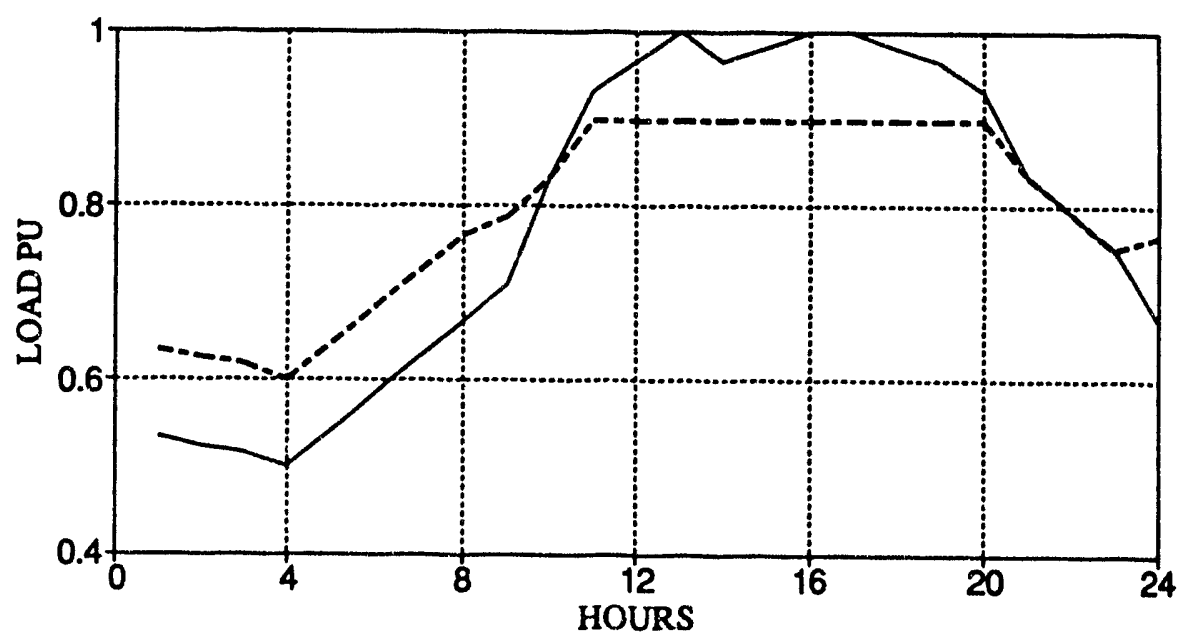

- NATIVE LOAD - -. WIBATTERY

FIGURE 6.2

PEAK LOAD SHAPE - VIDALIA 230/115 KV TRANSFORMER 
A number of load flows with outages of Vidalia $230 / 115 \mathrm{kV}$ transformer and the $230 \mathrm{kV}$ and $115 \mathrm{kV}$ lines connected to the Vidalia substation were run for the year 2001. These load flows showed that in the year 2001 the remaining transformer will be loaded to nearly $110 \%$ (156 MW) of its rating. Based on this information and the peak load curve of Figure 6.2 , the battery storage requirement is determined. The required battery ratings are as shown in Table 6.2. According to this table a $114 \mathrm{MWH}, 7$ hour discharge rated battery is needed. The battery size required to meet load growth beyond year 2001 is impractical. As can be seen from Figure 6.2, there are not sufficient charge hours unless a larger $\mathrm{KW}$ rating converter is used with the battery. Adding the thind transformer may be postponed for only 3 years with the proposed size of the battery. The battery may be placed on the $12 \mathrm{kV}$ bus of the Vidalia substation, thus deferring some distribution transformer additions also.

TABLE 6.2

\section{VIDALIA BATTERY RATING REQUIREMENTS \\ ONE TRANSFORMER CAPACITY $=140,000 \mathrm{KVA}$}

$\begin{array}{lcccc}\text { YEAR } & 1998 & 1999 & 2000 & 2001 \\ & & & & \\ \text { Transformer Overloading KVA } & 0 & 1,019 & 9,048 & 17,494 \\ \text { Peak Load kW } & 133,919 & 140,938 & 148,324 & 156,098 \\ \text { Battery KW } & 0 & 938 & 8,324 & 16,098 \\ \text { Battery Power (pu) } & 0.00 & 0.01 & 0.06 & 0.10 \\ \text { Battery KWH } & 0 & 4,228 & 51,419 & 114,472 \\ \text { Battery Hrs } & 0 & 5 & 6 & 7\end{array}$

Because the $230 \mathrm{kV}$ and $115 \mathrm{kV}$ transmission lines parallel each other, the battery output will reduce only a part of the load on the $230 / 115 \mathrm{kV}$ transformer. Through load flows it was determined that $53 \%$ reduction in the transformer and $47 \%$ reduction in $115 \mathrm{kV}$ lines occurs for every MW of battery output. Thus, the battery requirements in Table 6.2 need to be increased by 1.8 . Hence, a battery rated at $210 \mathrm{MWH}, 7$ hours discharge can defer the installation of transformer from presently planned 1997 to year 2001. 


\subsubsection{Warrenton $230 / 115 \mathrm{kV}$ Project}

This project involves several new construction parts. The main part is installation of a second $140 \mathrm{MVA}, 230 / 115 \mathrm{kV}$ autotransformer at the Warrenton station. The basis for the second transformer is that the loss of Evans-Warrenton $230 \mathrm{kV}$ line will force the power through the Warrenton 230/115 kV transformer and causes overloading of the only transformer. The total projected capital cost of this project is 4.7 million dollars out of which the second transformer costs $\$ 1,835,000$ in 1991 dollars.

The $230 \mathrm{kV}$ and $115 \mathrm{kV}$ lines connected to Warrenton substation are shown in Figure 6.3. The second transformer is being planned to meet the deterministic planning criteria, that upon outage of Evans-Warrenton $230 \mathrm{kV}$ line the Warrenton $230 / 115 \mathrm{kV}$ transformer should not be overloaded. The line outage could occur on a peak day during peak period. Hence the battery (which is expected to reduce or eliminate the overload) should be properly sized so that both discharging and charging can be made within a 24 hour period so that the battery is available for the next day peak period. Based on this premise, the peak day load shape, with and without the battery, is shown in Figure 6.4. All the charging and discharging limitations are observed in plotting the modified (shown dotted) load shape.

The battery rating requirements are shown in Table 6.3. These are based on peak load forecast and the peakday load shape (Figure 6.4). For example, also shown in Table 6.3 for the year 2001, a battery of $33 \mathrm{MWH}$ storage capacity with a maximum discharge rating of $10 \mathrm{MW}$ is needed. However, there is another consideration in selecting the battery. As shown in Figure 6.3, the $115 \mathrm{kV}$ transmission lines parallel the $230 \mathrm{kV}$ transmission lines. Hence, out of every MW of battery discharge, only part of this load relief goes to the $230 / 115 \mathrm{kV}$ transformer. By using load flow runs, it was determined that for every $10 \mathrm{MW}$ battery discharge at the $115 \mathrm{kV}$ side of the transformer, only $3.6 \mathrm{MVA}$ or $36 \%$ relief in loading is obtained for the $230 / 115 \mathrm{kV}$ transformer. Hence, the battery ratings need to be multiplied by a factor of $2.8(=1 / 3.6)$ to get the desired relief or divided by a factor of 2.8 to determine actual relief from a given battery size. Thus, the final battery ratings selected for evaluation is $218,000 \mathrm{KWH}$ with 5 hour discharge rating. 
Power Technologies, Inc.

TABLE 6.3

\section{WARRENTON BATTERY RATING REQUIREMENTS ONE TRANSFORMER CAPACITY = 140,000 KVA}

$\begin{array}{lcccccccc}\text { YEAR } & 1997 & 1998 & 1999 & 2000 & 2001 & 2002 & 2003 & 2004 \\ \text { Transf. Overloading KVA } & 3,513 & 5,333 & 7,174 & 9.036 & 10,920 & 12,826 & 14,754 & 16,705 \\ \text { Peak Load kW } & 143,232 & 144,906 & 146,600 & 148,313 & 150,046 & 151,800 & 153,574 & 155,369 \\ \text { Battery KW } & 3,232 & 4,906 & 6,600 & 8,313 & 10,046 & 11,800 & 13,574 & 15,369 \\ \text { Battery Power (pu) } & 0.02 & 0.03 & 0,06 & 0.06 & 0.07 & 0.08 & 0.09 & 0.10 \\ \text { Battery KWH } & 3,683 & 6,831 & 16,754 & 23,730 & 33,010 & 43,805 & 58,358 & 77,684 \\ \text { Battery Hrs } & 2 & 2 & 3 & 3 & 4 & 4 & 5 & 5\end{array}$

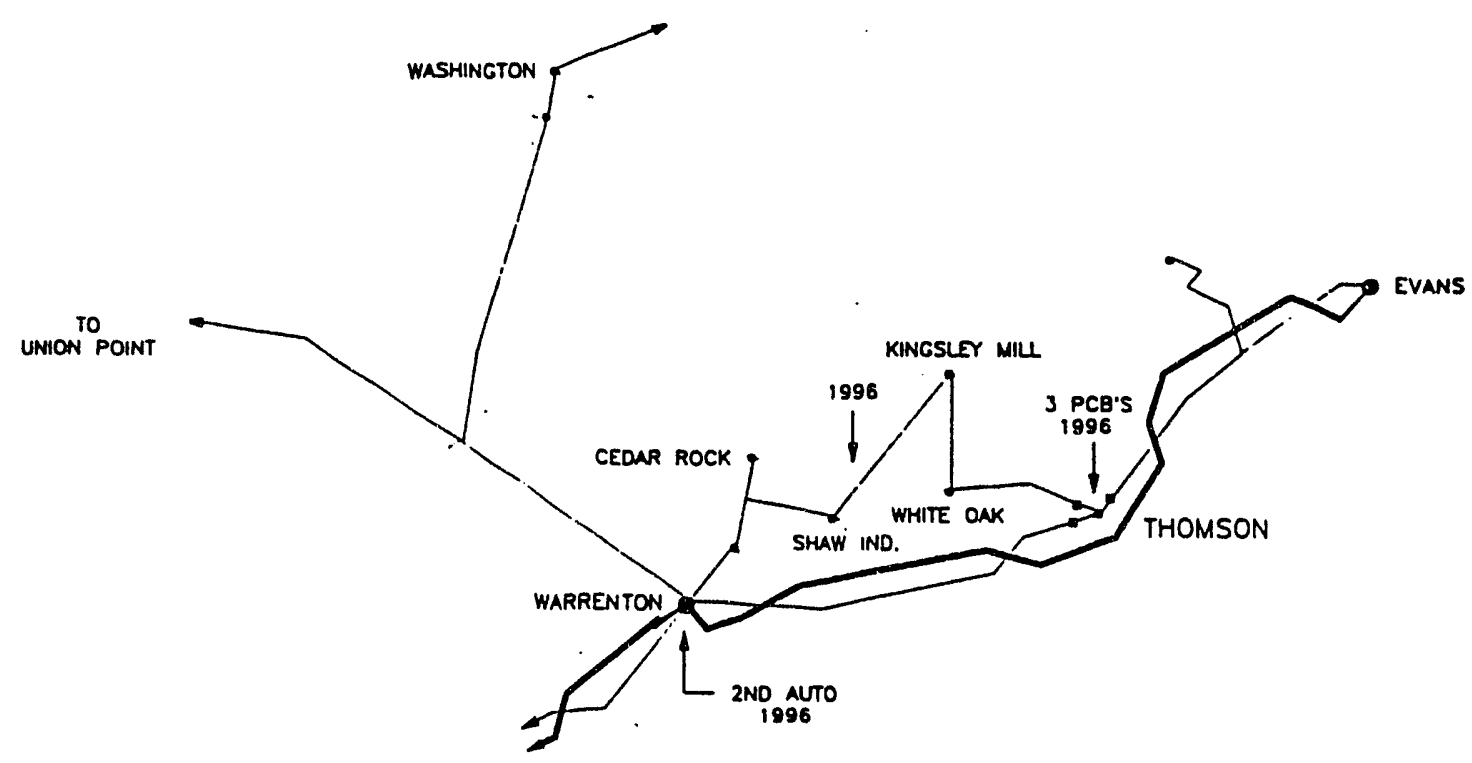

FIGURE 6.3

WARRENTON-THOMSON 115 KV PROJECT 


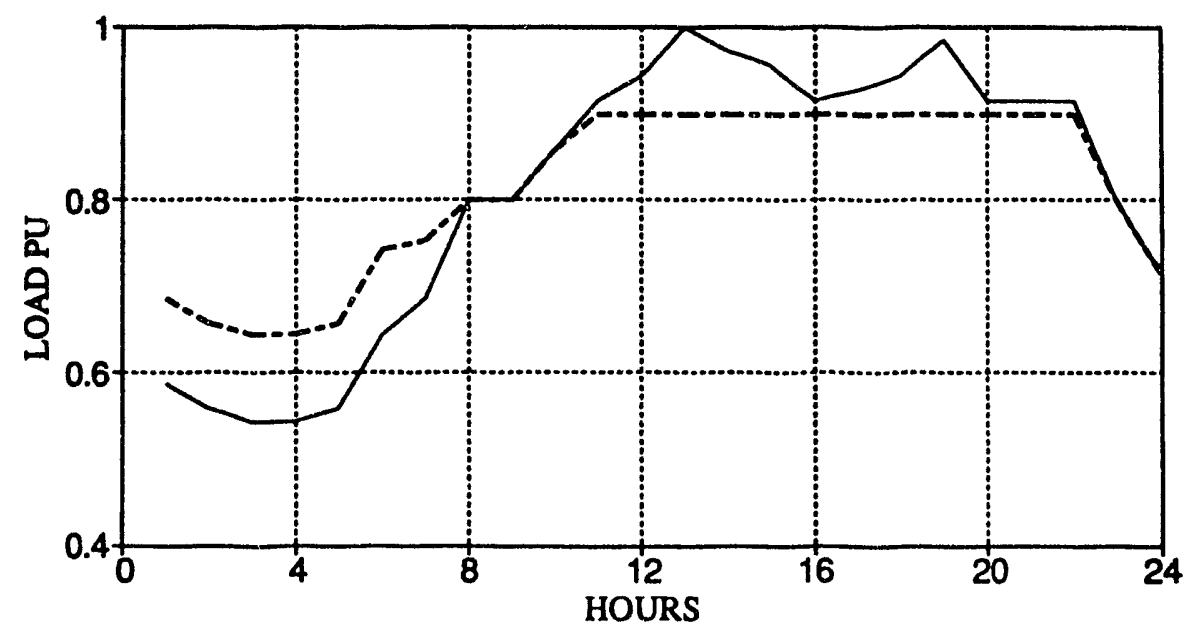

NATIVE LOAD - - W/BATTERY

FIGURE 6.4

PEAKDAY LOAD SHAPE - WARRENTON 230/115 KV TRANSFORMER

\subsection{Loss Reduction}

Batteries can reduce transmission losses by shifting load from the peak period to the offpeak period. This results from the square law that governs resistive losses. Reducing transmission system loading during daily peak load times by discharging batteries reduces peak load losses by more than they are increased at night when the batteries are recharged.

The potential loss reduction benefit is reduced if batteries are used to defer transmission. When transmission is deferred, it is possible for a high penetration of batteries to actually increase losses and incur a negative benefit. This can occur if the load shape is greatly flattened by batteries, so that average transmission loading is very high. The levels of battery penetration that are likely to be attractive in the foreseeable future will reduce losses. 
If the proposed application requires the battery to be cycled frequently, consideration of losses will be more important than in applications where the batteries are to be cycled only occasionally, or where only small amounts of energy are involved. Of course, if the loss benefits themselves are significant, they should be a factor in determining the frequency of cycling.

The location of the generation used to charge the batteries and the location of the generation displaced when the batteries are discharged will each have a significant impact on the relative magnitude of the peak and off-peak losses and the loss benefit.

The daily load shape on the local transmission system in the vicinity of the battery may not coincide with the native daily OPC load shape. When there is a difference, the battery cannot provide maximum loss reduction throughout the network. If the battery discharge pattern is dictated by resource consideration associated with the system-wide peak, and the local peak does not coincide with it, the local loss reduction will be modest. So long as the local substation or feeder peak falls within the system native load peak, loss reduction will be high.

In battery storage applications where transmission loss benefits are to be determined, the best available marginal generation costs and corresponding marginal loss factors should be determined. Although the daily load shapes fluctuate significantly, the hourly marginal generation costs are relatively constant on a daily on-peak/off-peak basis for the different seasons. Thus, on the OPC system, relative cost of transmission losses may be quickly estimated using incremental on-peak/off-peak transmission loss calculations, without resorting to hourly production simulation.

The two previously discussed battery applications for deferment of 230/115 kV transformers would actually be used only after contingency. Thus, the number of hours that the battery would be used in a year is small. Hence, any change in losses in the transmission system is considered insignificant for the two cases evaluated here. 


\subsection{Voltage Requlation}

Regulation is the drop in voltage that occurs when load increases on the system. The larger the voltage change, the poorer the regulation. For the same level of load, when system impedance is high (the system is weak), regulation will be poor. Adding lines and transformers can strengthen the system, but are a costly way to solve poor voltage regulation problems. Conventional voltage control devices such as generators, synchronous condensers, switched capacitor banks, static var systems (SVS), and load tap changers on transformers 'regulate' voltage and improve regulation. The voltage regulation response times for the various voltage control devices are:

$\begin{array}{ll}\text { LTC } & 1 \text { to } 2 \text { minutes } \\ \text { Capacitors } & 1 \text { to } 2 \text { minutes } \\ \text { Generators } & 1 \text { to } 2 \text { seconds } \\ \text { Condenser } & 1 \text { to } 2 \text { seconds } \\ \text { SVS } & 0.1 \text { to } 0.2 \text { seconds }\end{array}$

The SVS is clearly the most effective because of its speed. An SVS consists of some combination of thyristor switched shunt capacitors and thyristor controlled shunt reactors. An SVS can respond to a drop in voltage before it becomes a problem for voltage-sensitive equipment or before a person can see the voltage drop in the light output of fixtures. Generators are often located too far from the load to be useful. Synchronous condensers are no longer competitive compared to SVS. LTCs and switched capacitors are slow, but are economical and very effective at combating slow changes in voltage, such as those resulting from normal load variations.

Judiciously placed batteries can improve voltage regulation in two ways. One is by supplying power locally when heavy transmission loading or transmission outages are the cause of the low voltage. Increasing battery power to reduce line loading will improve voltage. Each MW of battery power is equivalent to 2 to 3 Mvar of reactive power in terms of its impact on voltage in heavily loaded systems. 
Batteries can also improve voltage regulation through reactive supply from their gate-turn-off (GTO) or similar power converters. The converters between the ac system and the battery dc bus can be designed to behave like an SVS while charging or discharging the battery. A modest increase in converter rating, over that required to supply full battery power, is necessary to supply reactive power during charging or discharging operation. For example, an 11 MVA converter on a $10 \mathrm{MW}$ battery can provide up to 4.6 Mvar of capacitive or inductive reactive power while operating at $10 \mathrm{MW}$. The reactive power is also continuously variable and controllable with a voltage regulator. The extra 1 MVA of converter capacity thus provides the same dynamic range as a 9.2 MVAR SVS. Because most SVSs provide primarily capacitive reactive power, a 4.6 Mvar capacitor is required to make the converter fully comparable to an SVS. However, even with the cost of the capacitor, and recognizing that GTO based converters are more costly (per MVA) than thyristor based SVS, the battery converter is a very economical alternative to SVS capacity.

There were no specific and imminent shunt capacitor or SVS installation projects selected for the analysis. However, there is potential for battery storage to defer T\&D projects as well as eliminate shunt capacitor by supplying reactive power. Hence, a generic example is shown here to illustrate computation of voltage benefits from voltage regulation capability of batteries.

Consider a $10 \mathrm{MW}$ battery with additional $1 \mathrm{Mvar}$ of converter capacity. This is equivalent to 4.6 Mvar of switched shunt capacitors or 9.2 Mvar of SVS capacity.

The installed cost for new conventional capacitor banks at the transmission voltage level may be about $\$ 33.00 / \mathrm{kvar}$. SVS is estimated to cost three times as much or about $\$ 100 / k v a r$. Both numbers are reasonable, though some utilities are finding actual costs of conventional capacitor banks to be up to $50 \%$ higher where land costs are high. The $\$ 100 / k v a r$ number for SVS is for relatively large SVS. Costs can be much higher for smaller size SVS. 
A $10 \mathrm{MW}$ battery is likely to have a converter cost of about $\$ 150 / \mathrm{kVA}$ if utility battery volume picks up (today the number is $\$ 200 / \mathbf{k V A}$ ). Assuming that the incremental cost of converter capacity is $2 / 3$ of this overall $\$ / \mathrm{kVA}$ cost, an incremental kVA would cost about $\$ 100$. As described above, adding an additional MVA of converter capacity will provide 4.6 Mvar of capacitive reactive power (more at reduced MW output) at a cost of about $\$ 100,000$ (Appendix B). The cost of $4,600 \mathrm{kvar}$ from a $10 \mathrm{MW}$ battery converter is thus about $\$ 22$ per kvar. Cost comparison of battery converter, shunt capacitor and SVS is shown in Table 6.4. The battery converter thus appears economically competitive (\$20.00/kvar savings) with switched shunt capacitors installed at the transmission level.

TABLE 6.4

COST COMPARISON OF BATTERY CONVERTER, SHUNT CAPACITOR \& SVS

\begin{tabular}{|l|c|c|c|c|c|}
\hline \multicolumn{1}{|c|}{ Type } & $\begin{array}{c}\text { Cost } \\
(\$ / K V A R)\end{array}$ & $\begin{array}{c}\text { Size } \\
(\text { KVAR })\end{array}$ & $\begin{array}{c}\text { Capital } \\
\text { Cost }\end{array}$ & $\begin{array}{c}\text { Total } \\
\text { Net PV }\end{array}$ & $\begin{array}{c}\text { Net PV } \\
(\$ \mathbf{K V A})\end{array}$ \\
\hline Shunt Capacitor & 33 & 4,600 & $\$ 151,800$ & 265,551 & 58 \\
\hline Battery Converter & 22 & 4,600 & $\$ 101,200$ & 177,034 & 38 \\
\hline SVS & 100 & $\mathbf{9 , 2 0 0}$ & $\$ 920,000$ & $1,609,401$ & 175 \\
\hline
\end{tabular}

Note: (a) Economic Parameters as in Table 8.1

(b) PV - Present Value

\subsection{Damping}

Batteries are especially adept at providing system damping. Batteries can respond instantaneously to control signals with no measurable wear and tear. The control signal to improve system damping can be derived from the frequency of the voltage at the battery terminals. The only limitation is that the battery must be within the 'sending' or 'receiving' system to provide damping. 


\subsubsection{Background}

Power systems are like large spring-mass systems. The generator and turbine rotors are the masses, and the network is the spring. Every generator and every group of generators will have a natural frequency at which it will oscillate against the remainder of the network when perturbed. These natural frequencies are usually in the range of 0.2 to $2 \mathrm{~Hz}$. Unfortunately, there is 'noise' in the system such as customers switching loads, pulsating loads, generator trips, line faults and line trips that excite these oscillations. At oscillation frequencies above about $1 \mathrm{~Hz}$ "amortisseur torques" in the generator usually provide enough damping to cause oscillations to decay quickly (within 5 to 10 seconds). However, below $1 \mathrm{~Hz}$ excitation systems may provide enough negative damping to overcome damping from amortisseurs and cause oscillations to grow. This is especially likely when a system is stressed by high transfers or loss of a line. Fast response excitation systems, or newer static systems that inherently provide fast response, are much more prone to cause negative damping than standard designs. They are often installed as replacements for older ailing or high maintenance systems, on utility generators to solve first-swing stability problems, or on QF, IPP and cogeneration plants because of low maintenance and modest first-cost.

If negative damping from excitation systems exceeds positive damping from amortisseurs at any natural frequency under any system condition (e.g., during line outages), oscillations will occur. Governors, turbines, and customer loads also affect damping somewhat, especially when the natural frequency is below about $0.5 \mathrm{~Hz}$. Oscillations may grow without bound until loss of synchronism occurs or they may reach some magnitude and stay at that level for an extended period of time. Both consequences are unacceptable.

To help combat the problem of poor or negative damping, stabilizers are placed on the excitation systems of larger generators. Stabilizers modulate excitation so as to produce a component of generator power that is in phase with generator speed, and thus provide damping. Stabilizer effectiveness depends on the response characteristics of the excitation system. A well tuned stabilizer will usually overcome the negative damping caused by the excitation system on which it is installed. It will help compensate for other generators without stabilizers only if the excitation system on which it is located is of the "high initial 
response" type and has a relatively high ceiling voltage. A stabilizer can provide a component of positive damping power from about $1 \%$ to $5 \%$ of the generator rating, depending on the excitation system performance.

Excitation systems contribute more negative damping as power transfers increase, but firstswing stability, steady state stability and thermal limits also come into play. However, multiple interconnections have made first-swing and thermal limits less limiting than damping in many systems. This occurs in part because multiple interconnections allow each line to be loaded more heavily, and heavy loading, through high reactive losses, causes excitation systems to contribute more negative damping.

Damping problems commonly fall into two categories. One is oscillations between a single plant and the remainder of the system. Usually, loss of one of the lines serving the plant puts the plant in an unstable condition. The other is oscillations between groups of machines. Oscillations between groups of machines are usually labeled as 'area' or 'regional' damping problems. The oscillations involving a single plant are usually in the 0.8 to $1.3 \mathrm{~Hz}$ range, while area or regional oscillations are usually in the 0.2 to $0.8 \mathrm{~Hz}$ range.

\subsubsection{Damping in the Oglethorpe System}

In planning and operating the Oglethorpe system the engineers must deal with both single plant damping and area or regional damping. The Sherer plant is a good example of the single plant damping problem. Until recently, there were just two $500 \mathrm{kV}$ lines serving the plant, so loss of either one significantly increases the impedance between the plant and the system and degraded damping. With the recent addition of the Ohara-Sherer $500 \mathrm{kV}$ line there may still be a damping (or dynamic stability) problem. Computer results are showing inter-area (i.e. Alabama-Georgia, Georgia-Florida, etc.) oscillations at 0.7 Hertz due to faults at Sherer. The Power System Stabilizer (PSS) at Votgle was placed in-service, and the PSS for Farley units \#1-2 were retuned to provide more positive damping. It is also possible that generators on other surrounding systems may contribute to the damping 
problem. The system data and outside equivalents are being reviewed. Consideration is being given to making the outside equivalents larger which may help the problem.

Though system study models rarely portray the damping of such modes accurately, they do confirm their existence. Also, the fact that they exist and can be troublesome is well recognized throughout the US.

\subsubsection{Battery Contribution to Damping}

While stabilizers are usually able to control oscillations, increasing numbers of aggressively tuned stabilizers are required as transfers increase. Having enough stabilizers and keeping enough of them operating to keep oscillations under control is difficult. Stabilizers are costly and are a fairly high maintenance item. Hence any help from batteries would be very useful, especially if the stabilizer can be a simple device integrated with the battery controls.

Batteries can contribute to damping if they are equipped with a stabilizer and if they are located in a portion of the system in which generators experience measurable rotor speed oscillations when plant or inter-area oscillations occur. Such rotor speed oscillations exist at the extremes of two oscillating areas, and are zero at the 'electrical center' of the two. The oscillations will also be largest in the smaller of the two systems (the magnitude of the oscillation is inversely proportional to the inertia of the area or plant). In the case of a single generating plant oscillating against the 'outside world,' the oscillations at the plant will be large, while the 'world' oscillations will be very small. In the case of two areas such as Florida oscillating against the remainder of the Southeast, the Florida oscillations will be large and the oscillations in the remainder of the Southeast will be small.

A generator stabilizer provides damping by increasing generator rotor flux when generator speed is high to increase generator power, and decreasing flux to reduce generator power when speed is low. A battery nearby provides damping by being modulated so that it absorbs power when the speed of local generators is high and supplies power when the speed of local generators is low. Because the frequency of the voltage in an area follows 
closely the speed of local generators, the system frequency at the battery location provides the information needed to modulase the battery power.

The battery thus needs to be near a plant or group of generators in a 'sending system' or within the receiving system. It also will be most effective if it is in the smaller of the two oscillating areas.

The battery power can be modulated to provide damping regardless of the power level or direction of power level in the battery at th ime the oscillations occur. If the battery is floating, the output will alternate between the charge and discharge regions, and average battery output will remain zero. If the battery is operating at a high charge or discharge level, the average power will move toward zero. If oscillations are large, the average may go to zero as the stabilizer causes battery power to cycle between its charge and discharge limits.

Because a stabilizer on a generator can provide damping power of just a few percent of generator rating, a battery of, for instance, $2 \mathrm{MW}$, modulated fully ( $4 \mathrm{MW}$ peak to peak), can provide as much damping as a stabilizer on a generator rated 100 to 200 MVA. Beyond this, because a battery is essentially solid state and less subject to control oscillations than a generator, the stabilizer gain can be high and can contribute more to damping of modest oscillations (that would otherwise not drive the battery to ceiling) than can a generator stabilizer.

While the stabilizer is responding to a disturbance it will reduce average battery power when the battery is initially operating at maximum discharge rate. The effect will be less at lower discharge levels, and nonexistent when the battery is floating (operating at zero $\mathrm{MW}$ ). Likewise, there will be a momentary reduction in the charge rate when the battery is initially operating in the charge region. This occurs when the stabilizer drives the battery between its maxim um discharge and charge limits. With battery output essentially a square wave, the average povver is zero. This effect is essential if the battery is to make a major contribution to damping under all battery operating conditions. Because 
Power Technologies, Inc.

the change in battery power or charge level is temporary, lasting only 10 to 30 seconds or less, it should not present operating problems.

\subsubsection{Battery Contribution to Damping on the Oglethorpe System}

In a system such as that covering Georgia, with generating plants distributed across the system, batteries will nrovide useful darnping wherever they are located. However, the value will be low unless the battery is located with or close to a generator or group of generators that exhibit troublesome oscillations.

The oscillations between Georgia and Florida exhibit large oscillations only in Florida. Hence a battery in Georgia will contribute little to this mode. Any troub'esome mode within Georgia is not readily available. 


\title{
7.0 POTENTIAL SUBTRANSMISSION AND DISTRIBUTION SYSTEM BENEFITS
}

\subsection{Subtransmission System}

The subtransmission system (less than $115 \mathrm{kV}$ ) within the OPC delivers power to the EMC substations. The EMCs have the responsibility to deliver the power from these substations to the ultimate customer. The subtransmission lines and/or distribution lines serving the EMC substations include $115 \mathrm{kV}, 69 \mathrm{kV}, 46 \mathrm{kV}, 25 \mathrm{kV}$ and $12 \mathrm{kV}$ lines.

In the OPC system there are approximately twenty-four $115 \mathrm{kV}$ and $46 \mathrm{kV}$ subtransmission lines which are radial and supply EMC substations. Whenever there is an outage of one of these radial subtransmission lines, the customer loads experience an interruption. Batteries located at the low side of these substations can provide multiple benefits, including:

\author{
-- $\quad$ increased reliability (back up power source) \\ -- second line deferral benefits \\ -- transformer deferral benefits \\ -. voltage regulation \\ -. reduction of losses
}

\subsection{Backup Source Reliability Credit for Battery Storage}

A battery is a 'local source' and thus is not dependent on upstream components as are, for instance, the transmission or distribution lines. The battery is, in effect, an independent source of power (temporary or backup) and thus may make a more significant contribution to reliability than its outage rate and duration statistics would seem to indicate. It is an independent source because it is not part of a series string of devices, and one of which can cause an outage or reduced capacity. However, the benefit a battery can provide as a backup source depends upon three factors: 
1. Battery availability and reliability

2. Outage or interruption of load experience (or expectation)

3. Value or cost of the load interruption.

These three factors are discussed in the following.

\subsubsection{Battery Availability}

Unlike transformers, transmission and distribution lines, batteries are not necessarily "available" just because they are on-line. Generally, batteries need to be in a charged state, and have a specific energy storage capability to be considered reliable backup to various T\&D facilities. A battery that is normally discharged to $20 \%$ of capacity can be discharged to 90 or $100 \%$ in an emergency. It may be able to supply energy for the time needed for switching actions to restore or re-configure lines and transformers to carry the full substation load, and thus may provide useful backup to T\&D equipment.

A probabilistic reliability assessment may be needed to fully recognize a battery's contribution to reliability. Utilities still depend heavily on deterministic criteria, ad thus may have difficulty measuring the reliability at a substation load served in part from a battery. The contribution a battery can make in meeting utility distribution reliability criteria has not been analyzed. A simple approach to battery availability will be used here.

\subsubsection{Value or Cost of Interruption}

The interruption cost or value of service (VOS) data is considered to be suitable to relate the worth of service reliability to the cost of service. The value of service or outage costs depends upon type of load, frequency and duration of interruption and timing of the interruption. However, some of these costs have a wide range. The cost range for one hour interruption has been reported in the literature. A sample of such costs is shown in 
Table 7.1. The interruption cost data are reported in the literature for farming type loads. ${ }^{1}$ In a parallel study on dispersed generation benefits, a survey of chicken farm owners in the Habersham EMC (Hollywood substation) area was conducted. In this survey it was established that $\$ 14.8$ per $\mathrm{KWH}$ is VOS or outage cost. This same cost will be used for Habersham EMC's poultry and egg farm loads.

Because the EMC customers are predominantly residential type, followed by commercial and industrial, an average residential outage cost of $\$ 2.50$ per $\mathrm{KWH}$ will be used for transmission level deferral application.

\section{TABLE 7.1}

VALUE OF SERVICE OR OUTAGE COST FOR ONE HOUR INTERRUPTION

\begin{tabular}{|l|c|c|}
\hline & \multicolumn{2}{|c|}{ \$/KWH Not Served } \\
\hline & Low & High \\
\hline Residential $^{2}$ & 0.05 & 5.00 \\
\hline Industrial $^{2}$ & 2.00 & 53.00 \\
\hline Commercial $^{2}$ & 2.00 & 35.00 \\
\hline Poultry \& Eggs $^{1}$ & 0.12 & 5.68 \\
\hline
\end{tabular}

\subsection{Habersham Hollywood Motering Point \#8 Substation}

This metering point is served by two $115 \mathrm{kV}$ lines from Tallulah and Clarksville. There is one $115 / 12 \mathrm{kV} ; 10,500 \mathrm{KVA}$ transformer at this substation. At present, there are five, threephase $12 \mathrm{kV}$ circuits emanating from this substation. Circuits \#1 and \#2 serve the area

1 G. Walker and R. Billinton, "Farm Losses Resulting from Electric Service Interruptions - A Canadian Survey," IEEE Transactions on Power Systems, Vol. 4, No. 2, May 1989, pp 472-478.

2 A.P. Sanghvi et al, "Power System Reliability Planning Practices in North America", IEEE Transactions on Power Systems, Vol. 6, No. 4, Nov. 1991, pp 1485-1492. 
Power Technologies, Inc.

generally north of the substation. Circuit \#3 serves the area generally east and southeast of the metering point. This circuit has a TV station load and a county water pump house load. A battery of suitable size located near these loads can provide improved reliability to these large power loads. Circuit \#4 serves the area generally west of the metering point. Circuit \#5 serves the area generally to the northwest of the substation. This feeder (New Liberty) has the highest number of chicken farms. Power supply interruption to these chicken farm loads can result in substantial loss to their owners. Hence, there is ans active consideration of using diesel generators as backup power source. The feasibility and conomics of diesel generators are being evaluated through a separate study. The role of batteries for providing the backup service and deferment of distribution facilities is evaluated in this study.

\subsubsection{Deferment of Substation Transformer Replacement}

Load on this circuit (area) is expected to grow at a rate of about $3.4 \%$ per year. The existing transformer of $10,500 \mathrm{kVA}$ can serve the load up to year 1998. By then a replacement or an addition is required. If batteries are installed at the substation or near the loads, the batteries can be used to peak shave the loads whenever the total coincident load exceeds the transformer capacity. A typical peak day charge/discharge load profile is shown in Figure 7.1. The battery rating required to defer the addition and/or replace the transformer is shown in Table 7.2. The selected battery is 7,500 KW and 5 hours discharge rating.

TABLE 7.2

HABERSHAM HOLLYWOOD METERING POINT \#8 BATTERY RATING REQUIREMENTS EXISTING TRANSFORMER CAPACITY 10,500 KVA

$\begin{array}{lccccc}\text { YEAR } & 1999 & 2000 & 2001 & 2002 & 2003 \\ \text { Forecast Peak Load kW } & 9,837 & 10,171 & 10,517 & 10,874 & 11,244 \\ \text { Battery KW } & 177 & 511 & 857 & 1,21.9 & 1,584 \\ \text { Battery KWH } & 327 & 1,105 & 2,387 & 4,094 & 6,658 \\ \text { Battery Hrs } & 2 & 3 & 3 & 4 & 5 \\ \text { Cycles/Xr } & 1 & 8 & 10 & 12 & 32\end{array}$



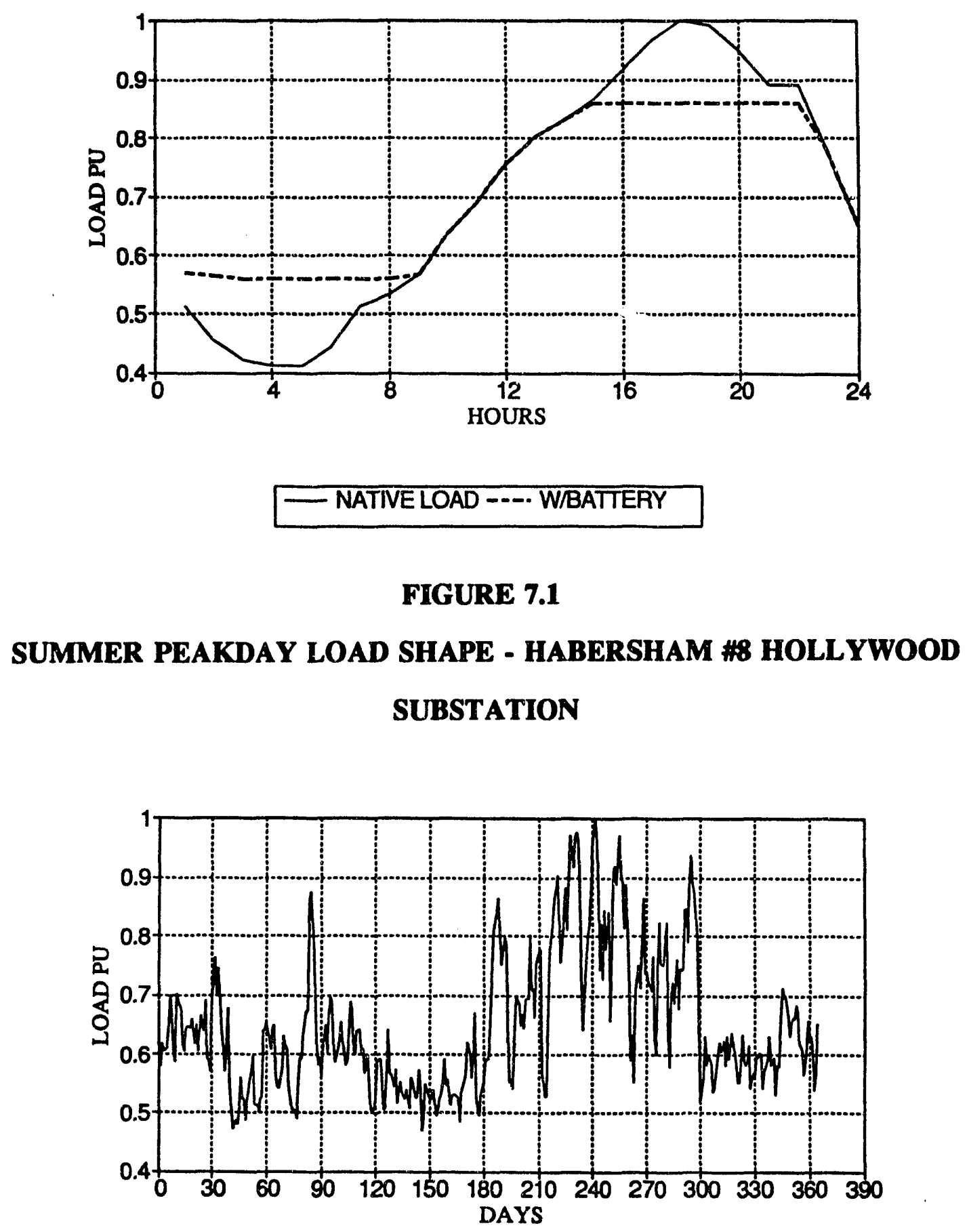

- NOV 25,90-24,91

FIGURE 7.2

DAILY PEAK LOAD - HABERSHAM HOLLYWOOD SUBSTATION 
Based on the values in Table 7.1, a maximum of $1500 \mathrm{~kW}$ of load growth for this area can be served without replacing the existing transformer or adding another transformer. Because the peak load is experienced only a few times in a year (Figure 7.2), the battery is called on to discharge only these few instances. As shown in Table 7.1, the load on the transformer in the early years is exceeded only a few times a year and increased as the load growth occurs. By the year 2003, on 32 days (mostly during the summer), the battery could be used to limit the transformer loading. Also, the battery is expected to be in the discharge mode for about 8 hours. Based on these two factors, it appears that $7500 \mathrm{kWH}$ battery storage is nearly the penetration limit, as far as the transformer deferment is concerned.

Assuming this size of battery application, a transformer addition can be postponed up to 5 years. If the batteries are not installed, then the most likely action would be to add another transformer of $20,500 \mathrm{~kW}$ capacity at an estimated cost of $\$ 300,000$ (1991 dollars).

\subsubsection{Losses}

Regarding losses on the $115 \mathrm{kV}$ lines, the Hollywood substation load is about $7 \%$ of the line flow. Further, battery reduces the peak substation demand by $15 \%$ (Table 7.2) in the year 2003. Peak line flow is reduced by about $1 \%$ only. After year 2003 the transformer can no longer be deferred. Hence, cost of loss reduction is not significant in this case. If the batteries are located near the loads, rather than in the substation, then there is reduced losses on the $12 \mathrm{kV}$ feeders. Because actual locations are indefinite, the reduction in loss are difficult to compute.

\subsubsection{Backup Power Supply Credit}

The outage data for Habersham \#8, Hollywood distribution substation are as shown in Table 7.3 for the period January 1, 1986 through November 1, 1991. The availability of a battery to serve as backup will depend on asmirnative functions it may serve.

If a battery is on a single radial feeder, so that the battery must be available to continue serving the load whenever the outage occurs, then the battery must remain fully charged whenever the critical load is on the system. 
The longest outage seen at this substation, during the last 5 years, is 21 minutes. The outage experience downstream at the customer premises may be longer. Assuming an outage duration of 1 hour, the value of service credit is estimated to be $\$ 14.78 / \mathrm{KWH}$ (from survey of Habersham chicken farm customers in another companion EPRI study). At a first glance, this credit may appear to be high. However, a single outage of 1 hour or longer can result in a loss of $\$ 300,000$ to a chicken farm with a peak load of $500 \mathrm{kVA}$.

Because there is no demand charge for these chicken farm load customers, there is no demand charge credit to the battery storage.

TABLE 7.3

OUTAGE STATISTICS SUMMARY

\begin{tabular}{||l|c|c|c|}
\hline & Hollywood & Lanes Bridge & Planters Egypt \\
\hline No. of Outages in 2130 days & 4 & 4 & 7 \\
\hline Frequency of Outages (Occ. per yr) & 0.685 & 0.685 & 1.2 \\
\hline Average Duration (Min.) & 11.5 & 361.5 & 109.7 \\
\hline Probability of Outage & 0.000015 & 0.00047 & 0.00025 \\
\hline Longest Outage (Min) & 21 & 1133 & 267 \\
\hline
\end{tabular}

\subsection{Satilla EMC Metering Point \#12 Lanes Bridge Substation}

This metering point is served by a radial $46 \mathrm{kV}$ line from Baxley Substation. Baxley Substation has three $115 \mathrm{kV}$ lines from three different substations. The outage data for Lanes Bridge Substation for the reported period Jan. 1, 1986 through Nov. 1, 1991 are shown in Table 7.3.

Even though there have been only four outages in nearly 6 years, Lanes Bridge Substation experienced one long outage lasting 6 hours, probably due to an ice storm. Adding a battery at this substation and/or customer locations will provide backup power supply. 


\subsubsection{Deferment of Substation Transformer}

The load on this substation is growing at about $2 \%$ per year. At this rate, the existing transformer capacity will exceed its rating of $7000 \mathrm{kVA}$ in the year 1997. Battery energy storage could be used to supply the load whenever the transformer is fully loaded. Transformer per unit loading with and without a battery is shown in Figure 7.3. The battery storage requirements through the years 1997 to 2001 are shown in Table 7.4. The battery use in terms of cycles per year are also shown in this table, based on the relative daily peaks for this substation (Figure 7.4). For example, in the year 2001, the batteries are projected to be used on 47 days to limit the loading on the transformer. Based on these load profiles, a battery storage rating of $9000 \mathrm{kWH}$ and 6 hours will be able to defer adding new or replacing the existing transformer by 5 years.

TABLE 7.4

SATILLA \#12 EMC

BATTERY RATING REQUIREMENTS

EXISTING TRANSFORMER CAPACITY 7000 KVA

$\begin{array}{lrcccc}\text { YEAR } & 1997 & 1998 & 1999 & 2000 & 2001 \\ \text { Forecast Peak Load kW } & 6,840 & 6,797 & 7,130 & 7,480 & 7,846 \\ \text { Battery KW } & 40 & 357 & 690 & 1,040 & 1,406 \\ \text { Battery KWH } & y-2 & 1,021 & 2,968 & 5,042 & 7,986 \\ \text { Battery Hrs } & 3 & 3 & 5 & 5 & 6 \\ \text { Cycles/Yr } & 1 & 2 & 17 & 33 & 47 \\ \text { Selected Battery Rating } & & 9000 \mathrm{KWH}, 6 \text { Hour battery } & & \end{array}$


Power Technologies, Inc.
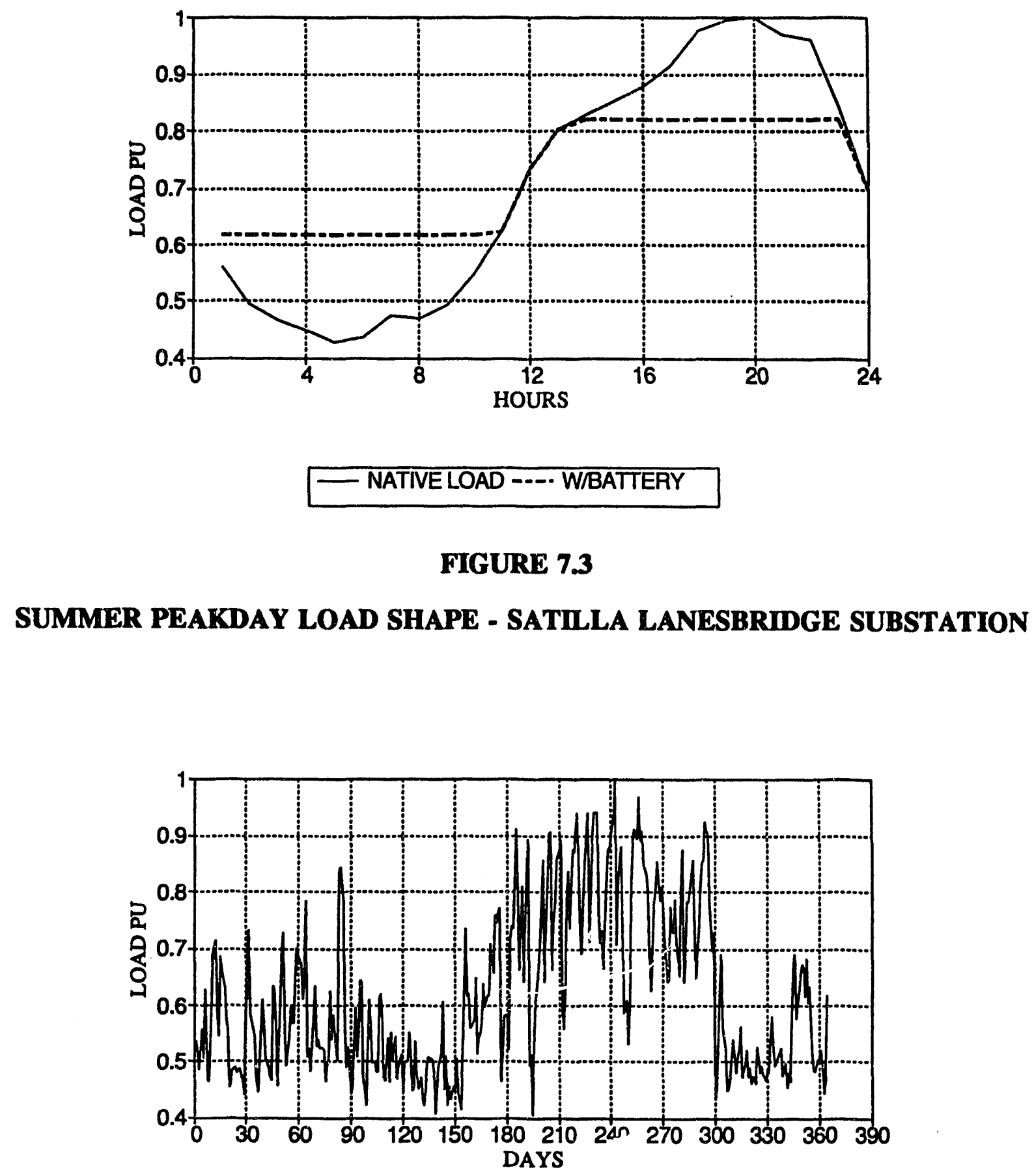

FIGURE 7.4

\section{DAILY PEAK LOAD - SATILAA LANESBRIDGE SUBSTATION}




\subsection{Planters \#9 Egypt Substation}

This substation is fed through a long $46 \mathrm{kV}$ radial line traversing swamp area.

Because of swampy terrain, when outages occur, relatively longer time is needed to repair and restore the line back into service. This line has experienced 7 outages in the last 70 months with the longest outage lasting over 4 hours (Table 7.3). The seven outages are almost twice as many as Hollywood Substation. Effort is being made to improve the rightof-way and clearances to reduce the number of outages.

\subsubsection{Deferment of $46 / 12 \mathrm{kV}$ transformer}

The load in the Planters \#19 Egypt Substation is projected to grow at a rate of about 5\% for the first year of this study, $2 \%$ for the second year and $1 \%$ for subsequent years. The existing 46/12 kV transformer has a capacity of $5250 \mathrm{MVA}$. The existing transformer is sufficient to serve the projected load up to the year 2005. By then if the batteries are in place, then the transformer addition can be postponed. The summer peak day load shape with and without a battery is shown in Figure 7.5. The daily peaks are shown in Figure 7.6. As can be seen from this figure, the 1991 annual peak occurred in winter. However, the winter peak occurred for only a 4-day period with sharp peaks and low energy content. The summer peak day load shapes are relatively flat and peak energy requirements are higher than the winter peak days. Hence, the battery energy capacity must be determined by using the summer peak day load shape. The number of cycles used per year will be fairly small. Because existing distribution transformer capacity is sufficient for over 10 years; distribution related benefit is considered to be zero. 


\subsubsection{Another Supply Source}

Providing a second feed into the Egypt Substation will reduce the number and duration of outages experienced by customers served by Egypt Substation. Several alternatives are available, namely, upgrading the $46 \mathrm{kV}$ line to $115 \mathrm{kV}$, adding another $46 \mathrm{kV}$ line or taping a nearby Guyton-Newington $230 \mathrm{kV}$ line (owned by Savannah Electric Power Co.) via a $230 / 46 \mathrm{kV}$ transformer. Upgrading from $46 \mathrm{kV}$ to $115 \mathrm{kV}$ is the preferred alternative. The estimated cost of this alternative is $\$ 5,339,510$. This alternative will be used to determine cost savings from deferment due to battery installation.

In order for the battery storage to truly qualify as a substitute second source (in place of a $115 \mathrm{kV}$ line), the battery $\mathrm{kW}$ rating should be equal to or greater than the forecast peak load (4841 kW in year 2001 from Table 7.4) and the longest outage experienced in the last 6 years (4 hours and 27 minutes from Table 7.2). A minimum rating of $22,000 \mathrm{kWH}$ and 4 hours rating for the battery will meet these requirements.

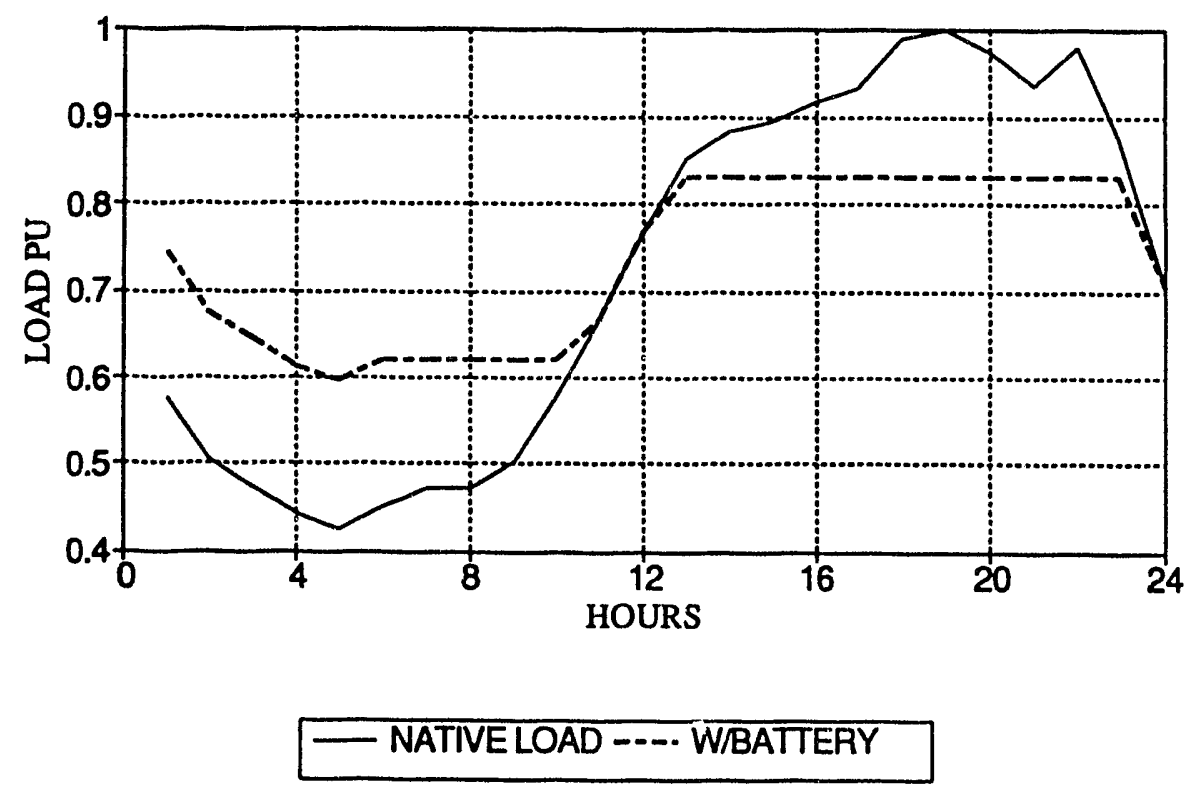

FIGURE 7.5

SUMMER PEAKDAY LOAD SHAPE - PLANTERS \#9 EGYPT SUBSTATION 

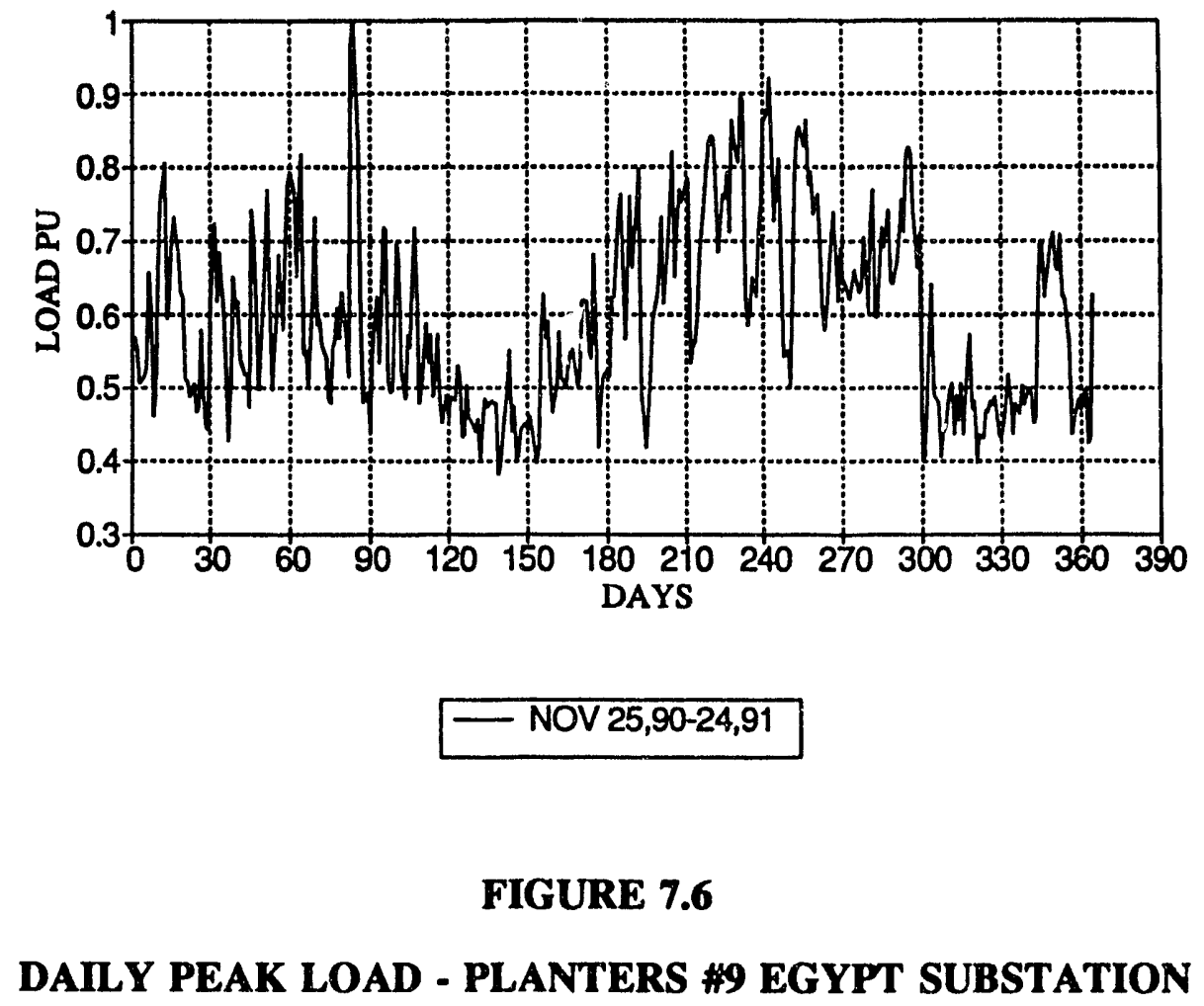


\subsection{BENEFITS - COST COMPARISON}

The results of a benefit to cost comparison for the five battery storage applications to defer transmission and distribution projects are presented in this section. The methodology used for benefit to cost comparison is essentially based on calculating the present worth of all the annual cost savings/benefits accruing due to the battery application, compared to the annual cost of owning and operating the corresponding battery plant.

Only four major benefits due to battery storage application are considered. They are:
- Generation capacity
- Transmission deferment
o Distribution deferment
- Value of service or cost of outage.

\subsection{Basis}

The battery storage identified in this study is mostly in the form of a backup or reserve source. It is not used in the general sense of load leveling. As stated in the end of Section 5.1 , a generation capacity (KW) credit based on a 10 hour discharge rating is applicable. The battery KW (based on 10 hour discharge rating) is essentially a generation reserve source. This may not be needed at the peak load condition. However, if a probabilistic generation reliability criteria (such as loss of load expectation - LOLE), is used, most of the contribution to the LOLE is during the peak load months. Hence a 10 hour discharge rating is used so that even if this reserve is called upon during the annual peak load condition, the battery will be in a position to provide the power (KW) equal to the credit it has received for the longes! peak load period of 10 hours. Thus, for example, a $10 \mathrm{MW}$, 1 hour battery will be given a credit of $1 \mathrm{MW}$. 
The cost of the battery credit is based on the least expensive generation altemative, which is a combustion turbine. A base cost of $\$ 526 / \mathrm{KW}$ (in 1991 dollars) is used for this credit. The annual cost savings from avoiding the investment in this generation is credited to the battery.

The transmission credit is basically computed on the basis of the cost of deferring the project. The actual capital cost expenditure is considered to be postponed by a number of years. The annual cost savings due to the postponement is credited to the battery benefits. The distribution benefits are also calculated similarly.

The fourth and last benefit computed in this study is the value of service or cost of outages. The actual cost or value of service used in this study is discussed in Section 7.2. For each of the five candidates of battery application analyzed in this study, it is assumed that the total amount of energy not served or KWH interrupted per year is equal to the total battery KWH rating. This means that, on the average, the sum of energy supplied to the customers by the battery during the interruptions over a period of one year is equal to its total energy rating. The implication of this assumption will be discussed later.

The economic parameters used in computing the annual cost and net present value (NPV) are shown in Table 8.1.

TABLE 8.1

GENERAL ECONOMIC PARAMETERS

$\begin{array}{llc}\text { Interest Rate } & = & 7.71 \% \\ \text { O\&M } & = & 2.50 \% \\ \text { Insurance } & = & 0.11 \% \\ \text { Ad Val Tax } & = & 0.74 \% \\ \text { Plant Life (Years) } & = & 30 \\ \text { Escalation Rate } & = & 4.50 \% \\ \text { Discount Rate } & = & 7.70 \%\end{array}$


The battery storage system costs assumed for base cases are shown in Table 8.2

TABLE 8.2

\section{BATTERY STORAGE COSTS FOR BASE CASES}

\author{
Estimated Battery Capital Cost \\ Battery Salvage Value \\ Battery Shelf Life(Years) \\ Battery O\&M \\ Estimated Battery Replacement Cost \\ Estimated PC+BOP Capital Cost \\ Escalation Rate
}

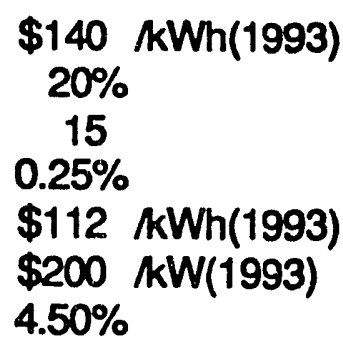

For the battery alone a different life is used than for the entire battery storage plant. The O\&M used is $0.25 \%$ of the capital cost. Amortising the capital cost is levelized over the plant life. All other costs are escalated at the rate shown in Table 8.1. The salvage value ofthe battery cells is included in computing the levelized annual cost. The cost of replacing the battery is calculated first, and its percent of cost reduction due to salvage is determined. The present worth of the cost reduction is computed and subtracted from the capital cost of the battery. The resulting cost is amortized over the life of the battery to compute the annual cost of the battery. The replacement cost of battery cells is included as needed. The converter and balance of plant are assumed to have a 30 year life and no salvage value.

\subsection{Summary of Five Application Cases}

Benefit to cost ratio for battery application at five different locations for T\&D deferment have been computed. The results are summarized in Table 8.3.

The benefit to cost ratio of Habersham EMC Meter Point \#8 (Hollywood substation) is greater than 1. The next best benefit to cost is at Planters \#9 (Egypt substation). The remaining three are ran'sed as Satilla \#12 Lanes Bridge substation, Vidalia and Warrentown. The detailed results for each case are presented in the next few sections. 
TABLE 8.3

SUMMARY OF NET PRESENT VALUE

\begin{tabular}{|c|c|c|c|c|c|}
\hline BENEFIT ITEMS & HOLWWOOD & EGYPT & SATILLA & VIDALIA & WARRENTON \\
\hline $\begin{array}{l}\text { GENERATION } \\
\text { TRANSMISSION }\end{array}$ & $\$ 667,972$ & $\begin{array}{r}\$ 1,959,385 \\
3,677,200\end{array}$ & $\$ 801,566$ & $\begin{array}{r}\$ 19,326,656 \\
1,432,366\end{array}$ & $\begin{array}{r}\$ 19,415,719 \\
1,263,723\end{array}$ \\
\hline $\begin{array}{l}\text { DISTRIBUTION } \\
\text { BACK-UP SOURCE }\end{array}$ & 206,603 & 0 & 206,603 & 206,603 & 0 \\
\hline CREDT & $2,058,127$ & $1,953,778$ & 417,220 & $9,635,678$ & $10,106,005$ \\
\hline TOTAL SAVINGS & $2,932,702$ & $7,590,363$ & $1,425,389$ & $30,601,303$ & $30,785,447$ \\
\hline BATTERY COST & $1,966,781$ & $6,022,418$ & $2,291,083$ & $54,051,315$ & $57,167,755$ \\
\hline BENEFIT/COST & 1.49 & 1.26 & 0.62 & 0.57 & 0.54 \\
\hline \multicolumn{6}{|l|}{ BATTERY SIZE } \\
\hline $\begin{array}{r}\text { KWH } \\
\text { HOURS }\end{array}$ & $\begin{array}{r}7,500 \\
5\end{array}$ & $\begin{array}{r}22,000 \\
4\end{array}$ & $\begin{array}{r}9,000 \\
6\end{array}$ & $\begin{array}{r}217,000 \\
7\end{array}$ & $\begin{array}{r}218,000 \\
5\end{array}$ \\
\hline
\end{tabular}

\subsubsection{Habersham \#8 Hollywood}

The detailed economic analysis for a battery application at this location is shown in Table 8.4. The benefit to cost ratio, as shown at the bottom of the table, is 1.49 and is the highest of the five applications investigated. The generation capacity (reserve) benefit is calculated for $750 \mathrm{KW}(7500 \div 10$ hours). There is no transmission deferral here. The distribution deferment avoids adding a second transformer. By placing batteries further down in the distribution system, additional benefits (deferment, loss reduction, shunt capacitor credit, etc.) may be possible. However, these are expected to be a smaller percentage of the total benefits and are more difficult to determine with reasonable accuracy. Hence, these are ignored.

In terms of benefits, the value of service [costed at $\$ 15.45$ per KWH (1993)] accounts for $70 \%$ of the total benefit, followed by generation capacity credit and distribution deferment. The back-up source or value of source benefit alone is sufficient to pay for the estimated battery costs. 
Power Technologies, Inc.

TABUE 8.4

ESTIMATED VAUE OF BENEATS AND BATTERY COSTS

FOR

HABERSHAM WB HOU YMOOD

ASSUMED BATTEPY SIZE=

7,800 KWH :

5 HFs

\begin{tabular}{|c|c|c|c|c|c|c|c|}
\hline YEAR & CENERATION & $\begin{array}{l}\text { WUAL SAVINGS } \\
\text { TRAMSMISSON }\end{array}$ & DSTRIBUTION & $\begin{array}{r}\text { BACKUPI } \\
\text { REUABILTY } \\
\text { CPEDT }\end{array}$ & $\begin{array}{l}\text { TOTAL } \\
\text { SAVNGS }\end{array}$ & $\begin{array}{l}\text { NET } \\
\text { VNUE } \\
\text { SNWH }\end{array}$ & $\begin{array}{l}\text { ANNUN } \\
\text { QATTERY } \\
\text { COST }\end{array}$ \\
\hline $\begin{array}{l}1907 \\
1908\end{array}$ & $\begin{array}{l}61,602 \\
62,378\end{array}$ & $\begin{array}{l}0 \\
0\end{array}$ & $\begin{array}{l}35,973 \\
36,425\end{array}$ & $\begin{array}{l}138,183 \\
144,401\end{array}$ & $\begin{array}{l}235,758 \\
243,200\end{array}$ & $\begin{array}{l}31 \\
32\end{array}$ & $\begin{array}{l}174,048 \\
174,845\end{array}$ \\
\hline $\begin{array}{l}1900 \\
2000 \\
2001\end{array}$ & $\begin{array}{l}69,186 \\
64,001 \\
64,915\end{array}$ & $\begin{array}{l}0 \\
0 \\
0\end{array}$ & $\begin{array}{l}36,897 \\
37,331 \\
37, \infty 07\end{array}$ & $\begin{array}{l}150,800 \\
157,600 \\
164,786\end{array}$ & $\begin{array}{l}250,980 \\
250,113 \\
287,608\end{array}$ & $\begin{array}{l}33 \\
35 \\
36\end{array}$ & $\begin{array}{l}175,677 \\
176,548 \\
177,457\end{array}$ \\
\hline $\begin{array}{l}2002 \\
2000 \\
2004 \\
2005 \\
2006\end{array}$ & $\begin{array}{l}65,850 \\
66,804 \\
67,812 \\
68,866 \\
69,868\end{array}$ & $\begin{array}{l}0 \\
0 \\
0 \\
0 \\
0\end{array}$ & $\begin{array}{l}38,447 \\
39,010 \\
39,509 \\
40,215 \\
40,858\end{array}$ & $\begin{array}{l}172,201 \\
179,850 \\
188,048 \\
196,510 \\
205,353\end{array}$ & $\begin{array}{l}278,487 \\
205,765 \\
295,460 \\
305,591 \\
316,179\end{array}$ & $\begin{array}{l}37 \\
38 \\
30 \\
41 \\
42\end{array}$ & $\begin{array}{l}178,407 \\
179,400 \\
180,488 \\
181,620 \\
182,658\end{array}$ \\
\hline $\begin{array}{l}2007 \\
2000\end{array}$ & $\begin{array}{l}71,119 \\
72,321\end{array}$ & & & $\begin{array}{l}214,504 \\
224,251\end{array}$ & $\begin{array}{l}285,713 \\
206,572\end{array}$ & $\begin{array}{l}38 \\
40\end{array}$ & $\begin{array}{l}183,810 \\
185,078\end{array}$ \\
\hline $\begin{array}{l}2000 \\
2010 \\
2011\end{array}$ & $\begin{array}{l}73,578 \\
74,802 \\
76,264\end{array}$ & & & $\begin{array}{l}24,342 \\
244,888 \\
255,907\end{array}$ & $\begin{array}{l}307,920 \\
319,770 \\
332,172\end{array}$ & $\begin{array}{l}41 \\
43 \\
44\end{array}$ & $\begin{array}{l}186,371 \\
187,722 \\
180,136\end{array}$ \\
\hline $\begin{array}{l}2012 \\
2013 \\
2014 \\
2015 \\
2016\end{array}$ & $\begin{array}{l}77,008 \\
79,197 \\
80,764 \\
82,400 \\
84,111\end{array}$ & & & $\begin{array}{l}\mathbf{2 6 7 , 4 2 0} \\
227,457 \\
202,003 \\
305,174 \\
318,007\end{array}$ & $\begin{array}{l}345,122 \\
358,655 \\
372,796 \\
387,575 \\
408,018\end{array}$ & $\begin{array}{l}48 \\
48 \\
60 \\
52 \\
54\end{array}$ & $\begin{array}{l}302,665 \\
303,968 \\
305,328 \\
306,751 \\
308,237\end{array}$ \\
\hline $\begin{array}{l}2017 \\
2018 \\
2019 \\
2020 \\
2001\end{array}$ & $\begin{array}{l}85,808 \\
87,766 \\
89,718 \\
91,757 \\
90,860\end{array}$ & & & $\begin{array}{l}333,258 \\
348,255 \\
363,026 \\
380,303 \\
307,416\end{array}$ & $\begin{array}{l}419,156 \\
456,021 \\
453,644 \\
472,050 \\
401,305\end{array}$ & $\begin{array}{l}56 \\
58 \\
60 \\
68 \\
68\end{array}$ & $\begin{array}{l}309,720 \\
311,413 \\
313,100 \\
314,681 \\
316,730\end{array}$ \\
\hline $\begin{array}{l}2002 \\
20023 \\
2024 \\
2005 \\
2005\end{array}$ & $\begin{array}{r}86,116 \\
88,444 \\
100,876 \\
100,418 \\
106,074\end{array}$ & & & $\begin{array}{l}415,300 \\
433,009 \\
453,518 \\
473,027 \\
405,253\end{array}$ & $\begin{array}{l}511,416 \\
652,432 \\
554,324 \\
577,344 \\
601,327\end{array}$ & $\begin{array}{l}68 \\
71 \\
74 \\
77 \\
80\end{array}$ & $\begin{array}{l}318,608 \\
320,601 \\
322,601 \\
325,013 \\
327,321\end{array}$ \\
\hline P.V. & 667,972 & 0 & 206,600 & $0,058,127$ & $2,932,700$ & 301 & $1,906,781$ \\
\hline
\end{tabular}

Value of Uheenved Energy

Extimitad Batery Cepitat Coet

Betary Salveoo Valuo

Betwery Shat Lite(Years)

Batery OQM

Extinemod Bentary Replecoment Cost Extinated PC+BOP Cepies Cost

(a) Generestion Cepitend Deflered

(b) Trunenisedion Cepitel Doflered

(c) Distribution Ceppint Deffered

Estimatod Bestary Cepital Cost

Extimead PCS+BOP Cepiter Cost

Extineted Bentary Peplecoment Cout

Extmabd Bumery and Roplacement Cost

Equivedent 30 Yeer Lis coet

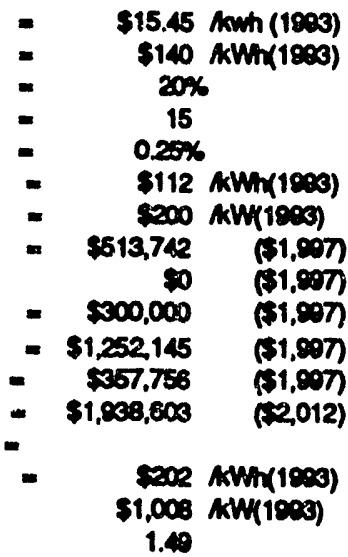

BENETIKOST RATIO

,

1.40 
Because the base case showed positive benefits, several sensitivity cases were run. The results of these sensitivity cases are summarized in Table 8.5.

TABLE 8.5

BATTERY COST(SNWH)

PCS+BOP COST(EKM)

BATTERY SHEF LIFEYYAS)

SALVAGE VALUE

VALUE OF UNSERVED

ENERGY(SNWH)

DISTRIBUTION BENEFTSMRS)

BENEFT/COSTRATIO

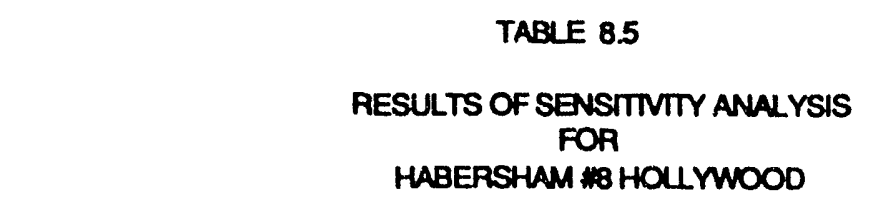

BATTERYSIZE $\quad 7500 \mathrm{KWH}: \quad 5$ HOURS

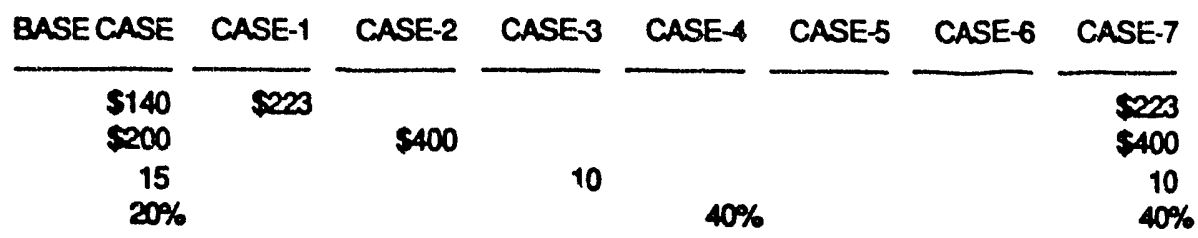

$\$ 15.45$

10

$\$ 8.25$

$\$ 8.25$

$\begin{array}{llllllll}1.49 & 1 & 1.27 & 1.42 & 1.68 & 1 & 1.58 & 0.76\end{array}$

NOTE: ONLY CHANGED VALUES ARE SHOWN; OTHER VALUS SAME AS BASE CASE

Detailed estimated benefits are contained in Appendix F. In the first case, (Case-1), it is shown that the battery's cost can be as high as \$223/KWH (1993), which is about 60\% higher than the base case, for the value of benefits to equal the cost of battery storage. In the second case, the converter and balance of plant (PCS + BOP) cost was doubled to $\$ 400 / K W H$ (1993) and this reduced the benefit to cost ratio from 1.49 to 1.27 . These two sensitivity cases show that the battery cells cost has a higher effect on the overall cost as compared to the converter and other costs. 
In the thind case, the battery life was reduced to 10 years from 15 years. This means two battery replacements are included in this case-3 as compared to only one battery replacement in the base case. The benefit to cost ratio decreased from 1.49 to 1.42 which is not a substantial reduction. Thus, there may be economic advantages in improving the cycle life of lead acid batteries, but the shelf life is not significant as compared to the battery cost itself.

In the fourth case, the salvage value was doubled from $20 \%$. Surprisingly, the benerit to cost ratio increased to 1.68 . This may be parly explained by the escalation used in computing replacement battery cost. Essentially, the salvage part of the battery cost is escalated by $4.5 \%$ because at the end of battery life, the trade-in value of the battery is assumed to be equal to the salvage percentage of the new battery cost.

The fifth sensitivity case involved the value of service or backup source credit. As noted earlier, this item contributed most to the battery benefits. Hence, the question is how low can this value of service be for the breakeven cost. As shown in Table 8.5, for this cost $\$ 8.25 / \mathrm{KWH}$ (1993) the benefits and cost of battery are breakeven. The $\$ 8.25$ per $\mathrm{KWH}$ is fairly close to $\$ 5.68 / \mathrm{KWH}$ in Table 7.1 .

In the sixth sensitivity case, the distribution benefits were extended to 30 years. The base case showed the distribution transformer deferment for 10 years only. Because the battery can be moved to another location, similar distribution benefits may continue to accrue. This case shows an increased benefit to cost ratio of 1.58 . The cost of moving the battery and any change in value of service are not recognized in this case.

The seventh case consists of taking a pessimistic approach and the cost components are a combination of all the sensitivity values used in the earlier 6 cases. Only salvage value and distribution benefits are positive assumptions. As expected, the benefit to cost ratio decreased to 0.76 . 
Based on the base case and the sensitivity cases, a range of 0.75 (low) - 1.68 (high) for the benefit to cost ratio has been calculated for Habersham \#8 Hollywood substation.

\subsubsection{Planters *9 Egypt Substation}

The estimated value of benefits due to battery storage and the battery costs are presented in Table 8.6. The benefit to cost ratio is 1.26 for base case assumptions. This is the second highest benefit to cost ratio of the five applications evaluated in this study. The largest benefit is from transmission deferral. The second largest benefit is from the generation reserve credit and the third benefit is the credit for value of unserved energy or: backup source. The distribution related benefits are not included in this table. As mentioned earlier, Egypt substation is served by a radial $46 \mathrm{kV}$ line and it traverses swampy right-of-way. Hence, any outage and repair may take longer than the typical outage to restore power. The outage history shows the average outage duration to be almost 2 hours (Table 7.2). The frequency of outages has been 1.2 occurrences per year. The value of service for residential customers ranges from $\$ 0.02$ to $\$ 5.00$ for one hour interruption (Table 7.1). Based on longer outage duration and higher frequency of outages the highest residential cost of outage of $\$ 5.00 / \mathrm{KWH}$ was used in this case.

The transmission deferral was assumed to be good for 10 years. Beyond ten years, the load in the area may be sufficiently higher to require a ney or second transmission line. The time horizon for transmission plans is about 10 years, beyond which the picture becomes unclear.

Two sensitivity cases were run for the Egypt substation. The first case was to determine the value of service (or cost of outage) which makes the sum of the benefits to be breakeven with cost. 
TABLE 8.6

ESTIMATED VALUE OF BENEFTSS AND BATTERY STORAGE COSTS FOP

PLANTERS 19 EGYPT

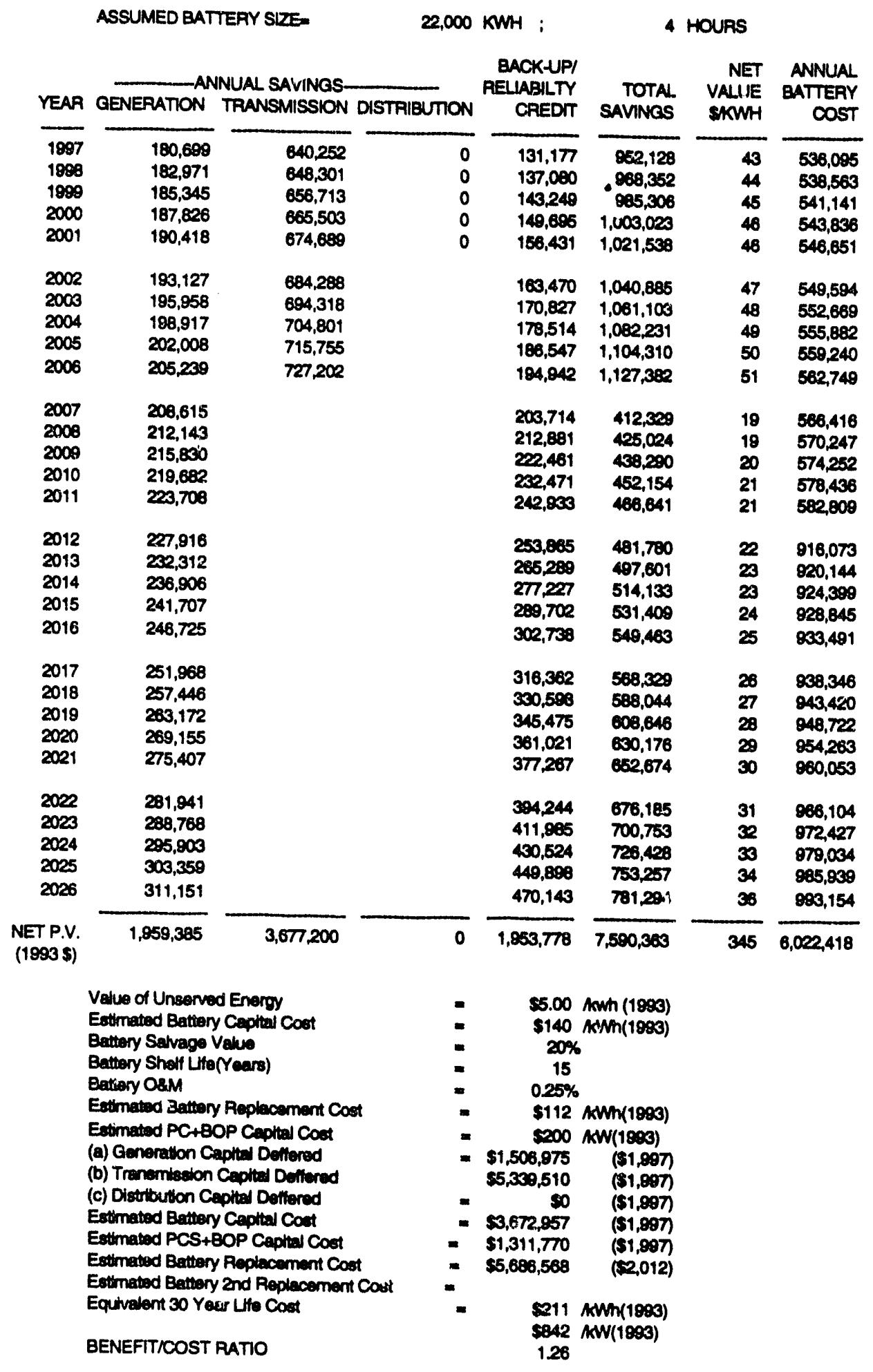


At value of service $\$ 1.00 / \mathrm{KWH}$ and all the other values being the same, this ratio was 1.0. The detailed results from this analysis are included in Appendix F (Table F8). The second sensitivity case involved extending the transmission benefit to 30 years upon the premise that battery can be moved to another location when transmission can not be deferred anymore. The benefit to cost ratio in this case turned out to be 1.8 , assuming the same amount of deferred credit is available. Because the ratio is greater than unity, even if the T\&D benefit in the later years is less than in the earlier years, the benefit may be higher than the cost incurred. Thus, the battery storage at Egypt substation shows beneficial application potential and may be considered as a serious candidate for demonstration.

\subsubsection{Sattila \#12 Lanes Bridge}

The battery storage as studied for this location is sized to defer the distribution transformer by 10 years. The calculated benefit to cost ratio is 0.62 (Table 8.7) which is much smaller than the two previously discussed locations. The largest benefit is from generation capacity reserve (900 KW) credit. The backup source credit is next highest with the distribution transformer deferment credit being the least.

Because Satilla \#12 Lanes Bridge is a small substation serving mostly residential customers, average value of service of $\$ 2.50 / \mathrm{KWH}$ (in 1993 dollars) from Table 7.1 , was assumed. A sensitivity case (Table F10, Appendix F) indicated that at $\$ 8.00 / \mathrm{KWH}$ (in 1993 dollars) for value of service, the benefit to cost ratio is unity. As shown in Table 7.2, average outage duration in the last 5 years is about 6 hours. Hence, a higher value of service credit than indicated in Table 7.1 may be applicable. If such high backup source credit can be justified, then Lanes Bridge could be a candidate for battery energy storage application.

\subsubsection{Vidalia}

The main reason for considering battery storage at this location is to defer installation of an additional 140 MVA, 230/115 kV transformer. As discussed in Section 7.0, because of parallel $115 \mathrm{kV}$ lines, a rather large battery storage is needed to reduce overload on the existing transformers. The benefit to cost ratio is 0.57 (Table 8.8) with generation reserve capacity benefit (for $21.7 \mathrm{MW}$ ) being the largest. Back-up source credit is the next largest benefit. 
Power Technologies, Inc.

TABUE 8.7

ESTIMATED VAWUE OF BENEFTIS AND BATTERY STORAGE COSTS

FCA

SATILA :12 LANES BAIDGE

ASSUMED BATTEFY SIZE = $9,000 \mathrm{KWH}$ : 6 HOURS

\begin{tabular}{|c|c|c|c|c|c|c|c|}
\hline YEAR & GENERATION & $\begin{array}{l}\text { NNUAL SAYNGS } \\
\text { TRANSMSSION }\end{array}$ & N DISTRIBUTION & $\begin{array}{r}\text { BACKUPI } \\
\text { REVABLTY } \\
\text { CFEDT }\end{array}$ & $\begin{array}{l}\text { TOTAL } \\
\text { SAVINGS }\end{array}$ & $\begin{array}{l}\text { NET } \\
\text { VALUE } \\
\text { SKWWH }\end{array}$ & $\begin{array}{r}\text { ANNULAL } \\
\text { BATTERAY } \\
\text { COST }\end{array}$ \\
\hline 1897 & 73,922 & 0 & 35,973 & 28,012 & 197,007 & 15 & 201,887 \\
\hline 1900 & 74,852 & 0 & 36,425 & 29,273 & 140,540 & 16 & 202,800 \\
\hline 1890 & 75,823 & 0 & 36,697 & 30,500 & 143,310 & 16 & 203,771 \\
\hline 2000 & 76,838 & 0 & 37,391 & 31,967 & 146,196 & 16 & 204,776 \\
\hline 2001 & 77,698 & 0 & 37,907 & 33,405 & 140,211 & 17 & 205,827 \\
\hline 2002 & 79,007 & 0 & 38,447 & 34,908 & 152,362 & 17 & 206,925 \\
\hline 2003 & 80,165 & 0 & 39,010 & 36,479 & 155,654 & 17 & 208,073 \\
\hline $\begin{array}{l}2004 \\
2005\end{array}$ & $\begin{array}{l}81,375 \\
82,640\end{array}$ & $\begin{array}{l}0 \\
0\end{array}$ & $\begin{array}{l}39,509 \\
40,215\end{array}$ & $\begin{array}{l}38,121 \\
30,856\end{array}$ & $\begin{array}{l}150,005 \\
1 \times 2,601\end{array}$ & $\begin{array}{l}18 \\
18\end{array}$ & $\begin{array}{l}209,272 \\
210,525\end{array}$ \\
\hline 2006 & 83,861 & 0 & 40,858 & 41,200 & 166,448 & 18 & 211,805 \\
\hline 2007 & 85,342 & 0 & 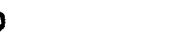 & 43,502 & 128,815 & 14 & 213,203 \\
\hline 2008 & 86,786 & 0 & b & 45,460 & 132,246 & 15 & 214,633 \\
\hline 2009 & 88,294 & 0 & o & 47,505 & 135,790 & 15 & 216,128 \\
\hline 2010 & 80,870 & 0 & D & 40,643 & 130,513 & 16 & 217,680 \\
\hline 2011 & 91,517 & 0 & 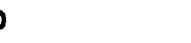 & 51,877 & 143,304 & 16 & 218,321 \\
\hline 2012 & 93,238 & 0 & כ & 54,212 & 147,450 & 16 & 365,402 \\
\hline 2013 & 85,037 & 0 & b & 56,651 & 151,688 & 17 & 366,987 \\
\hline 2014 & 86,916 & 0 & 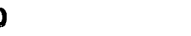 & $\boldsymbol{5 0 , 2 0 0}$ & 156,117 & 17 & 358,548 \\
\hline 2015 & 98,880 & 0 & o & 61,664 & 160,745 & 18 & 360,180 \\
\hline 2016 & 100,933 & 0 & 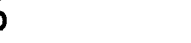 & 64,648 & 165,581 & 18 & 361,885 \\
\hline $\begin{array}{l}2017 \\
2018\end{array}$ & $\begin{array}{l}105,078 \\
105,319\end{array}$ & $\begin{array}{l}0 \\
0\end{array}$ & b & $\begin{array}{l}67,558 \\
70,508\end{array}$ & $\begin{array}{l}170,065 \\
175,917\end{array}$ & $\begin{array}{l}19 \\
20\end{array}$ & $\begin{array}{l}363,667 \\
365,520\end{array}$ \\
\hline 2019 & 107,661 & 0 & 0 & $73,7 / 5$ & 181,436 & 20 & 367,475 \\
\hline 2000 & $.110,100$ & 0 & o & 77,004 & 187,200 & 21 & 369,500 \\
\hline 2021 & 112,667 & 0 & 0 & 80,564 & 193,200 & 21 & 371,633 \\
\hline 2022 & 115,399 & 0 & 0 & 84,189 & 189,528 & 22 & 373,854 \\
\hline 2023 & 118,133 & 0 & o & 87,978 & 206,110 & 23 & 376,175 \\
\hline 2004 & 121,051 & 0 & 0 & 91,937 & 212,908 & 24 & 378,600 \\
\hline 2005 & 124,101 & 0 & o & 96,074 & 220,175 & 24 & 381,134 \\
\hline 2006 & 127,200 & 0 & 0 & 100,397 & 227,686 & 25 & 383,782 \\
\hline $\begin{array}{l}\text { ETP.V. } \\
\text { (8003\$) }\end{array}$ & 801,566 & 0 & 206,600 & 417,220 & 125,300 & 158 & $2,291,083$ \\
\hline
\end{tabular}

Velwo of Uncenved Enorgy

Estimatod Bettory Cepital Cost

Betrany Solvapo Valus

Betwy Shel Lifo(Yeers)

Batory OsM

Eximated Bentary Replacornent Cost Extiminad PC+BOP Cepibal Coet

(a) Generation Cepital Detiered

(b) Transmistion Cepital Deffored

(c) Distribution Capital Deffered

Extimatad Bettory Capital Coct

Estimeted PCS +BOP Capital Cost

Extiminad Battery Ropktsoment Cost

Extimeted Bentary and Poplacement Cost

Equivedent 30 Yeer Lito Cost

BENEFTTCOST RATIO

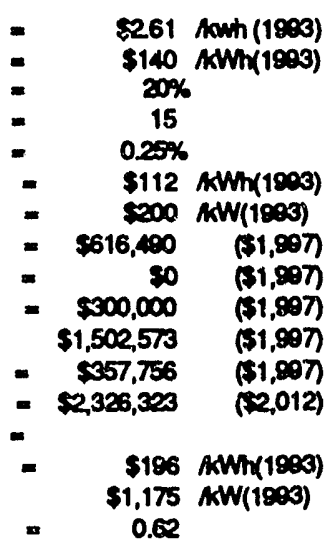


Power Technologies, Inc.

TABLE 8.8

ESTMMTED VAUE OF EENERTS AND BATTERY STORMGE COSTS FOP VIDALA

ASSUMED BATTERY SIZE- 217,000 KWH :

7 HOURS

\begin{tabular}{|c|c|c|c|c|c|c|c|}
\hline YEAA & GENERATION & $\begin{array}{l}\text { NNUAL SAYNG } \\
\text { TRANSAMSSE }\end{array}$ & $\overline{\text { XSTRIBUTION }}$ & $\begin{array}{l}\text { BACKUUPI } \\
\text { RELABBITY } \\
\text { CFEDIT }\end{array}$ & $\begin{array}{r}\text { TOTAL } \\
\text { SAYMESS }\end{array}$ & $\begin{array}{l}\text { NET } \\
\text { VALE } \\
\text { SNWH }\end{array}$ & $\begin{array}{l}\text { ANMUAL } \\
\text { BATTERY } \\
\text { COST }\end{array}$ \\
\hline $\begin{array}{l}1907 \\
1908 \\
1900 \\
2000 \\
2001\end{array}$ & $\begin{array}{l}1,782,309 \\
1,804,757 \\
1,828,173 \\
1,852,643 \\
1,873,215\end{array}$ & $\begin{array}{l}434,068 \\
439,528 \\
445,223 \\
451,188 \\
457,415\end{array}$ & $\begin{array}{l}35,973 \\
36,425 \\
36,897 \\
37,391 \\
37,907\end{array}$ & $\begin{array}{l}646,941 \\
675,05: \\
706,476 \\
738,263 \\
771,480\end{array}$ & $\begin{array}{l}2,099,350 \\
2,956,761 \\
3,016,775 \\
3,079,490 \\
3,145,027\end{array}$ & $\begin{array}{l}13 \\
14 \\
14 \\
14 \\
14\end{array}$ & $\begin{array}{l}4,747,608 \\
4,709,291 \\
4,791,856 \\
4,815,466 \\
4,840,077\end{array}$ \\
\hline $\begin{array}{l}2000 \\
2003 \\
2004 \\
2005 \\
2006\end{array}$ & $\begin{array}{l}1,904,906 \\
1,932,861 \\
1,962,041 \\
1,992,505 \\
2,024,402\end{array}$ & & $\begin{array}{l}38,447 \\
39,010 \\
39,509 \\
40,215 \\
40,858\end{array}$ & $\begin{array}{l}806,207 \\
842,486 \\
880,398 \\
920,016 \\
961,416\end{array}$ & $\begin{array}{l}2,749,500 \\
2,814,357 \\
2,082,008 \\
2,952,766 \\
3,026,676\end{array}$ & $\begin{array}{l}13 \\
13 \\
13 \\
14 \\
14\end{array}$ & $\begin{array}{l}4,865,827 \\
4,802,736 \\
4,920,866 \\
4,960,241 \\
4,900,949\end{array}$ \\
\hline $\begin{array}{l}2007 \\
2000 \\
2000 \\
2010 \\
2011\end{array}$ & $\begin{array}{l}2,057,702 \\
2,092,501 \\
2,128,865 \\
2,166,866 \\
2,206,578\end{array}$ & & & $\begin{array}{l}1,004,680 \\
1,049,801 \\
1,097,136 \\
1,146,507 \\
1,198,100\end{array}$ & $\begin{array}{l}3,062,382 \\
3,142,391 \\
3,226,001 \\
3,313,373 \\
3,404,677\end{array}$ & $\begin{array}{l}14 \\
14 \\
15 \\
15 \\
16\end{array}$ & $\begin{array}{l}5,013,0038 \\
5,046,571 \\
5,081,614 \\
5,118,233 \\
5,156,500\end{array}$ \\
\hline $\begin{array}{l}2012 \\
2013 \\
2014 \\
2015 \\
2016\end{array}$ & $\begin{array}{l}2248,076 \\
2,291,441 \\
2,336,758 \\
2,384,115 \\
2,432,608\end{array}$ & & & $\begin{array}{l}1,252,014 \\
1,308,355 \\
1,367,231 \\
1,428,756 \\
1,493,050\end{array}$ & $\begin{array}{l}3,500,000 \\
3,599,796 \\
3,703,969 \\
3,812671 \\
3,926,652\end{array}$ & $\begin{array}{l}16 \\
17 \\
17 \\
18 \\
18\end{array}$ & $\begin{array}{l}8,438,607 \\
8,473,454 \\
8,509,870 \\
8,547,924 \\
8,587,601\end{array}$ \\
\hline $\begin{array}{l}2017 \\
2018 \\
2019 \\
2020 \\
2021\end{array}$ & $\begin{array}{l}2,485,316 \\
2,539,357 \\
2,595,831 \\
2,654,845 \\
2,716,515\end{array}$ & & & $\begin{array}{l}1,560,238 \\
1,630,448 \\
1,700,818 \\
1,780,490 \\
1,860,612\end{array}$ & $\begin{array}{l}4,045,554 \\
4,169,806 \\
4,299,649 \\
4,435,335 \\
4,577,128\end{array}$ & $\begin{array}{l}19 \\
19 \\
20 \\
20 \\
21\end{array}$ & $\begin{array}{l}8,629,247 \\
8,672,674 \\
8,718,054 \\
8,765,477 \\
8,815,033\end{array}$ \\
\hline $\begin{array}{l}2002 \\
20003 \\
2001 \\
2005 \\
2005\end{array}$ & $\begin{array}{l}2,780,961 \\
2,848,306 \\
2,918,602 \\
2,992,225 \\
3,069,077\end{array}$ & & & $\begin{array}{l}1,944,340 \\
2,031,835 \\
2,123,268 \\
2,218,815 \\
2,318,661\end{array}$ & $\begin{array}{l}4,725,301 \\
4,880,141 \\
5,041,950 \\
5,211,040 \\
5,387,730\end{array}$ & $\begin{array}{l}22 \\
22 \\
23 \\
24 \\
25\end{array}$ & $\begin{array}{l}8,866,820 \\
8,920,937 \\
8,977,400 \\
9,006,587 \\
9,068,343\end{array}$ \\
\hline & 9,32 & $1,432,36$ & 200,4 & $9,635,678$ & $30,601,300$ & 141 & $54,051,315$ \\
\hline
\end{tabular}

Valie of Uncenved Energy

Estimeted Batiory Cepitit Cost

Bedery Sohnoe Value

Betery Shet Lite(Yoers)

Banary OAM

Estimued Betery Raphacement Cost

Extimeted PC+BOP Cepited Coet

(a) Genoration Cepital Doflered

(b) Trenemiacion Ceplted Deflered

(c) Distribution Cepitut Doflered

Eximated Bctany Capitul Cost

Extimed PCS+BOP Capitol Coet

Extimated Bumery Roplacoment Cost

Estmated Bewary and Reptacement Cost

Equivalent 30 Yeer Lllo Cost

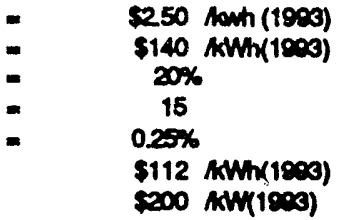

BENETT/COST RATTO

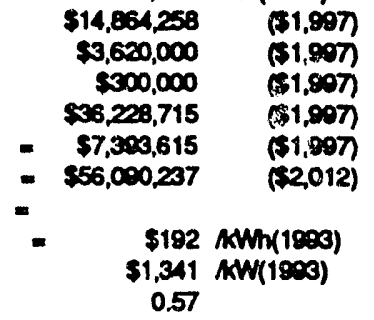


An average value of $\$ 2.50 / \mathrm{KWH}$ was used, because multiple $230 \mathrm{kV}$ and $115 \mathrm{kV}$ lines are cennected to this substation. Hence, longer interruptions are expected to be rare and also infrequent.

Maximum deferral of an additional transformer is only 5 years with this battery size. Hence, the deferment benefit is not very high. The battery may be placed at a lower voltage (46 kV or below) location thus postponing some distribution transformer addition or replacement. Here it was assumed that at least one such deferment is possible for a period of 10 years. This was the smallest calculaied benefit. By placing smaller sized batteries considerably more distribution benefit may be possible.

Again two sensitivity cases were run. The first case assumed a higher value of service of $\$ 8.60 / K W H$ (1993 dollars) to give a breake' en benefit to cost ratio (Table F11, Appendix F). Any higher backup source credit needs to oe justified from three principal factors (alone or in combination). They are type of customer load, duration of interruption and frequency of interruption. In the economic evaluation, the number of outages multiplied by their duration per year (i.e., when batiery storage is called upon in one year on the average as a backup source) is assumed to be equal to the battery energy rating. The second case extended the T\&D benefits to 30 years, and the benefit to cost ratio increased to 0.63 only (Table F12, Appendix F).

\subsubsection{Warrenton}

This is a second transmission/transformer deferment candidate considered in this study. The battery energy (KWH) storage is almost the same as Vidalia, but would require a faster discharge rate. Hence, the converter costs are higher in this case as compared to Vidalia. The benefit to cost ratio was calculated to be 0.54 (Table 8.9) which is the lowest of the five cases. The generation benefits were the highest, followed by back-up source credit and transmission credit. As in the case of Vidalia, there are multiple $230 \mathrm{kV}$ and $115 \mathrm{kV}$ transmission lines serving Warrenton station. Because $230 \mathrm{kV}$ and $115 \mathrm{kV}$ lines are paralleles, a rather large capacity battery is needed. The transformer addition could be postponed at most only 10 years. 
Power Technologies, Inc.

TABLE 6.9

ESTIMATED VAWE OF BENEFIS AND BATTERY COSTS FOR WARRENTON

ASSUMED BATTERY STEE= $\quad 218,000 \mathrm{KWH} \mathrm{:}$

6 HOUPS

\begin{tabular}{|c|c|c|c|c|c|c|c|}
\hline YEAR & GEIEATION & $\begin{array}{l}\text { NNUAL SAVINGS- } \\
\text { TRAMSIMSSION DISTRIBUTIO }\end{array}$ & & $\begin{array}{c}\text { BACK-UPI } \\
\text { REUABLTY } \\
\text { CFEDT }\end{array}$ & $\begin{array}{l}\text { TOTAL } \\
\text { SAVINGS }\end{array}$ & $\begin{array}{l}\text { NET } \\
\text { VALUE } \\
\text { SAWWH }\end{array}$ & $\begin{array}{l}\text { ANMUNL } \\
\text { BATIERY } \\
\text { COST }\end{array}$ \\
\hline $\begin{array}{l}1007 \\
1000 \\
1000 \\
2000 \\
2001\end{array}$ & $\begin{array}{l}1,700,553 \\
1,813,074 \\
1,856,508 \\
1,861,181 \\
1,886,870\end{array}$ & $\begin{array}{l}220,032 \\
222,703 \\
225,689 \\
228,710 \\
231,067\end{array}$ & $\begin{array}{l}0 \\
0 \\
0 \\
0 \\
0\end{array}$ & $\begin{array}{l}678,510 \\
700,053 \\
740,960 \\
774,300 \\
809,147\end{array}$ & $\begin{array}{l}2,680,114 \\
2,744,925 \\
2,000,217 \\
2,864,194 \\
2,927,863\end{array}$ & $\begin{array}{l}12 \\
13 \\
13 \\
13 \\
13\end{array}$ & $\begin{array}{l}5,008,024 \\
5,082,148 \\
5,108,369 \\
5,131,618 \\
5,158,001\end{array}$ \\
\hline $\begin{array}{l}2002 \\
2000 \\
2004 \\
2005 \\
2000\end{array}$ & $\begin{array}{l}1,013,715 \\
1,241,768 \\
1,971,083 \\
2001,718 \\
2003,731\end{array}$ & $\begin{array}{l}235,165 \\
238,613 \\
212,215 \\
245,960 \\
249,913\end{array}$ & $\begin{array}{l}0 \\
0 \\
0 \\
0 \\
0\end{array}$ & $\begin{array}{r}845,558 \\
883,600 \\
923,371 \\
961,923 \\
1,008,344\end{array}$ & $\begin{array}{l}2,994,430 \\
3,063,960 \\
3,136,669 \\
3,212,600 \\
3,291,808\end{array}$ & $\begin{array}{l}14 \\
14 \\
14 \\
15 \\
15\end{array}$ & $\begin{array}{l}5,185,704 \\
5,214,560 \\
5,244,734 \\
5,276,266 \\
5,300,196\end{array}$ \\
\hline $\begin{array}{l}2007 \\
2000 \\
2000 \\
2010 \\
2011\end{array}$ & $\begin{array}{l}2,067,184 \\
2,102,144 \\
2,133,676 \\
2,176,852 \\
2,216,746\end{array}$ & & & $\begin{array}{l}1,053,720 \\
1,101,137 \\
1,150,688 \\
1,202,460 \\
1,256,580\end{array}$ & $\begin{array}{l}3,120,904 \\
3,200,281 \\
3,280,364 \\
3,379,321 \\
3,473,326\end{array}$ & $\begin{array}{l}14 \\
15 \\
15 \\
16 \\
16\end{array}$ & $\begin{array}{l}5,313,619 \\
5,379,591 \\
5,417,182 \\
5,456,464 \\
5,407,513\end{array}$ \\
\hline $\begin{array}{l}2012 \\
2013 \\
2014 \\
2015 \\
2016\end{array}$ & $\begin{array}{l}2,258,456 \\
2,302,001 \\
2,347,527 \\
2,395,101 \\
2,444,817\end{array}$ & & & $\begin{array}{l}1,313,126 \\
1,372,217 \\
1,433,967 \\
1,498,495 \\
1,565,928\end{array}$ & $\begin{array}{l}3,571,562 \\
3,674,218 \\
3,781,494 \\
3,693,597 \\
4,010,744\end{array}$ & $\begin{array}{l}16 \\
17 \\
17 \\
18 \\
18\end{array}$ & $\begin{array}{l}8,707,400 \\
8,855,323 \\
8,874,881 \\
8,916,219 \\
8,950,417\end{array}$ \\
\hline $\begin{array}{l}2017 \\
2018 \\
2019 \\
2000 \\
2001\end{array}$ & $\begin{array}{l}2,495,700 \\
2,551,000 \\
2,607,700 \\
2667,000 \\
2729,004\end{array}$ & & & $\begin{array}{l}1,686,304 \\
1,710,032 \\
1,786,984 \\
1,867,303 \\
1,961,431\end{array}$ & $\begin{array}{l}4,133,164 \\
4,261,002 \\
4,304,777 \\
4,534,477 \\
4,680,466\end{array}$ & $\begin{array}{l}19 \\
20 \\
20 \\
21 \\
21\end{array}$ & $\begin{array}{l}9,001,560 \\
9,051,732 \\
0,101,023 \\
0,152,512 \\
0,206,375\end{array}$ \\
\hline $\begin{array}{l}2002 \\
2003 \\
2001 \\
2005 \\
2000\end{array}$ & $\begin{array}{l}2,793,776 \\
2,861,412 \\
2,932,132 \\
3,006,014 \\
3,063,200\end{array}$ & & & $\begin{array}{l}2,009,245 \\
2,131,011 \\
2,226,007 \\
2,327,117 \\
2,431,808\end{array}$ & $\begin{array}{l}4,833,001 \\
4,992,43 \\
5,150,030 \\
5,330,131 \\
5,515,068\end{array}$ & $\begin{array}{l}22 \\
23 \\
24 \\
24 \\
25\end{array}$ & $\begin{array}{l}9,262,630 \\
9,321,416 \\
9,302,848 \\
9,447,045 \\
9,514,130\end{array}$ \\
\hline $\begin{array}{l}\text { NET P.V. } \\
\text { (18039) }\end{array}$ & $10,415,719$ & $1,263,723$ & & $10,106,005$ & $30,785,48$ & 141 & $57,167,750$ \\
\hline & 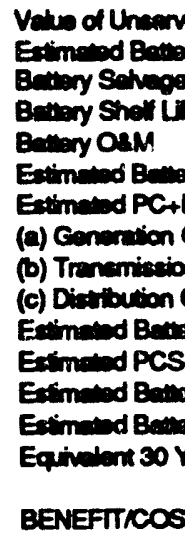 & 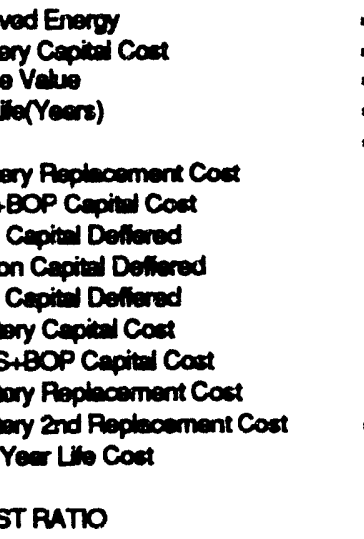 & & $\begin{array}{r}\$ 2,61 \\
\$ 140 \\
20 \% \\
15 \\
0,25 \% \\
\$ 112 \\
\$ 000 \\
\$ 14, \$ 32,756 \\
\$ 1,835,000 \\
\$ 0 \\
\$ 56, \$ 05,668 \\
\$ 10,308,752 \\
\$ 56,348,717 \\
\$ \$ 202 \\
\$ 1,008 \\
0.54\end{array}$ & 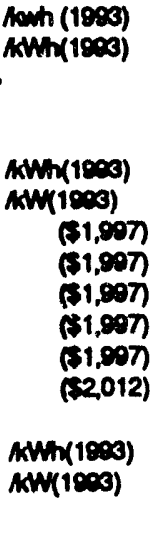 & & \\
\hline
\end{tabular}


Power Technologies, Inc.

There is no obvious distribution deferment. However, several smaller size batteries could be located in order to obtain deferment of distribution facilities and equipment.

Again two sensitivity cases were run. Increasing backup source credit to $\$ 9.40 / \mathrm{KWH}$ (in 1993 dollars) made the benefit to cost ratio to be unity (Table F13, Appendix F). Extending the transmission benefits to 30 years, increased the benefit to cost ratio to 0.56 (from 0.54 ). 
Power Technologies, Inc.

APPENDIX A

BENEFTTS OF BATTERY STORAGE 


\section{APPENDIX A \\ BENEFITS OF BATTERY STORAGE}

Battery potential benefits that battery attributes and control capability can provide are described in this appendix. There are two considerations to be kept in mind in evaluating the potential benefits of batteries:

Battery storage systems are different from other power generation and transmission facilities. They are even quite different from the forms of energy storage that are presently in use (compressed air and pumped hydro). The unique terms and attributes of battery storage systems are described in Appendix B. Brief descriptions of battery energy storage system controls and hardware are given in Appendix C. The unique attributes and control capability need to be considered when evaluating them as an alternative to other power generation and T\&D equipment.

Battery storage systems may not be able to provide all of the benefits listed below at the same time. Some of them are what has been termed "mutually exclusive." That is, if credit is taken for one benefit, some others may not qualify for credit. For instance, if a battery is used to defer a T\&D equipment, some of the reduction in losses it can provide will be lost because the average loading of the existing lines will increase. However, some apparently mutually exclusive benefits may be less mutually exclusive than they at first appear. For instance, if two potential benefits do not each require the battery at the same time, or during the same season, then perhaps the battery can provide both. Further, there may be times when a battery can provide only one of two benefits, but at times one is more valuable, and at other times the other is more valuable. When this is the case, a battery may not fully provide either benefit, but will be of more value that either alone would indicate. In this situation, operators would decide on a day to day or hour to hour basis just how the battery should best be used. This kind of shared battery use is difficult to evaluate without a detailed year-long chronological simulation, but may 
bs important to a fair evaluation. Other examples of mutual exclusivity are listed in Appendix $\mathbf{D}$.

The potential benefits include:

Generation - batteries can provide spinning reserve, load following, area regulation, and load leveling or peak shaving to:

Defer generating capacity

Reduce

production cost

Provide spinning

reserve

Provide area and frequency regulation
By storing energy at night and releasing it during peak load times, batteries can reduce generation requirements. The spinning reserve and area and frequency regulation applications described below also contribute to a reduced generation requirement.

Batteries can be charged at night when energy costs are low, and discharged during the day when costs are high. Batteries may also be charged from off-system purchases during off-peak hours.

Each utility in a pool has an obligation to have a certain amount of generation on-line over and above the forecasted load so that sufficient generation is available to meet load when a generating unit trips. Because there is more generation on-line than load, some units are operated at less than their full capacity. Ramping rate also enters into the picture. Batteries can sit efficiently at zero output and be activated quickly and automatically when needed, so it can provide spinning reserve at far less operating cost than a spinning generator. Generating units capable of providing spinning reserve can also be operated at their most efficient power level rather than at a lower power level when a battery provides spinning reserve.

Each utility in a pool has an obligation to follow its own load to prevent tie line loading from deviating significantly from scheduled interchanges. Doing so also keeps frequency constant. When deviations from schedule do occur, each utility must correct and "net out" those deviations within 10 minutes. This usually means having highly rusponsive generating units well operating below maximum capability, or far from their most efficient operating points, equal to as much as $3 \%$ of the system load operating in a regulating mode. Using batteries to follow load allows generation to be operated in its most efficient manner. The generation would need to be maneuvered only enough to 
keep the battery charged to 70 to $80 \%$ of its capacity so it can handle both increases and decreases in load.

Reduce operating constraints and minimum load problems, and reduce plant $O \& M$ costs
Utilities often have limitations such as generators that can't be cycled, generators that are costly to cycle, generators whose loading can't be changed quickly and rapid load changes. Solutions include leaving units on-line around the clock and starting combustion turbines or starting cycled units ahead of the load. Batteries can follow load and level the load to reduce cycling.

Transmission \& Distribution -- batteries can serve load peaks and respond quickly to:

Defer lines and transformers

Reduce line losses

Regulate voltage
Transmission and distribution systems are planned to carry the system peak load with one or more lines or transformers out of service. The T\&D investment is reduced when batteries are used to store energy during off-peak hours and serve the load during the daytime peak. Overall this could save $\$ 100$ to $\$ 200$ per $\mathrm{kW}$ of load, but the savings can be much greater if batteries are placed jualiciously where T\&D costs are high. Some utilities have locations where T\&D costs are several times the system-wide $\$ 100$ to $\$ 200$ per $\mathrm{kW}$ number. Batteries do not need to be cycled to qualify for this benefit, but they do need to be at least charged and ready to cover a T\&D equipment outage should it occur during peak load.

Because line losses are about four times higher during peak load hours than they are during off peak hours, charging batteries at night and discharging them during the day will reduce $T \& D$ losses from their usual 5 to $8 \%$ by $0.5 \%$ to $1.0 \%$ when the battery is operating. A battery which is cycled daily or almost daily provides significant loss reduction benefit.

Batteries can improve voltage regulation in two ways. One is by supplying active power to customers and thereby reducing the loading on the network. The second is by supplying reactive power to the network. Battery power converters can readily be designed to supply active and reactive power. If the converter is designed to a power factor rating like a generator, it will be capable of supplying both active and reactive power at the same time. The converter is capable of responding to voltage 
Power Technologies, Inc.

excursior: much more quickly than a generator, thus provides excellent voltage control.

Increase transfers

Batteries can respond quickly to controls or operators to improve voltage stability, first-swing stability, and steady state oscillatory stability, and thereby increase transfers in stability limited systems. Batteries can improve voltage stability by supplying both active and reactive power when a system is hit by a contingency which threatens voltage stability. Batteries can improve first-swing stability by quickly injecting power into a decelerating system or absorbing power from an accelerating system immediately following fault clearing. Battery power can also be modulated by a power system stabilizer to provide system damping.

Environmental benefits include:

Reduced air emissions

Improved urban air quality
Batteries can reduce air emissions by storing energy from low emission plants at night, and supplying load during the day so high emission plants can be operated at lower output or left offline. Because batteries have virtually no emissions themselves, they are ideal for this purpose. Battery turn-around losses (about $20 \%$ ) need to be recognized as there will be emissions associated with them.

Urban air quality can be improved by importing power from remote plants at night and storing it in batteries for use the next day. 
Reduced

electromagnetic

fields

Reduce land

requirements for

$T \& D$ and

generation
Batteries located near customers, and cycled to level the load, will reduce the high daytime current in transmission lines. This, in turn, will reduce the magnetic fields. Charging the batteries at night will increase the current in lines at night. However, the reduction in the high current during the day may be more beneficial than the increase in low night currents is harmful.

Use of land for electric utility equipment is a sensitive subject today. To the extent batteries can defer generation and T\&D equipment without using a lot of land themselves, batteries may help where land simply isn't available for lines and generating plants.

Strategic -- batteries can reduce the risk of high, unnecessary system investments through:

Acting as an anyFuel source

Hedge to avoid unneeded

investment

Means to serve difficult to reach load
Batteries may be able to store energy from various sources to help cover contingencies such as a nuclear moratorium or other major upset in fuel supply.

Batteries can be a hedge to avoid unneeded investment in T\&D facilities or generating plants. Because a battery can be installed quickly, and can later be moved, it allows a wait-and-see attitude toward high load growth.

Because of low environmental impact, batteries can be installed anywhere there is space for them. They thus may provide service to growing load that cannot be quickly reached by overhead lines or cables.

Other -- batteries can provide other miscellaneous benefits such as:

Power quality

Batteries are, in effect, a 'local' power source independent of the T\&D system. They can thus ride through temporary T\&D system outages like an uninterruptable power supply (UPS). The converter on a battery can also regulate voltage, thereby improving power quality further. 
Reliability

(Backup source)

Black start

System modeling

Take advantage of energy buy-sell opportunities
Batteries can supply load for up to several hours, and thus can not only act as a UPS, but can also carry critical loads through outages lasting several hours.

Batteries can operate independently of the grid, and thus can startup and carry critical loads following outages. Transformers, subtransmission and distribution lines can be energized. Motors can be started. A battery might be used to help startup a generating plant that normally requires power from the grid for startup.

Batteries can be modulated to excite low level system oscillations and provide very useful information on system stability. This can improve analytical studies used to set transfer limits.

Batteries may help utilities that both buy and sell energy. To the extent that such transactions can be scheduled ahead of time, a battery could serve this purpose when it is not needed for onsystem services.

Customer-side-of-the-meter applications -- from the customer perspective, batteries might provide:

Demand limiting

Reliability

(Backup source)
Most utilities impose demand charges on larger customers to cover the cost of T\&D and generating equipment needed to serve short-duration peaks. These customers could ise batteries to control their $\mathbf{3 0}$ minute demand and avoid these penalties.

Some customers could make use of utility type battery installations in much the same way they use UPS systems or diesel generators for smaller loads. 
Power Technologies, Inc.

\section{APPENDIX B}

TERMS, ATTRIBUTES, AND OTHER 


\section{APPENDIX B}

\section{TERMS, ATTRIBUTES, AND OTHER}

\section{Attribute}

An 'attribute' is a characteristic of batteries that can be used to advantage by an electric utility. Energy storage, fast response, site flexibility, and unattended operation are examples.

\section{Benefit}

A battery energy storage 'benefit' is a monetary, strategic, or societal benefit of placing a battery on the utility grid. Benefits include deferred or avoided generation or T\&D equipment investments, reduced losses, improved reliability, lower spinning reserve costs, and more efficient operation of generation.

\section{Application}

An 'application' is a battery of specific size and in a specific location. It is a 'good' application if the benefits exceed battery cost.

\section{Ratings}

Batteries have two key ratings. One is the power rating ( $\mathrm{kW}$ or $\mathrm{MW})$. It is the maximum power that the battery can provide for an extended period during the discharge part of its cycle. The power rating is dictated by the lowest continuous rating among the components that make up the system: the cells, the busbars, the converter, or the converter transformer. In an optimized design all components will have about the same continuous capability. However, the converter is usually the most limiting device and the one with the least margin. While cell life will be reduced somewhat when a battery is operated above its power rating, GTOs in the converter may fail at a power level as little as $10 \%$ above their rating. The converter controls are thus designed to prevent converter overloading.

The maximum continuous charge power level is dictated by the same considerations, and is thus usually the same as the power rating. Note, however, that in practice the charge rate may be lower than the rating to increase battery life if low-cost energy is available over a period sufficient to fully charge the battery at the lower rate.

The second battery rating is its energy storage rating ( $\mathrm{kWh}$ or $\mathrm{MWh}$ ). The storage rating is the energy that the battery can provide to the system during a normal continuous discharge. In current designs the energy rating is usually $80 \%$ of the energy the battery could provide if discharged fully. The energy rating is solely a function of the individual cell ratings and the number of cell strings in parallel. The battery energy rating can be increased by adding parallel strings of cells.

$$
\text { B - } 1
$$


The batteries produced to date have not been given an overload rating. However, batteries, buswork, transformers, and circuit breakers tolerate some overload. Though a converter cannot be significantly overloaded, a converter could be oversized to take advantage of the overload capability of other components.

\section{KWh Capacity Versus Dischirge Rate}

The types of cells utilized in utility energy storage are special designs, and do not have a standardized capacity rating based on a certain discharge time such as 20 hours. Such a rating would be of little use in any event in the kinds of applications we are considering. But, more important, is that the amount of energy that can be extracted from a charged battery varies with the discharge time. For instance, in a spinning reserve application we may discharge a battery fully in one hour, while in a T\&D deferral or load leveling application we may discharge the same battery over a 4 hour period. In the one-hour discharge we may only get 60 to $80 \%$ of the MWh that we could get from a four-hour discharge. The battery discharge characteristics thus need to be considered in specifying the battery, and in costing the battery in cost-benefit studies.

\section{Cell Types}

Two types of lead-acid cells are in use. Tne one first used in utility energy storage applications is the 'flooded' cell. It is typically 14 to 18 inches square and 24 to 30 inches tall. It has a vent on the top covered by a filter so that only hydrogen escapes from the battery. The Southern California Edison installation uses flooded cells, as will the $20 \mathrm{MW}$ battery to be commissioned in Puerto Rico in 1993.

The second type is the "sealed' or "valve regulated" lead acid battery (sometimes called VRLA for valve regulated lead acid). In this design gelled electrolyte is normally used and contained in a sealed plastic case.

\section{Cycle}

The normal 'load-leveling' cycle for a battery is a diurnal one in which the battery is charged at night and discharged to follow load during the day. In most load-leveling applications, batteries will be cycled only on weekdays. In spinning reserve applica ons there will be no regular charge-discharge cycle. In some special applications multiple shallow charge-discharge cycles may occur over periods of minutes or hours.

\section{Cycle Depth}

Batteries can be cycled daily to 'shift' load from peak hours to off-peak hours. However, because battery life is reduced as the depth of discharge is increased, there is an optimum depth of discharge for each application. The optimum depth occurs where the incremental benefit of load-leveling equals the cost of incremental battery loss of life. Though the relationship of the depth of discharge and life loss is not very well known, current practice with flooded cells is to limit the depth of discharge to $80 \%$ of the full battery capacity (the 
batter, rated capacity may be defined as the capacity that can be used reguiarly while achieving a stated battery life).

Sealed batteries presently appear to have a shorter life than flooded cells for the same depth of discharge. New designs may close this difference in performance between the two types. Of course, sealed batteries require less maintenance, and this may offset the shorter life. If the reduced life is a constraint for sealer, batteries, the sealed types may have an advantage where cycling is infrequent or only partial cycles are needed, and spinning reserve or other uses are the primary function.

In some applications there will be value to the ability to discharge a battery fully. The cell capacity that remains after a normal-depth discharge may be used for spinning reserve is to backup transmission or distribution equipment. Manufacturers indicate that flooded cells can be discharged fully on occasion without significant loss of life. Sealed or valve regulated batteries may eventually have this capability. To achieve full discharge, the power converter must be capable of operating at the end-of-discharge battery voltage.

\section{Life}

The life of lead-acid batteries in utility service is not yet well known. Accelerated life tests indicate the life may be as low as five years or as much as 15 to 20 years depending on the application and the type of battery. Life will be at the low end of this range where the battery is cycled frequently and where the depth of discharge is high (Cycle Life, i.e., useful life dependent on number of cycles). It will be near the high end where the battery is essentially in standby service (Shelf Life, i.e., useful life dependent on the age of the battery).

\section{Rapid Cycling}

There are two benefits that batteries can provide that will require the battery to be cycled more than once per day. One is frequency regulation and the other is tie line control or area control error (ACE) corrections. Frequency regulation will require many shallow cycles lasting only seconds or minutes. Tie line control cycles will be of modest depth, and will typically last 5 or 10 minutes. These cycles may be in addition to a normal diurnal storage cycle.

Batteries are likely to be useful for frequency regulation only in systems of modest size where variations in customer load are large compared to the total on-line generation. In these systems frequency will vary from second to second and minute to minute unless one or more generators are assigned to tightly control frequency. This kind of duty on generators reduces plant equipment life and increases maintenance. And, even the fastest plants may have difficulty following load, and some utilities do not attempt to regulate frequency tightly because of the cost. Batteries can provide very rapid response to load changes. When called upon to do so frequently (dozens of times each day), the frequent, shallow cycling will reduce battery life somewhat.

$$
\text { B }-3
$$


Large interconnected systems inherently control frequency well. Even the largest customer load variations are small compared to the mass of many turbine-generator rotors, and thus will not measurably change frequency. However, in these systems each utility has a responsibility of limiting variations in tie flow, or correcting variations quickly when they do occur. Tie flow variations can result from variations in customer load or unscheduled changes in the loading of generating plants. Batteries may provide a significant benefit by taking over the load following task from generators.

\section{Response}

A battery system can also be moved almost instantaneously from one operating point to another within its real and reactive operating range shown in Figure B-1. In addition, it can continuously move about its operating region in response to a stabilizer or voltage regulator.

Fast response makes the battery a candidate to:

- Respond rapidly to generation shortages or transmission overload (via control signais from control center software or operators),

- Provide LFC or Area Regulation (via control signals from control center software),

- Tightly regulate voltage for the benefit of nearby customers or a larger load area,

- Regulate voltage for improved voltage stability in areas with little generation,

- Fruvide a damping component of power to raise transfer limits imposed by dyr:amic stability,

In supplying reactive power to control voltage, the battery system is competing directly with Static Var Systems (SVSs) and generators. The battery system has an advantage over generators in that generators can rarely be sited where voltage control is needed, while batteries are very likely to be sited in areas needing voltage control. A battery system also responds much more quickly to system voltage changes that a generator can.

The reactive capability of a battery system converter is quite similar to that of an SVS. More information on this is in the next section. 
Power Technologies, Inc.

APPENDIX C

HARDWARE AND CONTROL 


\section{APPENDIX C}

\section{HARDWARE AND CONTROL}

\section{Major Components}

A battery system consists of several components as shown in Figure C-1. The key components are the battery and the power conversion unit (converter).

The battery consists of parallel 'strings' of cells connected in series. Each cell is nominally 1.2 volts, and a string may be from a few hundred volts up to about 2000 volts. The Chino battery, capable of $10 \mathrm{MW}$, operates at 2000 volts. The string voltage is selected to minimize converter and buswork costs. Converter costs dominate the selection, however, with the optimum design being a function of the available thyristor voltage and current

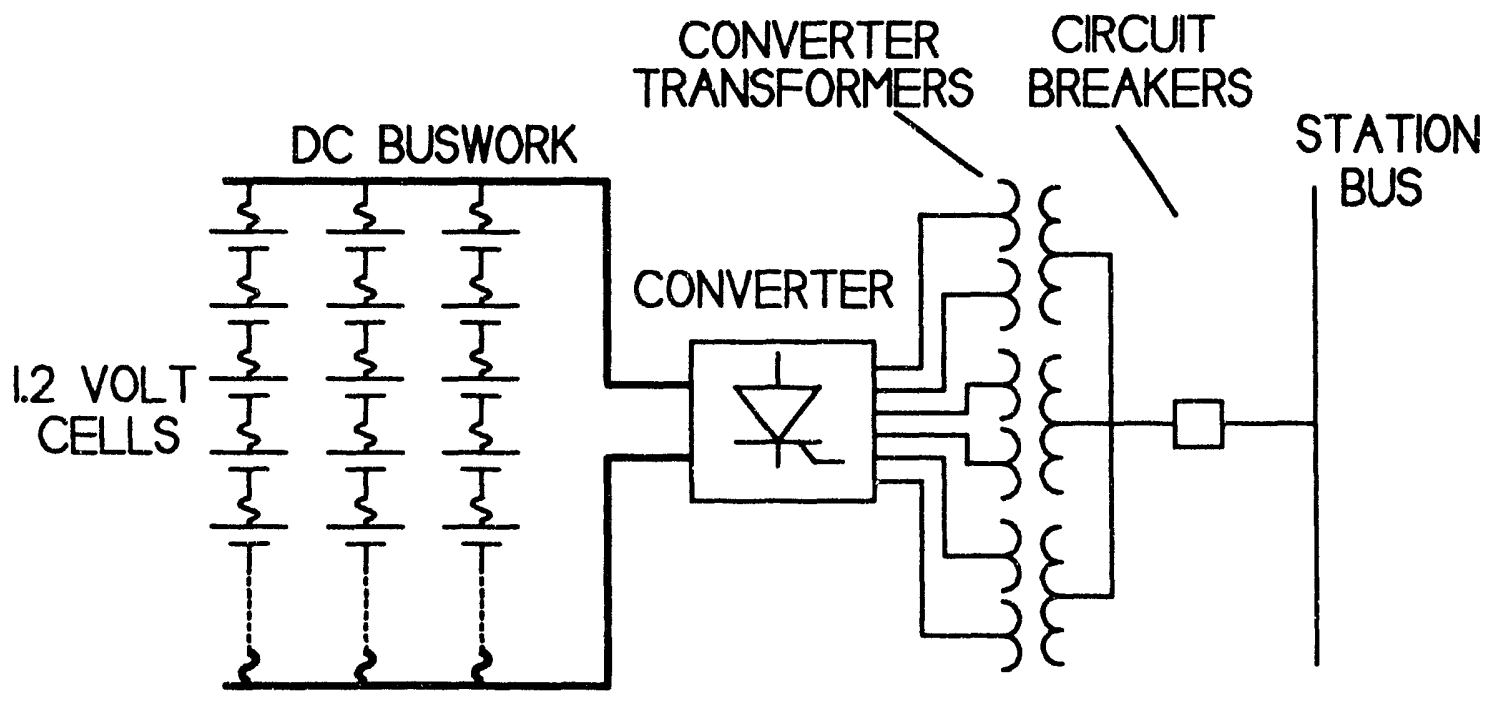

Figure C-1 A battery system consists of several major components.

ratings. Each cell is fused, and each string is fused. The fuse at the cell protects against faults within the string, and the string fuse protects against faults outside the string. The string fuse and the individual battery fuses are coordinated so that the string fuse will open before battery fuses open when a fault external to the string occurs.

The converter consists of a combination rectifier and inverter and a transformer. When the battery is being charged, the converter behaves like a rectifier, changing the ac voltage into dc. When the battery is being discharged, that is, it is supplying power to the system, the converter operates as an inverter. 
In the rectifier mode the converter controls the voltage across the battery or the charging current. The voltage and resulting current are adjusted for the desired charge rate. The converter converts the ac voltage to dc by firing the thyristors so that the voltage from each of the transformer windings sums to that needed to cause the desired charge current to flow in the battery.

In the inverter mode the converter essentially chops the dc current into segments, and builds a voltage wave that is an approximation of the normal ac system sine wave. In the case of the Chino battery, a "36 pulse" converter is used.

The converter causes power to flow into the ac bus by shifting its waveform ahead of the waveform of the bus voltage. It charges the battery by making its waveform lag the bus voltage. Reactive power is delivered by making the magnitude of the waveform larger than that of the bus voltage and reactive power is absorbed by making it smaller.

Converters are normally given ratings in MVA, but this rating only applies at rated voltage. Converters are, in reality, current-limited devices. A converter can be used to provide active or reactive current or a combination within its current handling capability. Because real and imaginary current are in quadrature, the square root of the sum of the squares of the reactive and active currents must remain within converter current capability.

A 10 MVA converter can thus supply $7 \mathrm{MW}$ and $7 \mathrm{MVAR}, 8 \mathrm{MW}$ and $6 \mathrm{MVAR}$, etc. at rated voltage. Figure $C-2$ shows the active and reactive current relationship in a converter. In this example the converter can provide reactive power only when it is operating below its rated active power. 


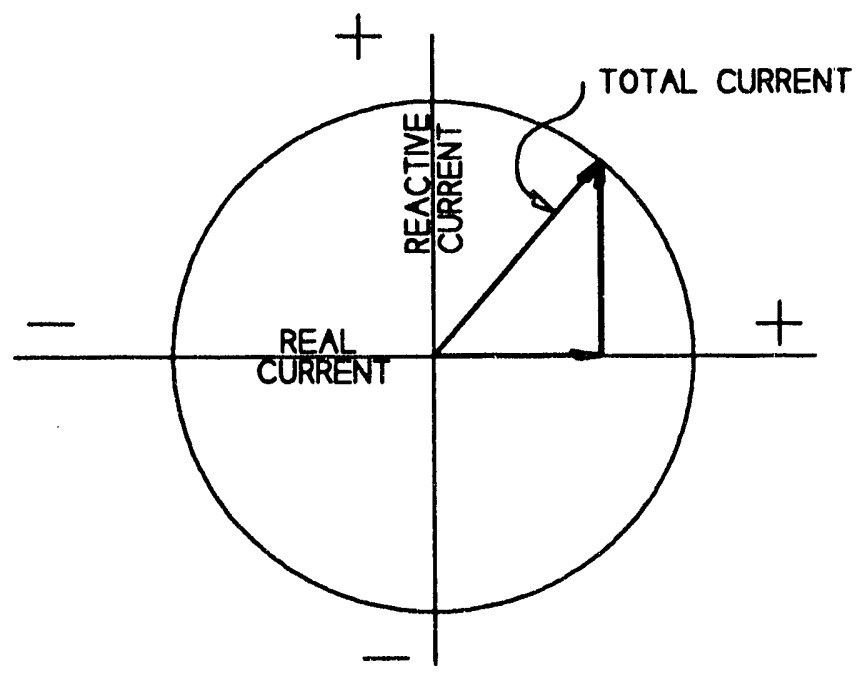

Figure C-2 The total current is the vector sum of the active and reactive current and must be within the converter current rating.

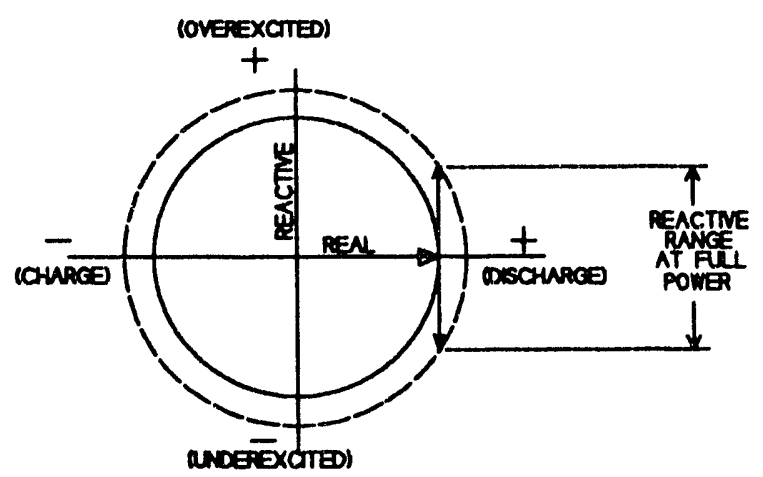

Figure C-3 A modest increase in converter rating will provide a large reactive power capability.

For example, as shown in Figure C-3, increasing the converter MVA (or current) rating by $15 \%$ will allow it to provide reactive power up to $57 \%$ of the battery MW rating while operating at its MW rating. The battery can supply or absorb reactive power, and can provide a 'dynamic' reactive range of $114 \%$ of rated power in this example. 


\section{Controls}

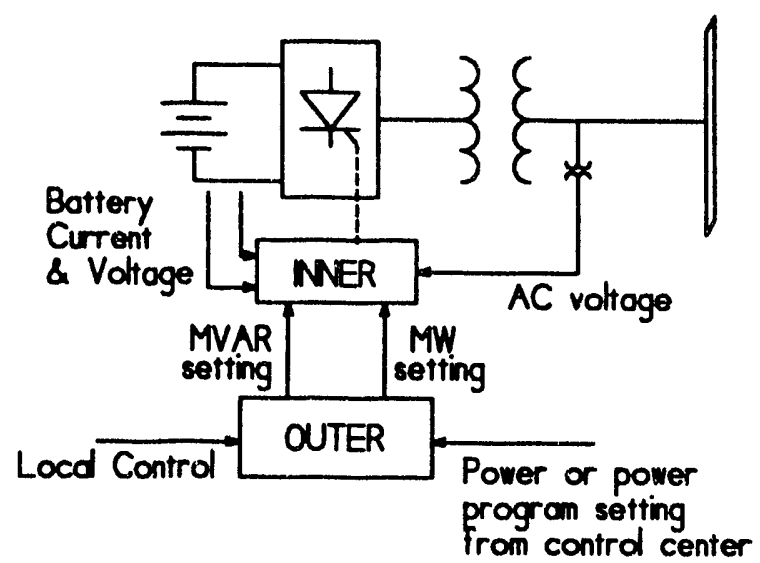

Figure C-4 A battery system has two levels of control, one to drive GTO firing circuits, and one to issue the real power setting.

The battery control system has two levels as shown in Figure C-4. The 'inner loop' provides high speed regulation of the battery power. For instance, if the battery is being controlled to a certain power level, the controller will adjust the GTO firing pulses so that power level is maintained even when the bus voltage is varying. It will also go into a current control mode when a drop in voltage would require converter current to go above the converter rating to hold power.

The inner loop may also include voltage control circuitry. This circuitry adjusts firing pulses to the GTOs so that the converter will produce or absorb reactive current as needed to regulate bus voltage. Again, the controller will go into a current control mode if the GTO current would have to exceed GTO rating in order to hold the desired bus voltage.

The GTO based converter, effectively, synthesizes a waveform that is either larger or smaller in magnitude than the bus voltage, and either leads or lags the bus voltage. The voltage and power level control circuits operate simultaneously to control the magnitude and phase of the waveform respectively. A larger magnitude delivers reactive power to the bus while a lower magnitude absorbs reactive power. A leading voltage delivers active power to the bus (discharge mode) and a lagging voltage absorbs power from the bus (charge mode).

The converter controls must, however, keep total current in the GTOs within their thermal capability. When converter loading is high, one or both of the currents must be limited so that the total current does not exceed the converter rating (see Figure C-2). An additional circuit is used to decide whether the converter provides active power or reactive power 
when loading is high. In most applications active power will be given priority. Hence as the active power is increased, the reactive current capability will decrease, reaching zero as the active power reaches the full rating of the converter. However, in some applications it may be useful to give reactive power priority when voltage drops excessively. This must be done cautiously, because the drop in active power may, through increased line loading, increase line reactive power losses by more than is provided by the converter. In most cases there will be a net gain until the battery power is down to about $75 \%$ of converter rating.

The 'outer loop' control is slower, and typically is no more than a desired power level signal received from the system control center. If it is provided by an AGC system, it will be similar to the raise and lower signals sent to generating plants. It may also be just a time clock that 'schedules' the battery charge and discharge times so as to coincide with system peak load and low load periods respectively.

The outer loop may also include a stabilizer. The stabilizer would modulate battery power when oscillations in line power or frequency occur. The battery power will be modulated in step with the oscillations so that it provides damping power. The battery power would oscillate around its power setting until the oscillations subside. If the battery is being discharged or charged at the time of the oscillations, the average battery power will be reduced by the oscillations. Large oscillations which cause battery output to alternate between maximum charge and maximum discharge will reduce battery power to zero until the oscillations subside.

\section{Flicker Control and Momentary Battery Overload}

One potential benefit of a battery is its ability to improve power quality through control of voltage. Flicker is one of the most common power quality problems. The word flicker comes from the fact that voltage variations are visible in the output of lighting fixtures. However, while variations in light output are a real problem, variations in voltage also cause malfunctions in computers, electronic process controls, and similar devices that industry depends upon for high production rates and product quality.

A battery converter equipped with a voltage regulator can vary its reactive output rapidly enough to correct most voltage variations that would trouble customers. However, as noted earlier, the converter loading, including real and reactive power, must remain within the converter rating. A modest increase in converter capacity is thus required if reactive power and voltage control are to always be available.

Though increasing the converter rating to allow it to provide reactive power will usually be very cost effective, it may also be feasible to utilize the momentary overload capability of a converter to regulate voltage. Though a converter cannot be overloaded in the usual sense of the word, it will withstand overloads of $120 \%$ or more for times of 1 to 2 seconds. The thyristors have little mass, and thus heat up quickly when overloaded. This limits their

$$
\text { C - } 5
$$



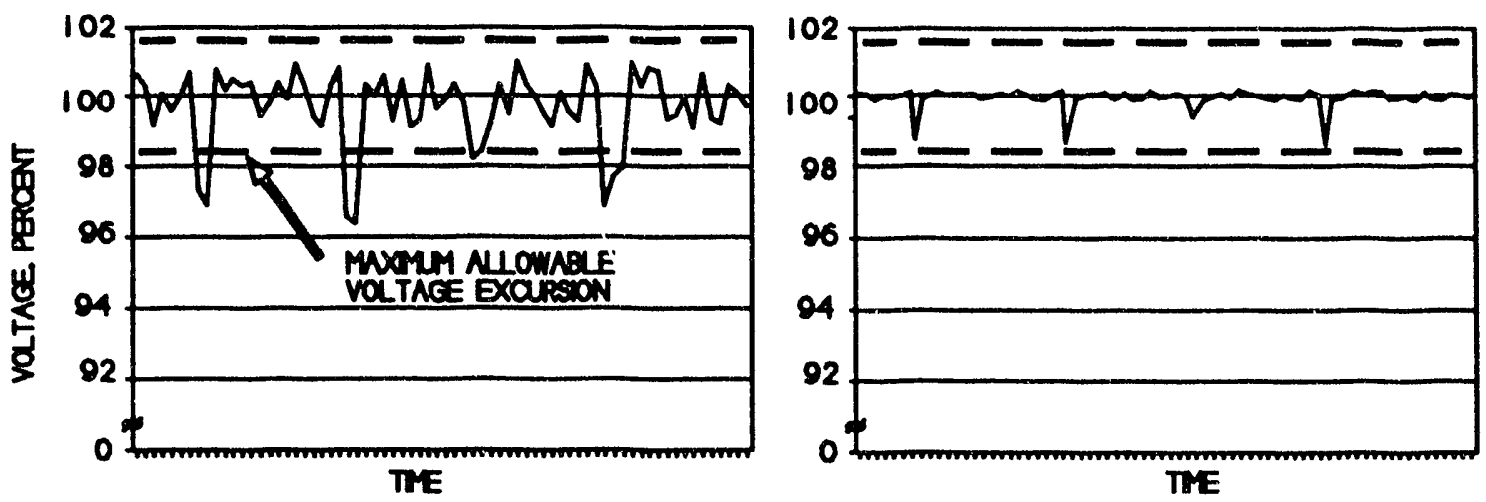

Figure C-5 A battery converter can significantly reduce flicker, thus eliminating one of the most common power quality problems.

inherent overload capability to 1 or 2 seconds. The maximum loading is limited by the ability of the GTO to turn-off current. Overload duration beyond 1 to 2 seconds would require a higher capacity converter (larger or parallel GTOs) or a significant change in the GTO and heat sink design.

Because the duration of most types of flicker is well under one second, the thermal duty caused by exceeding the continuous current limit will be small. A converter may thus be able to control flicker nearly up to the GTO current turn-off limit while operating at or very close to its continuous rating. Figure C-5 shows a typical flicker pattern, and the kind of improvement that the converter could make. Note that the voltage excursion magnitude is reduced modestly, while the duration of the larger excursions is reduced greatly. This is because voltage excursions that cause flicker are usually large rapid changes and the converter cannot change its reactive output instantaneously. However, within a fraction of a cycle, the converter output is changed and restores voltage. Reducing the duration of a voltage excursion is just as effective as reducing its magnitude.

If the converter rating is made somewhat larger than required to deliver the battery rated power, and the extra converter capacity is not used to supply reactive power on a continuous basis, the ability to handle flicker will be larger. The converter can make occasional excursions approaching its current turn-off limit so long as the excursions are short and the accumulated effect on GTO temperature is not excessive. Figure C-6 shows both the increased converter rating to provide reactive power, and the additional momentary operating range that might be provided without exceeding the GTO turn-off current level. Where there will occasionally be a series of voltage excursions over a short period of time, the converter capacity reserved for flicker must account for the accumulative heating from the several excursions.

One type of flicker that has a duration that is usually longer than one second is large motor starting. Large motors can take several seconds to start. The frequency of starting is usually low, however, the duration may exceed the thermal capability of the converter when

$$
\text { C - } 6
$$




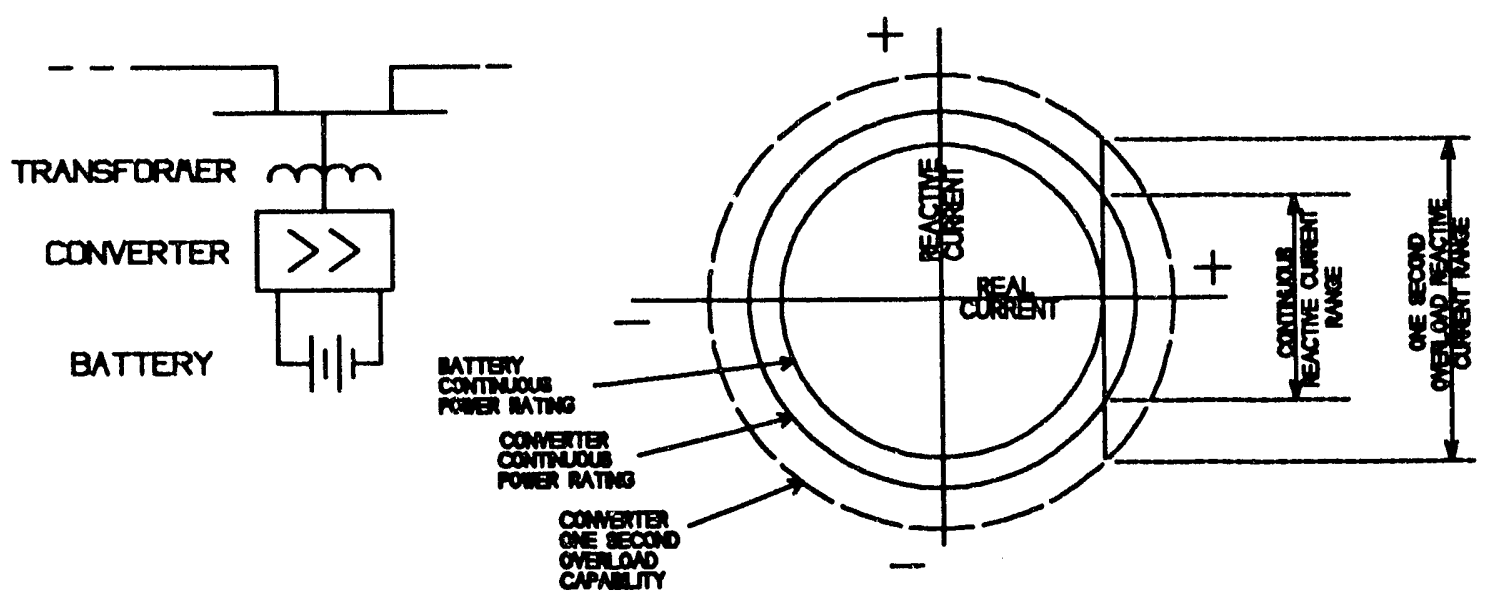

Figure C-6 Battery converters can be sized to provide reactive power and can also endure momentary reactive overload.

it is operating near its continuous rating.

\section{Harmonics}

Because the waveform of the converter is not a perfect sinusoid (see Figure C-7a), the converter generates some harmonic current. The harmonic current is caused by the difference between the converter waveform and the system voltage waveform. The difference between the converter voltage and the system voltage (see Figure C-7b) causes a sawtooth current to flow. This sawtooth current can, mathematically, be described as the sum of a collection of sinusoidal currents. Though the converter does not in fact generate the individual harmonic currents (it generates only the sawtooth current), it is convenient to consider it as doing so.

If these currents are excessive, filters can be instalied on the ac bus to absorb them locally rather than allow them to flow further into the network. The filters are either an inductor and capacitor in series or simply a capacitor, and provide a low impedance path for the harmonics so they won't flow further into the network. The permissible harmonic levels are detailed in IEEE Standard 519. 


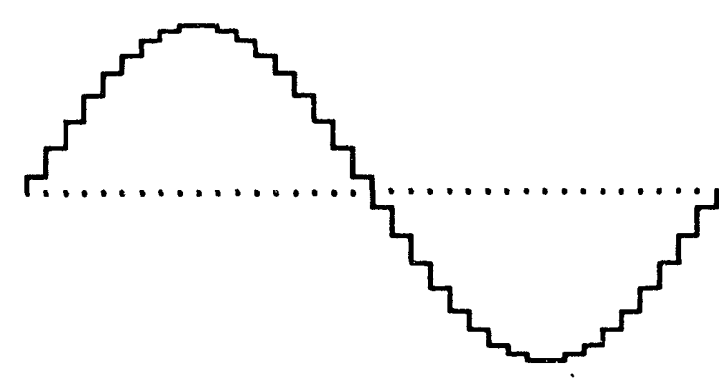

(a)

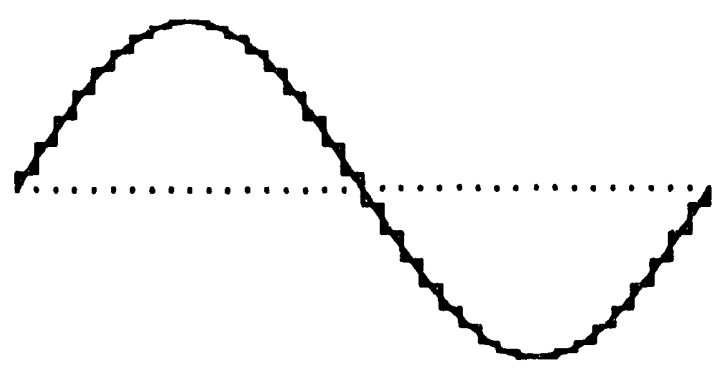

(b)

Figure C-7 (a) Waveform generated by a 36 pulse converter.

(b) Comparison of the converter waveform with the normal $60 \mathrm{~Hz}$ waveform.

$$
\text { C - } 8
$$


Power Technologies, Inc.

APPENDIX D

MUTUAL EXCLUSIVITY 


\section{APPENDIX D \\ MUTUAL EXCLUSIVITY}

As a matter of nomenclature the reader must be careful to observe that battery storage systems and their application to the power system possess certain attributes or characteristics. Each of these attributes, individually, or in combination, provides certain benefits that may help justify the installation of a battery.

While each of the individual benefits might be the sole economic justification for a battery, typically a battery is going to have to provide several benefits in order to be justified. However, there are instances where operating a battery to provide one benefit will prevent another from being realized. We refer to this condition as a mutual exclusivity.

This means that operators may at times have to pick one benefit or another and operate the battery accordingly. It also means that in battery justification studies we may not be able to give the battery credit for both benefits or may have to discount one of them.

We examine several examples of mutual exclusivity in the following paragraphs:

\section{Transformer Life}

Battery storage systems can change the loading pattern of distribution substation transformers. The impact will be:

- reduced loading during the peak load period,

- increased off-peak loading for battery recharging, and

- a higher average loading because of the battery turn-around losses.

The change may occur daily, during certain seasons, or just when there is a local T\&D equipment outage. If it occurs often, and changes the loading pattern on transformers, the transformer life may be affected. Considerations and questions may include:

- how often the load pattern is changed,

- how much the maximum transformer hotspot temperature is affected,

- how transformer top oil temperature is affected,

$$
\text { D - } 1
$$


- how much reduced thermal cycling occurs, etc.

It is clear that this is a complex question. Reducing the peak loading may reduce the maximum hotspot temperature and reduce thermal cycling, but it will increase the average transformer temperature. Further, if the load pattern is changed only infrequently, or if the effect on life is just a few years one way or the other, transformer life may not be a significant factor in the battery benefit evaluation.

\section{System Loss Reduction}

System loss reduction is fully available only if batteries are not used to defer transmission. The load leveling that reduces transmission losses also facilitates transmission deferral, and it is likely that some deferral will occur where batteries are used for load leveling. If transmission is deferred by load leveling, and batteries are spotted in modest sizes to maximize the deferral, average line loading will incnease. For modest load leveling and $T \& D$ equipment deferral, the loss reduction will be reduced, but will still be positive. However, in the limit, with complete load leveling, every line will be loaded around the clock close to its thermal rating. Only forced and maintenance line outages will limit line loading. And, if batteries are used to backup T\&D outages, the loading can be even higher. Under this scenario there will be fewer lines, but average line loading will be very high and losses will be up to about $35 \%$ higher than without the extensive load leveling from batteries.

\section{Voltage Regulation and Voltage Stability}

Though the reactive power available from a battery with a converter rating equal to the battery power rating can provide significant reactive power at intermediate and low active po:ver levels, the benefit may be insignificant if the battery is cycled often and thus spends most of the time at full discharge or full charge power levels (where it cannot provide reactive power).

A battery used primarily for spinning reserve would float much of the time, and could thus provide reactive power. However, because active and reactive power demands may coincide, the reactive power from a nominally rated converter may not be deemed useful.

\section{Spinning Reserve}

If a battery is used for load leveling, and is operating at full output, it is not available for spinning reserve. It thus cannot be given credit for load leveling benefits and spinning reserve. On the other hand, if it is operated at partial output, the difference between the operating point and full output is available for spinning reservc. In this case, after a spinning reserve event, there will be less charge left for load leveling.

Some studies have shown that it may be practical to design a battery with an oversized converter so that the battery could occasionally (a few times per year) be discharged at a

D - 2 
higher rate and thus provide spinning reserve while providing load leveling. A battery can be discharged over about 1 hour with only modest loss of life, so a "50 MW 4 hour battery" could provide up to $200 \mathrm{MW}$ of spinning reserve for one hour or $100 \mathrm{MW}$ for two hours early when fully charged. If it is used for load leveling at $50 \mathrm{MW}$, the energy available for spinning reserve would drop as the day progresses.

With flooded cells, the current practice is to discharge the battery routinely only to about a $20 \%$ charge level. This type of battery can, however, be discharged fully a few times per year without significant loss of life, and thus can provide about 1 hour of spinning reserve after being "fully discharged" in load leveiling service (i.e. a 4 hour battery could provide an extra hour).

The above indicates that there is some room for a battery to provide both spinning reserve and load leveling benefits. However, there is also some potentially significant mutual exclusivity that should be recognized in battery evaluations.

\section{T\&D Deferral Versus Generation Benefits}

The application of batteries for T\&D equipment deferral presents a rather significant opportunity for postponing capital cost expenditures. In this use the battery would be employed to defer the installation of a new line or substation transformer.

However, the mutually exclusive condition arises when this same battery is considered to defer generation, provide generation spinning reserve, or improve economic operation through load leveling. The main question is whether the local peak coincides with the system peak. If it does, discharging a battery during a T\&D outage would inherently cover any need for the battery to cover a generation shortage or provide load leveling. Similarly, discharging the battery for reasons associated with the generation would also cover a T\&D outage. However, if the local peak occurs after the system peak, the battery might be discharged to cover a generation problem and then be unavailable to cover a $T \& D$ problem later (or vice versa if the T\&D peak precedes the system peak). 
APPENDIX E

TYPES OF LEAD-ACID BATTERIES 


\section{APPENDIX E \\ TYPES OF LEAD-ACID BATTERIES}

Lead-acid batteries are available in two types: the "flooded-cell" or the "sealed" lead-acid battery, technically described as a "Valve Regulated Lead-Acid" or VRLA battery. The flooded-cell is the oldest and more commonly used lead-acid battery type whereas the VRLA is a more resent derivative of the flooded-cell type.

Flooded-cell batteries contain the electrolyte within their case in liquid form and are commercially available in a wide range of applications in several sizes. Historically, this type of battery has been the preferred choice for utility applications due to its commercial availability. However, due to its flooded-cell design, these batteries require water addition as part of their regular maintenance. In contrast, the electrolyte in the VRLA battery is immobilized either as a "gel" or absorbed in a glass mat between the positive and negative plates of the cell. This allows the battery to be sealed and removes the need for water addition during its operating life. Its sealed construction offers greater flexibility in configuring the layout of the battery energy storage plant while reducing O\&M costs.

The flooded-cell battery is free to "breath" to the atmosphere through openings in the lid. Appropriate filters and a flash arrestor are installed to capture toxic gasses and hydrogen that are evolved in small quantities during charge/overcharge conditions. The VRLA battery is sealed from the atmosphere and almost all hydrogen and oxygen evolved are trapped inside to recombine and form water that is reused by the battery. However, under some operating conditions gas could be generated faster than it can combine inside the battery. This excess gas is vented to the atmosphere through a one-way valve that operates in the 2 to 5 psi range. Figures $x$ and $y$ show the schematic comparison of flooded and VRLA batteries and the schematic of a VRLA battery.

The $10 \mathrm{MW} / 40 \mathrm{Mwh}$ battery at Chino, CA, owned by Southern California Edison, as well as the $20 \mathrm{MW} / 14 \mathrm{Mwh}$ battery recently purchased by Puerto Rico Electric Power Authority are both flooded-cell batteries. The $210 \mathrm{Kw} / 420 \mathrm{Kwh}$ battery purchased by San Diego Gas \& Electric for a commuter trolley peak-shaving demonst ation is a VRLA battery and was chosen primarily for its low maintenance and smaller footprint dictated by the limited land available at the site. A comparable flooded-cell battery would not be able to meet either of these requirements. 
Power Technologies, Inc.

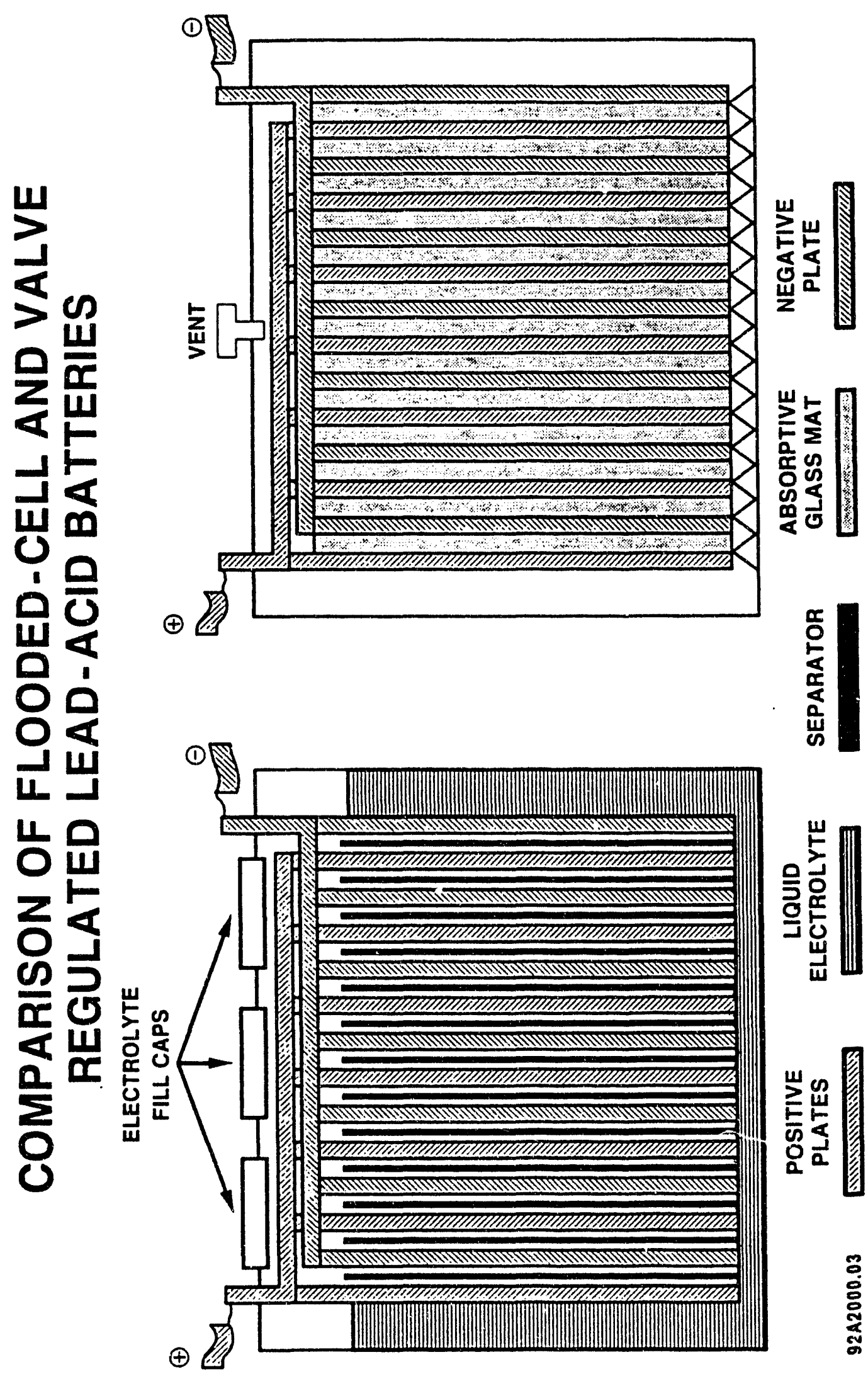

E - 2 
Power Technologies, Inc.
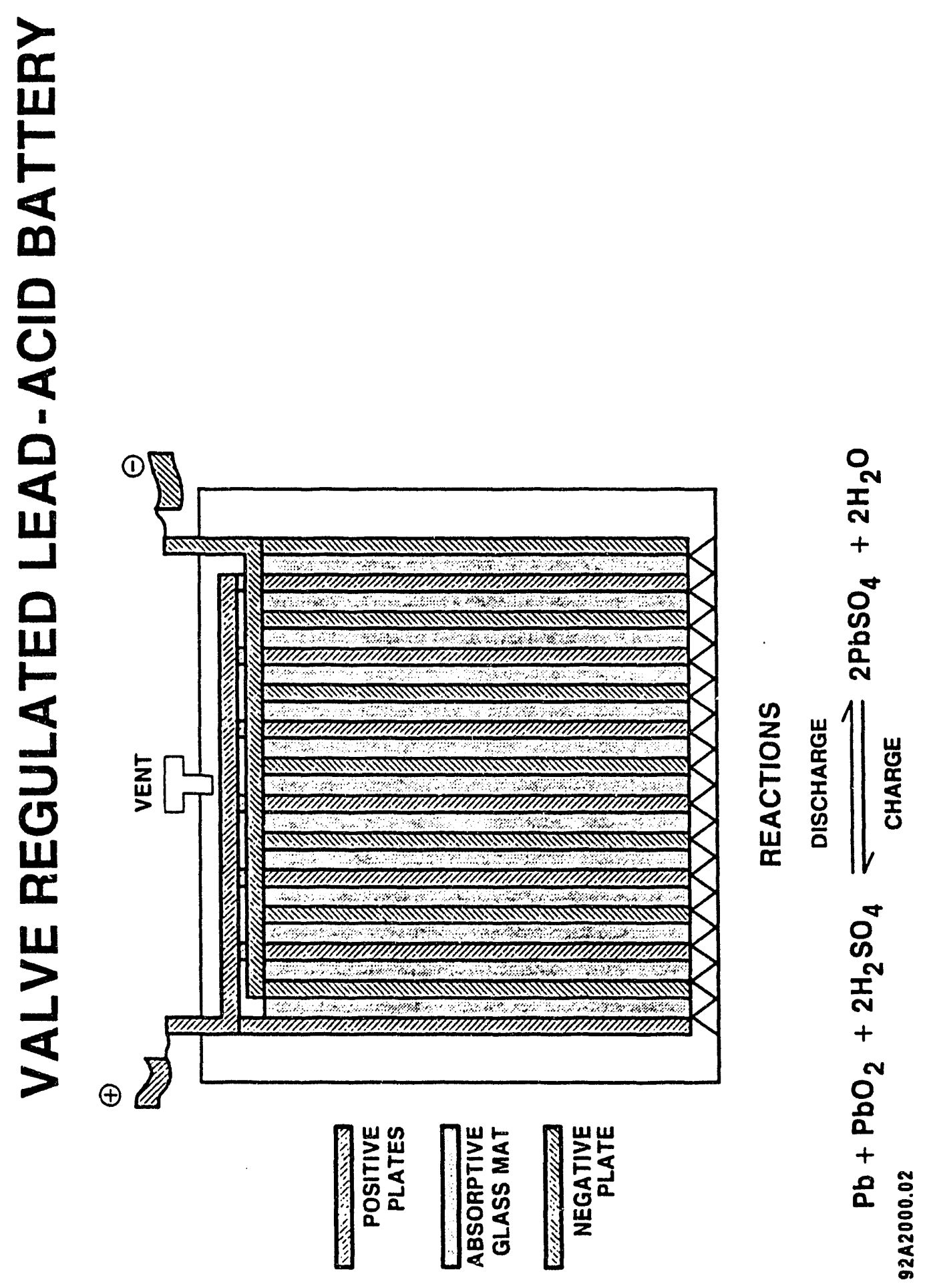

E - 3 
Power Technologies, Inc.

APPENDIX F

SENSITIVITY ANALYSIS

DETAILED RESULTS 
TABLE F1

ESTMATED VAWE OF BENEATS AND BATTERY COSTS

FOR

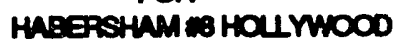

ASSUMED BATTERY STE=

$7,500 \mathrm{KWH}$;

BACK-UP/

ANNUAL SAVNGS

YEAR CENERATION TRANSMSSION DISTRIBUTION

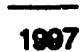

1997

1068

1000

2000

2001

2002

2000

2004

2005

2006

2007

2000

2000

2010

2011

2012

2013

2014

2015

2018

2017

2018

2019

2020

2021

2000

$200 x$

2004

2005

2006

NET P.V. (1908s)

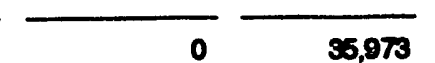

61,602

62,376

63,166

64,031

64,915

65,850

65,804

67,812

68,866

60,968

71.119

72,321

73,578

74,802

76,264

77,608

70,197

80,764

82,400

84,111

85,808

87,766

89.718

91,757

$\$ 3,800$

96,116

98,44

100,876

100,418

106,074

667,972

206,600

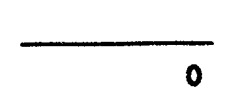

PEUABLTY

CPEDT

138,183

36,425

36,897

37,391

37,007

38,447

30,010

30,500

40,215

40,858

0

144,401

150,800

157,690

164,786

172,201

179,050

188,048

198,510

205,353
214,504

224,251

234,342

24,888

255,807

267,423

279,457

202,033

305,174

318,907

333,258

348,255

363,026

300,300

397,416

415,300

433,980

453,518

473,027

$\frac{495,253}{2,058,127}$

285,713

206,572

307,920

319,779

392,172

345,122

358,655

372,706

387,575

403,018

419,156

436,021

453,644

472,050

401,305

511,416

582,432

551,304

577,344

601,327

$2,030,700$

5 HAS

NET ANMUAL

VAUE BATTERY

SNWH COST

$=\quad \$ 15.45 \mathrm{Amh}(1903)$

Vabue of Unsenved Energy

Eximetad Bettory Cepitis Cost

Betery Sotveos Valuo

Benery Shell Lite(Yeans)

Bany OAM

Extmend Babeny Replecement Coot

Extimend PC+BOP Cepint Cost

(a) Generetion Cepitas Deflered

(b) Trunsmiscion Cepital Defiered

(c) Distibution Cespint Deflered

Extineted Bentery Cepind Cost

Extinened PCS+BOP Cepittl Coet

Exin ad Benary Poplecement Coet

Exinated Benary and Pleptacennent Cost

Equivalent 30 Yoer Lib Coat

$$
\begin{aligned}
& =\quad \text { \$OS KWh(1903) } \\
& =20 \% \\
& \text { - } 15 \\
& =0.20 \% \\
& =\quad \$ 178 \text { AWh(1003) } \\
& =\quad 200 \mathrm{~kW}(1000) \\
& =\$ 513,742 \quad \$ 1,807 \\
& \infty \quad(\$ 1, \infty 7) \\
& \text { - } \$ \$ 00,000 \quad(\$ 1,907) \\
& \text { - \$1,004,487 (\$1,007) } \\
& \text { - \$357,756 \$1,907 } \\
& \text { - \$3,087,017 } \quad(\$ 2,012) \\
& =\quad \$ 500 \text { AWh(1903) } \\
& \$ 1,501 \text { AW(1823) } \\
& 1.00
\end{aligned}
$$

BENEFTICOST RATIO 
TABLE F2

ESTIMATED VAWE OF BENEFTS AND BATTERY COSTS

POR

HABERSHM 1 HOLWWOOD

ASSUMED BATTERY STE:

$7,500 \mathrm{KWH}$;

BACKUPI

ANHUL SAMNCS

PEINBLTY

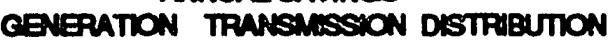

20

20
10
19
200
200
200
200
200
2005
200

1007
1008
1000
2000
2001
2002
2005
2004
2005
2005

$\begin{array}{ll}2007 & 71,118 \\ 2008 & 72,321 \\ 2000 & 73,578 \\ 2010 & 74,602\end{array}$

201176,264

$2012 \quad 77,608$

$2013 \quad 79,197$

201480,764

$2015 \quad 82,400$

$2016 \quad 8,111$

$2017 \quad 85,808$

$2018 \quad 87,766$

$2019 \quad 80.718$

$2000 \quad 91,757$

$2021 \quad 93,890$

$2020 \quad 86,116$

$2000 \quad 98,44$

$20024 \quad 100,876$

2005103,418

2005

NET P.V. (10039)

CREDT

138,183

144,401

150,800

157,600

164,786

37,907

38,477

39,010

30,500

40,215

40,858

172,201

179,850

188,048

196,510

205,353

214,504

224,251

234,342

24,688

255,007

267,423

279,457

202,038

305,174

318,007

330,258

348,255

363,228

300,300

397,416

415,300

433,800

453,518

473,927

405,253 106,074

667,972

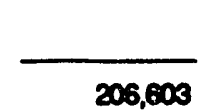

206,600 $\frac{40,253}{2,058,127}$
5 HAS

\begin{tabular}{|c|c|c|}
\hline $\begin{array}{l}\text { TOTAL } \\
\text { SAVines }\end{array}$ & $\begin{array}{l}\text { NET } \\
\text { VAUE } \\
\text { SKWH }\end{array}$ & $\begin{array}{l}\text { ANRUNL } \\
\text { BATTEFY } \\
\text { COST }\end{array}$ \\
\hline $\begin{array}{l}205,758 \\
243,203\end{array}$ & $\begin{array}{l}31 \\
32\end{array}$ & $\begin{array}{l}200,6006 \\
200,870\end{array}$ \\
\hline $\begin{array}{l}250,892 \\
250,113 \\
267,608\end{array}$ & $\begin{array}{l}33 \\
35 \\
36\end{array}$ & $\begin{array}{l}210,888 \\
211,851 \\
213,063\end{array}$ \\
\hline
\end{tabular}

276,487

205,765

205,400

305,501

316,179

285,713

206,572

307,920

319,779

332,172

345,122

358,655

372,796

387,575

403,018

419.156

456,021

453,644

472,000

491,305

37

214,224

215,453

216,707

218,032

210,417

\section{1,416}

532,432

554,394

577,344

601,327

$2,002,700$

220,865

222,37

220,058

225,610

227,336

341,194

46

342,850

$52 \quad 346,356$

$54 \quad 348,232$

56

360,104

362,244

354,396

366,625

358,964

Vitue of Unsenved Energy

Eximued Betery Cepienal Coet

Banary Sehnopo Velus

Bdery Sheil Lib(Yeers)

Bensy OsM

Eximetad Betmeny Replecement Coot

Extimatod PC+BOP Cepind Cost

(a) Cenerdion Cepital Deftered

(b) Tranemiacion Cepind Deflared

(C) Distibution Cepival Deflered

Extmated Batery Capital Coet

Estineded PCS+BOP Ceppited Cost

Extmad Bentry Rephocement Coct

Extineded Bemany and Replacoment Cost

Equindent 30 Yeer L 10 CoAt

$$
\begin{aligned}
& \text { - } \$ 15.45 \operatorname{manh}(1800) \\
& \text { - } \$ 140 \text { AWh(1903) } \\
& =20 \% \\
& =15 \\
& \text { - } 020 \% \\
& \text { - } \$ 112 \text { Akwr(te03) } \\
& \text { - \$100 AnW(1000) } \\
& \text { - \$513,742 \$1,07) } \\
& \$ 0 \quad(1, \infty 97 \\
& \text { - } \$ 00,000 \quad \$ 1,007 \\
& =\$ 1,252,145 \quad(\$ 1,097 \\
& \text { - \$715,511 (\$1,07) } \\
& \text { - \$1,038,603 (R,012) } \\
& \text { - }
\end{aligned}
$$

BENEFITCOST RATIO 
TAPLE FB

ESTMMATED VAUE OF BENEFTS AND BATTERY COSTS

FOR

HABERSHAM $*$ HOU WWOOO

ASSUMED BATTERY SIZE=

7,500 KWH :

5 HRS

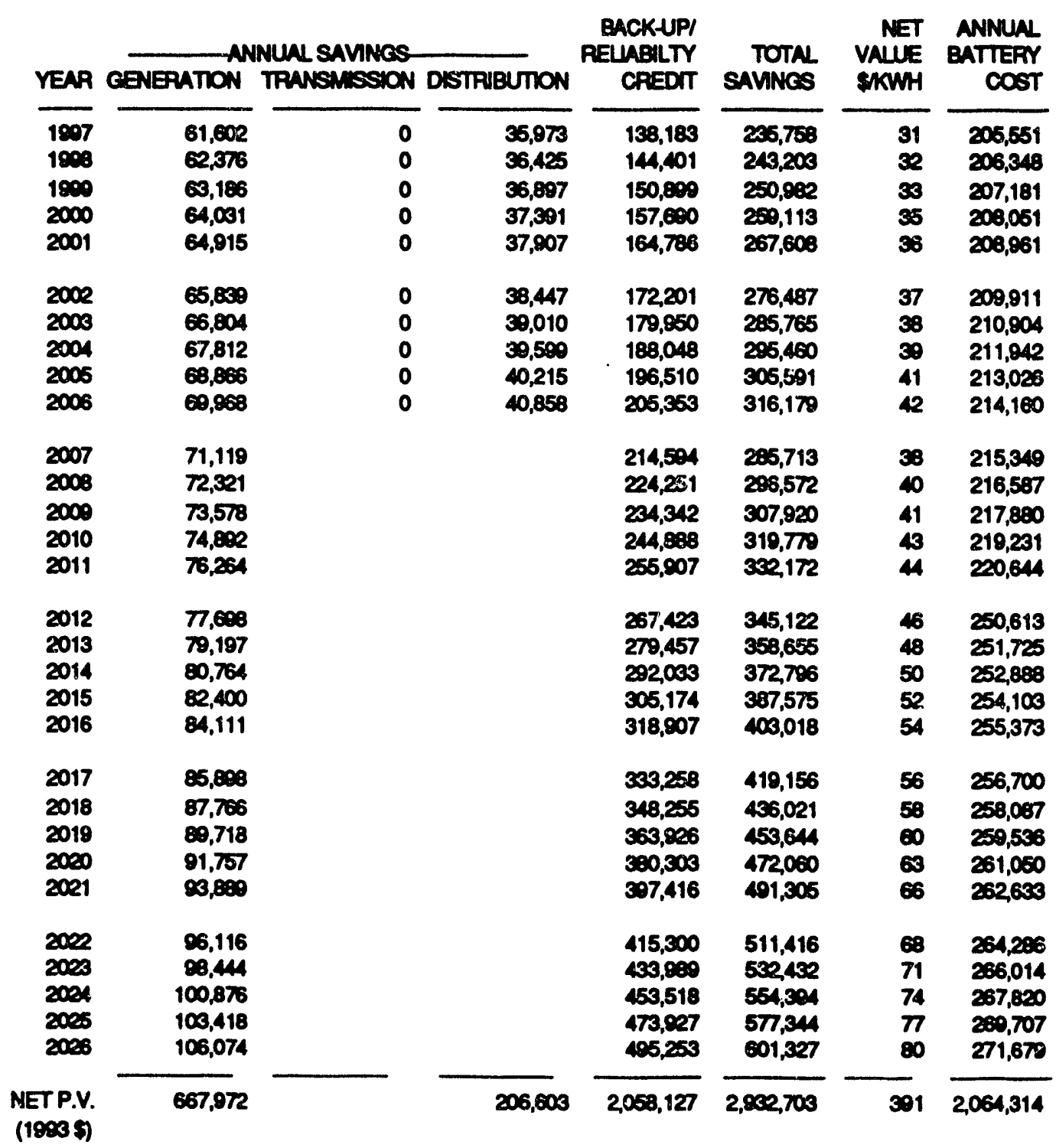

Verwo of Uneerved Energy

Extimadod Baniony Ceapitel Con

Bentery Sahnego Valuo

Benery Shel LiterYeers)

Banary OaM

Extimetad Bentary Replacement Cost

Extinated PC+BOP Cepiet Coet

(a) Genercion Cepitol Defiared

(b) Trenemiection Capited Dentered

(c) Distribution Cepiet Deffered

Extimad Benary Cepited Cost

Extineied PCS+BOP Cepited Cost

Eximed Butiony Replacoment Cost

Eximated Bentery and Preptacement Cost

Equivelent 30 Yeer Lib Coet

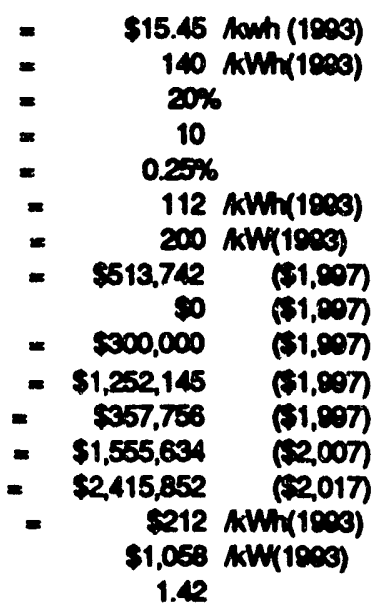

BENEFITKOST RATIO

1.42 
TABLE FA

ESTIMATED VNLUE OF BENEFTS AND BATIERY COSTS

FOA

HABEASHAM

ASSUMED BATTERY SIZE= $\quad 7,500 \mathrm{KWH}$; $\quad 5$ HRS

\begin{tabular}{|c|c|c|c|c|c|c|c|}
\hline YEAR $G$ & GENERATION & $\begin{array}{l}\text { NUAL SAVINGS- } \\
\text { TRANSAISSION }\end{array}$ & DISTRIBUTION & $\begin{array}{r}\text { BACKUUPI } \\
\text { REUABILTY } \\
\text { CREDTT }\end{array}$ & $\begin{array}{l}\text { TOTAL } \\
\text { SAVNGS }\end{array}$ & $\begin{array}{l}\text { NET } \\
\text { VALUE } \\
\text { SKWH }\end{array}$ & $\begin{array}{r}\text { ANNUAL } \\
\text { BATTEPY } \\
\text { COST }\end{array}$ \\
\hline $\begin{array}{l}1097 \\
1008\end{array}$ & $\begin{array}{l}61,602 \\
62,376\end{array}$ & $\begin{array}{l}0 \\
0\end{array}$ & $\begin{array}{l}35,973 \\
36,425\end{array}$ & $\begin{array}{l}138,183 \\
144,401\end{array}$ & $\begin{array}{l}235,758 \\
243,200\end{array}$ & $\begin{array}{l}31 \\
32\end{array}$ & $\begin{array}{l}155,766 \\
156,560\end{array}$ \\
\hline $\begin{array}{l}1000 \\
2000 \\
2001\end{array}$ & $\begin{array}{l}63,186 \\
64,031 \\
64,915\end{array}$ & $\begin{array}{l}0 \\
0 \\
0\end{array}$ & $\begin{array}{l}36,697 \\
37,391 \\
37,907\end{array}$ & $\begin{array}{l}150,899 \\
157,680 \\
164,780\end{array}$ & $\begin{array}{l}200,982 \\
209,113 \\
267,608\end{array}$ & $\begin{array}{l}33 \\
35 \\
36\end{array}$ & $\begin{array}{l}157,308 \\
158,208 \\
159,175\end{array}$ \\
\hline $\begin{array}{l}2002 \\
2000 \\
2004 \\
2005 \\
2005\end{array}$ & $\begin{array}{l}65,859 \\
66,604 \\
67,812 \\
68,866 \\
69,868\end{array}$ & $\begin{array}{l}0 \\
0 \\
0 \\
0 \\
0\end{array}$ & $\begin{array}{l}38,447 \\
39,010 \\
39,500 \\
40,215 \\
40,858\end{array}$ & $\begin{array}{l}172,201 \\
179,950 \\
188,048 \\
196,510 \\
205,353\end{array}$ & $\begin{array}{l}276,487 \\
285,765 \\
205,460 \\
305,501 \\
316,179\end{array}$ & $\begin{array}{l}37 \\
38 \\
39 \\
41 \\
42\end{array}$ & $\begin{array}{l}160,125 \\
161,119 \\
162,156 \\
163,241 \\
164,374\end{array}$ \\
\hline $\begin{array}{l}2007 \\
2008\end{array}$ & $\begin{array}{l}71,119 \\
72,321\end{array}$ & & & $\begin{array}{l}214,524 \\
224,251\end{array}$ & $\begin{array}{l}295,713 \\
296,572\end{array}$ & $\begin{array}{l}38 \\
40\end{array}$ & $\begin{array}{l}165,558 \\
166,796\end{array}$ \\
\hline $\begin{array}{l}2000 \\
2010 \\
2011\end{array}$ & $\begin{array}{l}73,578 \\
74,802 \\
76,264\end{array}$ & & & $\begin{array}{l}2 \times 4,342 \\
244,8: 88 \\
255,907\end{array}$ & $\begin{array}{l}307,920 \\
319,770 \\
332,172\end{array}$ & $\begin{array}{l}41 \\
43 \\
44\end{array}$ & $\begin{array}{l}168,080 \\
160,441 \\
170,853\end{array}$ \\
\hline $\begin{array}{l}2012 \\
2013 \\
2014 \\
2015 \\
2016\end{array}$ & $\begin{array}{l}77,608 \\
79,197 \\
80,764 \\
82,400 \\
84,111\end{array}$ & & & $\begin{array}{l}267,423 \\
279,457 \\
292,033 \\
305,174 \\
318,007\end{array}$ & $\begin{array}{l}345,122 \\
358,655 \\
372,796 \\
387,575 \\
400,018\end{array}$ & $\begin{array}{l}46 \\
48 \\
50 \\
52 \\
54\end{array}$ & $\begin{array}{l}262,031 \\
263,004 \\
264,204 \\
265,364 \\
266,576\end{array}$ \\
\hline $\begin{array}{l}2017 \\
2018 \\
2019 \\
2020 \\
2021\end{array}$ & $\begin{array}{l}85,898 \\
87,766 \\
89,718 \\
91,757 \\
93,869\end{array}$ & & & $\begin{array}{l}333,258 \\
348,255 \\
363,926 \\
330,303 \\
397,416\end{array}$ & $\begin{array}{l}419,156 \\
436,021 \\
453,644 \\
472,000 \\
401,305\end{array}$ & $\begin{array}{l}56 \\
58 \\
60 \\
63 \\
66\end{array}$ & $\begin{array}{l}\mathbf{2 6 7 , 8 4 3} \\
\mathbf{2 6 9 , 1 6 7} \\
270,551 \\
271,997 \\
273,508\end{array}$ \\
\hline $\begin{array}{l}2002 \\
2003 \\
2024 \\
20025 \\
2026\end{array}$ & $\begin{array}{r}\bullet 6,116 \\
\bullet 8,444 \\
100,876 \\
108,418 \\
106,074\end{array}$ & & & $\begin{array}{l}415,300 \\
433,080 \\
453,518 \\
475,027 \\
405,250\end{array}$ & $\begin{array}{l}511,416 \\
552,432 \\
554,3044 \\
577,344 \\
601,327\end{array}$ & $\begin{array}{l}68 \\
71 \\
74 \\
77 \\
80\end{array}$ & $\begin{array}{l}275,086 \\
276,736 \\
278,461 \\
280,282 \\
282,145\end{array}$ \\
\hline ET P.V. & 667,972 & 0 & 206,603 & $2,058,127$ & $2,862,703$ & 391 & $1,742,261$ \\
\hline
\end{tabular}

(1993\$)

Value of Uneenved Erergy

Estinetad Bemary Cepital Coet

Beciery Selvepo Velue

Berery Show LiforYeers)

Bemery OsM

Extineted Bamery Replescement Cost

Extinated PC+BOP Cequit Cost

(a) Ceneration Ceppital Defiered

(b) Trenamiscion Cepital Deffered

(c) Distribution Capies Deffered

Extimened Bettary Capital Cost

Estimedid PCS+BOP Capital Cost

Extinestad Bentery Reptecoment Cost

Eximetsd Bentery and Replacement Cost

Equivadent 30 Yeer Lito Cost

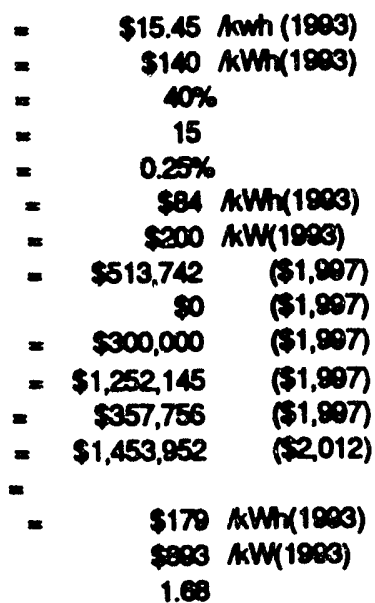

BENEFTICOST RATIO 
TABLE F5

ESTIMATED VNWUE OF BENEFTIS AND BATTERY COSTS

FOR

HABERSHM W HOU YMOOO

ASSUNED BATTERY SZZE=

$7,500 \mathrm{KWH}$;

5 HAS

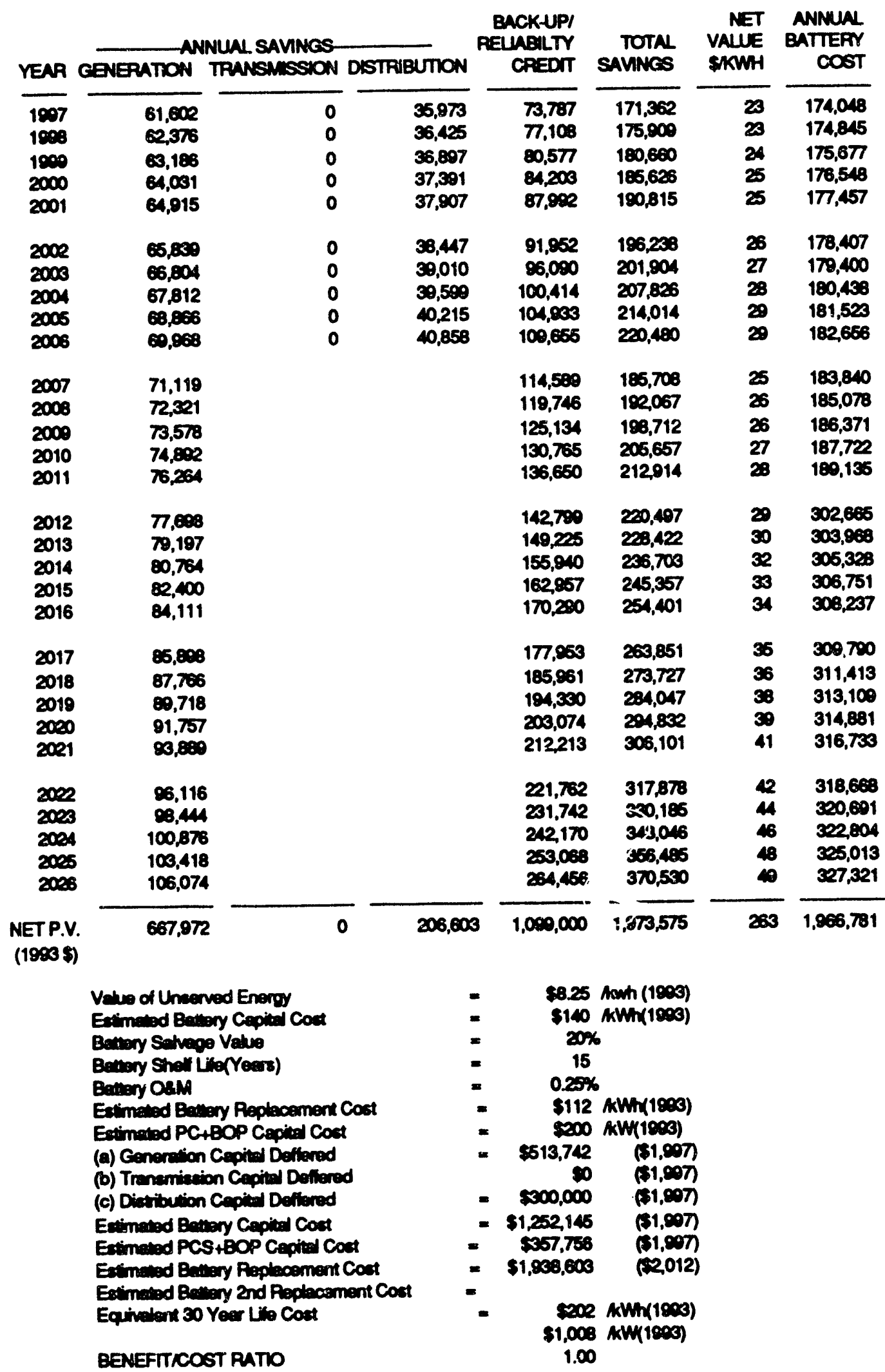


TABLE F6

ESTMMATED VAWE OF BENERTS AND BATTERY COSTS

POR

HABERSHM W HOLYMOOO

ASSUMED BATIERY SIZE:

$7,500 \mathrm{KWH}$;

BACKUPI

AMUUA savmes TRANSAMSSON DSTRABUTION

VEAR GENEAATION

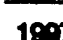

199

189

1800

2000

2001

2002

2003

2004

2005

2005

200

2008

2009

2010

2011

2012

2013

2014

2015

2016

2017

2018

2019

2000

2021

2002

2003

2024

2025

2006

NET P.V. (19035)

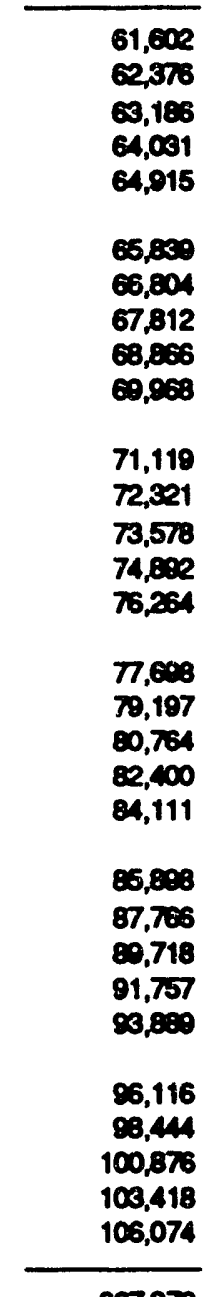

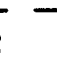

0

183

4,915

5859

67.812

83,856

2,321

74,892

cons

0,734

2,400

85,898

.100

157

9,116

8.44

0,873

$0.5,074$

667,972
RELABDLTY

CPEDT

138,185

144,01

150,800

157,600

164,783

172,201

179,950

188,048

186,510

205,353

40,858

41,500

12,262

42,853

40,730

4,555

45,372

46,247

47,162

48,118

4,117

50,160

51,251

52591

53,582

54,805

214,504

224,251

24,312

244,8:88

255,007

257,403

279,457

202,033

305,174

318,907

338,258

348,255

350,926

3:0,00

307,416

56,127

57,488

58,007

60,301

61,012

300,053

453,518

473,027

405,253

$2,058,127$
415,300

433,900

$3,116,162$ savines enMH cost

265,758

213200

200,902

209,113

257,60:

276,487

205,765

295,400

305,591

316,170

327,240

$3<3,805$

$350,8: 87$

$\mathbf{3 8 3 , 5 1 2}$

376,708

300,404

404,902

419,058

455,602

452,134

469,316

487,271

505,055

505,642

548,132

567,54

589,919

613,301

607,755

$6 \times 3,20$

$$
\begin{aligned}
& \text { - \$15.45 Muh (1903) } \\
& \text { - \$140 AMT(1003) } \\
& \text { - 20x } \\
& \text { - } 15 \\
& \text { - } 0.20 \% \\
& \text { - } \$ 112 \mathrm{ANMm}(190 \mathrm{~s}) \\
& \text { - } \quad 200 \text { ixw(100s) } \\
& =\quad 513,742 \quad(1,097) \\
& \text { \$0 } \$ 1,097 \\
& \text { - } \$ 000,000 \quad(1,, 997) \\
& \text { - \$1,202,145 (\$1,007) } \\
& \text { - \$57,753 (51,07) } \\
& \text { - } \$ 1,038,003 \quad \text { (2,012) } \\
& \text { - 8002 AWh(1000) } \\
& 81,008 \mathrm{Ak}(1003) \\
& 1.59
\end{aligned}
$$

HPS

$31 \quad 174,048$

$32 \quad 174,845$

$33 \quad 175,677$

s5 176,548

$\begin{array}{ll}36 & 177,457\end{array}$

$37 \quad 178,407$

$38 \quad 179,400$

$39 \quad 180,438$

$41 \quad 181,523$

42182,656

$\begin{array}{ll}4 & 183,840 \\ 45 & 185,078 \\ 47 & 186,371\end{array}$

$48 \quad 187,722$

$\begin{array}{ll}48 & 187,722 \\ 50 & 180,135\end{array}$

$52 \quad 302,665$

$56 \quad 305,328$

$58 \quad 306,751$

$60 \quad 308,237$

$\infty 300,700$

$65 \quad 311,413$

$73 \quad 316,733$

$76 \quad 318,668$

320,601

322,804

325,013

327,321

$4151,968,781$
$54 \quad 303,968$

BENEFTICOST RATIO 
TABLE F7

ESTIMATED VAWE OF BENEFTS AND BATTERY COSTS

FOR

HABERSHAM 1 HOLIMWOO

ASSUMED BATIERY STEE.

YEAR GENEPATION TRANSASSION DISTRIBUTION

\begin{tabular}{|c|c|}
\hline $\begin{array}{l}1097 \\
1098\end{array}$ & $\begin{array}{l}61,602 \\
60,376\end{array}$ \\
\hline $\begin{array}{l}1000 \\
2000 \\
2001\end{array}$ & $\begin{array}{l}63,186 \\
64,031 \\
64,915\end{array}$ \\
\hline 2002 & 65,850 \\
\hline 2000 & 66,804 \\
\hline 2004 & 67,812 \\
\hline 2005 & 68,856 \\
\hline 2006 & $60,0 \times 8$ \\
\hline 2007 & 71,119 \\
\hline 2000 & 72,321 \\
\hline 2000 & 73,578 \\
\hline 2010 & 74,602 \\
\hline 2011 & 76,264 \\
\hline 2012 & $7,6 \times 8$ \\
\hline 2013 & 79,197 \\
\hline 2014 & 80,704 \\
\hline 2015 & 82,400 \\
\hline 2016 & 84,111 \\
\hline 2017 & 85,808 \\
\hline 2018 & $87,7 \in 6$ \\
\hline 2010 & 80,718 \\
\hline 2000 & 91,757 \\
\hline 2021 & $\bullet 3,680$ \\
\hline $\begin{array}{l}2002 \\
20003\end{array}$ & $\begin{array}{l}96,116 \\
88,444\end{array}$ \\
\hline 2002 & 100,876 \\
\hline 2005 & 103,418 \\
\hline 2008 & 106,074 \\
\hline & 667,972 \\
\hline
\end{tabular}

Velup of Uneenved Enerpy

Extimad Benery Copied Coct

Bevery Setwaog Vetwe

Beftary Sha Lilo(Yeere)

Batiary OSM

Extimated Bumeny Replecement Cost

Extimeted PC+BOP Capivel Cost

(a) Cenernion Ceapital Deflered

(b) Trenamiasion Cepitel Deflered

(c) Distribution Cepitel Deffered

Extimated Bumery Cepited Coet

Eximeded PCS+BOP Capital Cout

Eximesod Bunary Peptacement Coet

Eximedod Betiony and Replacement Cost

Equivelent 30 Yeer Lito Cost

BENEFTICOST RATLO
$7,500 \mathrm{KWH}$ :

BACKUPI

REUABLTY

5 HPS

CREDT

TOTAL

NET ANNUN savines

70,787

7.108

60,577

84,203

$87, \mathrm{men}$

37,301

37,007

91,052

96,000

100,414

104,933

100,655

40,858

114,589

41,550

42,232

119,746

42,966

43,730

125,134

130,765

44,535

136,650

45,372

46,247

142,700

140,225

155,040

47,162

48,118

162,957

40,117

170,200

50,160

177,968

51,251

52,301

53,582

54,8056

185,961

194,350

203,074

212,213

171,362

175,000

180,660

186,628

100,816

VALUE

BATTEFY

186,253

201,004

207,826

214,014

220,480

227,238

234,290

241,670

240,300

257,448

205,800

274,669

203,865

203,475

$\mathbf{3 0 0 , 5 1 7}$

314,012

324,978

356,458

348,413

390,928

\begin{tabular}{cr|r}
56,127 & 221,762 \\
57,486 & 221,742 \\
58,007 & 212,170 \\
60,301 & 253,068 \\
61,042 & 234,456 \\
\hline 300,063 & & $1,000,000$
\end{tabular}

374,006

387,672

401,053

416,876

402472

$2,157,055$

288

$2,834,731$

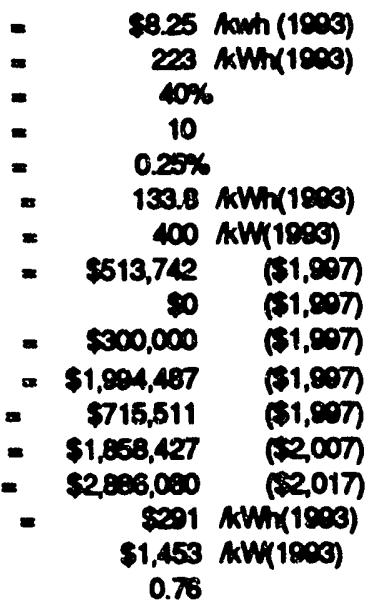


TABLE FB

ESTIMATED VALUE OF BENEFTS AND BATTERY STORAGE COSTS FOR

PLANTERS $* 9$ EGYPT

ASSUMED BATTERY SIZE:

$22,000 \mathrm{KWH}$;

RELUABILTY

YEAR GENERATION TRANSMISSION DISTRIBUTION

\section{7}

1998

1999

2000

2001

2002

2003

2004

2005

2006

2007

2008

2000

2010

2011

2012

2013

2014

2015

2016

2017

2018

2019

2020

2021

2020

2023

2024

2025

2026

NET P.V. (1993\$)

\begin{tabular}{l}
\hline 180,699 \\
182,971 \\
185,345 \\
187,826 \\
190,418 \\
193,127 \\
195,958 \\
198,917 \\
202,008 \\
205,239 \\
\\
208,615 \\
212,143 \\
215,830 \\
219,682 \\
223,708 \\
\\
227,916 \\
232,312 \\
236,906 \\
241,707 \\
246,725 \\
251,968 \\
257,446 \\
263,172 \\
269,155 \\
275,407 \\
281,941 \\
288,768 \\
295,903 \\
303,359 \\
311,151 \\
\hline $1,959,385$ \\
\hline
\end{tabular}

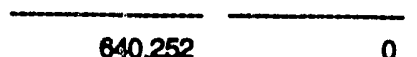

640,252

648,301

656,713

665,503

674,689

684,288

694,318

704,801

715,755

727,202

$1,859,385$

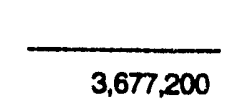

Value of Unserved Energy

Estimated Battery Capital Cost

Battery Salvago Value

Battery Shelf Lffe(Yeers)

Bettory OsM

Estimated Battery Replacement Cost

Estimated PC+BOP Capital Cost

(a) Generation Capital Deffered

(b) Transmission Capital Deffered

(c) Distribution Capital Deffered

Estimated Battery Capital Cost

Estimated PCS+BOP Capital Cost

Estimated Baitery Replecement Cost

Estimated Battery and Replacement Cost

Equivalent 30 Year Life Cost

BENEFIT/COST RATIO
BACK-UP

CREDIT

4 HOURS

NET ANNUAL

TOTAL

VALUE BATTERY

SKWH

COST

847,187

858,688

870,707

883,268

896,393

910,109

924,442

839,420

$\mathbf{9 5 5 , 0 7 2}$

971,429

38,988

40,743

42,576

44,492

46,494

48,587

249,358

254,719

260,322

266,177

272,295

50,773

53,058

55,445

57,940

60,548

278,688

285,370

292,352

299,648

307,272

63,272

66,120

315,240

323,566

332,267

341,359

72,204

75,453

350,860

78,849

360,790

371,165

382,008

86,105

89,980

393,339

405,179

0

39,029

$6,027,341$

536,095

538,563

541,141

543,836

546,651

549,594

552,669

555,882

559,240

562,749

$566,: 16$

570,247

574,252

578,436

582,809

916,073

820,144

924,399

928,845

$\mathbf{8 3 3 , 4 9 1}$

938,346

843,420

848,722

954,263

960,053

966,104

972,427

979,034

885,939

993,154

274

$6,022,418$

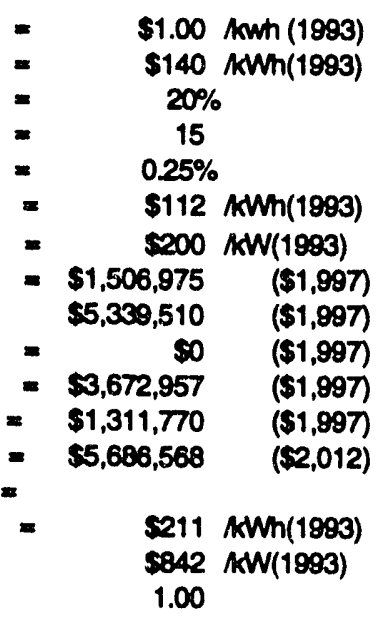


TABLE F9

ESTIMATED VALUE OF BENEFTSS AND BATTERY STORAGE COSTS FOR

PLANTERS *9 EGYPT

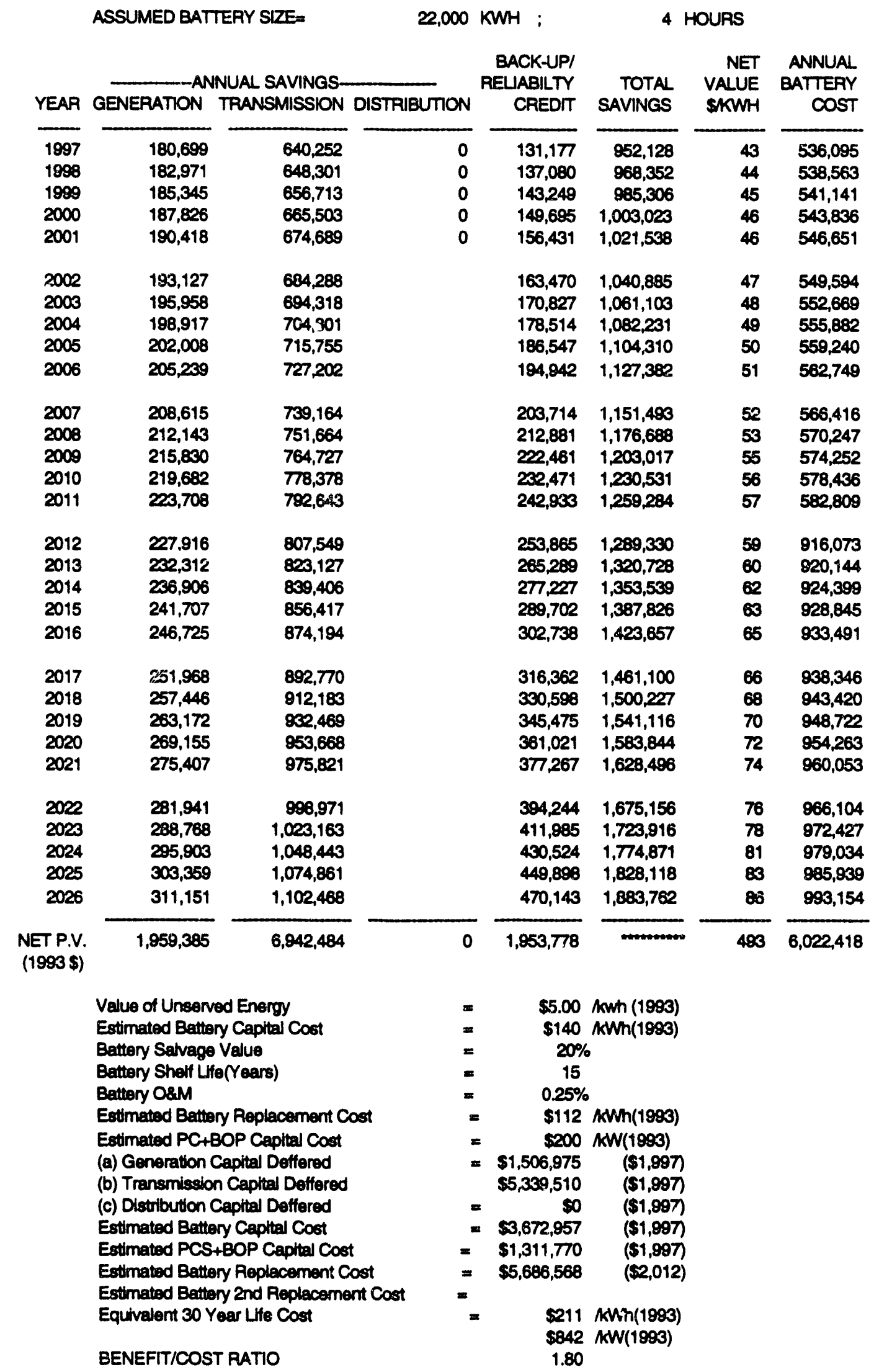


TABLE F10

ESTIMATED VAWE OF BENEFIS AND BATTERY STORNEE COSTS roR

SATULA H2 LANES ERIDEE

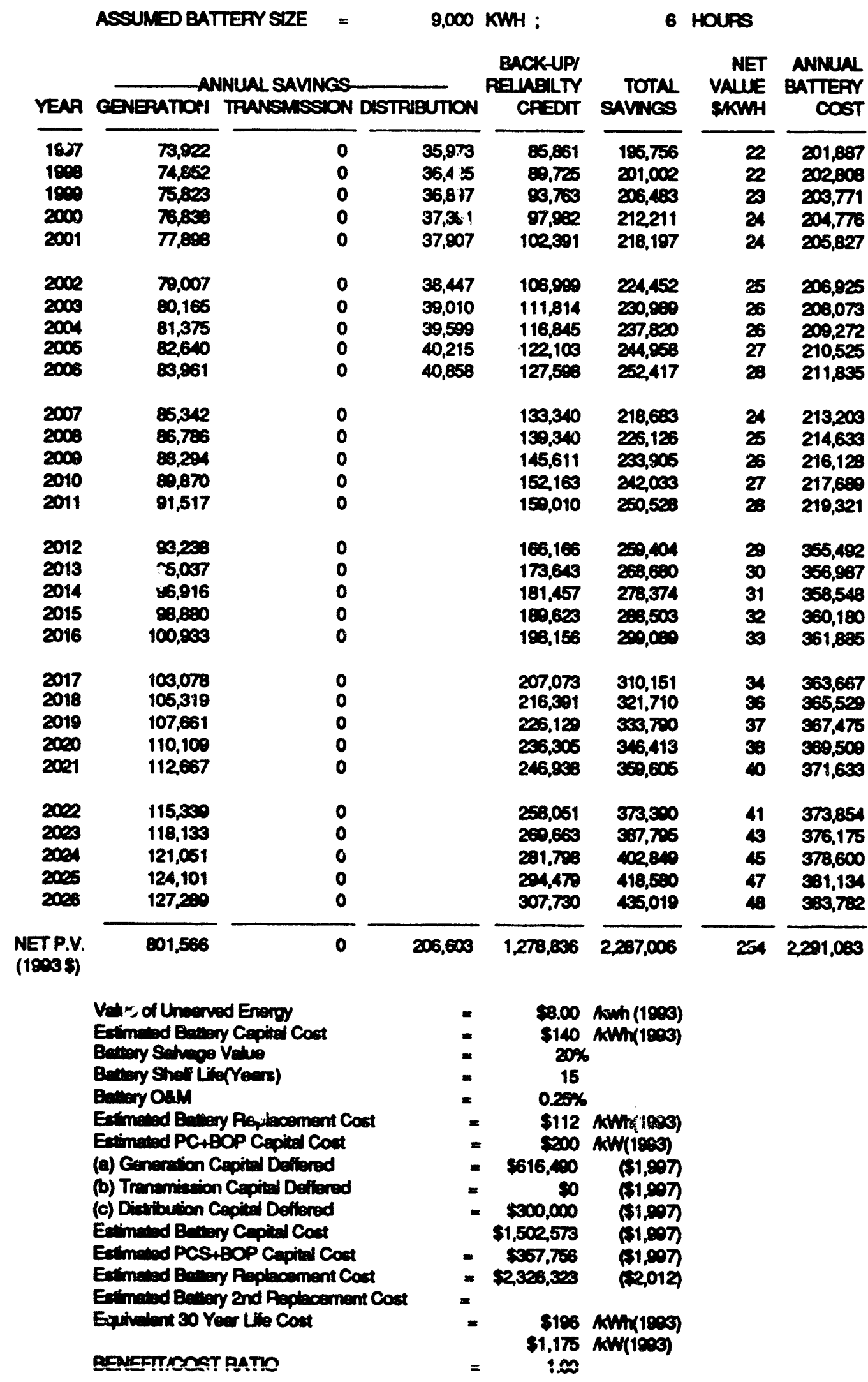




\section{TABLEF11}

ESTIMATED VALUE OF BENEFIS AND BATTERY STORAGE COSTS FOR VIDALA

ASSUNED BATTEFY SZIE $=\quad 217,000 \mathrm{KWH} \mathrm{:}$

7 HOURS

\begin{tabular}{|c|c|c|c|c|c|c|c|}
\hline YEAR & CENERATION & $\begin{array}{l}\text { NNUAL SAMNGS- } \\
\text { TRWNAMSSON DISTF }\end{array}$ & Bumo:s & $\begin{array}{r}\text { BACKUPI } \\
\text { PEUABITY } \\
\text { CPEDT }\end{array}$ & $\begin{array}{l}\text { TOTAL } \\
\text { SAVNCS }\end{array}$ & $\begin{array}{l}\text { NET } \\
\text { VNUE } \\
\text { SKMH }\end{array}$ & $\begin{array}{l}\text { ANNWAL } \\
\text { BATTEPY } \\
\text { COST }\end{array}$ \\
\hline $\begin{array}{l}1097 \\
1009 \\
1000 \\
2000 \\
2001\end{array}$ & $\begin{array}{l}1,782,340 \\
1,804,757 \\
1,828,173 \\
1,852,843 \\
1,878,215\end{array}$ & $\begin{array}{r}434,068 \\
400,528 \\
445,228 \\
451,188 \\
457,415\end{array}$ & $\begin{array}{l}35,072 \\
36,105 \\
33,807 \\
37,301 \\
37,007\end{array}$ & $\begin{array}{l}2,205,478 \\
2,305,605 \\
2,400,278 \\
2,680,640 \\
2,653,024\end{array}$ & $\begin{array}{l}4,477,860 \\
4,608,3 \times 2 \\
4,740,677 \\
4,800,863 \\
5,027,461\end{array}$ & $\begin{array}{l}21 \\
21 \\
22 \\
22 \\
23\end{array}$ & $\begin{array}{l}4,747,608 \\
4,700,201 \\
4,701,698 \\
4,815,498 \\
4,890,077\end{array}$ \\
\hline $\begin{array}{l}2002 \\
2000 \\
2004 \\
2005 \\
2006\end{array}$ & $\begin{array}{l}1,904,856 \\
1,032,861 \\
1,002,041 \\
1,992,555 \\
2,024,402\end{array}$ & & $\begin{array}{l}38,447 \\
39,010 \\
39,599 \\
40,215 \\
40,858\end{array}$ & $\begin{array}{l}2,773,551 \\
2,898,152 \\
3,028,568 \\
3,164,854 \\
3,307,272\end{array}$ & $\begin{array}{l}4,716,704 \\
4,870,022 \\
5,0<0,200 \\
5,197,004 \\
5,372,532\end{array}$ & $\begin{array}{l}22 \\
22 \\
23 \\
24 \\
25\end{array}$ & $\begin{array}{l}4,865,827 \\
4,802,756 \\
4,020,856 \\
4,900,241 \\
4,080,040\end{array}$ \\
\hline $\begin{array}{l}2007 \\
2000 \\
2000 \\
2010 \\
2011\end{array}$ & $\begin{array}{l}2,057,702 \\
2,092,501 \\
2,128,855 \\
2,166,856 \\
2,206,578\end{array}$ & & & $\begin{array}{r}3,456,100 \\
3,611,624 \\
r 774,147 \\
3,943,984 \\
4,121,463\end{array}$ & $\begin{array}{l}5,513,802 \\
5,704,125 \\
5,803,013 \\
6,110,850 \\
6,328,041\end{array}$ & $\begin{array}{l}25 \\
26 \\
27 \\
28 \\
29\end{array}$ & $\begin{array}{l}5,013,038 \\
5,046,571 \\
5,081,614 \\
5,118,233 \\
5,156,500\end{array}$ \\
\hline $\begin{array}{l}2012 \\
2013 \\
2014 \\
2015 \\
2016\end{array}$ & $\begin{array}{l}2,248,076 \\
2,291,441 \\
2,356,758 \\
2,384,115 \\
2,430,600\end{array}$ & & & $\begin{array}{l}4,306,000 \\
4,500,741 \\
4,703,274 \\
4,914,021 \\
5,138,003\end{array}$ & $\begin{array}{l}6,555,005 \\
6,702,182 \\
7,040,0<2 \\
7,209,006 \\
7,569,695\end{array}$ & $\begin{array}{l}30 \\
31 \\
32 \\
34 \\
35\end{array}$ & $\begin{array}{l}8,488,607 \\
8,473,454 \\
8,500,870 \\
8,547,024 \\
8,587,691\end{array}$ \\
\hline $\begin{array}{l}2017 \\
2018 \\
2019 \\
2020 \\
2021\end{array}$ & $\begin{array}{l}2,485,316 \\
2,539,357 \\
2,595,831 \\
2,654,845 \\
2,716,515\end{array}$ & & & $\begin{array}{l}5,367,217 \\
5,608,742 \\
5,661,135 \\
6,124,886 \\
6,400,506\end{array}$ & $\begin{array}{l}7,852,533 \\
8,148,000 \\
8,456,966 \\
8,779,731 \\
9,117,002\end{array}$ & $\begin{array}{l}38 \\
38 \\
30 \\
40 \\
42\end{array}$ & $\begin{array}{l}8,629,247 \\
8,672,674 \\
8,718,054 \\
8,765,477 \\
8,815,0<3\end{array}$ \\
\hline $\begin{array}{l}2002 \\
2003 \\
20021 \\
2005 \\
20026\end{array}$ & $\begin{array}{l}2,780,961 \\
2,848,306 \\
2,918,682 \\
2,002,200 \\
3,060,077\end{array}$ & & & $\begin{array}{l}6,689,520 \\
6,989,513 \\
7,304,041 \\
7,682,723 \\
7,976,185\end{array}$ & $\begin{array}{r}9,460,400 \\
9,837,610 \\
10,202,723 \\
10,624,047 \\
11,045,272\end{array}$ & $\begin{array}{l}44 \\
45 \\
47 \\
49 \\
51\end{array}$ & $\begin{array}{l}8,868,820 \\
8,920,037 \\
8,977,400 \\
0,0<8,587 \\
9,008,343\end{array}$ \\
\hline $\begin{array}{l}\text { NET P.V. } \\
\text { (1903\$) }\end{array}$ & $19,326,656$ & $1,432,366$ & 206,6003 & $33,146,731$ & $54,112,356$ & 240 & $54,051,315$ \\
\hline & 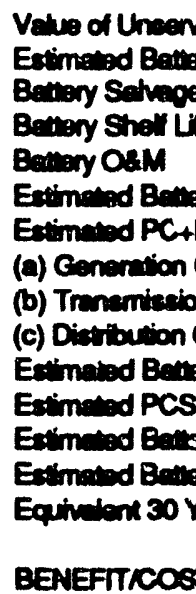 & 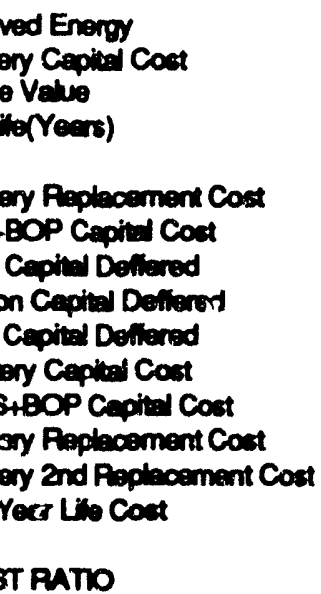 & $\begin{array}{l}\text { = } \\
= \\
=\end{array}$ & $\begin{array}{r}\$ 8.60 \\
\$ 140 \\
20 \% \\
15 \\
0.28 \% \\
\$ 112 \\
\$ 200 \\
\$ 14,864,258 \\
\$ 3,620,000 \\
\$ \$ 00,000 \\
\$ 36,228,715 \\
\$ 7,300,615 \\
\$ 56,000,237 \\
\\
\$ 192 \\
\$ 1,341 \\
1.00\end{array}$ & 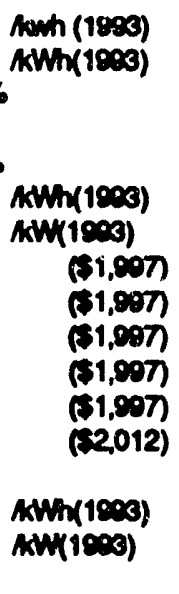 & & \\
\hline
\end{tabular}


TABLEF12

ESTIMATED VNWE OF BENEFTS AND BATTERY STORAGE COSTS FOR VIDALA

ASSUMED BATTERY SIZE= $\quad 217,000 \mathrm{KWH} \mathrm{:} 7$ HOURS

\begin{tabular}{|c|c|c|c|c|c|c|c|}
\hline YEAR & GENERATION & $\begin{array}{l}\text { NNUAL SAMNGS } \\
\text { TRAMSIMSSION DIST }\end{array}$ & IBUTION & $\begin{array}{r}\text { BACK-UPI } \\
\text { REUABLTY } \\
\text { CREDT }\end{array}$ & $\begin{array}{l}\text { TOTAL } \\
\text { SAVNES }\end{array}$ & $\begin{array}{l}\text { NET } \\
\text { VAUE } \\
\text { SKNH }\end{array}$ & $\begin{array}{l}\text { ANNUNL } \\
\text { BATTERY } \\
\text { COST }\end{array}$ \\
\hline $\begin{array}{l}1897 \\
1808 \\
1900 \\
2000 \\
2001\end{array}$ & $\begin{array}{l}1,782,349 \\
1,804,757 \\
1,828,173 \\
1,852,643 \\
1,878,215\end{array}$ & $\begin{array}{l}434,068 \\
450,526 \\
445,228 \\
451,188 \\
457,415\end{array}$ & $\begin{array}{l}35,973 \\
36,425 \\
36,897 \\
37,391 \\
37,907\end{array}$ & $\begin{array}{l}646,841 \\
676,054 \\
706,476 \\
738,268 \\
771,490\end{array}$ & $\begin{array}{l}2,890,352 \\
2,856,761 \\
3,016,775 \\
3,079,400 \\
3,145,027\end{array}$ & $\begin{array}{l}13 \\
14 \\
14 \\
14 \\
14\end{array}$ & $\begin{array}{l}4,747,608 \\
4,769,201 \\
4,791,856 \\
4,815,466 \\
4,80,077\end{array}$ \\
\hline $\begin{array}{l}2000 \\
2000 \\
2004 \\
2005 \\
2006\end{array}$ & $\begin{array}{l}1,004,065 \\
1,052,861 \\
1,002,041 \\
1,802,556 \\
2,024,402\end{array}$ & $\begin{array}{l}463,923 \\
470,724 \\
477,850 \\
485,257 \\
493,017\end{array}$ & $\begin{array}{l}38,447 \\
39,010 \\
39,598 \\
40,215 \\
40,858\end{array}$ & $\begin{array}{l}806,207 \\
842,486 \\
880,398 \\
820,016 \\
861,416\end{array}$ & $\begin{array}{l}3,213,512 \\
3,285,080 \\
3,350,800 \\
3,483,002 \\
3,519,603\end{array}$ & $\begin{array}{l}15 \\
15 \\
15 \\
16 \\
16 \\
16\end{array}$ & $\begin{array}{l}4,806,827 \\
4,802,766 \\
4,820,856 \\
4,050,241 \\
4,800,049\end{array}$ \\
\hline $\begin{array}{l}2007 \\
2000 \\
2000 \\
2010 \\
2011\end{array}$ & $\begin{array}{l}2,057,702 \\
2,002,501 \\
2,128,865 \\
2,166,866 \\
2,206,573\end{array}$ & $\begin{array}{l}501,127 \\
509,602 \\
518,458 \\
527,713 \\
537,384\end{array}$ & $\begin{array}{l}41,530 \\
42,232 \\
42,966 \\
43,733 \\
44,535\end{array}$ & $\begin{array}{l}1,004,680 \\
1,049,691 \\
1,097,136 \\
1,146,507 \\
1,198,100\end{array}$ & $\begin{array}{l}3,605,030 \\
3,604,225 \\
3,787,425 \\
3,884,819 \\
3,896,506\end{array}$ & $\begin{array}{l}17 \\
17 \\
17 \\
18 \\
18\end{array}$ & $\begin{array}{l}5,013,038 \\
5,046,571 \\
5,081,614 \\
5,118,238 \\
5,156,500\end{array}$ \\
\hline $\begin{array}{l}2012 \\
2013 \\
2014 \\
2015 \\
2016\end{array}$ & $\begin{array}{l}2,248,076 \\
2,291,441 \\
2,356,758 \\
2,384,115 \\
2,433,602\end{array}$ & $\begin{array}{l}547,490 \\
558,051 \\
569,088 \\
580,621 \\
592,673\end{array}$ & $\begin{array}{l}45,372 \\
46,247 \\
47,162 \\
48,118 \\
49,117\end{array}$ & $\begin{array}{l}1,252,014 \\
1,308,355 \\
1,367,201 \\
1,428,756 \\
1,403,050\end{array}$ & $\begin{array}{l}4,002,952 \\
4,204,085 \\
4,320,220 \\
4,441,600 \\
4,568,441\end{array}$ & $\begin{array}{l}19 \\
19 \\
20 \\
20 \\
21\end{array}$ & $\begin{array}{l}8,458,607 \\
8,473,454 \\
8,509,870 \\
8,547,924 \\
8,587,691\end{array}$ \\
\hline $\begin{array}{l}2017 \\
2018 \\
2019 \\
2020 \\
2021\end{array}$ & $\begin{array}{l}2,485,316 \\
2,589,357 \\
2,585,851 \\
2,654,845 \\
2,716,515\end{array}$ & $\begin{array}{l}605,267 \\
618,428 \\
632,181 \\
646,554 \\
661,573\end{array}$ & $\begin{array}{l}50,160 \\
51,251 \\
52,391 \\
53,582 \\
54,826\end{array}$ & $\begin{array}{l}1,560,238 \\
1,630,448 \\
1,703,818 \\
1,700,490 \\
1,860,612\end{array}$ & $\begin{array}{l}4,700,981 \\
4,859,485 \\
4,984,221 \\
5,136,471 \\
5,283,527\end{array}$ & $\begin{array}{l}22 \\
22 \\
23 \\
24 \\
24\end{array}$ & $\begin{array}{l}8,629,247 \\
8,672,674 \\
8,718,054 \\
8,765,477 \\
8,815,033\end{array}$ \\
\hline $\begin{array}{l}2002 \\
2023 \\
20024 \\
2005 \\
2008\end{array}$ & $\begin{array}{l}2,700,961 \\
2,848,306 \\
2,918,682 \\
2,902,226 \\
3,009,077\end{array}$ & $\begin{array}{l}677,267 \\
6 \times 3,669 \\
710,808 \\
728,718 \\
747,435\end{array}$ & $\begin{array}{l}56,127 \\
57,486 \\
58,907 \\
60,391 \\
61,942\end{array}$ & $\begin{array}{l}1,244,340 \\
2,031,835 \\
2,123,268 \\
2,218,815 \\
2,318,661\end{array}$ & $\begin{array}{l}5,458,605 \\
5,631,296 \\
5,811,664 \\
6,000,140 \\
6,197,115\end{array}$ & $\begin{array}{l}25 \\
26 \\
27 \\
28 \\
20\end{array}$ & $\begin{array}{l}8,866,820 \\
8,020,937 \\
8,077,400 \\
9,068,587 \\
9,008,343\end{array}$ \\
\hline $\begin{array}{l}\text { T P.V. } \\
803 \$ 1\end{array}$ & $19,326,656$ & $4,706,760$ & 300,063 & $9,655,678$ & $34,050,157$ & 157 & $54,051,315$ \\
\hline & 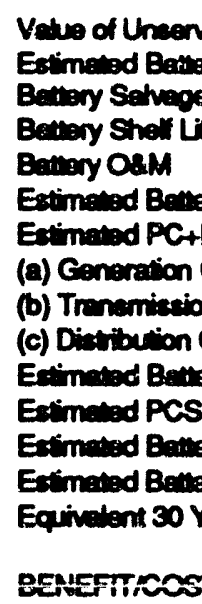 & 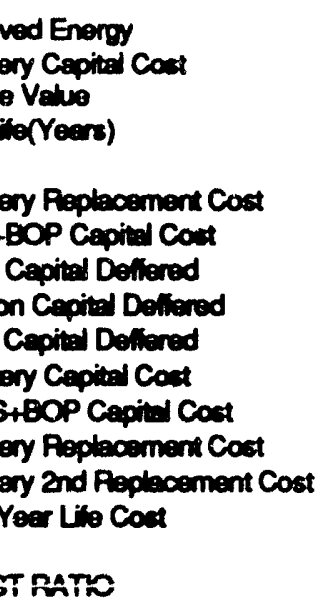 & $\begin{array}{l}= \\
=\end{array}$ & $\begin{array}{r}\$ 250 \\
\$ 140 \\
20 \% \\
15 \\
0.25 \% \\
\$ 112 \\
\$ 200 \\
\$ 14,864,258 \\
\$ 3,620,000 \\
\$ \$ 00,000 \\
\$ \$ 6,228,715 \\
\$ 7,303,615 \\
\$ 56,000,207 \\
\\
\$ 192 \\
\$ 1,341 \\
\$ .03\end{array}$ & 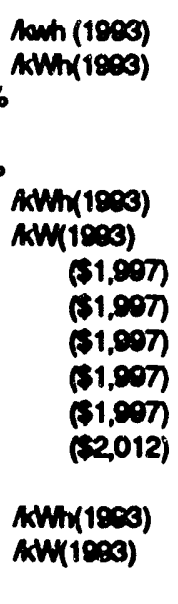 & & \\
\hline
\end{tabular}


TABLE F13

ESTIMATED VAWE OF BENEFTIS AND EATTERY COSTS FOA WARPENTON

ASSUMED BATTERY SZEE= $\quad 218,000 \mathrm{KWH} \mathrm{:}$

5 HOUPS

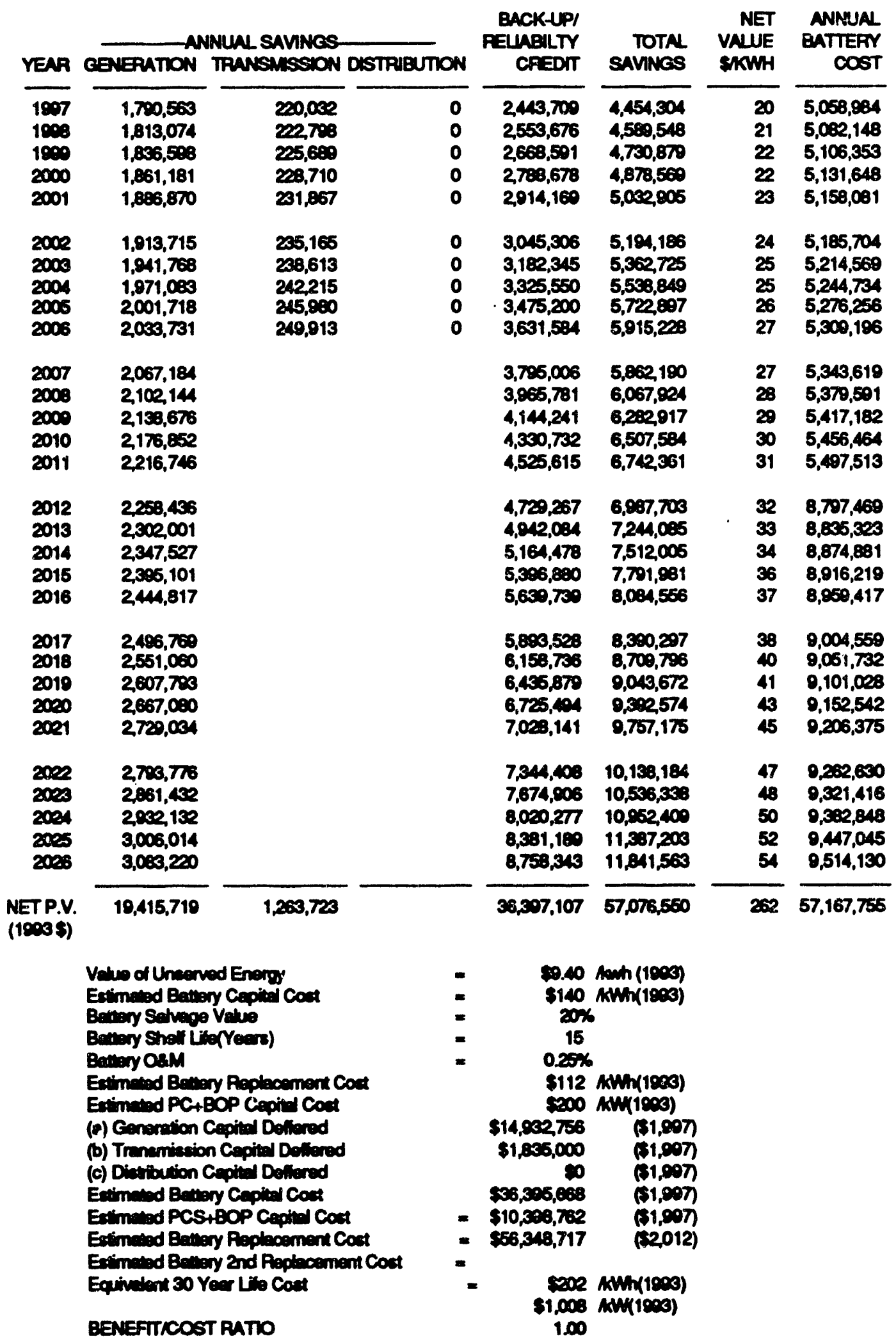


TABLE F14

ESTIMATED VAUE OF BENEATS AND BATTERY COSTS

FOR WAPRENTON

ASSUNED BATTERY STZE= $\quad 218,000 \mathrm{KMH}$;

5 HOUPS

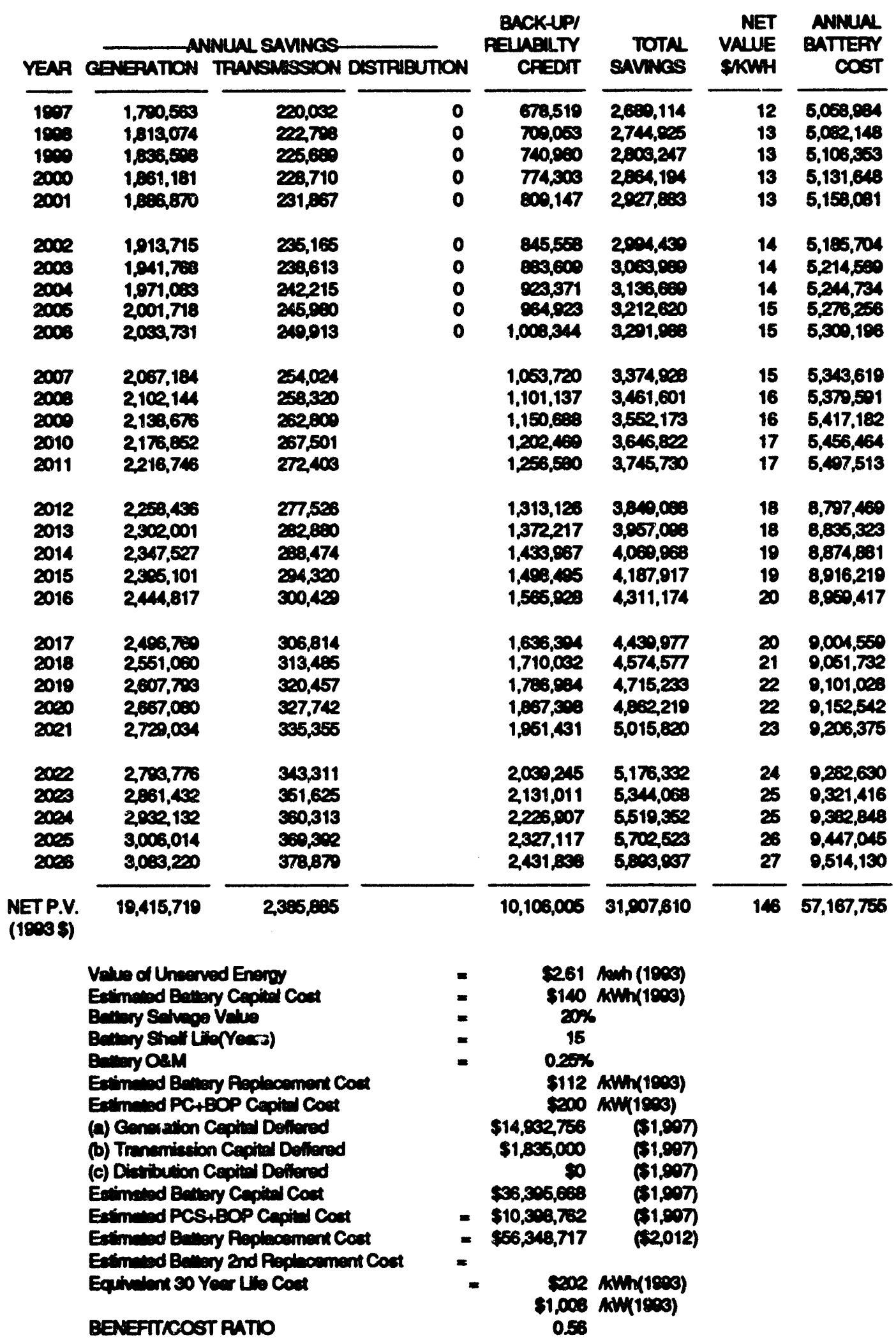




\section{Distribution}

ABB Power T\&D Co., Inc.

630 Sentry Parkway

Blue Bell, PA 19422

Attn: $\quad H$. Weinrich

Alaska Energy Authority (2)

P.O. Box 190869

Anchorage, AK 99519-0869

Attn: D. Denig-Chakroff

A. Sinha

American Electric Power Service Corp.

1 Riverside Plaza

Columbus, $\mathrm{OH} 43215$

Attn: C. Shih

Argonne National Laboratories (3)

CTD, Building 205

9700 South Cass Avenue

Argonne, IL 60439

Attn: C. Christianson

W. DeLuca

K. Myles

Arizona Public Service

P.O. Box 5399

Phoenix, AZ 85072

Attn: R. Hobbs

AT\&T Energy Systems

3000 Skyline Drive

Mesquite, TX 75149

Attn: M. Bize

Bechtel

P.O. Box 193965

San Francisco, CA 94119-3965

Attn: W. Stolte

Best Facility

321 Sunnymeade Road

Somerville, NJ 08876

Altn: G. Grefe

Bonneville Power Administration

Routing EO

P.O. Box 3621

Portland, OR 97208

Attn: J. Ray
C\&D Charter Power Systems, Inc.

3043 Walton Road

P.O. Box 239

Plymouth Meeting, PA 19462-0239

Attn: S. Misra

California State Air Resources Board Research Division

P.O. Box 2815

Sacramento, CA 95812

Attn: J. Holmes

Charter Power Systems, Inc.

3043 Walton Road

P.O. Box 239

Plymouth Meeting, PA 19462-0239

Attn: S. Misra

Chugach Electric Association, Inc.

P.O. Box 196300

Anchorage, AK 99519-6300

Attn: T. Lovas

Consolidated Edison (2)

4 Irving Place

New York, NY 10003

Attn: M. Lebow

N. Tai

Corn Belt Electric Cooperative

P.O. Box 816

Bloomington, IL 61702

Attn: R. Stack

Decision Focus, Inc.

650 Castro Street, Suite 300

Mountain View, CA 94041

Altn: S. Jabtour

Delco-Remy

7601 East 88th Place

Indianapolis, IN 46256

Attn: R. Rider

EG\&G Idaho, Inc.

Idaho National Engineering Laboratory

P. O. Box 1625

Idaho Falls, ID 83415

Attn: G. Hunt 
Eagle-Picher Industries

$C$ \& Porter Street

Joplin, MO 64802

Attn: J. DeGruson

East Penn Manufacturing Co., Inc.

Deka Road

Lyon Station, PA 19536

Attn: $\quad$ M. Stanton

Electric Power Research Institute (4)

3412 Hillview Avenue

P. O. Box 10412

Palo Alto, CA 94303

Attn: S. Eckroad

R. Schainker

P. Symons

R. Weaver

Electrotek Concepts, Inc.

P.O. Box 16548

Chattanooga, TN 37416

Attn: H. Barnett

Eltech Research Corporation

625 East Street

Fairport Harbor, OH 44077

Attn: E. Rudd

Energetics, Inc. (3)

7164 Columbia Gateway Drive

Columbia, MD 21046

Attn: J. Hurwitch

D. Baker

C. Matzdorf

Energy Systems Consulting

41 Springbrook Road

Livingston, NJ 07039

Attn: A. Pivec

Exxon Research Company

P.O. Box 536

1900 East Linden Avenue

Linden, NJ 07036

Attn: P. Grimes

Firing Circuits, Inc.

P.O. Box 2007

Norwalk, CT 06852-2007

Attn: J. Mills
General Electric Company (2)

Building 2, Room 605,

1 River Road

Schenectady, NY 12345

Attn: D. Swann

E. Larson

Generai Electric Drive Systems

1501 Roanoke Blvd.

Salem, VA 24153

Attn: C. Romeo

General Motors

Tech. Cir. Engineering West, W3-EVP

30200 Mound Road

P. O. Box 9010

Warren, MI 48090-9010

Attn: M. Eskra

Giner, Inc.

14 Spring Street

Waltham, MA 02254-9147

Attn: A. LaConti

GNB Industrial Battery Company (3)

Woodlake Corporate Park

829 Parkview Blvd.

Lombard, IL 60148-3249

Altn: S. Deshpande'

G. Hunt

J. Szymborski

Hawaii Electric Light Co.

P.O. Box 1027

Hilo, HI 96720

Attn: C. Nagata

Hughes Aircraft Company

P.O. Box 2999

Torrance, CA 90509-2999

Attn: R. Taenaka

Integrated Power Corp. (2)

7524 Standish Place

Rockville, MD 20855

Attn: T. Blumenstock

D. Danley 
ILZRO (2)

P.O. Box 12036

Research Triangle

Park, NC 27709

Attn: J. Sharpe III

R. Nelson

Johnson Controls Battery Group, Inc. (4)

5757 N. Green Bay Avenue

P. O. Box 591

Milwaukee, WI 53201

Attn: P. Eidler

R. Miles

T. Ruhlmann

W. Tiedeman

Johnson Controls Battery Group, Inc. 12500 W. Silver Spring Drive

P. O. Box 591

Milwaukee, WI 53201-0591

Attn: J. Zagrodnik

Lawrence Berkeley Laboratory (3)

University of California

One Cyclotron Road

Berkeley, CA 94720

Attn: E. Cairns

K. Kinoshita

F. McLarnon

N.E.T.S.

P.O. Box 32584

Juneau, Ak 99803

Attn: T. Neubauer

National Renewable Energy Laboratory (2)

1617 Cole Blvd.

Golden, CO 80401-3393

Attn: J. Ohi

L. Goldstein

New York Power Authority

1633 Broadway

New York, NY 10019

Attn: B. Chezar

Northern States Power

414 Nicollet Mall

Minneapolis, MN 55401

Attn: M. Rogers
Oglethorpe Power Company

2100 E. Exchange Place

P.O. box 1349

Tucker, GA 30085-1349

Attn: K. Scruggs

Omnion Power Corporation

P.O. Box 879

East Troy, WI 53120

Attn: H. Meyer

Pacific Gas \& Electric (4)

3400 Crow Canyon Road

San Ramon, CA 94583

Attn: G. Ball

R. Winter

B. Norris

J. Meglen

Power Technologies, Inc.

1 Sierragate Plaza, Suite 340

Roseville, CA 95678

Attn: H. Clark

Puerto Rico Power Authority

G.P.O. Box 4267

San Juan, Puerto Rico 00936-426

Attn: W. Torres

R\&D Associates

2100 Washington Blvd.

Arlington, VA 22204-5706

Attn: J. Thompson

Robicon Corporation 100 Sagomore Hill Road

Pittsburgh, PA 15239

Attn: A. Maruschak

Sacramento Municipal Utility District 6201 S. Street

Sacramento, CA 95817

Attn: L. Wittrup

Salt River Project

MS PAB 357, Box 52025

Phoenix, AZ 85072-2025

Attn: H. Lundstrom

San Diego Gas \& Electric Company

P.O. Box 1831

San Diego, CA 92112

Attn: J. Wight 
W. J. Schafer Associates

303 Lindbergh Avenue

Livermore, CA 94550-9551

Attn: S. Schoenung

R. K. Sen \& Associates 3808 Veazey Street NW Washington, DC 20016

Attn: R. Sen

Silent Power, Inc.

163 West 1700 South

Salt Lake City, UT 84115

Attn: J. Rassmussen

Silent Power, Inc. (5)

489 Devon Park Drive

Suite 315

Wayne, PA 19087

Attn: W. Auxer
A. Koenig (3)
G. Smith

Silent Power, Ltd. (2)

Davy Road, Astmoor

Runcorn, Cheshire

UNITED KINGDOM WA7 1PZ

Attn: W. Jones

M. McNamee

Southern California Edison

2244 Walnut Grove Avenue

P.O. Box 800

Rosemeade, CA 91770

Attn: A. Rodriguez

Stuart Kuritzky

347 Madison Avenue

New York, NY 10017

Superconductivity, Inc.

2114 Eagle Drive

Middleton, WI 53562

Attn: J. Emerick

United Engineers and Contractors

700 South Ash St.

P.O. Box 5888

Denver, CO 80217

Attn: A. Randall
University of Missouri - Rolla

112 Electrical Engineering Building

Rolla, MO 65401-0249

Attn: $\quad$ M. Anderson

University of Wisconsin - Madison

Dept. of Electrical \& Computer Eng.

1415 Johnson Drive

Madison, WI 53706

Attn: D. Divan

U.S. Department of Energy (21)

Office of Energy Management

CE-142 FORSTL

Washington, DC 20585

Attn: R. Eaton (20)

K. Klunder

U.S. Department of Energy (9)

Office of Propulsion Systems

CE-321 FORSTL

Washington, DC 20585

Attn: K. Barber

J. Brogan

E. Dowgiallo

K. Heitner

A. Landgrebe

R. Miner

D. O'Hara

P. Patil

R. Sutula

U.S. Department of Energy

Albuquerque Operations Office Energy Technologies Division Albuquerque, NM 87115

Attn: G. Buckingham

U.S. Windpower, Inc. 6952 Preston Avenue Livermore, CA 94550

Attn: D. Richardson

Westinghouse STC

1310 Beulah Road

Pittsburgh, PA 15235

Attn: H. Saunders

W. R. Grace \& Company

62 Whittemore Avenue

Cambridge, MA 02140

Attn: S. Strzempko 
Yuasa-Exide

P.O. Box 14205

Reading, PA 19612-4205

Attn: F. Tarantino

Zaininger Engineering Co., Inc. 1590 Oakland Road, Suite B211

San Jose, CA 95131

Attn: H. Zaininger

2000

2500

2504

2504

2522

2523

2525
H. Schmitt

G. Beeler

R. Clark

L. Lachenmeyer

K. Grothaus

D. Doughty

P. Butler (10)
2525

2525

2525

2525

2525

2525

3714

6200

6213

6218

6218

8523-2

7141

7151

7613-2
A. Akhil

J. Braithwaite

N. Clark

J. Freese

R. Jungst

S. Klassen

J. Kerr, Attn: D. Wilt

D. Arvizu

T. Bickell

W. Bower

R. Bonn

Central Technical Files

Technical Library (5)

Technical Publications

Document Processing for DOE/OSTI (10) 

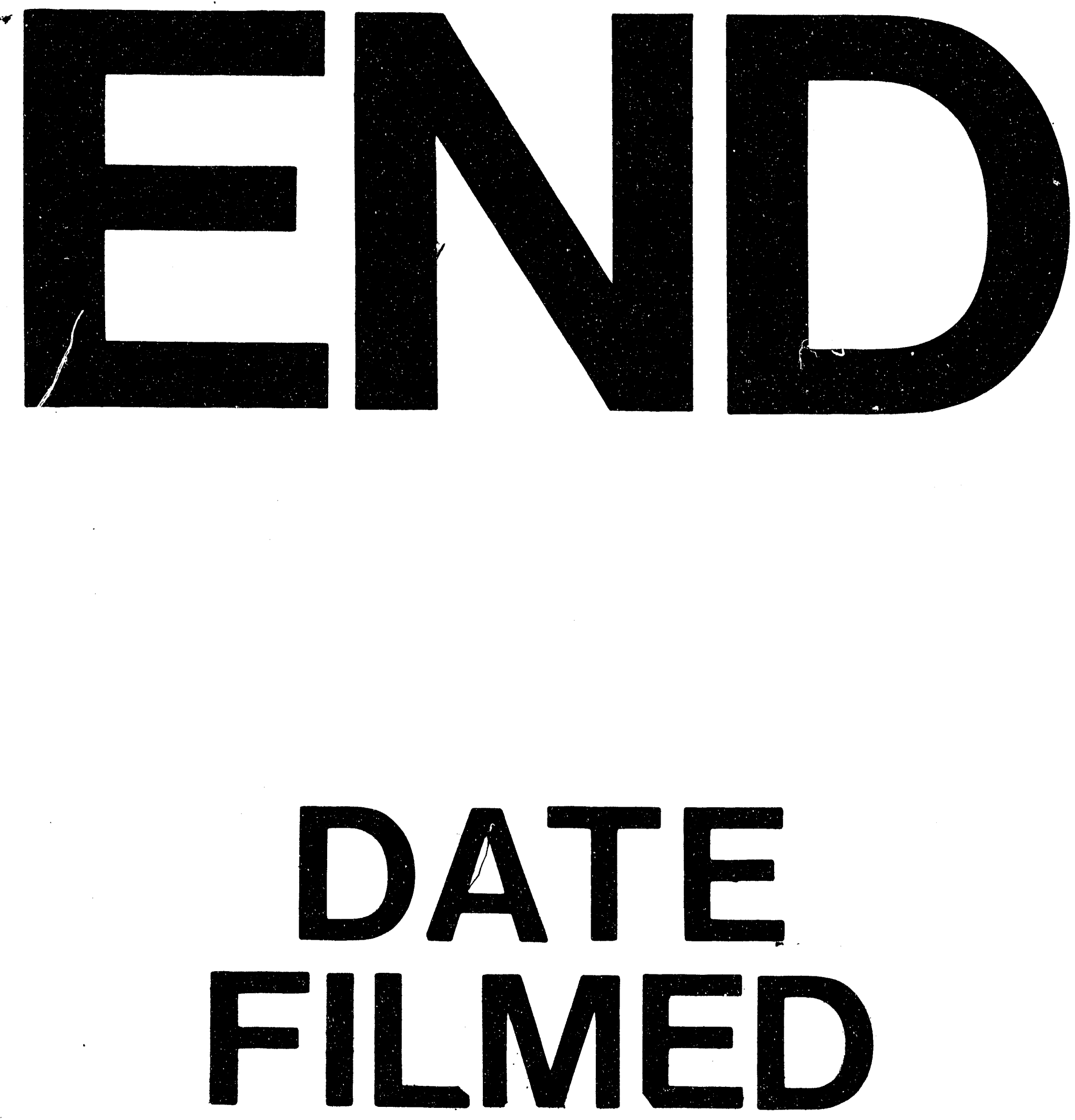

1

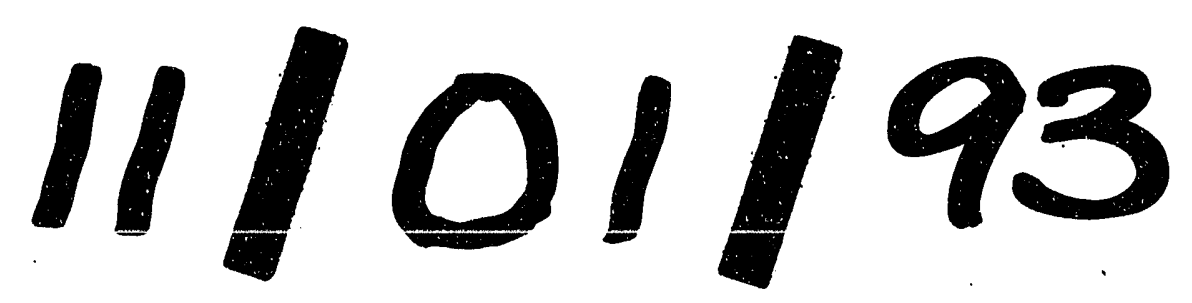


